\title{
\&
}

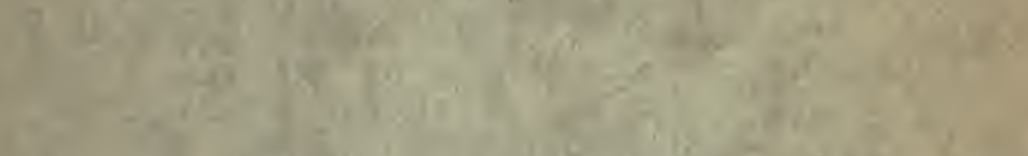

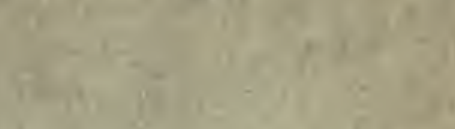

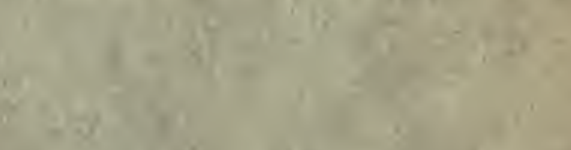

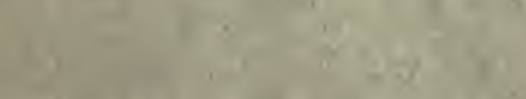

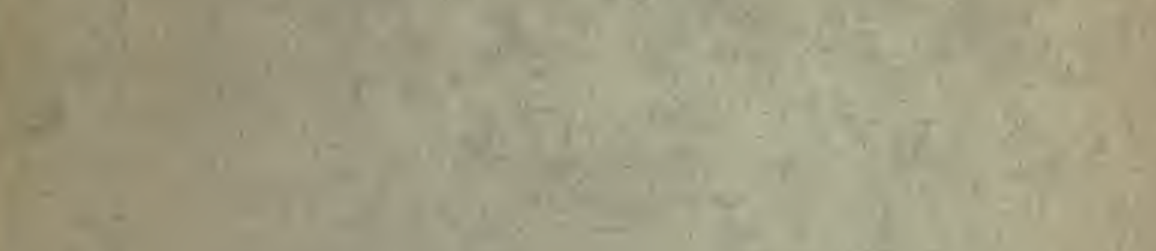

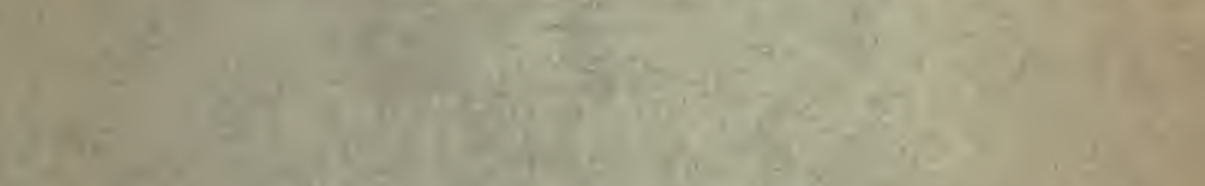

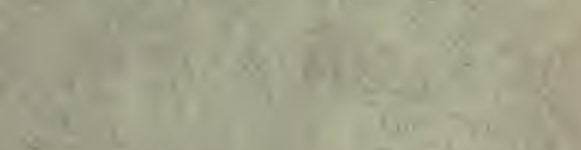
xhe

$7=x-2 x^{2}$

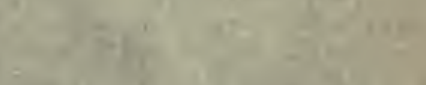

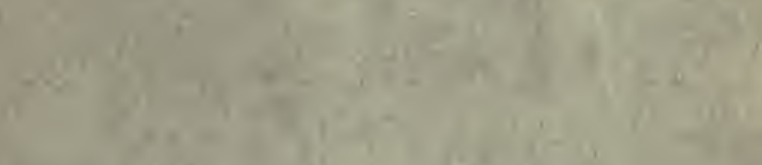

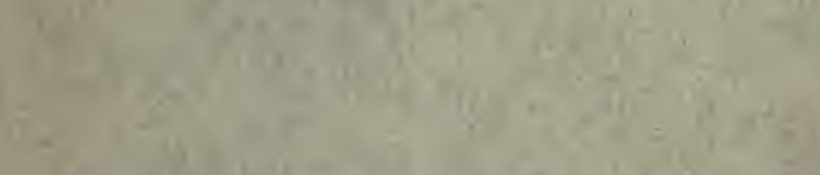




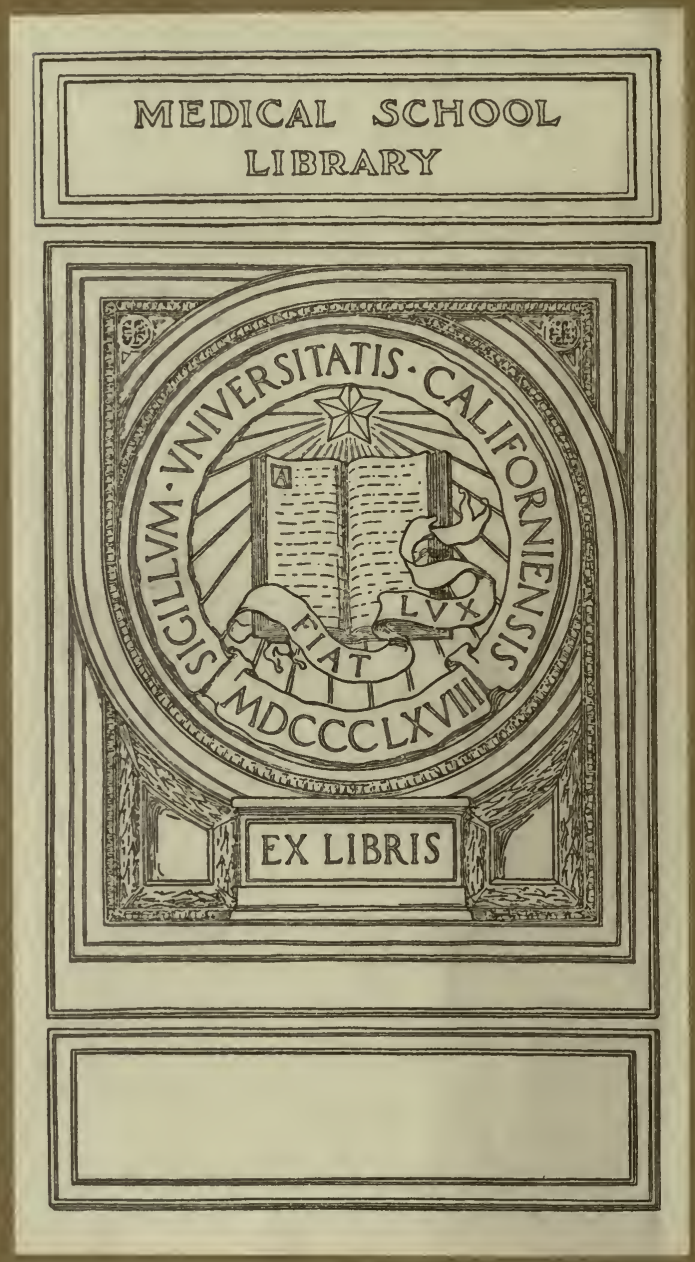


wat $=$

1

*

$x=1$

(1)

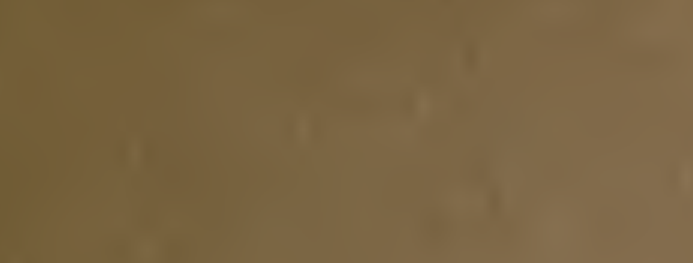

(1)

,

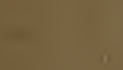

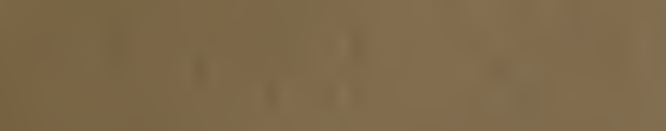

ifing

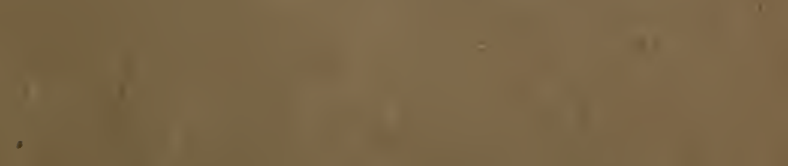

I

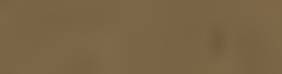

$15+1$ 

Digitized by the Internet Archive - in 2007 with funding from Microsoft Corporation 

SMITHSONIAN MISCELLANEOUS COLLECTIONS

\section{THE CONSTANTS OF NATURE}

\section{PART V}

A RECALCULATION

\section{$\infty$ \\ THE ATOMIC WEIGHTS}

BY

FRANK WIGGLESWORTH CLARKE

Chief Chemist of the U. S. Geological Survey

NEW EDITION, REVISED AND ENLARGED

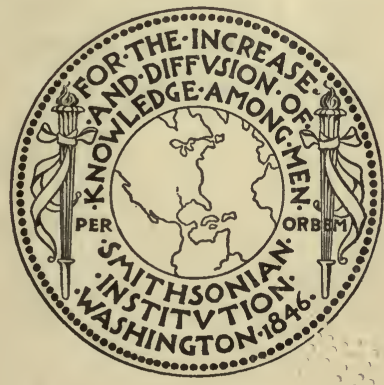

R

CITY OF WASHINGTON

PUBLISHED BY THE SMITHSONIAN INSTITUTION 
Judd \& Detweiler, Printers WASHINGTON, D. C. 


\section{ADVERTISEMENT:}

The present publication is one of a series devoted to the discussion and more precise determination of various "Constants of Nature;" and forms the Fifth contribution to that subject published by this Institution.

The First number of the series, embracing tables of "Specific Gravities "and of Melting and Boiling Points of Bodies, prepared by the same author, Prof. F. W. Clarke, was published in 1873. The Fourth part of the series, comprising a complete digest of the various "Atomic Weight" determinations of the chemical elements published since 1814, commencing with the well-known "Table of Equivalents" by Wollaston (given in the Philosophical Transactions for that year), compiled by Mr. George F. Becker, was published by the Institution in 1880. The present work comprises a very full discussion and recalculation of the "Atomic Weights" from all the existing data, and the assignment of the most probable value to each of the elements.

The first edition of this work was published in 1882, and this new edition, revised and enlarged by Professor Clarke, contains new information accumulated during the past fifteen years.

S. P. Langley,

Secretary of the Smithsonian Institution.

Washington, January, 1897. 



\section{TABLE OF CONTENTS}

PAGE.

Introduction

Formulæ for the Calculation of Probable Error.................. 7

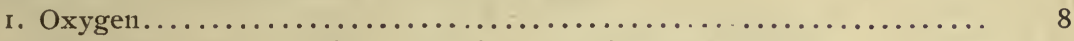

2. Silver, Potassium, Sodium, Chlorine, Bromine, and Iodine........ 34

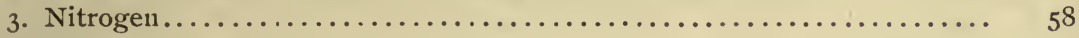

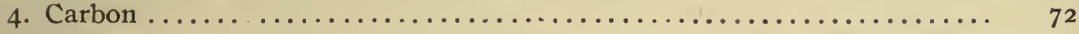

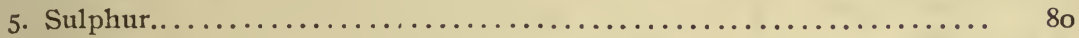

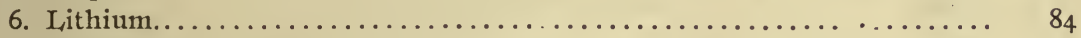

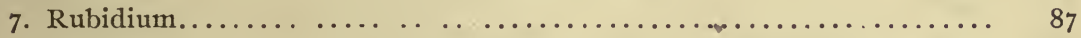

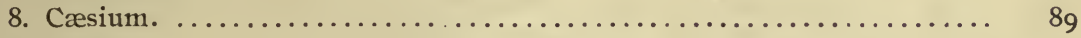

9. Copper........................... 9 I

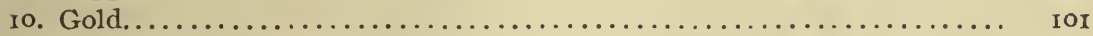

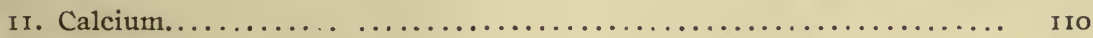

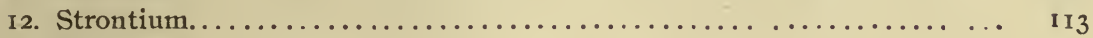

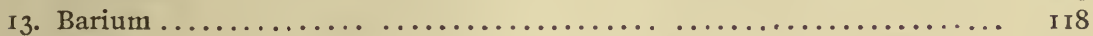

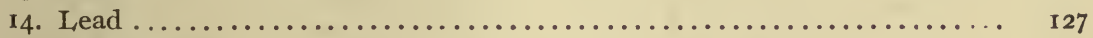

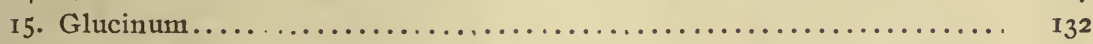

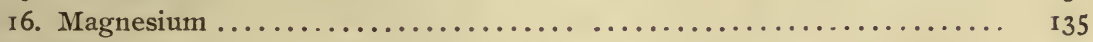

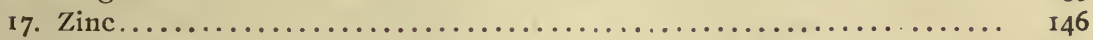

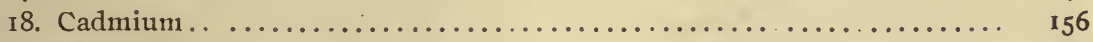

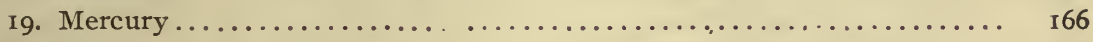

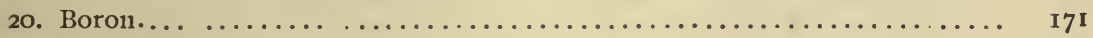

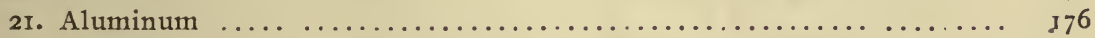

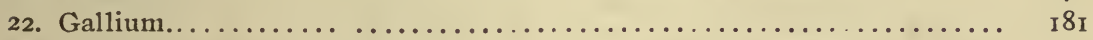

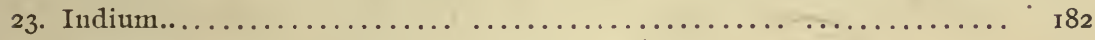

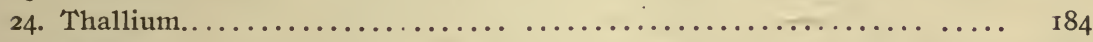

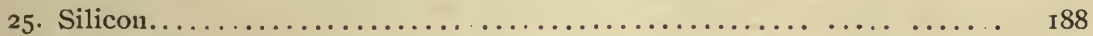

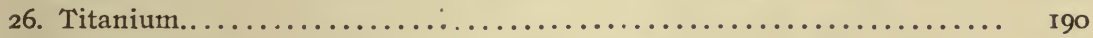

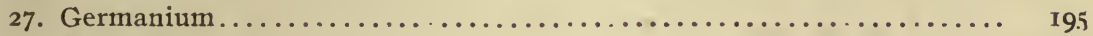

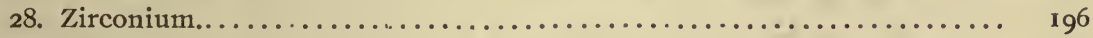

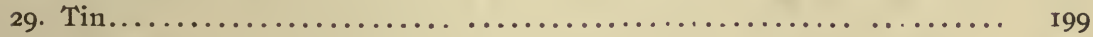

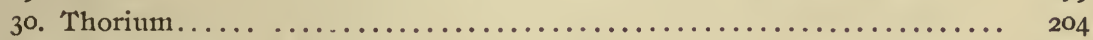

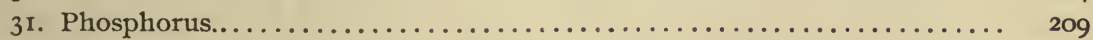

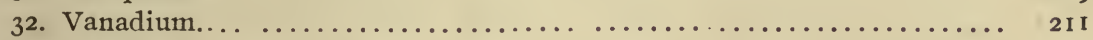

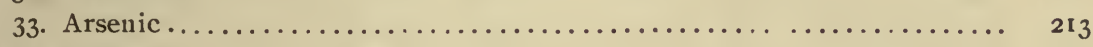

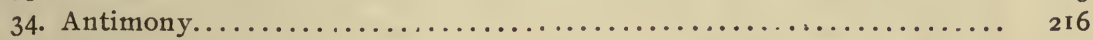

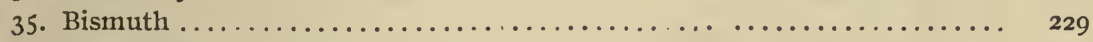

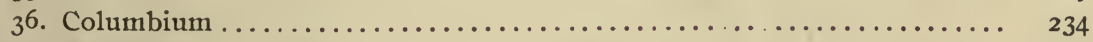

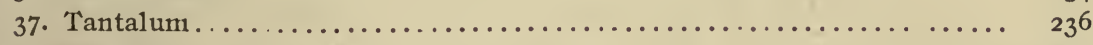

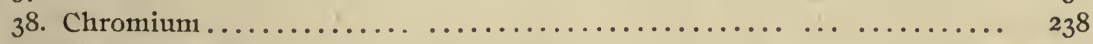

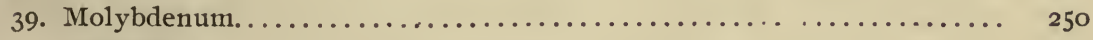

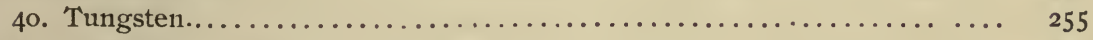

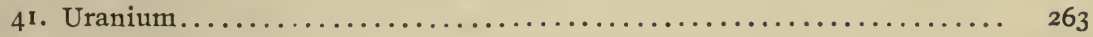

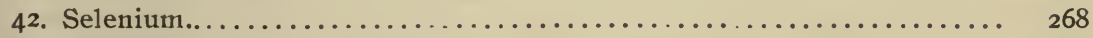

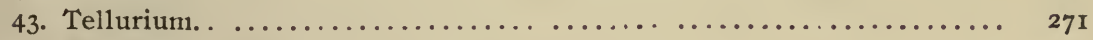

44. Fluorine........................................ 277 
PAGE.

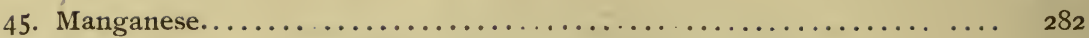

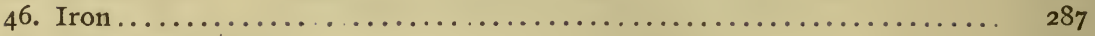

47. Nickel and Cobalt.. ... . . . . . .

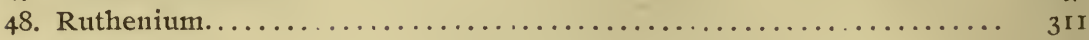

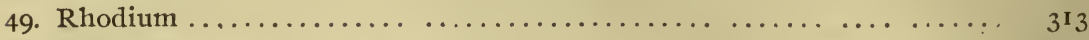

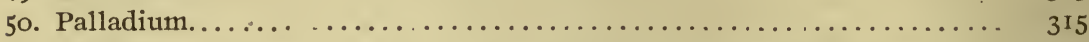

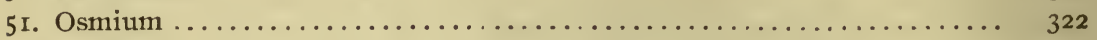

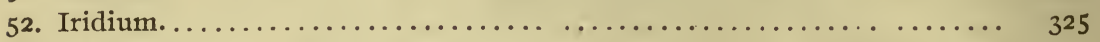

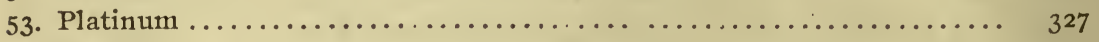

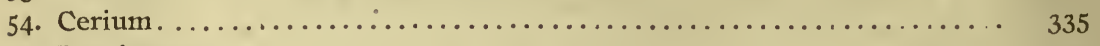

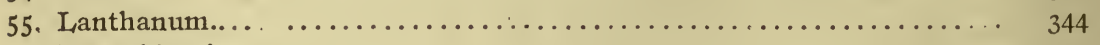

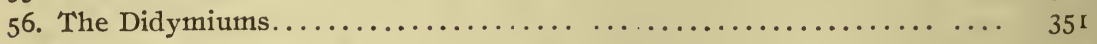

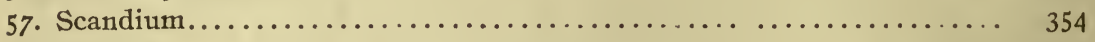

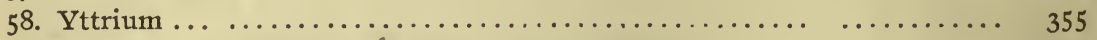

59. Samarium, Gadolinium, Erbium, and Ytterbium ............. 359

6o. Terbium, Thulium, Holmium, Dysprosium, etc............... ${ }_{362}$

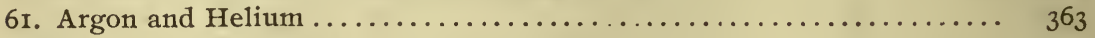

Table of Atomic Weights ................................... ${ }_{364}$

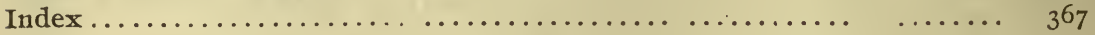




\title{
A RECALCULATION OF THE ATOMIC WEIGHTS.
}

\author{
BY FRANK WIGGLESWORTH CLARKE.
}

\section{INTRODUCTION.}

In the autumn of 1877 the writer began collecting data relative to determinations of atomic weight, with the purpose of preparing a complete résumé of the entire subject, and of recalculating all the estimations. The work was fairly under way, the material was collected and partly discussed, when I received from the Smithsonian Institution a manuscript by Professor George F. Becker, entitled "Atomic Weight Determinations: a Digest of the Investigations Published since 1814." This manuscript, which has since been issued as Part IV of the "Constants of Nature," covered much of the ground contemplated in my own undertaking. It brought together all the evidence, presenting it clearly and thoroughly in compact form; in short, that portion of the task could not well be improved upon. Accordingly, I decided to limit my own labors to a critical recalculation of the data; to combine all the figures upon a common mathematical basis, and to omit everything which could as well be found in Professor Becker's "Digest."

In due time my work was completed, and early in 1882 it was published. About a year later Meyer and Seubert's recalculation appeared, to be followed later still by the less elaborate discussions of Sebelien and of Ostwald. All of these works differed from one another in various essential particulars, presenting the subject from different points of view, and with different methods of calculation. Each one, therefore, has its own special points of merit, and, in a sense, reinforces the others. At the same time, the scientific activity which they represent shows how widespread was the interest in the subject of atomic weights, and how fundamentally important these constants undoubtedly are.

The immediate effect of all these publications was to render manifest the imperfections of many of the data, and to point out most emphatically in what directions new work needed to be done. Consequently, there has been since 1884 an extraordinary activity in the determination of atomic weights, and a great mass of new material has accumulated. The assimilation of this material, and its combination with the old data, is the object of the present volume. 
At the very beginning of my work, certain fundamental questions confronted me. Should I treat the investigations of different individuals separately, or should I combinesimilar data together in a manner irrespective of persons? For example, ought I, in estimating the atomic weight of silver, to take Stas' work by itself, Marignac's work by itself, and so.on, and then average the results together; or should I rather combine all series of figures relating to the composition of potassium chlorate into one mean value, and all the data concerning the composition of silver chloride into another mean, and, finally, compute from such general means the constant sought to be established? The latter plan was finally adopted; in fact, it was rendered necessary by the method of least squares, which, in a special, limited form, was chosen as the best method of dealing with the problem.

The mode of discussion and combination of results was briefly as follows. The formulæ employed are given in another chapter. I began with the ratio between oxygen and hydrogen; in other words, with the atomic weight of oxygen referred to hydrogen as unity. Each series of experiments was taken by itself, its arithmetical mean was found, and the probable error of that mean was computed. Then the several means were combined according to the appropriate formula, each receiving a weight dependent upon its probable error. The general mean thus established was taken as the most probable value for the atomic weight of oxygen, and, at the same time, its probable error was mathematically assigned.

Next in order came a group of elements which were best discussed together, namely, silver, chlorine, potassium, sodium, bromine, and iodine. For these elements there were data from many experimenters. All similar figures were first reduced to common standards, and then the means of individual series were combined into general means. Thus all the data were condensed into nineteen ratios, from which several independent values for the atomic weight of each element could be computed. The probable errors of these values, however; all involved the probable error of the atomic weight of oxygen, and were, therefore, higher than they would have been had the latter element not entered into consideration. Here, then, we have suggested a chief peculiarity of this whole revision. The atomic weight of each element involves the probable errors of all the other elements to which it is directly or indirectly referred. Accordingly, an atomic weight determined by reference to elements whose atomic weights have been defectively ascertained will receive a high probable error, and its weight, when combined with other values, will be relatively low. For example, an atomic weight ascertained by direct comparison with hydrogen will, other things being equal, have a lower probable error than one which is referred to hydrogen through the intervention of oxygen; and a metal whose equivalent involves only the probable error of oxygen should be more exactly 
known than one which depends upon the errors of silver and chlorine. These points will appear more clearly evident in the subsequent actual discussions.

But although the discussion of atomic weights is ostensibly mathematical, it cannot be purely so. Chemical considerations are necessarily involved at every turn. In assigning weights to mean values I have been, for the most part, rigidly guided by mathematical rules; but in some cases I have been compelled to reject altogether series of data which were mathematically excellent, but chemically worthless because of constant errors. In certain instances there were grave doubts as to whether particular figures should be included or rejected in the calculation of means, there having been legitimate reasons for either procedure. Probably many chemists would differ with me upon such points of judgment. In fact, it is doubtful whether any two chemists, working independently, would handle all the data in precisely the same way, or combine them so as to produce exactly the same final results. Neither would any two mathematicians follow identical rules or reach identical conclusions. In calculating the atomic weight of any element those values are assigned to other elements which have been determined in previous chapters. Hence a rariation in the order of discussion might lead to slight differences in the final results.

As a matter of course the data herein combined are of very unequal value. In many series of experiments the weighings have been reduced to a vacuum standard; but in most cases chemists have neglected this correction altogether. In a majority of instances the errors thus introduced are slight; nevertheless they exist, and.interfere more or less with all attempts at a theoretical consideration of the results:

Necessarily, this work omits many details relative to experimental methods, and particulars as to the arrangement of special forms of apparatus. For such details original memoirs must be consulted. Their inclusion here would have rendered the work unwarrantably bulky. There is such a thing as over-exhaustiveness of treatment, which is equally objectionable with under-thoroughness.

Of course, none of the results reached in this revision can be considered as final. Every one of them is liable to repeated corrections. 'To my mind the real value of the work, great or little, lies in another direction. The data have been brought together and reduced to common standards, and for each series of figures the probable error has been determined. Thus far, however much my methods of combination may be criticised, I feel that my labors will have been useful. The ground is cleared, in a measure, for future experimenters; it is possible to see more distinctly what remains to be done; some clues are furnished as to the relative merits of different series of results.

On the mathematical side my method of recalculation has obvious deficiencies. . It is special, rather than general, and at some future time, when a sufficiently large mass of evidence has accumulated, it must 
give way to a more thorough mode of treatment. For example, the ratio $\mathrm{Ag}_{2}: \mathrm{BaBr}_{2}$ has been used for computing the atomic weight of barium, the atomic weights of silver and bromine being supposed to be known. But these atomic weights are subject to small errors, and they are superimposed upon that of the ratio itself in the process of calculation. Obviously, the ratio should contribute to our knowledge of all three of the atomic weights involved in it, its error being distributed into three parts instead of appearing in one only. The errors may be in part compensatory; but that is not certainly known.

Suppose now that for every element we had a goodly number of atomic weight ratios, connecting it with at least a dozen other elements, and all measured with reasonable accuracy. These hundreds of ratios could then be treated as equations of observation, reduced to linear form, and combined by the general method of least squares into normal equations. All errors would thus be distributed, never becoming cumulative; and the normal equations, solved once for all, would give the atomic weights of all the elements simultaneously. The process would be laborious but the result would be the closest possible approach to accuracy. The data as yet are inadequate, although some small groups of ratios may be handled in that way; but in time the method is sure to be applied, and indeed to be the only general method applicable. Even if every ratio was subject to some small constant error, this, balanced against the similar errors of other ratios, would become accidental or unsystematic with reference to the entire mass of material, and would practically vanish from the final means.

Concerning this subject of constant and accidental errors, a word may be said here. My own method of discussion eliminates the latter, which are removable by ordinary averaging; but the constant errors, vicious and untractable, remain, at least partially. Still, where many ratios are considered, even the systemàtic errors may in part compensate each other, and do less harm than might be expected. They have, moreover, a peculiarity which deserves some attention.

In the discussion of instrumental observations, the systematic errors are commonly constant, both as to direction and as to magnitude. They are therefore independent of the accidental errors, and computation of means leaves them untouched. But in the measurement of chemical ratios the constant errors are most frequently due to an impurity in one of the materials investigated. If different samples of a substance are studied, although all may contain the same impurity, they are not likely to contain it in the same amount; and so the values found for the ratio will vary. In other words, such errors may be constant in direction but variable in magnitude. That variation appears in the probable error computed for the series of observations, diminishes its weight when combined with other series, and so, in part, corrects itself. It is not removed from the result, but it is self-mitigated. The constant errors familiar to the physicist and astronomer are obviously of a different order. 
That all methods of averaging are open to objections, I am of course perfectly aware. I also know the doubts which attach to all questions of probable error, and to all combinations of data which depend upon them. I have, however, preferred to face these objections and to recognize these doubts rather than to adopt any arbitrary scheme which permits of a loose selection of data. After all, the use of probable error as a means of weighting is but a means of weighting, and perhaps more justifiable than any other method of attaining the same result. When observations are weighted empirically-that is, by individual judgment-far greater dangers arise. Almost unconsciously, the work of a famous man is given greater weight than that of some obscure chemist, although the latter may ultimately prove to be the best. But the probable error of a series of measurements is not affected by the glamor of great names; and the weight which it assigns to the observations is at least as safe as any other. In the long run, I believe it assigns weight more accurately, and therefore I have trusted to its indications, not as if it were a mathematical fetish, but regarding it as a safe guide, even though sometimes fallible.

In Meyer and Seubert's recalculation, weights are assigned in quite a novel manner. In each series of experiments the maximum and minimum results are given, but instead of the mean there is a value deduced from the sum of the weighings - that is, each experiment is weighted proportionally to the mass of the material handled in it. For this method I am unable to find any complete justification. Of course, the errors due to the operations of weighing become proportionally smaller as the quantity of material increases, but these errors, with modern apparatus, are relatively unimportant. The real errors in atomic weight determinations are much larger than these, and due to different causes. Hence an experiment upon ten grammes of material may be a little better than one made upon five grammes, but it is by no means necessarily twice as good. The ordinary mean of a series of observations, with its measure of concordance, the probable error, is a better value than one obtained in the manner just described. If only errors of weighing were to be considered, Meyer and Seubert's summation method would be valid, but in the presence of other and greater errors it seerns to have but little real pertinency to the problem at hand.

In addition to the usual periodicals, the following works have been freely used by me in the preparation of this volume:

Berzelius, J. J. Lehrbuch der Chemie. 5 Auflage. Dritter Band. SS. $1147-1231.1845$.

Van Geuns, W. A. J. Prœve eener Geschiedenis van de Equivalentgetallen der Scheikundige Grondstoffen en van hare Soortelijke Gewigten in Gasvorm, voornamelijk in Betrekking tot de vier Grondstoffen der Bewerktuigde Natuur. Amsterdam, 1853. 
Mulder, E. Historisch-Kritisch Overzigt van de Bepalingen der Æquivalent-Gewigten van 13 Eenvoudige Ligchamen. Utrecht, 1853.

Mulder, L. Historisch-Kritisch Overzigt van de Bepalingen der Equivalent-Gewigten van 24 Metalen. Utrecht, 1853.

Oudemans, A. C., Jr. Historisch-Kritisch Overzigt van de Bepaling der \&quivalent-Gewigten van Twee en Twintig Metalen. Leiden, 1853.

Stas, J. S. Untersuchungen über die Gesetze der Chemischen Proportionen über die Atomgewichte und ihre gegenseitigen Verhältnisse. Uebersetzt von Dr. L. Aronstein. Leipzig, 1867.

See also his "Oeuvres Complètes," 3 vols., published at Bruxelles in 1894 .

Meyer, L., and Seubert, K. Die Atomgewichte der Elemente, aus den Originalzahlen neu berechnet. Leipzig, 1883.

Sebelien, J. Beiträge zur Geschichte der Atomgewichte. Braunschweig, 1884 .

Ostwald, W. Lehrbuch der allgemeinen Chemie. Zweite Aufl. I Band. SS. 18-138. Leipzig, 1891.

The four Dutch monographs above cited are especially valuable. They represent a revision of all atomic weight data down to 1853, as divided between four writers.

For the sake of completeness the peculiar volume by Hinrichs * must also be cited, although the methods and criticisms embodied in it have not been generally endorsed. Hinrichs' point of view is so radically different from mine that I have been unable to make use of his discussions. His objections to the researches of Stas seem to be quite unfounded; and the rejoinders by Spring and by Van der Plaats are sufficiently thorough.

* The True Atomic Weight of the Chemical Elements and the Unity of Matter. St. Louis, 1894 . Compare Spring, Chem. Zeitung, Feb. 22, 1893, and Van der Plaats, Compt. Rend., 116, 1362. See also a paper by Vogel, with adverse criticisms by Spring and L. Henry, in Bull. Acad. Bruxelles, (3), 26, 469 . 


\section{FORMULA FOR THE CALCULATION OF PROBABLE ERROR.}

The formula for the probable error of an arithmetical mean, familiar to all physicists, is as follows:

$$
e=0.6745 \sqrt{\frac{S}{n(n-1)}}
$$

Here $n$ represents the number of observations or experiments in the series, and $\mathrm{S}$ the sum of the squares of the variations of the individual results from the mean.

In combining several arithmetical means, representing several series, into one general mean, each receives a weight inversely proportional to the square of its probable error. Let A, B, C, etc., be such means, and $a, b, c$ their probable errors respectively. Then the general mean is determined by the formula:

$$
\mathrm{M}=\frac{\frac{\mathrm{A}}{a^{2}}+\frac{\mathrm{B}}{b^{2}}+\frac{\mathrm{C}}{c^{2}}}{\frac{\mathrm{I}}{a^{2}}+\frac{\mathrm{I}}{b^{2}}+\frac{\mathrm{I}}{c^{2}}} \cdots \cdots
$$

For the probable error of this general mean we have:

$$
e=\frac{\mathrm{I}}{\sqrt{\frac{\mathrm{I}}{a^{2}}+\frac{\mathrm{I}}{b^{2}}+\frac{\mathrm{I}}{c^{2}}}} \ldots .
$$

In the calculation of atomic and molecular weights the following formulæ are used: Taking, as before, capital letters to represent known quantities, and small letters for their probable errors respectively, we have for the probable error of the sum or difference of two quantities, $A$ and $B$ :

$$
e=\sqrt{a^{2}+b^{2}}
$$

For the product of A multiplied by B the probable error is

$$
e=\sqrt{(\mathrm{A} b)^{2}+(\mathrm{B} a)^{2}}
$$

For the product of three quantities, $\mathrm{ABC}$ :

$$
e=\sqrt{(\mathrm{BC} a)^{2}+(\mathrm{AC} b)^{2}+(\mathrm{ABC})^{2}}
$$

For a quotient, $\frac{\mathrm{B}}{\mathrm{A}}$, the probable error becomes

$$
e=\frac{\sqrt{\left(\frac{\mathrm{B} a}{\mathrm{~A}}\right)^{2}+b^{2}}}{\mathrm{~A}}
$$


Given a proportion, $\mathrm{A}: \mathrm{B}: \mathrm{C}: x$, the probable error of the fourth term is as follows:

$$
e=\frac{\sqrt{\left(\frac{B C a}{A}\right)^{2}+(C b)^{2}+(B c)^{2}}}{A}
$$

This formula is used in nearly every atomic weight calculation, and is, therefore, exceptionally important. Rarely a more complicated case arises in a proportion of this kind:

$$
\mathrm{A}: \mathrm{B}:: \mathrm{C}+x: \mathrm{D}+x
$$

In this proportion the unknown quantity occurs in two terms. Its probable error is found by this expression, and is always large:

$$
e=\sqrt{\frac{(\mathrm{C}-\mathrm{D})^{2}}{(\mathrm{~A}-\mathrm{B})^{4}}\left(\mathrm{~B}^{2} a^{2}+\mathrm{A}^{2} b^{2}\right)+\frac{\mathrm{B}^{2} c^{2}+\mathrm{A}^{2} d^{2}}{(\mathrm{~A}-\mathrm{B})^{2}}}
$$

When several independent values have been calculated for an atomic weight they are treated like means, and combined according to formulæ (2) and (3). Each final result is, therefore, to be regarded as the general or weighted mean of all trustworthy determinations. This method of combination is not theoretically perfect, but it seems to be the one most available in practice.

\section{OXYGEN.}

The ratio between oxygen and hydrogen is the foundation upon which the entire system of atomic weights is sustained. Hence, the accuracy of its determination has, from the beginning, been recognized as of extreme importance. A trifling error here may become cumulative when repeated through a moderate series of other ratios. But few of the elements have, so far, been compared directly with the unit, hydrogen; practically all of them are referred to it through the intervention of oxygen, and therefore the ratio in question requires discussion before any other can be profitably considered.

Leaving out of account the earliest researches, which now have only historical value, the first determinations to be noted are those of Dulong and Berzelius,* who, like some of their successors, effected the synthesis of water over heated oxide of copper. The essential features of the method are in all cases the same. Hydrogen gas is passed over the hot oxide, and the water thus formed is collected and weighed. From this weight and the loss of weight which the oxide undergoes, the exact com- 
position of water is readily calculated. Dulong and Berzelius made but three experiments, with the following results for the percentages of oxygen and hydrogen in water:

O.

88.942

88.809

88.954
H.

11.058

II. I9'

$11.0+6$

From these figures we get, for the atomic weight of oxygen, the values-

$$
\begin{gathered}
16.124 \\
15.863 \\
16.106 \\
\frac{16.031}{\text { Mean, }} \pm .057
\end{gathered}
$$

As the weighings were not reduced to a vacuum, this correction was afterwards applied by Clark,* who showed that these syntheses really make $\mathrm{O}=15.894$; or, in Berzelian terms, if $\mathrm{O}=100, \mathrm{H}=12.583$. The value $15.894, \pm .057$ we may therefore take as the true result of Dulong and Berzelius' experiments, a result curiously close to that reached in the latest and best researches.

In 1842.Dumas $\dagger$ published his elaborate investigation upon the composition of water. The first point was to get pure hydrogen. This gas, evolved from zinc and sulphuric acid, might contain oxides of nitrogen, sulphur dioxide, hydrosulphuric acid, and arsenic hydride. These impurities were removed in a series of wash bottles; the $\mathrm{H}_{2} \mathrm{~S}$ by a solution of lead nitrate, the $\mathrm{H}_{3} \mathrm{As}$ by silver sulphate, and the-others by caustic potash. Finally, the gas was dried by passing through sulphuric acid, or, in some of the experiments, over phosphorus pentoxide. The copper oxide was thoroughly dried, and the bulb containing it was weighed. By a current of dry hydrogen all the air was expelled from the apparatus. and then, for ten or twelve hours, the oxide of copper was heated to dull redness in a constant stream of the gas. The reduced copper was allowed to cool in an atmosphere of hydrogen. The weighings were made with the bulbs exhausted of air. The following table gives the results:

Column A contains the symbol of the drying substance; B gives the weight of the bulb and copper oxide; $\mathrm{C}$, the weight of bulb and reduced copper; D, the weight of the vessel used for collecting the water; E, the same, plus the water; $F$, the weight of oxygen; $G$, the weight of water formed ; $\mathrm{H}$, the crude equivalent of $\mathrm{H}$ when $\mathrm{O}=10,000$; I, the equivalent of $\mathrm{H}$, corrected for the air contained in the sulphuric acid employed. This correction is not explained, and seems to be questionable. 


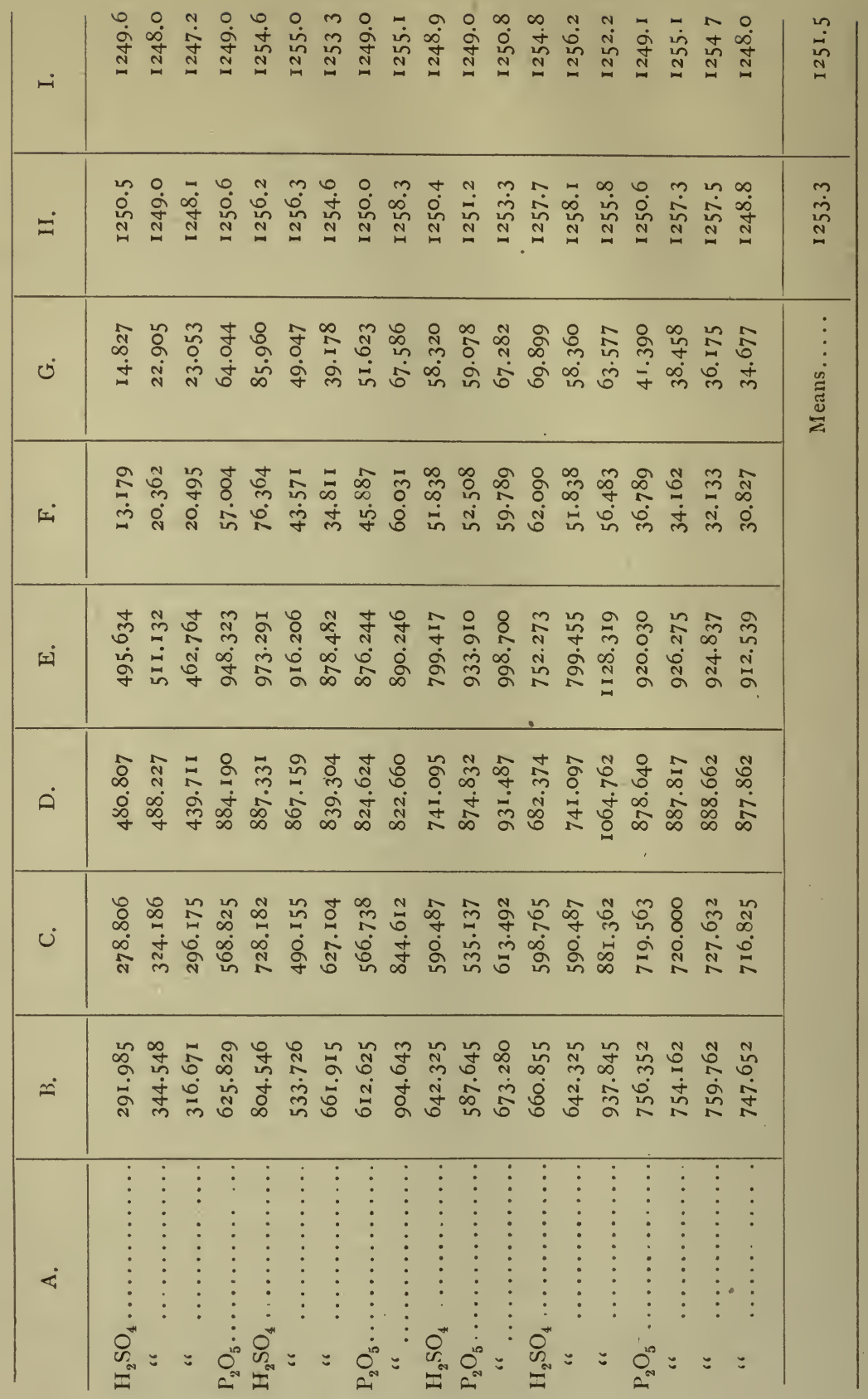


In the sum total of these nineteen experiments, 840.161 grammes of oxygen form 945.439 grammes of water. This gives, in percentages, for the composition of water-oxygen, 88.864; hydrogen, 11.136. Hence the atomic weight of oxygen, calculated in mass, is 15.9608. In the following column the values are deduced from the individual data given under the headings $\mathrm{F}$ and $\mathrm{G}$ :

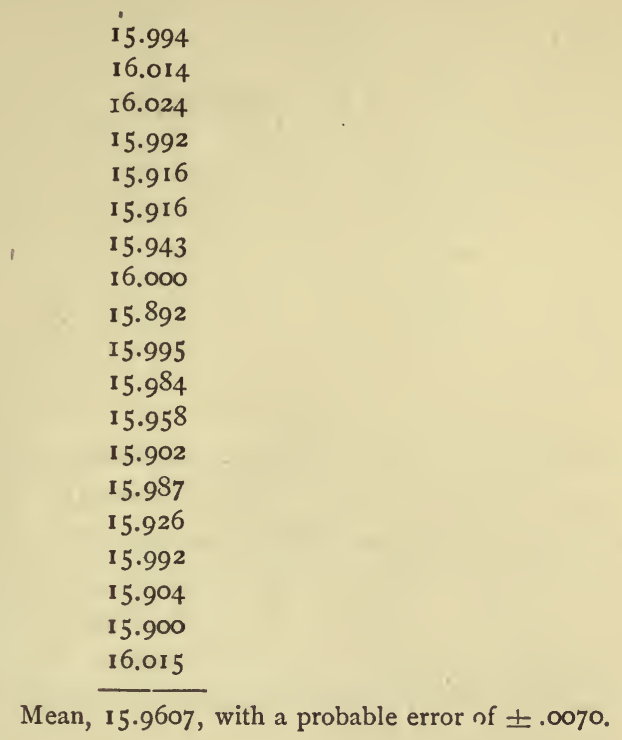

In calculating the above column several discrepancies were noted, probably due to misprints in the original memoir. On comparing columns $\mathrm{B}$ and $\mathrm{C}$ with $\mathrm{F}$, or $\mathrm{D}$ and $\mathrm{E}$ with $\mathrm{G}$, these anomalies chiefly appear. They were detected and carefully considered in the course of my own calculations; and, I believe, eliminated from the final result.

The investigation of Erdmann and Marchand $*$ followed closely after that of Dumas. The method of procedure was essentially that of the latter chemist, differing from it only in points of detail. The hydrogen used was prepared from zinc and sulphuric acid, and the zinc, which contained traces of carbon, was proved to be free from arsenic and sulphur. The copper oxide was made partly from copper turnings and partly by the ignition of the nitrate. The results obtained are given in two series, in one of which the weighings were not actually made in vacuo, but were, nevertheless, reduced to a vacuum standard. In the second series the copper oxide and copper were weighed in vacuo. The following table contains the corrected weights of water obtained and of the oxygen in it, with the value found for the atomic weight of oxygen in a third column. The weights are given in grammes. 
First Series.

$\begin{array}{ccc}\text { Wt. Water. } & \text { Wt. O. } & \text { At. Wt. O. } \\ 62.980 & 55.950 & \text { 15.917 } \\ 95.612 & 84.924 & \text { 15.891 } \\ 94.523 & 84.007 & \text { 15.977 } \\ 35.401 & 31.461 & \frac{15.970}{} \\ & & \text { Mean, } 15.939, \pm .014 \\ & \text { Second Series. } & \\ \text { Wt. Water. } & \text { Wt. O. } & \text { At. Wt. O. } \\ 41.664 & 37.034 & \text { I5.996 } \\ 44.089 & 39.195 & 16.018 \\ 53.232 & 47.321 & \text { 16.01 I } \\ 55.636 & 49.460 & \text { 16.017 } \\ & & \text { Mean, } 16.010, \pm .0036\end{array}$

The effect of discussing these two series separately is somewhat startling. It gives to the four experiments in Erdmann and Marchand's second group a weight vastly greater than their other four and Dumas' nineteen taken together. For so great a superiority as this there is no adequate reason; and it is highly probable that it is due almost entirely to fortunate coincidences, rather than to greater accuracy of work. We will, therefore, treat Erdmann and Marchand's experiments as one series, giving all equal weight, the mean now becoming $\mathrm{O}=15.975, \pm .0113$. If we take the sum of the eight experiments, 483.137 grammes water and 429.352 grammes oxygen, and compute from these figures, then $\mathrm{O}=15.966$.

It would be easy to point out the sources of error in the foregoing sets of determinations, but it is hardly worth while to do so in detail. A few leading suggestions are enough for present purposes. First, there is an insignificant error due to the occlusion of hydrogen by metallic copper, rendering the apparent weight of the latter a trifle too high. Secondly, as shown by Dittmar and Henderson, hydrogen dried by passage through sulphuric acid becomes perceptibly contaminated with sulphur dioxide. In the third place, Morley * has found that hydrogen prepared from zinc always contains carbon compounds not removable by absorption and washing. Erdmann and Marchand themselves note that their zinc contained traces of carbon. Finally, copper oxide, especially when prepared by the ignition of the nitrate, is very apt to contain gaseous impurities, and particularly occluded nitrogen. $\dagger$ Any or all of these sources of error may have vitiated the three investigations so far considered, but it would be useless to speculate as to the extent of their influence. They 
amply account, however, for the differences between the older and the later determinations of the constant under discussion.

Leaving out of account all measurements of the relative densities of hydrogen and oxygen, to be considered separately later, the next determination to be noted is that published by J. Thomsen in 1870.* Unfortunately this chemist has not published the details of his work, but only the end results. Partly by the oxidation of hydrogen over heated copper oxide, and partly by its direct union with oxygen, Thomsen finds that at the latitude of Copenhagen, and at sea level, one litre of dry hydrogen at $0^{\circ}$ and $760 \mathrm{~mm}$. pressure will form .8041 gramme of water. According to Regnault, at this latitude, level, temperature, and pressure, a litre of hydrogen weighs .08954 gramme. From these data, $\mathrm{O}=15.9605$. It will be seen at once that 'Thomsen's work depends in great part upon that of Regnault, and is therefore subject to the corrections recently applied by Crafts and others to the latter. These corrections, which will be discussed further on, reduce the value of $\mathrm{O}$ from 15.9605 to 15.91 . In order to combine this value with others, it is necessary to assign it weight arbitrarily, and as Thomsen made eight experiments, which are said to be concordant, it may be fair. to rank his determination with that of Erdmann and Marchand, and to assume for it the same probable error. The value $15.91, \pm .0113$ will therefore be taken as the outcome of Thomsen's research.

In 1887 Cooke and Richards published the results of their elaborate investigation. $\dagger$ 'These chemists weighed hydrogen, burned it over copper oxide, and weighed the water produced. The copper oxide was prepared from absolutely pure electrolytic copper, and the hydrogen was obtained from three distinct sources, as follows: First, from pure zinc and hydrochloric acid; second, by electrolysis, in a generator containing dilute hydrochloric acid and zinc-mercury amalgam; third, by the action of caustic potash solution upon sheet aluminum. The gas was dried and purified by passage through a system of tubes and towers containing potash, calcium chloride, glass beads drenched with sulphuric acid, and phosphorus pentoxide. No impurity could be discovered in it, and even nitrogen was sought for spectroscopically without being found.

The hydrogen was weighed in a glass globe holding nearly five litres and weighing 570.5 grammes, which was counterpoised by a second globe of exactly the same external volume. Before filling, the globe was exhausted to within $1 \mathrm{~mm}$. of mercury and weighed. It was then filled with hydrogen and weighed' again. The difference between the two weights gives the weight of hydrogen taken.

In burning, the hydrogen was swept from the globe into the combustion furnace by means of a stream of air which had previously been passed over hot reduced copper and hot cupric oxide, then through potash

* Berichte d. Deutsch. Chem. Gesell., I870, s. 928.

† Proc. Amer. Acad., 23, I49. Am. Chem. Journ., I0, 81. 
bulbs, and finally through a system of driers containing successively calcium chloride, sulphuric acid, and phosphorus pentoxide. The water formed by the combustion was collected in a condensing tube connected with a U tube containing phosphorus pentoxide. The latter was followed by a safety tube containing either calcium chloride or phosphorus pentoxide, added to the apparatus to prevent reflex diffusion. Full details as to the arrangement and construction of the apparatus are given. The final results appear in three series, representing the three sources from which the hydrogen was obtained. All weights are corrected to a vacuum.

First Series.-Hydrogen from Zinc and Acid.

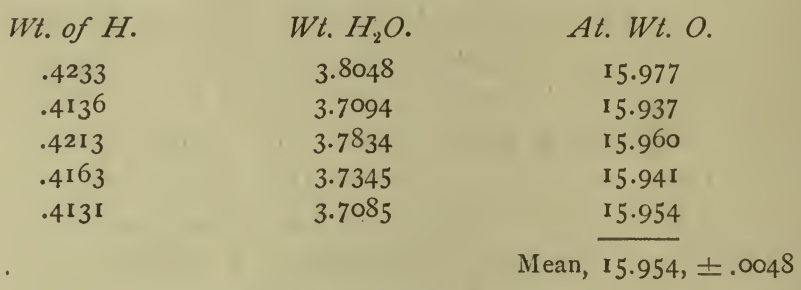

Second Series.-Electrolytic Hydrogen.

$\begin{array}{lll}.4112 & 3.6930 & 15.962 \\ .4089 & 3.6709 & 15.955 \\ .4261 & 3.8253 & 15.955 \\ .4197 & 3.7651 & 15.942 \\ .4144 & 3.7197 & 15.953 \\ & & \text { Mean, } 15.953, \pm .0022\end{array}$

Third Series.--Hydrogen from Aluminum.

\begin{tabular}{lll}
.42205 & 3.7865 & 15.943 \\
.4284 & 3.8436 & 15.944 \\
.4205 & 3.7776 & 15.967 \\
.43205 & 3.8748 & 15.937 \\
.4153 & 3.7281 & 15.954 \\
.4167 & 3.7435 & 15.967 \\
\cline { 2 - 2 } & & Mean, $15.952, \pm .0035$ \\
& Mean of all as one series, $15.953, \pm .0020$
\end{tabular}

Shortly after the appearance of this paper by Cooke and Richards Lord Rayleigh pointed out the fact, already noted by Agamennone, that a glass globe when exhausted is sensibly condensed by the pressure of the surrounding atmosphere. This fact involves a correction to the foregoing data, due to a change in the tare of the globe used, and this correction was promptly determined and applied by the authors.* By a

* Proc. Amer. Acad., 23, I82. Am. Chem. Journ., Io, I9I. 
careful series of measurements they found that the correction amounted to an average increase of 1.98 milligrammes to the weight of hydrogen taken in each experiment. Hence $\mathrm{O}$ equals not 15.953 , but 15.869 , the probable error remaining unchanged. The final result of Cooke and Richards' investigation, therefore, is

$$
\mathrm{O}=\mathrm{I} 5.869, \pm .0020 .
$$

Keiser's determinations of the atomic weight of oxygen were published almost simultaneously with Cooke and Richards'. He burned hydrogen occluded by palladium, and weighed the water so formed. In a preliminary paper* the following results are given:

$\begin{array}{ccc}W t . \text { of } H . & \text { Wt. of } \mathrm{H}_{2} \mathrm{O} . & \text { At. Wt. O. } \\ .65100 & 5.81777 & 15.873 \\ .60517 & 5.41540 & 15.897 \\ .33733 & 3.00655 & \mathrm{15.822} \\ & & \text { Mean, } \overline{\mathrm{r} 5.864}, \pm .015\end{array}$

Not long after the publication of the foregoing data Keiser's full paper appeared. $\dagger$ Palladium foil, warmed to a temperature of $250^{\circ}$, was satu. rated with hydrogen prepared from dilute sulphuric acid and zinc free from arsenic. From 100 to 140 grammes of palladium were taken, and it was first proved that the metal did not absorb other gases which might contaminate the hydrogen. Before charging, the foil was heated to bright redness in vacuo. After charging, the tube containing the palladium hydride was exhausted by means of a Geissler pump to remove any nitrogen which might have been present. In the preliminary investigation cited above, the latter precaution was neglected, which may account for the low results.

Between the palladium tube and the combustion tube a $U$ tube was interposed, containing phosphorus pentoxide. This was to determine the amount of moisture in the hydrogen. The combustion tube was filled with granular copper oxide, prepared by reducing the commercial oxide in hydrogen, heating the metal so obtained to bright redness in a vacuum, and then reoxidizing with pure oxygen.

Upon warming the palladium tube, which was first carefully weighed, hydrogen was given off and allowed to pass into the combustion tube. When the greater part of it had been burned, the tube was cut off by means of a stopcock and allowed to cool. Meanwhile a stream of nitrogen was passed through the combustion tube, sweeping hydrogen before it. This was followed by a current of oxygen, reoxidizing the reduced copper; and the copper oxide was finally cooled in a stream of dry air. The water produced by the combustion was collected in a weighed bulb tube, followed by a weighed U tube containing phosphorus pentoxide. 
A second phosphorus pentoxide tube served to prevent the sucking back of moisture from the external air. The loss in weight of the palladium tube, corrected by the gain in weight of the first phosphorus pentoxide, gave the weight of hydrogen taken. The gain in weight of the two collecting tubes gave the weight of water formed. All weights in the following table of results are reduced to a vacuum:

$W t$. of $H$.
.34145
.68394
.65529
.65295
.66664
.66647
.57967
.66254
.87770
.77215

$$
\begin{gathered}
\text { Wt. } \mathrm{H}_{2} \mathrm{O} . \\
3.06338 \\
6.14000 \\
5.88200 \\
5.86206 \\
5.98116 \\
5.9834 \mathrm{I} \\
5.20493 \\
5.94758 \\
7.86775 \\
6.93036
\end{gathered}
$$

At. Wt. $O$.

I 5.943

15.955

$15.95^{2}$

I 5.954

15.944

15.955

15.958

$15.95^{2}$

I 5.950

I 5.951

Mean, $\overline{15.9514} \pm .0011$.

In sum, 6.55880 grammes of hydrogen gave 52.30383 of water, whence $\mathrm{O}=15.9492$.

In March, 1889, Lord Rayleigh * published a few determinations of the atomic weight of oxygen obtained by still a new method. Pure hydrogen and pure oxygen were both weighed in glass globes. From these they passed into a mixing chamber, and thence into a eudiometer, where they were gradually exploded by a series of electric sparks. After explosion the residual gas remaining in the eudiometer was determined and measured. The results, given without weighings or explicit details, are as follows :

$$
\begin{gathered}
15.93 \\
15.98 \\
15.98 \\
15.93 \\
15.92 \\
\text { Mean, } 15.948, \pm .009
\end{gathered}
$$

Correcting this result for shrinkage of the globes and consequent change of tare, it becomes $\mathrm{O}=15.89, \pm .009$.

In the same month that Lord Rayleigh's paper appeared, Noyes $†$ published his first series of determinations. His plan was to pass hydrogen into an apparatus containing hot copper oxide, condensing the water formed in the same apparatus, and from the gain in weight of the latter getting the weight of the hydrogen absorbed. The apparatus devised for

* Proc. Roy. Soc., 45, 425 .

† Amer. Chem. Journ., II, I55. 1889. 
this purpose consisted essentially of a glass bulb of 30 to 50 cc. capacity, with a stopcock tube on one side and a sealed condensing tube on the other. In weighing, it was counterpoised by another apparatus of nearly the same volume but somewhat less weight, in order to obviate reductions to a racuum. After filling the bulb with commercial copper oxide (90 to 150 grammes), the apparatus was heated in an airbath, exhausted by means of a Sprengel pump, cooled, and weighed. It was next replaced in the airbath, again heated, and connected with an apparatus delivering purified hydrogen. When a suitable amount of the latter had been admitted, the stopcock was closed, and the heating continued long enough to convert all gaseous hydrogen within it into water. The apparatus was then cooled and weighed, after which it was connected with a Sprengel pump, in order to extract the small quantity of nitrogen which was always present. The latter was pumped out into a eudiometer, where it was measured and examined. The gain in weight of the apparatus, less the weight of this very slight impurity, gave the weight of hydrogen oxidized.

The next step in the process consisted in heating the apparatus to expel water, and weighing again. After this, pure oxygen was admitted and the heating was resumed, so as to oxidize the traces of hydrogen which had been retained by the copper. Again the apparatus was cooled and weighed, and then reheated, when the water formed was received in a bulb filled with phosphorus pentoxide, and the gaseous contents were collected in a eudiometer. On cooling and weighing the apparatus, the loss of weight, less the weight of gases pumped out, gave the amount of water produced by the traces of residual hydrogen under consideration. This weight, added to the loss of weight when the original water was expelled, gives the weight of oxygen taken away from the copper oxide. Having thus the weight of hydrogen and the weight of oxygen, the atomic weight sought for follows. Six results are given, but as they are repeated, with corrections, in Noyes' second paper, they need not be considered now.

Noyes' methods were almost immediately criticised by Johnson,* who suggested several sources of error. This chemist had already shown in an earlier paper $\dagger$ that copper reduced in hydrogen persistently retains traces of the latter, and also that when the reduction is effected below $700^{\circ}$, water is retained too. The possible presence of sulphur in the copper oxide was furthermore mentioned. Errors from these sources would tend to make the apparent atomic weight of oxygen too low.

In his second paper $\ddagger$ Noyes replies to the foregoing criticisms, and shows that they carry no weight, at least so far as his work is concerned. He also describes a number of experiments in which oxides other than copper oxide were tried, but without distinct success, and he gives fuller 
details as to manipulations and materials. His final results are in four series, as follows:

First Series.-Hydrogen from Zinc and Hydrochloric Acid.

$\begin{array}{ccc}W t . \text { of } H . & \text { Wt. of } O . & \text { At. Wt. O. } \\ .9443 & 7.5000 & 15.885 \\ .6744 & 5.3555 & 15.882 \\ .7866 & 6.2569 & 15.909 \\ .5521 & 4.3903 & 15.904 \\ .4274 & 3.3997 & 15.909 \\ .8265 & 6.5686 & 15.895 \\ & & -\frac{1}{15.8973} \pm .0032 .\end{array}$

This series appeared in the earlier paper, but with an error which is here corrected.

Second Series.-Electrolytic Hydrogen, Dried by Phosphorus Pentoxide.

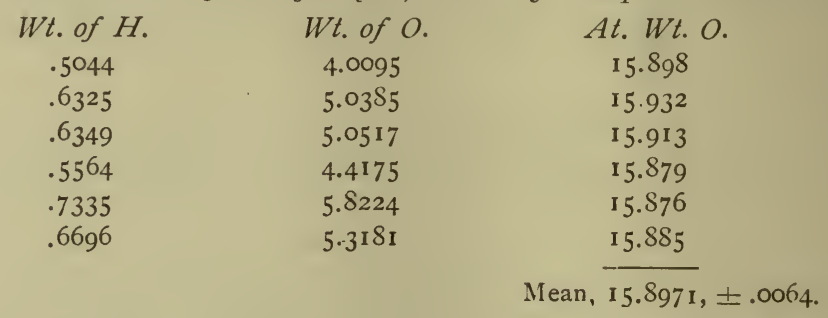

Third Series.-Electrolytic Hydrogen, Dried by Passage Through a Tube Packed with Sodium Wire.

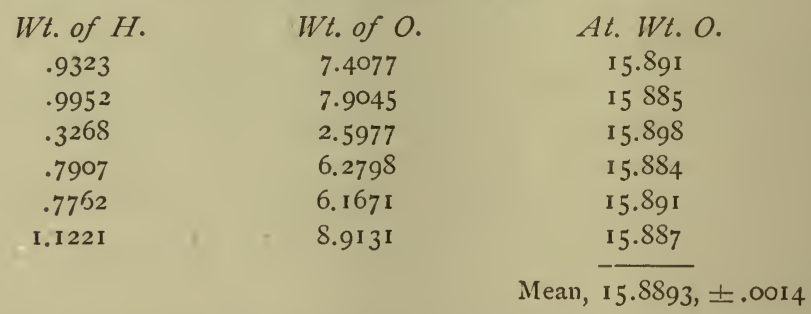

At the end of this series it was found that the hydrogen contained a trace of water, estimated to be equivalent to an excess of three milligrammes in the total hydrogen of the six experiments. Correcting for this, the mean becomes $\mathrm{O}=15.859$.

Fourth Series.-Electrolytic Hydrogen, Dried over Freshly Sublimed Phosphorus Pentoxide.

$\begin{array}{ccc}\text { Wt. of } H . & \text { Wt. of } O . & \text { At. Wt. O. } \\ 1.0444 & 8.3017 & 15.898 \\ .7704 & 6.1233 & 15.896 \\ .8231 & 6.5421 & 15.896 \\ .8872 & 7.0490 & 15.890 \\ .9993 & 7.9403 & 15.892 \\ 1.1910 & 9.4595 & 15.885 \\ & & -\frac{15.8929,}{} \pm .0013\end{array}$


The mean of all the twenty-four determinations, taken as one series, with the correction to the third series included, is $\mathrm{O}=15.8966, \pm .0017$. In sum, there were consumed 18.5983 grammes of hydrogen and 147.8145 of oxygen; whence $\mathrm{O}=15.8955$.

Dittmar and Henderson,* who effected the synthesis of water over copper oxide by what was essentially the old method, begin their memoir with an exhaustive criticism of the work done by Dumas and by Erdmann and Marchand. They show, as I have already mentioned, that hydrogen dried by sulphuric acid becomes contaminated with sulphur dioxide, and also that a gas passed over calcium chloride may still retain as much as one milligramme of water per litre. Fused caustic potash they found to dry a gas quite completely.

In their first series of syntheses, Dittmar and Henderson generated their hydrogen from zinc and acid, sometimes hydrochloric and sometimes sulphuric, and dried it by passage, first through cotton wool, then through vitrioled pumice, then over red-hot metallic copper to remove oxygen. In later experiments it first traversed a column of fragments of caustic soda to remove antimony derived from the zinc. The oxide of copper used was prepared by heating chemically pure copper clippings in a muffle, and was practically free from sulphur. In weighing the several portions of apparatus it was tared with somewhat lighter similar pieces of as nearly as possible the same displacement. The results of this series of experiments, which are vitiated by the presence, unsuspected at first, of sulphur dioxide in the hydrogen, are stated in values of $\mathrm{H}$ when $\mathrm{O}=16$, but in the following table.have been recalculated to the usual unit:

\begin{tabular}{|c|c|c|}
\hline Wt. of Water. & Wt. of $O$. & At. Wt. O. \\
\hline 4.7980 & 4. 26195 & 15.901 \\
\hline 7.55025 & 6.71315 & I 6.039 \\
\hline 6.2372 & $5 \cdot 53935$ & I 5.875 \\
\hline I 1.29325 & 10.03585 & I 5.963 , \\
\hline 11.6728 & I0.371 5 & 15.940 \\
\hline I 1.8433 & $10.5^{2} 5^{6}$ & I 5.976 \\
\hline 11.7317 & 10.4243 & 15.947 \\
\hline 19.2404 & 17.0926 & I 5.916 \\
\hline 20.83435 & 18.5234 & $16.03 I$ \\
\hline I 7.40235 & $15.459^{8}$ & I 5.917 \\
\hline $19.263 \mathrm{I}$ & 17.11485 & I 5.934 \\
\hline
\end{tabular}

Reducing to a vacuum, this becomes 15.843 , while a correction for the sulphur dioxide estimated to be present in the hydrogen brings the value 
up again to 15.865. Still another correction is suggested, namely, that as the reduced copper in the combustion tube, before weighing, was exposed to a long-continued current of dry air, it may have taken up traces of oxygen chemically, thereby increasing its weight. As this correction, however, is quantitatively uncertain, it may be neglected here, and the result of this series will be taken as $\mathrm{O}=15.865, \pm .0103$. Its weight, relatively to some other series of experiments, is evidently small.

In their second and final series. Dittmar and Henderson dried their hydrogen, after deoxidation by red-hot copper, over caustic potash and subsequently phosphorus pentoxide. The copper oxide and copper of the combustion tube were both weighed in vacuo. The results were as follows, vacuum weights being given:

$\begin{array}{ccc}\text { Wt. Water. } & \text { Wt. O. } & \text { At. Wt. O. } \\ 19.2057 & 17.0530 & 15.843 \\ 19.5211 & 17.3342 & {[15.853]} \\ 19.4672 & 17.2882 & 15.868 \\ 22.9272 & 20.3540 & 15.820 \\ 23.0080 & 20.4421 & {[15.934]} \\ 23.4951 & 20.8639 & 15.859 \\ 23.5612 & 20.9226 & {[15.859]} \\ 23.7542 & 21.0957 & 15.870 \\ 23.6568 & 21.8994 & 15.884 \\ 23.6179 & 21.8593 & 15.848 \\ 24.6021 & 21.8499 & 15.878 \\ 24.3047 & 21.5788 & 15.832 \\ 23.6172 & 20.9709 & \\ & & \text { Mean, } 15.861, \pm .0052 .\end{array}$

The authors reject the three bracketed determinations, because of irregularities in the course of the experiments. The mean of the ten remaining determinations is $15.855, \pm .0044$. Both means, however, have to be corrected for the minute trace of hydrogen occluded by the reduced copper. This correction, experimentally measured, amounts to +.006 . Hence the mean of all the experiments in the series becomes $15.867, \pm .0052$, and of the ten accepted experiments, $15.861, \pm .0044$. The authors themselves select out seven experiments, giving a corrected mean of 15.866 , which they regard as the best value. Taking all their evidence, their two series combine thus:

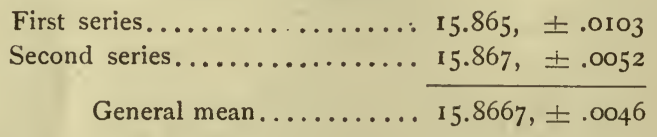

Leduc,* who also effected the synthesis of water over copper oxide, 
following Dumas' method with slight modifications, gives the results of only two experiments, as follows:

$\begin{array}{ccc}\text { Wt. Water. } & \text { Wt. O. } & \text { At. Wt. O. } \\ 22.16_{32} & 19.6844 & 15.882 \\ 19.7403 & 17.5323 & \text { I5.880 } \\ & & \text { Mean, } \overline{15.881}\end{array}$

These experiments we may arbitrarily assign equal weight with two in Dittmar and Henderson's later series, when the result becomes $15.881, \pm .0132$, the value to be accepted. Leduc states that his copper oxide, which was reduced at as low a temperature as possible, was prepared by heating clippings of electrolytic copper in a stream of oxygen.

To E. IV. Morley * we owe the first complete quantitative syntheses of water, in which both gases were weighed separately, and afterwards in combination. The hydrogen was weighed in palladium, as was done by Keiser, and the oxygen was weighed in compensated globes, after the manner of Regnault. The globes were contained in an artificial "cave," to protect them from moisture and from changes of temperature; being so arranged that they could be weighed by the method of reversals without opening either the "cave" or the balance case. For each weighing of hydrogen about 600 grammes of palladium were employed. After weighing, the gases were burnt by means of electric sparks in a suitable apparatus, from which the unburned residue could be withdrawn for examination. Finally, the apparatus containing the water produced was closed by fusion and also weighed. Rubber joints were avoided in the consiruction of the apparatus, and the connections were continuous throughout. The weights are as follows:

\begin{tabular}{ccc}
$H$ taken & O taken. & $\mathrm{H}_{2} \mathrm{O}$ formed. \\
3.2645 & $25.9 ! 76$ & 29.1788 \\
3.2559 & $25.853 \mathrm{I}$ & 29.1052 \\
3.8193 & $30.32 \mathrm{IO}$ & 34.1389 \\
3.8450 & 30.5294 & Lost \\
3.8382 & 30.4700 & $34.315 \mathrm{I}$ \\
3.8523 & 30.5818 & 34.4327 \\
3.8298 & 30.4013 & 34.2284 \\
3.8286 & 30.3966 & $34.226 \mathrm{I}$ \\
3.8225 & 30.3497 & $34 \mathrm{I} 742$ \\
3.8220 & 30.3479 & 34.1743 \\
3.7637 & 29.8865 & 33.6540 \\
$3.82 \mathrm{I}$ & 30.3429 & 34.1559 \\
\hline
\end{tabular}

* "On the Density of Oxygen and Hydrogen, and on the Ratio of their Atomic Weights," by Edward W. Morley. Smithsonian Contributions to Knowledge, I895, 4to, xi +.II7 pp., 40 cuts. Abstract in Am. Chem. Journ., 17, 267 (gravimetric), and Ztschr. Phys. Chem., 17, 87 (gaseous densities); also note in Am. Chem. Journ., 17, 396. Preliminary notice in Proc. Amer. Association, I89i, p. I85. 
Hence we have-

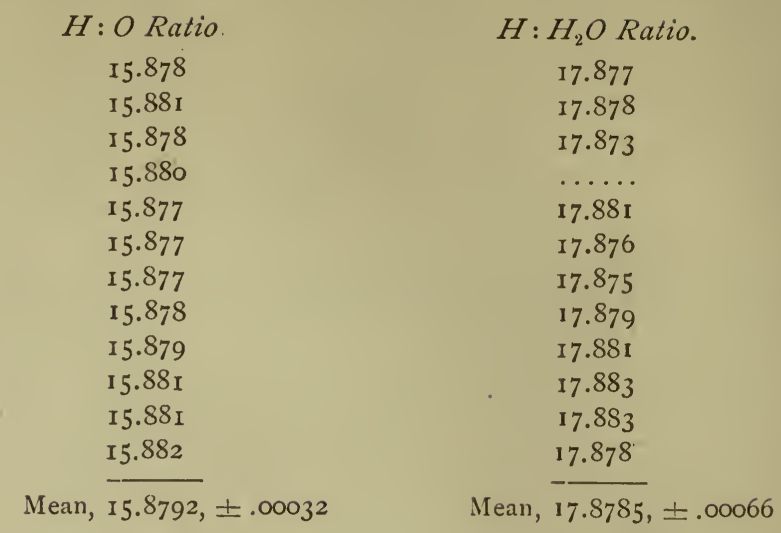

Combined, these data give:

$$
\begin{aligned}
& \text { From ratio } \mathrm{H}_{2}: \mathrm{O} . \ldots \ldots \mathrm{O}=15.8792, \pm .00032 \\
& \text { " } \mathrm{H}_{2}: \mathrm{H}_{2} \mathrm{O} \ldots \ldots . \mathrm{O}=15.8785, \pm .00066 \\
& \text { General mean..... } \mathrm{O}=15.8790, \pm .00028
\end{aligned}
$$

For details, Morley's full paper must be consulted. No abstract can do justice to the remarkable work therein recorded.

Two other series of determinations, by Julius Thomsen, remain to be noticed.' In the earlier paper* he determined the ratio between $\mathrm{HCl}$ and $\mathrm{NH}_{3}$, and thence, using Stas' values for $\mathrm{Cl}$ and $\mathrm{N}$, fixed by reference to $\mathrm{O}=16$, computed the ratio $\mathrm{H}: \mathrm{O}$. This method was so indirect as to be of little importance, and gave for the atomic weight of oxygen approximately the round number 16 . I shall use the data farther on in calculating the atomic weight of nitrogen. The paper has been sufficiently criticised by Meyer and Seubert, $\uparrow$ who have discussed its sources of error.

In Thomsen's later paper $\ddagger$ a method of determination is described which is, like the preceding, quite novel, but more direct. First, aluminum, in weighed quantities, was dissolved in,caustic potash solution. In one set of experiments the apparatus was so constructed that the hydrogen evolved was dried and then expelled. The loss of weight of the apparatus gave the weight of the hydrogen so liberated. In the second set of experiments the hydrogen passed into a combustion chamber in which it was burned with oxygen, the water being retained. The increase in weight of this apparatus gave the weight of oxygen so taken up. The two series, reduced to the standard of a unit weight of aluminum, gave the ratio between oxygen and hydrogen.

*Zeitsch. Physikal. Chem., 13, 398. 1894. 
The results of the two series, reduced to a vacuum and stated as ratios, are as follows :

First.

Weight of $\mathrm{H}$.

Weight of $\mathrm{Al}$.

0.11180

0.11175

0.11194

0.11205

0.11189

Ọ. II 200

O.III 94

O.III75

O.III 190

O. I I I 82

O.II 204

0. 11202

O. II 204

O. III 79

O. 11178

O. II 202

O. I I I 88

0. 1 I 186

0. 11185

O. I I I 90

O. III 87

$0 . \operatorname{III} 90, \pm 0.000015$
Second.

Weight of $\mathrm{O}$.

0.88788

0.88799

0.88774

0.88779

0.88785

0.88789

c. 88798

0.88787

0.88773

0.88798

0.88785

$0.88787, \pm 0.000018$

Dividing the mean of the second column by the mean of the first, we have for the equivalent of oxygen :

$$
\frac{0.88787, \pm 0.000018}{0.11190, \pm 0.000015}=7.9345, \pm 0.001 \mathrm{I}
$$

Hence $\mathrm{O}=15.8690, \pm 0.0022$.

The details of the investigation are somewhat complicated, and involve various corrections which need not.be considered here. The result as stated includes all corrections and is evidently good. The ratios, however, cannot be reversed and used for measuring the atomic weight of aluminum, because the metal employed was not absolutely pure.

We have now before us, representing syntheses of water, thirteen series, as follows:

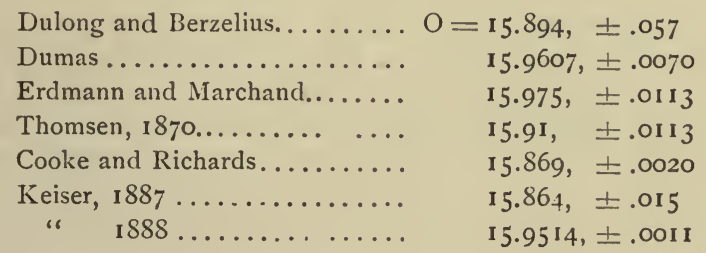




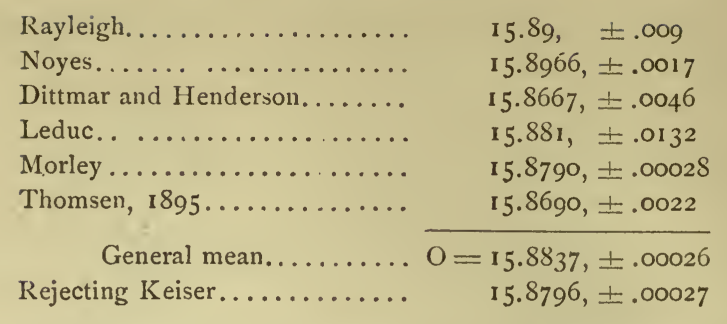

If we reject all except the determinations of Cooke and Richards, Rayleigh, Noyes, Dittmar and Henderson, Leduc, Thomsen, and Morley, the general mean of these becomes $15.8794, \pm .00027$. From this it is evident that Keiser's determinations alone, among the higher values for $\mathrm{O}$, carry any appreciable weight; and it also seems clear that the roundedoff number, $\mathrm{O}=15.88, \pm .0003$, cannot be very far from the truth; at least so far as the synthetic evidence goes.

In discussing the relative densities of oxygen and hydrogen gases we need consider only the more modern determinations, beginning with those of Dumas and Boussingault. As the older work has some historical value, I may in passing just cite its results. For the density of hydrogen we have .0769, Lavoisier; .0693, Thomson; .092, Cavendish; .0732 , Biot and Arago ; .0688, Dulong and Berzelius. For̈ oxygen there are the following determinations: 1.087 , Fourcroy, Vauquelin, and Séguin; 1.103, Kirwan; 1.128, Davy; 1,088, Allen and Pepys; 1.1036 , Biot and Arago ; 1.1117, Thomson; 1.1056, De Saussure; 1.1026, Dulong and Berzelius; 1.106, Buff; 1.1052, Wrede.*

In 1841 Dumas and Boussingault $\dagger$ published their determinations of gaseous densities. For hydrogen they obtained values ranging from .0691 to .0695 ; but beyond this mere statement they give no details. For oxygen three determinations were made, with the following results:

$$
\begin{aligned}
& \text { I. } 1055 \\
& \text { I. } 1058 \\
& \text { 1. } 1057 \\
& \text { Mean, } \overline{1.10567}, \pm .00006
\end{aligned}
$$

If we take the two extreme values given above for hydrogen, and regard them as the entire series, they give us a mean of $.0693, \pm .00013$. This mean hydrogen value, combined with the mean for oxygen, gives for the latter, when $\mathrm{H}=1$, the density ratio $15.9538, \pm .031$.

Regnault's researches, published four years later, $\ddagger$ were much more

\footnotetext{
* For Wrede's work, see Berzelius' Jahresbericht for 1843. For Dulong and Berzelius, see the paper already cited. All the other determinations are taken from Gmelin's Handbook, Cavendish edition, v. I, p. 279.

† Compt. Rend., 12, roo5. Compare also with Dumas, Compt. Rend., 14, 537.

$\ddagger$ Compt. Rend., 20, 975 .
} 
elaborately executed. Indeed, they have long stood among the classics of physical science, and it is only recently that they have been supplanted by other measurements.

For hydrogen three determinations of density gave the following results :

$$
\begin{gathered}
.06923 \\
.06932 \\
.06924 \\
-\frac{.069263}{\text { Mean, }} .0692000019
\end{gathered}
$$

For oxygen four determinations were made, but in the first one the gas was contaminated by traces of hydrogen, and the value obtained, 1.10525 , was, therefore, rejected by Regnault as too low. The other three are as follows:

$$
\begin{aligned}
& \text { I. } 1056 \mathrm{I} \\
& \text { I. } 10564 \\
& \text { I. } 10565 \\
& \text { Mean, } \overline{\text { 1.105633 }} \pm .000008
\end{aligned}
$$

Now, combining the hydrogen and oxygen series, we have the ratio $\mathrm{H}: \mathrm{O}:: 1: 15.9628, \pm .0044$. A ccording to Le Conte, ${ }^{*}$ Regnault's reductions contain slight numerical errors, which, corrected, give for the density of oxygen, 1.105612, and for hydrogen, .069269. Ratio, $1: 15.9611$.

A much weightier correction to Regnault's data has already been indicated in the discussion of Cooke and Richards' work. He assumed that the globes in which the gases were weighed underwent no changes of volume, but Agamennone, $\dagger$ and after him, but independently, $\$$ Lord Rayleigh showed that an exhausted vessel was perceptibly compressed by atmospheric pressure. Hence its volume when empty was less than its volume when filled with gas. Crafts, having access to Regnault's original apparatus, has determined the magnitude of the correction indicated.§ Unfortunately, the globe actually used by Regnault had been destroyed, but another globe of the same lot was available. With this the amount of shrinkage during exhaustion was measured, and Regnault's densities were thereby changed to 1.10562 for oxygen, and .06949 for hydrogen. Corrected ratio, $1: 15.9105$. Doubtless Dumas and Boussingault's data are subject to a similar correction, and if we assume that it is proportionally the same in amount, the ratio derived from their experiments becomes $1: 15.9015$.

In the same paper, that which contained the discovery of this correction, Lord Rayleigh gives a short series of measurements of his own.

* Private communication. See also Phil. Mag. (4), 27, 29, 1864, and Smithsonian Report, I878, p. 428 .

† Atti Rendiconti Acad. Lincei, 1885.

‡ Proc. Roy. Soc., 43, 356. Feb., 1888.

\& Compt. Rend., 106, 1662. 
His hydrogen was prepared from zinc and sulphuric acid, and was purified by passage over liquid potash, then through powdered mercuric chloride, and then through pulverized solid potash. It was dried by means of phosphorus pentoxide. His oxygen was derived partly from potassium chlorate, and partly from the mixed chlorates of sodium and potassium. Equal volumes of the two gases weighed as follows:

$$
\begin{array}{cc}
H . & O . \\
.15811 & 2.5186, \pm .0006 I^{*} \\
.15807 & \\
.15798 & \\
.15792 & \\
\text { Mean, } & .15802, \pm 000029 .
\end{array}
$$

Corrected for shrinkage of the exhausted globe these become- $\mathrm{H}$, $0.15860 ; 0,2.5192$. Hence the ratio $1: 15.884, \pm .0048$.

In 1892 Rayleigh published a much more elaborate determination of this ratio. $\dagger$ The gases were prepared electrolytically from caustic potash, and dried by means of solid potash and phosphorus pentoxide. The hydrogen was previously passed over hot copper. The experiments, stated like the previous series, are in five groups; two for oxygen and three for hydrogen; but for present purposes the similar sets may be regarded as equal in weight, and so discussable together. The weights of equal volumes are as follows:

$$
\begin{aligned}
& H \text {. } O \text {. } \\
& \text { First set }\left\{\begin{array}{ll}
.15807 & 2.5182 \\
.15816 & 2.5173 \\
.15811 & 2.5172 \\
.15803 & 2.5193 \\
.15801 & 2.5174 \\
.15809 & 2.5177
\end{array}\right\} \text { First set. } \\
& \text { Third set }\left\{\begin{array}{l}
.15807 \\
.15801 \\
.15817 \\
.15790 \\
.15810 \\
.15798 \\
.15802 \\
.15807 \\
\text { Mean, .15804 } \\
\text { Mean, } 15804, \pm .000019 .
\end{array}\right.
\end{aligned}
$$

* Arbitrarily assigned the probable error of a single experiment in Rayleigh's paper of 1892 . † Proc. Roy. Soc., 50, 448, Feb. 18, 1892. 
These weights with various corrections relative to temperatures and pressures, and also for the compression of the exhausted globe, ultimately become for $\mathrm{H}, .158531$; and for $\mathrm{O}, 2.51777$. Hence the ratio $1: 15.882$, \pm .0023 . For details relative to corrections the original memoir should be consulted.

In his paper "On a new method of determining gas densities," * Cooke gives three measurements for hydrogen, referred to air as unity. They are:

$$
\begin{aligned}
& .06957 \\
& .0695 \text { I } \\
& .06966 \\
& \text { Mean, } \overline{.05958}, \pm .000029
\end{aligned}
$$

Combining this with Regnault's density for oxygen, as corrected by Crafts, $1.10562, \pm .000008$, we get the ratio $\mathrm{H}: \mathrm{O}:: 1: 15.890, \pm .0067$.

Leduc, working by Regnault's method, somewhat modified, and correcting for shrinkage of exhausted globes, gives the following densities $: \uparrow$

$H$.

.06947

.06949

Mean, $\frac{.06947}{.06948}, \pm .00006745$
0.

I. 10501

1. 10516

The two oxygen measurements are the extremes of three, the mean being $1.10506, \pm .0000337$. Hence the ratio $1: 15.905, \pm .0154$.

The first two hydrogen determinations were made with gas produced by the electrolysis of caustic potash, while the third sample was derived from zinc and sulphuric acid. The oxygen was electrolytic. Both gases were passed over red-hot platinum sponge, and dried by phosphorus pentoxide.

Much more elaborate determinations of the two gaseous densities are those made by Morley. $\$$ For oxygen he gives three series of data; two with oxygen from potassium chlorate, and one with gas partly from the same source and partly electrolytic. In the first series, temperature and pressure were measured with a mercurial thermometer and a manobarometer. In the second series they were not determined for each experiment, but were fixed by comparison with a standard volume of hydrogen by means of a differential manometer. In the third series the gas was kept at the temperature of melting ice, and the mano-barometer

* Proc. Amer. Acad., 24, 202. 1889. Also Am. Chem. Journ., II, 509.

$\ddagger$ Paper already cited, under the gravimetric portion of this chapter. 
alone was read. The results for the weight in grammes, at latitude $45^{\circ}$, of one litre of oxygen are as follows:

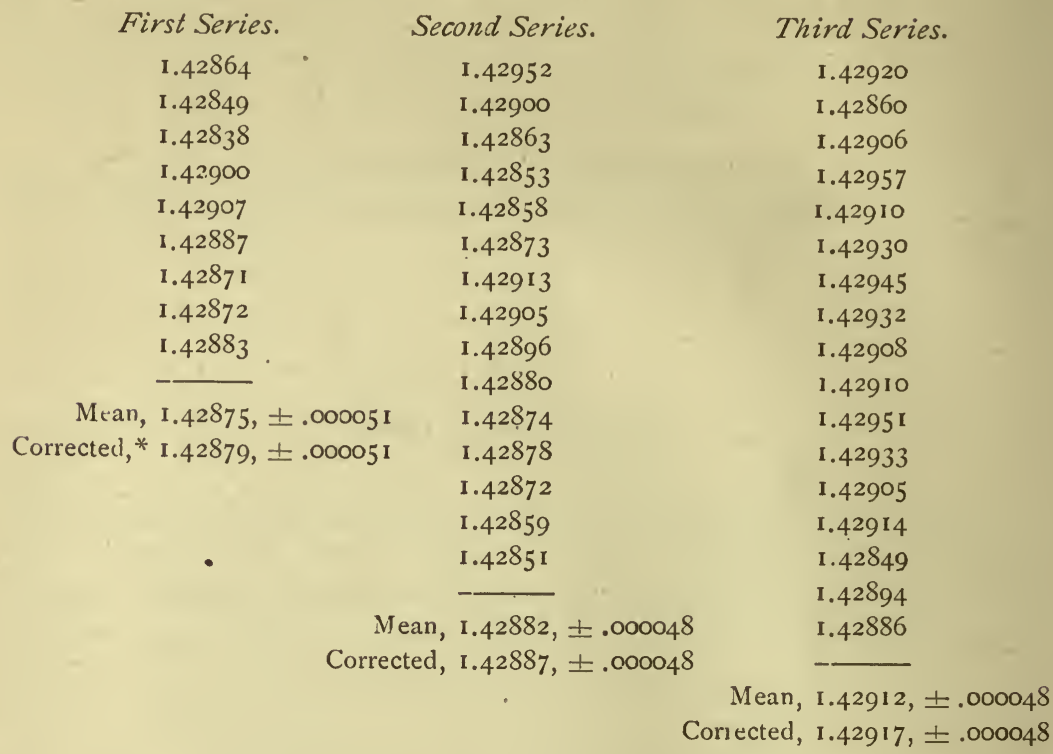

General mean of all three series, $1.42896, \pm .000028$.

Morley himself, for experimental reasons, prefers the last series, and gives it double weight, getting a mean density of 1.42900 . The difference between this mean and that given above is insignificant with reference to the atomic weight problem.

In the case of hydrogen, Morley's determinations fall into two groups, but in both the gas was prepared by the electrolysis of pure dilute sulphuric acid, and was most elaborately purified. In the first group there are two series of measurements. Of these, the first involved the reading of temperature and pressure by means of a mercurial thermometer and mano-barometer. In the second series, the gas was delivered into the weighing globes after occlusion in palladium; it was then kept at the temperature of melting ice, and only the syphon barometer was read. In this group the hydrogen was possibly contaminated with mercurial vapor, and the results are discarded by Morley in his final summing up. For present purposes, however, it is unnecessary to reject them, for they have confirmatory value, and do not appreciably affect the final mean. The weight of one litre of hydrogen at $45^{\circ}$ latitude, as found in these two sets of determinations, is as follows:

* Correction applied by Morley to all his series, for a slight error, $\frac{1}{3000 \overline{0}}$, in the length of his standard metre bar. 


\begin{tabular}{cc} 
First Series. & Second Series. \\
.089904 & .089977 \\
.089936 & .089894 \\
.089945 & .089987 \\
.089993 & .089948 \\
.089974 & .089951 \\
.089941 & .089960 \\
.089979 & .090018 \\
.089936 & .089909 \\
.089904 & .089953 \\
.089863 & .089974 \\
.089878 & .089922 \\
.089920 & .090093 \\
.089990 & .090007 \\
.089926 & .089899 \\
.089928 & .089974 \\
\hline Mean, & $.089934, \pm .000007$ \\
$.089938, \pm .000007$ & .089900 \\
& .089869 \\
Corrected, & .090144 \\
& .089984 \\
\hline & Corrected, \\
& $.089970, \pm .000011$
\end{tabular}

In the second group of experiments, the hydrogen was weighed in palladium before transfer to the calibrated globe; and in weighing, the palladium tube was tared by a similar apparatus of nearly equal volume and weight. After transfer, which was effected without the intervention of stopcocks, the volume and pressure of the gas were taken at the temperature of melting ice. A preliminary set of measurements was made, followed by three regular series; of these, the first and second were with the same apparatus, and are different only in point of time, a vacation falling between them. The last series was with a different apparatus. The data are as follows, with the means as usual:

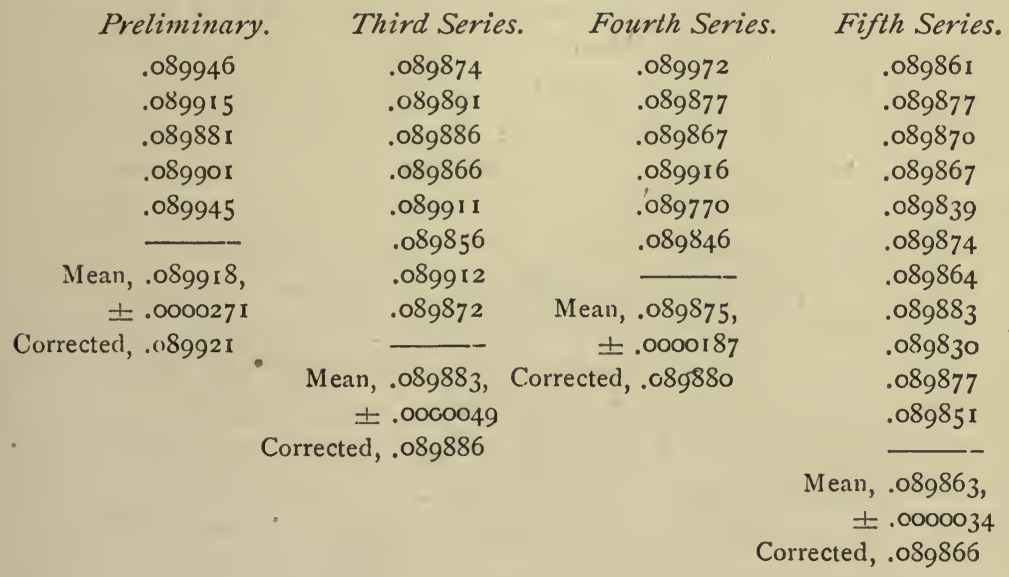


Now, rejecting nothing, we may combine all the series into a general mean, giving the weight of one litre of hydrogen as follows :

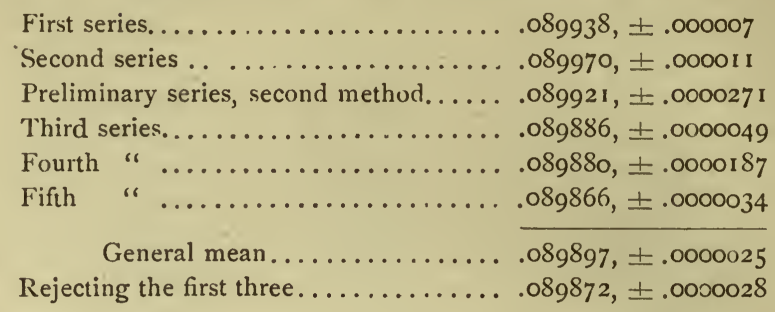

This last mean value for hydrogen will be used in succeeding chapters of this work for reducing volumes of the gas to weights. Combining the general mean of all with the value found for the weight of a litre of oxygen, $1.42896, \pm .000028$, we get for the ratio $\mathrm{H}: \mathrm{O}$,

$$
\mathrm{O}=\mathrm{I} 58955, \pm .0005
$$

If we take only the second mean for $\mathrm{H}$, excluding the first three series, we have-

$$
\mathrm{O}=15.900 \mathrm{I}, \pm .0005
$$

This value is undoubtedly nearest the truth, and is preferable to all other determinations of this ratio. Its probable error, however, is given too low; for some of the oxygen weighings involved reductions for temperature and pressure. These reductions involve, again, the coefficient of expansion of the gas, and its probable error should be included. Since, however, that factor has been disregarded elsewhere, it would be an overrefinement of calculation to include it here.

In a memoir of this kind it is impossible to do full justice to so elaborate an investigation as that of Morley. The details are so numerous, the corrections so thorough, the methods for overcoming difficulties so ingenious, that many pages would be needed in order to present anything like a satisfactory abstract. Hardly more than the actual results can be cited here; for all else the original memoir must be consulted.

Still more recently, by a novel method, J. Thomsen has measured the two densities in question.* In his gravimetric research, already cited, he ascertained the weights of hydrogen and of oxygen equivalent to a unit weight of aluminum. In his later paper he describes a method of measuring the corresponding volumes of both gases during the same reactions. Then, having already the weights of the gases, the volumeweight ratio, or density, is in each case easily computat)le. From 1.0171 to 2.3932 grammes of aluminum were used in each experiment. Omitting details, the volume of hydrogen in litres, equivalent to one gramme of the metal, is as follows: 


$$
\begin{gathered}
1.24297 \\
1.24393 \\
1.24286 \\
1.24271 \\
1.24283 \\
1.24260 \\
1.24314 \\
1.24294 \\
\text { Mean, } \frac{1.24289}{1.00004}
\end{gathered}
$$

The weight of hydrogen evolved from one gramme of aluminum was found in Thomsen's gravimetric research to be $0.11190, \pm .000015$. Hence the weight of one litre at $0^{\circ}, 760 \mathrm{~mm}$., and 10.6 meters above sea level at Copenhagen is :

$$
.090032, \pm .000012
$$

or at sea level in latitude $45^{\circ}$,

$$
.089947, \pm .000012 \text { gramme. }
$$

The data for oxygen are given in somewhat different form, namely, for the volume of one gramme of the gas at $0^{\circ}, 760$, and at Copenhagen. The values are, in litres:

$$
\begin{array}{r}
.69902 \\
.69923 \\
.69912 \\
.69917 \\
.69903 \\
.69900 \\
.69901 \\
.69921 \\
.69901 \\
.69922 \\
\frac{.69910, \pm .00002}{\text { Mean, }} \\
\text { At sea level in latitude } 45^{\circ}, .69976, \pm .00002
\end{array}
$$

Hence one litre weighs $1.42906, \pm .00004$ grammes.

Dividing this by the weight found for hydrogen, $0.089947, \pm .000012$ we have for the ratio $\mathrm{H}: \mathrm{O}$,

$$
15.8878, \pm .0022 \text {. }
$$

The density ratios, $\mathrm{H}: \mathrm{O}$, now combine as follows :

Dumas and Boussingault, corrected....... 15.9015, $\pm .03 \mathrm{I}$

Regnault, corrected............... 15.9105, \pm .0044

Rayleigh, $1888 \ldots \ldots \ldots \ldots \ldots \ldots \ldots$. 15.884, \pm .0048

“ $\quad 1892 \ldots \ldots \ldots \ldots \ldots \ldots \ldots$ 15.882, \pm .0023

Cooke....................... 15.890, \pm .0067

Leduc ...................... 15.905, \pm .0154

Morley, including all the data......... 15.8955, \pm .0005

Thomsen................... 15.8878, \pm .0022

General mean............ 15.8948, $\pm .000+8$ 
If we reject all of Morley's data for the density of hydrogen except his third, fourth, and fifth series, the mean becomes

$$
\mathrm{O}=\mathrm{I} 5.899 \mathrm{I}, \pm .00048 \text {. }
$$

In either case Morley's data.vastly outweigh all others.

If oxygen and hydrogen were perfect gases, uniting by volume to form water exactly in the ratio of one to two, then the density of the first in terms of the second would also express its atomic weight. But in fact, the two gases vary from Boyle's law in opposite directions, and the true composition of water by volume diverges from the theoretical ratio to a measurable extent. Hence, in order to deduce the atomic weight of oxygen from its density, a small correction must be applied to the latter, dependent upon the amount of this divergence. Until recently, our knowledge of the volumetric composition of water rested entirely upon the determinations made by Humboldt and Gay-Lussac* early in this century, which gave a ratio between $\mathrm{H}$ and $\mathrm{O}$ of a little less than $2: 1$, but their data need no farther consideration here.

In $1887 \mathrm{Scott} \uparrow$ published his first series of experiments, 21 in number, finding as the most probable result a value for the ratio of $1.994: 1$. In March, 1888, $\$$ he gave four more determinations, ranging from 1.9962 to $1.998: 1$; and later in the same year $\S$ another four, with values from 1.995 to 2.001 . In $1893, \|$ however, by the use of improved apparatus, he was able to show that his previous work was vitiated by errors, and to give a series of measurements of far greater value. Of these, twelve were especially good, being made with hydrogen from palladium hydride, and with oxygen from silver oxide. In mean the value found is $2.00245, \pm .00007$, with a range from 2.0017 to 2.0030 .

In 1891 an elaborate paper by Morley appeared, in which twenty concordant determinations of the volumetric ratio gave a mean value of $2.00023, \pm .000015$. These measurements were made in eudiometer tubes, and were afterwards practically discarded by the author. In his later and larger paper, ** however, he redetermined the ratio from the density of the mixed electrolytic gases, and found it to be, after applying all corrections, 2.00274 . The probable error, roughly estimated, is .00005. Morley also reduces Scott's determinations, which were made at the temperature of the laboratory, to $0^{\circ}$, when the value becomes 2.00285 . The mean value of both series may, therefore be put at $2.0028, \pm .00004$, with sufficient accuracy for present purposes. Leduc's $\dagger$ i single determination,

* Journ. de Phys., 60, r29.

† Proc. Roy. Soc., 42, 396.

$\ddagger$ Nature, 37, 439 .

British Assoc. Report, I888, 631 .

\| Proc. Roy. Soc., 53, I30. In full in Philosophical Transactions, I84, 543. I893.

I A mer. Jouru. Sci. (3), 46, 220, and 276.

**Already cited with reference to syntheses of water.

† Compt. Rend., II5, 3II. I892. 
based upon the density of the mixed gases obtained by the electrolysis of water, gave 2.0037; but Morley shows that some corrections were neglected. This determination, therefore, may be left out of account.

Now, including all data, we have a mean value for the density ratio:

$$
H: O:: 1: 15.8948, \pm .00048 \text {; }
$$

or, omitting Morley's rejected series,

$$
\mathrm{H}: \mathrm{O}:: 1: 15.899 \mathrm{I}, \pm .00048 \text {. }
$$

Correcting these by the volume ratio, $2.0028, \pm .00004$, the final result for the atomic weight of oxygen as determined by gaseous densities becomes :

$$
\begin{aligned}
& \text { From } A \ldots \ldots \ldots \ldots \ldots \ldots . . .015 .8726, \pm .0005^{8} \\
& \text { From B........... }=15.8769, \pm .0005^{8}
\end{aligned}
$$

Combining these with the result obtained from the syntheses of water, rejecting nothing, we have-

$$
\begin{aligned}
& \text { By synthesis of water......... O }=15.8837, \pm .00026 \\
& \text { By gaseous densities........... O }=15.8726, \pm .0005^{8} \\
& \text { General mean............ } \mathrm{O}=15.882 \mathrm{r}, \pm .00024
\end{aligned}
$$

If we reject Keiser's work under the first heading, and omit Morley's defective hydrogen series under the second, we get-

$$
\begin{aligned}
\text { By synthesis of water } \ldots \ldots \ldots \ldots \ldots . O & =15.8796, \pm .00027 \\
\text { By gaseous densities............ } & =15.8769, \pm .00258 \\
\text { General mean........... } & =15.8794, \pm .00025
\end{aligned}
$$

Morley, discussing his own data, gets a final value of $\mathrm{O}=15.8790, \pm$ .00026 , a result sensibly identical with the second of the means given above. These results cannot be far from the truth; and accordingly, rounding off the last decimals, the value

$$
\mathrm{O}=\mathbf{1} 5.879, \pm .0003
$$

will be used in computation throughout this work.

Note.-A useful "short bibliography" upon the composition of water, by T. C. Warrington, may be found in the Chemical News, vol. 73, pp. $137,145,156,170$, and 184 . 
SILVER, POTASSIUM, SODIUM, CHLORINE, BROMINE, AND IODINE.

The atomic weights of these six elements depend upon each other to so great an extent that they can hardly be considered independently. Indeed, chlorine, potassium, and silver have always been mutually determined. From the ratio between silver and chlorine, the ratio between silver and potassium chloride, and the composition of potassium chlorate, these three atomic weights were first accurately fixed. Similar ratios, more recently worked out by Stas and others, have rendered it desirable to include bromine, iodine, and sodium in the same general discussion.

Several methods of determination will be left altogether out of account. For example, in 1842 Marignac* sought to fix the atomic weight of chlorine by estimating the quantity of water formed when hydrochloric acid gas is passed over heated oxide of copper. His results were wholly inaccurate, and need no further mention here. A little later Laurent $\dagger$ redetermined the same constant from the analysis of a chlorinated derivative of naphthalene. This method did not admit of extreme accuracy, and it presupposed a knowledge. of the atomic weight of carbon ; hence it may be properly disregarded. Maumené's $\ddagger$ analyses of the oxalate and acetate of silver gave good results for the atomic weight of that metal; but they also depend for their value upon our knowledge of carbon, and will, therefore, be discussed farther on with reference to that element. Hardin's $\S$ work also, relating to the nitrate, acetate, and benzoate of silver, will be found in the chapters upon nitrogen and carbon.

Let us now consider the ratios upon which we must rely for ascertaining the atomic weights of the six elements in question. After we have properly arranged our data we may then discuss their meaning. First in order we may conveniently take up the percentage of potassium chloride obtainable from the chlorate.

The first reliable series of experiments to determine this percentage was made by Berzelius. II All the earlier estimations were vitiated by the fact that when potassium chlorate is ignited under ordinary circumstances a little solid material is mechanically carried away with the oxygen gas. Minute portions of the substance may even be actually volatilized. These sources of loss were avoided by Berzelius, who devised means for collecting and weighing this trace of potassium chloride.

* Compt. Rend., I4, 570. Also, Journ. f. Prakt. Chem., 26, 304.

+ Compt. Rend., I4, 456. Journ. f. Prakt. Chem., 26, 307.

† Ann. d. Chim et d. Phys. (3), 18, 4I. I846.

\& Journ. Amer. Chem. Soc. 18, 990 . 1896 .

॥ Poggend. Annalen, 8, I. I826. 
All the successors of Berzelius in this work have benefited by his example, although for the methods by which loss has been prevented we must refer to the original papers of the several investigators. In short, then, Berzelius ignited potassium chlorate, and determined the percentage of chloride which remained. Four experiments gave the following results:

$$
\begin{array}{r}
60.854 \\
60.850 \\
60.850 \\
60.851 \\
\hline \text { Mean, } 60.851, \pm .0006
\end{array}
$$

The next series was made by Penny, $*$ in England, who worked after a somewhat different method. He treated potassium chlorate with strong hydrochloric acid in a weighed flask, evaporated to dryness over a sand bath, and then found the weight of the chloride thus obtained. His results are as follows, in six trials:

$$
\begin{array}{r}
60.825 \\
60.822 \\
60.815 \\
60.820 \\
60.823 \\
60.830 \\
\frac{60.8225}{\text { Mean, }} \pm .0014
\end{array}
$$

In 1842 Pelouze $\dagger$ made three estimations by the ignition of the chlorate, with these results:

$$
\begin{array}{r}
60.843 \\
60.857 \\
60.830 \\
\text { Mean, } 60.843, \pm .0053
\end{array}
$$

- Marignac, in 1842, $\ddagger$ worked with several different recrystallizations of the commercial chlorate. He ignited the salt, with the usual precautions for collecting the material carried off mechanically, and also examined the gas which was evolved. He found that the oxygen from 50 grammes of chlorate contained chlorine enough to form .003 gramme of silver chloride. Here are the percentages found by Marignac:

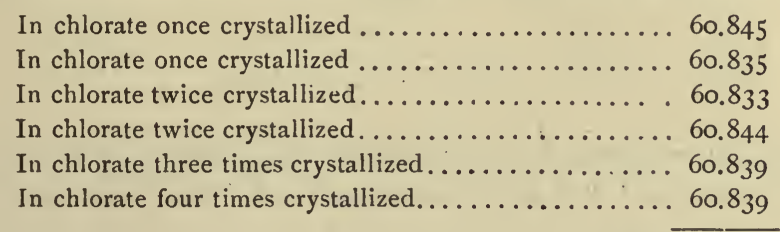

Mean, $60.8392, \pm .0013$ 
In the same paper Marignac describes a similar series of experiments made upon potassium perchlorate, $\mathrm{KClO}_{4}$. In three experiments it was found that the salt was not quite free from chlorate, and in three more it contained traces of iron. A single determination upon very pure material gave 46.187 per cent. of oxygen and 53.813 of residue.

In 1845 two series of experiments were published by Gerhardt.* The first, made in the usual way, gave these results:

$$
\begin{gathered}
60.87 \mathrm{I} \\
60.88 \mathrm{I} \\
60.875 \\
\hline \text { Mean, } 60.8757, \pm .0020
\end{gathered}
$$

In the second series the oxygen was passed through a weighed tube containing moist cotton, and another filled with pumice stone and sulphuric acid. Particles were thus collected which in the earlier series escaped. From these experiments we get-

$$
\begin{gathered}
60.947 \\
60.947 \\
60.95^{2} \\
\hline \text { Meán, } 60.9487, \pm .0011
\end{gathered}
$$

These last results were afterwards sharply criticised by Marignac, $\dagger$ and their value seriously questioned.

The next series, in order of time, is due to Maumené. $\$$ This chemist supposed that particles of chlorate, mechanically carried away, might continue to exist as chlorate, undecomposed; and hence that all previous series of experiments might give too high a value to the residual chloride. In his determinations, therefore, the ignition tube, after expulsion of the oxygen, was uniformly heated in all its parts. Here are his percentages of residue:

$$
\begin{gathered}
60.788 \\
60.790 \\
60.793 \\
60.791 \\
60.785 \\
60.795 \\
60.795 \\
\hline \text { Mean, } 60.791, \pm .0009
\end{gathered}
$$

The question which most naturally arises in connection with these results is, whether portions of chloride may not have been volatilized, and so lost. 
Closely followịng Maumené's paper, there is a short note by Faget,* giving certain mean results. According to this chemist, when potassium chlorate is ignited slowly, we get 60.847 per cent. of residue. When the ignition is rapid, we get 60.942 . As no detailed experiments are given, these figures can have no part in our discussion.

Last of all we have two series determined by Stas. $\dagger$ In the first series are the results obtained by igniting the chlorate. In the second series the chlorate was reduced by strong hydrochloric acid, after the method followed by Penny:
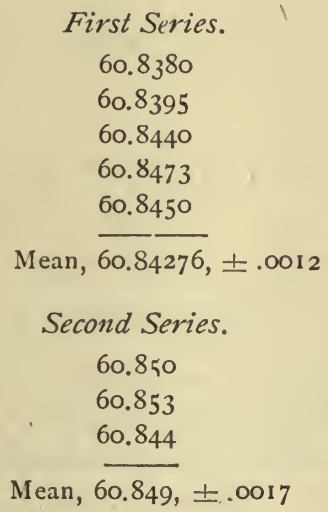

In these experiments every conceivable precaution was taken to avoid error and insure accuracy. All weighings were reduced to a vacuum standard ; from 70 to 142 grammes of chlorate were used in each experiment; and the chlorine carried away with the oxygen in the first series was absorbed by finely divided silver and estimated. It is difficult to see how any error could have occurred.

Now, to combine these different series of experiments.

\begin{tabular}{|c|c|c|c|}
\hline \multicolumn{3}{|c|}{ Berzelius, mean result............... } & $60.851, \pm .0006$ \\
\hline l'enny, & “ & $\ldots \ldots \ldots \ldots \ldots \ldots$ & $60.8225, \pm .0014$ \\
\hline Pelouze, & “ & $\ldots \ldots \ldots \ldots$ & $60.843, \pm .0053$ \\
\hline Marignac, & “ & $\ldots \ldots \ldots \ldots \ldots \ldots$ & $60.8392, \pm .0013$ \\
\hline Gerhardt, Ist & “ & $\ldots \ldots \ldots \ldots \ldots \ldots$ & $60.8757, \pm .0020$ \\
\hline . $62 \mathrm{~d}$ & 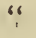 & & $60.9487, \pm .001 \mathrm{I}$ \\
\hline Maumené, & “ & .. & $60.79 \mathrm{r}, \pm .0009$ \\
\hline Stas, Ist & “ & .... & $60.8428, \pm .0012$ \\
\hline " $2 \mathrm{~d}$ & “ & $\ldots \ldots$ & $60.849, \pm .0017$ \\
\hline
\end{tabular}

This value is exactly that which Stas deduced from both of his own series combined, and gives great emphasis to his wonderfully accurate 
work. It also finely illustrates the compensation of errors which occurs in combining the figures of different experimenters.

Similar analyses of silver chlorate have been made by Marignac and by Stas. Marignac's data are as follows:* The third column gives the percentage of $\mathrm{O}$ in $\mathrm{AgClO}_{3}$ :

\begin{tabular}{|c|c|c|c|c|}
\hline 24.510 & $\mathrm{gCl}$ & I 8.36 I 6 & $\mathrm{AgCl}$. & $25 \cdot \mathrm{IO}_{3}$ \\
\hline 25.809 & “ & I9. 3345 & " & 25.086 \\
\hline 30.306 & " & 22.7072 & “ & 25.074 \\
\hline $28.35^{8}$ & " & 21.2453 & “ & 25.082 \\
\hline 28.287 & " & 21. I 833 & " & 25.113 \\
\hline 57.170 & “ & 42.8366 & “ & 25.072 \\
\hline
\end{tabular}

Stas $\uparrow$ found the following percentages in two experiments only:

$$
\begin{gathered}
25.08 \mathrm{I} \\
\frac{25.078}{-25.0795} \pm .0010
\end{gathered}
$$

Combined with Marignac's mean this gives a general mean of 25,080 , \pm .0010 ; that is, Marignac's series practically vanishes.

For the direct ratio between silver and chlorine there are seven available series of experiments. Here, as in many other ratios, the first reliable work was done by Berzelius. $\ddagger$

He made three estimations, using each time tiventy grammes of pure silver. This was dissolved in nitric acid. In the first experiment the silver chloride was precipitated and collected on a filter. In the second and third experiments the solution was mixed with hydrochloric acid in a flask, evaporated to dryness, and the residue then fused and weighed without transfer. One hundred parts of silver formed of chloride :

$$
\begin{gathered}
132.700 \\
132.780 \\
132.790 \\
\hline \text { Mean, } 132.757, \pm .019
\end{gathered}
$$

Turner's work $\S$ closely resembles that of Berzelius. Silver was dissolved in nitric acid and precipitated as chloride. In experiments one, two, and three the mixture was evaporated and the residue fused. In experiment four the chloride was collected on a filter. A fifth experiment was made, but has been rejected as worthless.

The results were as follows: In a third column I put the quantity of $\mathrm{AgCl}$ proportional to 100 parts of $\mathrm{Ag}$.

* Bib̧l. Univ. de Genéve, $46,356 . \quad$ I843.

† A ronstein's translation, p. 214.

$\ddagger$ Thomson's Annals of Philosophy, 1820, v. 15, 89 .

3. Phil. Transactions, 1829, $29 \mathrm{I}$. 


$$
\begin{aligned}
& 28.407 \text { grains } \mathrm{Ag} \text { gave } 37.737 \mathrm{\Lambda gCl} \text { I32.844 } \\
& 41.917 \text { " " } 55.678 \text { " } \quad 132.829 \\
& 40.006 \text { " " } 53.143 \text { " } 50132.837 \\
& 30.922 \text { " } 41.070 \text { " } 132.818 \\
& \text { Mean, } 132.82, \pm .0038
\end{aligned}
$$

The same general method of dissolving silver in nitric acid, precipitating, evaporating, and fusing without transfer of material was also adopted by Penny. * His results for 100 parts of silver are as follows, in parts of chloride:

$$
\begin{array}{r}
132.836 \\
132.840 \\
132.830 \\
132.840 \\
132.840 \\
132.830 \\
132.838 \\
\hline \text { Mean, } 132.8363, \pm .0012
\end{array}
$$

In 1842 Marignac $\dagger$ found that 100 parts of silver formed 132.74 of . chloride, but gave no available details. Later, $\ddagger$ in another series of determinations, he is more explicit. and gives the following data. The weighings were reduced to a vacuum standard :

$$
\begin{aligned}
& 79.853 \mathrm{grm} \text {. Ag gave } 106.080 \mathrm{AgCl} \text {. Ratio, } 132.844 \\
& 69.905 \text { " " } 92.864 \text { " } \quad 132.843 \\
& 64.905 \text { " " } 86.210 \text { " } \quad 132.825 \\
& \begin{array}{lllll}
92.362 & 122.693 & \text { " } & \mathbf{1} 32.839
\end{array} \\
& 99.653 \text { “ } 132.383 \text { “ } 132.844 \\
& \text { Mean, } \overline{132.839}, \pm .0024
\end{aligned}
$$

The above series all represent the synthesis of silver chloride. Maumené $\S$ made analyses of the compound, reducing it to metal in a current of hydrogen. His experiments make 100 parts of silver equivalent to chloride :

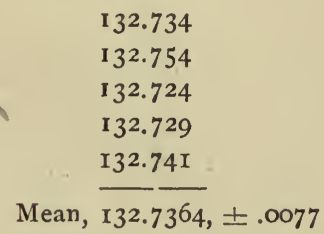

By Dumas || we have the following estimations:

$$
\begin{aligned}
& \text { 9.954 } \mathrm{Ag} \text { gave } 13.227 \mathrm{AgCl} \text {. Ratio, } 132.882 \\
& \text { I } 9.976 \text { " } 26.542 \text { “ } 132.869 \\
& \text { Mean, } \overline{\mathbf{1} 32.8755} \pm .0044
\end{aligned}
$$


Finally, there are seven determinations by Stas, ${ }^{*}$ made with his usual accuracy and with every precaution against error. In the first, second, and third, silver was heated in chlorine gas, and the synthesis of silver chloride thus effected directly. In the fourth and fifth silver was dissolved in nitric acid, and the chloride thrown down by passing hydrochloric acid gas over the surface of the solution. The whole was then evaporated in the same vessel, and the chloride fused, first in an atmosphere of hydrochloric acid, and then in a stream of air. The sixth synthesis was similar to these, only the nitric solution was precipitated by hydrochloric acid in slight excess, and the chloride thrown down was washed by repeated decantation. All the decanted liquids were afterwards evaporated to dryness, and the trace of chloride thus recorered was estimated in addition to the main mass. The latter was fused in an atmosphere of $\mathrm{HCl}$. The seventh experiment was like the sixth, only ammonium chloride was used instead of hydrochloric acid. From 98.3 to 399.7 grammes of silver were used in each experiment, the operations were performed chiefly in the dark, and all weighings were reduced to vacuum. In every case the chloride obtained was beautifully white. The following are the results in chloride for 100 of silver:

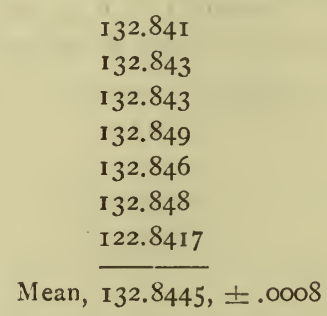

We may now combine the means of these seven series, representing in all thirty-three experiments. One hundred parts of silver are equiralent to chlorine, as follows:

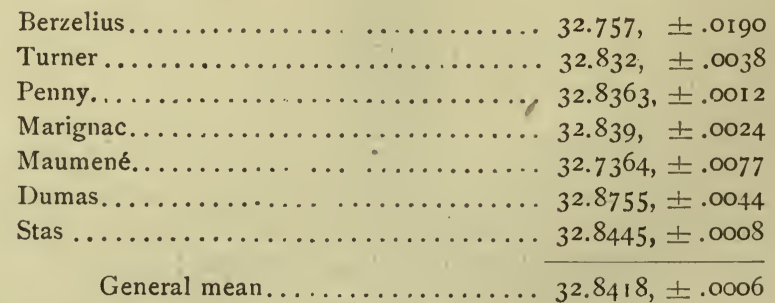

Here. again, we have a fine example of the evident compensation of errors among different series of experiments. We have also another tribute to the accuracy of Stas, since this general mean varies from the mean of his results only within the limits of his own variations. 
The ratio between silver and potassium chloride, or, in other words, the weight of silver in nitric acid solution which can be precipitated by a known weight of $\mathrm{KCl}$, has been fixed by Marignac and by Stas. Marignac,* reducing all weighings to vacuum, obtained these results. In the third column I give the weight of $\mathrm{KCl}$ proportional to 100 parts of $\mathrm{Ag}$ :

\begin{tabular}{|c|c|c|c|c|}
\hline 4.7238 & 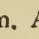 & 3.2626 & $\mathrm{KCl}$. & 69.067 \\
\hline 22.725 & " & $15.00 \mathrm{I}$ & " & 69.050 \\
\hline 21.759 & “" & 15.028 & " & 69.066 \\
\hline 2 I.909 & " & $15.13 \mathrm{I}$ & " & 69.063 \\
\hline 22.032 & “ & 15.216 & "، & 69.063 \\
\hline 25.122 & “ & $17.35^{\circ}$ & “ & 69.063 \\
\hline
\end{tabular}

The work of Stas falls into several series, widely separated in point of time. His earlier experiments $\dagger$ upon this ratio may be divided into two sets, as follows: In the first set the silver was slightly impure, but the impurity was of known quantity, and corrections could therefore be applied. In the second series pure silver was employed. The potassium chloride was from several different sources, and in every case was purified with the utmost care. From 10.8 to 32.4 grammes of silver were taken in each experiment, and the weighings were reduced to vacuum. The method of operation was, in brief, as follows: A definite weight of potassium chloride was taken, and the exact quantity of silver necessary, according to Prout's hypothesis, to balance it was also weighed out. The metal, with suitable precautions, was dissolved in nitric acid, and the solution mixed with that of the chloride. After double decomposition the trifling excess of silver remaining in the liquid was determined by titration with a normal solution of potassium chloride. One hundred parts of silver required the following of $\mathrm{KCl}$ :

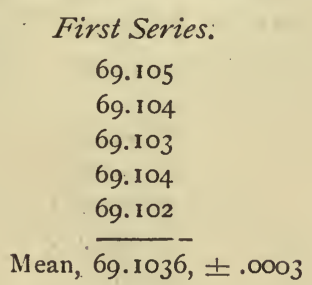

Second Series.

69.105
69.099
69.107
69.103
69.103
69.105
69.104

* See Berzelius' Lehrbuch, 5th Ed., Vol. 3, pp. IIg2-3.

$\dagger$ A ronstein's translation, pp. 250-257. 


69.099
69.1034
69.104
69.103
69.102
69.104
69.104
69.105
69.103
69.101
69.105
69.103
$\frac{69.1033, \pm .0003}{\text { Mean, }}$

In these determinations Stas did not take into account the slight solubility of precipitated silver chloride in the menstrua employed in the experiments. Accordingly, in $1882 *$ he published a new series, in which by two methods he remeasured the ratio, guarding against the indicated error, and finding the following values:

$$
\begin{gathered}
69.1198 \\
69.11965 \\
69.121 \\
69.123 \\
\text { Mean, } 69.1209, \pm .0003
\end{gathered}
$$

Corrected for a minute trace of silica contained in the potassium chloride, this mean becomes

$$
\text { 69. I I903, } \pm .0003 . \dagger
$$

Still later, in order to establish the absolute constancy of the ratio in question, Stas made yet another series of determinations, $\$$ in which he employed potassium chloride prepared from four different sources. One lot of silver was used throughout. The values obtained were as follows:

$$
\begin{aligned}
& 69.1227 \\
& 69.1236 \\
& 69.1234 \\
& 69.1244 \\
& 69.1235 \\
& 69.1228 \\
& 69.1222 \\
& 69.1211 \\
& 69.1219 \\
& 69.1249 \\
& 69.1238 \\
& 69.1225 \\
& 69.1211
\end{aligned}
$$

* Mémoires Acad. Roy. de Belge, t. 43. I882. 
A series was also begun in which one sample of potassium chloride was to be balanced against silver from various sources, but only one result is given, namely, 69.1240. This, with the previous series, gives a mean of $69.1230, \pm .0002$.

Five series of determinations are now at hand for the ratio $\mathrm{Ag}: \mathrm{KCl}$. They combine as follows:

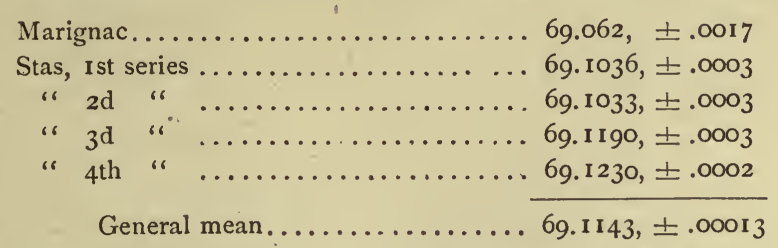

The difference between the highest and the lowest of Stas' series corresponds to a difference of 0.021 in the atomic weight of potassium. The rejection of the earlier work might be quite justifiable, but would exert a very slight influence upon our final result.

The quantity of silver chloride which can be formed from a known weight of potassium chloride has also been determined by Berzelius, Marignac and Maumené. Berzelius * found that 100 parts of $\mathrm{KCl}$ were equivalent to 194.2 of $\mathrm{AgCl}$; a value which, corrected for weighings in air, becomes 192.32. This experiment will not be included in our discussion.

In 1842 Marignac $\dagger$ published two determinations, with these results from $100 \mathrm{KCl}$ :

Mean, corrected for weighing in air, $\frac{\begin{array}{l}\mathbf{1 9 2 . 3 3} \\ \mathbf{1 9 2 . 3 4}\end{array}}{192.26, \pm .003}$

In 1846 Marignac $\ddagger$ published another set of results, as follows. The weighings were reduced to vacuum. 'The usual ratio is in the third column :

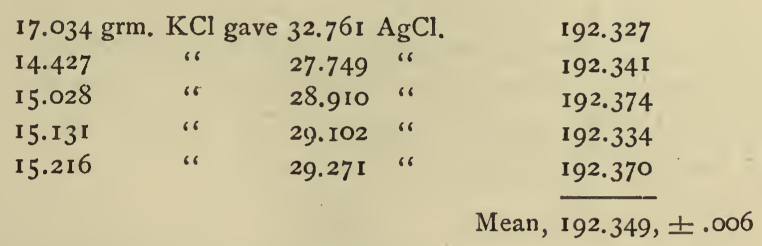

Three estimations of the same ratio were also made by Maumené as follows : 


$\begin{array}{llll}10.700 \mathrm{grm} . \mathrm{KCl} \text { gave } 20.627 \mathrm{AgCl} & 192.776 \\ 10.5195 & \text { " } & 20.273 \text { “ } & 192.716 \\ 8.587 & 16.556 \text { “ } & 19.503 & 192.803 \\ & & & \text { Mean, } 192.765, \pm .017\end{array}$

The three series of ten experiments in all foot up thus:

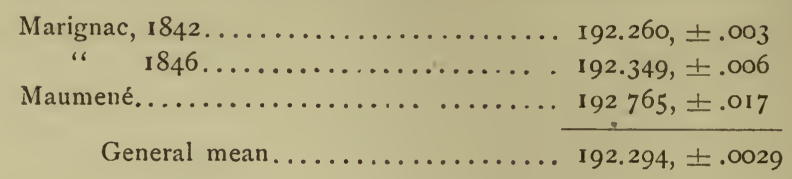

These figures show clearly that the ratio which they represent is not of very high importance. It might be rejected altogether without impropriety, and is only retained for the sake of completeness. It will obviously receive but little weight in our final discussion.

In estimating the atomic weight of bromine the earlier experiments of Balard, Berzelius, Liebig, and Löwig may all be rejected. 'Their results were all far too low, probably because chlorine was present as an impurity in the materials employed. Wallace's determinations, based upon the analysis of arsenic tribromide, are tolerably good, but need not be considered here. In the present state of our knowledge, Wallace's analyses are better fitted for fixing the atomic weight of arsenic, and will, therefore, be discussed with reference to that element.

The ratios with which we now have to deal are closely similar to those involving chlorine. In the first place, there are the analyses of silver bromate by Stas.* In two careful experiments he found in this salt the following percentages of oxygen:

$$
\text { Mean, } \frac{20.35 \mathrm{I}}{20.347}, \pm .0014
$$

There are also four analyses of potassium bromate by Marignac. $\dagger$ The salt was heated, and the percentage loss of oxygen determined. The residual bromide was feebly alkaline. We cannot place much reliance upon this series. The results are as follows:

\begin{aligned} 28.7016 \\ 28.6496 \\ 28.6050 \\ 28.7460 \\ \hline Mean, $28.6755, \pm .0207 \\$\hline\end{aligned}

* Aronstein's translation, pp. 200-206.

† See E. Mulder's Overzigt, p. I17 ; or Berzelius' Jahresbericht, 24, 72. 
When silver bromide is heated in chlorine gas, silver chloride is formed. In 1860 Dumas* employed this method for estimating the atomic weight of bromine. His results are as follows. In the third column I give the weight of $\mathrm{AgBr}$ equivalent to 100 parts of $\mathrm{AgCl}$ :

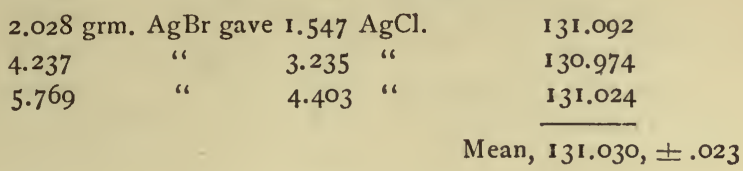

This series is evidently of but little value.

The two ratios upon which, in connection with Stas' analyses of silver bromate, the atomic weight of bromine chiefly depends, are those which connect silver with the latter element directly and silver with potassium bromide.

Marignac, $\dagger$ to effect the synthesis of silver bromide, dissolved the metal in nitric acid, precipitated the solution with potassium bromide, washed, dried, fused, and weighed the product. The following quantities of bromine were found proportional to 100 parts of silver:

74.072

74.055

74.066

Mean, reduced to a vacuum standard, $\overline{74.077} \pm .003$

Much more elaborate determinations of this ratio are due to Stas. $f$ In one experiment a known weight of silver was converted into nitrate, and precipitated in the same vessel by pure hydrobromic acid. The resulting bromide was washed thoroughly, dried, and weighed. In four other estimations the silver was converted into sulphate. Then a known quantity of pure bromine, as nearly as possible the exâct amount necessary to precipitate the silver, was transformed into hydrobromic acid. This was added to the dilute solution of the sulphate, and, after precipitation was complete, the minute trace of an excess of silver in the clear supernatant fluid was determined. All weighings were reduced to a vacuum. From these experiments, taking both series as one, we get the following quantities of bromine corresponding to 100 parts of silver:

$$
\begin{gathered}
\frac{74.0830}{74.0790} \\
74.0795 \\
74.0805 \\
\frac{74.0830}{74.081, \pm .0006}
\end{gathered}
$$

*Ann. Chem. Pharm., Ir3, 20.

† E. Mulder's Overzigt, p. I16. Berzelius' Jahresbericht, 24, 72.

$\ddagger$ Aronstein's translation, pp. $154-170$. 
In his paper on the atomic weight of cadmium,* Huntington gives three syntheses and three analyses of silver bromide. 'The data are as follows, with the usual ratio given in the last column:

\begin{tabular}{|c|c|c|c|}
\hline I. $4852 \mathrm{grm}$. & Ag gave & $2.5^{8} 55 \mathrm{AgBr}$. & 74.084 \\
\hline I. 4080 & “ & 2.4510 & 74.077 \\
\hline I.4449 & “ & 2.5150 & 74.060 \\
\hline 4. $1450 \mathrm{grm}$. & $\mathrm{AgBr}$ gave & $2.3817 \mathrm{Ag}$. & 74.035 \\
\hline 1.8172 & "6 & 1.0437 " & 74. I I I \\
\hline $4.960 \mathrm{I}$ & “ & 2.8497 ، & 74.057 \\
\hline
\end{tabular}

Similar synthetic data are also given by Richards, incidentally to his work on copper. $\dagger$ There are two sets of three experiments each, which can here be treated as one series, thus:

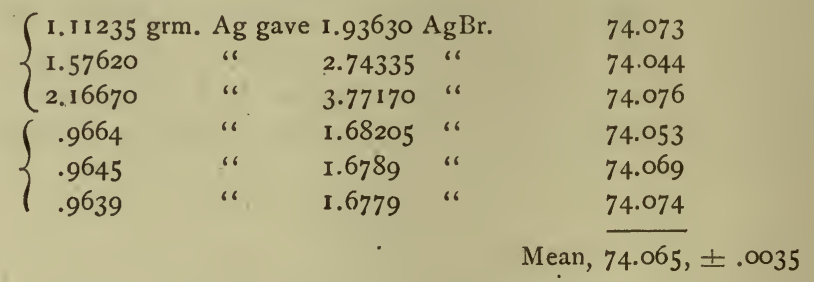

Another set of data by Richards appears in his research upon the atomic weight of barium; $\ddagger$ in which $\mathrm{BaBr}_{2}$ was balanced against silver, and the $\mathrm{AgBr}$ was also weighed. Richards gives from these data the percentage of $\mathrm{Ag}$ in $\mathrm{AgBr}$, which figures are easily restated in the usual form as follows:

Percentage.

57.460

57.455

57.447

57.445

57.448

57.442

57.451

57.455

57.443

57.445

57.445
Ratio.

74.034
74.049
74073
74.074
74.070
74.089
74.061
74.049
74.086
74.074
$\frac{74.074}{74.067} \pm .0034$

The same ratio can also be computed indirectly from Cooke's experiments upon $\mathrm{SbBr}_{3}$, Huntington's on $\mathrm{CdBr}_{2}$, 'Thorpe's on ' $\mathrm{TiBr}_{4}$, and

* Proc. Amer. Acad., 188r.

† Proc. Amer. Acad., 25, pp. 199, 210, 21r. 1890.

$\ddagger$ Proc. Amer. Acad., vol. 28. 1893 . 
Thorpe and Laurie's on gold. The values so obtained all confirm the results already given, varying within their limits, but having probable errors so high that their use would not affect the final mean. The latter is obtained as follows:

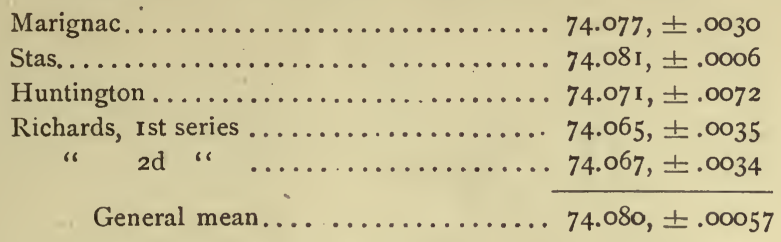

In this case again, as in so many others, Stas' work alone appears at the end, the remaining data having only corroborative value.

The ratio between silver and potassium bromide was first accurately determined by Marignac.* I give, with his weighings, the quantity of $\mathrm{KBr}$ proportional to 100 parts of $\mathrm{Ag}$ :

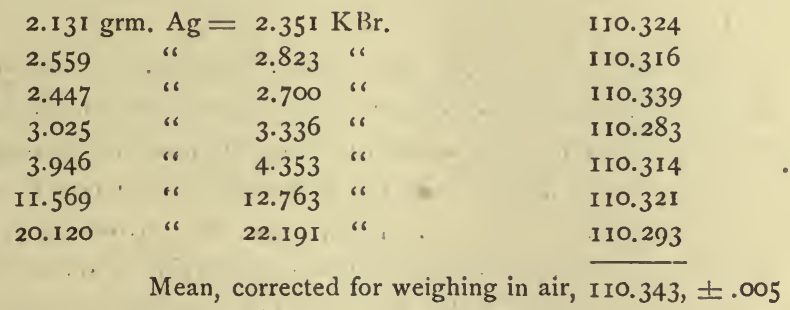

Stas, $\dagger$ working in essentially the same manner. as when he fixed the ratio between potassium chloride and silver, obtained the following results :

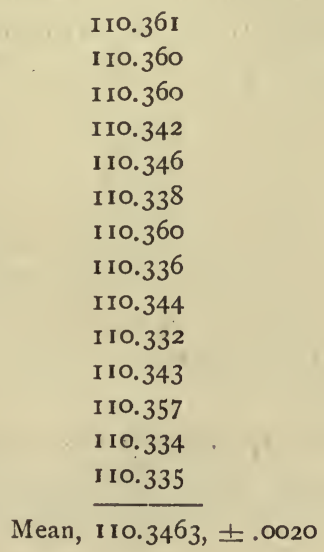

Combining this with Marignac's mean result, 110.343, \pm .005 , we get a general mean of $110.3459, \pm .0019$. 
The ratios upon which we must depend for the atomic weight of iodine are exactly parallel to those used for the determination of bromine.

To begin with, the percentage of oxygen in potassium iodate has been determined by Millon.* In three experiments he found:

$$
\begin{aligned}
& 22.46 \\
& 22.49 \\
& 22.47 \\
& \text { Mean, } 22.473, \pm .005
\end{aligned}
$$

Millon also estimated the oxygen in silver iodate, getting the following percentages :

$$
\begin{aligned}
& 17.05 \\
& 17.03 \\
& 17.06 \\
& \text { Mean, } 17.047, \pm .005
\end{aligned}
$$

The analysis of silver iodate has also been performed with extreme care by Stas. $\dagger$ From 76 to 157 grammes were used in each experiment, the weights being reduced to a vacuum standard. As the salt could not be prepared in an absolutely anhydrous condition, the water expelled in each analysis was accurately estimated and the necessary corrections applied. In two of the experiments the iodate was decomposed by heat, and the oxygen given off was fixed upon a weighed quantity of copper heated to redness. Thus the actual weights, both of the oxygen and the residual iodide, were obtained. 'In a third experiment the iodate was reduced to iodide by a solution of sulphurous acid, and the oxygen was estimated only by difference. In the three percentages of oxygen given below, the result of this analysis comes last. The figures for oxygen are as follows:

$$
\begin{gathered}
16.976 \\
16.972 \\
16.9761 \\
\text { Mean, } 16.9747, \pm .0009
\end{gathered}
$$

This, combined with Millon's series above cited, gives us a general mean of $16.9771, \pm .0009$.

The ratio between silver and potassium iodide seems to have been determined only by Marignac, $\ddagger$ and without remarkable accuracy. In five experiments 100 parts of silver were found equivalent to potassium iodide as follows: 


$\begin{array}{rlr}1.6 \mathrm{r} 6 \mathrm{grm} . & \mathrm{Ag}= & 2.483 \mathrm{KI} \\ 2.503 & \text { " } & 3.846 \\ 3.427 & \text { " } & 5.268 \text { " } \\ 2.14 \mathrm{I} & \text { " } & 3.290 \\ 10.82 \mathrm{I} & \text { " } & \mathrm{I} 6.642 \text { " }\end{array}$

$$
\begin{array}{cr}
\text { Ratio, } & 153.65 \mathrm{I} \\
\text { “ } & \mathrm{I} 53.665 \\
“ & 153.720 \\
\text { “ } & \mathrm{I} 53.667 \\
\text { Mean, } & \frac{153.794}{\mathrm{I} 53.6994} \pm .0178
\end{array}
$$

The synthesis of silver iodide has been effected by both Marignac and Stas. Marignac, in the paper above cited, gives these weighings. In the last column $\mathrm{I}$ add the ratio between iodine and 100 parts of silver:

$$
\begin{aligned}
& \text { I5.000 grm. Ag gave 31.625 AgI. II } \quad \text {. } 500 \\
& 14.790 \quad \text { " } 32.170 \text { " } 117.512 \\
& \text { I8.545 " " } 40.339 \text { " II } 7.519
\end{aligned}
$$

Stas * in his experiments worked after two methods, which gave, however, results concordant with each other and with those of Marignac.

In the first series of experiments Stas converted a known weight of silver into nitrate, and then precipitated with pure hydriodic acid. The iodide thus thrown down was washed, dried, and weighed without transfer. By this method 100 parts of silver were found to require of iodine:

$$
\text { Mean, } \frac{117.5325, \pm .0024}{117.536}
$$

In the second series a complete synthesis of silver iodide from known weights of jodine and metal was performed. The iodine was dissolved in a solution of ammonium sulphite, and thus converted into ammonium iodide. The silver was transformed into sulphate and the two solutions were mixed. When the precipitate of silver iodide was completely deposited the supernatant liquid was titrated for the trifling excess of iodine which it always contained. As the two elements were weighed out in the ratio of 127 to 108, while the atomic weight of iodine is probably a little under 127, this excess is easily explained. From these experiments two sets of values were deduced; one from the weights of silver and iodine actually employed, the other from the quantity of iodide of silver collected. From the first set we have of iodine for 100 parts of silver:

$$
\begin{gathered}
117.5390 \\
117.5380 \\
\text { I } 17.5318 \\
\text { I } 17.5430 \\
\text { II } 7.5420 \\
117.5300 \\
\text { Mean, } 117.5373, \pm .0015
\end{gathered}
$$


From the weight of silver iodide actually collected we get as follows. For experiment number three in the above column there is no equivalent here:

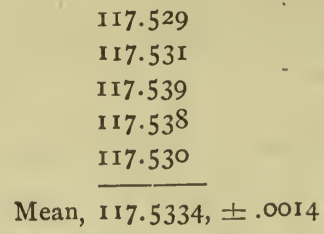

Now, combining these several sets of results, we have the following general mean:

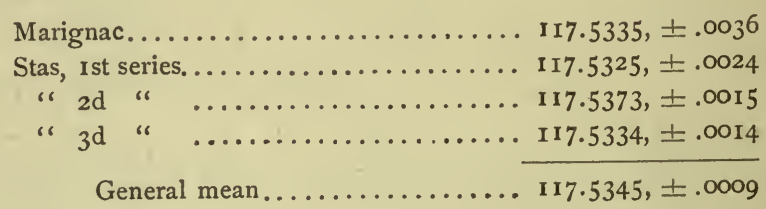

One other comparatively unimportant iodine ratio remains for us to notice. Silver iodide, heated in a stream of chlorine, becomes converted into chloride; and the ratio between these two salts has been thus determined by Berzelius and by Dumas.

From Berzelius* we have the following data. In the third column I give the ratio between $\mathrm{AgI}$ and 100 parts of $\mathrm{AgCl}$ :

$$
\begin{aligned}
& \text { 5.000 grm. AgI gave } 3.062 \mathrm{AgCl} \text {. } \quad 163.292 \\
& \begin{array}{llll}
12.212 ~ & & &
\end{array} \\
& \text { Mean, } \overline{16_{3} \cdot 326} \pm .023
\end{aligned}
$$

Dumas' $\dagger$ results were as follows:

$$
\begin{array}{lll}
\text { 3.520 grm. AgI gave 2.149 AgCl. } & \text { I63.793 } \\
\text { 7.0II } & 4.28 \mathrm{I} \cdots & \mathrm{I63.770} \\
& & \text { Mean, } \frac{163.782, \pm .008}{}
\end{array}
$$

General mean from the combination of both series, $163.733, \pm .0076$.

For sodium there are but four ratios of any value for present purposes. The early work of Berzelius we may disregard entirely, and confine ourselves to the consideration of the results obtained by Penny, Pelouze, Dumas, and Stas, together with a single ratio measured incidentally by Ramsay and Aston.

The percentage of oxygen in sodium chlorate has been determined only by Penny $\ddagger$, who used the same method which he applied to the potassium salt. Four experiments gave the following results : 


$$
\begin{gathered}
45.060 \\
45.075 \\
45.080 \\
\frac{45.067}{45.0705} \pm .0029
\end{gathered}
$$

The ratio between silver and sodium chloride has been fixed by Pelouze, Dumas, and Stas. Pelouze* dissolved a weighed quantity of silver in nitric acid, and then titrated with sodium chloride. Equivalent to 100 parts of silver he found of chloride :

$$
\begin{gathered}
54.158 \\
54.125 \\
54.139 \\
\hline \text { Mean, } 54.141, \pm .0063
\end{gathered}
$$

By Dumas $\dagger$ we have seven experiments, with results as follows. The third column gives the ratio between 100 of silver and $\mathrm{NaCl}$ :

$$
\begin{aligned}
& 2.0535 \mathrm{grm} . \mathrm{NaCl}=3.788 \mathrm{grm} . \mathrm{Ag} \text {. } \\
& 2.169 \text { " } 4.0095 \text { " } \\
& 4.3554 \text { " } 6.0425 \text { " } 54.155 \\
& 6.509 \text { " } 612.0140 \text { " } 195 \\
& 6.413 \text { " } 11.8375 \text { " } 125 \\
& \text { 2.1746 " " } 4.012 \text { " } 54.202 \\
& 5.113 \text { “ } 9.434 \text { “ } 54.187 \\
& \text { Mean, } \overline{54.172, \pm .0096}
\end{aligned}
$$

Stas $\$$ applying the method used in establishing the similar ratio for potassium chloride, and working with salt from six different sources, found of sodium chloride equivalent to 100 parts of silver:

$\begin{array}{r}54.2093 \\ 54.2088 \\ 54.2070 \\ 54.2070 \\ 54.2070 \\ 54.2060 \\ 54.2076 \\ 54.2081 \\ 54.2083 \\ 54.2089 \\ \hline 54.2078, \pm .0002\end{array}$

As in the case of the corresponding ratio for potassium chloride, these data needed to be checked by others which took into account the solu- 
bility of silver chloride. Such 'data are given in Stas' paper of $1882, *$ and four results are as follows:

$$
\begin{array}{cl}
54.2065 \\
54.20676 \\
54.209 \mathrm{I} \\
\frac{54.2054}{\text { Mean, }} 54.20694, \pm .00045
\end{array}
$$

Corrected for a trace of silica in the sodium chloride, this mean becomes $54.2046, \pm .00045 . \dagger$ Combining all four series, we have for the $\mathrm{NaCl}$ equivalent to 100 parts of $\mathrm{Ag}$ -

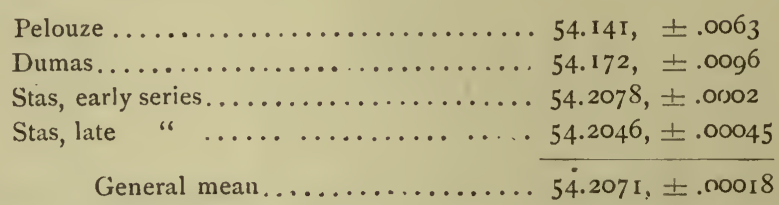

Here the work of Stas is of such superior excellence that the other determinations might be completely rejected without appreciably affecting our final results.

In their research upon the atomic weight of boron, Ramsay and Aston $\ddagger$ converted borax into sodium chloride. In the latter the chlorine was afterwards estimated gravimetrically by weighing as silver chloride on a Gooch filter. Hence the ratio, $\mathrm{AgCl}: \mathrm{NaCl}:: 100: x$, as follows :

$\begin{array}{lll}3.076 \mathrm{I} \text { grm. } \mathrm{NaCl} \text { gave } 7.5259 \mathrm{AgCl} \text {. } \\ 2.7700 & \text { “ } & 6.7794 \\ 2.8930 & \text { “ } & 7.0804 \\ 2.7360 & \text { “ } & 6.6960 \\ 1.9187 & \text { “ } & 46931\end{array}$

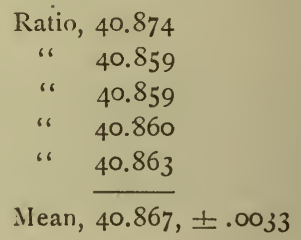

Finally, for the ratios between silver and sodium bromide we have one set of measurements by Stas. $\$$ The bromide was prepared by saturating $\mathrm{Na}_{2} \mathrm{CO}_{3}$ with $\mathrm{HBr}$. The $\mathrm{NaBr}$ proportional to 100 parts of silver was-

$$
\begin{gathered}
95.4420 \\
95.4383 \\
95.4426 \\
\frac{95.4392}{\text { Mean, }} 95.4405, \pm .0007
\end{gathered}
$$

We have now before us the data for computing, with greater or less accuracy, the atomic weights of the six elements under discussion. In

* Mémoires Acad. Roy. de Belge., 43. I882.

† See Van der Plaats, Ann. Chim. Phys. (6), 7, 16. 1886.

$\ddagger$ Chem. News, 66, 92. I $\$ 92$.

¿ Mémoires Acad. Roy. Belge., 43. 1882. 
all there are nineteen ratios, involving about two hundred and fifty separate experiments. These ratios may now be tabulated and numbered for reference, it being understood that the probable error in each ease is that of the last term in the proportion.

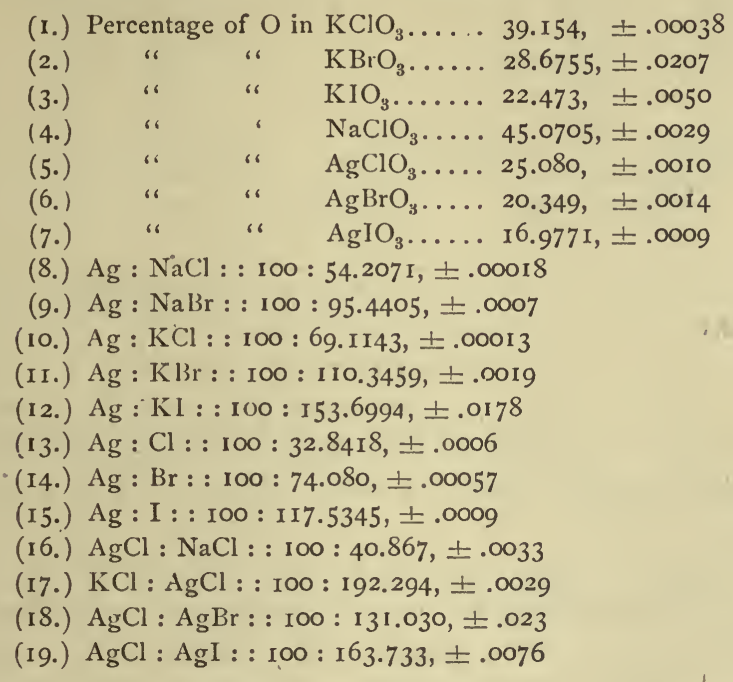

Now, from ratios 1 to 7 , inclusive, we can at once, by applying the known atomic weight of oxygen, deduce the molecular weights of seven haloid salts. Let us consider the first calculation somewhat in detail.

Potassium chlorate yields 39.154 per cent. of oxygen and 60.846 per cent. of residual chloride. For each of these quantities the probable error is \pm .00038 . The atomic weight of oxygen is $15.879, \pm .0003$, so that the value for three atoms becomes 47.637, \pm .0009 . We have now the following simple proportion :

$$
\text { 39. } 154: 60.846:: 47.637: x \text {, }
$$

whence the molecular weight of potassium chloride becomes $=74.029$.

The probable error being known for the first, second, and third term of this proportion, we can easily find that of the fourth term by the formula given in our introduction. It is \pm .0073 . By this method we obtain the following series of values, which may conveniently be numbered consecutively with the foregoing ratios:

\begin{tabular}{|c|c|c|}
\hline 0 & $\mathrm{Cl}$, & $29, \pm .0073$ \\
\hline & $\mathrm{B}$ & $(2)=118.487, \pm .0923$ \\
\hline$(2$ & $\mathrm{KI}$, & $(3)=\mathrm{x} 64.337, \pm .0382$ \\
\hline & $\mathrm{NaCl}$, & $(4)=5^{8.057, \pm .0050}$ \\
\hline & $\mathrm{AgC}$ & $(5)=142.303, \pm .00$ \\
\hline & $\mathrm{Agl}$ & $(6)=186.463, \pm .01$ \\
\hline & $\mathrm{AgI}$ & $"(7)=232.959, \pm .01$ \\
\hline
\end{tabular}


With the help of these molecular weights, we are now able to compute seven independent values for the atomic weight of silver.

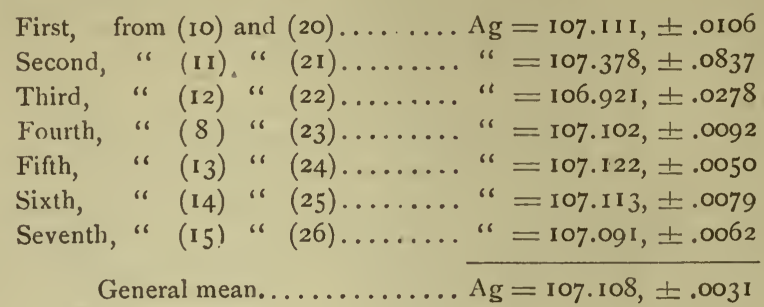

It is noticeable that five of these values agree very well. The second and third, however, diverge widely from the average, but in opposite directions; they have, moreover, high probable errors, and consequently little weight. Of these two, one represents little and the other none of Stas' work. Their trifling influence upon our final results becomes curiously apparent in the series of silver values given a little further along.

When we consider closely, in all of its bearings, any one of the values just given, we shall see that for certain purposes it must be excluded from our general mean. For example, the first is derived partly from the ratio between silver and potassium chloride. From this ratio, the atomic weight of one substance being known, we can deduce that of the other. We have already used it in ascertaining the atomic weight of silver, and the value thus obtained is included in our general mean. But if from it we are to determine the molecular weight of potassium chloride, we must use a silver value derived from other sources only, or we should be assuming a part of our result in advance. In other words, we must now use a general mean for silver from which this ratio with reference to silver has been rejected. Hence the following series of silver values, which are lettered for reference:
A. General mean from all eight......... 107.108, \pm .0031
B. " excluding the first....... 107.108, \pm .0032
C. " " " second.... $107.107, \pm .003$ I
D. " " " third...... 107.110, \pm .0031
E. " "
F. " " $\quad$ fifth....... 107.099, \pm .0039
G. " " " sixth...... 107.106, \pm .0034
H. " " seventh ... I07.113, \pm .0036

We are now in a position to determine more closely the molecular weights of the haloid salts which we have already been considering.

For silver chloride, still employing the formula for the probable error of the last term of a proportion, we get the following values: 


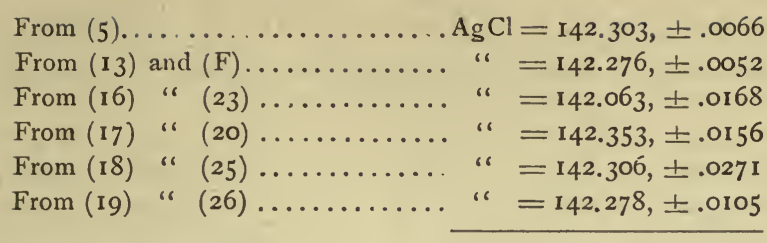

General mean...........AgCl $=142.277, \pm .0036$

The third of these values is certainly too low, and although it reduces the atomic weight of chlorine by only 0.01 , it ought to be rejected. The general mean of the other five values is $\mathrm{AgCl}=142.287$, \pm .0037 . Subtracting from this the atomic weight of silver, 107.108, \pm .0031 , we have for the atomic weight of chlorine-

$$
\mathrm{Cl}=35 \cdot 179, \pm .0048 \text {. }
$$

For silver bromide three ratios are available:

$$
\begin{aligned}
& \text { From }(6) \ldots \ldots \ldots \ldots \ldots \ldots \ldots . . . .6 \mathrm{Agr}=186.463, \pm .0137 \\
& \text { From (14) and }(\mathrm{G}) \ldots \ldots \ldots \ldots \ldots . .6=186.450, \pm .0050 \\
& \text { From (18) " }(24) \ldots \ldots \ldots \ldots \ldots \text { " }=\mathbf{1} 86.459, \pm .0339 \\
& \text { General mean.......... } \overline{\mathrm{AgBr}=186.45^{2}, \pm .0054}
\end{aligned}
$$

Hence, applying the atomic weight of silver as before-

$$
\mathrm{Br}=79.344, \pm .0062 \text {. }
$$

For silver iodide we have-

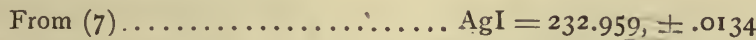

$$
\begin{aligned}
& \text { From (I5) and }(\mathrm{H}) \ldots \ldots \ldots \ldots \ldots \text {. }=233.008, \pm .0079 \\
& \text { From (19) “ (24).......... “ }=232.997, \pm .0153 \\
& \text { General mean...........AgI }=232.996, \pm .0062
\end{aligned}
$$

Hence,

$$
I=125.888, \pm .0069
$$

For the molecular weight of sodium chloride three values appear, as follows:

$$
\begin{aligned}
& \text { From (4)............... NaCl }=58.057, \pm .0050 \\
& \text { From }(8) \text { and }(\mathrm{E}) \ldots \ldots \ldots \ldots \ldots \ldots, "=58.061, \pm .0018 \\
& \text { From (I6) " } \mathrm{AgCl} . . . \ldots \ldots \ldots \ldots \text { " }=58.148, \pm .0049 \\
& \text { General mean.......... } \overline{\mathrm{NaCl}}=58.069, \pm .0016
\end{aligned}
$$

Rejecting the third value, which corresponds to the rejected value for $\mathrm{AgCl}$ and throws out ratio (16) entirely, the mean becomes

$$
\mathrm{NaCl}=58.060, \pm .0017
$$

From (9) and (A) .......... NaBr $=102.224, \pm .003 \mathrm{I}$ 
Deducting from these molecular weights the values already found for $\mathrm{Cl}$ and $\mathrm{Br}$, two measurements of the atomic weight of sodium are obtained, thus:

$$
\begin{aligned}
& \text { From } \mathrm{NaCl} \ldots \ldots \ldots \ldots \ldots \ldots \ldots \mathrm{Na}=22.88 \mathrm{I}, \pm .005 \mathrm{I} \\
& \text { From } \mathrm{NaBr} \ldots \ldots \ldots \ldots \ldots \ldots \ldots \ldots \text { " }=22.88 \mathrm{C} \text {, } \pm \text {. OI I } 2 \\
& \text { General mean............ } \overline{\mathrm{Na}=22.88 \mathrm{I}, \pm 0046}
\end{aligned}
$$

The rejection of ratio (16) in connection with the atomic weights of sodium and chlorine is fully justified by the fact that the data which it represents were never intended for use in such computations. They were obtained incidentally in connection with work upon boron, and their consideration here may have some bearing later upon the discussion of the last-named element.

For potassium, the ratios available give molecular weights for the chloride, bromide, and iodide. For the chloride,

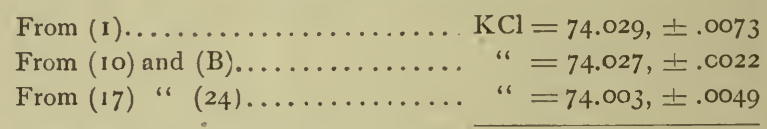

General mean........... $\mathrm{KCl}=74.025, \pm .0019$

For the bromide we have-

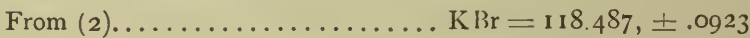

$$
\begin{aligned}
& \text { From }(\mathrm{II}) \text { and }(\mathrm{C}) \ldots \ldots \ldots \ldots \ldots . " \mathrm{w}=\mathrm{II} 8.188, \pm .0073 \\
& \text { General mean........... } \overline{\mathrm{KBr}=118.200, \pm .0073}
\end{aligned}
$$

And for the iodide-

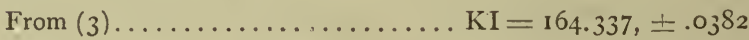

$$
\begin{aligned}
& \text { From (12) and (D) ........... " }=164.627, \pm .0052 \\
& \text { General mean........... KI }=164.622, \pm .005 \mathrm{I}
\end{aligned}
$$

Combining these values with those found for chlorine, bromine, and iodine, we have three values for the atomic weight of potassium, as follows:

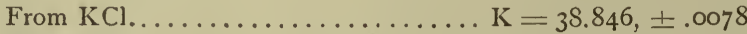

$$
\begin{aligned}
& \text { From } \mathrm{KBr} \ldots \ldots \ldots \ldots \ldots \ldots \ldots \ldots \ldots \text {............ }=38.856, \pm .0096 \\
& \text { From KI................. " }=38.734, \pm .0086 \\
& \text { General mean............ } \mathrm{K}=38.817, \pm .005 \mathrm{I}
\end{aligned}
$$

To sum up, the six atomic weights, under discussion may be tabulated as follows, both for the standard chosen, and with $\mathrm{O}=16$ as the base of the system: 
SILVER, POTASSIUM, ETC.

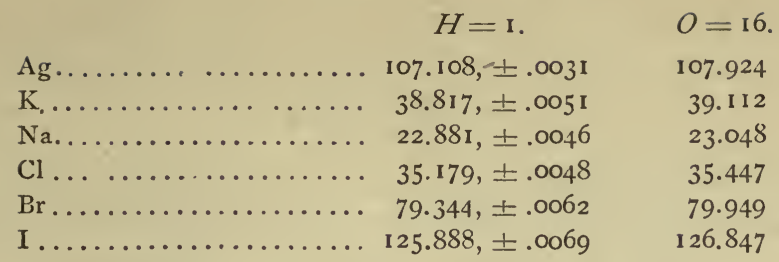

It must be remembered that these values represent the summing up of work done by many investigators. Stas' ratios. taken by themselves, give various results, according to the method of combining them. This computation has been made by Stas himself, with his older determinations, and more recently by Ostwald,* Van der Plaats, $\dagger$ and Thomsen, $\ddagger$ all with the standard of $\mathrm{O}=16$. By Van der Plaats two sets of results are given : one with Stas' ratios assigned equal weight (A), and the other with each ratio given weight inversely proportional to the square of its mean error (B). The results of these several computations may well be tabulated in comparison with the values obtained in my own general discussion, thus :

Clarke. Stas. Ostwald. V.derP.,A. V.der P., B. Thomsen.

$\begin{array}{rrrrrrr}\mathrm{Ag} \ldots \ldots . & 107.924 & 107.930 & 107.9376 & 107.9202 & 107.9244 & 107.9299 \\ \mathrm{~K} \ldots \ldots . & 39.112 & 39.137 & 39.1361 & 39.1414 & 39.1403 & 39.1507 \\ \mathrm{Na} \ldots \ldots . & 23.048 & 23.043 & 23.0575 & 23.0453 & 23.0443 & 23.0543 \\ \mathrm{Cl} \ldots \ldots . & 35.447 & 35.457 & 35.4529 & 35.4516 & 35.4565 & 35.4494 \\ \mathrm{Br} \ldots \ldots . & 79.949 & 79.952 & 79.9628 & 79.9407 & 79.9548 & 79.9510 \\ \mathrm{I} \ldots \ldots \ldots & 126.847 & 126.850 & 126.8640 & 126.8445 & 126.8494 & 126.8556\end{array}$

The agreement between the new values and the others is highly satisfactory, and gives a strong emphasis to the magnificent accuracy of Stas' determinations. No sererer test could be applied to them.

* Lehrbuch der allgemeinen Chemie, I, 4I. 1885 .

† Compt. Rend., 116, 1362. I893.

$\ddagger$ Zeitsch. Physikal. Chem., 13, 726. I894. 


\section{NITROGEN.}

The atomic weight of nitrogen has been determined from the density of the gas, and from a considerable variety of purely chemical ratios.

Upon the density of nitrogen a great many experiments have been made. In early times this constant was determined by Biot and Arago, Thomson, Dulong and Berzelius, Lavoisier, and others. But all of these investigations may be disregarded as of insufficient accuracy; and, as in the case of oxygen, we need consider only the results obtained by Dumas and Boussingault, by Regnault, and by recent investigators.

Taking air as unity, Dumas and Boussingault* found the density of nitrogen to be-

$$
\begin{gathered}
.970 \\
.972 \\
.974 \\
\text { Mean, } .972, \pm .00078
\end{gathered}
$$

For hydrogen, as was seen in our discussion of the atomic weight of oxygen, the same investigators found a mean of $.0693, \pm .00013$. Upon combining this with the above nitrogen mean, we find for the atomic weight of the latter element, $\mathrm{N}=14.026, \pm .0295$.

By Regnault $\dagger$ much closer work was done. He found the density of nitrogen to be as follows:

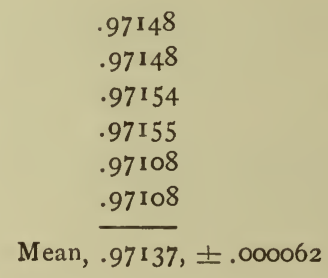

For hydrogen, Regnault's mean value is $.069263, \pm .000019$. Hence, combining as before, $\mathrm{N}=14.0244 \pm .0039$.

Both of the preceding values are affected by a correction for the difference in volume between the weighing globes when full and when empty. This correction, in the case of Regnault's data, has been measured by Crafts, $\$$ who gives .06949 for the density of $\mathrm{H}$, and .97138 for $\mathrm{N}$. Corrected ratio, $\mathrm{N}=13.9787$. If we assume the same proportional correction for the determination by Dumas and Boussingault, that becomes $\mathrm{N}=13.9771$. 
Von Jolly,* working with electrolytic oxygen and with nitrogen prepared by passing air over hot copper, but not with hydrogen, compared the weights of equal volumes of the two gases, with results as follows :

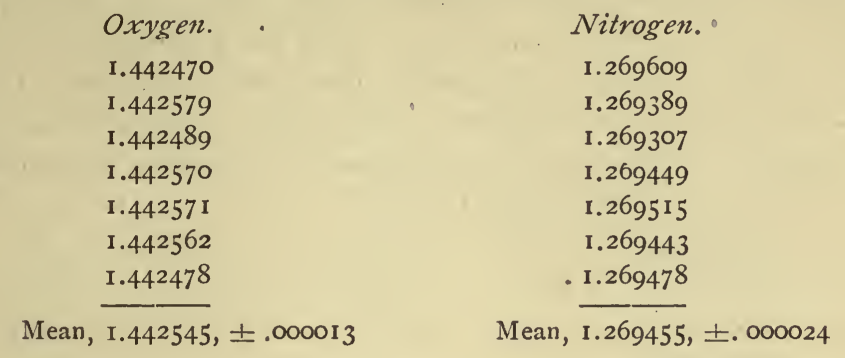

The ratio, when $\mathrm{O}=16$, is $\mathrm{N}=14.0802, \pm .0003$. Corrected by Rayleigh, the ratio between the weights becomes 14.0805 . If $\mathrm{O}=15.879$, \pm .0003 , the final value for $\mathrm{N}$, deducible from Von Jolly's data, is $\mathrm{N}=$ $13.974, \pm .0004$.

The next determination in order of time is Leduc's. $\dagger$ He made nine measurements of the density of nitrogen, giving a mean of .97203 , with extremes of .9719 and .9721 ; but he neglects to cite the intermediate values. Taking the three figures given as representative, and assuming a fair distribution of the other values between the indicated limits, the probable error of the mean is not far from 0.00002 . For hydrogen he found $.06948, \pm .00006745$. The ratio between the two densities gives $\mathrm{N}=13.9901, \pm .0138$.

Lord Rayleigh, $\$$ preparing nitrogen by passing air over hot copper, and weighing in a standard globe, obtained the following weights:

$$
\begin{gathered}
2.31035 \\
2.31026 \\
2.31024 \\
2.31012 \\
2.31027 \\
\text { Mean, } 2.31025, \pm 000025
\end{gathered}
$$

With corrections for temperature, shrinkage of the globe when exhausted, etc., this becomes 2.30883 , aś against 2.37512 for the same volume' of air. Hence the density of $\mathrm{N}=.97209, \pm .00001$. His former work on hydrogen gives $.06960, \pm .0000084$, for the density of that gas. The ratio is $\mathrm{N}=13.9678, \pm .0017$.

The foregoing data, however, all apply to nitrogen derived from the atmosphere. In a later memoir Rayleigh $\S$ found that nitrogen from 
chemical sources, such as oxides of nitrogen, ammonium nitrate, etc., was perceptibly lighter; and not long afterwards the discrepancy was explained by the astonishing discovery of argon. The densities given, therefore, are all too high, and unavailable for any discussion of atomic weight. As, however, the reductions had been completed in nearly all their details before the existence of argon was announced, they may be allowed to remain here as part of the record. Summing up, the ratios found between hydrogen and atmospheric " nitrogen " are as follows:

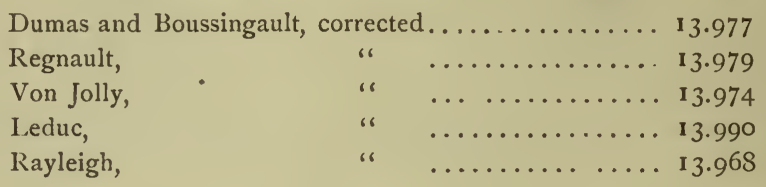

Perhaps at some future time, when the density of argon is accurately known and its amount in the atmosphere has been precisely determined, these figures may be so corrected as to be useful for atomic weight calculations.

In discussing the more purely chemical ratios for establishing the atomic weight of nitrogen, we may ignore, for the present, the researches of Berzelius and of Anderson. These chemists experimented chiefly upon lead nitrate, and their work is consequently now of greater value for fixing the atomic weight of lead. Their results will be duly considered in the proper connection further on.

The ratio between ammonium chloride and silver has been determined by Pelouze, by Marignac, and by Stas. The method of working is essentially that adopted in the similar experiments with the chlorides of sodium and potassium.

For the ammonium chloride equivalent to 100 parts of silver, Pelouze * found:

$$
\text { Mean, } \frac{49.556}{49.5365, \pm .013}
$$

Narignac $\dagger$ obtained the following results. The usual ratio for 100 parts of silver is given also:

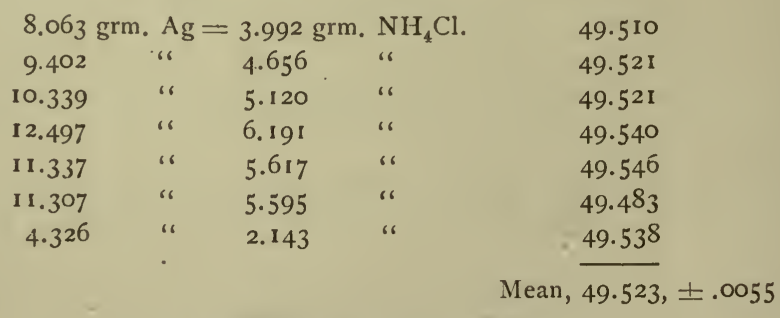

* Compt. Rend., 20. 1047. I845.

† Berzelius' Lehrbuch, 5th ed., vol. 3, i184, ri 85 . 
But neither of these series can for a moment compare with that of Stas. * He used from 12.5 to 80 grammes of silver in each experiment, reduced his weighings to a vacuum standard, and adopted a great variety of precautions to insure accuracy. He found for every 100 parts of silver the following quantities of $\mathrm{NH}_{4} \mathrm{Cl}$ :

49.600
49.599
49.597
49.598
49.597
49.593
49.597
49.5974
49.602
49.597
49598
$\frac{49.592}{49.5973}, \pm .0005$

In this work, as with the similar ratios for potassium and sodium chloride, the solubility of silver chloride was not guarded against so fully as is needful. Accordingly Stas published a new series of determinations in $1882, \dagger$ carefully checked in this particular, with the subjoined values for the ratio:

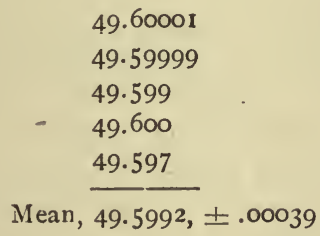

Combining all four series, we have-

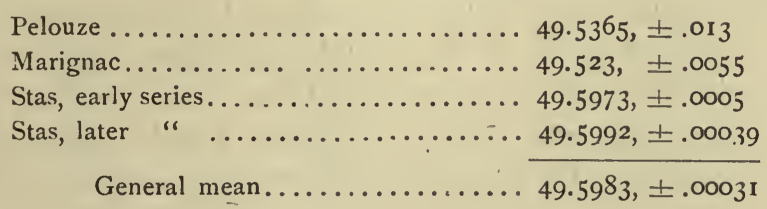

In the paper last cited Stas also gives a similar series of determinations for the ratio $\mathrm{Ag}: \mathrm{NH}_{4} \mathrm{Br}:: 100: x$. The results are as follows, with re= duction to vacuum: 


\author{
90.831 \\ $90.83 \mathrm{I}$ \\ 90.8297 \\ 90.823 \\ 90.8317 \\ 90.8311 \\ 90.832 \\ Mean, $\overline{90.8299}, \pm .0008$
}

The quantity of silver nitrate which can be formed from a known weight of metallic silver has been determined by Penny, by Marignac, and by Stas. Penny* dissolved silver in nitric acid in a flask, evaporated to dryness without transfer, and weighed. One hundred parts of silver thus gave of nitrate:

$$
\begin{gathered}
157.430 \\
157.437 \\
157.458 \\
157.440 \\
157.430 \\
157.455 \\
\text { Mean, } 157.4417, \pm .0033
\end{gathered}
$$

\begin{tabular}{|c|c|c|c|c|}
\hline $68.987 \mathrm{grm}$. & Ag gave & $108.608 \mathrm{grm}$ & $\mathrm{AgNO}_{3}$ & 157.433 \\
\hline 57.844 & “" & 91.047. & “ & $157.40 \mathrm{I}$ \\
\hline 66.436 & “ & 104.592 & “ & 157.433 \\
\hline 70.340 & “ & I 10.718 & & I 57.404 \\
\hline 200.000 & “ & 314.894 & "6 & I 57.447 \\
\hline
\end{tabular}

Marignac's $\dagger$ results were as follows. In the third column they are reduced to the common standard of 100 parts of silver :

Stas, $\$$ employing from 77 to 405 grammes of silver in each experiment, made two different series of determinations at two different times. The silver was dissolved with all the usual precautions against loss and against impurity, and the resulting nitrate was weighed, first after long drying without fusion, just below its melting point; and again, fused. Between the fused and the unfused salt there was in every case a slight difference in weight, the latter giving a maximum and the former a minimum value.

In Stas' first series there are eight experiments; but the serenth he himself rejects as inexact. The values obtained for the nitrate from 100

* Phil. Trans., I839.

† Berzelius' Lehrbuch, 5 th ed., 3, pp. 1184,1185 .

$\ddagger$ Aronstein's translation, pp. 305 and 315 . 
parts of silver are given below in two columns, representing the two conditions in which the salt was weighed. The general mean given at the end I have deduced from the means of the two columns considered separately :

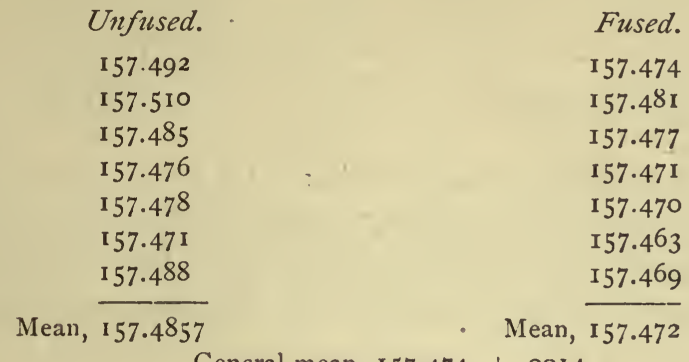

General mean, $157.474, \pm .0014$

In the later series there are but two experiments, as follows :

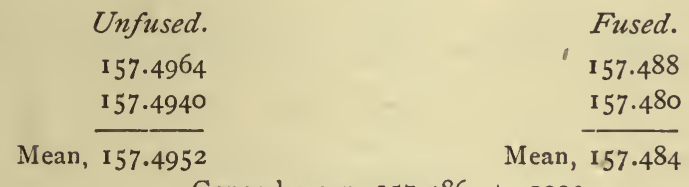

General mean, $157.486, \pm .0003$

The reverse ratio, namely, the amount of silver obtainable from a weighed quantity of nitrate, has been determined electrolytically by Hardin.* The data obtained, however, are reducible to the same form as in the preceding series, and all are properly combinable together. Pure silver was dissolved in pure aqueous nitric acid, and the crystalline salt thus formed was dried, fused, and used for the determinations. The silver nitrate, mixed with an excess of pure potassium cyanide solution, was electrolyzed in a platinum dish. The results obtained, reduced to vacuum weights, were as follows:

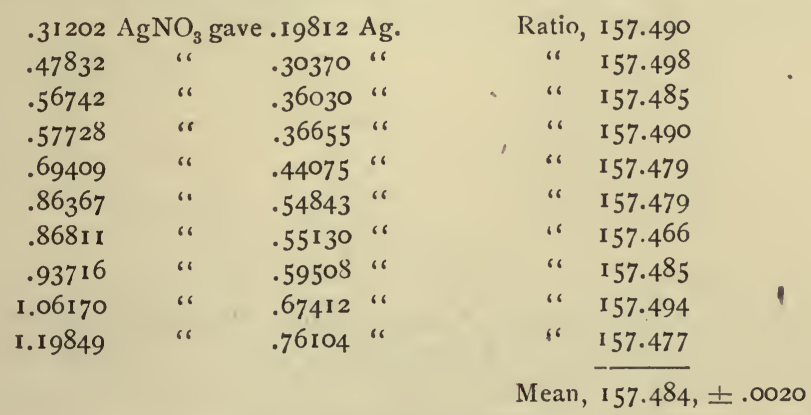

* Journ. Amer. Chem. Soc., 18, 995.1896. 
Now, to combine all five sets of results :

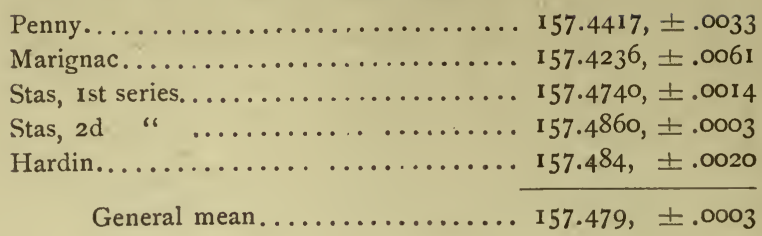

For the direct ratio between silver nitrate and silver chloride there are two series of estimations. A weighed quantity of nitrate is easily converted into chloride, and the weight of the latter ascertained. In two experiments Turner* found of chloride from 100 parts of nitrate:

$$
\text { Mean, } \frac{84.357}{84.373}, \text { 上.01 I }
$$

Penny, $\dagger$ in five determinations, found the following percentages:

$$
\begin{array}{r}
84.370 \\
84.388 \\
84.377 \\
84.367 \\
84.370 \\
\hline 84.3744, \pm .0025
\end{array}
$$

The general mean from both series is $84.3743, \pm .0025$.

The ratio directly connecting silver nitrate with ammonium chloride has been determined only by Stas. $\ddagger$ The usual method of working was followed, namely, nearly equivalent quantities of the two salts were weighed out, the solutions mixed, and the slight excess of one estimated by titration. In four experiments 100 parts of silver nitrate were found equivalent to chloride of ammonium, as follows:

$$
\begin{array}{r}
31.489 \\
31.490 \\
31.487 \\
31.486 \\
\frac{31.488}{\text { Mean, }} \pm .0006
\end{array}
$$

The similar ratio between potassium chloride and silver nitrate has been determined by both Marignac and Stas. 
Marignac* gives the following weights. I add the quantity of $\mathrm{KCl}$ proportional to 100 parts of $\mathrm{AgNO}_{3}$ :

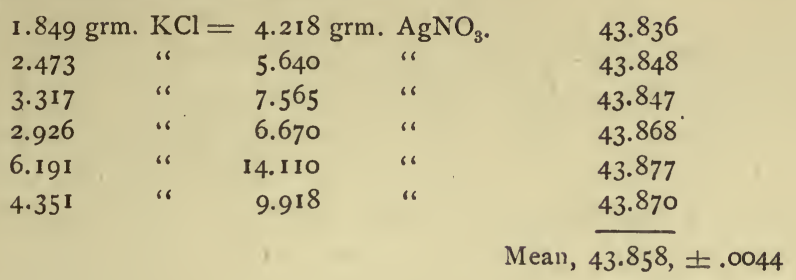

Stas' $\dagger$ results are given in three series, representing silver nitrate from three different sources. In the third series the nitrate was weighed in vacuo, while for the other series this correction was applied in the usual way. For the $\mathrm{KCl}$ equiralent to 100 parts of $\mathrm{AgNO}_{3}$ Stas found:

First Series.

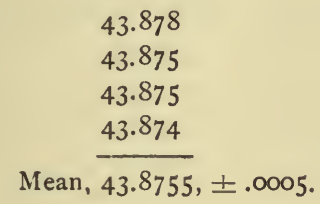

Second Series.

\begin{tabular}{c}
43.864 \\
43.869 \\
43.876 \\
\hline Mean, $43.8697, \pm .0023$.
\end{tabular}

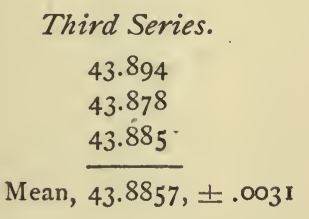

Combining all four series we have:

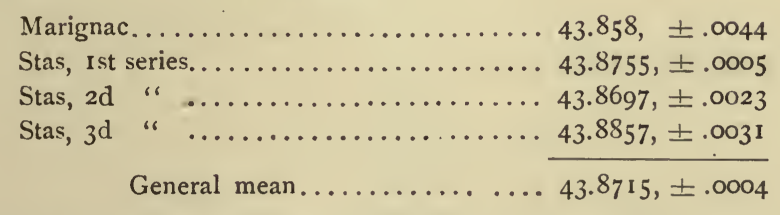

There have also been determined by Penny, by Stas, and by Hibbs a series of ratios connecting the alkaline chlorides and chlorates with the corresponding nitrates. One of these, relating to the lithium salts, will be studied farther on with reference to that metal. 
The general method of working upon these ratios is due to Penny.* Applied to the ratio between the chloride and nitrate of potassium, it is as follows: A weighed quantity of the chloride is introduced into a flask which is placed upon its side and connected with a receiver. An excess of pure nitric acid is added, and the transformation is gradually brought about by the aid of heat. Then, upon evaporating to dryness over a sand bath, the nitrate is brought into weighable form. The liquid in the receiver is also evaporated, and the trace of solid matter which had been mechanically carried over is recovered and also taken into account. In another series of experiments the nitrate was taken, and by pure hydrochloric acid converted into chloride, the process being the same. In the following columns of figures I have reduced both series to one standard, namely, so as to express the number of parts of nitrate corresponding to 100 of chloride:

First Series. $-\mathrm{KCl}$ treated with $\mathrm{HNO}_{3}$.

$\mathbf{1} 35.639$
$\mathrm{r} 35.637$
$\mathrm{r} 35.640$
$\mathrm{I} 35.635$
$\mathrm{r} 35.630$
$\mathrm{I} 35.640$
$\mathrm{I} 35.630$
Mean, $\mathbf{1} 35.636, \pm .001 \mathrm{I}$

Second Series. $-\mathrm{KNO}_{3}$ treated with $\mathrm{HCl}$.

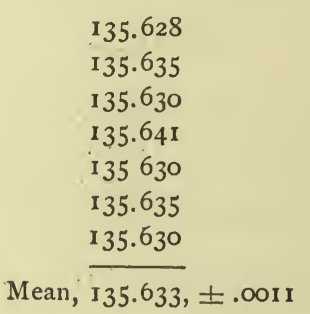

Stas' $†$ results are as follows:

$$
\begin{gathered}
\mathbf{1} 35.643 \\
\mathbf{1} 35.638 \\
\mathbf{1} 35.647 \\
\mathbf{1} 35.649 \\
135.640 \\
\mathbf{1} 35.645 \\
\mathbf{1} 35.655 \\
\hline \text { Mean, } 135.6453, \pm .0014
\end{gathered}
$$


These figures by Stas represent weighings in the air. Reduced to a vacuum standard, this mean becomes 135.6423 .

The determinations made by Hibbs* differ slightly in method from those of Penny and Stas. He converted the nitrate into the chloride by heating in a stream of gaseous hydrochloric acid. His results were as follows, vacuum weights being given .

$\begin{array}{ccc}\text { Weight } \mathrm{KNO}_{3} & \text { Weight } \mathrm{KCl} & \text { Ratio. } \\ .11090 & .08177 & 135.624 \\ .14871 & .10965 & 135.622 \\ .21067 & .15533 & 135.627 \\ .23360 & .17225 & 135.620 \\ .24284 & .17903 & 135.642 \\ & 1 & \text { Mean, } 135.627, \pm .0026\end{array}$

Now, combining, we have:

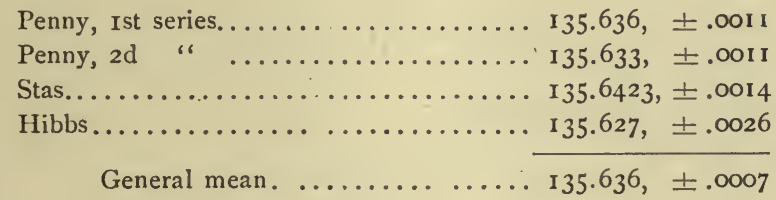

By the same general process Penny $\dagger$ determined how much potassium nitrate could be formed from 100 parts of chlorate. He found as follows :

$$
\begin{array}{r}
82.505 \\
82.497 \\
82.498 \\
82.500 \\
\hline \text { Mean, } 82.500, \pm .0012
\end{array}
$$

For 100 parts of sodium chlorate he found of nitrate:

$$
\begin{gathered}
79.875 \\
79.882 \\
\frac{79.890}{\text { Mean, }}= \\
79.8823, \pm .0029
\end{gathered}
$$

For the ratio between the chloride and nitrate of sodium Penny made two sets of estimations, as in the case of potassium salts. The subjoined figures give the amount of nitrate equivalent to 100 parts of chloride:

* Thesis for Doctor's degree, University of Pennsylvania, 1896. Work done under the direction of Professor E. F. Smith.

† Phil. Trans., 1839 . 
First Series. - $\mathrm{NaCl}$ treated with $\mathrm{HNO}_{3}$.

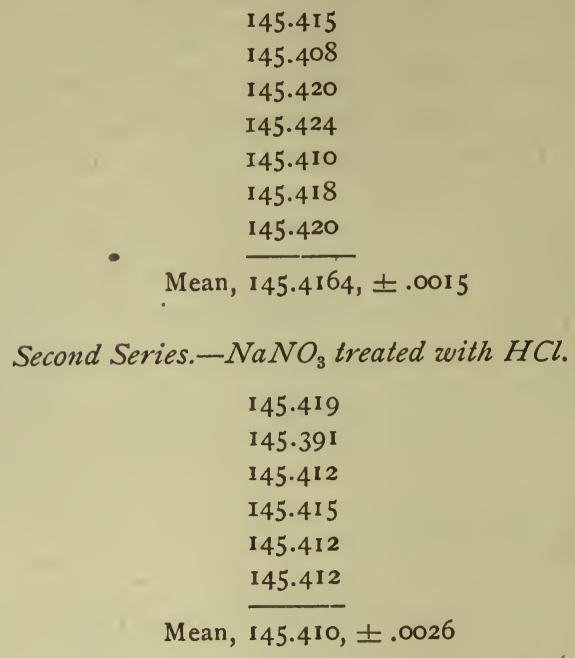

Second Series. $-\mathrm{NaNO}_{3}$ treated with $\mathrm{HCl}$.

$$
\begin{gathered}
145.419 \\
145.391 \\
145.412 \\
145.415 \\
145.412 \\
145.412 \\
\text { Mean, } 145.410, \pm .0026
\end{gathered}
$$

Stas * gives the following series :

$$
\begin{array}{r}
145.453 \\
145.468 \\
145.465 \\
145.469 \\
I 45.443
\end{array}
$$

Mean, after reducing to vacuum standard, $145.4526, \pm .0030$

Hibbs' $\dagger$ data, obtained by the method employed in the case of the potassium compounds, are as follows, vacuum weights being stated:

$\begin{array}{cc}\text { Weight } \mathrm{NaNO}_{3} . & \text { Weight } \mathrm{NaCl} \\ .01550 & .01066 \\ .20976 & .14426 \\ .26229 & .18038 \\ .66645 & .45829 \\ .93718 & .64456\end{array}$

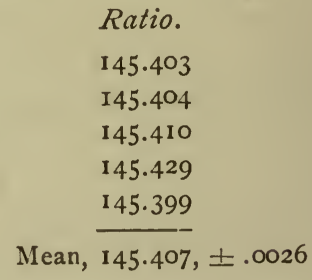

Combining, we have as follows:

$$
\begin{aligned}
& \text { Penny, Ist series................ 145.4164, } \pm .0015 \\
& \text { Penny, 2d " } \ldots \ldots \ldots \ldots \ldots \ldots \ldots \text { 145.410, } \pm .0026 \\
& \text { Stas......................... 145.4526, } \pm .0030 \\
& \text { Hibbs..................... 145.407, } \pm .0026 \\
& \text { General mean............. } 145.418, \pm .0012
\end{aligned}
$$


Julius 'Thomsen, * for the purpose of fixing indirectly the ratio $\mathrm{H}: \mathrm{O}$, has made a valuable series of determinations of the ratio $\mathrm{HCl}: \mathrm{NH}_{3}$, which may properly be used toward establishing the atomic weight of nitrogen. First, pure, dry, gaseous hydrochloric acid is passed into a weighed absorption apparatus containing pure distilled water. After noting the increase in weight, pure ammonia gas is passed in until a very slight excess is present, and the apparatus is weighed again. The excess of $\mathrm{NH}_{3}$, which is always minute, is measured by titration with standard hydrochloric acid. In weighing, the apparatus is tared by one of similar form, and containing about the same amount of water. Three series of determinations were made, differing only in the size of the absorption apparatus; so that for present purposes the three may be taken as one. Thomsen considers them separately, and so gives greatest weight to the experiments involving the largest masses of material. I give his weighings, and also, as computed by him, the ratio $\frac{\mathrm{HCl}}{\mathrm{NH}_{3}}$.

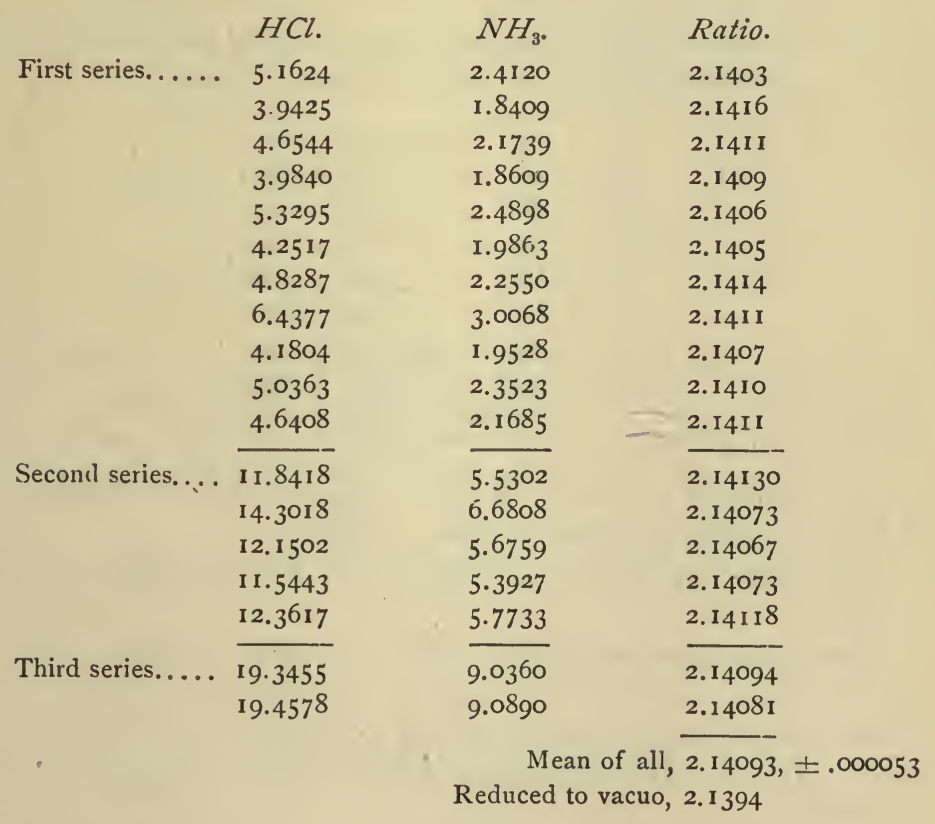

From the sums of the weights Thomsen finds the ratio to be 2.14087, or 2.13934 in vacuo. From this, using Ostwald's reductions of Stas' data for the atomic weights of $\mathrm{N}$ and $\mathrm{Cl}$, he finds the atomic weight of $\mathrm{H}=$ 0.99946 , when $\mathrm{O}=16$.

We have now, apart from the determinations of gaseous density, eleven ratios, representing one hundred and sixty-four experiments, from which 
to calculate the atomic weight of nitrogen. Let us first collect and number these ratios:

(I.) $\mathrm{Ag}: \mathrm{AgNO}_{3}:: 100: 157.479, \pm .0003$

(2.) $\mathrm{AgNO}_{3}: \mathrm{AgCl}:: 100: 84.3743, \pm .0025$

(3.) $\mathrm{AgNO}_{3}: \mathrm{KCl}:: 100: 43.8715, \pm .0004$

(4.) $\mathrm{AgNO}_{3}: \mathrm{NH}_{4} \mathrm{Cl}:: 100: 3 \mathrm{I} .488, \pm .0006$

(5.) $\mathrm{Ag}: \mathrm{NH}_{4} \mathrm{Cl}:: 100: 49.5983, \pm .0003 \mathrm{I}$

(6.) $\mathrm{Ag}: \mathrm{NH}_{4} \mathrm{Br}:: 100: 90.8299, \pm .0008$

(7.) $\mathrm{KCl}: \mathrm{KNO}_{3}:: 100: 135.636, \pm .0007$

(8.) $\mathrm{KClO}_{3}: \mathrm{KNO}_{3}:: 100: 82.500, \pm .0012$

(9.) $\mathrm{NaCl}: \mathrm{NaNO}_{3}::$ I00: $145418, \pm .001 \mathrm{I}$

(10.) $\mathrm{NaClO}_{3}: \mathrm{NaNO}_{3}::$ : $00: 79.8823, \pm .0029$

(II.) $\mathrm{NH}_{3}: \mathrm{HCl}::$ I.00: $: 2.1394, \pm .000053$

From these ratios we are now able to deduce the molecular weight of ammonium chloride, ammonium bromide, and three nitrates. For these calculations we must use the already ascertained atomic weights of oxygen, silver, chlorine, bromine, sodium and potassium, and the molecular weights of sodium chloride, potassium chloride, and silver chloride. The following are the antecedent values to be employed:

$$
\begin{aligned}
& \mathrm{Ag}=107.108, \pm .003 \mathrm{I} \\
& \mathrm{K}=38.8 \mathrm{I} 7 \pm .005 \mathrm{I} \\
& \mathrm{Na}=22.88 \mathrm{I}, \pm .0046 \\
& \mathrm{Cl}=35.179, \pm .0048 \\
& \mathrm{Br}=79.344, \pm .0062 \\
& \mathrm{O}_{3}=47.637, \pm .0009 \\
& \mathrm{AgCl}=\mathrm{I} 42.287, \pm .0037 \\
& \mathrm{KCl}=74.025, \pm .0019 \\
& \mathrm{NaCl}=58.060, \pm .0017
\end{aligned}
$$

Now, from ratio number five we get the molecular weight of $\mathrm{NH}_{4} \mathrm{Cl}=$ $53.124, \pm .0016$, and $\mathrm{N}=13.945, \pm .0051$.

From ratio number six, $\mathrm{NH}_{4} \mathrm{Br}=97.286, \pm .0029$, and $\mathrm{N}=13.942$, \pm .0077 .

From ratio number eleven, $\mathrm{NH}_{3}=16.911, \pm .0048$, and $\mathrm{N}=13.911$, \pm .0048 .

From ratio number four, which involves an expression of the type $\mathrm{A}: \mathrm{B}:: \mathrm{C}+x: \mathrm{D}+x$, an independent value is deducible, $\mathrm{N}=13.935$, \pm .0073 .

For the molecular weight of silver nitrate there are three values, namely :

$$
\begin{aligned}
& \text { From }(\mathrm{I}) \ldots \ldots \ldots \ldots \ldots \ldots \ldots \mathrm{AgNO}_{3}=168.673, \pm .0049 \\
& \text { From (2).............. " }=168.634, \pm .0066 \\
& \text { From (3) ........... " } \quad=168.731, \pm .0046 \\
& \text { General mean.......... } \mathrm{AgNO}_{3}=168.690, \pm .0030
\end{aligned}
$$

Hence $\mathrm{N}=13.945, \pm .0044$. 
Thé molecular weight of potassium nitrate is twice calculable, as follows :

$$
\begin{aligned}
& \text { From }(7) \ldots \ldots \ldots \ldots \ldots \ldots \mathrm{KNO}_{3}=100.405, \pm .0026 \\
& \text { From (8)............... " }=100.371, \pm .0059 \\
& \text { General mean........... } \mathrm{KNO}_{3}=100.401, \pm .0024
\end{aligned}
$$

Hence $\mathrm{N}=13.947, \pm .0057$.

And for sodium nitrate we have :

$$
\begin{aligned}
& \text { From (9)............... NaNO } \mathrm{NaN}_{3}=84.430, \pm .0026 \\
& \text { From (10)............. “ }=84.433, \pm .0053 \\
& \text { General mean......... } \mathrm{NaNO}_{3}=34.431, \pm .0023
\end{aligned}
$$

\section{Hence $\mathrm{N}=13.913, \pm .0052$.}

There are now seven estimates of the atomic weight of nitrogen, to be combined by means of the usual formula.

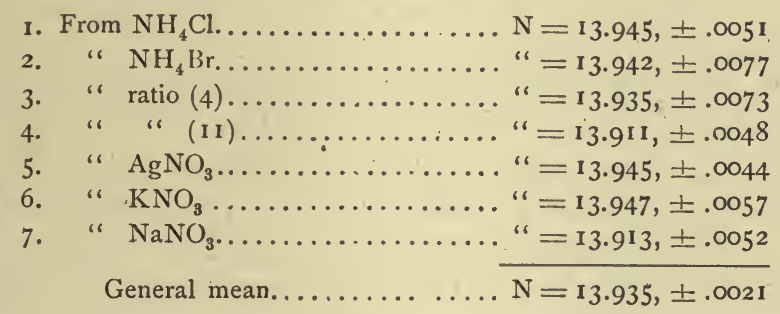

If oxygen is 16, this becomes 14.041. From Stas' data alone, Stas finds 14.044; Ostwald, 14.0410 ; Van der Plaats, 14.0421 (A), and 14.0519 (B); and Thomsen, 14.0396. The new value, representing all available data, falls between these limits of variation. 


\section{CARBON.}

Although there is a large mass of material relating to the atomic weight of carbon, much of it may be summarily set aside as having no value for present purposes: The density of carbon dioxide, which has been scrupulously determined by many investigators, $*$ leads to no safe estimate of the constant under consideration. The numerous analyses of hydrocarbons, like the analyses of naphthalene by Mitscherlich, Woskresensky, Fownes, and Dumas, give results scarcely more satisfactory. In short, all the work done upon the atomic weight of carbon before the year 1840 may be safely rejected as unsuited to the present requirements of exact science. As for methods of estimation we need consider but four, as follows:

First. The analysis of organic salts of silver.

Second. The determination of the weight of carbon dioxide formed by the combustion of a known weight of carbon.

Third. The method of Stas, by the combustion of carbon monoxide.

Fourth. From the density of carbon monoxide.

The first of these methods, which is probably the least accurate, was employed by Liebig and Redtenbacher $\dagger$ in 1840. They worked with the acetate, tartrate, racemate, and malate of silver, making five ignitions of each salt, and determining the percentage of metal. From one to nine grammes of material were used in each experiment.

In the acetate the following percentages of silver were found:

$$
\begin{gathered}
64.615 \\
64.624 \\
64.623 \\
64.614 \\
64.610 \\
\frac{64.6172}{64} \pm .0018
\end{gathered}
$$

After applying corrections for weighing in air, this mean becomes 64.6065 .

In the tartrate the silver came out as follows:

$$
\begin{array}{r}
59.297 \\
59.299 \\
59.287 \\
59.293 \\
59.293 \\
\text { Mean, } 592938, \pm .0014
\end{array}
$$

\footnotetext{
* Notably by Lavoisier, Biot and Arago, De Saussure, Dulong and Berzelius, Buff, Von Wrede, Regnault, and Marchand. For details, Van Geun's monograph may be consulted.

† Ann. Chem. Pharm., 38, I37. Mem. Chem. Soc., I, 9. Phil. Mag. (3), I9, 2 Io.
} 
In the racemate we have:

59.290
59.292
59.287
59.283
59.284
$\frac{59.2872}{\text { Mean, }} \pm .0012$
Or, corrected, 59.2769

And from the malate:

61.996
61.972
62.015
62.059
62.011
Mean, $62.0106, \pm .0096$
Or, corrected, 62.0016

Now, applying to these mean results the atomic weights already found for oxygen and silver, we get the following values for carbon :

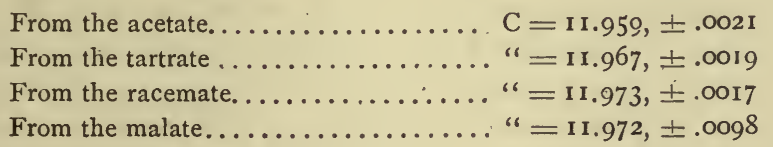

Now these results, although remarkably concordant, are by no means unimpeachable. They involve two possible sources of constant error, namely, impurity of material and the volatility of the silver. These objections have both been raised by Stas, who found that the silver tartrate, prepared as Liebig and Redtenbacher prepared it, always carried traces of the nitrate, and that he, by the ignition of that salt, could not get results at all agreeing with theirs. In the case of the acetate a similar impurity would lower the percentage of silver, and thus both sources of error would reinforce each other and make the atomic weight of carbon come out too high. With the three other salts the two sources of error act in opposite directions, although the volatility of the silver is probably far greater in its influence than the impurity. Even if we had no other data relating to the atomic weight of carbon, it would be clear from these facts that the results obtained by Liebig and Redtenbacher must be decidedly in excess of the true figure.

Strecker, * however, discussed the data given by Liebig and Redtenbacher by the method of least squares, using the Berzelian scale, and assuming $\mathrm{H}=12.51$. Thus treated, they gave $\mathrm{C}=75.415$, and $\mathrm{Ag}=$ 1348.79 ; or, with $\mathrm{O}=16, \mathrm{C}=12.066$ and $\mathrm{Ag}=107.903$. These values

*Ann. Chem. Pharm., 59, 280. I846. 
of course would change somewhat upon adoption of the modern ratio between $\mathrm{O}$ and $\mathrm{H}$.

Observations upon silver acetate, dike those of Liebig and Redtenbacher, were also made by Marignac.* The salt was prepared by dissolving silver carbonate in acetic acid, and repeatedly recrystallizing. Two experiments gave as follows:

$$
\begin{aligned}
& 3.3359 \mathrm{grm} \text {, acetate gave } 2.156 \mathrm{r} \mathrm{Ag} \text {. } \quad 64.633 \text { per cent. } \\
& 3.0527 \text { " } 1.9727 \text { " } \\
& 64.621 \\
& \text { Mean, } \overline{64.627} \pm .0040
\end{aligned}
$$

Reduced to a vacuum, this becomes 64.609 .

In a second series, conducted with special precautions to avoid mechanical loss by spurting, Marignac found:

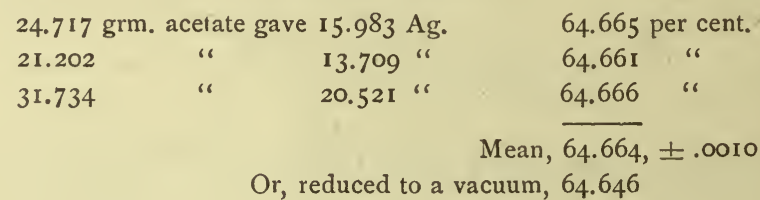

Other experiments, comparable with the preceding series, have recently been published by Hardin, $\dagger$ who sought to redetermine the atomic weight of silver. Silver acetate and silver benzoate, carefully purified,

\begin{tabular}{|c|c|c|c|c|c|}
\hline \multicolumn{4}{|c|}{$.32470 \mathrm{grm}$. acetate gave $.20987 \mathrm{Ag}$. } & \multicolumn{2}{|c|}{64.635 per cent. } \\
\hline .40566 & “ & .26223 & 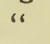 & 64.643 & “ \\
\hline .52736 & “ & .34086 & “ & 64.635 & “ \\
\hline .60300 & “ & .38976 & “ & 64.637 & “ \\
\hline .67235 & “ & .43455 & “ & $64.63 \mathrm{I}$ & “ \\
\hline $.7245^{2}$ & “ & .46830 & “ & 64.636 & “ \\
\hline .78232 & “ & .50563 & “ & 64.632 & “ \\
\hline .79804 & $w$ & .51590 & “ & 64.646 & “ \\
\hline .92101 & “ & .59532 & “ & 64.638 & “ \\
\hline r.02495 & " & $.6625^{\circ}$ & “ & 64.637 & “ \\
\hline
\end{tabular}
were subjected to electrolysis in a platinum dish, and the percentage of silver so determined. For the acetate, using vacuum weights, he gives the following data, the percentage column being added by myself:

Combining this series with those of the earlier investigators we have:

$$
\begin{aligned}
& \text { Liebig and Redtenbacher............6 64.6065, } \pm .0018 \\
& \text { Marignac, Ist series................ 64.609, } \pm .0040 \\
& \text { Marignac, 2d " ...............64.646, } \pm .0010 \\
& \text { Hardin..................... 64.637, } \pm .00 \mathrm{II} \\
& \text { General mean.............. } \overline{64.636, \pm .0007}
\end{aligned}
$$


With silver benzoate, $\mathrm{C}_{7} \mathrm{H}_{5} \mathrm{AgO}_{2}$, Hardin's results are as follows:

\begin{tabular}{|c|c|c|c|c|c|c|}
\hline \multicolumn{5}{|c|}{$.4085^{8} \mathrm{grm}$. benzoate gave $.19255^{-} \mathrm{Ag}$. } & \multicolumn{2}{|c|}{ 47.127 per cent. } \\
\hline .46674 & “ & .21999 & “ & $=$ & 47. 133 & ، \\
\hline .48419 & “ & .22815 & “ & & 47.120 & “ \\
\hline .62432 & “ & .29418 & “ & & 47.120 & “ \\
\hline .66496 & “ & .31340 & “ & & $47 \cdot 13 \mathrm{I}$ & “ \\
\hline .75853 & “ & .35745 & “ & & 47.124 & “ \\
\hline .76918 & “ & .36247 & “ & & 47. 124 & “ \\
\hline .81254 & “ & .38286 & “ & & 47.119 & " \\
\hline .95673 & “ & .45079 & “ & & 47.118 & “ \\
\hline 1.00840 & “ & .47526 & "6 & & 47.130 & 66 \\
\hline
\end{tabular}

A different method of dealing with organic silver salts was adopted by Maumené, $*$ in 1846 , for the purpose of establishing by reference to carbon the atomic weight of silver. We will simply reverse his results and apply them to the atomic weight of carbon. He effected the combustion of the acetate and the oxalate of silver, and, by weighing both the residual metal and the carbon dioxide formed, he fixed the ratio between these two substances. In the case of the acetate his weighings show that for every gramme of metallic silver the weights of $\mathrm{CO}_{2}$ were produced which are shown in the third column:

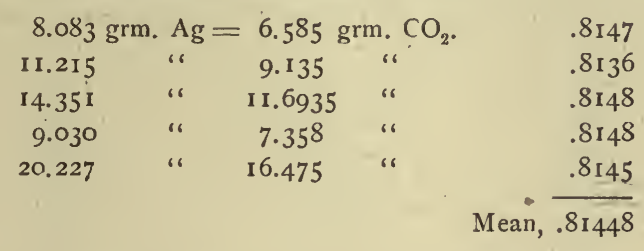

The oxalate of silver, ignited by itself, decomposes too violently to give good results; and for this reason it was not used by Liebig and Redtenbacher. Maumené, however, found that when the salt was mixed with sand the combustion could be tranquilly effected. The oxalate employed, however, with the exception of the sample represented in the last experiment of the series, contained traces of nitrate, so that these results involve slight errors. For each gramme of silver the appended weights of $\mathrm{CO}_{2}$ were obtained :

\begin{tabular}{|c|c|c|c|c|}
\hline $\mathrm{I} 4.299 \mathrm{~g}$ & A & 5.835 & $\mathrm{CO}_{2}$ & $.408 \mathrm{I}$ \\
\hline I 7.754 & “" & 7.217 & " & .4059 \\
\hline II. $55^{\circ}$ & " & 4.703 & “" & .4072 \\
\hline 10.771 & " & $4 \cdot 3^{87}$ & “ & .4073 \\
\hline 8.674 & "“ & 3.533 & " & .4073 \\
\hline II. 4355 & “ & $4.65^{8}$ & “" & .4073 \\
\hline
\end{tabular}


Now, one of these salts being formed by a bivalent and the other by a univalent acid, we have to reduce both to a common standard. Doing this, we have the following results for the ratio between the atomic weight of silver and the molecular weight of $\mathrm{CO}_{2}$; if $\mathrm{Ag}=1.00$ :

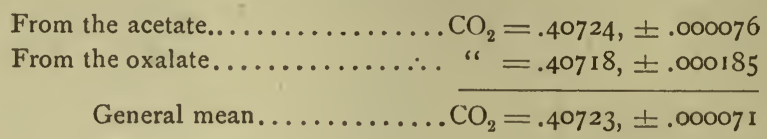

Here the slight error due to the impurity of the oxalate becomes of such trifling weight that it practically vanishes.

As has already been said, the volatility of silver renders all the foregoing results more or less uncertain. Far better figures are furnished by the combustion of carbon directly, as carried out by Dumas and Stas * in 1840 and by Erdmann and Marchand $\dagger$ in 1841. In both investigations weighed quantities of diamond, of natural graphite, and of artificial graphite were burned in oxygen, and the amount of dioxide produced was estimated by the usual methods. The graphite employed was purified with extreme care by treatment with strong nitric acid and by fusion with caustic alkali. I have reduced all the published weighings to a common standard, so as to show in the third column the amount of oxygen which combines with a unit weight (say one gramme) of carbon. Taking Dumas and Stas' results first in order, we have from natural graphite:

$$
\begin{aligned}
& \text { I.000 grm. C gave } 3.67 \mathrm{I} \mathrm{grm.} \mathrm{CO}_{2} \text {. } \quad 2.6710 \\
& \begin{array}{llll}
.998 \text { " " } 3.660 \text { " } & 2.6673
\end{array} \\
& .994 \text { " " } 3.645 \text { " } \quad 2.6670 \\
& \begin{array}{llll}
1.216 & \text { " " } & & \\
1.461 & & 2.6686
\end{array} \\
& \text { I.47 I " } \quad 5.395 \text { " } 2.6676 \\
& \text { Mean, } \overline{2.6683}, \pm .0005
\end{aligned}
$$

\begin{tabular}{|c|c|c|c|}
\hline $.992 \mathrm{grm}$ & C gave 3.642 & in. $\mathrm{CO}_{2}$. & 2.6714 \\
\hline .998 & " $\quad 3.662$ & " & 2.6682 \\
\hline 1.660 & 6.085 & " & 2.6654 \\
\hline I. 465 & 5.365 & " & 2.6744 \\
\hline
\end{tabular}

With artificial graphite:

And with diamond:

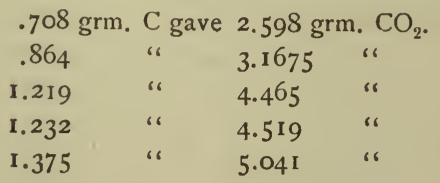

$\begin{array}{r}2.6695 \\ 2.666 \mathrm{I} \\ 2.6628 \\ 2.6680 \\ 2.6662 \\ \hline \text { Mean, } 5.6665 \pm .0007\end{array}$

* Compt. Rend., Ir, 991-I008. Ann. Chim. Phys. (3), I, I.

† Jour. f Prakt. Chem., 23, 159. 
Erdmann and Marchand's figures for natural graphite give the following results:

$\begin{array}{lllll}\text { I. } 5376 \text { grm. gave } 5.6367 & \text { grm. } \mathrm{CO}_{2} \text {. } & 2.6659 \\ \text { I. } 6494 & \text { " } & 6.0384 & \text { " } & 2.6609 \\ \text { I. } 4505 & \text { " } & 5.31575 & \text { " } & 2.6647\end{array}$

In one experiment $1.8935 \mathrm{grm}$. of artificial graphite gave $6.9355 \mathrm{grm}$. $\mathrm{CO}_{2}$. Ratio for $\mathrm{O}, 2.6628$. This, combined with the foregoing series, gives a mean of $2.6636, \pm .0007$.

With the diamond they found:

$\begin{array}{lllll}.8052 \text { grm. gave } 2.9467 & \text { grm. } \mathrm{CO}_{2} . & 2.6596 \\ 1.0858 & \text { “ } & 3.9875 & \text { “ } & 2.6632 \\ 1.3557 & \text { “ } & 4.9659 & \text { “ } & 2.6629 \\ 1.6305 & \text { “ } & 5.97945 & \text { “ } & 2.6673 \\ .7500 & \text { “ } & 2.7490 & \text { " } & 2.6653 \\ & & & & \text { Mean, } 2.6637, \pm .0009\end{array}$

In more recent years the ratio under consideration has been carefully redetermined by Roscoe, by Friedel, and by Van der Plaats. Roscoe* made use of transparent Cape diamonds, and in a sixth experiment he burned carbonado. The combustions were effected in a platinum boat, contained in a tube of glazed Berlin porcelain; and in each case the ash was weighed and its weight deducted from that of the diamond. The results were as follows, with the ratios stated as in the preceding series:

\begin{tabular}{|c|c|c|c|}
\hline $\mathrm{r} .2820 \mathrm{grm}$. & $\mathrm{C}$ gave $4: 7006$ & $\mathrm{CO}_{2}$. & 2.6666 \\
\hline I. 1254 & 4. 1245 & “ & 2.6649 \\
\hline 1.5287 & 5.6050 & “ & 2.6665 \\
\hline .7112 & 2.6070 & “ & 2.6656 \\
\hline 1.3842 & 5.0765 & “ & 2.6675 \\
\hline .4091 & 1.4978 & “6 & 2.6612 \\
\hline
\end{tabular}

Friedel's work, $\dagger$ also upon Cape diamond, was in all essential particulars like Roscoe's. The data, after deduction of ash, were as follows:

$$
\begin{array}{lrrr}
.4705 \mathrm{grm} . \mathrm{C} \text { gave } \mathbf{1 . 7 2 0 8} \mathrm{CO}_{2} . & 2.6628 \\
.8616 & 3.1577 " & 2.6640 \\
. & & \text { Mean, } 2.6634, \pm .0004
\end{array}
$$

By Van der Plaats $\ddagger$ we have six experiments, numbers one to three on graphite, numbers four and five on sugar charcoal, and number six on charcoal made from purified filter paper. Each variety of carbon was submitted to elaborate processes of purification, and all weights were

*Ann. Chim. Phys. (5), 26, 136. Zeit. Anal. Chem., 22, 306. 1883. Compt. Rend., 94, I180. I882. $\dagger$ Bull. Soc. Chim., 42, 100, 1884 .

$\ddagger$ Compt. Rend., I00, 52. 1885 . 
reduced to vacuum standards. The data, with ash deducted, are subjoined :

I. 5.1217 grm. $\mathrm{C}$ gave $18.7780 \mathrm{CO}_{2}$. $\quad 2.6664$

2. 9.0532 " 33.193 I " 2.6664

3. 13.0285 " 404.766 I

4. 11.7352 " " 43.0210 " 102.6660

5. 19.1335 " " 70.1336 " 2.6655

6. 4.4017 " " 6.1352 " 2.6657

Mean, $\overline{2.6660} \pm .0001$

This combines with the previous series thus:

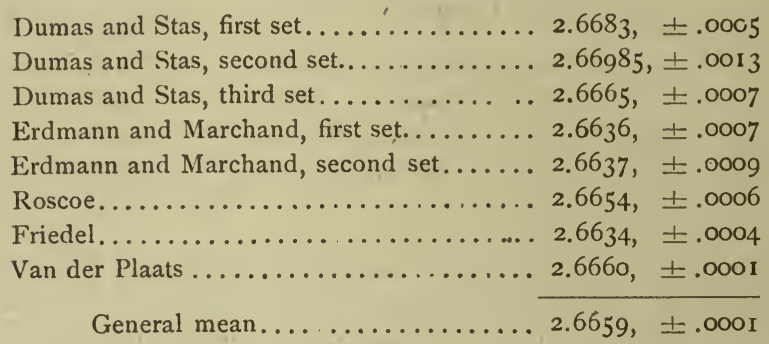

Another very exact method for determining the atomic weight of earbon was employed by Stas* in 1849. Carefully purified carbon monoxide was passed over a known weight of copper oxide at a red heat, and both the residual metal and the carbon dioxide formed were weighed. The weighings. were reduced to a vacuum standard, and in each experiment a quantity of copper oxide was taken representing from eight to twenty-four grammes of oxygen. The method, as will at once be seen, is in all essential features similar to that usually employed for determining the eomposition of water. The figures in the third column, deduced from the weights given by Stas, represent the quantity of earbon monoxide corresponding to one gramme of oxygen:

\begin{tabular}{|c|c|c|c|c|}
\hline \multicolumn{4}{|c|}{$9.265 \mathrm{grm} . \mathrm{O}=25.483 \mathrm{CO}_{2}$. } & I. 75046 \\
\hline 8.327 & “ & 22.900 & “" & 1.75010 \\
\hline $13.943^{8}$ & " & $3^{8.351}$ & " & I. 75040 \\
\hline I 1.6124 & “ & 31.935 & “ & 1. 75008 \\
\hline 18.763 & “ & 51.6055 & “ & 1.75039 \\
\hline 19.581 & ، & 53.8465 & “" & I.74994 \\
\hline 22.515 & “ & 61.926 & “ & 1.75043 \\
\hline 24.360 & “ & 67.003 & “ & 1.75053 \\
\hline
\end{tabular}

For the density of earbon monoxide the determinations made by Leduc $\dagger$ are available. The globe used contained $2.9440 \mathrm{grm}$. of air. 
Filled with $\mathrm{CO}$, it held the following weights, which give the accompanying densities:

$$
\begin{gathered}
W t . C O . \\
2.8470 \\
2.8468 \\
2.8469
\end{gathered}
$$

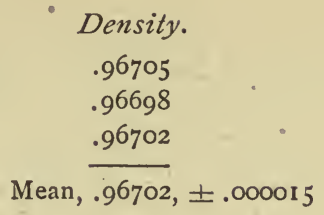

Combining this density with Leduc's determination of the density of hydrogen, $0.6948, \pm .00006745$, it gives for the atomic weight of carbon:

$$
\mathrm{C}=\mathrm{II} .957, \pm .0270 \text {. }
$$

Leduc himself combines the data with the density of oxygen, taken as 1.10503 , and finds $\mathrm{C}=11.913$. In either case, however, the probable error of the result is so high that it can carry little weight in the final combination.

For carbon, including all the foregoing series, we now have the subjoined ratios:

(I.) Per cent. Ag in silver acetate... 64.636, \pm .0007

(2.) " " tartrate... 59.2806, \pm .0014

(3.) " " " racemate.. $59.2769, \pm .0012$

(4.) " " " malate...6 62.0016, \pm .0096

(5.) " " benzoate...47.125, \pm .0012

(6.) $\mathrm{Ag}: \mathrm{CO}_{2}:$ : $1.00: 0.40723, \pm .00007 \mathrm{I}$

(7.) $\mathrm{C}: \mathrm{O}_{2}:: \mathrm{r} .00: 2.6659, \pm .000 \mathrm{I}$

(8.) $\mathrm{O}: \mathrm{CO}:: \mathbf{1 . 0 0 : 1 . 7 5 0 2 9 , \pm . 0 0 0 0 5}$

(9.) Density of CO (air $=1), 0.96702, \pm .000015$

Now, computing with $\mathrm{O}=15.879, \pm .0003$, and $\mathrm{Ag}=107.108, \pm .0031$, we get nine values for the atomic weight of carbon, as follows:

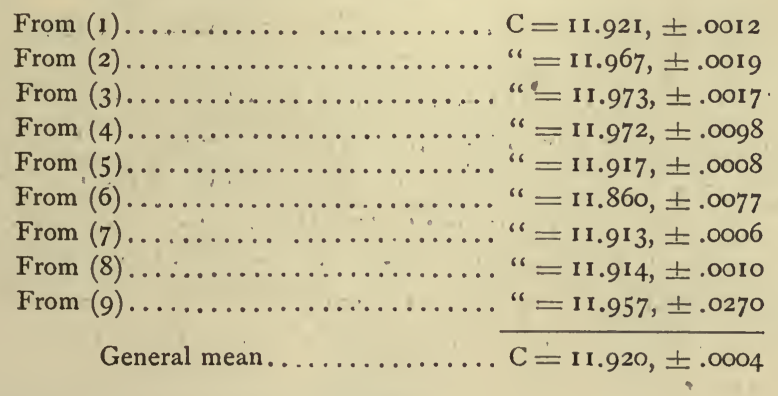

If $\mathrm{O}=16$, this becomes $\mathrm{C}=12.011$. 


\section{SULPHUR.}

The atomic weight of sulphur has been determined by means of four ratios connecting it with silver, chlorine, oxygen, sodium and carbon. Other ratios have also been considered, but they are hardly applicable here. The earlier results of Berzelius were wholly inaccurate, and his later experiments upon the synthesis of lead sulphate will be used in discussing the atomic weight of lead. Erdmann and Marchand determined the amount of calcium sulphate which could be formed from a known weight of pure Iceland spar; and later they made analyses of cinnabar, in order to fix the value of sulphur by reference to calcium and to mercury. Their results will be applied in this discussion toward ascertaining the atomic weights of the metals just named.

First in order let us take up the composition of silver sulphide, as directly determined by Dumas, Stas, and Cooke. Dumas'* experiments were made with sulphur which had been thrice distilled and twice crystallized from carbon disulphide. A known weight of silver was heated in a tube in the vapor of the sulphur, the excess of the latter was distilled away in a current of carbon dioxide, and the resulting silver sulphide was weighed.

I subjoin Dumas' weighings, and also the quantity of $\mathrm{Ag}_{2} \mathrm{~S}$ proportional to 100 parts of $\mathrm{Ag}$, as deduced from them:

\begin{tabular}{|c|c|c|c|c|c|}
\hline 9.9393 & . A & $=1.473$ & $\therefore$ & Ratio, & I 14.820 \\
\hline 9.962 & " & I. 4755 & "I & ، & I I $4.8 \mathrm{II}$ \\
\hline 30.637 & " & 4.546 & "6 & "6 & I 14.838 \\
\hline 30.936 & ، & 4.586 & " & " & 114.824 \\
\hline 30.720 & $"$ & 4.554 & " & “" & 114.824 \\
\hline
\end{tabular}

Dumas used from ten to thirty grammes of silver in each experiment. Stas, $\dagger$ however, in his work employed from sixty to two hundred and fifty grammes at a time. 'Three of Stas' determinations were made by Dumas' method, while in the other two the sulphur was replaced by pure sulphuretted hydrogen. In all cases the excess of sulphur was expelled by carbon dioxide, purified with scrupulous care. Impurities in the dioxide may cause serious error. The five results come out as follows for 100 parts of silver:

$$
\begin{aligned}
& \text { I I } 4.854 \\
& \text { I } 4.853 \\
& \text { I } 4.854 \\
& \text { I } 14.851 \\
& \text { II } 4.849 \\
& \text { Mean, I } 4.8522, \pm .0007
\end{aligned}
$$

* Ann. Chem. Pharm., I13, 24. 1860.

† A ronstein's translation, p. 179. 
The experiments made by Professor Cooke $*$ with reference to this ratio were only incidental to his elaborate researches upon the atomic weight of antimony. They are interesting, however, for two reasons: they serve to illustrate the volatility of silver, and they represent, not syntheses, but reductions of the sulphide by hydrogen. Cooke gives three series of results. In the first the silver sulphide was long heated to full redness in a current of hydrogen. Highly concordant and at the same time plainly erroneous figures were obtained, the error being eventually traced to the fact that some of the reduced silver, although not heated to its melting point, was actually volatilized and lost. The second series, from reductions at low redness, are decidedly better. In the third series the sulphide was fully reduced below a visible red heat. Rejecting the first series, we have from Cooke's figures in the other two the subjoined quantities of sulphide corresponding to 10 n parts of silver:

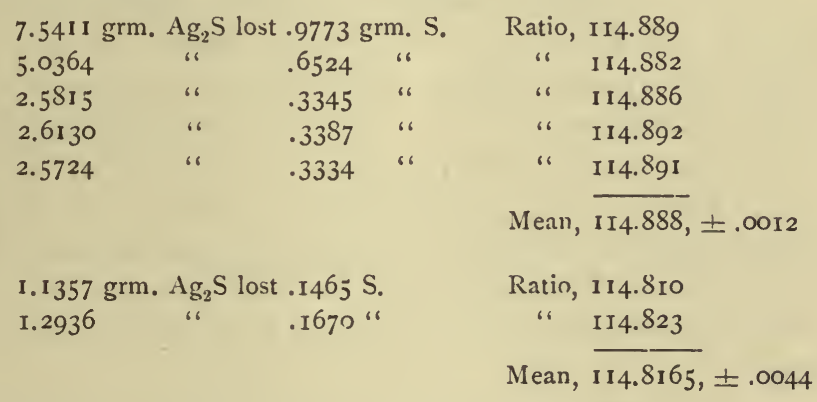

Now, combining all four series, we get the following results:

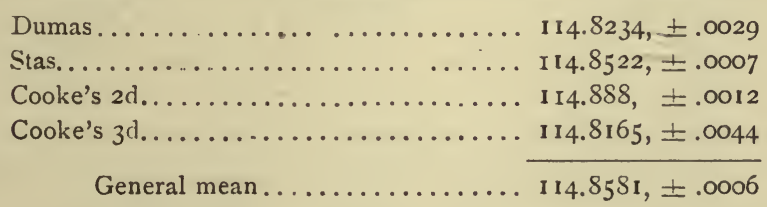

Here again we encounter a curious and instructive compensation of errors, and another evidence of the accuracy of Stas.

The percentage of silver in silver sulphate has been determined by Struve and by Stas. Struve $\uparrow$ reduced the sulphate by heating in a current of hydrogen, and obtained these results:

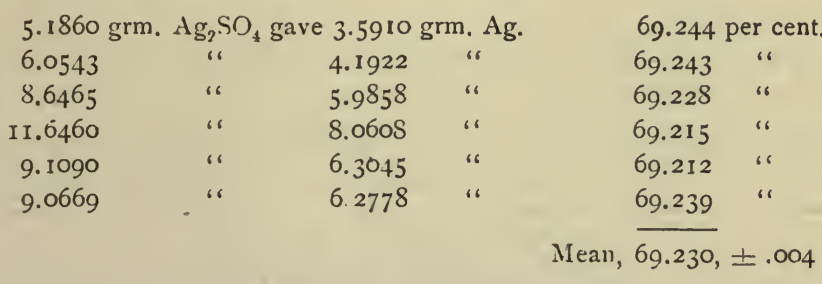


Stas,* working by essentially the same method, with from 56 to 83 grammes of sulphate at a time, found these percentages:

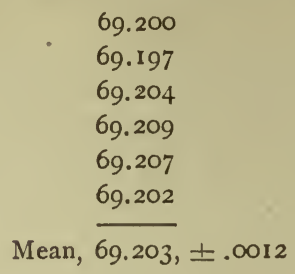

Combining this mean with that from Strure's series, we get a general mean of $69.205, \pm 0011$.

The third sulphur ratio with which we have now to deal is one of minor importance. When silver chloride is heated in a current of sulphuretted hydrogen the sulphide is formed. This reaction was applied by Berzelius $\dagger$ to determining the atomic weight of sulphur. He gives the results of four experiments; but the fourth varies so widely from the others that I have rejected it. I have reason to believe that the variation is due, not to error in experiment, but to error in printing; nevertheless, as I am unable to track out the cause of the mistake, I must exclude the figures involving it entirely from our discussion.

The three available experiments, however, give the following results : The last column contains the ratio of silver sulphide to 100 parts of chloride.

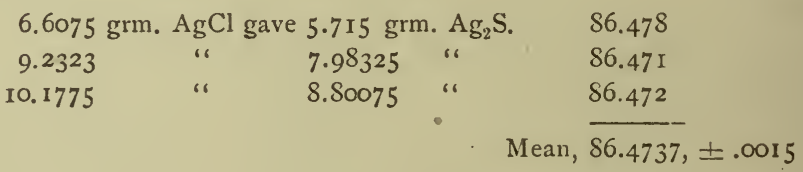

We have also a single determination of this value by Svanberg and Struve. $\neq$ After converting the chloride into sulphide they dissolved the latter in nitric acid. A trifling residue of chloride, which had been enclosed in sulphide, and so protected against change, was left undissolved. Hence a slight constant error probably affects this whole ratio. The experiment of Svanberg and Struve gave 86.472 per cent. of silver sulphide derived from 100 of chloride. If we assign this figure equal weight with the results of Berzelius, and combine, we get a general mean of $86.4733, \pm .0011$.

The work done by Richards $\S$ relative to the atomic weight of sulphur is of a different order from any of the preceding determinations. Sodium carbonate was converted into sodium sulphate, fixing the ratio $\mathrm{Na}_{2} \mathrm{CO}_{3}$ : $\mathrm{Na}_{2} \mathrm{SO}_{4}:: 100: x$. The data are as follows, with vacuum weights:

* Aronstein's translation, pp. 214-218.

† Berzelius' Lehrbuch, 5 th ed., vol. 3 , p. II 87 .

$\ddagger$ Journ. Prakt. Chem., 44, 320. 1848 .

\& Proc. Amer. Acad., 26, 268. 189r. 
SULPHUR.

$\begin{array}{ccc}\mathrm{Na}_{2} \mathrm{CO}_{3} . & \mathrm{Na}_{2} \mathrm{SO}_{4} . & \text { Ratio. } \\ 1.29930 & \mathrm{I} .741 \mathrm{I} 3 & \mathrm{1} 34.005 \\ 3.18620 & 4.26790 & \mathrm{I} 33.950 \\ 1.01750 & 1.36330 & 133.985 \\ 2.07680 & 2.78260 & 133.985 \\ 1.22427 & 1.63994 & 133.952 \\ 1.77953 & 2.3^{8} 465 & 134.005 \\ 2.04412 & 2.73920 & 134.004 \\ 3.06140 & 4.10220 & 133.997 \\ & & \text { Mean, } \mathrm{I} 33.985 \pm .0055\end{array}$

The available ratios for sulphur are now as follows:

(I.) $\mathrm{Ag}_{2}: \mathrm{Ag}_{2} \mathrm{~S}:: \mathrm{I00}: \mathrm{II} 4.858 \mathrm{I}, \pm .0006$

(2.) Per cent. $\mathrm{Ag}$ in $\mathrm{Ag}_{2} \mathrm{SO}_{4}, 69.205, \pm .00 \mathrm{II}$

(3.) $2 \mathrm{AgCl}: \mathrm{Ag}_{2} \mathrm{~S}::$ : $100: 86.4733$, $\pm .00 \mathrm{II}$

(4.) $\mathrm{Na}_{2} \mathrm{CO}_{3}: \mathrm{Na}_{2} \mathrm{SO}_{4}:: 100: 133.985$, \pm .0055

From these ratios, four values for the atomic weight of sulphur are deducible. Calculating with-

$$
\begin{aligned}
& \mathrm{O}=\mathrm{I} 5.879, \pm .0003 \\
& \mathrm{Ag}=107.108, \pm .003 \mathrm{I} \\
& \mathrm{Cl}=35.179, \pm .0048 \\
& \mathrm{Na}=22.88 \mathrm{I}, \pm .0046 \\
& \mathrm{C}=11.920, \pm .0004 \\
& \mathrm{AgCl}=142.287, \pm .0037,
\end{aligned}
$$

we have:

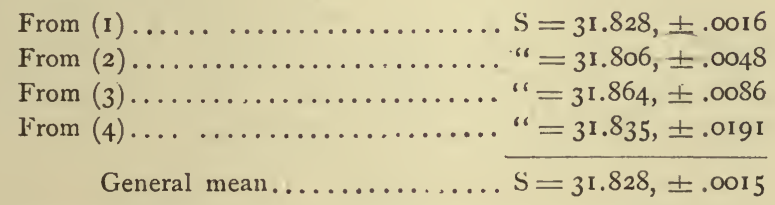

If $\mathrm{O}=16, \mathrm{~S}=32.070$. From Stas' ratios alone, Stas found 32.074; Ostwald, 32.0626 ; Van der Plaats, (A) 32.0576, (B) 32.0590, and Thomsen, 32.0606. Here again Stas' determinations far outweigh all others. 


\section{LITHIUN.}

The earlier determinations of the atomic weight of lithium by Arfvedson, Stromeyer, C. G. Gmelin, and Kralovanzky were all erroneous, because of the presence of sodium compounds in the material employed. The results of Berzelius, Hagen, and Hermann were also incorrect, and need no further notice here. The only investigations which we need to consider are those of Mallet, Diehl, Troost, Stas, and Dittmar.

Mallet's experiments* were conducted upon lithium chloride, which had been purified as completely as possible. In two trials the chloride was precipitated by nitrate of silver, which was collected upon a filter and estimated in the ordinary way. The figures in the third column represent the $\mathrm{LiCl}$ proportional to 100 parts of $\mathrm{AgCl}$ :

$$
\begin{aligned}
& \text { 7. } 1885 \mathrm{grm} . \mathrm{LiCl} \text { gave } 24.3086 \mathrm{grm} . \mathrm{AgCl} . \quad 29.606 \\
& 8.5947 \text { " } 29.0621 \text { “ } 29.574
\end{aligned}
$$

In a third experiment the $\mathrm{LiCl}$ was titrated with a standard solution of silver. 3.9942 grm. LiCl balanced $10.1702 \mathrm{grm}$. Ag, equivalent to $13.511 \mathrm{grm}$. AgCl. Hence $100 \mathrm{AgCl}=29.563 \mathrm{LiCl}$. Mean of all three experiments, $29.581, \pm .0087$.

Diehl $†$ whose paper begins with a good résumé of all the earlier determinations, describes experiments made with lithium carbonate. This salt, which was spectroscopically pure, was dried at $130^{\circ}$ before weighing. It was then placed in an apparatus from which the carbon dioxide generated by the action of pure sulphuric acid upon it could be expelled, and the loss of weight determined. From this loss the following percentages of $\mathrm{CO}_{2}$ in $\mathrm{Li}_{2} \mathrm{CO}_{3}$ were determined:

$$
\begin{array}{r}
59.422 \\
59.404 \\
59.440 \\
59.401 \\
\text { Mean, } 59.417, \pm .006
\end{array}
$$

Diehl's investigation was quickly followed by a confirmation from Troost. + This chemist, in an earlier paper, $\S$ had sought to fix the atomic weight of lithium by an analysis of the sulphate, and had found a value not far from 6.5, thus confirming the results of Berzelius and of Hagen, who had employed the same method. But Diehl showed that the $\mathrm{BaSO}_{4}$ precipitated from $\mathrm{Li}_{2} \mathrm{SO}_{4}$ always retained traces of $\mathrm{Li}$, which were recog-

* Silliman's Amer. Journal, November, 1856. Chem. Gazette, 15, 7.

† Ann. Chem. Pharm., I2I, 93.

$\ddagger Z$ eit. Anal. Chem., I, 402.

\& Annales d. Chim. et d. Phys., 5I, I08. 
nizable by spectral analysis, and which accounted for the error. In the later paper Troost made use of the chloride and the carbonate of lithium, both spectroscopically pure. The carbonate was strongly ignited with pure quartz powder, thus losing carbon dioxide, which loss was easily estimated. The subjoined results were obtained:

$$
\begin{aligned}
& .970 \text { grm. } \mathrm{Li}_{2} \mathrm{CO}_{3} \text { lost } .577 \mathrm{grm} . \mathrm{CO}_{2} \text {. } \quad 59.485 \text { per cent. } \\
& 1.782 \text { " } 1.059 \text { " } 59.427 \text { " } \\
& \text { Mean, } \overline{59.456}, \pm .020
\end{aligned}
$$

The lithium chloride employed by Troost was heated in a stream of dry hydrochloric acid gas, of which the excess, after cooling, was expelled by a current of dry air. The salt was weighed in the same tube in which the foregoing operations had been performed, and the chlorine was then estimated as silver chloride. The usual ratio between $\mathrm{LiCl}$ and 100 parts of $\mathrm{AgCl}$ is given in the third column :

$$
\begin{aligned}
& \text { I. } 309 \mathrm{grm} \text {. } \mathrm{LiCl} \text { gave } 4.420 \mathrm{grm} \text {. } \mathrm{AgCl} .29615 \\
& 2.750 \text { " } \quad 9.300 \text { " } 29.570 \\
& \text { Mean, } \overline{29.5925}, \pm .0145
\end{aligned}
$$

This, combined with Mallet's mean, 29.581, \pm .0087 , gives a general mean of $59.584, \pm .0075$.

Next in order is the work of Stas, * which was executed with his usual wonderful accuracy. In three titrations, in which all the weights were reduced to a vacuum standard, the following quantities of $\mathrm{LiCl}$ balanced 100 parts of pure silver :

$$
\begin{gathered}
39.356 \\
39.357 \\
39.36 \mathrm{r} \\
\hline \text { Mean, } 39.35^{8}, \pm .00 \mathrm{I}
\end{gathered}
$$

In a second series of experiments, intended for determining the atomic weight of nitrogen, $\mathrm{LiCl}$ was converted into $\mathrm{LiNO}_{3}$. The method was that employed for a similar purpose with the chlorides of sodium and of potassium. One hundred parts of $\mathrm{LiCl}$ gave of $\mathrm{LiNO}_{3}$ :

$$
\begin{gathered}
162.588 \\
162.600 \\
162.599 \\
\text { Mean, } \frac{162.5953}{16.0025}
\end{gathered}
$$

The determinations of Dittmar $†$ resemble those of Diehl; but the lithium carbonate used was dehydrated by fusion in an atmosphere of carbon dioxide. The carbonate was treated with sulphuric acid, and 
the $\mathrm{CO}_{2}$ was collected and weighed in an absorption apparatus, which was tared by a similar apparatus after the method of Regnault. The following percentages of $\mathrm{CO}_{2}$ in $\mathrm{Li}_{2} \mathrm{CO}_{3}$ were found:

$\begin{array}{ll} & 59.601 \\ 59.645 & \\ 59.529-\text { rejected. } & 59.655 \\ 59.683 \\ 59.604 \\ 59.517 \\ 59.663 \\ 60.143 \text {-rejected. } \\ 59.794 \\ \frac{59.584}{\text { Mean of all, }} 59.674\end{array}$

Rejecting the two experiments which Dittmar regards as untrustworthy, the mean of the remaining nine becomes $59.638, \pm .0173$. This combines with the work of Diehl and Troost, as follows:

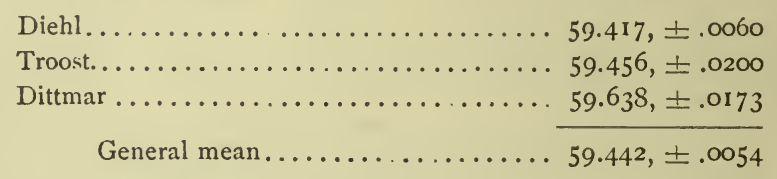

Dittmar's determinations give a much lower value for the atomic weight of lithium than any of the others, and therefore seem to be questionable. As, however, they carry little weight in the general combination, it is not necessary to speculate upon their possible sources of error.

The ratios for lithium are now as follows:
(r.) $\mathrm{AgCl}: \mathrm{LiCl}:: 100: 29.584, \pm .0075$
(2.) Ag: $\mathrm{LiCl}::$ roo : 39.358, $\pm .00 \mathrm{r}$.
(3.) $\mathrm{LiCl}: \mathrm{LiNO}_{3}:: 100: 162.5953, \pm .0025$
(4.) Per cent. of $\mathrm{CO}_{2}$ in $\mathrm{Li}_{2} \mathrm{CO}_{3}, 59.442, \pm .0054$

And the data to use in their reduction are-

$$
\begin{array}{ll}
\mathrm{O}=15.879, \pm .0003 & \mathrm{~N}=13.935, \pm .0015 \\
\mathrm{Ag}=107.108, \pm .003 \mathrm{I} & \mathrm{C}=11.920 \pm .0004 \\
\mathrm{Cl}=35.179, \pm .0048 & \mathrm{AgCl}=142.287 \pm .0037
\end{array}
$$

These factors give two values for the molecular weight of lithium chloride, thus :

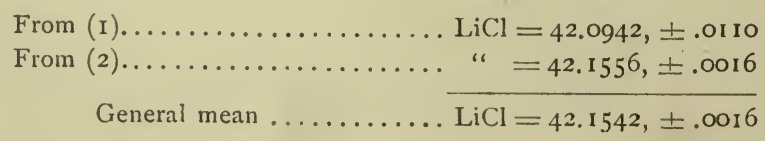


For lithium itself there are three values:

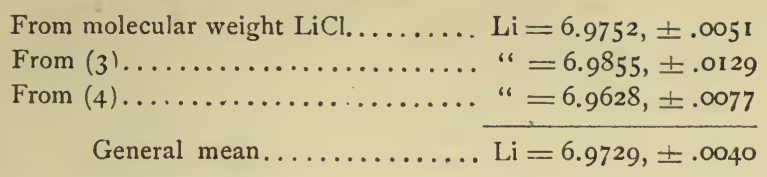

If $\mathrm{O}=16, \mathrm{Li}=7.026$. From Stas' ratios, Stas found $\mathrm{Li}=7.022$; Ostwald, 7.0303; Van der Plaats (A), 7.0273; (B), 7.0235; and Thomsen, 7.0307 .

\section{RUBIDIUM.}

The atomic weight of rubidium has been determined by Bunsen, Piccard, Godeffroy, and Heycock from analyses of the chloride and bromide.

Bunsen,* employing ordinary gravimetric methods, estimated the ratio between $\mathrm{AgCl}$ and $\mathrm{RbCl}$. His rubidium chloride was purified by fractional crystallization of the chloroplatinate. He obtained the following results, to which, in a third column, I add the ratio between $\mathrm{RbCl}$ and 100 parts of $\mathrm{AgCl}$ :

$\begin{array}{cccc}\text { One grm. RbCl gave I.1873 grm. AgCl. } & 84.225 \\ \text { "، } & \text { I.1873 } & \text { “. } & 84.225 \\ \text { " } & \text { I.1850 } & \text { 1.1880 } & 84.388 \\ & & & 84.175 \\ & & & \text { Mean, } 84.253, \pm .031\end{array}$

The work of Piccard $\dagger$ was similar to that of Bunsen. In weighing, the crucible containing the silver chloride was balanced by a precisely similar crucible, in order to avoid the correction for displacement of air. The filter was burned separately from the $\mathrm{AgCl}$, as usual; but the small amount of material adhering to the ash was reckoned as metallic silver. The rubidium chloride was purified by Bunsen's method. The results, expressed according to the foregoing standard, are as follows:

$$
\begin{aligned}
& \text { I. } 1587 \mathrm{grm} . \mathrm{RbCl}=\mathbf{1} .372 \mathrm{AgCl}+.0019 \mathrm{Ag} . \quad 84.300 \\
& \text { I. } 4055 \text { " " } 1.6632 \text { " } \quad .0030 \text { " } \quad 84.303
\end{aligned}
$$

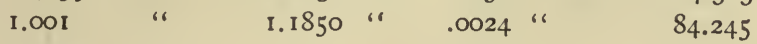

$$
\begin{aligned}
& \text { I.514I " } 1.7934 \text { " } 0018 \text { " } 44.313 \\
& \text { Mean, } \overline{84.290}, \pm .0105
\end{aligned}
$$

Godeffroy, $\ddagger$ starting with material containing both rubidium and

*Zeit. Anal. Chem., I, I36. Poggend. Annal., I13, 339. I86r.

† Journ. für Prakt. Chem., 86, 454. I862. Zeit. Anal. Chem., I, 518.

$\ddagger$ Ann. Chem. Pharm., I8r, 185. 1876. 
crsium, separated the two metals by fractional crystallization of their alums, and obtained salts of each spectroscopically pure. The nitric acid employed was tested for chlorine and found to be free from that impurity, and the weights used were especially rerified. In two of his analyses of $\mathrm{RbCl}$ the $\mathrm{AgCl}$ was handled by the ordinary process of filtration. In the other two it was washed by decantation, dried, and weighed in a glass dish. The usual ratio is appended in the third column :

I.4055 grm. $\mathrm{RbCl}$ gave $1.6665 \mathrm{grm}$. AgCl.

1.8096

2.2473

2.273

$$
\begin{aligned}
& 2.146 \text { I } \\
& 2.665 \\
& 2.6946
\end{aligned}
$$

84.338

84320

84.326

84.354

Mean, $\overline{84.3345}, \pm .0051$

Combining the three series, we get the following result:

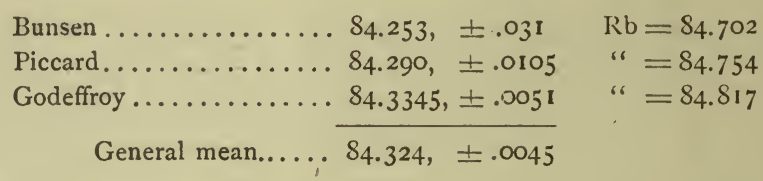

Heycock* worked by two methods, but unfortunately his results are given only in abstract, without details. First, silver solution was added in slight deficiency to a solution of rubidium chloride, and the excess of the latter was measured by titration. The mean of seren experiments gave-

$$
\mathrm{Ag}: \mathrm{RbCl}:: 107.93: 120.801
$$

Hence $\mathrm{Rb}=84.702$.

Two similar experiments with the bromide gare-

$$
\begin{aligned}
& \mathrm{Ag}: \mathrm{RbBr}:: \text { I07.93 : } 165.437 \\
& \text { Ag : } \mathrm{RbBr}:: 107.93: 165.342 \\
& \text { Mean, } \overline{165.3895} \pm .0320
\end{aligned}
$$

There are now three ratios for the metal rubidium, as follows:

(1.) $\mathrm{AgCl}: \mathrm{RbCl}:: 100: 84.324, \pm .0045$

(2.) $\mathrm{Ag}: \mathrm{RbCl}:: 107.93: 120.801$

(3.) $\mathrm{Ag}: \mathrm{RbBr}:: 107.93: 165.3895, \pm .0320$

To reduce these ratios we have-

$$
\begin{aligned}
& \mathrm{Ag}=107.108, \pm .0031 \\
& \mathrm{Br}=79.344, \pm .0062 \\
& \mathrm{Cl}=35.179, \pm .0048 \\
& \mathrm{AgCl}=142.287, \pm .0037
\end{aligned}
$$


For the molecular weight of $\mathrm{RbCl}$, two values are calculable:

$$
\begin{aligned}
& \text { From }(\mathrm{r}) \ldots \ldots \ldots \ldots \ldots \ldots . . \mathrm{RbCl}=119.98 \mathrm{r},+.0109 \\
& \text { From }(2) \ldots \ldots \ldots \ldots \ldots \ldots \ldots \text {. }=119.88 \mathrm{r}, \pm .0218 \\
& \text { General mean.......... } \mathrm{KbCl}=119.961, \pm .0097
\end{aligned}
$$

To the value from ratio (2) I have arbitrarily assigned a weight represented by the probable error as written above. 'The data for systematic weighting are deficient, and no other course of procedure seemed advisable.

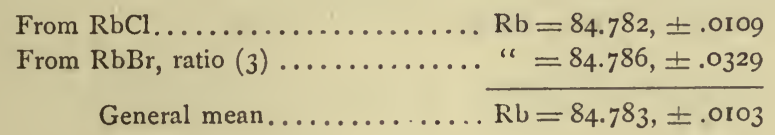

If $\mathrm{O}=16, \mathrm{Rb}=85.429$.

\section{CESIUN.}

The atomic weight of cæsium, like that of rubidium, has been determined from the analysis of the chloride. The earliest determination, by Bunsen,* was incorrect, because of impurity in the material employed.

In 1863 Johnson and Allen published their results.t Their material was extracted from the lepidolite of Hebron, Maine, and the cæsium was separated from the rubidium as bitartrate. From the pure cæsium bitartrate cæsium chloride was prepared, and in this the chlorine was estimated as silver chloride by the usual gravimetric method. Reducing their results to the convenient standard adopted in preceding chapters, we have, in a third column, the quantities of $\mathrm{CsCl}$ equivalent to 100 parts of $\mathrm{AgCl}$ :

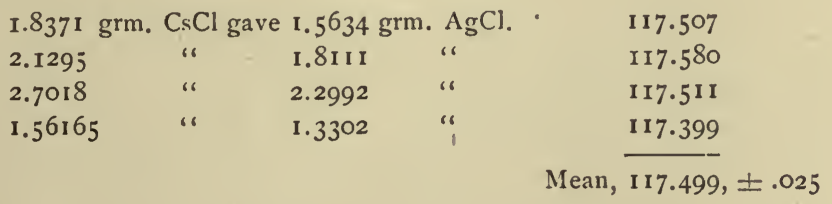

Shortly after the results of Johnson and Allen appeared a new series of estimations was published by Bunsen. $\ddagger$ His cæsium chloride was purified by repeated crystallizations of the chloroplatinate, and the ordi-

* Zeit. Anal. Chem., I, I37.

† Amer. Journ. Sci. and Arts (2), 35, 94.

$\ddagger$ Poggend. Annalen, IIg, r. 1863 . 
nary gravimetric process was employed. The following results represent, respectively, material thrice, four times, and five times purified:

$$
\begin{aligned}
& \text { 1. } 3835 \mathrm{grm} \text {. } \mathrm{CsCl} \text { gave 1.1781 grm. AgCl. Ratio, I17.435 } \\
& \text { I. } 3682 \text { " " } 2 \text { "1644 " } 117.503 \\
& 1.2478 \text { " " } 1.0623 \text { " " } 117.462 \\
& \text { Mean, } 117.467, \pm .013
\end{aligned}
$$

Godeffroy's work* was, in its details of manipulation, sufficiently described under rubidium. In three of the experiments upon casium the silver chloride was washed by decantation, and in one it was collected upon a filter. The results are subjoined:

$$
\begin{aligned}
& \text { I. } 5825 \mathrm{grm} . \mathrm{CsCl} \text { gave } 1.35 \text { I grm. AgCl. Ratio, I17.135 } \\
& \text { I. } 3487 \text { " " } 8 \text { "I50I " " } \\
& \text { I.1880 " " } 1.0141 \text { " " } 117.148 \\
& 1.2309 \text { " } 1.051 \text { " " } 117.107 \\
& \text { Mean, } 117.164, \pm .023
\end{aligned}
$$

We may now combine the three series to form a general mean :

$$
\begin{aligned}
& \text { Johnson and Allen .... } 117.499, \pm .025 \quad C s=132.007 \\
& \text { Bunsen............ 117.467, } \pm .013 \quad \text { " }=131.961 \\
& \text { Godeffroy......... I I } 7.164, \pm .023 \quad \text { " }=131.560 \\
& \text { General mean... II } 7.413, \pm .010
\end{aligned}
$$

- Hence, if $\mathrm{AgCl}=142.287, \pm .0037$, and $\mathrm{Cl}=35.179, \pm .0048, \mathrm{Cs}=$ $131.885, \pm .0142$.

If $\mathrm{O}=16, \mathrm{Cs}=132.890$.

*Ann. Chem. Pharm., 181, 185. 1876. 
COPPER.

The atomic weight of copper has been chiefly determined by means of the oxide, the sulphate, and the bromide, and by direct comparison of the metal with silver.

.In dealing with the first-named compound all experimenters have agreed in reducing it with a current of hydrogen, and weighing the metal thus set free.

The earliest experiments of any value were those of Berzelius,* whose results were as follows:

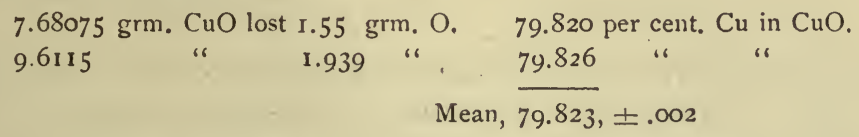

Erdmann and Marchand, $\dagger$ who come next in chronological order, corrected their results for weighing in air. Their weighings, thus corrected, give us the subjoined percentages of metal in $\mathrm{CuO}$ :

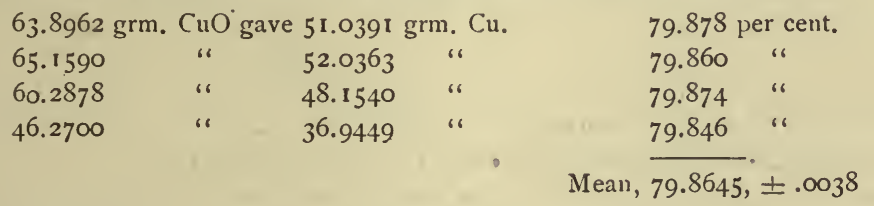

Still later we find a few analyses by Millon and Commaille. $\ddagger$ These chemists not only reduced the oxide by hydrogen, but they also weighed, in addition to the metallic copper, the water formed in the experiments. In three determinations the results were as follows:

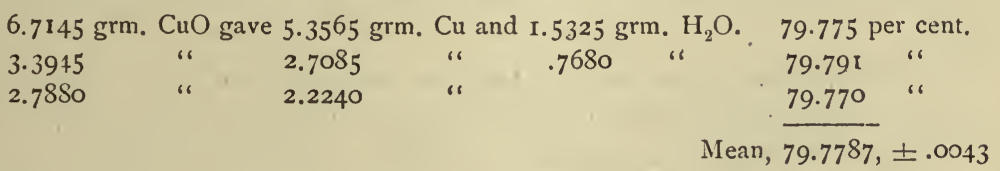

For the third of these analyses the water estimation was not made, but for the other two it yielded results which, in the mean, would make the atomic weight of copper 62.680. This figure has so high a probable error that we need not consider it further.

The results obtained by Dumas $§$ are wholly unavailable. Indeed. he does not even publish them in detail. He merely says that he reduced copper oxide, and also effected the synthesis of the subsulphide, but without getting figures which were wholly concordant. He puts $\mathrm{Cu}=63.5$. 
In 1873 Hampe* published his careful determinations, which were for many years almost unqualifiedly accepted. First, he attempted to estimate the atomic weight of copper by the quantity of silver which the pure metal could precipitate from its solutions. This attempt failed to give satisfactory results, and he fell back upon the old method of reducing the oxide. From ten to twenty grammes of material were taken in each experiment, and the weights were reduced to a vacuum standard :

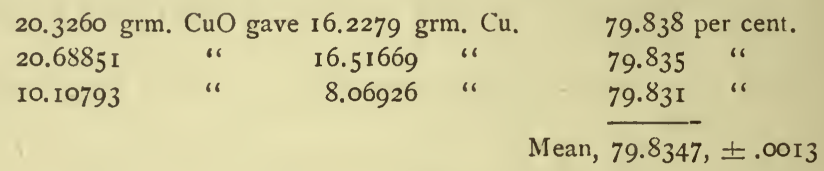

Hampe also determined the quantity of copper in the anhydrous sulphate, $\mathrm{CuSO}_{4}$. From 40 to 45 grammes of the salt were taken at a time; the metal was thrown down by electrolysis, and the weights were all corrected. I subjoin the results :

$$
\begin{aligned}
& 40.40300 \mathrm{grm} . \mathrm{CuSO}_{4} \text { gave } \mathrm{I} 6.0495^{8} \mathrm{grm} \text {. Cu. } 39.724 \text { per cent. } \\
& 44.64280 \text { " " } 17.73466 \text { " } 39.726 \text { " } \\
& \text { Mean, } 39 \cdot 725, \pm .0007
\end{aligned}
$$

The last series of data gives $\mathrm{Cu}=62.839, \pm .0035$, and is interesting for comparison with results obtained by Richards later.

In all of the foregoing experiments with copper oxide, that compound was obtained by ignition of the basic nitrate. But, as was shown in the chapter upon oxygen, copper oxide so prepared always carries occluded gases, which are not wholly expelled by heat. This point was thoroughly worked up by Richards $\dagger$ in his fourth memoir upon the atomic weight of copper, and it vitiates all the determinations previously made by this method.

By a series of experiments with copper oxide ignited at varying temperatures, and with different degrees of heat during the process of reduction, Richards obtained values for $\mathrm{Cu}$ ranging from 63.20 to 63.62 , when $\mathrm{O}=16$. In two cases selected from this series he measured the amount of gaseous impurity, and corrected the results previously obtained. The results were as follows, with vacuum standards:

$$
\begin{aligned}
& \text { I.06253 grm. } \mathrm{CuO} \text { gave. } .8483 \mathrm{I} \mathrm{grm.} \mathrm{Cu} . \quad 79.802 \text { per cent. } \\
& \text { r.91656 " " } 1.5298 \text { " } \\
& \text { Mean, } \overline{79.8 \mathrm{II}} \pm .006 \mathrm{I}
\end{aligned}
$$

Correcting for the occluded gases in the oxide. the sum of the two experiments gives 79.901 per cent. of copper, whence $\mathrm{Cu}=63.605$. Three

* Fresenius' Zeitschrift, ${ }_{3}, 352$

† Proc. Amer. Acad., 26, 276. I89r. 
other indirect results, similarly corrected, gave 79.900 per cent. $\mathrm{Cu}$ in $\mathrm{CuO}$, or $\mathrm{Cu}=63.603$. If we assign all five experiments equal weight, and judge their value by the two detailed above, the mean percentage becomes $79.900, \pm .0038$. This figure need not be combined with the data given by previous observers, so far as practical purposes are concerned; but as this work is, in part at least, a study of the compensation of errors, it may not be wasted time to effect the combination, as follows:

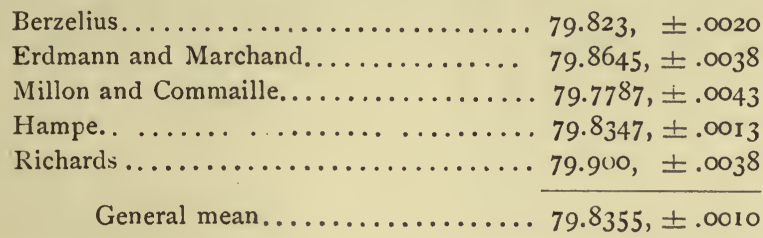

This result is practically identical with that of Hampe, whose work receives excessive weight, as does also that of Berzelius. The oxide of copper is evidently of doubtful value in the measurement of this atomic weight.

The composition of the sulphate his been studied, not only by Hampe, but also by Baubigny* and by Richards. $\dagger$ Baubigny merely ignited the anhydrous salt, weighing both it and the residual oxide, as follows :

$$
\begin{aligned}
& 4.022 \mathrm{grm} . \mathrm{CuSO}_{4} \text { gave } 2.0035 \mathrm{CuO} \text {. } 49.8 \mathrm{I} 3 \text { per cent. } \\
& 2.596 \text { " } 1.293 \text { " } \frac{49.807}{49.810,} \pm .002
\end{aligned}
$$

The same ratio, in reverse-that is, the synthesis of the sulphate from the oxide-was investigated by Richards (p. 275), who shows that the results obtained are vitiated by the same errors which affect the copper oxide experiments previously cited. The weights given are reduced to vacuum standards. The percentage of oxide in the sulphate is stated in the third column of figures.

I.008+ grm. $\mathrm{CuO}$ gave $2.0235 \mathrm{grm}$. $\mathrm{Cu}_{4} \mathrm{SO}_{4}$.

$$
2.7292
$$

1.0144

$$
5.4770
$$$$
2.0350
$$

49.835 per cent.

49.830 "

49.848 "

$$
\text { Mean, } \overline{49.838}, \pm .0036
$$

The tro series combine thus:

$$
\begin{aligned}
& \text { Baubigny...................... 49.810, } \pm .0020 \\
& \text { Richards......................... 49. } 838, \pm .0036 \\
& \text { General mean } \\
& 49.816, \pm .0017
\end{aligned}
$$

Here, plainly, the rigorous discussion gives Baubigny's work weight in excess of its merits. 
In the memoir by Richards now under consideration, his fourth upon copper, the greater part of his attention is devoted to the sulphate, Hampe being followed closely in order to ascertain what sources of error affected the work of the latter. Crystallized sulphate, $\mathrm{CuSO}_{4} \cdot 5 \mathrm{H}_{2} \mathrm{O}$ was purified with every precaution and made the basis of operations. Three series of experiments were carried out, the water being determined by loss of weight upon heating, and the copper being estimated electrolytically. In the first series the following data were found, the weights being reduced to a vacuum, as in all of Richards' determinations:

\begin{tabular}{|c|c|c|c|}
\hline & $\begin{array}{c}\mathrm{CuSO}_{4} .5 \mathrm{aq} . \\
2.8815\end{array}$ & $\mathrm{CuSO}_{4}$ at $250^{\circ}$. & $\mathrm{Cu}$. \\
\hline ............... & 2.7152 & $\begin{array}{l}\cdots \\
\cdots\end{array}$ & $\begin{array}{l}.601 \\
.6911\end{array}$ \\
\hline$\ldots$ & 3.4639 & 2.2184 & .8817 \\
\hline
\end{tabular}

Hence the subjoined percentages.

Water at $250^{\circ}$. Cu in Cryst. Salt. Cu in $\mathrm{CuSO}_{4}$.

\begin{tabular}{|c|c|c|c|}
\hline I............. & $\ldots \ldots$ & 25.462 & \\
\hline $2 \ldots \ldots \ldots \ldots$ & $\ldots \ldots$ & $25.45^{2}$ & $\ldots \ldots$ \\
\hline $3 \ldots \ldots \ldots \ldots$ & $35.95^{8}$ & 25.454 & 39.745 \\
\hline
\end{tabular}

In the second series of analyses, which are stated with much detail, several refinements were introduced, in order to estimate also the sulphuric acid. These will be considered later. The results, given below, are numbered consecutively with the former series.

\begin{tabular}{|c|c|c|c|c|}
\hline$\cdots$ & $\begin{array}{c}\mathrm{CuSO}_{4} .5 \mathrm{aq} . \\
3.06006\end{array}$ & $\begin{array}{c}\mathrm{CuSO}_{4} \text { at } 260^{\circ} . \\
\text { I. } 9597\end{array}$ & $\begin{array}{c}\mathrm{CuSO}_{4} \text { at } 360^{\circ} \text {. } \\
\text { I. } 95637\end{array}$ & $\begin{array}{c}C u . \\
.77886\end{array}$ \\
\hline & 2.81840 & I. 8048 & & .71740 \\
\hline 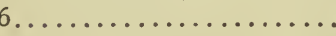 & 7.50490 & 4.8064 & 4.79826 & 1.90973 \\
\hline
\end{tabular}

Hence percentages as follows:

Water, $260^{\circ}$. Water, $360^{\circ}$. Cu in Cryst. Salt. Cu in CuSO, $260^{\circ}$. Ditto, $3600^{\circ}$

\begin{tabular}{|c|c|c|c|c|c|}
\hline $4 \ldots \ldots$ & 35.959 & 36.068 & $25.45^{2}$ & 39.744 & 39.8 I I \\
\hline $5 \ldots \ldots$ & 35.964 & $\ldots \ldots$ & 25.454 & 39.750 & ....... \\
\hline $6 \ldots \ldots$ & 35.957 & 36.065 & 25.446 & 39.733 & 39.799 \\
\hline & 35.960 & 36.067 & 25.450 & 39.742 & 39.80 \\
\hline
\end{tabular}

Hampe worked with a sulphate dried at $250^{\circ}$, but these data show that a little water is retained at that temperature, and consequently that his results must have been too low. The third of Richards' series resembles the second, but extra precautions were taken to avoid conceivable errors.

\begin{tabular}{|c|c|c|c|c|}
\hline & $\begin{array}{c}\mathrm{CuSO}_{4.5} \mathrm{aq} . \\
2.88307\end{array}$ & $\begin{array}{c}\mathrm{CuSO}_{4} \text { at } 260^{\circ} . \\
\ldots \ldots\end{array}$ & $\begin{array}{c}\mathrm{CuSO}_{4} \text { at } 370^{\circ} . \\
\ldots \ldots\end{array}$ & $\begin{array}{c}C u . \\
.733^{80}\end{array}$ \\
\hline & 3.62913 & 2.32373 & .... & .92344 \\
\hline & $5.8135^{2}$ & ...... & $3.7 \mathrm{I} \in 80$ & I.47926 \\
\hline
\end{tabular}


And the percentages are:

Water at $260^{\circ}$. At $370^{\circ}$. Cu in Cryst. Salt. Cu in $\mathrm{CuSO}_{4}$.

$\begin{array}{lllll}7 \ldots \ldots \ldots \ldots \ldots \ldots \ldots & \ldots \ldots & \ldots \ldots & 25.45^{2} & \ldots \ldots \\ 8 \ldots \ldots \ldots \ldots \ldots \ldots \ldots & 35.970 & \ldots \ldots . & 25.446 & 39.740\left(260^{\circ}\right) \\ 9 \ldots \ldots \ldots \ldots \ldots \ldots & 36.067 & \frac{25.445}{25.448} & 39.799\left(370^{\circ}\right)\end{array}$

In this series the determinations of sulphuric acid gave essentially the same results for all three samples of sulphate, although one was not dehydrated, and the others were heated to $260^{\circ}$ and $370^{\circ}$ respectirely. Hence the loss of weight in dehydration at either temperature represents water only; and does not involve partial decomposition of the sulphate. Between $360^{\circ}$ and $400^{\circ}$ copper sulphate is at essentially constant weight, but further experiments indicated that even at $400^{\circ}$ it retained traces of water, and possibly as much as .042 per cent. The last trace is not expelled until the salt itself begins to decompose.

Richards also effected two syntheses of the sulphate directly from the metal by dissolving the latter in nitric acid, then evaporating to dryness with sulphuric acid, and heating to constant weight at $400^{\circ}$.

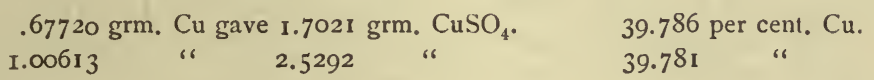

If we include these percentages in a series with the data from analyses 4,6 , and 9 , which gave percentages of $39.811,39.799$, and 39.799 respectively of copper in sulphate dried at $360^{\circ}$ and upwards, the mean becomes

$$
\mathrm{CuSO}_{4}: \mathrm{Cu}:: 100: 39.795, \pm .0036
$$

Since even this result is presumably too low, the other figures from sulphate dried at $250^{\circ}$ must be rejected. Since Hampe's work on the sulphate is affected by the same sources of error, and apparently to a still greater extent, it need not be considered farther. As for Richards' nine determinations of $\mathrm{Cu}$ in $\mathrm{CuSO}_{4} \cdot 5 \mathrm{H}_{2} \mathrm{O}$, we may take them as one series giving a mean percentage of $25.451, \pm .0011$. 'T'his salt seems to retain occluded water, for the percentage of copper in it leads to a ralue for the atomic weight which is inconsistent with the best evidence, as will be seen later.

In the second and third series of Richards' experiments upon copper sulphate, the sulphuric acid was estimated by a method. which gave valuable results. After the copper had been electrolytically precipitated, the acid which was set free was nearly neutralized by a weighed amount of pure sodium carbonate, and the slight excess remaining was determined by titration. Thus the weight of sodium carbonate equivalent to the copper was ascertained. The resulting solution of sodium sulphate was then evaporated to dryness, and a new ratio, connecting that salt with copper, was also determined. The cross ratio $\mathrm{Na}_{2} \mathrm{CO}_{3}: \mathrm{Na}_{2} \mathrm{SO}_{4}$ has 
already been utilized in a previous chapter. The results, ignoring the weights of hydrated copper sulphate, are as follows, with the experiments numbered as before:

\begin{tabular}{|c|c|c|c|}
\hline & $\mathrm{Cu}$. & $\mathrm{Na}_{2} \mathrm{CO}_{3}$. & $\begin{array}{l}\mathrm{Na}_{2} \mathrm{SO}_{4} \\
\text { I.74I I }\end{array}$ \\
\hline $4 \ldots$ & .77886 & I. 2993 & I.74I I \\
\hline $6 \ldots \ldots \ldots \ldots \ldots$ & I.90973 & 3. I $\$ 62$ & 4.2679 \\
\hline $7 \ldots \ldots \ldots \ldots \ldots$ & $.733^{80}$ & 1.22427 & 1. 63994 \\
\hline $8 \ldots \ldots \ldots \ldots$ & .92344 & I. 54075 & ...... \\
\hline $9 \ldots \ldots \ldots \ldots \ldots$ & I. 47926 & $\ldots \ldots$ & $3.3065^{8}$ \\
\hline
\end{tabular}

Hence,

$$
\begin{gathered}
\mathrm{Cu}: \mathrm{Na}_{2} \mathrm{CO}_{3}:: 100: x . \\
\mathrm{I} 66.824 \\
\mathrm{I} 66.840 \\
166.840 \\
\mathrm{I} 66.849 \\
\text { Mean, } 166.838, \pm .0035
\end{gathered}
$$

$$
\begin{gathered}
\mathrm{Cu}: \mathrm{Na}_{2} \mathrm{SO}_{4}:: 100: x . \\
223.549 \\
223.482 \\
223.538 \\
223.529 \\
\text { Nean, } 223.525, \pm .0098
\end{gathered}
$$

In one more experiment the sulphuric acid was weighed as barium sulphate, the latter being corrected for occluded salts. 3.1902 grm. Cus $\mathrm{O}_{4} .5 \mathrm{H}_{2} \mathrm{O}$ gave $2.9761 \mathrm{BaSO}_{4}$; hence $\mathrm{CuSO}_{4} .5 \mathrm{H}_{2} \mathrm{O}: \mathrm{BaSO}_{4}:: 100$ : 93.289. The sulphate contained 25.448 per cent. of $\mathrm{Ca}$; hence $\mathrm{BaSO}_{4}$ : Cu :: 93.289:25.448. Still other ratios can be deduced from Richards' work on the sulphate, but in view of the uncertainties relative to the water in the salt they are hardly worth computing.

In his third paper upon the atomic weight of copper, * Richards studied the dibromide, $\mathrm{CuBr}_{2}$. In preparing this salt he used hydrobromic acid made from pure materials, and further purified by ten distillations. This was saturated with copper oxide prepared from pure electrolytic copper, and the solution obtained was proved to be free from basic salts. As the crystallized compound was not easily obtained in a satisfactory condition, weighed quantities of the solution were taken for analysis, in which, after expulsion of bromine by nitric and sulphuric acids, the copper was determined by electrolysis. In other portions of solution the bromine was precipitated by silver nitrate, and weighed as silver bromide. The first preliminary series of experiments gave the subjoined results, with vacuum weights as usual:

\section{In 25 Grammes of Solution.}

$\begin{array}{cc}C u . & A g B r \\ .4164 & 2.4599 \\ .4 .164 & 2.4605 \\ .4164 & 2.4605 \\ .4165 & 2.4599\end{array}$

Hence $2 \mathrm{AgBr}: \mathrm{Cu}:: 100: 16.92 \bar{\imath}, \pm .0013$. 
The second, also preliminary series, was made with more dilute solutions, and came out as follows:

In 25 Grammes of Solution.

$\begin{array}{ll}\mathrm{Cu} . & \mathrm{AgBr} . \\ .26190 & \mathrm{1} .5478 \\ .26185 & 1.5477 \\ & 1.5479\end{array}$

Hence $2 \mathrm{AgBr}: \mathrm{Cu}:: 100: 16.919, \pm .0012$.

In the third series, two distinct lots of crystallized bromide were dissolved, and the solutions examined in the same way.

$\begin{array}{lcc}\mathrm{Cu} . & \mathrm{AgBr} . & \text { Ratio. } \\ .2500 & \mathrm{I} .477 \mathrm{I} & \mathrm{16.925} \\ .5473 & 3.2348 & \mathrm{16.919} \\ & & \text { Mean, } \frac{\mathrm{I} 6.922, \pm .0020}{}\end{array}$

In the final set of analyses, the materials used were purified even more scrupulously than before, and the process was distinctly modified, as regards the determination of the bromine. The solution of the bromide was added to a solution of pure silver in nitric acid, not quite sufficient for complete precipitation. The slight excess of bromine was then determined by titration with a solution containing one gramme of silver to the litre. Thus silver proportional to the copper in the bromide was determined, and the silver bromide was weighed in a Gooch crucible as before. The results are subjoined:

\section{In 50 Grammes of Solution.}

$\begin{array}{lcc}\mathrm{Cu} . & \mathrm{Ag} . & \mathrm{AgBr} . \\ .54755 & \mathrm{1} .8586 & 3.2350 \\ .54750 & \mathrm{1} .8579 & 3.2340 \\ & 1.8583 & 3.2348\end{array}$

Hence $\mathrm{Cu}: \mathrm{Ag}_{2}:: 100: 339.392, \pm .0108$, and $2 \mathrm{AgBr}: \mathrm{Cu}:: 100: 16.927$, \pm .0012 .

The latter ratio, combined with the results of the three preceding series, gives a general mean of :

$2 \mathrm{AgBr}: \mathrm{Cu}:: 100: 16.924, \pm .0007$

In his two earlier papers * Richards determined the çopper-silver ratio directly - that is, without the weighing of any compouning of either metal. By placing pure copper in an ice-cold solution of sil ser vitrąte, metallic silver is thrown down, and the weights of the two metals were in eciliv-... 
alent proportions. In the first paper the following results were obtained. The third column gives the value of $x$ in the ratio $\mathrm{Cu}: \mathrm{Ag}_{2}:: 100: x$.

Cu Taken
.53875
.56190
1.00220
1.30135
.99870
1.02050

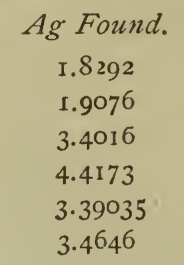

Ratio.

339.527

339.491

339.414

339.440

339.477

1339.500

Mean, $\overline{339.475} \pm .0114$

In the second paper Richards states that the silver of the fifth experiment, which had been dried at $150^{\circ}$, as were also the others, still retained water, to the extent of four-tenths milligramme in two grammes. If we assume this correction to be fairly uniform, as the concordance of the series indicates, and apply it throughout, the mean value for the ratio then becomes 339.408, \pm .0114 . This procedure, however, leaves the ratio in some uncertainty, and accordingly some new determinations were made, in which the silver, collected in a Gooch crucible, was heated to incipient redness before final weighing. Copper from two distinct sources was taken, and three experiments were carried out upon one sample to two with the other. Treating both sets as one series, the results were as follows:

$\begin{array}{ccc}\text { Cu Taken } & \text { Ag found } & \text { Ratio. } \\ .75760 & 2.5713 & 339.40 \\ .95040 & 3.2256 & 339.39 \\ .75993 & 2.5794 & 339.42 \\ 1.02060 & 3.4640 & 339.42 \\ .90460 & 3.0701 & 339.39 \\ & & \text { Mean, } 339.404, \pm .0046\end{array}$

a value practically identical with the corrected mean of the previous determinations, and with that found in the later experiments upon copper bromide.

In various electrical investigations the same ratio, the electrochemical equivalent of copper, has been repeatedly measured, and the later results of Lord Rayleigh and Mrs. Sidgewick,* Gray, $\dagger$ Shaw, $\ddagger$ and Vanni $§$ may properly be included in this discussion. As the data are somewhat differently stated, I have reduced them all to the common standard adopted above. Gray gives two sets of measurements, one made with large and

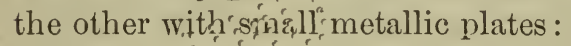

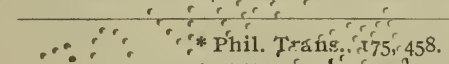

+Phil. Mrg." (s) $(522,389$.

†ritist. Ássoc. Report, 1886. Abstract in Phil. Mag. (5), 23, 138 .

$\because \because 3$ Arín' der Phys. (Wiedemann's) (2), 44, 214. 


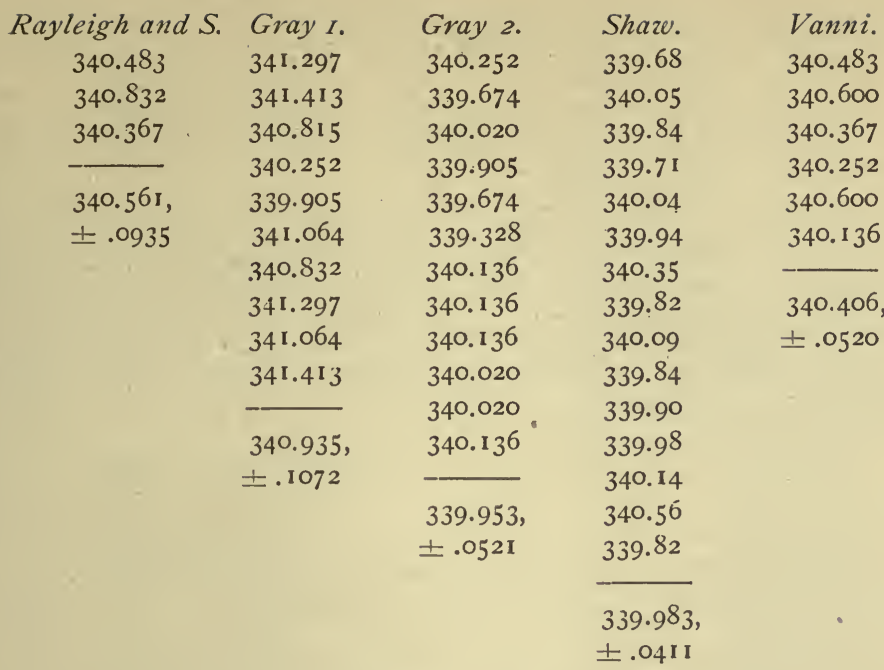

The lack of sharp concordance in these data and the consequently high probable errors seem to indicate a distinct superiority of the purely chemical method of determination over that adopted by the physicist. The eight distinct series now combine as follows:

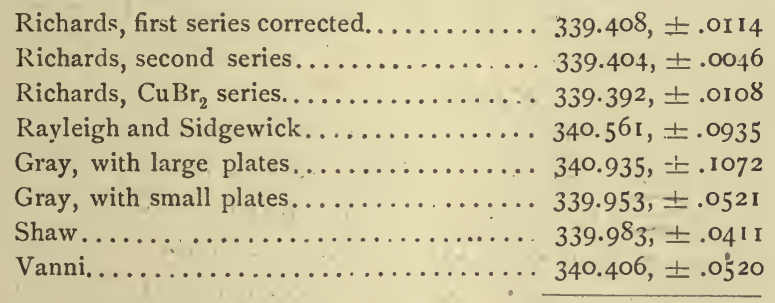

General mean.............. 339.411, \pm .0039

If we combine Richards' three series into a general mean separately, we get $339.402, \pm .0040$. Hence the other determinations, having high probable errors, practically vanish from the result, and it is a matter of indifference whether they are retained or rejected.

We now have the following ratios from which to compute the atomic weight of copper:

(I.) Percentage of $\mathrm{Cu}$ in $\mathrm{CuO} \ldots \ldots \ldots$ 79.8355, \pm .0010

(2.) " of $\mathrm{Cu}$ in $\mathrm{CuSO}_{4} \ldots \ldots$ 39.795, \pm .0036

(3.) " of $\mathrm{Cu}$ in $\mathrm{CuSO}_{4}, 5 \mathrm{H}_{2} \mathrm{O} .25 .45 \mathrm{I}$, $\pm .001 \mathrm{I}$

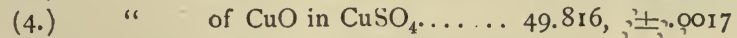

(5.) $\mathrm{Cu}: \mathrm{Na}_{2} \mathrm{CO}_{3}:$ : $100: 166.838, \pm .0035$

(6.) $\mathrm{Cu}: \mathrm{Na}_{2} \mathrm{SO}_{4}:: 100: 223.525, \pm .0098$ ?

(7.) $\mathrm{BaSO}_{4}: \mathrm{Cu}:: 93.289: 25.448$.

(8.) $2 \mathrm{AgBr}: \mathrm{Cu}:: \mathrm{I00}: \mathrm{r} 6.924, \pm .0007$

(9.) $\mathrm{Cu}: \mathrm{Ag}_{2}::$ 100:339.4I \pm .0039

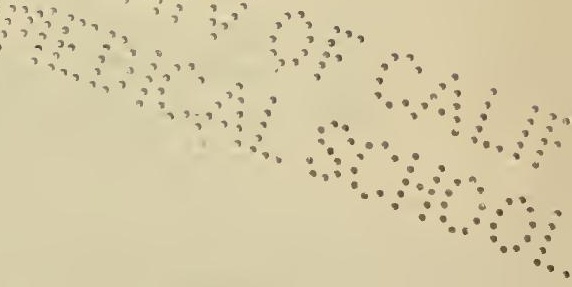


Reducing these ratios with the subjoined data:

$$
\begin{array}{ll}
\mathrm{O}=15.879, \pm .0003 & \mathrm{Na}=22.88 \mathrm{I}, \pm .0046 \\
\mathrm{Ag}=107.108, \pm .0031 & \mathrm{Ba}=136.392, \pm .0086 \\
\mathrm{~S}=31.828, \pm .0015 & \mathrm{AgBr}=186.45^{2} \pm .0054 \\
\mathrm{C}=11.920 \pm .0004 &
\end{array}
$$

We have nine values for the atomic weight of copper. Since ratio (7) depends upon one experiment only, it is necessary to assign the value derived from it arbitrary weight. This will be taken as indicated by a probable error double that of the next highest, obtained from ratio (2). The values then are as follows: .

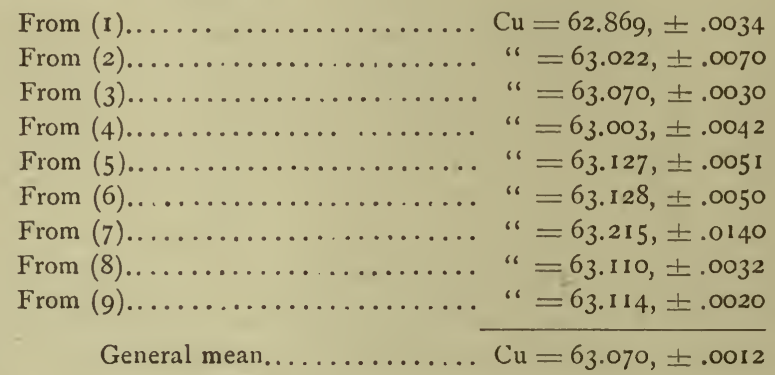

If $\mathrm{O}=16, \mathrm{Cu}=63.550$. If we include Hampe's analyses of copper sulphate, which gave $\mathrm{Cu}=62.839, \pm .0035$, the general mean becomes $\mathrm{Cu}=63.046, \pm .0011$.

The foregoing means, however, are significant only as showing the effect and weight of the older data upon the newer determinations of Richards. The seventh of the individual values is also interesting, for the reason that the experiment upon which it depends was published by Richards previous to his investigation of the atomic weight of barium. With the old value for $\mathrm{Ba}, 137$, it gives a value for copper in close agreement with Richards' other determinations. With the new value for barium it becomes discordant, although its weight is so low that it produces no appreciable effect upon the final mean.

Rejecting values 1 to 4 , inclusive, the remaining five values give a general mean of

$$
\mathrm{Cu}=63.119, \pm .0015 \text {. }
$$

If $\mathrm{O}=16$, this becomes 63600 , and in the light of all the evidence these figures are to be preferred. If, again, we combine with this mean the results of Richards' work on the oxide and sulphate of copper, the final value becomes

$$
\mathrm{Cu}=63.108, \pm .0013,
$$

and rivith $0=16,53,58 \%$ This departs but little from the previous mean

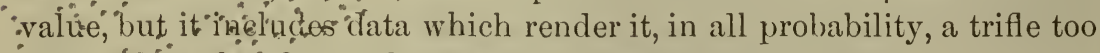
low, 'T́ho'valué $\mathrm{Cu}=63.119$ will be regarded as the best. 
GOLD.

Among the early estimates of the atomic weight of gold the only ones worthy of consideration are those of Berzelius and Levol.

The earliest method adopted by Berzelius* was that of precipitating a solution of gold chloride by means of a weighed quantity of metallic mercury. The weight of gold thus thrown down gave the ratio between the atomic weights of the two metals. In the single experiment which Berzelius publishes, 142.9 parts of $\mathrm{Hg}$ precipitated 93.55 of $\mathrm{Au}$. Hence if $\mathrm{Hg}=200, \mathrm{Au}=196.397$.

In a later investigation $\uparrow$ Berzelius resorted to the analysis of potassioauric chloride, $2 \mathrm{KCl} . \mathrm{AuCl}_{3}$, Weighed quantities of this salt were ignited in hydrogen; the resulting gold and potassium chloride were separated by means of water, and both were collected and estimated. The loss of weight upon ignition was, of course, chlorine. As the salt could not be perfectly dried without loss of chlorine, the atomic weight under investigation must be determined by the ratio between the $\mathrm{KCl}$ and the $\mathrm{Au}$. If we reduce to a common standard, and compare with 100 parts of $\mathrm{KCl}$, the equivalent amounts of gold will be those which I give in the last of the subjoined columns :

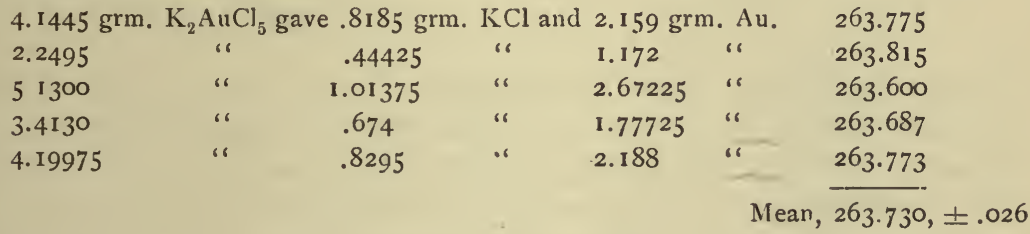

Still a third series of experiments by Berzelius $\$$ may be included here. In order to establish the atomic weight of phosphorus he employed that substance to precipitate gold from a solution of gold chloride in excess. Between the weight of phosphorus taken and the weight of gold obtained it was easy to fix a ratio. Since the atomic weight of phosphorus has been better established by other methods, we may properly reverse this ratio and apply it to our discussion of gold. 100 parts of $\mathrm{P}$ precipitate the quantities of Au given in the third column:

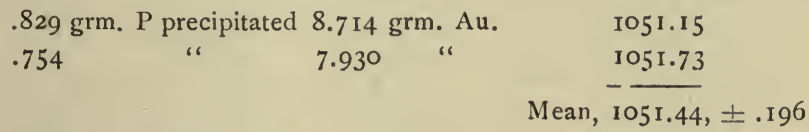

Hence if $\mathrm{P}=31, \mathrm{Au}=195.568$. 
Levol's* estimation of the atomic weight under consideration can hardly have much value. A weighed quantity of gold was converted in a flask into $\mathrm{AuCl}_{3}$. This was reduced by a stream of sulphur dioxide, and the resulting sulphuric acid was determined as $\mathrm{BaSO}_{4}$. One gramme of gold gave $1.782 \mathrm{grm}$. $\mathrm{BaSO}_{4}$. Hence $\mathrm{Au}=195.06$.

All these values may be neglected as worthless, except that derived from Berzelius' $\mathrm{K}_{2} \mathrm{AuCl}_{5}$ series.

In 1886 Krüss $\dagger$ published the first of the recent determinations of the atomic weight under consideration, several distinct methods being recorded. First, in a solution of pure auric chloride the gold was precipitated by means of aqueous sulphurous acid. In the filtrate from the gold the chlorine was thrown down as silver chloride, and thus the ratio $\mathrm{Au}: 3 \mathrm{AgCl}$ was measured. I subjoin Krüss' weights, together with a third column giving the gold equivalent to 100 parts of silver chloricle:

$\begin{array}{ccc}\text { Au. } & \mathrm{AgCl} & \text { Ratio. } \\ 7.72076 & 16.84737 & 45.828 \\ 5.68290 & 12.40425 & 45.814 \\ 3.24773 & 7.08667 & 45.828 \\ 4.49167 & 980475 & 45.81 \mathrm{I} \\ 3.47949 & 7.59300 & 45.825 \\ 3.26836 & 713132 & 45.832 \\ 5.1618 \mathrm{I} & 11.26524 & 45.821 \\ 4.860+4 & 10.6043 \mathrm{I} & 45.834 \\ & & \text { Mean, } 45.824, \pm .0020\end{array}$

The remainder of Krüss' determinations were made with potassium auribromide, $\mathrm{KAuBr}_{4}$, and with this salt several ratios were measured. The salt was prepared from pure materials, repeatedly recrystallized under precautions to exclude access of atmospheric dust, and dried over phosphorus pentoxide. First, its percentage of gold was determined, sometimes by reduction with sulphurous acid, sometimes by heating in a stream of hydrogen. For this ratio, the weights and percentages are as follows, the experiments being numbered for further reference, and the reducing agent being indicated.

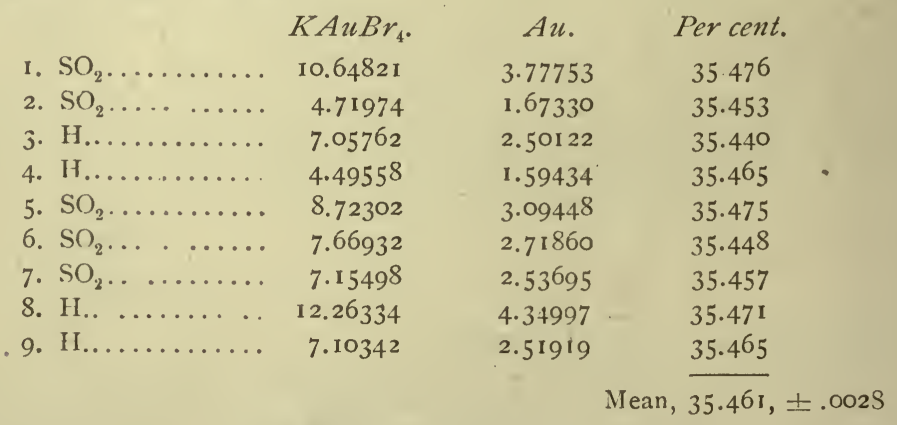

* Ann. Chim. Phys. (3), 30, 355. 1850.

'† Untersuchungen über das A tomgewicht des Goldes. München, I8S6. Ir 2 pp., Svo. 
In five of the foregoing experiments the reductions were effected with sulphurous acid; and in these, after filtering off the gold, the bromine was thrown down and weighed as silver bromide. This, in comparison with the gold, gives the ratio $\mathrm{Au}: 4 \mathrm{AgBr}:: 100: x$.

\begin{tabular}{|c|c|c|c|}
\hline & $A u$. & ${ }_{4} A g B r$ & Ratio. \\
\hline г $\ldots \ldots \ldots \ldots$ & 3.77753 & $14.3954^{2}$ & 381.080 \\
\hline $2 \ldots \ldots$ & 1.67330 & $6.3795^{2}$ & 381.254 \\
\hline$\ldots$ & 3.09448 & I I.78993 & 380.999 \\
\hline & 2.71860 & 10.35902 & 381.042 \\
\hline $7 \ldots \ldots \ldots \ldots$ & 2.53695 & 9.66117 & $380.73 \mathrm{I}$ \\
\hline
\end{tabular}

Hence $\mathrm{Au}: \mathrm{AgBr}:: 100: 95.255, \pm .0142$.

In the remaining experiments, Nos. $3,4,8$, and 9 , the $\mathrm{KAuBr}_{4}$ was reduced in a stream of hydrogen, the loss of weight, $\mathrm{Br}_{3}$, being noted. In the residue the gold was determined, as noted above, and the $\mathrm{KBr}$ was also collected and weighed. The weights were as follows:

\begin{tabular}{cccr} 
& $A u$. & Loss, $\mathrm{Br}_{3}$. & \multicolumn{1}{c}{$K B r}$. \\
$3 \ldots \ldots \ldots \ldots$ & 2.50122 & 3.04422 & $\mathrm{r} .51090$ \\
$4 \ldots \ldots \ldots \ldots$ & 1.59434 & 1.93937 & .96243 \\
$8 \ldots \ldots \ldots \ldots$ & 4.34997 & 5.29316 & 2.62700 \\
$9 \ldots \ldots \ldots \ldots$ & $2.5^{1919}$ & 3.06534 & 1.52153
\end{tabular}

From these data we obtain two more ratios, viz., $\mathrm{Au}: \mathrm{Br}_{3}:: 100: x$, and $\mathrm{Au}: \mathrm{KBr}:: 100: x$, thus :

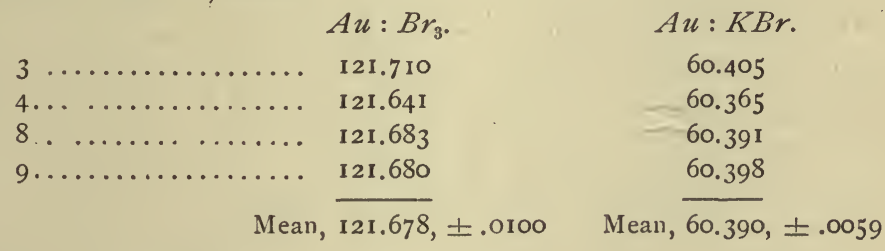

From all the ratios, taken together, Krüss deducés a final value of $\mathrm{Au}=197.13$, if $\mathrm{O}=16$. It is obviously possible to derive still other ratios from the results given, but to do so would be to depart unnecessarily from the author's methods as stated by himself.

Thorpe and Laurie, * whose work appeared shortly after that of Krüss, also made use of the salt $\mathrm{KAuBr}_{4}$, but, on account of difficulty in drying it without change, they did not weigh it directly. After proving the constancy in it of the ratio $\mathrm{Au}: \mathrm{KBr}$, even after repeated crystallizations, they adopted the following method: The unweighed salt was heated with gradual increase of temperature, up to about $160^{\circ}$, for several hours, and afterwards more strongly over a small Bunsen flame. This was done in a porcelain crucible, tared by another in weighing, which latter was treated in precisely the same way. The residue, $\mathrm{KBr}+\mathrm{Au}$, was weighed, the $\mathrm{KBr}$ dissolved out, and the gold then weighed separately. The 
weight "of $\mathrm{KBr}$ was taken by difference. The ratio $\mathrm{Au}: \mathrm{KBr}:: 100: x$ appears in a third column.

$\begin{array}{ccc}\text { Au. } & \text { KBr. } & \text { Ratio. } \\ 6.19001 & 3.73440 & 60.329 \\ 4.76957 & 2.87715 & 60.323 \\ 4.14050 & 2.49822 & 60.336 \\ 3.60344 & 2.17440 & 60.342 \\ 3.67963 & 2.21978 & 60.326 \\ 4.57757 & 2.76195 & 60.337 \\ 5.36659 & 3.23821 & 60.326 \\ 5.16406 & 3.11533 & 60.327 \\ & & \text { Mean, } 60.331 \pm .0016\end{array}$

'This mean combines with Krüss' thus:

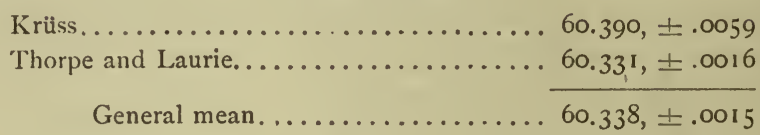

The potassium bromide of the previous experiments was next titrated with a solution of pure silver by Stas' method, the operation being performed in red light. Thus we get the following data for the ratio Ag: Au : : $100: x$, using the weights of gold already obtained :

$\begin{array}{ccc}A g . & \text { Au. } & \text { Ratio. } \\ 3.38451 & 6.19001 & 182.893 \\ 2.60896 & 4.76957 & 182.813 \\ 2.28830 & 4.18266 & 182.786 \\ 2.26415 & 4.14050 & 182.868 \\ 1.97147 & 3.60344 & 182.775 \\ 2.01292 & 3.67963 & 182.801 \\ 2.50334 & 4.57757 & 182.863 \\ 2.93608 & 5.36659 & 182.780 \\ 2.82401 & 5.16406 & 182.865 \\ & & - \text { Mean, } 182.827\end{array}$

Finally, in eight of these experiments, the silver bromide formed during titration was collected and weighed, giving values for the ratio $\mathrm{Au}: \mathrm{AgBr}:: 100: x$, as follows :

$\begin{array}{cl}\text { Au. } & A g B r \\ 6.19001 & 5.89199 \\ 4.76557 & 4.54261 \\ 4.18266 & 3.98288 \\ 4.14050 & 3.94309 \\ 3.60344 & 3.43015 \\ 3.67963 & 3.50207 \\ 4.57757 & 4.35736 \\ 5.36659 & 5.11045\end{array}$

Ratio.

95. i 86

95.242

95.224

95.232

95. I 91

95. I 75

95. 189

95.227

Mean, $95.208, \pm .006 \mathbf{I}$

Krüss found, $95.255, \pm .0142$

General mean, 95.222, \pm .0056 
From the second and third of the ratios measured by Thorpe and Laurie an independent value for the ratio $\mathrm{Ag}: \mathrm{Br}$ may be computed. It becomes $100: 74.072$, which agrees closely with the determinations made by Stas and Marignac. Similarly, the ratios $\mathrm{Ag}: \mathrm{KBr}$ and $\mathrm{AgBr}: \mathrm{KBr}$ may be calculated, giving additional checks upon the accuracy of the manipulation, though not upon the purity of the original material studied.

Thorpe and Laurie suggest objections to the work done by Krüss, on the ground that the salt $\mathrm{KAuBr}_{4}$ cannot be completely dried without loss of bromine. This suggestion led to a controversy between them and Krüss, which in effect was briefly as follows:

First, Krüss * urges that the potassium auribromide ordinarily contains traces of free gold, not belonging to the salt, produced by the reducing action of dust particles taken up from the air. He applies a correction for this supposed free gold to the determinations made by Thorpe and Laurie, and thus brings their results into harmony with his own. To this argument Thorpe and Laurie $†$ reply, somewhat in detail, stating that the error indicated was guarded against by them, and that they had dissolved quantities of from eight to nineteen grammes of the auribromide without a trace of free gold becoming visible. A final note in defense of his own work was published by Krüss a little later.

In 1889 an elaborate set of determinations of this constant was published by Mallet, $\S$ whose experiments are classified into seven distinct series. First, a neutral solution of auric chloride was prepared, which was weighed off in two approximately equal portions. In one of these the gold was precipitated by pure sulphurous acid, collected, washed, dried, ignited in a Sprengel vacuum, and weighed. To the second portion a solution containing a known weight of pure silver was added. After filtering, with all due precautions, the silver remaining in the filtrate was determined by titration with a weighed solution of pure hydrobromic acid. We have thus a weight of gold, and the weight of silver needed to precipitate the three atoms of chlorine combined with it; in other words, the ratio $\mathrm{Ag}_{3}: \mathrm{Au}:: 100: x$. All weights in this and the subsequent series are reduced to vacuum standards, and all weighings were made against corresponding tares.

\begin{tabular}{ccc} 
Au. & $\mathrm{Ag}_{3}$. & Ratio. \\
7.6075 & $\mathrm{I} 2.4875$ & $60.92 \mathrm{I}$ \\
8.4212 & 13.8280 & 60.900 \\
6.9407 & 11.3973 & 60.898 \\
3.3682 & 5.5286 & 60.923 \\
2.8244 & $4.637 \mathrm{I}$ & 60.909 \\
\hline
\end{tabular}

Hence Ag: Au : : $100: 182.730, \pm .0102$.

Mean, $\overline{60.910} \pm .0034$

* Ber. Deutsch. Chem. Gesell., 20, 2365. I887.

+ Berichte, 20, 3036, and Journ. Chem. Soc., 5I, 866. I887.

$\ddagger$ Berichte, 21, I26. I888.

\& Philosophical Transactions, $180,395 . \quad 1889$. 
The second series of determinations was essentially like the first, except that auric bromide was taken instead of the chloride. The ratio measured, $\mathrm{Ag}_{3}: \mathrm{Au}$, is precisely the same as before. Results as follows:

$\begin{array}{ccc}A u . & A g_{3} . & \text { Ratio. } \\ 8.2345 & 13.5 \mathrm{I} 49 & 60.929 \\ 7.690 \mathrm{I} & \mathrm{1} 2.625 \mathrm{I} & 60.9 \mathrm{II} \\ 10.5233 & 17.2666 & 60.945 \\ 2.7498 & 4.514 \mathrm{I} & 60.916 \\ 3.5620 & 5.847 \mathrm{I} & 60.919 \\ 3.908 \mathrm{I} & 6.4 \mathrm{I} 29 & 60.94 \mathrm{I} \\ & & \text { Mean, } 60.927, \pm .0038\end{array}$

Hence Ag: Au : : 100: 182.781, \pm .0114 .

In the third series of experiments the salt $\mathrm{KAuBr}_{4}$ was taken, purified by five recrystallizations. The solution of this was weighed out into nearly equal parts, the gold being measured as in the two preceding series in one portion, and the bromine thrown down by a standard silver solution as before. This gives the ratio $\mathrm{Ag}_{4}: \mathrm{Au}:: 100: x$.

$\begin{array}{cc}A u . & A g . \\ 5.7048 & 12.48 ; \mathrm{I} \\ 7.9612 & 17.4193 \\ 2.4455 & 5.3513 \\ 4.1632 & 9.1153\end{array}$

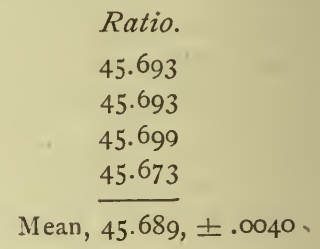

Hence Ag: Au : : $100: 182.756, \pm .0160$.

The fifth series of determinations, which for present purposes naturally precedes the fourth, was electrolytic in character, gold and silver being simultaneously precipitated by the same current. 'The gold was in solution as potassium auro-cyanide, and the silver in the form of potassium silver cyanide. The equivalent weights of the two metals, thrown down in the same time, were as follows, giving directly the ratio $\mathrm{Ag}: \mathrm{Au}:: 100: x$.

$\begin{array}{ccc}A \cdot u . & A g . & \text { Ratio. } \\ 5.272 \mathrm{I} & 2.8849 & \mathrm{r} 82.748 \\ 6.3088 & 3.4487 & \mathrm{I} 82.933 \\ 4.2770 & 2.3393 & \mathrm{I} 82.832 \\ 3.5123 & 1.9223 & \mathrm{I} 82.713 \\ 3.6804 & 2.0132 & \mathrm{r} 82.814 \\ & & \text { Mean, } 182.808, \pm .0256\end{array}$

This mean may be combined with the preceding means, and also with the determination of the same ratio by Thorpe and Laurie, thus:

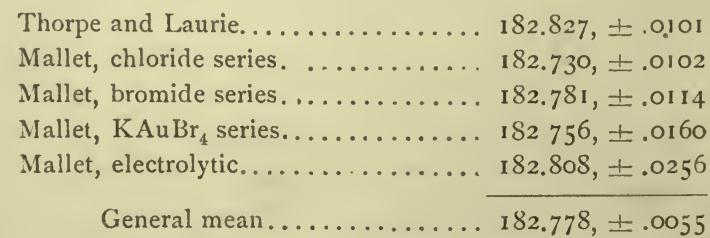


In Mallet's fourth series a radically new method was employed. Trimethyl-ammonium aurichloride, $\mathrm{N}\left(\mathrm{CH}_{3}\right)_{3} \mathrm{HAuCl}_{4}$, was decomposed by heat, and the residual gold was determined. In order to avoid loss by spattering; the salt was heated in a crucible under a layer of fine siliceous sand of known weight. Several crops of crystals of the salt were studier, as a check against impurities, but all gave concordant values.

\begin{tabular}{ccc}
\multicolumn{1}{c}{ Salt. } & Residual Au. & Per cent. Au. \\
14.9072 & 7.3754 & 49.475 \\
15.5263 & 7.6831 & 49.484 \\
10.4523 & 5.1712 & 49.474 \\
6.5912 & 3.2603 & 49.464 \\
5.5744 & 2.7579 & 49.474 \\
& & Nean, $49.474, \pm .002 \mathrm{I}$
\end{tabular}

In his sixth and seventh series Mallet seeks to establish, by direct measurement, the ratio between hydrogen and gold. In their experimental details his methods are somewhat elaborate, and only the processes, in the most general way, can be indicated here. First, gold was precipitated electrolytically from a solution of potassium aurocyanide, and its weight was compared with that of the amount of hydrogen simultaneously liberated in a voltameter by the same current in the same time. The hydrogen was measured, and its weight was then computed from its density. The volumes are given, of course, at $0^{\circ}$ and $760 \mathrm{~mm}$.

$\begin{array}{ccc}\text { Wt. Au. } & \text { Vol. } H, c c . & \text { Wt. H. } \\ 4.0472 & 228.64 & .0205483 \\ 4.0226 & 227.03 & .0204046 \\ 4.0955 & 231.55 & .0208103\end{array}$

These data, with the weight of one litre of hydrogen taken as 0.89872 gramme, give the subjoined values in the ratio $\mathrm{H}: \mathrm{Au}:: 1: x$.

$$
\begin{gathered}
196.960 \\
197.151 \\
196.805 \\
\text { Mean, } 196.972, \pm .0675
\end{gathered}
$$

In the-last series of experiments a known quantity of metallic zinc was dissolved in dilute sulphuric acid, and the amount of hydrogen evolved was measured. Then a solution of pure auric chloride or bromide was treated with a definite weight of the same zinc, and the quantity of gold thrown down was determined. The zinc itself was purified by practical distillation in a Sprengel vacuum. From these data the ratio $\mathrm{H}_{3}: \mathrm{Au}$ was computed by direct comparison of the weight of gold and that of the liberated hydrogen. The results were as follows: 


$\begin{array}{rrr}\text { Wt. Au. } & \text { Vol. H, cc. } & \text { Wt. H. } \\ \text { 10.3512 } & \text { 1756.10 } & .157824 \\ 8.2525 & 1400.38 & .125857 \\ 8.1004 & 1374.87 & .123565 \\ 3.2913 & 558.64 & .050206 \\ 3.4835 & 590.93 & .053109 \\ 3.6421 & 618.11 & .05555^{1}\end{array}$

Hence for the ratio $\mathrm{H}_{3}: \mathrm{Au}:: 1: x$ we have :

$$
\begin{array}{r}
65.587 \\
65.571 \\
65.557 \\
65.556 \\
65.593 \\
65.563 \\
\hline \text { Mean, } 65.571, \pm .00436
\end{array}
$$

And $\mathrm{H}: \mathrm{Au}:: 1: 196.713, \pm .0131$. This, combined with the value found in the preceding series, gives a general mean of $196.722, \pm .01 \dot{2} 9$.

The ratios available for gold are now as follows:

(I.) $2 \mathrm{KCl}: \mathrm{Au}:: 100: 263.730, \pm .026$

(2.) $3 \mathrm{AgCl}: \mathrm{Au}:: 100: 45.824, \pm .0020$

(3.) $\mathrm{KAuBr}_{4}: \mathrm{Au}:: 100: 35.46 \mathrm{r}, \pm .0028$

(4.) $\mathrm{Au}: \mathrm{AgBr}:: \mathrm{I00}: 95.222, \pm .0056$

(5.) $\mathrm{Au}: \mathrm{Br}_{3}:: 100: 121.678, \pm .0100$

(6.) $\mathrm{Au}: \mathrm{KBr}:: 100: 60.338, \pm 0015$

(7.) $\mathrm{Ag}: \mathrm{Au}:: 100: \mathbf{1} 82.778, \pm .0055$

(8.) $\mathrm{NC}_{3} \mathrm{H}_{10} \mathrm{AuCl}_{4}: \mathrm{Au}:: 100: 49.474, \pm .0021$

(9.) $\mathrm{H}: \mathrm{Au}:: \mathrm{I}: 196.722, \pm .0129$

For the reduction of these ratios the antecedent data are:

$$
\begin{array}{ll}
\mathrm{Ag}=107.108, \pm .0031 & \mathrm{C} \quad=11.920 \pm .0004 \\
\mathrm{Cl}=35.179, \pm .0048 & \mathrm{AgCl}=\mathrm{I} 42.287, \pm .0037 \\
\mathrm{Br}=79.344, \pm .0062 & \mathrm{AgBr}=186.452, \pm .0054 \\
\mathrm{~K}=38.817 \pm .005 \mathrm{I} & \mathrm{KCl}=74.025, \pm .0019 \\
\mathrm{~N}=\mathrm{I} 3.935, \pm .002 \mathrm{I} & \mathrm{KBr}=\mathrm{I} 18.200, \pm .0073
\end{array}
$$

Hence for the atomic weight of gold we have nine values:

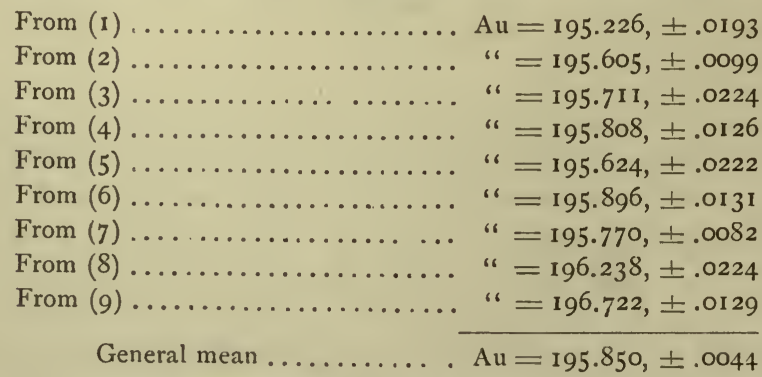

If $\mathrm{O}=16$, this becomes $\mathrm{A} u=197.342$. 
Of the foregoing values the first one, which is derived from Berzelius' work, should certainly be rejected. So also, apparently, should the eighth and ninth values. Excluding these, values 2 to 7 , inclusive, give a general mean of $\mathrm{Au}=195.743 . \pm .0049$. With $\mathrm{O}=16$, this becomes $\mathrm{Au}=$ 197.235. Probably these values are more nearly correct than those which include all the determinations.

The ninth value in the list given above represents Mallet's comparisons of gold directly with hydrogen, and is peculiarly instructive. In Mallet's paper the other determinations are discussed upon the basis of $\mathrm{O}=15.96$, which brings them more nearly into harmony with the hydrogen series. The great divergence shown in this recalculation is due to the new value for oxygen, 15.879 , and its effect upon the atomic weights of silver, bromine, etc. The former agreement between the several series of gold values was therefore only apparent, and we are now able to see that concordance among determinations may be only coincidence, and no proof of accuracy. It is probable, furthermore, that direct comparisons of metals with hydrogen cannot give good measurements of atomic weights, for several reasons. First, it is not possible to be certain that every trace of hydrogen has been collected and measured, and any loss tends to raise the apparent atomic weight of the metal studied; secondly, the weight of the hydrogen is computed from its volume, and a slight change in the factors used in reduction of the observations may make a considerable difference in the final result. These uncertainties exist in all determinations of atomic weights hitherto made by the hydrogen method. 


\section{CALCIUN.}

For determining the atomic weight of calcium we have sets of experiments by Berzelius, Erdmann and Marchand, and Dumas. Salvétat* also has published an estimation, but without the details necessary to enable us to make use of his results. I also find a reference $\dagger$ to some work of Marignac, which, howerer, seems to have been of but little importance. The earlier work of Berzelius was very inexact as regards calcium, and it is not until we come down to the year 1824 that we find any material of decided value.

The most important factor in our present discussion is the composition of calcium carbonate, as worked out by Dumas and by Erdmann and Marchand.

In 1842 Dumas $\$$ made three ignitions of Iceland spar, and determined the percentages of carbon dioxide driven off and of lime remaining. The impurities of the material were also determined, the correction for them applied, and the weighings reduced to a vacuum standard. The percentage of lime came out as follows:

$$
\begin{gathered}
56.12 \\
56.04 \\
\frac{5^{6.06}}{5^{6.073}}, \pm . \text { or6 }
\end{gathered}
$$

About this same time Erdmann and Marchand $\S$ began their researches upon the same subject. Two ignitions of spar, containing .04 per cent. of impurity, gave respectively 56.09 and 56.18 per cent. of residue; but these results are not exact enough for us to consider further. Four other results obtained with artificial calcium carbonate are more noteworthy. The carbonate was precipitated from a solution of pure calcium chloride by ammonium carbonate, was washed thoroughly with hot water, and dried at a temperature of $180^{\circ}$. With this preparation the following residues of lime were obtained :

$$
\begin{gathered}
56.03 \\
55.98 \\
56.00 \\
55.99 \\
\frac{56 a n, 00, \pm .007}{56.00}
\end{gathered}
$$

It was subsequently shown by Berzelius that calcium carbonate prepared by this method retains traces of water even at $200^{\circ}$, and that

* Compt. Rend., I7, 3 I8. 1843 .

† See Oudeman's monograph, p. 5 I.

† Compt. Rend., 14, 537. 1842.

¿ Journ. für Prakt. Chem., 26, 472. I842. 
minute quantities of chloride are also held by it. These sources of error are, however, in opposite directions, since one would tend to diminish and the other to increase the weight of residue.

In the same paper there are also two direct estimations of carbonic acid in pure Iceland spar, which correspond to the following percentages of lime :

$$
\text { Mean, } \frac{5^{6.00}}{5^{6.02}}=
$$

In a still later paper* the same investigators give another series of results based upon the ignition of Iceland spar. The impurities were carefully estimated, and the percentages of lime are suitably corrected :

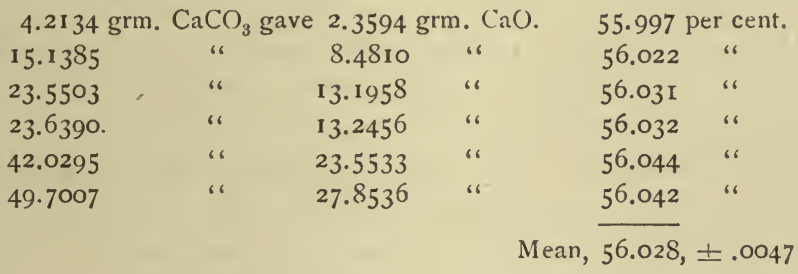

Six years later Erdmann and Marchand $\dagger$ published one more result upon the ignition of calcium carbonate. They found that the compound began giving off carbon dioxide below the temperature at which their previous samples had been dried, or about $200^{\circ}$, and that, on the other hand, traces of the dioxide were retained by the lime after ignition. These two errors do not compensate each other, since both tend to raise the percentage of lime. In the one experiment now under consideration these errors were accurately estimated, and the needful corrections were applied to the final result. The percentage of residual lime in this case came out 55.998. This agrees tolerably well with the figures found in the direct estimation of carbonic acid, and, if combined with those two, gives a mean for all three of $56.006, \pm .0043$.

Combining all these series, we get the following result:

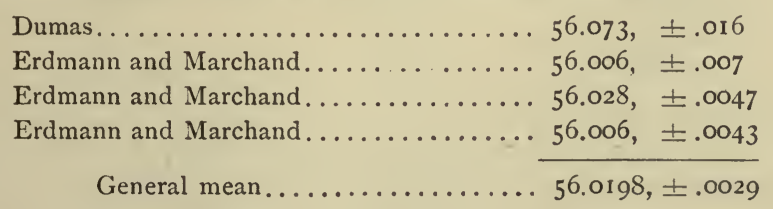

For reasons given above, this mean is probably vitiated by a slight constant error, which makes the figure a trifle too high.

* Journ. für Prakt. Chem., 31, 269. I844.

† Journ. für Prakt. Chem., 50, 237. 1850. 
In the earliest of the three papers by Erdmann and Marchand there is also given a series of determinations of the ratio between calcium carbonate and sulphate. Pure Iceland spar was carefully converted into calcium sulphate, and the gain in weight noted. One hundred parts of spar gave of sulphate:

$$
\begin{gathered}
136.07 \\
136.06 \\
136.02 \\
\text { Mean, } \frac{136.06}{136.0525} \pm .0071
\end{gathered}
$$

In 1843 the atomic weight of calcium was redetermined by Berzelius, * who investigated the ratio between lime and calcium sulphate. The calcium.was first precipitated from a pure solution of nitrate by means of ammonium carbonate, and the thoroughly washed precipitate was dried and strongly ignited in order to obtain lime wholly free from extraneous matter. This lime was then, with suitable precautions, treated with sulphuric acid, and the resulting sulphate was weighed. Correction was applied for the trace of solid impurity contained in the acid, but not for the weighing in air. The figures in the last column represent the percentage of weight gained by the lime upon conversion into sulphate:

$$
\begin{aligned}
& \mathbf{I . 8 0 4 2 5} \text { grm. CaO gained } 2.56735 \text { grm. } \quad \mathbf{I} 42.295 \\
& \text { 2.50400 " " } 3.57050 \text { " } 142.592 \\
& 3.90000 \text { " " } 5.55140 \text { " } 5142.343 \\
& 3.04250 \text { " " } 4.32650 \text { " } 142.202 \\
& 3.45900 \text { " " } 4.93140 \text { " } \quad 142.567 \\
& \text { Mean, } 142.3998, \pm .0518
\end{aligned}
$$

Last of all we have the ratio between calcium chloricle and silver, as determined by Dumas. $\dagger$ Pure calcium chloride was first ignited in a stream of dry hydrochloric acid, and the solution of this salt was afterwards titrated with a silver solution in the usual way. The $\mathrm{CaCl}_{2}$ proportional to 100 parts of $\mathrm{Ag}$ is given in a third column:

$$
\begin{aligned}
& 2.73^{8} \mathrm{grm} . \mathrm{CaCl}_{2}=5.309 \mathrm{grm} . \mathrm{Ag} . \quad 5 \mathrm{I} .573 \\
& \begin{array}{lllll}
2.436 & \text { " } & 4.73 \mathrm{I} & & \\
1.859 & 1.490
\end{array} \\
& \text { 1.859 " " " } 3.617 \text { “ } 51.396 \\
& \begin{array}{lllll}
2.771 & \text { " } & & 3.617 & 5.3885
\end{array} \\
& 2.240 \text { " " } 4.3585 \text { " } 51.394 \\
& \text { Mean, } 51.4554, \pm .0230
\end{aligned}
$$

We have now four ratios to compute from, as follows:
(I.) Percentage $\mathrm{CaO}$ in $\mathrm{CaCO}_{3}, 56.0198, \pm .0029$
(2.) $\mathrm{CaO}: \mathrm{SO}_{3}:: 100: 142.3998, \pm .0518$
(3.) $\mathrm{CaCO}_{3}: \mathrm{CaSO}_{4}:: 100: 136.0525, \pm .007 \mathrm{I}$
(4.) $\mathrm{Ag}_{2}: \mathrm{CaCl}_{2}:: 100: 51.4554, \pm .0230$ 
The antecedent values are-

$$
\begin{array}{ll}
\mathrm{O}=15.879, \pm .0003 & \mathrm{C}=1 \mathrm{11} .920, \pm .0004 \\
\mathrm{Ag}=107.108, \pm .003 \mathrm{I} & \mathrm{S}=31.828, \pm .0015 \\
\mathrm{Cl}=35.179, \pm .0048 &
\end{array}
$$

Hence the subjoined values for the atomic weight of calcium :

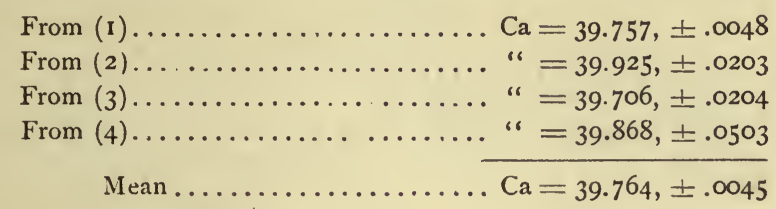

If $\mathrm{O}=16, \mathrm{Ca}=40.067$.

\section{STRONTIUM.}

The ratios which fix the atomic weight of strontium resemble in general terms those relating to barium, only they are fewer in number and represent a smaller amount of work. The early experiments of Stromeyer,* who measured the volume of $\mathrm{CO}_{2}$ evolved from a known weight of strontium carbonate, are hardly available for the present discussion. So also we may exclude the determination by Salvétat, $\dagger$ who neglected to publish sufficient details.

Taking the ratio between strontium chloride and silver first in order, we have series of figures by Pelouze and by Dumas. Pelouze $\ddagger$ employed the volumetric method to be described under barium, and in two experiments obtained the subjoined results. In another column I append the ratio between $\mathrm{SrCl}_{2}$ and 100 parts of silver :

$$
\begin{array}{lll}
\text { I. } 480 \mathrm{grm} . \mathrm{SrCl}_{2}=2.014 \mathrm{grm} . \mathrm{Ag} . & 73.486 \\
2.210 & 3.008 \text { " } & \frac{73.47 \mathrm{I}}{} \\
& & \text { Mean, } 73.478 \mathrm{I}, \pm .0050
\end{array}
$$

Dumas, $\S$ by the same general method, made sets of experiments with three samples of chloride which had previously been fused in a current of dry hydrochloric acid. His results, expressed in the usual way, are as follows:

* schweigg. Journ., I9, 228. I8I6. 
Series $A$.

\begin{tabular}{|c|c|c|c|c|c|}
\hline 3.137 & $\mathrm{SrC}$ & 4.280 & m. $\mathrm{Ag}$ & Ratio & 73.2944 \\
\hline 1.982 & “ & 2.705 & " & “ & 73.2717 \\
\hline $3.04 \mathrm{I}$ & " & 4.142 & " & ") & 73.4186 \\
\hline 3.099 & " & 4.219 & “" & " & 73.4534 \\
\hline
\end{tabular}

Series $B$.

$3.356 \mathrm{grm} . \mathrm{SrCl}_{2}=4.574 \mathrm{grm} . \mathrm{Ag}$.

Ratio, 73.3713

6.3645

8.667 "

“ 73.4327

7.131

9.712 "

“ 73.4246

Mean, 73.4095

Series $C$.

$7.213 \mathrm{grm} . \mathrm{SrCl}_{2}=9.811 \mathrm{grm} . \mathrm{Ag}$

2.206

" $\quad 3.006$

Ratio, 73.5195

4.268

5.816

“ 73.3866

4.018

5.477

“ 73.5529

“ 73.3613

Mean, $73.455^{\mathrm{I}}$.

Mean of all as one series, $73.4079, \pm .0170$

Combining these data we have:

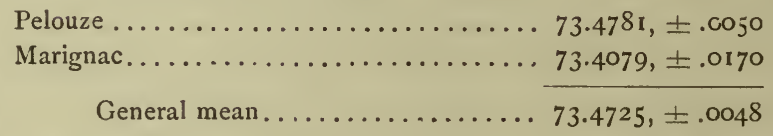

The foregoing figures apply to anhydrous strontium chloride. The ratio between silver and the crystallized salt, $\mathrm{SrCl}_{2} \cdot 6 \mathrm{H}_{2} \mathrm{O}$, has also been determined in two series of experiments by Marignac.* Five grammes of salt were used in each estimation, and, in the second series, the percentage of water was first determined. The quantities of the salt corresponding to 100 parts of silver are given in the last column :

Series $A$.

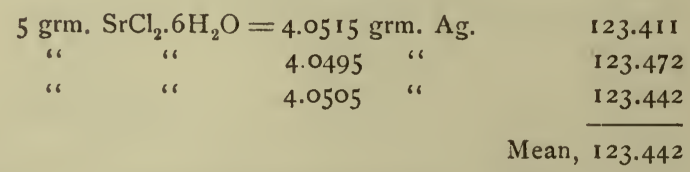

Series $B$.

$$
\begin{aligned}
& 5 \text { grm. } \mathrm{SrCl}_{2} \cdot 6 \mathrm{H}_{2} \mathrm{O}=4.0490 \mathrm{grm} . \mathrm{Ag} . \quad \mathrm{I} 23.487 \\
& \text { " " } 4.0500 \text { " } 40123.457 \\
& \text { " " } 4.0490 \text { " } 123.487 \\
& \text { Mean, } 123.477
\end{aligned}
$$


In the same paper Marignac gives two sets of determinations of the percentage of water in crystallized strontium chloride. The first set, corresponding to " $\mathrm{B}$ " above, is as follows:

$$
\begin{array}{r}
40.556 \\
40.568 \\
40.566 \\
\hline \text { Mean, } \\
\hline 0.563
\end{array}
$$

In the second set ten grammes of salt were taken at a time, and the following percentages were found :

$$
\begin{array}{r}
40.58 \\
40.59 \\
\frac{40.58}{40.583} \\
\text { Mean, } 40.573, \pm .0033
\end{array}
$$

The chloride used in the series of estimations last given was subsequently employed for ascertaining the ratio between it and the sulphate. Converted directly into sulphate, 100 parts of chloride yield the quantities given in the third column:

$$
\begin{aligned}
& 5.942 \mathrm{grm} . \mathrm{SrCl}_{2} \text { gave } 6.887 \mathrm{grm} . \mathrm{SrSO}_{4} . \quad \text { II } 5.932 \\
& \begin{array}{llll}
5.941 & \text { " } & & \\
5.942 & 6.8855 & \text { II } 5.949
\end{array} \\
& 5.942 \text { " } 6.884 \text { “ } 115.927 \\
& \text { Mean, } \overline{115.936}, \pm .004
\end{aligned}
$$

Richards:* in his study of strontium bromide, followed pretty much the lines laid down in his work on barium. The properties of the bromide itself were carefully investigated, and its purity established beyond reasonable doubt, and then the two usual ratios were determined. First, the ratio $\mathrm{Ag}_{2}: \mathrm{SrBr}_{2}:: 100: x$, by titration with standard solutions of silver. For this ratio there are three series of measurements, by varied processes, concerning which full details are given. The data obtained, with weights reduced to a vacuum, are as follows:

First Series.

$\begin{array}{lcc}\text { Wt. } A g . & \text { Wt. } S r B r_{2} & \text { Ratio. } \\ \mathbf{1 . 3 0 7 5 5} & \mathbf{1} .49962 & \mathbf{1 1 4 . 6 8 9} \\ 2.10351 & 2.41225 & 114.677 \\ 2.23357 & 2.56153 & 114.683 \\ 5.3684 & 6.15663 & \mathbf{1 1 4 . 6 8 3} \\ & & \text { Mean, } 114.683\end{array}$


Second Series.

$$
\begin{aligned}
& \text { Wt. Ag. } \\
& 1.30762 \\
& 2.10322 \\
& 4.57502 \\
& 5.3680
\end{aligned}
$$

2.5434

3.3957

3.9607

4.5750

$$
\begin{gathered}
W t . S r B r_{2} . \\
1.49962 \\
2.41225 \\
5.24727 \\
6.15663
\end{gathered}
$$

Ratio.

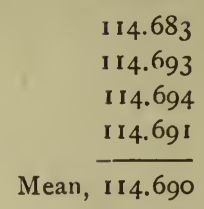

Third Series.

$$
\begin{array}{ll}
2.9172 & \\
3.8946 & 14.697 \\
4.5426 & \text { I } 4.692 \\
5.2473 & \text { I } 4.692 \\
& 114.695
\end{array}
$$

Mean of all as one series, $114.689, \pm .0012$

For the ratio, measured gravimetrically, $2 \mathrm{AgBr}: \mathrm{SrBr}_{2}:: 100: x$, two series of determinations are given:

First Series.

Wt. $A g B r$.
2.4415
2.8561
6.9337

2.27625

3.66140

3.88776

$9 \cdot 34497$
Wt. $\mathrm{SrBr}_{2}$.
I. 6086
I. 8817
4.5681

Ratio.

65.886

65.884

65.883

Second Series.

$$
\begin{array}{lr}
1.49962 & 65.88 \mathrm{I} \\
2.41225 & 65.883 \\
2.56153 & 65.887 \\
6.15663 & 65.882 \\
& \text { Mean, } 65.883
\end{array}
$$

Mean of all as one series, $65.884, \pm .0006$

For the atomic weight of strontium we now have the subjoined ratios:
(r.) $\mathrm{Ag}_{2}: \mathrm{SrCl}_{2}:: 100: 73.4725, \pm .0048$
(2.) $\mathrm{Ag}_{2}: \mathrm{SrCl}_{2} \cdot 6 \mathrm{H}_{2} \mathrm{O}::$ : $100: 123.460, \pm .0082$
(3.) Per cent. $\mathrm{H}_{2} \mathrm{O}$ in $\mathrm{SrCl}_{2} \cdot 6 \mathrm{H}_{2} \mathrm{O}, 40.573, \pm .0033$
(4.) $\mathrm{SrCl}_{2}: \mathrm{SrSO}_{4}:: 100: 115.936, \pm .0040$
(5.) $\mathrm{Ag}_{2}: \mathrm{SrBr}_{2}:$ : $100:$ II 4.689 , \pm .0012
(6.) $2 \mathrm{AgBr}: \mathrm{SrBr}_{2}:: 100: 65.884, \pm .0006$

The antecedent values are-

$$
\begin{array}{ll}
\mathrm{O}=15.879, \pm .0003 & \mathrm{Br}=79.344, \pm .0062 \\
\mathrm{Ag}=107.108, \pm .0031 & \mathrm{~S}=31.828, \pm .0015 \\
\mathrm{Cl}=35.179, \pm .0048 & \mathrm{AgBr}=186.452, \pm .0054
\end{array}
$$


For the molecular weight of $\mathrm{SrCl}_{2}$ three estimates are available:

$$
\begin{aligned}
& \text { From (1) } \ldots \ldots \ldots \ldots \ldots \ldots . \mathrm{SrCl}_{2}=157.390, \pm .0112 \\
& \text { From }(2) \ldots \ldots \ldots \ldots \ldots \ldots \ldots \text { " }=\text { 157.197, } \pm .0192 \\
& \text { From }(3) \ldots \ldots \ldots \ldots \ldots \ldots \ldots \text { " }=157.123, \pm .0157 \\
& \text { General mean.......... } \mathrm{SrCl}_{2}=157.28 \mathrm{I}, \pm .008_{3}
\end{aligned}
$$

For $\mathrm{SrBr}_{2}$ there are two values:

$$
\begin{aligned}
& \text { From }(5) \ldots \ldots \ldots \ldots \ldots \ldots . . .6 \mathrm{SrBr}_{2}=245.682, \pm .0076 \\
& \text { From }(6) \ldots \ldots \ldots \ldots \ldots \ldots \ldots \ldots \text { " }=245.684, \pm .0075 \\
& \text { General mean.......... } \overline{\mathrm{SrBr}_{2}=245.683, \pm .0053}
\end{aligned}
$$

Finally, with these intermediate data we obtain three independent measures of the atomic weight of strontium, as follows:

$$
\begin{aligned}
& \text { From molecular weight } \mathrm{SrCl}_{2} \ldots \ldots . . \mathrm{Sr}=86.923, \pm .0127 \\
& \text { From molecular weight } \mathrm{SrBr}_{2} \ldots \ldots \ldots \text { " }=86.995, \pm .0135 \\
& \text { From ratio (4).............. " }=86.434, \pm .08 \text { I I } \\
& \text { General mean............. } \mathrm{Sr}=86.948, \pm .0092
\end{aligned}
$$

If $\mathrm{O}=16, \mathrm{Sr}=87.610$. Rejection of the third value, which is worthless, raises these means by 0.01 only. The second value, 86.995 , which represents Richards' work, is undoubtedly the best of the three. 


\section{BARIUM.}

For the atomic weight of barium we have a series of eight ratios, established by the labors of Berzelius, Turner, Struve, Marignac, Dumas, and Richards. Andrews* and Salvétat, $†$ in their papers upon this subject, gave no details nor weighings, and therefore their work may be properly disregarded. First in order, we may consider the ratio between silver and barium chloride, as determined by Pelouze, Marignac, Dumas, and Richards.

Pelouze, $¥$ in 1845 , made the three subjoined estimations of this ratio, using his well known volumetric method. A quantity of pure silver was dissolved in nitric acid, and the amount of barium chloride needed to precipitate it was carefully ascertained. In the last column I give the quantity of barium chloride proportional to 100 parts of silver :

$$
\begin{aligned}
& 3.860 \text { grm. } \mathrm{BaCl}_{2} \text { ppt. } 4.002 \mathrm{grm} \text {. Ag. } \quad 96.452 \\
& 5.790 \text { " " } 6.003 \text { " } 96.452 \\
& 2.895 \text { " } 3.001 \text { " } 96.468 \\
& \text { Mean, } \overline{96.4573}, \pm .0036
\end{aligned}
$$

Essentially the same method was adopted by Marignac $\$$ in 1848 . His experiments were made upon four samples of barium chloride, as follows. A, commercial barium chloride, purified by recrystallization from water. B, the same salt, calcined, redissolved in water, the solution saturated with carbonic acid, filtered, and allowed to crystallize. C, the

\begin{tabular}{|c|c|c|c|}
\hline$A g$ & $\mathrm{BaCl}_{2}$. & Ratio. & \\
\hline $\int 3.4445$ & 3.3190 & 96.3567 & \multirow{3}{*}{ Mean, 96.354} \\
\hline A. $\{3.7480$ & 3.6110 & $96.345\}$ & \\
\hline$(6.3446$ & 6.1140 & $96.362)$ & \\
\hline$\{4.3660$ & 4. 1780 & $\left.96.35^{6}\right\}$ & \multirow{2}{*}{ Mean, 96.354} \\
\hline$\left\{\begin{array}{l}4.8390 \\
\text { s. }\end{array}\right.$ & 4.6625 & $96.352\}$ & \\
\hline C. $\{6.9200$ & 6.6680 & $\left.96.35^{8}\right\}$ & \multirow{2}{*}{ Mean, 96.360} \\
\hline C. $\{5.6230$ & $5 \cdot 4185$ & $\left.9^{6.36} 3\right\}$ & \\
\hline 5.8435 & 5.6300 & 96.3467 & \multirow{4}{*}{ Mean, 96.367} \\
\hline $8.575^{\circ}$ & 8.2650 & 96.384 & \\
\hline 4.8225 & 4.6470 & $96.36 \mathrm{I}$ & \\
\hline \multirow[t]{2}{*}{6.8460} & 6.5980 & 96.377 & \\
\hline & & 60, & \pm .0024 \\
\hline
\end{tabular}
preceding salt, washed with alcohol, and again recrystallized, D, the same, again washed with alcohol. For 100 parts of silver the following quantities of chloride were required, as given in the third column :

* Chemical Gazette, October, 1852.

† Compt. Rend., 17, 318.

† Compt. Rend., 20, 1047. Journ. für Prakt. Chem., 35, 73.

\& Arch. d. Sci. Phys. et Nat., 8, 27 I. 
Dumas* employed barium chloride prepared from pure barium nitrate, and took the extra precaution of fusing the salt at a red heat in a current of dry hydrochloric acid gas. Three series of experiments upon three samples of chloride gave the following results :
Ag.
$\mathrm{BaCl}_{2}$.
Ratio.
A. $\left\{\begin{array}{l}1.8260 \\ 3.9980 \\ 2.2405 \\ 4.1680\end{array}\right.$
1.7585
3.8420
2.1585
4.0162
1.6625
2.4987
3.4468
4.0822
4.2062
4.4564
8.6975
2.2957
C. $\left\{\begin{array}{l}2.3835 \\ 4.2930 \\ 4.4300 \\ 4.6470 \\ 5.8520\end{array}\right.$
4. 1372
4.2662
4.4764
5.6397
$\left.\begin{array}{l}\left.\begin{array}{l}96.303 \\ 96.339 \\ 96.340 \\ 96.358\end{array}\right\} \text { Mean, } 96.333 \\ 96.265 \\ 96.304 \\ 96.306 \\ 96.290 \\ 96.289 \\ 96.271 \\ 96.307 \\ 96.316 \\ 96.371 \\ 96.303 \\ 96.329 \\ 96.372\end{array}\right\}$ Mean, 96.290
Mean, $\overline{96.316}, \pm .0055$

The work done by Richards $\dagger$ was of a much more elaborate kind, for it involved some collateral investigations as to the effect of heat upon barium chloride, etc. Every precaution was taken to secure the spectroscopic purity of the material, which was prepared from several sources, and similar care was taken with regard to the silver. For details upon these points the original paper must be consulted. As for the titrations, three methods were adopted, and a special study was made with reference to the accurate determination of the end point; in which particular the investigations of Pelouze, Marignac, and Dumas were at fault. In the first series of determinations, silver was added in excess, and the latter was measured with a standard solution of hydrochloric acid. The end point was ascertained by titrating backward and forward with silver solution and acid, and was taken as the mean between the two apparent end points thus observed. The results of this series, with weights reduced to vacuum standards, were as follows:

$\begin{array}{ccc}\mathrm{Ag} . & \mathrm{BaCl}_{2} . & \text { Ratio. } \\ 6.1872 & 5.9717 & 96.517 \\ 5.6580 & 5.4597 & 96.495 \\ 3.5988 & 3.4728 & 96.499 \\ 9.4010 & 9.0726 & 96.507 \\ .7199 & .6950 & 96.541 \\ & & \text { Mean, } 96.512, \pm .0055\end{array}$

*Ann. Chem. Pharm., I13, 22. 1860. Ann. Chim. Phys. (3), 55, 120. † Proc. Amer. Acad., 29, 55. 1893. 
In the second series of experiments a small excess of silver was added as before, and the precipitate of silver chloride was removed by filtration. The filtrate and wash waters were concentrated to small bulk whereupon a trace of silver chloride was obtained and taken into account. The excess of silver remaining was then thrown down as silver bromide, and from the weight of the latter the silver was calculated, and subtracted from the original amount.

$\begin{array}{ccc}\mathrm{Ag.} & \mathrm{BaCl}_{2} . & \text { Ratio. } \\ 6.59993 & 6.36974 & 96.512 \\ 5.55229 & 5.36010 & 96.539 \\ 4.06380 & 3.92244 & \frac{96.522}{} \\ & & \text { Mean, } 96.5^{24}, \pm .0054\end{array}$

The third series involved mixing solutions of barium chloride and silver in as nearly as possible equivalent amounts, and then determining the actual quantities of silver and chlorine left unprecipitated. The filtrate and wash waters were divided into two portions, one-half being evaporated with hydrobromic acid and the other with silver nitrate. The small amounts of silver bromide and chloride thus obtained were determined by reduction and the use of Volhard's method:

$\begin{array}{ccc}\mathrm{Ag} . & \mathrm{BaCl}_{2} & \text { Ratio. } \\ 4.4355 & 4.28 \mathrm{I} 5 & 96.528 \\ 2.7440 & 2.6488 & 96.53 \mathrm{r} \\ 6.1865 & 5.97 \mathrm{I} 2 & 96.520 \\ 34023 & 3.284 \mathrm{r} & 96.526 \\ & & \text { Mean, } 96.526, \pm .0035\end{array}$

Two final experiments were carried out by Stas' method, somewhat as in the first series, with variations and greater refinement in the observation of the end point. The results were as follows :

$\begin{array}{rrr}\mathrm{Ag} . & \mathrm{BaCl}_{2} . & \text { Ratio. } \\ 6.7342 & 6.50022 & 96.525 \\ 10.6023 & 10.23365 & \frac{96.523}{} \\ & & \text { Mean, } 96.524, \pm .0007\end{array}$

A careful study of Richards' paper will show that, although the last two experiments are probably the best, they are not entitled to such preponderance of weight as the "probable error" here computed would give them. I therefore treat Richards' work as I have already done that of Marignac and Dumas, regarding all of his series as one, which gives for the value of the ratio $96.520, \pm .0025$. This combines with the previous series thus: 


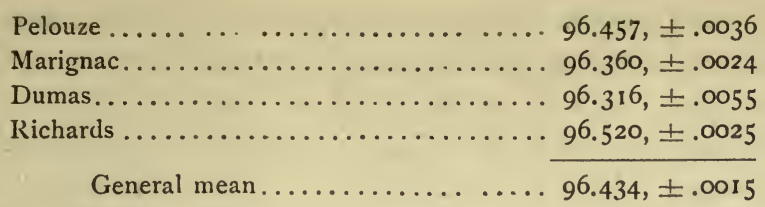

The ratio between silver and crystallized barium chloride has also been fixed by Marignac.* The usual method was employed, and two series of experiments were made, in the second of which the water of crystallization was determined previous to the estimation. Five grammes of chloride were taken in each determination. The following quantities of $\mathrm{BaCl}_{2} \cdot 2 \mathrm{H}_{2} \mathrm{O}$ correspond to 100 parts of silver:

$$
\begin{aligned}
& \text { A. }\left\{\begin{array}{l}
\text { II } 3.109 \\
\text { II } 3.135 \\
\text { II } 3.097
\end{array}\right\} \text { Mean, II3.II } 4 \\
& \text { B. }\left\{\begin{array}{l}
\text { II } 3.135 \\
\text { II } 3.122 \\
\text { II } 3.060
\end{array}\right\} \text { Mean, II3.106 } \\
& \text { Mean, II } 3.110, \pm .0079
\end{aligned}
$$

The direct ratio between the chlorides of silver and barium has been measured by Berzelius. Turner, and Richards. Berzelius $\dagger$ found of barium chloride proportional to 100 parts of silver chloride-

72.432

72.422

Mean, $\overline{72.427}$

Turner $\ddagger$ made five experiments, with the following results :

$$
\begin{gathered}
72.754 \\
72.406 \\
72.622 \\
72.664 \\
\frac{72.653}{72.680}, \pm .0154
\end{gathered}
$$

Of these, Turner regards the fourth and fifth as the best; but for present purposes it is not desirable to so discriminate.

Richards' determinations $\S$ fall into three series, and all are characterized by their taking into account chloride of silver recovered from the wash waters. In the first series the barium chloride was ignited at low redness in air or nitrogen; in the second series it was fused in a stream of pure hydrochloric acid; and in the third series it was not ignited at all. In the last series it was weighed in the crystallized state, and the 
amount of anhydrous chloride was computed from the data so obtained. The data, corrected to vacuum standards, are as follows:

\begin{tabular}{|c|c|c|c|c|}
\hline & $\mathrm{AgCl}$. & $\mathrm{BaCl}_{2}$. & Ratio. & \\
\hline \multirow{5}{*}{ A. } & 8.7673 & 6.3697 & 72.653 & \multirow{5}{*}{ - Mean, 72.649} \\
\hline & 5.1979 & 3.7765 & 72.654 & \\
\hline & $4.934^{2}$ & $3 \cdot 5^{8} 46$ & 72.648 & \\
\hline & 2.0765 & I. 5085 & 72.646 & \\
\hline & $4.427 \mathrm{I}$ & 3.2163 & 72.650 & \\
\hline & $\int 2.09750$ & 1.52384 & 72.650 & \multirow{3}{*}{ Mean, 72.6563} \\
\hline & 7.37610 & 5.36010 & 72.669 & \\
\hline \multirow{3}{*}{ C. } & (5.39906 & 3.92244 & 72.650 & \\
\hline & $\int 8.2189$ & 5.97123 & 72.6524 & \multirow{2}{*}{ Mean, 72.6555} \\
\hline & 4.5199 & 3.28410 & 72.6587 & \\
\hline
\end{tabular}

If we assign Berzelius' work equal weight with that of 'Turner, the three series representing the ratio $2 \mathrm{AgCl}: \mathrm{BaCl}_{2}$ combine as follows .

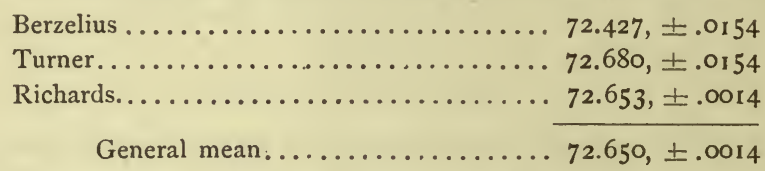

Incidentally to some of his other work, Marignac* determined the percentage of water in crystallized barium chloride. Two sets of three experiments each were made, the first upon five grammes and the socond upon ten grammes of salt. The following are the percentages obtained:

$$
\begin{aligned}
& \text { A. }\left\{\begin{array}{l}
14.790 \\
14.796 \\
14.800
\end{array}\right\} \text { Mean, } 14.795 \\
& \text { B. }\left\{\begin{array}{l}
14.80 \\
14.81 \\
14.80
\end{array}\right\} \text { Mean, } 14.803 \\
& \text { Mean, } 14.799, \pm .0018
\end{aligned}
$$

The ratio between barium nitrate and barium sulphate has been determined only by Turner. $\dagger$ According to his experiments 100 parts of sulphate correspond to the following quantities of nitrate:

$$
\begin{gathered}
\text { II } 2.060 \\
\text { II } 1.990 \\
\text { I I } 2.035 \\
{2.028,} \pm .014 }
\end{gathered}
$$

For the similar ratio between barium chloride and barium sulphate, there are available determinations by Turner, Berzelius, Struve, Marignac, and Richards. 
Turner* found that 100 parts of chloride ignited with sulphuric acid gave 112.19 parts of sulphate. By the common method of precipitation and filtration a lower figure was obtained, because of the slight solubility of the sulphate. This point bears directly upon many other atomic weight determinations.

Berzelius $\uparrow$ treating barium chloride with sulphuric acid, obtained the following results in $\mathrm{BaSO}_{4}$ for 100 parts of $\mathrm{BaCl}_{2}$ :

$$
\text { Mean, } \frac{112.17}{112.18}
$$

Struve, $\ddagger$ in two experiments, found :

$$
\text { Mean, } \begin{array}{r}
I 12.0912 \\
I 12.0964
\end{array}
$$

Marignac's $§$ three results are as follows :

$$
\begin{aligned}
& 8.520 \text { grm. } \mathrm{BaCl}_{2} \text { gave } 9.543 \mathrm{BaSO}_{4} \text {. } \\
& 8.519 \text { " } 9.544 \text { " } \\
& 8.520 \text { " } 9.542 \text { “ } \\
& \begin{array}{l}
\text { Ratio, II2.007 } \\
\text { “ } 112.032 \\
\text { “ } 111.995 \\
\text { Mean, II2.01I, } \pm .007 \text { I }
\end{array}
\end{aligned}
$$

Richards, in his work on this ratio, regards the results as of slight value, because of the occlusion of the chloride by the sulphate. This source of error he was never able to avoid entirely. Another error in the opposite direction is found in the retention of sulphuric acid by the precipitated sulphate. Eight experiments were made in two series, one set by adding sulphuric acid to a strong solution of barium chloride in a platinum crucible, the other by precipitation in the usual way. Richards gives in his published paper only the end results and the mean of his determinations; the details cited below I owe to his personal kindness. The weights are reduced to vacuum standards:

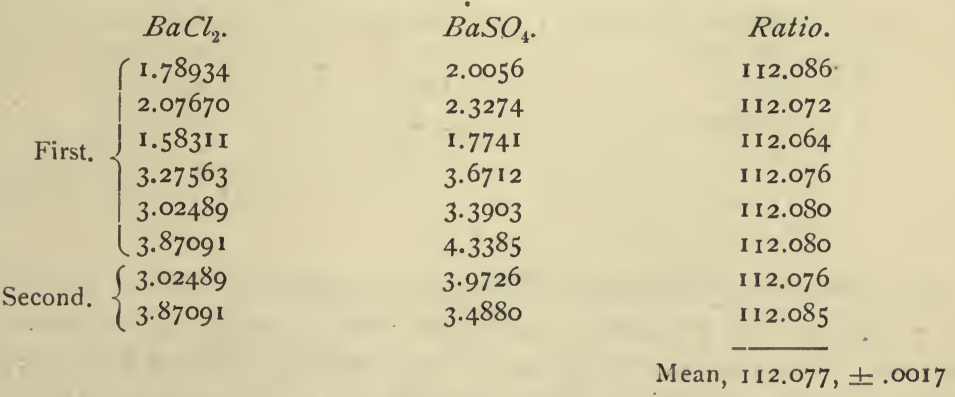

* Phil. Trans., I829, 291.

† Poggend. Annalen, 8, 177.

$\ddagger$ Ann. Chem. Pharm., 80, 204. 1851 .

\& Journ. für Prakt. Chem., 74, 212. 1858 . 
This mean is subject to a small correction due to loss of chlorine on drying the chloride, which reduces it to 112.073. Omitting Turner's single determination as unimportant, and assigning to the work of Berzelius and of Struve equal weight with that of Marignac, the measurements of this ratio combine thus:

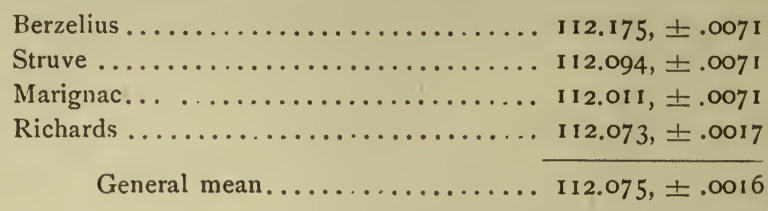

In an earlier paper than the one previously cited, Richards* studied with great care the ratios connesting barium bromide with silver and silver bromide. The barium bromide was prepared by sereral distinct processes, its behavior upon dehydration and even upon fusion "was studied, and its specific gravity was determined. The ratio with silver was measured by titration, a solution of hydrobromic acid being used for titrating back. The data are subjoined, with the $\mathrm{BaBr}_{2}$ equivalent to 100 parts of silver stated:

$\begin{array}{lcc}\mathrm{BaBr}_{2} . & \mathrm{Ag} . & \text { Ratio. } \\ 2.28760 & 1.66074 & 137.746 \\ 3.47120 & 2.52019 & 137.736 \\ 2.19940 & 1.59687 & 137.732 \\ 2.35971 & 1.71323 & 137.735 \\ 2.94207 & 2.13584 & 137.748 \\ 1.61191 & 1.17020 & 137.747 \\ 2.10633 & 1.52921 & 137.740 \\ 2.19682 & 2.11740 & 137.755 \\ 2.37290 & 1.72276 & 137.738 \\ 1.84822 & 1.34175 & 137.747 \\ 5.66647 & 4.11360 & 137.750 \\ 3.52670 & 2.56010 & 137.756 \\ 4.31690 & 3.13430 & 137.731 \\ 3.36635 & 2.44385 & 137.748 \\ 3.46347 & 2.51415 & 137.759 \\ & & -137.745, \pm .0015\end{array}$

The silver bromide in most of these determinations, and in some others, was collected and weighed in a Gooch crucible with all necessary precautions. Vacuum standards were used throughout for both ratios. I give in a third column the $\mathrm{BaBr}_{2}$ equivalent to 100 parts of $\mathrm{AgBr}$ : 


$\begin{array}{lll}\mathrm{BaBr}_{2} . & \mathrm{AgBr} . & \text { Ratio. } \\ 2.28760 & 2.89026 & 79.149 \\ 3.47120 & 4.38635 & 79.136 \\ 3.81086 & 4.81688 & 79.133 \\ 2.35971 & 2.98230 & 79.124 \\ 2.94207 & 3.71809 & 79.129 \\ 2.10633 & 2.66191 & 79.128 \\ 2.91682 & 3.68615 & 79.129 \\ 2.37290 & 2.99868 & 79.131 \\ 1.84822 & 2.33530 & 79.143 \\ 1.90460 & 2.40733 & 79.116 \\ 5.66647 & 7.16120 & 79.127 \\ 3.52670 & 4.45670 & 79.133 \\ 2.87743 & 3.63644 & 79.127 \\ 3.46347 & 4.37669 & 79.135 \\ & & \text { Mean, } 79.132, \pm .0015\end{array}$

The ratios for barium now sum up as follows:

(I.) $\mathrm{Ag}_{2}: \mathrm{BaCl}_{2}:: 100: 96.434, \pm .0015$

(2.) $\mathrm{Ag}_{2}: \mathrm{BaCl}_{2} \cdot 2 \mathrm{H}_{2} \mathrm{O}:: 100:$ I13.110, \pm .0079

(3.) $2 \mathrm{AgCl}: \mathrm{BaCl}_{2}:: 100: 72.650, \pm .0014$

(4.) Per cent. of $\mathrm{H}_{2} \mathrm{O}$ in $\mathrm{BaCl}_{2} \cdot 2 \mathrm{H}_{2} \mathrm{O}$, 14.799, \pm .0018

(5.) $\mathrm{BaSO}_{4}: \mathrm{BaN}_{2} \mathrm{O}_{6}::$ : $100:$ I I $2.028, \pm .014$

(6.) $\mathrm{BaCl}_{2}: \mathrm{BaSO}_{4}:: \mathrm{I00}: \mathrm{I} 12.075, \pm .0016$

(7.) $\mathrm{Ag}_{2}: \mathrm{BaBr}_{2}:: 100: 137.745, \pm .0015$

(8.) $2 \mathrm{AgBr}: \mathrm{BaBr}_{2}:: 100: 79.132, \pm .0015$

The reduction of these ratios depends upon the subjoined antecedent values:

$$
\begin{array}{ll}
\mathrm{Ag}=107.108, \pm .003 \mathrm{I} & \mathrm{N}=13.935, \pm .002 \mathrm{I} \\
\mathrm{Cl}=35.179, \pm .0048 & \mathrm{~S}=31.828, \pm .0015 \\
\mathrm{Br}=79.344, \pm .0062 & \mathrm{AgCl}=\mathrm{I} 42.287, \pm .0037 \\
\mathrm{O}=15.879 \pm .0003 & \mathrm{AgBr}=186.452, \pm .0054
\end{array}
$$

With these factors four estimates are obtainable for the molecular weight of barium chloride:

$$
\begin{aligned}
& \text { From (I) .............. } \mathrm{BaCl}_{2}=206.577, \pm .0068 \\
& \text { From (2).............. " }=206.542, \pm .0183 \\
& \text { From (3).............. " }=206.745, \pm .0067 \\
& \text { From }(4) \ldots \ldots \ldots \ldots \ldots \ldots \ldots \text { " }=205.866, \pm .0257 \\
& \text { General mean.......... } \mathrm{BaCl}_{2}=206.629, \pm .0045
\end{aligned}
$$

For barium bromide we have:

$$
\begin{aligned}
& \text { From }(7) \ldots \ldots \ldots \ldots \ldots \ldots \ldots \mathrm{BaBr}_{2}=295.070, \pm .009 \mathrm{I} \\
& \text { From }(8) \ldots \ldots \ldots \ldots \ldots \ldots \ldots \text { " }=295.086, \pm .0102 \\
& \text { General mean .......... } \mathrm{BaBr}_{2}=295.078, \pm .0068
\end{aligned}
$$


And for barium itself, four values are finally available, thus:

$$
\begin{aligned}
& \text { From molecular weight } \mathrm{BaCl}_{2} \ldots \ldots \mathrm{Ba}=\mathrm{I}_{3} 6.27 \mathrm{I}, \pm .0 \mathrm{IO} 6 \\
& \text { From molecular weight } \mathrm{BaBr}_{2} \ldots \ldots \text { " }=\mathrm{I} 36.390 \text {, } \pm .014 \mathrm{I} \\
& \text { From ratio }(5) \ldots \ldots \ldots \ldots \ldots \ldots \ldots \text { " }=\mathrm{I} 35.600, \pm .27 \mathrm{II} \\
& \text { From ratio }(6) \ldots \ldots \ldots \ldots \ldots \ldots \ldots . "=136.563, \pm .0946 \\
& \text { General mean. } \\
& \mathrm{Ba}=\mathrm{r} 36.315, \pm .0085
\end{aligned}
$$

Or, if $\mathrm{O}=16, \mathrm{Ba}=137.354$.

In the foregoing computation all the data, good or bad, are included. Some of them, as shown by the weights, practically vanish ; but others, as in the chloride series, carry an undue influence. A more trustworthy result can be deduced from Richards' experiments alone, which reduce as follows:

$$
\begin{aligned}
& \text { From } \mathrm{Ag}_{2}: \mathrm{BaCl}_{2} \ldots \ldots \ldots \ldots . . \mathrm{BaCl}_{2}=206.76 \mathrm{I}, \pm .0080 \\
& \text { From } 2 \mathrm{AgCl}: \mathrm{BaCl}_{2} \ldots \ldots \ldots \ldots \ldots \text { " }=206.754, \pm .0067 \\
& \text { General mean.......... BaCl} 2=206.755, \pm .005 \mathrm{I}
\end{aligned}
$$

From the bromide, as given above, $\mathrm{Ba}=136.390, \pm .0141$. From the value just found for the chloride, $\mathrm{Ba}=136.397, \pm .0109$. Combining the two values-

$$
\mathrm{Ba}=\mathrm{I} 36.392, \pm .0086
$$

Or, if $\mathrm{O}=16, \mathrm{Ba}=137.434$. This determination will be adopted in subsequent calculations as the most probable. 


\section{LEAD.}

For the atomic weight of lead we have to consider experiments made upon the oxide, chloride, nitrate, and sulphate. The researches of Berzelius upon the carbonate and various organic salts need not now be considered, nor is it worth while to take into account any work of his done before the year 1818. The results obtained by Döbereiner* and by Longchamp $\dagger$ are also without special present value.

For the exact composition of lead oxide we have to depend upon the researches of Berzelius. His experiments were made at different times through quite a number of years; but were finally summed up in the last edition of his famous "Lehrbuch." † In general terms his method of experiment was very simple. Perfectly pure lead oxide was heated in a current of hydrogen, and the reduced metal weighed. From his weighings I have calculated the percentages of lead thus found and given them in a third column :

Earlier Results.

\begin{tabular}{|c|c|c|c|c|c|}
\hline 8.045 & bO gave & 7.4675 & m. $\mathrm{Pb}$. & 92.8217 & cent. \\
\hline 14.183 & “ & 13. 165 & "6 & 92.8224 & " \\
\hline 10.8645 & “ & 10.084 & “ & 92.8160 & “ \\
\hline 13.1465 & “ & I 2.2045 & " & 92.8346 & “ \\
\hline 21.9425 & & 20.3695 & “ & 92.8313 & “ \\
\hline 11. 159 & “ & 10. 359 & “ & 92.8309 & “ \\
\hline & & Late & & & \\
\hline 6.6155 & " & $6.14 \mathrm{I}$ & “ & 92.8275 & “ \\
\hline 14.487 & " & I 3.448 & " & 92.8280 & " \\
\hline 14.626 & " & I 3.5775 & "6 & 92.8313 & " \\
\hline
\end{tabular}

For the synthesis of lead sulphate we have data by Berzelius, Turner, and Stas. Berzelius, $\S$ whose experiments were intended rather to fix the atomic weight of sulphur, dissolved in each estimation ten grammes of pure lead in nitric acid, then treated the resulting nitrate with sulphuric acid, brought the sulphate thus formed to dryness, and weighed. One hundred parts of metal yield of $\mathrm{PbSO}_{4}$ :

$$
\begin{gathered}
146.380 \\
146.400 \\
146.440 \\
146.458 \\
\text { Mean, } 146.419, \pm .012
\end{gathered}
$$


Turner,* in three similar experiments, found as follows :

$$
\begin{gathered}
146.430 \\
146.398 \\
146.375 \\
\text { Mean, } 146.401, \pm .011
\end{gathered}
$$

In these results of 'Turner's, absolute weights are implied.

'The results of Stas' syntheses, $\uparrow$ effected after the same general method, but with variations in details, are as follows. Corrections for weighing in air were applied :

$$
\begin{gathered}
146.443 \\
146.427 \\
146.419 \\
146.432 \\
146.421 \\
146.423 \\
\frac{146.4275}{\text { Mean, }} \pm .0024
\end{gathered}
$$

Combining, we get the subjoined result:

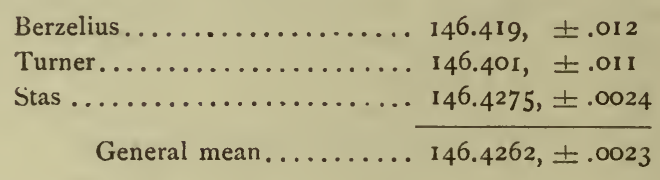

Turner, in the same paper, also gives a series of syntheses of lead sulphate. in which he starts from the oxide instead of from the metal. One hundred parts of $\mathrm{PbO}$, upon conversion into $\mathrm{PbSO}_{4}$, gained weight as follows :

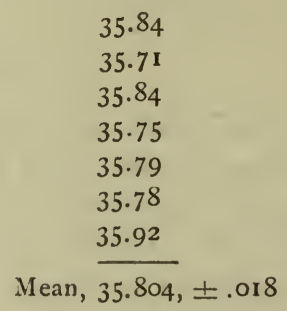

'These figures are not wholly reliable. Numbers one, two, and three represent lead oxide contaminated with traces of nitrate. The oxide of four, five, and six contained traces of minium. Number seven was free from these sources of error, and, therefore, deserves more consideration. The series as a whole undoubtedly gives too low a figure, and this error would tend to slightly raise the atomic weight of lead. 
Still a third series by Turner establishes the ratio between the nitrate and the sulphate, a known weight of the former being in each experiment converted into the latter. One hundred parts of sulphate represent of nitrate:

$$
\begin{gathered}
109.312 \\
109.310 \\
109.300 \\
\hline \text { Mean, } 109.307, \pm .002
\end{gathered}
$$

In all these experiments by Turner the necessary corrections were made for weighing in air.

In 1846 Marignac* published two sets of determinations of only moderate value. First, chlorine was conducted over weighed lead, and the amount of chloride so formed was determined. The lead chloride was fused before weighing. The ratio to $100 \mathrm{~Pb}$ is given in the last column :

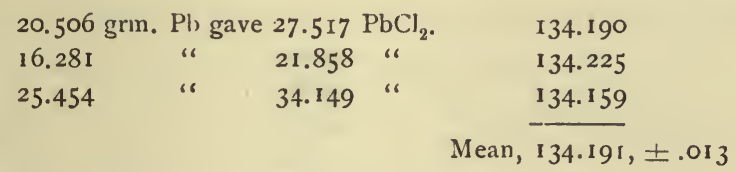

Secondly, lead chloride was precipitated by silver nitrate and the ratio between $\mathrm{PbCl}_{2}$ and $2 \mathrm{AgCl}$ determined. The third column gives the $\mathrm{AgCl}$ formed by 100 parts of $\mathrm{PbCl}_{2}$ :

$$
\begin{aligned}
& \text { 12.534 grm. } \mathrm{PbCl}_{2} \text { gave } 12.9 \text { I I AgCl. IO3.0I } \\
& 14.052 \text { " } 14.506 \text { " } 103.23 \\
& 25.533 \text { " " } 26.399 \text { " } 103.39 \\
& \text { Mean, } \overline{\text { IO3.2I }} \pm .0745
\end{aligned}
$$

For the ratio between lead chloride and silver we have a series of results by Marignac and one experiment by Dumas. 'There are also unarailable data by Turner and by Berzelius.

Marignac, $\uparrow$ applying the method used in his researches upon barium and strontium, and working with lead chloride which had been dried at $200^{\circ}$, obtained these results. The third column gives the ratio between $\mathrm{PbCl}_{2}$, and 100 parts of $\mathrm{Ag}$ :

$$
\begin{aligned}
& 4.9975 \text { grm. } \mathrm{PbCl}_{2}=3.88 \text { ro grm. Ag. } \quad 128.768 \\
& 4.9980 \text { " " } 3.8835 \text { " } 128.695 \\
& 5.0000 \text { " " } 3.8835 \text { “ } 128.750 \\
& \begin{array}{llll}
5.0000 \quad \text { " } & 3.8860 & 128.667
\end{array} \\
& \text { Mean, } \overline{128.721}, \pm .016
\end{aligned}
$$

Dumas,, in his investigations, found that lead chloride retains traces 
of water eren at $250^{\circ}$, and is sometimes also contaminated with oxychloride. In one estimation 8.700 grammes $\mathrm{PbCl}_{2}$ saturated 6.750 of $\mathrm{Ag}$. The chloride contained .009 of impurity; hence, correcting, $\mathrm{Ag}: \mathrm{PbCl}_{2}:$ : $100: 128.750$. If we assign this figure equal weight with those of Marignac, we get as the mean of all $128.7266, \pm .013$. The sources of error indicated by Dumas, if they are really involved in this mean, would tend slightly to raise the atomic weight of lead.

The synthesis of lead nitrate, as carried out by Stas,* gives excellent results. Two series of experiments were made, with from 103 to 250 grammes of lead in each determination. The metal was dissolved in nitric acid, the solution evaporated to dryness with extreme care, and the nitrate weighed. All weighings were reduced to the vacuum standard. In series $A$ the lead nitrate was dried in an air current at a temperature of about $155 .^{\circ}$ In series B the drying was effected in vacuo. 100 of lead yield of nitrate:

A.

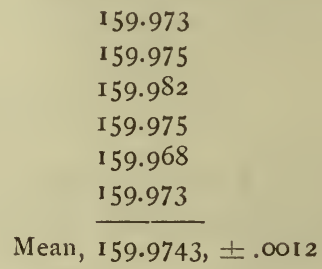

B.

159.970

159.964

I59.959

I 59.965

Mean, $159.9645, \pm .0015$

Mean from both series, $159.9704, \pm .0010$

There is still another set of experiments upon lead nitrate, originally intended to fix the atomic weight of nitrogen, which may properly be included here. It was carried out by Anderson $\dagger$ in Svanberg's laboratory, and has also appeared under Svanberg's name. Lead nitrate was carefully ignited, and the residual oxide weighed, with the following results :

5.19485 grm. $\mathrm{PbN}_{2} \mathrm{O}_{6}$ gave 3.5017 grm. $\mathrm{PbO} .67 .407$ I per cent.

\begin{tabular}{|c|c|c|c|c|}
\hline 9.7244 & “" & 6.5546 & "6 & 67.4037 \\
\hline 9.2181 & ، & $6.2 \mathrm{I} 34$ & "، & 67.4044 \\
\hline 9.6530 & "، & 6.5057 & " & 67.3957 \\
\hline
\end{tabular}

* A ronstein's translation, 316

† Ann. Chim. Phys. (3), 9, 254. 1843. 
We have now nine ratios from which to compute:

(1.) Per cent. of $\mathrm{Pb}$ in $\mathrm{PbO}, 92.827 \mathrm{I}, \pm .0013$

(2.) Per cent of $\mathrm{PbO}$ in $\mathrm{PbN}_{2} \mathrm{O}_{6}, 67.4027, \pm .0016$

(3.) $\mathrm{Pb}: \mathrm{PbSO}_{4}:: 100: 146.4262, \pm .0023$

(4.) $\mathrm{PbO}: \mathrm{PbSO}_{4}:: 100: 135.804, \pm .0180$

(5.) $\mathrm{PbSO}_{4}: \mathrm{PbN}_{2} \mathrm{O}_{6}:: 100: 109.307, \pm .0020$

(6.) $\mathrm{Pb}: \mathrm{PbN}_{2} \mathrm{O}_{6}:: 100: 159.9704, \pm .0010$

(7.) $\mathrm{Pb}: \mathrm{PbCl}_{2}:: 100: \mathrm{I} 34.19 \mathrm{I}, \pm .013$

(8.) $\mathrm{PbCl}_{2}: 2 \mathrm{AgCl}:: 100: 103.21, \pm .0745$

(9.) $\mathrm{Ag}_{2}: \mathrm{PbCl}_{2}:: 100: 128.7266, \pm .0130$

To reduce these ratios we must use the following data :

$$
\begin{array}{ll}
\mathrm{O}=15.879, \pm .0003 & \mathrm{~S}=31.828, \pm .0015 \\
\mathrm{Ag}=107.108, \pm .003 \mathrm{I} & \mathrm{N}=\mathrm{I} 3.935, \pm .002 \mathrm{I} \\
\mathrm{Cl}=35.179, \pm .0048 & \mathrm{AgCl}=\mathrm{I} 42.287, \pm .0037
\end{array}
$$

For the molecular weight of lead oxide we now get three estimates:

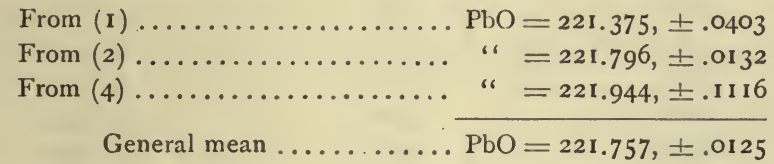

For lead chloride we have-

$$
\begin{aligned}
& \text { From (8) .............. } \mathrm{PbCl}_{2}=275.723, \pm .1989 \\
& \text { From }(9) \ldots \ldots \ldots \ldots \ldots \ldots \ldots \text {. } "=275.753, \pm .0290 \\
& \text { General mean ......... } \mathrm{PbCl}_{2}=275.75^{2}, \pm .0287
\end{aligned}
$$

Including these results, six values are calculable for the atomic weight of lead:

$$
\begin{aligned}
& \text { From molecular weight of } \mathrm{PbO} \ldots \ldots \mathrm{Pb}=205.878, \pm .0126 \\
& \text { From molecular weight of } \mathrm{PbCl}_{2} \ldots \ldots "=205.394, \pm .0302 \\
& \text { From (3)................ " }=205.367, \pm .0051 \\
& \text { From (5)................." }=203.352, \pm .0479 \\
& \text { From (6)................. } "=205.341, \pm .0068 \\
& \text { From }(7) \ldots \ldots \ldots \ldots \ldots \ldots \ldots \ldots \text {. }=205.779, \pm .083 \mathrm{I} \\
& \text { General mean........... Pb }=205.395, \pm .0038
\end{aligned}
$$

If $\mathrm{O}=16, \mathrm{~Pb}=206.960$. If we reject the first, fourth, and sixth of these values, which are untrustworthy, the remaining second, third, and fifth give a general mean of $\mathrm{Pb}=205.358, \pm .0040$. If $\mathrm{O}=16$, this becomes $\mathrm{Pb}=206.923$. From Stas' ratios alone Stas calculates $\mathrm{Pb}=$ 206.918 to 206.934; Ostwald finds 206.911; Van der Plaats (A), 206.9089, (B), 206.9308, and Thomsen 206.9042. The value adopted here represents mainly the work of Stas, and with $\mathrm{H}=1$ is

$$
\mathrm{Pb}=205 \cdot 358, \pm .0040 \text {. }
$$




\section{GLUCINUM.}

Our knowledge of the atomic weight of glucinum is chiefly derived from experiments made upon the sulphate. Leaving out of account the single determination by Berzelius, * we have to consider the data furnished by Awdejew, Weeren, Klatzo, Debray, Nilson and Pettersson, and Krüss and Moraht.

Awdejew, $†$ whose determination was the earliest of any value, analyzed the sulphate. The sulphuric acid was thrown down as barium sulphate; and in the filtrate, from which the excess of barium had been first removed, the glucina was precipitated by ammonia. The figures which Awdejew publishes represent the ratio between $\mathrm{SO}_{3}$ and $\mathrm{GlO}$, but not absolute weights. As, however, his calculations were made with $\mathrm{SO}_{3}=$ 501.165 , and Ba probably $=855.29$, we may add a third column showing how much $\mathrm{BaSO}_{4}$ is proportional to 100 parts of $\mathrm{GlO}$ :

$\begin{array}{rcc}\mathrm{SO}_{3} . & \mathrm{GlO} & \text { Ratio. } \\ 4457 & \mathrm{I} 406 & 921.242 \\ 453 \mathrm{I} & 1420 & 927.304 \\ 7816 & 2480 & 915.903 \\ 12880 & 4065 & 920814 \\ & & \text { Mean, } 921.316, \pm \mathrm{I} .577\end{array}$

The same method was followed by. Weeren and by Klatzo, except that Weeren used ammonium sulphide instead of ammonia for the precipitation of the glucina. Weeren $\$$ gives the following weights of $\mathrm{GlO}$ and $\mathrm{BaSO}_{4}$. The ratio is given in a third column, just as with the figures by Awdejew :

$\begin{array}{lll}\mathrm{GlO} & \mathrm{BaSO}_{4} & \text { Ratio. } \\ .3163 & 2.9332 & 927.03 \mathrm{I} \\ .2872 & 2.6377 & 9184 \mathrm{I9} \\ .2954 & 2.7342 & 925.592 \\ .5284 & 4.8823 & 902.946 \\ & & \text { Mean, } 918.497, \pm 3.624\end{array}$

Klatzo's $\S$ figures are as follows, with the third column added by the writer :

$\begin{array}{ccc}\mathrm{GlO} . & \mathrm{BaSO}_{4} & \text { Ratio. } \\ .2339 & 2.1520 & 920.05^{2} \\ .1910 & 1.755^{2} & 919.162 \\ .2673 & 2.4872 & 930.490 \\ .3585 & 3.3115 & 923.710 \\ .2800 & 2.5842 & 922.989 \\ & & \text { Mean, } 923.281, \pm 1.346\end{array}$

* Poggend. Annal., 8, r.

† Poggend. Annal., 56, 106. 1842.

† Poggend. Annal., 92, 124. 1854 .

\& Zeitschr. A nal. Chem., 8, 523. 1869 . 
Combining these series into a general mean, we get the subjoined result:

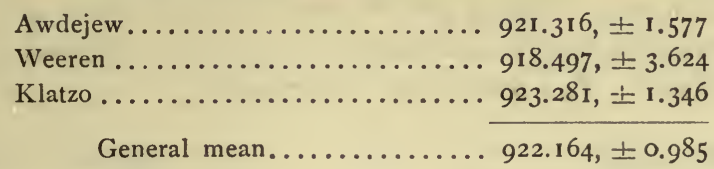

Hence $\mathrm{GlO}=25.130, \pm .0269$.

Debray* analyzed a double oxalate of glucinum and ammonium, $\mathrm{Gl}\left(\mathrm{NH}_{4}\right)_{2} \mathrm{C}_{4} \mathrm{O}_{8}$. In this the glucina was estimated by calcination, after first converting the salt into nitrate. The following percentages were found :

$$
\text { Mean, } \frac{11.433}{11.2}, \pm .081
$$

The carbon was estimated by an organic combustion. I give the weights, and put in a third column the percentages of $\mathrm{CO}_{2}$ thus obtained :

$\begin{array}{llc}\text { Salt. } & \mathrm{CO}_{2 .} . & \text { Per cent. } \mathrm{CO}_{2} . \\ .600 & .477 & 79500 \\ .603 & .478 & 79.270 \\ .600 & .477 & \overline{79.500} \\ & & \text { Mean, } \overline{79.423}, \pm .052\end{array}$

Calculating the ratio between $\mathrm{CO}_{2}$ and $\mathrm{GlO}$, we have for the molecular weight of the latter, $\mathrm{GlO}=25.151, \pm .1783$.

In 1880 the careful determinations of Nilson and Pettersson appeared. $\dagger$ These chemists first attempted to work with the sublimed chloride of glucinum, but abandoned the method upon finding the compound to be contaminated with traces of lime derived from a glass tube. They finally resorted to the crystallized sulphate as the most available salt for their purposes. This compound, upon strong ignition, yields pure glucina. The data are as follows:

$\begin{array}{cc}\mathrm{GlSO}_{4} \cdot 4 \mathrm{H}_{2} \mathrm{O} . & \mathrm{GlO} . \\ 3.8014 & .5387 \\ 2.6092 & .3697 \\ 4.3072 & .6099 \\ 3.009 \mathrm{I} & .4266\end{array}$

Per cent. Glo.

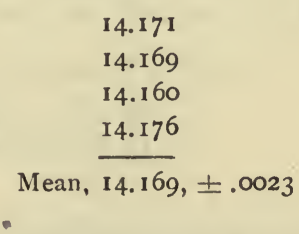

Krüss and Moraht $\ddagger$ in their work follow the general method adopted

*Ann. Chim. Phys. (3), 44, 37. 185.5.

$\dagger$ Berichte d. Deutsch. Chem. Gesell., I3, I45I. 1880.

† Ann. d. Chem., 262, 38. I89r. 


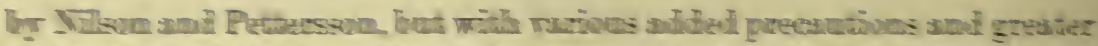

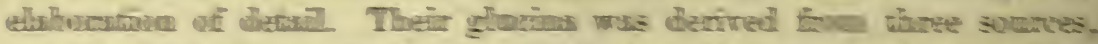

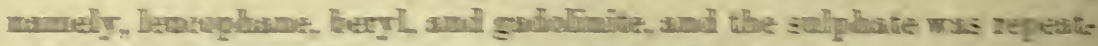

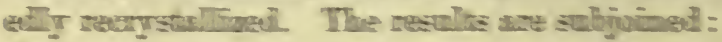

\begin{tabular}{|c|c|c|}
\hline CSOP,,$F E R$ & GaO & 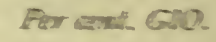 \\
\hline en oges & $5=0000$ & It neteo \\
\hline 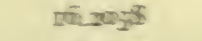 & $=200453$ & "4. \\
\hline Isuesjos & = nower & 14150 \\
\hline$=0003^{\circ}$ & 24453 & 141435 \\
\hline szeaffs & 5ा10: & 18150 \\
\hline 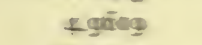 & foog & 14.156 \\
\hline Ex joy & I Inger & 14.145 \\
\hline 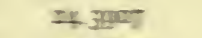 & 30053 & $14 \pi 5$ \\
\hline nen Ethous & $=85055$ & 12155 \\
\hline$z=0053$ & $28 \pi 5$ & 2425 \\
\hline II qusteos & $2 A B=$ & 12파나 \\
\hline 15.6002 & =eers & 12155 \\
\hline 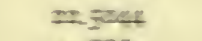 & jolses & $12 \pi 35$ \\
\hline 2005865 & 2esties & 12.554 \\
\hline mest & $=\log 305$ & $14=130$ \\
\hline $\mathrm{rg}-\mathrm{Sem}$ & 250005 & 11153 \\
\hline
\end{tabular}

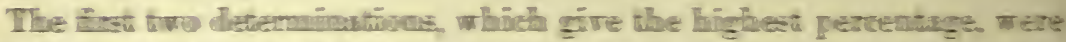

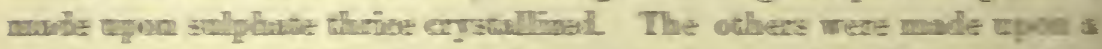

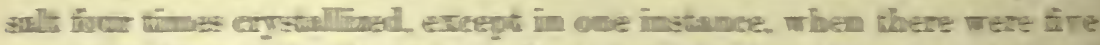

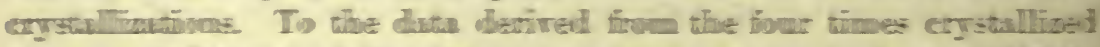

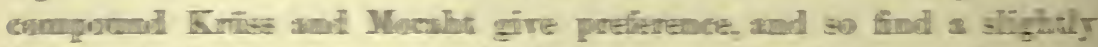

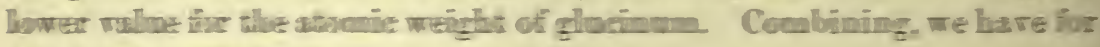

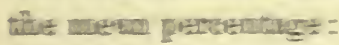

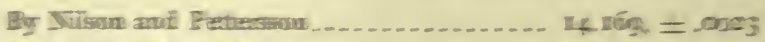

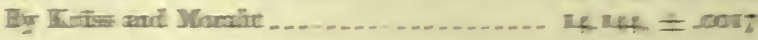

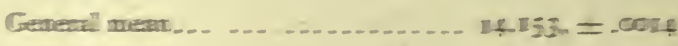

Taking wow all the dita loc glveinum, we here-
(1.) GTO = BasD, $==100=902164,=-915$

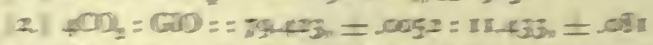

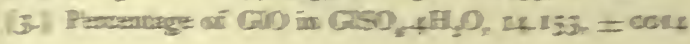

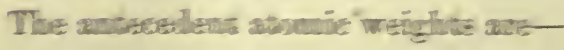

$$
\begin{aligned}
& \sigma=158-2 \mathrm{a}=1000 \mathrm{~s} \\
& s=j e r l a t .=005 \\
& c=11.002,1=0004 \\
& \text { Be }=135020=0015
\end{aligned}
$$


Hence the sulfisedsed ralues for glotion:

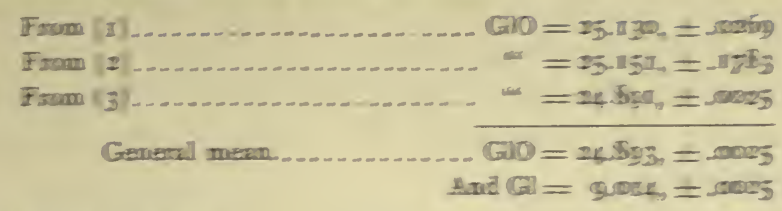

If $\mathrm{O}=1 \mathrm{6}, \mathrm{G} 1=9.0 \mathrm{~s} 3$.

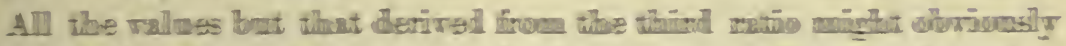

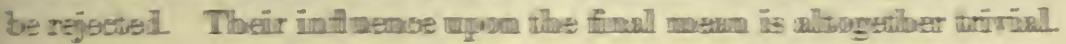

\section{MAGNESICMI}

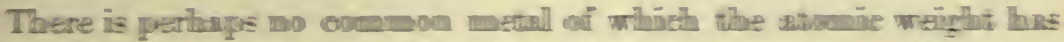

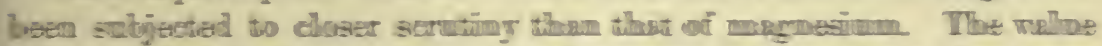

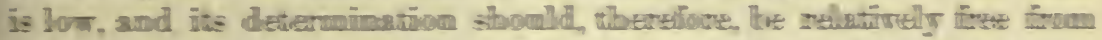

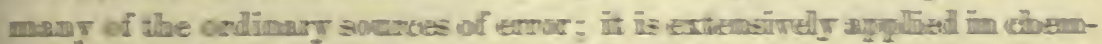

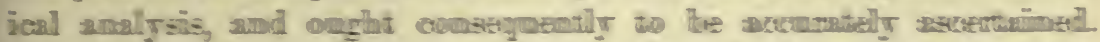

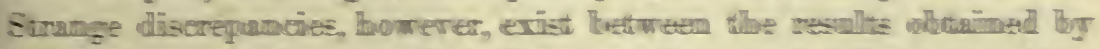

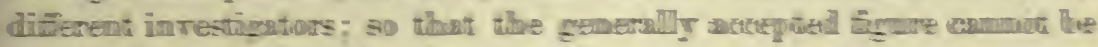
regarded as altsolewely free from doulth

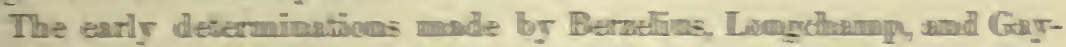

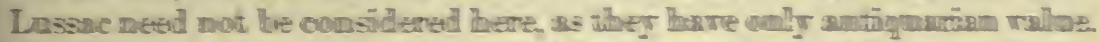

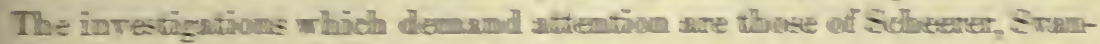

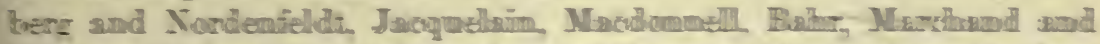

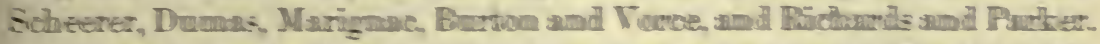

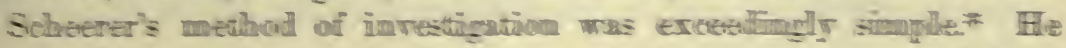

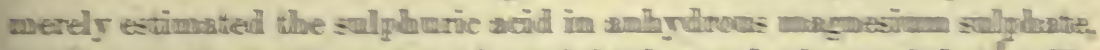

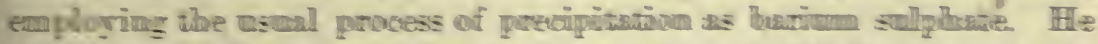

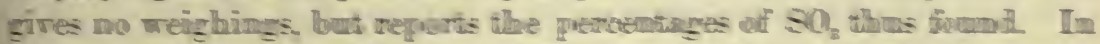

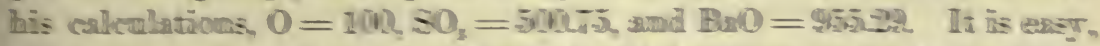

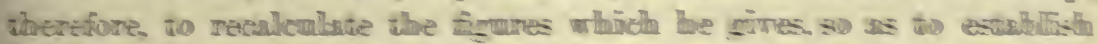

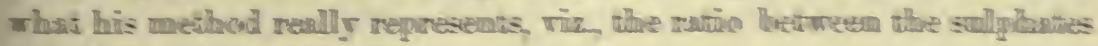
of hariuas and ancwesium.

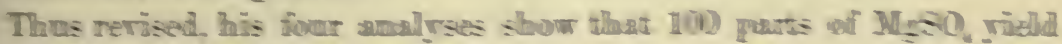
the fillowirg quanatities of $\mathrm{BaO}_{4}$ :

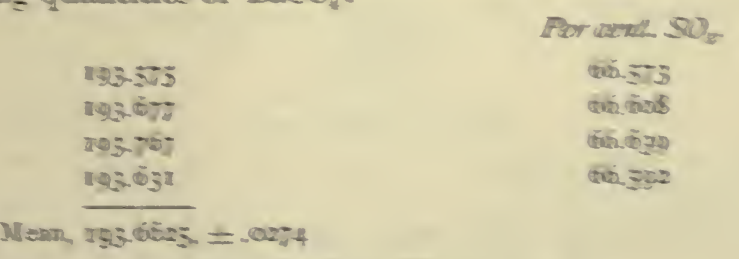

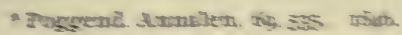


In a later note $*$ Scheerer shows that the barium sulphate of these experiments carries down with it magnesium salts in such quantity as to make the atomic weight of magnesium 0.039 too low.

The work of Bahr, Jacquelain, Macdonnell, and Marignac, and in part that of Svanberg and Nordenfeldt, also relates to the composition of magnesium sulphate.

Jacquelain's experiments were as follows : $†$ Dry magnesium sulphate was prepared by mixing the ordinary hydrous salt to a paste with sulphuric acid, and calcining the mass in a platinum crucible over a spirit lamp to constant weight and complete neutrality of reaction. This dry sulphate was weighed and intensely ignited three successive times. The weight of the residual $\mathrm{MgO}$ having been determined, it was moistened with sulphuric acid and recalcined over a spirit lamp, thus reproducing the original weight of $\mathrm{MgSO}_{4}$. Jacquelain's weighings for these two experiments show that 100 parts of $\mathrm{MgO}$ correspond to the quantities of $\mathrm{MgSO}_{4}$ given in the last column :

$$
\begin{array}{cllll}
1.466 \mathrm{grm} . \mathrm{MgSO}_{4} \text { gave } & .492 & \mathrm{grm} . & \mathrm{MgO} . & 297.968 \\
.492 \text { " } & \mathrm{MgO} \text { " } 1.466 & \text { "“ } & \mathrm{MgSO}_{4} . & 297.968
\end{array}
$$

Jacquelain also made one estimation of sulphuric acid in the foregoing sulphate as $\mathrm{BaSO}_{4}$. His result (1.464 grm. $\mathrm{MgSO}_{4}=2.838 \mathrm{grm} . \mathrm{BaSO}_{4}$ ), reduced to the standard adopted in dealing with Scheerer's experiments, gives for 100 parts of $\mathrm{MgSO}_{4}, 193.852 \mathrm{BaSO}_{4}$. If this figure be given equal weight with a single experiment in Scheerer's series, and combined with the latter, the mean will be $193.700, \pm .0331$. This again is subject to the correction pointed out by Scheerer for magnesium salts retained by the barium sulphate, but such a correction determined by Scheerer for a single experiment is only a rough approximation, and hardly worth applying.

The determinations published by Macdonnell $\ddagger$ are of slight importance, and all depend upon magnesium sulphate. First, the crystallized salt, $\mathrm{MgSO}_{4} .7 \mathrm{H}_{2} \mathrm{O}$, was dried in vacuo over sulphuric acid and then dehydrated at a low red heat. The following percentages of water were found:

$$
\begin{gathered}
51.17 \\
51.13 \\
51.14 \\
51.26 \\
51.28 \\
51.29 \\
\frac{51.21, \pm .020}{\text { Mean, }}
\end{gathered}
$$

* Poggend. Annalen, 70, 407 .

† Ann. Chim. Phys. (3), 32, 202.

$\ddagger$ Proc. Royal Irish Acad., 5, 303. British Association Report, 1852, part 2, p. 36. 
Secondly, anhydrous magnesium sulphate was precipitated with barium chloride. From the weight of the barium sulphate, with $\mathrm{SO}_{3}=$ 80 and $\mathrm{Ba}=137$, Macdonnell computes the percentages of $\mathrm{SO}_{3}$ given below. I calculate them back to the observed ratio in uniformity with Scheerer's work :

Percent. $\mathrm{SO}_{3}$.
66.67
66.73
66.64
66.65
66.69

Ratio, $\mathrm{MgSO}_{4}: \mathrm{BaSO}_{4}$.

194. 177

194.35 I

194.089

194. 118

194.239

In another experiment 60.05 grains $\mathrm{MgSO}_{4}$ gave 116.65 grains $\mathrm{BaSO}_{4}$, a ratio of $100: 194.254$. Including this with the preceding figures, they give a mean of $194.205, \pm .027$. This, combined with the work of Scheerer and Jacquelain, $193.700, \pm .033$, gives a general mean of-

$$
\mathrm{MgSO}_{4}: \mathrm{BaSO}_{4}:: \mathrm{I00}: \mathrm{I} 94.003, \pm .02 \mathrm{I} \text {. }
$$

In one final experiment Macdonnell found that 41.44 grains of pure magnesia gave 124.40 grains of $\mathrm{MgSO}_{4}$, or 300.193 per cent.

Bahr's* work resembles in part that of Jacquelain. This chemist converted pure magnesium oxide into sulphate, and from the increase in weight determined the composition of the latter salt. From his weighings 100 parts of $\mathrm{MgO}$ equal the amounts of $\mathrm{MgSO}_{4}$ given in the third colnmn :

$$
\begin{aligned}
& \text { I. } 693^{8} \mathrm{grm} . . \mathrm{MgO} \text { gave } 5.0157 \mathrm{grm} . \mathrm{MgSO}_{4} . \quad 296.122 \\
& \begin{array}{lllll}
2.0459 & \text { " } & 6.0648 \text { " } & 296.437
\end{array} \\
& 1.0784 \text { " " } 3.1925 \text { " } 296.040 \\
& \text { Mean, } 296.200, \pm .0815
\end{aligned}
$$

About four years previous to the investigations of Bahr the paper of Svanberg and Nordenfeldt $\dagger$ appeared. These chemists started with the oxalate of magnesium, which was dried at a temperature of from $100^{\circ}$

\begin{tabular}{|c|c|c|c|c|}
\hline 6.3795 & “ & 1.7464 & " & $27 \cdot 375$ \\
\hline 6.3653 & " & 1.7418 & “ & $27 \cdot 364$ \\
\hline 6.2216 & " & 1.7027 & “ & 27.368 \\
\hline
\end{tabular}
to $105^{\circ}$ until it no longer lost weight. The salt then contained two molecules of water, and upon strong ignition it left a residue of $\mathrm{MgO}$. The percentage of $\mathrm{MgO}$ in the oxalate comes out as follows:

7.2634 grm. oxalate gave $\mathbf{1} .9872$ grm. oxide. 27.359 per cent.

* Journ. für Prakt. Chem., 56, $310 . \quad$ I852.

† Journ. für Prakt. Chem., 45, 473. 1848. 
In three of these experiments the $\mathrm{MgO}$ was treated with $\mathrm{H}_{2} \mathrm{SO}_{4}$, and converted, as by Jacquelain and by Bahr in their later researches, into $\mathrm{MgSO}_{4}$. One hundred parts of $\mathrm{MgO}$ gave of $\mathrm{MgSO}_{4}$ as follows:

$$
\begin{aligned}
& 1.9872 \text { grm. } \mathrm{MgO} \text { gave } 5.8995 \mathrm{grm} . \mathrm{MgSO}_{4} \text {. } 296.875 \\
& 1.7464 \text { " " } 5.1783 \text { " } 296.513 \\
& 1.7418 \text { " } 16066296.624 \\
& \text { Mean, } \overline{296.67 \mathrm{I}}, \pm .072
\end{aligned}
$$

In 1850 the elaborate investigations of Nlarchand and Scheerer* appeared. These chemists undertook to determine the composition of some natural magnesites, and, by applying corrections for impurities, to deduce from their results the sought-for atomic weight. The magnesite chosen for the investigation was, first, a yellow, transparent variety from Snarum; second, a white opaque mineral from the same locality; and, third, a very pure quality from Frankenstein. In each case the impurities were carefully determined; but only a part of the details need be cited here. Silica was of course easily corrected for by simple subtraction from the sum of all of the constituents; but iron and calcium, when found, having been present in the mineral as carbonates, required the assignment to them of a portion of the carbonic acid. In the atomic weight determinations the mineral was first dried at $300^{\circ}$. The loss in weight upon ignition was then carbon dioxide. It was found, however, that even here a correction was necessary. Magnesite, upon drying at $300^{\circ}$, loses a trace of $\mathrm{CO}_{2}$, and still retains a little water; on the other hand, a minute quantity of $\mathrm{CO}_{2}$ remains even after ignition. The $\mathrm{CO}_{2}$ expelled at $300^{\circ}$ amounted in one experiment to .054 per cent. ; that retained after calcination to .055 per cent. Both errors tend in the same direction, and increase the apparent percentage of $\mathrm{MgO}$ in the magnesite. On the yellow mineral from Snarum the crude results are as follows, giving percentages of $\mathrm{MgO}, \mathrm{FeO}$, and $\mathrm{CO}_{2}$ after eliminating silica :

$\begin{array}{ccc}\mathrm{CO}_{2} . & \mathrm{MgO} & \mathrm{FeO} . \\ 51.8958 & 47.3278 & .7764 \\ 51.8798 & 47.3393 & .7809 \\ 51.8734 & 47.3154 & .8112 \\ 51.8875 & 47.3372 & .7753\end{array}$

Mean, $\overline{47.3299}, \pm .0037$

After applying corrections for loss and retention of $\mathrm{CO}_{2}$, as previously indicated, the mean results of the foregoing series become-

$\begin{array}{ccc}\mathrm{CO}_{2} . & \mathrm{MgO} . & \mathrm{FeO} . \\ 5 \mathrm{I} .993^{\mathrm{I}} & 47.2743 & .7860\end{array}$

The ratio between the $\mathrm{MgO}$ and the $\mathrm{CO}_{2}$, after correcting for the iron, will be considered further on. 
Of the white magnesite from Snarum but a single analysis was made, which for present purposes may be ignored. Concerning the Frankenstein mineral three series of analyses were executed. In the first series the following results were obtained:

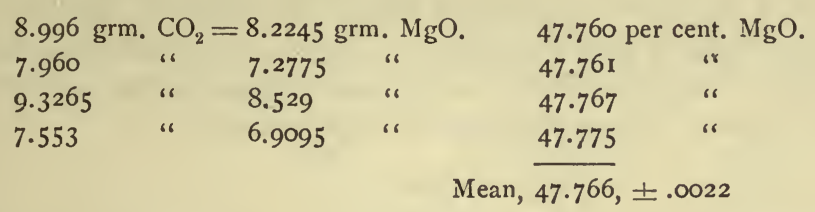

This mean, corrected for loss of $\mathrm{CO}_{2}$ in drying, becomes 47.681. I give series second with corrections applied:

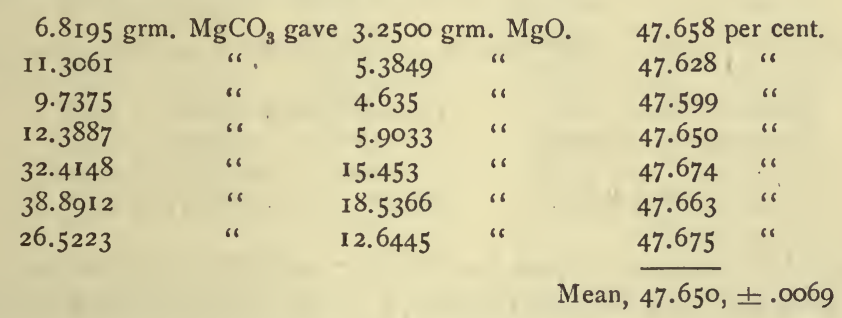

The third series was made upon very pure material, so that the correchions, although applied, were less influential. The results were as follows:

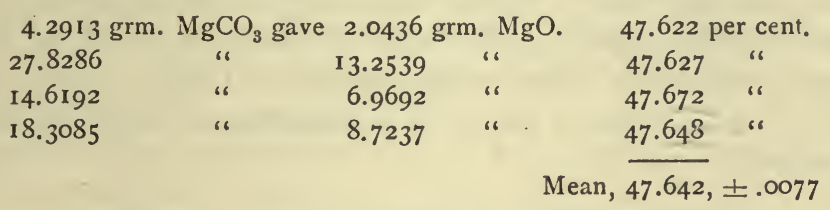

In a supplementary paper* by Scheerer, it was shown that an important correction to the foregoing data had been overlooked. Scheerer, reexamining the magnesites in question, discovered in them traces of lime, which had escaped notice in the original analyses. With this correction the two magnesites in question exhibit the following mean composition :

Snarum. Frankenstein.

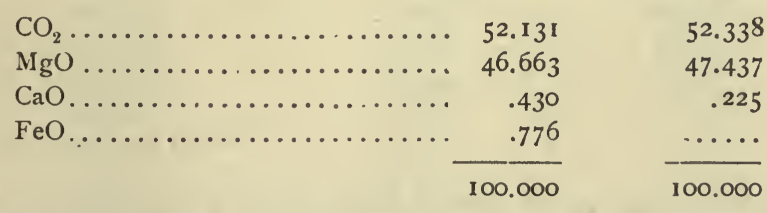

Correcting for lime and iron, by assigning each its share of $\mathrm{CO}_{2}$, the Snarum magnesite gives as the true percentage of magnesia in pure 
magnesium carbonate, the figure 47.624. To this, without serious mistake, we may assign the weight indicated by the probable error, \pm .0037 , the quantity previously deduced from the percentages of $\mathrm{MgO}$ given in the uncorrected analyses.

From the Frankenstein mineral, similarly corrected, the final mean percentage of $\mathrm{MgO}$ in $\mathrm{MgCO}_{3}$ becomes 47.628. 'This, howerer, represents three series of analyses, whose combined probable errors may be properly assigned to it. The combination is as follows:

$$
\begin{aligned}
& \pm .0022 \\
& \pm .0069 \\
& \pm .0077 \\
\text { Result, } & \pm .0020, \text { probable error of the general mean. }
\end{aligned}
$$

We may now combine the results obtained from both magnesites:

$$
\begin{array}{rr}
\text { Snarum mineral............ Per cent. } \mathrm{MgO}, 47.624, \pm .0037 \\
\text { Frankenstein mineral....... } & \text { “6 } \\
\text { General mean........ } & \text { Per cent. MgO, 47.628, } \pm .0020 \\
\hline
\end{array}
$$

The next investigation upon the atomic weight of magnesium which we have to consider is that of Dumas. * Pure magnesium chloride was placed in a boat of platinum, and ignited in a stream of dry hydrochloric acid gas. The excess of the latter having been expelled by a current of

\begin{tabular}{|c|c|c|c|c|}
\hline $2.203 \mathrm{grm}$. & $\mathrm{MgCl}_{2}$ & $4.964 \mathrm{~g}$ & Ag. & $44 \cdot 3^{80}$ \\
\hline 2.5215 & “ & 5.678 & " & 44.408 \\
\hline $2.3^{6} 3$ & " & $5 \cdot 325$ & "6 & $44 \cdot 376$ \\
\hline 3.994 & $" 6$ & 9.012 & " & 44.319 \\
\hline 2.578 & " & 5.834 & “ & 44.189 \\
\hline 2.872 & “ & 6.502 & “" & 44. I 7 I \\
\hline 2.080 & $\because 6$ & 4.710 & “" & $44.16 I$ \\
\hline 2.214 & " & 5.002 & “ & 44.262 \\
\hline 2.086 & “6 & 4.722 & “ & 44.176 \\
\hline I. 688 & " & 3823 & $"$ & 44.154 \\
\hline 1.342 & “ & 3.031 & " & 44.276 \\
\hline
\end{tabular}
dry carbon dioxide, the platinum boat, still warm, was placed in a closed vessel and weighed therein. After weighing, the chloride was dissolved and titrated in the usual manner with a solution containing a known quantity of pure silver. The weighings which Dumas reports give, as proportional to 100 parts of silver, the quantities of $\mathrm{MgCl}_{2}$ stated in the third column :

This determination gives a very high value to the atomic weight of magnesium, which is unquestionably wrong. The error, probably, is due to the presence of oxychloride in the magnesium chloride taken, an 
impurity tending to raise the apparent atomic weight of the metal. Richards' and Parker's revision of this ratio is more satisfactory.

Marignac, * in 1883, resorted to the old method of determination, depending upon the direct ratio between $\mathrm{MgO}$ and $\mathrm{SO}_{3}$. This ratio he measured both synthetically and analytically. First, magnesia from various sources was converted into sulphate. The $\mathrm{MgSO}_{4}$ from 100 parts of $\mathrm{MgO}$ is given in the third column:

\begin{tabular}{|c|c|c|c|}
\hline & $M g O$ & $\mathrm{MgSO}_{4}$. & Ratio. \\
\hline $1 \ldots \ldots \ldots \ldots$ & 1.5635 & 4.6620 & 298.17 \\
\hline $2 \ldots \ldots \ldots \ldots$ & I. 4087 & 4.2025 & 298.32 \\
\hline $3 \ldots \ldots \ldots \ldots$ & 1.5917 & 4.7480 & 298.30 \\
\hline $4 \ldots \ldots \ldots \ldots$ & 1.4705 & $4 \cdot 3^{855}$ & 298.23 \\
\hline $5 \ldots \ldots \ldots \ldots$ & 1.4778 & 4.4060 & 298.15 \\
\hline $6 \ldots \ldots \ldots \ldots$ & 1.6267 & 4.8530 & 298.33 \\
\hline $7 \ldots \ldots \ldots \ldots$ & 1.3657 & 4.0740 & 298.37 \\
\hline $8 \ldots \ldots \ldots \ldots$ & 1.9575 & 5.8390 & 298.29 \\
\hline $9 \ldots \ldots \ldots \ldots$ & 1.6965 & 5.0600 & 298.26 \\
\hline 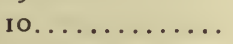 & I. 8680 & $5.57 \times 5$ & 298.26 \\
\hline
\end{tabular}

The magnesia for experiments 1 to 5 was prepared by calcination of the nitrate, that of 6 to 8 from the sulphate, and the remaining two from the carbonate. But Richards and Rogers $\dagger$ have shown that magnesia derived from the nitrate always contains occluded gaseous impurity, so that the experiments depending upon its use are somewhat questionable. The results tend to give an atomic weight for magnesium which is possibly too high. Whether the other samples of magnesia are subject to similar objections I cannot say.

Marignac's second series was obtained by the calcination of the sulphate, with results as follows:

$\begin{array}{ccc}\mathrm{MgSO}_{4} . & \mathrm{MgO} & \text { Ratio. } \\ 3.7705 & 1.2642 & 298.25 \\ 4.7396 & 1.5884 & 298.39 \\ 3.3830 & 1.1345 & 298.19 \\ 4.7154 & 1.5806 & 298.33 \\ 4.5662 & 1.5302 & 298.43 \\ 4.5640 & 1.5300 & 298.30 \\ 3.2733 & 1.0979 & 298.14 \\ 4.8856 & 1.6378 & 298.30 \\ 5.1092 & 1.6752 & 298.31 \\ 5.3396 & 1.7898 & 298.33 \\ 5.1775 & 1.7352 & 298.38 \\ 5.0126 & 1.6807 & 298.24 \\ 5.0398 & 1.6894 & 298.32 \\ & & \text { Mean, } 29830, \pm .0150\end{array}$

* Arch. Sci. Phys, et Nat. (3), 10, 206.

f Am. Chem. Journ., 15, 567. 1893 . 
These data may now be combined with the work of previous investigators, giving Macdonnell's one result and Jacquelain's two, each equal weight with a single experiment in Bahr's series:

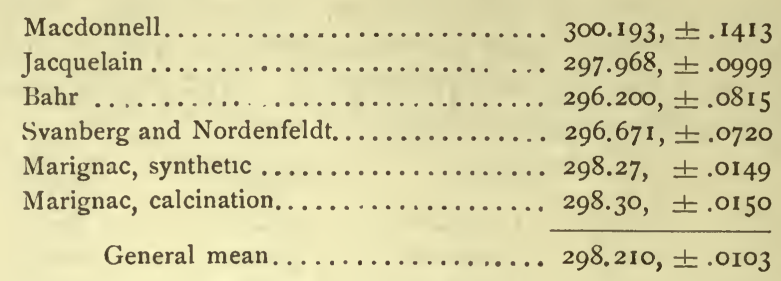

Burton and Vorce, ${ }^{*}$ who published their work on magnesium in 1890 ; started out with the metal itself, which had been purified by distillation in a Sprengel vacuum. This metal was dissolved in pure nitric acid, and the resulting nitrate was converted into oxide by calcination at a white heat. The oxide was carefully tested for oxides of nitrogen, which were proved to be absent, but occluded gases, the impurity pointed out by Richards and Rogers, were not suspected. This impurity must have been present, and it would tend to lower the apparent atomic weight of magnesium as calculated from the data obtained. The results were as follows, together with the percentage of $\mathrm{Mg}$ in $\mathrm{MgO}$ :

$\begin{array}{ccc}\text { Mg Taken. } & \text { MgO Formed. } & \text { Per cent. Mg. } \\ .33009 & .54766 & 60.273 \\ .34512 & .57252 & 60.28 \mathrm{I} \\ .26058 & .43221 & 60.290 \\ .28600 & .47432 & 60.297 \\ .30917 & .51273 & 60.299 \\ .27636 & .45853 & 60.27 \mathrm{I} \\ .36457 & .60475 & 60.284 \\ .32411 & .53746 & 60.304 \\ .32108 & .53263 & 60.282 \\ .28323 & .46988 & 60.262 \\ & & \text { Mean, } 60.2845, \pm .0027\end{array}$

The latest determinations of all are those of Richards and Parker, $\dagger$ who studied magnesium chloride with all the precautions suggested by the most recent researches. The salt itself was not only free from oxychloride, but also spectrosçopically pure as regards alkaline contaminations, and all weighings were reduced to a vacuum standard. The first series of experiments gives the ratio between silver chloride and magnesium chloride, and $\mathrm{I}$ have reduced the data to the form $2 \mathrm{AgCl}: \mathrm{MgCl}_{2}:$ : $100: x$. The weighings and values for $x$ are subjoined: 


$\begin{array}{ccc}\mathrm{MgCl}_{2} . & \mathrm{AgCl} & \text { Ratio. } \\ \mathrm{I} .33550 & 4.01952 & 33.225 \\ \mathrm{I} .5 \mathrm{I} 60 \mathrm{I} & 4.56369 & 33.219 \\ \mathrm{I} .324 \mathrm{I} 3 & 3.98528 & 33.226 \\ \mathrm{I.40664} & 4.23297 & 33.23 \mathrm{I} \\ \mathrm{I.25487} & 3.77670 & 33227 \\ & & \text { Mean, } 33.226, \pm .0013\end{array}$

The remaining series of experiments, three in number, relate to the ratio $2 \mathrm{Ag}: \mathrm{MgCl}_{2}$, which was earlier investigated by Dumas. For the elaborate details of manipulation the original memoir must be consulted. I can give little more than the weights found, and their reduction to the usual form of ratio, $\mathrm{Ag}_{2}: \mathrm{MgCl}_{2}:: 100: x$ :

Second Series.

$\begin{array}{ccc}\mathrm{MgCl}_{2} . & \mathrm{Ag} . & \text { Ratio. } \\ 2.78284 & 6.30284 & 44.152 \\ 2.29360 & 5.19560 & 44.145 \\ 2.36579 & 5.35989 & \underline{4.130} \\ & & \text { Mean, } 44.142, \pm .0043\end{array}$

This series gives slightly higher results than the others, and the authors, for reasons which they assign, discard it:

Third Series.

$\begin{array}{ccc}\mathrm{MgCl}_{2} . & \mathrm{Ag} . & \text { Ratio. } \\ \mathbf{1 . 9 9 2 7 6} & 4.51554 & 44.13 \mathrm{I} \\ \mathbf{1 . 7 8 5 7 0} & 4.05256 & 44.138 \\ 2.12832 & 4.82174 & 44.140 \\ 2.51483 & 5.69714 & 44.141 \\ 2.40672 & 5.45294 & 44.136 \\ 1.95005 & 4.41747 & 44.144 \\ & & \text { Mean, } 44.138, \pm .0013\end{array}$

The fourth series, because of the experience gained in the conduct of the preceding determinations, is best of all, and the authors adopt its results in preference to the others:

Fourth Series.

$\mathrm{MgCl}_{2}$.

2.03402

1.91048

2.09932

$1.8204 \mathrm{I}$

I. 92065

I. 11172
Ag.

4.60855

4.32841

4.75635

4. 12447

$4.35^{1} 5^{I}$

2.51876
Ratio.

44. 136

44. 138

44. 137

44. 137

44. 138

44. 138

Mean, $44.137, \pm .0003$ 
These series combine with that of Dumas as follows:

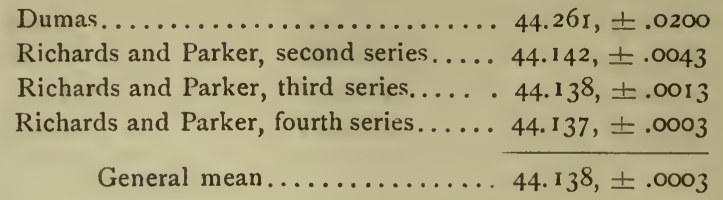

Here the first two values practically vanish, and the third and fourth series of Richards and Parker appear alone.

To sum up, we now have the subjoined ratios, bearing upon the atomic weight of magnesium :

(I.) $\mathrm{MgSO}_{4}: \mathrm{BaSO}_{4}:: 100: 194.003, \pm .02 \mathrm{I}$

(2.) $\mathrm{MgO}: \mathrm{MgSO}_{4}:: 100: 298.210, \pm .0103$

(3.) Per cent. of water in $\mathrm{MgSO}_{4}, 7 \mathrm{iH}_{2} \mathrm{O}, 5 \mathrm{I} .2 \mathrm{I}, \pm .02 \mathrm{O}$

(4.) Per cent, of $\mathrm{MgO}$ in oxalate, $27.3665, \pm .0023$

(5.) Per cent. of $\mathrm{MgO}$ in carbonate, $47.627, \pm .0018$

(6.) Per cent. of $\mathrm{Mg}$ in $\mathrm{MgO}, 60.2845, \pm .0027$

(7.) $2 \mathrm{Ag}: \mathrm{MgCl}_{2}:: 100: 44.138, \pm .0003$

(8.) $2 \mathrm{AgCl}: \mathrm{MgCl}_{2}:: 100: 33.226, \pm .0013$

To reduce these ratios we have-

$$
\begin{array}{ll}
\mathrm{O}=15.879, \pm .0003 & \mathrm{C}=11.920 \pm .0004 \\
\mathrm{Ag}=107.108, \pm .003 \mathrm{I} & \mathrm{Ba}=136.392, \pm .0086 \\
\mathrm{Cl}=35.179, \pm .0048 & \mathrm{AgCl}=142.287, \pm .0037 \\
\mathrm{~S}=31.828, \pm .0015 &
\end{array}
$$

For the molecular weight of $\mathrm{MgSO}_{4}$, two values are now calculable:

$$
\begin{aligned}
& \text { From (1) } \ldots \ldots \ldots \ldots \ldots \ldots . \mathrm{MgSO}_{4}=1 \mathrm{I} 9.450, \pm .0 \mathrm{I} 37 \\
& \text { From }(3) \ldots \ldots \ldots \ldots \ldots \ldots \ldots \text { " }=119.239, \pm .0675 \\
& \text { General mean......... } \mathrm{MgSO}_{4}=119.443, \pm .0135
\end{aligned}
$$

Hence $\mathrm{Mg}=24.099, \pm .0136$.

For $\mathrm{MgO}$, three values are found:

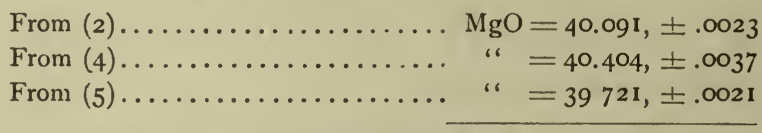

General mean

$$
\mathrm{MgO}=39.974, \pm .0014
$$

Hence $\mathrm{Mg}=24.095, \pm .0014$.

For $\mathrm{MgCl}_{2}$ there are two values:

From $(7) \ldots \ldots \ldots \ldots \ldots \ldots \mathrm{MgCl}_{2}=94.55 \mathrm{I}, \pm .0032$

From (8)............. " $=94.553, \pm .0044$

General mean.......... $\overline{\mathrm{MgCl}_{2}=94.55^{2}, \pm .0026}$

Hence $\mathrm{Mg}=24.194, \pm .0099$. 
With the aid of these intermediate values, four estimates of the atomic weight of magnesium are available, as follows :

From molecular weight of $\mathrm{MgSO}_{4} \ldots . \mathrm{Mg}=24.099, \pm .0136$

- From molecular weight of $\mathrm{MgO} . . .$. " $=24.095, \pm .0014$

From molecular weight of $\mathrm{MgCl}_{2} \ldots \ldots$ " $=24.194, \pm .0099$

From ratio $(6) \ldots \ldots \ldots \ldots \ldots \ldots \ldots$ " $=24.103, \pm .0020$

General mean ...........Mg $=24.100, \pm .001 \mathrm{I}$

If $\mathrm{O}=16$, this becomes $\mathrm{Mg}=24.283$.

On purely chemical grounds the third of the foregoing values, that derived from magnesium chloride, seems to be the best. I should unhesitatingly adopt it, rejecting the others, were it not for the fact that it rests upon one compound of magnesium alone, and therefore is not absolutely conclusive. It agrees admirably, however, with the sulphate determinations of Marignac, and it is highly probable that it may be fully confirmed later by evidence from other sources.

Marignac's data, taken alone, give $\mathrm{Mg}=24.197$. 'The fourth series of Richards and Parker, by itself, gives $\mathrm{Mg}=24.180$. The approximate mean of these, 24.19 , may be preferred by many chemists to the general mean derived from all the observations. 


\section{ZINC.}

The several determinations of the atomic weight of zinc are by no means closely concordant. The results obtained by Gay-Lussac* and Berzelius $\uparrow$ were undoubtedly too low, and may be disregarded here. We need consider only the work done by later investigators.

In 1842 Jacquelain published the results of his investigations upon this important constant. $\ddagger$ In two experiments a weighed quantity of zinc was converted into nitrate, and that by ignition in a platinum crucible was reduced to oxide. In two other experiments sulphuric acid took the place of nitric. As the zinc contained small quantities of lead and iron, these were estimated, and the necessary corrections applied. From the weights of metal and oxide given by Jacquelain the percentages have been calculated:

Nitric Series.

9.917 grm. $\mathrm{Zn}$ gave $12.3^{1} 3^{8} \mathrm{grm}$. $\mathrm{ZnO}$. 9.809

12. 1800

So. 536 per cent. $\mathrm{Zn}$.

80.534

Sulphuric Series.

$$
\begin{array}{llll}
3.197 \text { " } 3.968 \text { " } & \frac{80.570}{80.541} \pm .007
\end{array}
$$

Hence $\mathrm{Zn}=65.723$.

The method adopted by Axel Erdmann $\S$ is essentially the same as that of Jacquelain, but varies from the latter in certain important details. First, pure zinc oxide was prepared, ignited in a covered crucible with sugar, and then, to complete the reduction, ignited in a porcelain tube in a current of hydrogen. The pure zinc thus obtained was converted into oxide by means of treatment with nitric acid and subsequent ignition in a porcelain crucible. Erdmann's figures give us the following percentages of metal in the oxide:

$$
\begin{gathered}
80.247 \\
80.257 \\
80.263 \\
80.274 \\
\hline \text { Mean, } 80.260, \pm .0037
\end{gathered}
$$

Hence $\mathrm{Zn}=64.562$. 
Upon comparing Erdmann's results with those of Jacquelain two points are worth noticing: First, Erdmann worked with purer material than Jacquelain, although the latter applied corrections for the impurities which he knew were present; secondly, Erdmann calcined his zinc nitrate in a porcelain crucible, while Jacquelain used platinum. In the latter case it has been shown that portions of zinc may become reduced and alloy themselves with the platinum of the crucible; hence a lower weight of oxide from a given quantity of zinc, a higher percentage of metal, and an increased atomic weight. This source of constant error has undoubtedly affected Jacquelain's experiments, and vitiated his results. In Erdmann's work no such errors seem to be present.

Favre* employed two methods of investigation. First, zinc was dissolved in sulphuric acid, the hydrogen evolved was burned, and the weight of water thus formed was determined. To his weighings I append the ratio between metallic zinc and 100 parts of water:

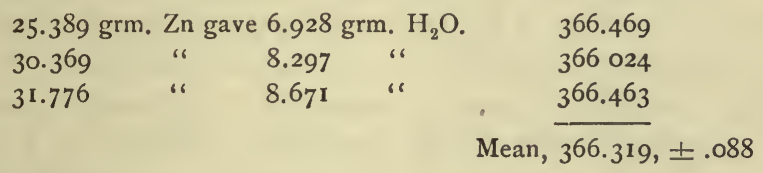

Hence $\mathrm{Zn}=65.494$.

The second method adopted by Favre was to burn pure zinc oxalate, and to weigh the oxide and carbonic acid thus produced. From the ratio between these two sets of weights the atomic weight of zinc is easily deducible. From Favre's weighings, if $\mathrm{CO}_{2}=100, \mathrm{ZnO}$ will be as given in the third column below :

$$
\begin{aligned}
& 7.796 \mathrm{grm} . \mathrm{ZnO}=8.365 \mathrm{grm} . \mathrm{CO}_{2} . \quad 93.198 \\
& 7.342 \text { " } 7.883 \text { " } 93.137 \\
& 5.2065 \text { " } 5.588 \text { " } 93.173 \\
& \text { Mean, } \overline{93.169}, \pm .012
\end{aligned}
$$

Hence $\mathrm{Zn}=65.521$.

Both of these determinations are open to objections. In the water series it was essential that the hydrogen should first be thoroughly dried before combustion, and then that every trace of water formed should be collected. A trivial loss of hydrogen or of water would tend to increase the apparent atomic weight of zinc.

In the combustion of the zinc oxalate equally great difficulties are encountered. Here a variety of errors are possible, such as are due, for example, to impurity of material, to imperfect drying of the carbon dioxide, and to incomplete collection of the latter. Indeed a fourth combustion is omitted from the series as given, having been rejected by Favre himself. In this case the oxide formed was contaminated by traces of sulphide. 
Baubigny,* in 1883 , resorted to the well-known sulphate method. Zinc sulphate, elaborately purified, was dried at $440^{\circ}$ to constant weight, and then calcined at a temperature equal to the fusing point of gold. These data were obtained:

$\begin{array}{llc}\mathrm{ZnSO}_{4} \cdot & \mathrm{ZnO} . & \text { Percent. } \mathrm{ZnO} . \\ 6.699 & 3.377 & 50.410 \\ 8.776 & 4.4245 & \frac{50.416}{50.413}, \pm .0020\end{array}$

Hence $\mathrm{Zn}=64.909$.

In Marignac's determinations of the atomic weight of zinc, published also in $1883, \dagger$ there is a peculiar complication. After testing and criticising some other methods, he finally decided to study the double salt $\mathrm{K}_{2} \mathrm{ZnCl}_{4}$, which, however, is difficult to obtai 11 in absolutely definite condition. Although the compound was purified by repeated crystallizations, it was found to deliquesce readily, and thereby to undergo partial dissociation, losing chloride of zinc, and leaving the porous layer on the crystalline surfaces richer in potassium. In order to evade this difficulty, Marignac placed a large quantity of the salt in a funnel, and collected the liquid product of deliquescence as it ran down. In this product he determined chlorine by volumetric titration with a standard solution of silver, and also estimated zine by precipitation with sodium carbonate, and weighing as oxide. From the data thus obtained equations were formed, giving for each a nalysis an atomic weight of zinc which is independent of the proportion between $\mathrm{ZnCl}_{2}$ and $\mathrm{KCl}$ in the substance analyzed. The data unfortunately are too bulky for reproduction here and the calculations are complex; but the results found for zinc, when $\mathrm{Ag}=107.93, \mathrm{Cl}=35.457$, and $\mathrm{K}=39.137$, are as follows :

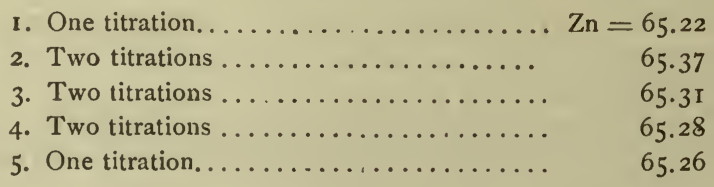

Each of these values represents a distinct sample of the deliquesced material, and the number of chlorine determinations is indicated.

A second set of determinations was made by the same analytical method directly upon the recrystallized and carefully dried $\mathrm{K}_{2} \mathrm{ZnCl}_{4}$. The values for $\mathrm{Zn}$ are as follows:

6. Two titrations $\ldots \ldots \ldots \ldots \ldots \ldots \ldots \ldots \ldots \ldots \ldots \ldots \ldots \ldots \ldots \ldots \ldots \ldots \ldots$
7. Two titrations $\ldots \ldots \ldots \ldots \ldots \ldots \ldots \ldots$

* Compt. Rend., 97, 906. I883.

† Arch. Sci. Phys. et Nat. (3), 10, 194. 
In order to adapt these data to the uniform scheme of calculation employed in this work, taking into account their probable error and the probable errors of the antecedent values for $\mathrm{K}, \mathrm{Cl}$, and $\mathrm{Ag}$, it seems to be best to calculate them back with the atomic weights used by Marignac into the form of the ratio $\mathrm{Ag}_{4}: \mathrm{K}_{2} \mathrm{ZnCl}_{4}:: 100: x$. Doing this, and taking each value as many times as there are titrations represented in itthat is, giving the results of a double determination twice the weight of a single one-we have the following series of data for the ratio in question :

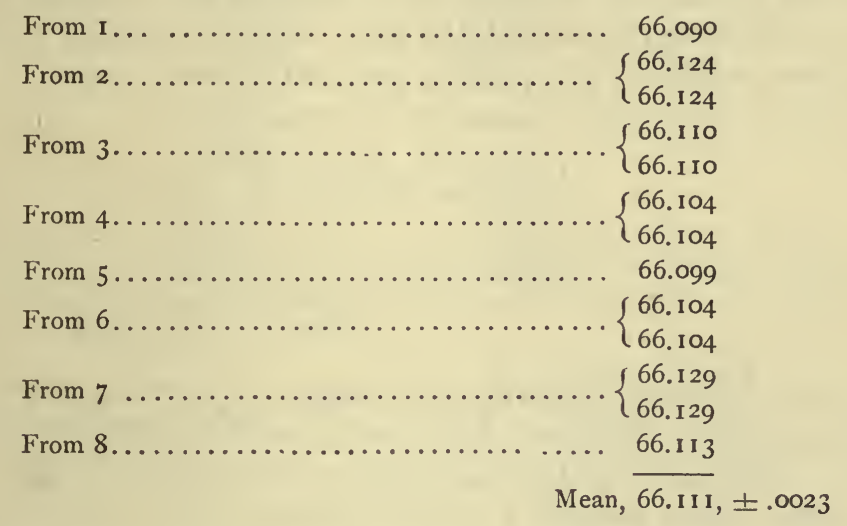

Hence, from Marignac's work, $\mathrm{Ag}_{4}: \mathrm{K}_{2} \mathrm{ZnCl}_{4}:: 100: 66.111, \pm .0023$, a ratio which can be discussed along with others at the close of this chapter.

During the years between 1883 and 1889, a number of determinations were made of the direct ratio between zinc and hydrogen-that is, weighed quantities of zinc were dissolved in acid, the hydrogen evolved was measured, and from its volume, with Regnault's data, the weight of $\mathrm{H}$ was computed. First in order are Van der Plaats' determinations; ${ }^{*}$ whose results, as given by himself, are subjoined. The weights are reduced to a vacuum. Sulphuric acid was the solvent.

$\begin{array}{rcc}Z n, \text { grms. } & H, \text { litres. } & Z n= \\ 6.6725 & \text { I.1424 } & 65.21 \\ 9.1271 & 1.5643 & 65.14 \\ 13.8758 & 2.3767 & 65.18 \\ & & \text { Mean, } \overline{65.177}, \pm .0137\end{array}$

With the new value for the weight of hydrogen, 089872 gramme per litre, this becomes $\mathrm{Zn}=64.980, \pm .0137$.

Reynolds and Ramsay made 29 determinations of this ratio. $\dagger$ rejecting, however, all but 5 . The weighings were reduced to vacuum, and in each experiment the volume of hydrogen was fixed by the mean of seven or eight readings. The values for $\mathrm{Zn}$ are as follows: 


\author{
65.5060 \\ 65.4766 \\ 65.4450 \\ 65.5522 \\ 65.4141 \\ Mean, $\overline{65.4787}, \pm .016 \mathrm{r}$
}

These values were computed with Regnault's data for the weight of $\mathrm{H}$. Corrected by the new value the mean becomes $\mathrm{Zn}=65.280, \pm .0161$.

A few determinations by Mallet were made incidentally to his work on the atomic weight of gold, and appear in the same paper.* According to these experiments, one gramme of zinc gives-

$$
\begin{aligned}
& 34 \mathrm{I} .85 \mathrm{cc} \text {. } \mathrm{H} \text {., and } \mathrm{Zn}=65.158 \\
& 341.91 \text { " " " } 65.146 \\
& 341.93 \text { " " } 65.143 \\
& 342.04 \text { " “ } 65.122 \\
& \text { Mean, } \overline{65.142}, \pm .0039
\end{aligned}
$$

In this case the Crafts-Regnault weight of $\mathrm{H}$ was taken, one litre = .08979 gramme. Corrected, the mean gives $\mathrm{Zn}=65.082, \pm .0039$.

Two other series of determinations of questionable value remain to be noticed before leaving the consideration of the direct $\mathrm{H}: \mathrm{Zn}$ ratio. They represent really the practice work of students, and are interesting as an illustration of the closeness with which such work can be done. The first series was made in the laboratory of the Johns Hopkins University, under the direction of Morse and Keiser, $\uparrow$ and contains 51 determinations, as follows:

$\begin{array}{lll} & Z n= & \\ 64.68 & 65.74 & 65.40 \\ 65.26 & 64.72 & 64.80 \\ 65.32 & 65.26 & 65.20 \\ 65.20 & 64.74 & 64.40 \\ 65.60 & 64.72 & 65.00 \\ 64.60 & 65.10 & 64.40 \\ 65.00 & 64.76 & 65.24 \\ 65.68 & 64.90 & 64.60 \\ 65.38 & 64.92 & 64.80 \\ 65.06 & 64.64 & 65.14 \\ 64.84 & 65.24 & 64.84 \\ 64.88 & 64.72 & 64.82 \\ 65.00 & 65.20 & 64.80 \\ 65.08 & 65.12 & 64.40 \\ 65.06 & 66.40 & 64.60 \\ 64.74 & 64.60 & 64.80 \\ 65.12 & 65.60 & 64.74\end{array}$

Mean of all, $\mathrm{Zn}=64.997, \pm .0328$

*Amer. Chem. Journ., I2, 205. 1890.

† Amer. Chem. Journ., 6, 347. 1884. 
Corrected for the difference between Regnault's value for $\mathrm{H}$ and the new value, this becomes $\mathrm{Zn}=64.800, \pm .0328$.

The second student series was published by Torrey,* who gives 15 determinations, as follows:

\begin{tabular}{ll}
\multicolumn{2}{c}{$Z n=$} \\
65.36 & 64.96 \\
65.30 & 64.70 \\
64.92 & 65.00 \\
64.72 & 64.78 \\
65.04 & 64.44 \\
64.80 & 65.24 \\
65.20 & 64.92 \\
64.90 & \\
Mean, 64.952, & .0436
\end{tabular}

Corrected as in the other series, this gives $\mathrm{Zn}=64.755, \pm .0436$.

The five corrected means for the ratio $\mathrm{H}: \mathrm{Zn}$ may now be combined, thus:

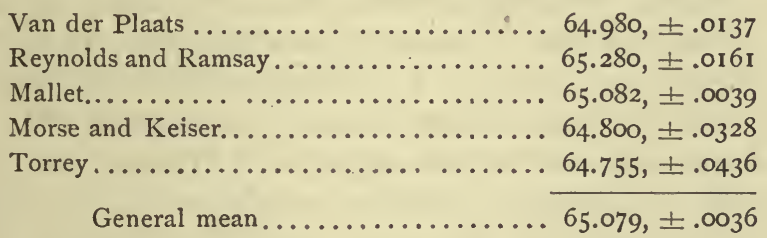

Morse and Burton, $\dagger$ in their determinations of the atomic weight of zinc, returned essentially to the old method adopted by Erdmann and by Jacquelain. Their zinc was obtained spectroscopically pure by distillation in a vacuum, and was oxidized by nitric acid which left absolutely no residue upon evaporation. The conversion to oxide was effected in a porcelain crucible, which was enclosed in a larger one, and the ignition of the nitrate was carried out in a muffle. In weighing, the crucible was tared by one of nearly equal weight. Results as follows:

\begin{tabular}{|c|c|c|}
\hline Wt. Zn. & $W t . Z n O$. & Per cent. $Z n$ in $Z n O$. \\
\hline 1.11616 & I. 38972 & 80.320 \\
\hline 1.03423 & I. 28782 & 80.308 \\
\hline 1. 11628 & I. 38987 & 80.315 \\
\hline I. 05760 & I.3I68I & 80.316 \\
\hline I. 04801 & 1. 30492 & $80.3^{1} 3$ \\
\hline 1.02957 & I. 28193 & 80.318 \\
\hline 1.09181 & 1. 35944 & 80.315 \\
\hline I. I64I 3 & I. 44955 & 80.305 \\
\hline I.0781 4 & I. 34248 & 80.305 \\
\hline I. 12754 & I. 40400 & 80.306 \\
\hline .91112 & I. I 3446 & 80.310 \\
\hline
\end{tabular}

* Amer. Chem. Journ., 10, 74, I 888.

† Amer. Chem. Journ., ro, 311. 1888. 


$\begin{array}{ccc}1.10011 & 1.36981 & 80.311 \\ 1.17038 & 1.45726 & 80.313 \\ 1.03148 & 1.28436 & 80.310 \\ 1.05505 & 1.31365 & 80.308 \\ & & \text { Mean, } 80.3115, \pm 00084 .\end{array}$

Combining this mean with the means found by the earlier investigators, we have-

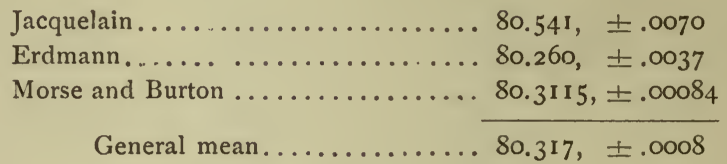

Morse and Burton verified by experiment the stability of oxide of zinc at the temperatures of ignition, and found that it did not dissociate. They also proved the absence of uxides of nitrogen from the zinc oxide. The investigations of Richards and Rogers, * however, have shown that zinc oxide prepared by ignition of the nitrate always carries gaseous occlusions, so that the atomic weight of zinc computed from the data of Morse and Burton is probably too low. But for that objection, their work would leave little to be desired on the score of accuracy.

The determinations made by Gladstone and Hibbard $\uparrow$ represent still another process for measuring the atomic weight of zinc. Zinc was dissolved in a voltameter, and the same current was used to precipitate metallic silver or copper in equivalent amount. The weight of zinc dissolved, compared with the weight of the other metal thrown down, gives the atomic weight sought for. Two voltameters were used in the experiments, giving duplicate estimates for zinc with reference to each weighing of silver or copper. The silver series is as follows, with the ratio $\mathrm{Ag}_{2}: \mathrm{Zn}:: 100: x$ in the third column :

$\begin{array}{lcc}Z n . & A g . & \text { Ratio. } \\ .7767 & 2.55^{89} & 30.353 \\ .7758 & 2.55^{89} & 30.318 \\ .5927 & 1.955^{1} & 30.316 \\ .5924 & 1.955 \mathrm{I} & 30.300 \\ .2277 & .7517 & 30.291 \\ .2281 & .7517 & 30.345 \\ .745^{2} & 2.4588 & 30.307 \\ .7475 & 2.4588 & 30.401 \\ .8770 & 2.9000 & 30.241 \\ .8784 & 2.9000 & 30.290 \\ .9341 & 3.0809 & 30.319 \\ .9347 & 3.0809 & 30.339 \\ & & \text { Mean, } 30.318, \pm .0077\end{array}$

* Proc. Amer. Acad., I893, 200.

† Journ. Chem. Soc., 55, 443. 1889 . 
To the copper series I add the ratio $\mathrm{Cu}: \mathrm{Zn}:: 100: x$.

$\begin{array}{ccc}Z n . & \mathrm{Cu} . & \text { Ratio. } \\ .7767 & .7526 & \text { 103.13 } \\ .7758 & .7526 & 103.08 \\ .5927 & .5737 & 103.3 \mathrm{I} \\ .5924 & .5737 & 103.26 \\ .2277 & .2209 & 103.08 \\ .228 \mathrm{r} & .2209 & 103.26 \\ .8770 & .8510 & 103.05 \\ .8784 & .8510 & 103.22 \\ .934 \mathrm{I} & .9038 & 103.36 \\ .9347 & .9038 & .103 .42 \\ & & \text { Mean, } 103.22, \pm .026 \mathrm{I}\end{array}$

Richards and Rogers, * in their investigation of the atomic weight of zinc, studied the anhydrous bromide. This was prepared by solution of zinc oxide in hydrobromic acid, evaporation to dryness, and subsequent distillation in an atmosphere of carbon dioxide. In some experiments, however, the bromide was heated in an atmosphere of nitrogen, mingled with gaseous hydrobromic acid. All water can thus be removed, without formation of oxybromides.

The zinc bromide so obtained was dissolved in water, and precipitated with a solution containing a known amount of silver in the form of nitrate. The silver bromide was weighed on a Gooch crucible, and the ratio $2 \mathrm{AgBr}: \mathrm{ZnBr}_{2}$ thus found. An excess of silver was always used, and in one series of experiments it was estimated by precipitation with hydrobromic acid. Deducting the excess thus found from the original quantity of silver, the amount of the latter proportional to the zinc bromide was found; hence the ratio $\mathrm{Ag}_{2}: \mathrm{ZnBr}_{2}$. The results, with vacuum weights, are as follows:

\section{Series $A$.}

$\begin{array}{lll}Z n \mathrm{Br}_{2} . & \mathrm{AgBr} . & \text { Ratio. } \\ \mathrm{1} .696 \mathrm{I} 6 & 2.82805 & 59.976 \\ 1.98198 & 3.30450 & 59.978 \\ \mathrm{I.70920} & 284949 & 59.984 \\ 2.35079 & 3.9194 \mathrm{I} & 59.978 \\ 2.66078 & 4.4375 \mathrm{I} & 59.96 \mathrm{I} \\ & & \text { Mean, } 59.975, \pm .0034\end{array}$

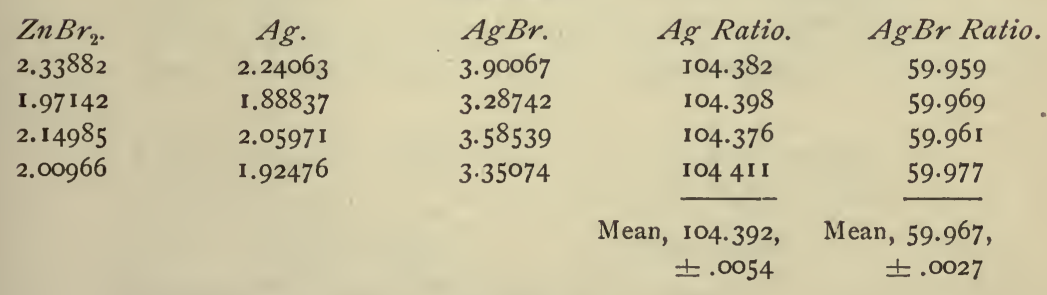


At the end of the same paper, Richards alone gives two more series of determinations made upon zinc bromide prepared by the action of pure bromine upon pure electrolytic zinc. The bromide so obtained was further refined by sublimation or distillation, and dried by heating in a stream of carbon dioxide and gaseous hydrobromic acid. Thus was ensured the absence of basic salts and of water. The weights and results found in the two series were as follows:

Series $C$.

$\begin{array}{lcc}Z u \mathrm{Br}_{2} . & \mathrm{Ag.} & \text { Ratio. } \\ 6.23833 & 5.9766 & 104.379 \\ 526449 & 5.0436 & 104.380 \\ 9.36283 & 8.9702 & 104.377 \\ & & \text { Mean, } 104.379, \pm .0007\end{array}$

Series $D$.

$\begin{array}{lll}\mathrm{ZnBr}_{2} . & \mathrm{AgBr} . & \text { Ratio. } \\ 2.65847 & 4.43358 & 59.962 \\ 2.30939 & 3.85149 & 59.96 \mathbf{1} \\ 5.26449 & 8.77992 & 59.96 \mathbf{r} \\ & & \text { Mean, } 59.96 \mathbf{r}, \pm .0004\end{array}$

In some details of manipulation these series differ from those given by Richards and Rogers jointly, but their minutiæ are not essential to the present discussion.

Combining these several series, we have-

For $\mathrm{Ag}_{2}: \mathrm{ZnBr}_{2}:: 100: x$.

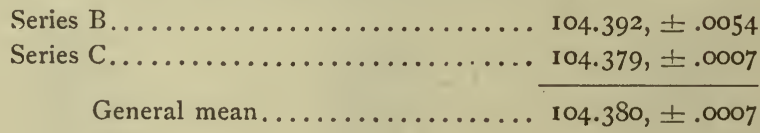

For $2 \mathrm{AgBr}: \mathrm{ZnBr}_{2}:: 100: x$.

Series A..................... 59.975, \pm .0034

Series B..................... 59.967, \pm .0027

Series D.................... 59.96r, \pm .0004

General mean.............. 59.962, \pm .0004

From the $\mathrm{Ag}$ ratio............ $\mathrm{ZnBr}_{2}=223.599, \pm .0066$

From the $\mathrm{AgBr}$ ratio.......... " $=223.601, \pm .0066$

General mean ........ $\mathrm{ZnBr}_{2}=223.600, \pm .0647$

And $\mathrm{Zn}=64.912, \pm .0133$ 
For computing the atomic weight of zinc we now have these ratios:

(I.) Per cent. $\mathrm{Zn}$ in $\mathrm{ZnO}, 80.317, \pm .0008$

(2.) Per cent. $\mathrm{ZnO}$ in $\mathrm{ZnSO}_{4}, 50.413, \pm .0020$

(3.) $\mathrm{H}_{2} \mathrm{O}: \mathrm{Zn}:: 100: 366.319$, \pm .088

(4.) $2 \mathrm{CO}_{2}: \mathrm{Zn}:: 100: 93.169, \pm .012$

(5.) $\mathrm{H}: \mathrm{Zn}:: \mathrm{I}: 65.079, \pm .0036$

(6.) $\mathrm{Ag}_{4}: \mathrm{K}_{2} \mathrm{ZnCl}_{4}:: 100: 66.1 \mathrm{II}, \pm .0023$

(7.) $\mathrm{Ag}_{2}: \mathrm{Zn}:: 100: 30.318, \pm .0077$

(8.) $\mathrm{Cu}: \mathrm{Zn}:: 100: 103.22, \pm .0261$

(9.) $\mathrm{Ag}_{2}: \mathrm{ZnBr}_{2}:: 100: 104.38, \pm .0007$

(10.) $2 \mathrm{AgBr}: \mathrm{ZnBr}_{2}:: 100: 59.962, \pm .0004$

The antecedent atomic weights, with $\mathrm{H}=1$, are-

$$
\begin{array}{ll}
\mathrm{O}=15.879, \pm .0003 & \mathrm{C}=11.920, \pm .0004 \\
\mathrm{Cl}=35.179, \pm .0048 & \mathrm{~S}=31.828, \pm .0015 \\
\mathrm{Br}=79.344, \pm .0062 & \mathrm{Cu}=63.119, \pm .0015 \\
\mathrm{Ag}=107.108, \pm .003 \mathrm{I} & \mathrm{AgBr}=186.452 \pm .0054 \\
\mathrm{~K}=38.817, \pm .005 \mathrm{I} &
\end{array}
$$

With these data, combining ratios 9 and 10 into one (see preceding paragraphs), we have nine independent values for the atomic weight of zinc, as follows:

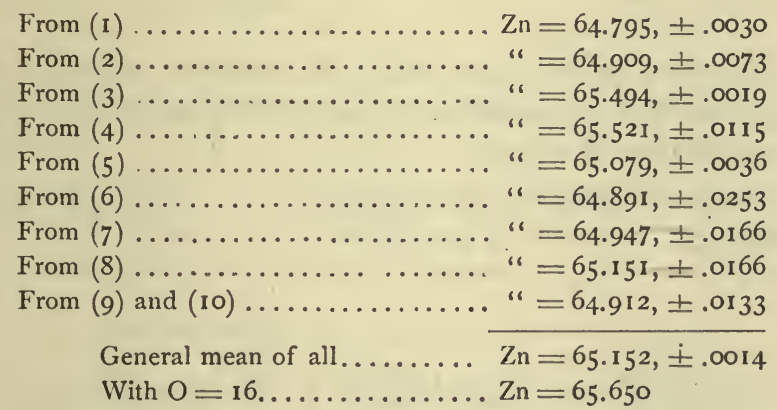

Of these values, Nos. 3 and 4, representing Favre's work, are unquestionably far wrong. Rejecting them, the general mean of the remaining seven values becomes-

$$
\mathrm{Zn}=64.912, \pm .0021
$$

If $\mathrm{O}=16$, this gives $\mathrm{Zn}=65.407$. These figures are identical, except as regards the lower probable error, with the result deduced from Richards and Rogers' determinations alone, and they may be taken as satisfactory. 


\section{CADMIUM.}

The earliest determination of the atomic weight of this metal was by Stromeyer, who found that 100 parts of cadmium united with 14.352 of oxygen.* With our value for the atomic weight of oxygen, these figures make $\mathrm{Cd}=110.64$. This result has now only a historical interest.

The more modern estimates of the atomic weight of cadmium begin with the work of v. Hauer. $\dagger$ He heated pure anhydrous cadmium sulphate in a stream of dry hydrogen sulphide, and weighed the cadmium sulphide thus obtained. His results were as follows, with the percentage of $\mathrm{CdS}$ in $\mathrm{CdSO}_{4}$ therefrom deduced:

\begin{tabular}{|c|c|c|c|c|c|}
\hline \multicolumn{4}{|c|}{$7.7650 \mathrm{grm} . \mathrm{CdSO}_{4}$ gave $5.374 \mathrm{r}$ grm. CdS. } & \multicolumn{2}{|c|}{69.209 per cent. } \\
\hline 6.6086 & “ & 4.5746 & “ & 69.222 & “ \\
\hline $7 \cdot 3821$ & “ & 5.1117 & “ & 69.245 & “ \\
\hline 6.8377 & “" & 4.7336 & “ & 69.228 & “ \\
\hline 8.1956 & “ & 5.6736 & “ & 69.227 & “ \\
\hline 7.6039 & “ & 5.2634 & “ & 69.220 & “ \\
\hline 7.1415 & “ & 4.9431 & “ & 69.217 & “ \\
\hline 5.8245 & “ & 4.0335 & “ & $69.25 \mathrm{I}$ & “" \\
\hline 6.8462 & “ & 4.7415 & “ & 69.257 & “ \\
\hline
\end{tabular}

Lenssen $\ddagger$ worked upon pure cadmium oxalate, handling, however, only small quantities of material. This salt, upon ignition, leaves the following percentages of oxide:

\begin{tabular}{|c|c|c|c|c|c|}
\hline \multicolumn{4}{|c|}{$.5128 \mathrm{grm}$. oxalate gave $.328 \mathrm{I} \mathrm{grm}$. CdO. } & \multicolumn{2}{|c|}{63.982 per cent. } \\
\hline .6552 & " & .4193 & 6 & 63.996 & "6 \\
\hline .4017 & “ & .2573 & "6 & 64.053 & " \\
\hline
\end{tabular}

Dumas || dissolved pure cadmium in hydrochloric acid, evaporated the solution to dryness, and fused the residue in hydrochloric acid gas. The cadmium chloride thus obtained was dissolved in water and titrated with a solution of silver after the usual manner. From Dumas' weighings I calculate the ratio between $\mathrm{CdCl}_{2}$ and 100 parts of silver:

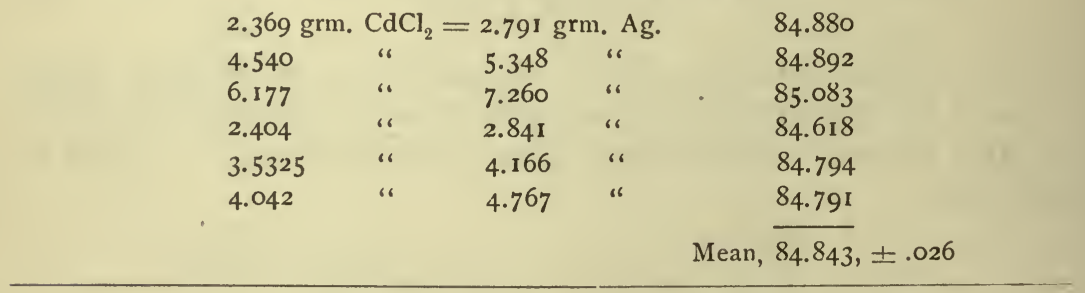

* See Berz. Lehrbuch, 5th Aufl., 3, r219.

† Journ. für Prakt. Chem., 72, 350. 1857.

$\ddagger$ Journ. für Prakt. Chem., 79, 28r. 1860.

\|Ann. Chem. Pharm., II3, 27. I860. 
Next in order comes Huntington's* work, carried out in the laboratory of J. P. Cooke.' Bromide of cadmium was prepared by dissolving the carbonate in hydrobromic acid, and the product, dried at $200^{\circ}$, was purified by sublimation in a porcelain tube. Upon the compound thus obtained two series of experiments were marde.

In one series the bromide was dissolved in water, and a quantity of silver not quite sufficient for complete precipitation of the bromine was then added in nitric acid solution. After the precipitate had settled, the supernatant liquid was titrated with a standard solution of silver containing one gramme to the litre. The precipitate was washed by decantation, collected by reverse filtration, and weighed. 'To the weighings $\mathrm{I}$ append the ratio between $\mathrm{CdBr}_{2}$ and 100 parts of silver bromide :

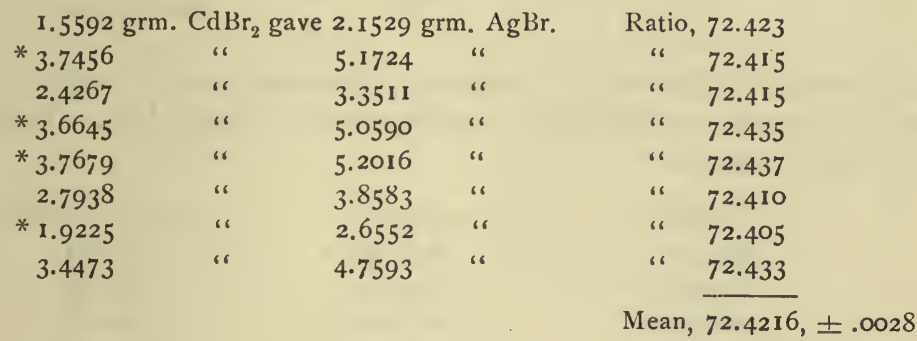

The second series was like the first, except that the weight of silver needed to effect precipitation was noted, instead of the weight of silver bromide formed. In the experiments marked with an asterisk, both the amount of silver required and the amount of silver bromide thrown down were determined in one set of weighings. The third column gives the $\mathrm{CdBr}_{2}$ proportional to 100 parts of silver :

\begin{tabular}{|c|c|c|c|c|}
\hline${ }^{*} 3.7456$ & $\mathrm{Cd}$ & 2.9715 & m. Ag. & $126.05 \mathrm{I}$ \\
\hline 5.0270 & “ & 3.9874 & “ & I 26.072 \\
\hline * 3.6645 & “ & 2.9073 & $" 6$ & I 26.045 \\
\hline * 3.7679 & “ & 2.9888 & “ & 126.067 \\
\hline${ }^{*} 1.9225$ & “ & 1.5248 & " & 126.082 \\
\hline $2.9 \mathrm{IOI}$ & “" & 2.3079 & " & 126.093 \\
\hline 3.6510 & “ & $2.895 \mathrm{I}$ & “ & 126.110 \\
\hline 3.9782 & “ & $3.155 \mathrm{r}$ & " & 126.088 \\
\hline
\end{tabular}

According to Huntington's own calculations, these experiments fix the ratio between silver, bromine, and cadmium as $\mathrm{Ag}: \mathrm{Br}: \mathrm{Cd}:: 108: 80$ : 112.31

In 1890, Partridge $\dagger$ published determinations of the atomic weight of cadmium, made by three methods, the weighings being reduced to 
vacuum standards throughout. First, Lenssen's method was followed, viz., the ignition of the oxalate, with the subjoined results:

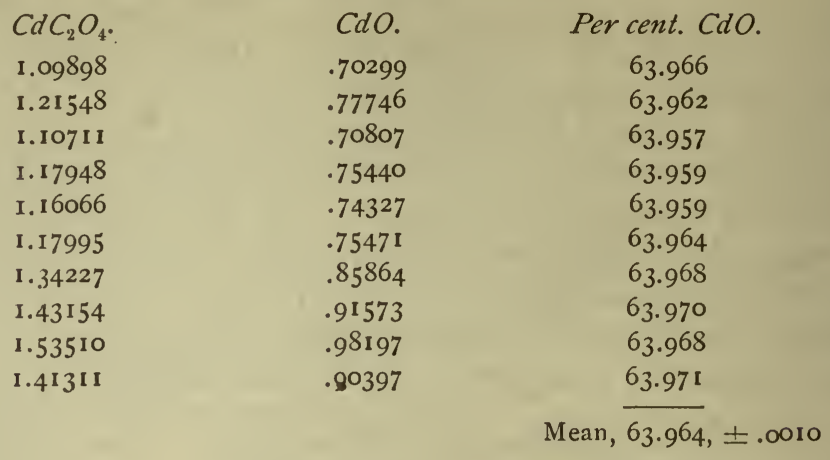

Secondly, v. Hauer's experiments were repeated, cadmium sulphate being reduced to sulphide by heating in a stream of $\mathrm{H}_{2} \mathrm{~S}$. The following data were obtained:

$\begin{array}{lrc}\mathrm{CdSO}_{4} . & \text { CdS. } & \text { Per cent. CdS. } \\ 1.60514 & 1.11076 & 69.204 \\ 1.55831 & 1.07 .834 & 69.197 \\ 1.67190 & 1.15669 & 69.185 \\ 1.66976 & 1.15554 & 69.200 \\ 1.40821 & .97450 & 69.202 \\ 1.56290 & 1.08156 & 69.205 \\ 1.63278 & 1.12985 & 69.194 \\ 1.58270 & 1.09524 & 69.198 \\ 1.53873 & 1.06481 & 69.201 \\ 1.70462 & 1.17962 & 69.201 \\ & & \text { Mean, } \overline{69.199, \pm .0012} \\ & & \text { v. Hauer found, } 69.231, \pm .0042 \\ & & \text { General mean, } 69.202, \pm .0012\end{array}$

In the third set of determinations cadmium oxalate was transformed to sulphide by heating in $\mathrm{H}_{2} \mathrm{~S}$, giving the ratio $\mathrm{CdC}_{2} \mathrm{O}_{4}: \mathrm{CdS}:: 100: x$.

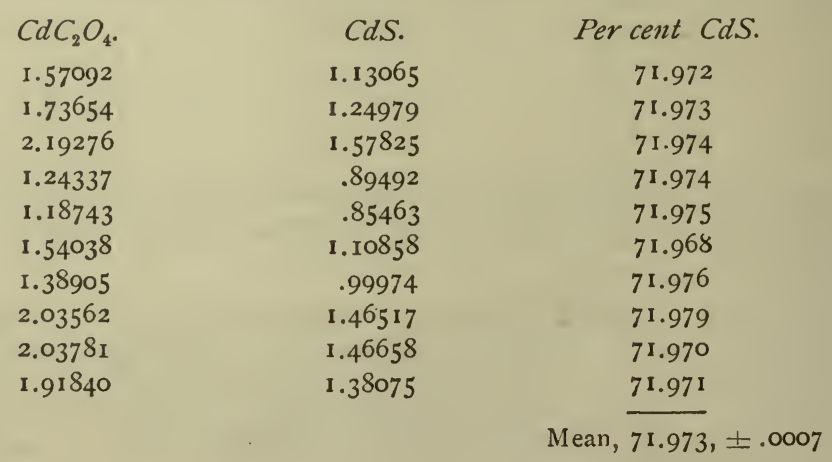


This work of Partridge was presently discussed by Clarke,* with reference to the concordance of the data, and it was shown that the three ratios determined could be discussed algebraically, giving values for the atomic weights of $\mathrm{Cd}, \mathrm{S}$, and $\mathrm{C}$, when $\mathrm{O}=16$. These values are-

$$
\begin{aligned}
& \mathrm{Cd}=111.7850 \\
& \mathrm{C}=11.995^{8} \\
& \mathrm{~s}=32.0002,
\end{aligned}
$$

and are independent of all antecedent values except that assumed for the standard, oxygen.

Morse and Jones, $\uparrow$ starting out from cadmium purified by fractional distillation in vacuo, adopted two methods for their determinations. First, they effected the synthesis of the oxide from known weights of metal by dissolving the latter in nitric acid, evaporating to dryness, and subsequent ignition of the product. The oxide thus obtained was found to be completely free from oxides of nitrogen. The weighings; which are given below, were made in tared crucibles. The third column gives the percentage of $\mathrm{Cd}$ in $\mathrm{CdO}$.

$\begin{array}{ccc}\text { Cd Taken. } & \text { CdO Found. } & \text { Per cent. Cd. } \\ 1.77891 & 2.03288 & 87.507 \\ 1.82492 & 2.08544 & 87.508 \\ 1.74688 & 1.99626 & 87.507 \\ 1.57000 & 1.79418 & 87.505 \\ 1.98481 & 2.26820 & 87.506 \\ 2.27297 & 2.59751 & 87.504 \\ 1.75695 & 2.00775 & 87.508 \\ 1.70028 & 1.94305 & 87.505 \\ 1.92237 & 2.19679 & 87.508 \\ 1.92081 & 2.19502 & 87.508 \\ & & \\ & & \text { Mean }, 87.506 .6, \pm .00032\end{array}$

The second method employed by Morse and Jones was that of Lenssen with cadmium oxalate. This salt they find to be somewhat hygroscopic, a property against which the operator must be on his guard. The data found are as follows:

$\begin{array}{lcc}\mathrm{CdC}_{2} \mathrm{O}_{4} . & \mathrm{CdO} . & \text { Percent. CdO. } \\ 1.53937 & .98526 & 64.004 \\ 1.77483 & 1.13582 & 63996 \\ 1.70211 & 1.08949 & 64.008 \\ 1.70238 & 1.08967 & 64.004 \\ 1.74447 & 1.11651 & 64.003 \\ & & \text { Mean, } \overline{64.003}, \pm .0042\end{array}$

Lorimer and Smith, like Morse and Jones, determined the atomic weight of cadmium by means of the oxide, but by analysis instead of 
synthesis. Weighed quantities of oxide were dissolved in potassium cyanide solution, from which metallic cadmium was thrown down electrolytically. The weights are reduced to vacuum standards.

$\begin{array}{ccc}\text { CdO Taken. } & \text { Cd Found. } & \text { Per cent. Cd. } \\ .34767 & .30418 & 87.491 \\ .41538 & .36352 & 87.515 \\ 1.04698 & .91618 & 87.507 \\ 1.04066 & .91500 & 87.493 \\ 1.26447 & 1.10649 & 87.506 \\ .78493 & .68675 & 87.492 \\ .86707 & .75884 & 87.518 \\ .67175 & .58785 & 87.510 \\ 1.44362 & 1.26329 & 87.508 \\ & & \text { Mean, } 87.5044, \pm .0023\end{array}$

Mr. Bucher's dissertation * upon the atomic weight of cadmium does not claim to give any final measurements, but rather to discuss the various methods by which that constant has been determined. Nevertheless, it gives many data which seem to have positive value, and which are certainly fit for discussion along with those which have preceded this paragraph. Bucher begins with cadmium purified by distillation nine times in vacuo, and from this his various compounds were prepared. His first series of determinations was made by reducing cadmium oxalate to oxide, the oxalate having been dried fifty hours at $150^{\circ}$. The reduction was effected by heating in jacketed porcelain crucibles, with various precautions, and the results obtained, reduced to vacuum standards, are as follows :

$\begin{array}{rrc}\text { Oxalate. } & \text { Oxide. } & \text { Percent. Oxide. } \\ 1.97674 & 1.26414 & 63.95 \mathrm{I} \\ 1.94912 & 1.24682 & 63.968 \\ 1.96786 & 1.25886 & 63.971 \\ 1.87099 & 1.19675 & 63.958 \\ 1.37550 & .87994 & 63.972 \\ 1.33313 & .85308 & 63.991 \\ 194450 & 1.24452 & 64.002 \\ 2.01846 & 1.29210 & 64.014 \\ & & \end{array}$

Combining this with the means found by previous experimenters, we have for the percentage of oxide in oxalate-

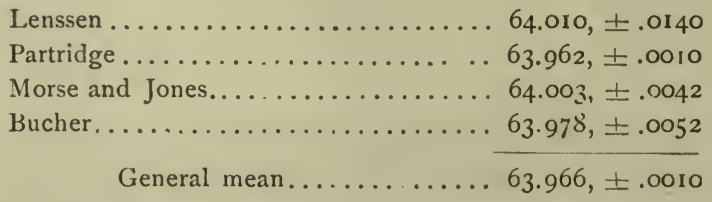

* "An examination of some methods employed in determining the atomic weight of cadmium." Johns Hopkins University doctoral dissertation. By John E. Bucher. Baltimore, I895. 
Bucher's next series of determinations was by Partridge's methodthe conversion of cadmium oxalate into cadmium sulphide by heating in a stream of sulphuretted hydrogen. The sulphide was finally cooled in a current of dry nitrogen. The vacuum weights and ratios are subjoined :

$$
\begin{array}{lcc}
\text { Oxalate. } & \text { Sulphide. } & \text { Percentage. } \\
2.56319 & 1.84716 & 72.065 \\
2.18364 & 1.57341 & 72.055 \\
2.11643 & 1.52462 & 72.037 \\
3.13105 & 2.25582 & \frac{72.047}{72.051}, \pm .0127 \\
& & \text { Mean, } 71.973, \pm .0007 \\
& & \text { Partridge found, } 71.974, \pm .0007
\end{array}
$$

Here Bucher's mean practically vanishes.

The third method employed by Bucher was that of weighing cadmium chloride, dissolving in water, precipitating with silver nitrate, and weighing the silver chloride found. The cadmium chloride was prepared, partly by solution of cadmium in hydrochloric acid, evaporation to dryness, and sublimation in vacuo; and partly by the direct union of the metal with chlorine. The silver chloride was weighed in a Gooch crucible, with platinum sponge in place of the asbestos. To the vacuum weights $\mathrm{I}$ append the ratio $2 \mathrm{AgCl}: \mathrm{CdCl}_{2}:: 100: x$.

$\begin{array}{lcc}\mathrm{CdCl}_{2} . & \mathrm{AgCl} & \text { Ratio. } \\ 3.09183 & 4.83856 & 63.900 \\ 2.26100 & 3.53854 & 63.896 \\ 1.35729 & 2.1243 \mathrm{I} & 63.893 \\ 2.05582 & 3.21727 & 63.899 \\ 1.89774 & 2.9704 \mathrm{I} & 63.886 \\ 3.50367 & 5.48473 & 63.880 \\ 2.70292 & 4.23087 & 63.886 \\ 4.24276 & 6.63598 & 63.936 \\ 3.40200 & 5.32314 & 63.910 \\ 4.60659 & 7.20386 & 63.946 \\ 2.40832 & 3.7 .6715 & 63.930 \\ 2.19144 & 3.42724 & 63.942 \\ 2.84628 & 4.45477 & 63.893 \\ 2.56748 & 4.01651 & 63923 \\ 2.31003 & 3.61370 & 63.924 \\ 1.25008 & 1.95652 & 63.893 \\ 1.96015 & 3.0654 \mathrm{I} & 63.944 \\ 2.29787 & 3.59391 & 63.938 \\ 1.94227 & 3.03811 & 63.915 \\ 1.10976 & 1.73547 & 63.946 \\ 1.63080 & 2.55016 & 63.949 \\ & & 63.916, \pm .0032\end{array}$

Bucher gives a rather full discussion of the presumable errors in this method, which, however, he regards as somewhat compensatory. The 
series is followed by a similar one with cadmium bromide, the latter having been sublimed in vacuo. Results as follows:

$\begin{array}{rrr}\mathrm{CdBr}_{2} . & \mathrm{AgBr} & \text { Ratio. } \\ 4.3994 \mathrm{I} & 6.07204 & 72.454 \\ 3.18030 & 4.3883 \mathrm{I} & 72.472 \\ 3.60336 & 4.97150 & 72.480 \\ 4.04240 & 5.58062 & 72.453 \\ 3.60505 & 4.97519 & 72.46 \mathrm{I} \\ & & \text { Mean, } 72.464, \pm .0035 \\ & & \text { Huntington found, } 72.4216, \pm .0028 \\ & & \text { General mean, } 72.438, \pm .0022\end{array}$

In order to fix a mininum value for the atomic weight of cadmium, Bucher effected the synthesis of the sulphate from the metal. 1.15781 grammes of cadmium gave 2.14776 of sulphate.

$$
\text { Hence } \mathrm{Cd}=\mathrm{III} .5 \mathrm{II} \text {. }
$$

The sulphate produced was dried at $400^{\circ}$, and afterwards examined for free sulphuric acid, giving a correction which was applied to the weighings. The corrected weight is given above. Any impurity in the sulphate would tend to lower the apparent atomic weight of cadmium, and therefore the result is believed by the author to be a minimum.

Finally, Bucher examined the oxide method followed by Morse and Jones. The syntheses of oxide were effected in double crucibles, first with both crucibles porcelain, and afterwards with the small inner crucible of platinum. Two experiments were made by the first method, three by the last. Weights and percentages (Cd in $\mathrm{CdO})$ as follows:

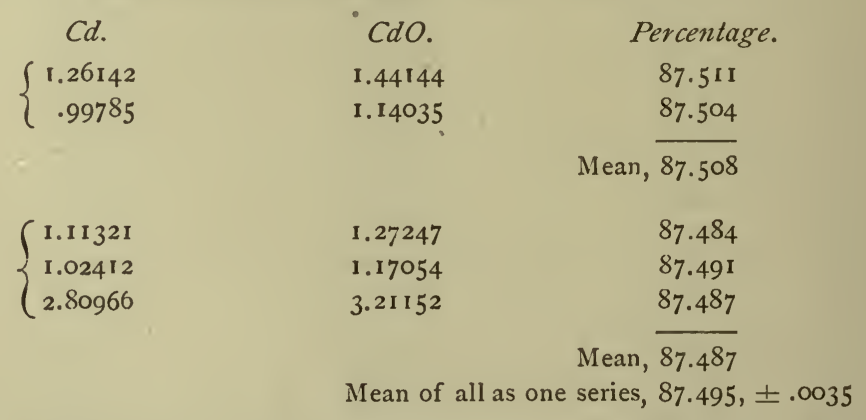

The two means given above, representing work done with porcelain and with platinum crucibles, correspond to a difference of about 0.2 in the atomic weight of cadmium. Experiments were made with pure oxide of cadmium by converting it into nitrate and then back to oxide, exactly as in the foregoing syntheses. In each case the oxide obtained at the end of the operation represented an increase in weight, but the increase was greater in platinum than in porcelain. Hence the weighings of cadmium oxide in the foregoing determinations probably are subject to constant errors, and cannot be trusted to fix the atomic weight 
of cadmium. Their mean, taken in one series, has really no significance; but as the computations in this work involve a study of compensation of errors, the data may be combined with their predecessors, as follows:

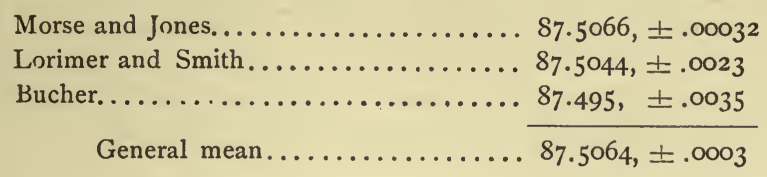

This is equivalent to the absolute rejection of Bucher's data, and is therefore not wholly fair to them. His work throws doubt upon the validity of the ratio, as determined, altogether.

The latest determinations relative to the atomic weight of cadmium are those of Hardin,* who effected the electrolysis of the chloride and bromide, and also made a direct comparison between cadmium and silver. The aqueous solutions of the salts, mixed with potassium cyanide, were electrolyzed in platinum dishes. The cadmium which served as the starting point for the investigation was purified by distillation in hydrogen. All weights are reduced to a vacuum. The data for the chloride series are as follows, with a column added for the percentage of $\mathrm{Cd}$ in $\mathrm{CdCl}_{2}$ :

Weight $\mathrm{CdCl}_{2}$.
.43140
.49165
.71752
.72188
.77264
.81224
.90022
1.02072
1.26322
1.52344

Weight Cd.
.26422
.30112
.43942
.44208
.47319
.49742
.55135
.62505
.77365
.93314

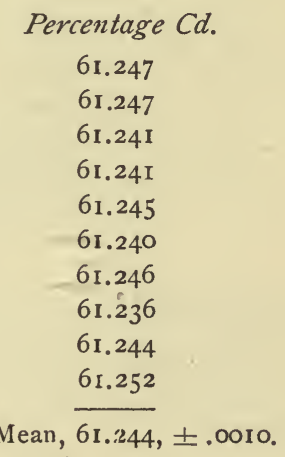

The results for the bromide, similarly stated, are these:

Weight $\mathrm{CdBr}_{2}$.
.57745
.76412
.91835
1.01460
1.15074
$\mathrm{I.24751}$
$\mathrm{I.25951}$
$\mathrm{I.51805}$
$\mathrm{I.63543}$
2.15342

Weight Cd.
.23790
.31484
.37842
.41808
.47414
.51392
.51905
.62556
.67378
.88722
Percentage $\mathrm{Cd}$.
41.198
41.203
41.207
41.206
41.203
41.196
41.210
$4 \mathrm{I} .208$
41.199
41.200
Mean, $\overline{41.203}, \pm 0010$


The direct comparison of cadmium and silver was effected by the simultaneous electrolysis, in the same current, of double cyanide solutions. Silver was thrown down in one platinum dish, and cadmium in another. The process was not altogether satisfactory, and gave divergent results, those which are cited below having been selected by Hardin from the mass of data obtained. I have added in a third column the cadmium proportional to 100 parts of silver :

$\begin{array}{ccc}\text { Weight Cd. } & \text { Weight Ag. } & \text { Ratio. } \\ .12624 & .24335 & 5 \mathrm{r} .876 \\ .11032 & .21262 & 51.886 \\ .12720 & .24515 & 51.887 \\ .12616 & .24331 & 51.852 \\ .22058 & .42520 & 51.877 \\ & & \text { Mean, } 51.876, \pm .0041\end{array}$

For cadmium we now have the following ratios:

(I.) Per cent. of $\mathrm{Cd}$ in $\mathrm{CdO}, 87.5064, \pm .0003$

(2.) Per cent. of $\mathrm{CdO}$ in $\mathrm{CdC}_{2} \mathrm{O}_{4}, 63.966, \pm .0010$

(3.) Per cent. of CdS from $\mathrm{CdC}_{2} \mathrm{O}_{4}, 7 \mathrm{r} .974, \pm .0007$

(4.) Per cent. of $\mathrm{CdS}$ from $\mathrm{CdSO}_{4}, 69.202, \pm .0012$

(5.) $\mathrm{Ag}_{2}: \mathrm{CdCl}_{2}:: 100: 84.843, \pm .0260$

(6.) $2 \mathrm{AgCl}: \mathrm{CdCl}_{2}:: 100: 63.916, \pm .0032$

(7.) $\mathrm{Ag}_{2}: \mathrm{CdBr}_{2}:: 100: 126.076, \pm .0052$

(8.) $2 \mathrm{AgBr}: \mathrm{CdBr}_{2}:: 100: 72.438, \pm .0022$

(9.) Per cent. of $\mathrm{Cd}$ in $\mathrm{CdCl}_{2}, 61.244, \pm .0010$

(10.) Per cent of $\mathrm{Cd}$ in $\mathrm{CdBr}_{2}, 41.203, \pm .0010$

(II.) $2 \mathrm{Ag}: \mathrm{Cd}:: 100: 5 \mathrm{I} .876, \pm .004 \mathrm{I}$

Bucher's single experiment upon the synthesis of the sulphate, although important and interesting, cannot carry weight enough to warrant its consideration in connection with the other ratios, and is therefore not included.

The antecedent values, for use in computation are-

$$
\begin{aligned}
& \mathrm{O}=15.879, \pm .0003 \\
& \mathrm{Ag}=107.108, \pm .003 \mathrm{I} \\
& \mathrm{Cl}=35.179, \pm .0048 \\
& \mathrm{Br}=79.344, \pm .0062
\end{aligned}
$$

$$
\begin{aligned}
& \mathrm{S}=31.828, \pm .0015 \\
& \mathrm{C}=11.920, \pm .0004 \\
& \mathrm{AgCl}=142.287, \pm .0037 \\
& \mathrm{AgBr}=186.452, \pm .0054
\end{aligned}
$$

For the molecular weight of cadmium chloride, two values are now deducible:

$$
\begin{aligned}
& \text { From }(5) \ldots \ldots \ldots \ldots \ldots \ldots \mathrm{CdCl}_{2}=\mathbf{1} 81.739, \pm .0560 \\
& \text { From }(6) \ldots \ldots \ldots \ldots \ldots \ldots \ldots . " \quad "=181.888, \pm .0103 \\
& \text { General mean.......... } \overline{\mathrm{CdCl}_{2}=\mathbf{1} 8 \mathbf{1} .883, \pm .0138}
\end{aligned}
$$

Hence $\mathrm{Cd}=111.525, \pm .0138$. 
For cadmium bromide we have-

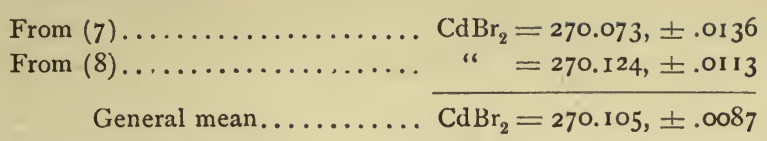

Hence $\mathrm{Cd}=111.417, \pm .0151$.

For cadmium there are nine independent values, as follows:

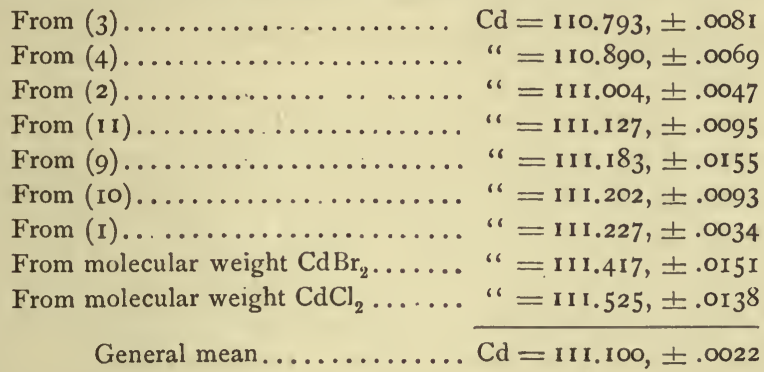

\section{If $\mathrm{O}=16, \mathrm{Cd}=111.947$.}

This result is obviously uncertain. The data are far from being conclusive, however, and I am therefore inclined to trust the mean rather than any one of the values taken separately. It is quite possible that the highest of all the figures may be nearest the truth, as Bucher's experiments seem to indicate; but until new evidence is obtained it would hardly be wise to make any selection. The mean obtained agrees well with the data of Morse and Jones, Lorimer and Smith, and Hardin. 


\section{MERCURY.}

In dealing with the atomic weight of mercury we may reject the early determinations by Sefström * and a large part of the work done by Turner. $\dagger$ The latter chemist, in addition to the data which will be cited below, gives figures to represent the percentage composition of both the chlorides of mercury; but these results are neither reliable nor in proper shape to be used.

First in order we may consider the percentage composition of mercuric oxide, as established by Turner and by Erdmann and Marchand. In both investigations the oxide was decomposed by heat, and the mercury was accurately weighed. Gold leaf served to collect the last traces of mercurial vapor.

Turner gives four estimations. Two represent oxide obtained by the ignition of the nitrate, and two are from commercial oxide. In the first two the oxide still contained traces of nitrate, but hardly in weighable proportions. A comparison of the figures from this source with the others is sufficiently conclusive on this point. The third column represents the percentage of mercury in $\mathrm{HgO}$ :

\begin{tabular}{|c|c|c|c|}
\hline 125.980 & "6 & 10.08 & " \\
\hline $173.56 \mathrm{I}$ & " & 13.82 & " \\
\hline 114.294 & " & $9.10 \mathrm{I}$ & " \\
\hline
\end{tabular}

$$
\begin{aligned}
92.619 \text { per cent. } \\
92.592 \text { " } \\
92.625 \text { " } \\
\frac{92.620}{\text { Mean, }} 92.614, \pm .0050
\end{aligned}
$$

\begin{tabular}{|c|c|c|c|c|c|}
\hline \multicolumn{6}{|c|}{$82.0079 \mathrm{grm} . \mathrm{HgO}$} \\
\hline 51.0320 & “ & $47.253^{8}$ & " & 92.597 & " \\
\hline 84.4996 & “ & 78.2501 & “ & 92.604 & " \\
\hline 44.6283 & " & 41.3285 & “ & 92.606 & “ \\
\hline I 18.4066 & “ & I09. 6408 & “ & 92.597 & “ \\
\hline
\end{tabular}

In the experiments of Erdmann and Marchand $\ddagger$ every precaution was taken to ensure accuracy. Their weighings, reduced to a vacuum standard, give the subjoined percentages :

Hardin's determination of the same ratio, being different in character, will be considered later.

With a view to establishing the atomic weight of sulphur, Erdimann and Marchand also made a series of analyses of pure mercuric sulphide. These data are now best available for discussion under mercury. The

* Sefström. Berz. Lehrb., 5th ed., 3, 1215. Work done in I8I2. $\dagger$ Phil. Trans., $1833,531-535$.

$\ddagger$ Journ. für Prakt. Chem., 3I, 395. 1844 . 
sulphide was mixed with pure copper and ignited, mercury distilling over and copper sulphide remaining behind. Gold leaf was used to retain traces of mercurial vapor, and the weighings were reduced to vacuum :

$\begin{array}{llllll}34.3568 & \text { grm. HgS gave } 29.6207 & \text { grm. Hg. } & 86.215 & \text { per cent. Hg. } \\ 24.8278 & \text { " } & 21.40295 & \text { " } & 86.206 & \text { " } \\ 37.2177 & \text { " } & 32.08416 & \text { " } & 86.207 & \text { " } \\ 80.7641 & \text { " } & 69.6372 & \text { " } & 86.223 & \text { " } \\ & & & & & \\ & & & & \end{array}$

For the percentage of mercury in mercuric chloride we have data by Turner, Millon, Svanberg, and Hardin. Turner,* in addition to some precipitations of mercuric chloride by silver nitrate, gives two experiments in which the compound was decomposed by pure stannous chloride, and the mercury thus set free was collected and weighed. The results were as follows :

$$
\begin{array}{lll}
44.782 \text { grains } \mathrm{Hg}=15.90 \text { grains Cl. } & 73.798 \text { per cent. } \\
73.09 & 25.97 \text { " } & \frac{73.784}{73.791}, \pm .005
\end{array}
$$

Millon $\dagger$ purified mercuric chloride by solution in ether and sublimation, and then subjected it to distillation with lime. The mercury was collected as in Erdmann and Marchand's experiments. Percentages of metal as follows :

$$
\begin{gathered}
73.87 \\
73.81 \\
73.83 \\
73.87 \\
\hline \text { Mean, } 73.845, \pm .010
\end{gathered}
$$

Svanberg, $\ddagger$ following the general method of Erdmann and Marchand, made three distillations of mercuric chloride with lime, and got the following results :

$$
\begin{aligned}
& 12.048 \mathrm{grm} . \mathrm{HgCl}_{2} \text { gave } 8.889 \mathrm{grm} . \mathrm{Hg} \text {. } \quad 73.780 \text { per cent. } \\
& \begin{array}{llllll}
12.529 & \text { " } & 9.2456 & 73.794 \text { “ } \\
12.649 \mathrm{I} & \text { " } & 9.3363 & & 73.810
\end{array} \\
& \text { Mean, } \overline{73.795}, \pm .006
\end{aligned}
$$

The most recent determinations of the atomic weight of mercury are due to Hardin, $\S$ whose methods were entirely electrolytic. First, pure mercuric oxide was dissolved in dilute, aqueous potassium cyanide, and

* Phil. Trans., I833, 53I-535.

† Ann. Chim. Phys. (3), I8, 345. 1846.

$\ddagger$ Journ. für Prakt. Chem., 45, 472. I848.

\& Journ. Amer. Chem. Soc., I8, 1003. '1896. 
electrolyzed in a platinum dish. Six determinations are published, out of a larger number, but without reduction of the weights to a vacuum. The data, with a percentage column added, are as follows:

$\begin{array}{cc}\text { Weight } \mathrm{HgO} & \text { Weight } \mathrm{Hg} . \\ .26223 & .2428 \mathrm{I} \\ .23830 & .22065 \\ .23200 & .21482 \\ .14148 & .13100 \\ .29799 & .27592 \\ .19631 & .18177\end{array}$

Per cent. $\mathrm{Hg}$. 92.594

92.593

92.595

92.593

92.594

92.593

Mean, $92.594, \pm 0003$.

Various sources of error were detected in these experiments, and the series is therefore rejected by Hardin. It combines with previous series as follows:

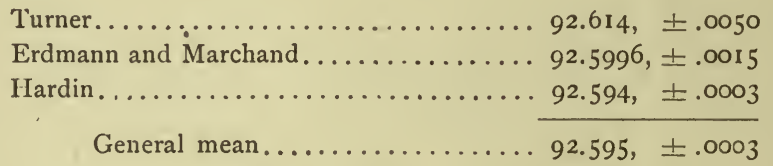

Hardin also studied mercuric chloride, bromide, and cyanide, and the direct ratio between mercury and silver, with reduction of weights to a vacuum. Electrolysis was conducted in a platinum dish, as usual. With the chloride and bromide, the solutions were mixed with dilute potassium cyanide. The data for the chloride are as follows, the percentage column being added by myself:

Weight $\mathrm{HgCl}_{2}$.
.45932
.54735
.56002
.63586
.64365
$.7328 \mathrm{I}$
.86467
$\mathrm{1.06776}$
$\mathrm{1.07945}$
$\mathrm{1} .51402$

Weight $H g$.

.33912
.40415
.41348
.46941
.47521
.54101
.63840
.78825
.79685
1.11780

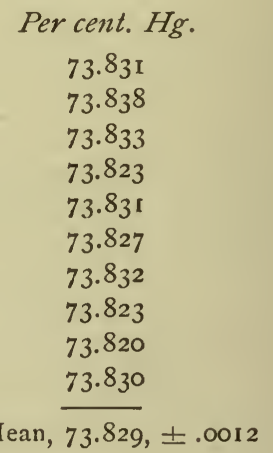

Combining this with the earlier determinations, we have-

$$
\begin{aligned}
& \text { Turner....................... 73.791, } \pm .0050 \\
& \text { Millon....................... 73.845, } \pm .0100 \\
& \text { Svanberg....................... 73.795, } \pm .0060 \\
& \text { Hardin...................... 73.829, } \pm .0012
\end{aligned}
$$


For the bromide Hardin's data are-

Weight $\mathrm{HgBr}_{2}$.
.70002
.56430
.57142
.77285
.80930
.85342
1.11076
117270
1.26186
1.40142

Weight $\mathrm{Hg}$.

.38892

.31350

.31750

.42932

.44955

.47416

.61708

.65145

.70107

.77870

\author{
Percent. Hg. \\ 55.558 \\ 55.555 \\ 55.563 \\ $55.55^{\circ}$ \\ 55.548 \\ 55.560 \\ 55.555 \\ $55.55 \mathrm{I}$ \\ 55.559 \\ 55.565 \\ Mean, $\overline{55.556}, \pm .0012$
}

And for the cyanide-

Weight $\mathrm{HgC}_{2} \mathrm{~N}_{2}$.
.55776
.63290
.70652
.80241
.65706
.81678
1.07628
1.22615
1.66225
2.11170

Weight Hg.

Per cent. Hg.

.44252
.50215
.56053
.63663
.52130
.64805
.85392
.97282
1.31880
1.67541

79.337

$79.34 \mathrm{I}$

79.337

79.340

$79.33^{8}$

79.342

79.340

79.339

$79 \cdot 338$

79.339

Mean, 79.339, \pm .0004

In the last series cited no potassium cyanide was used, but the solution of mercuric cyanide, with the addition of one drop of sulphuric acid, was electrolyzed directly.

The direct ratio between silver and mercury was determined by throwing down the two metals, simultaneously, in the same electric current. Both metals were taken in double cyanide solution. With Hardin's equivalent weights I give a third column, showing the quantity of mercury corresponding to 100 parts of silver. Many experiments were rejected, and only the following seven are published by the author:

Weight $\mathrm{Hg}$.
.06126
.06190
.07814
.10361
.15201
.26806
.82808

Weight Ag.
.06610
.06680
.08432
.11181
.16402
.28940
.89388

Ratio.

92.678

92.665

$92.67 \mathrm{I}$

92.666

92.678

92.626

92.639

Mean, $\overline{92.660}, \pm .0051$ 
We now have six ratios involving the atomic weight of mercury, as follows :
(1.) Per cent, of $\mathrm{Hg}$ in $\mathrm{HgO}, 92.595, \pm .0003$
(2.) Per cent. of $\mathrm{Hg}$ in $\mathrm{HgS}, 86.2127, \pm .0027$
(3.) Per cent. of $\mathrm{Hg}$ in $\mathrm{HgCl}_{2}, 73.826, \pm .00$ I
(4.) Per cent. of $\mathrm{Hg}$ in $\mathrm{HgBr}_{2}, 55.556, \pm .0012$
(5.) Per cent. of $\mathrm{Hg}$ in $\mathrm{HgC}_{2} \mathrm{~N}_{2}, 79.339, \pm .0004$
(6.) $2 \mathrm{Ag}: \mathrm{Hg}:: \mathrm{I00}: 92.660, \pm .005 \mathrm{I}$

The calculations involve the following values:

$$
\begin{array}{ll}
\mathrm{O}=15.879, \pm .0003 & \mathrm{Br}=79.344, \pm .0062 \\
\mathrm{Ag}=\mathrm{I0} 7.108, \pm .003 \mathrm{I} & \mathrm{S}=31.828, \pm .0015 \\
\mathrm{Cl}=35.179, \pm .0048 & \mathrm{C}=\mathrm{I} \mathrm{I} .920, \pm .0004 \\
& \mathrm{~N}=\mathrm{I} 3.935, \pm .002 \mathrm{I}
\end{array}
$$

Hence the values for mercury are--

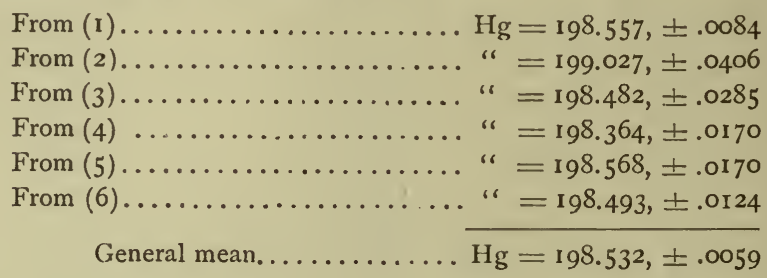

If $\mathrm{O}=16, \mathrm{Hg}=200.045$.

But according to Hardin the value derived from the analyses of mercuric oxide is untrustworthy. Rejecting this, and also the abnormally highiresult from the sulphide series, the general mean of the four remaining values is-

$$
\mathrm{Hg}=198.491, \pm .0083
$$

or, with $\mathrm{O}=16, \mathrm{Hg}=200.004$. These figures seem to be the best for the atomic weight of mercury. 


\section{BORON.}

In the former edition of this work the data relative to boron were few and unimportant. There was a little work on record by Berzelius and by Laurent, and this was eked out by a discussion of Deville's analyses of boron chloride and bromide. As the latter were not intended for atomic weight determinations they will be omitted from the present recalculation, which includes the later researches of Hoskyns-Abrahall, Ramsay and Aston, and Rimbach.

Berzelius* based his determination upon three concordant estimations of the percentage of water in borax. Laurent $†$ made use of two similar estimations, and all five may be properly put in one series, thus :

$\left.\begin{array}{r}\left.\begin{array}{r}47.10 \\ 47.10 \\ 47.10\end{array}\right\} \text { Berzelius. } \\ 47.15 \\ 47.20\end{array}\right\}$ Laurent.

In 1892 the posthumous notes of the late Hoskyns-Abrahall were edited and published by Ewan and Hartog. $\ddagger$ This chemist especially studied the ratio between boron bromide and silver, and also redetermined the percentage of water in crystallized borax. The latter work, which was purely preliminary, although carried out with great care, gave the following results, reduced to vacuum standards :

$\begin{array}{ccc}\mathrm{Na}_{2} \mathrm{~B}_{4} \mathrm{O}_{7} \cdot \mathrm{OOH}_{2} \mathrm{O} . & \mathrm{Na}_{2} \mathrm{~B}_{4} \mathrm{O}_{7} . & \text { Per cent. } \mathrm{H}_{2} \mathrm{O} . \\ 7.00667 & 3.69587 & 47.2069 \\ \mathrm{I} 2.95936 & 6.82560 & 47.3308 \\ 4.658 \mathrm{I} 2 & 2.45248 & 47.3504 \\ 4.47208 & 3.93956 & 47.2763 \\ 4.94504 & 2.60759 & 47.2686 \\ & & \text { Mean, } 47.2866, \pm .017 \mathrm{I}\end{array}$

Two sets of determinations were made with the bromide, which was prepared from boron and bromine directly, freed from excess of the latter by standing over mercury, and finally collected, after distillation, in small, weighed, glass bulbs. It was titrated with a solution of silver after all the ustual precautions. The first series of experiments was as follows, with $\mathrm{BBr}_{3}$ proportional to 100 parts of silver stated as the ratio:

* Poggend. Annalen, 8, x. 1826 .

† Journ. für Prakt. Chem., 47, 415. 1849.

$\ddagger$ Journ. Chem. Soc., 6r, 650. August, 1892 . 


\begin{tabular}{|c|c|c|}
\hline$B 5 \mathrm{r}_{5}$ & At & Retsin \\
\hline Lejexts & 1. Gevers & $77+4$ \\
\hline troveres: & $50-50 x$ & $x+5$ \\
\hline Sequiz: & Es setre? & $\pi+4$ \\
\hline angers & $S$ s sules & $72 .+53$ \\
\hline nessks & rea oltzis & $27+30$ \\
\hline
\end{tabular}

This series of ditat is reysurded by the editors as prelimimary, sed not

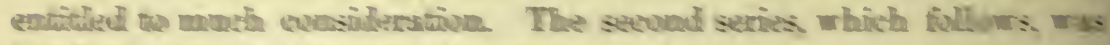

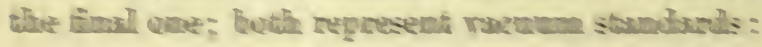

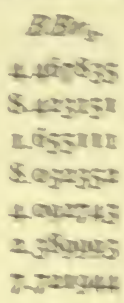

$$
B .5 x_{1}
$$

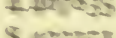$$
\text { Leisster }
$$$$
2 e^{2}=32
$$$$
\text { Levitis }
$$$$
\text { anderget }
$$

$$
\begin{aligned}
& \text { ty- } \\
& \text { sortaes } \\
& \text { rexlicuins } \\
& \text { 215255 } \\
& \text { 10. } 304000 \\
& \text { jusjay } \\
& \text { zususta } \\
& \text { equest }
\end{aligned}
$$

Retian

$\pi+15$

nitit

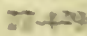

$n-426$

nuter

Thets

$2 \pi+60$

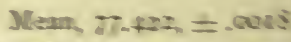

First series, $77 \cdot 4+42 \pm-\cos 5$

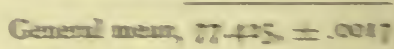

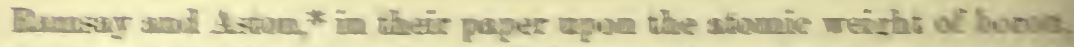

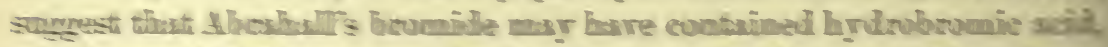

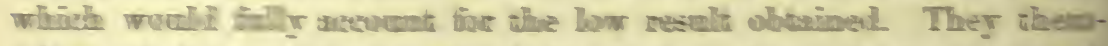
selires andogt two Ifstimet methouls, the finst one being the time-honosed

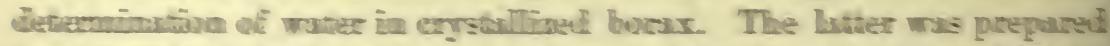

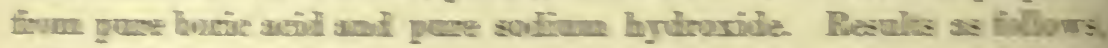

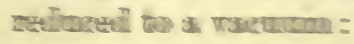

\begin{tabular}{|c|}
\hline $4-11009$ \\
\hline ft-11453 \\
\hline $4 \pi-3006$ \\
\hline$f 5-1 ;=12$ \\
\hline fil-1188 \\
\hline 4T-1865 \\
\hline $60-15=4$ \\
\hline
\end{tabular}

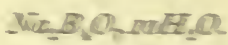

$$
\begin{aligned}
& \text { 1Cusanse: } \\
& \text { 5-jupatio } \\
& 4 \text { quafarso } \\
& 5700005
\end{aligned}
$$

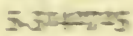

$$
\begin{aligned}
& \text { + anc ngas }
\end{aligned}
$$

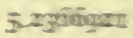$$
\operatorname{Rin} B_{1} Q
$$

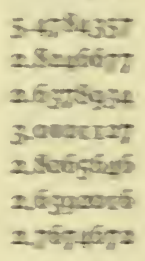

For cank $H_{2} \mathrm{O}$.

This we mat evonline with the pterivos deterninativns, thes:

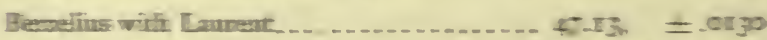

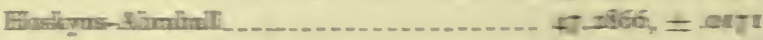

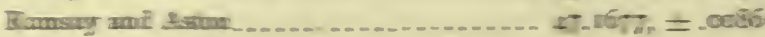

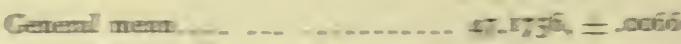




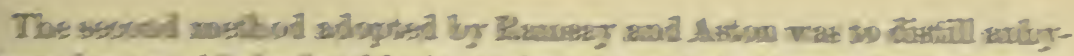

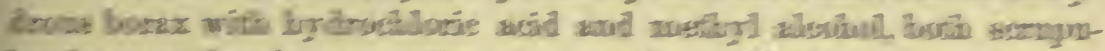

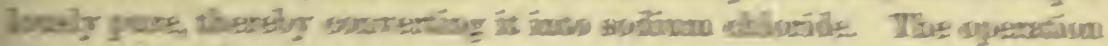

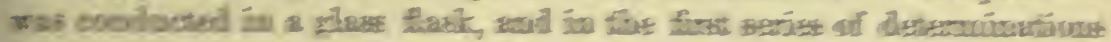

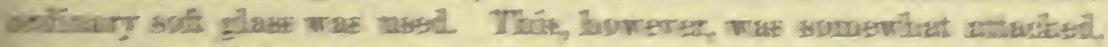

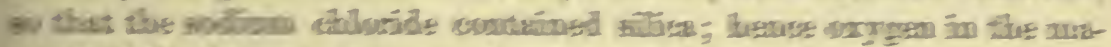

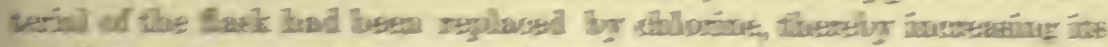

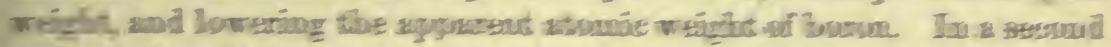

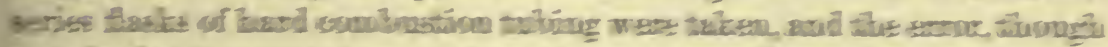

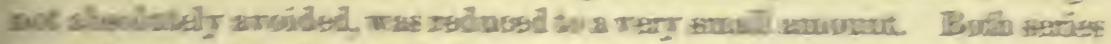

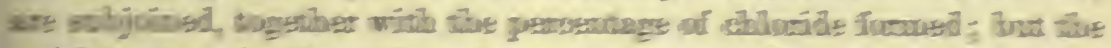

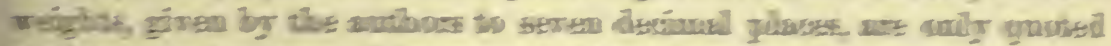

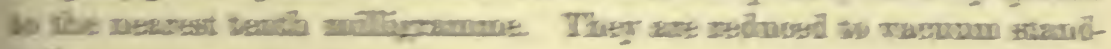
zente

Firs Seriar

\begin{tabular}{|c|c|c|}
\hline NEE, & $n=a$ & Par wat Woa \\
\hline anfibe & 2.598 & 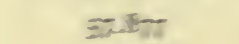 \\
\hline $5=0$ & $3 x-1$ & 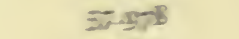 \\
\hline $3=346$ & uxts & selloge \\
\hline Lobie & $2=13$ & j5ioges \\
\hline 50520 & scaing & 52053 \\
\hline
\end{tabular}

Seand Sorieg.

\begin{tabular}{|c|c|c|}
\hline$N=3, a$ & $-\operatorname{ac} a$ & 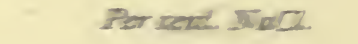 \\
\hline $5-5 \pm x$ & sagrid & Exgn \\
\hline L-7.506 & $=7700$ & serges \\
\hline L goper & $=2 x 30$ & Sengios \\
\hline aras & $=-3$ 3io & $50 y=13$ \\
\hline \multirow[t]{2}{*}{ 5. $\$ y^{5}$} & $\mathbb{Z}$ guste & 50 \\
\hline & & 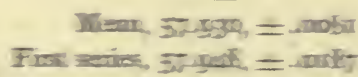 \\
\hline
\end{tabular}

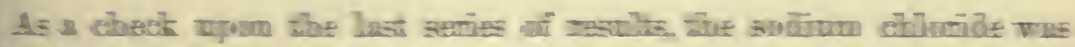

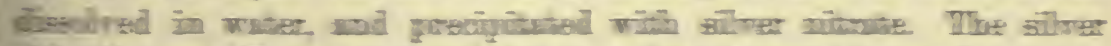

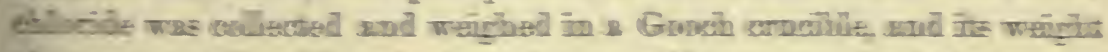

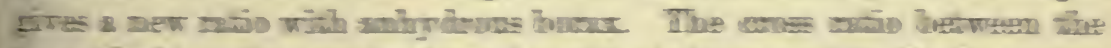

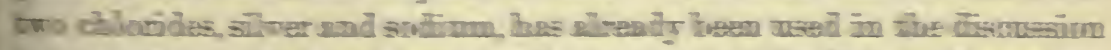

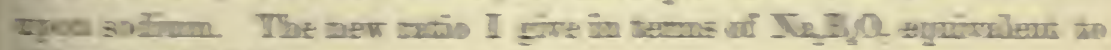
109 guate ad AgCl. 


$\begin{array}{ccc}\mathrm{Na}_{2} \mathrm{~B}_{4} \mathrm{O}_{7} . & \mathrm{AgCl} & \text { Ratio. } \\ 5.3118 & 7.5259 & 70.580 \\ 4.7806 & 6.7794 & 70.517 \\ 4.9907 & 7.0801 & 70.489 \\ 4.7231 & 6.6960 & 70.536 \\ 3.3138 & 4.6931 & 70.610 \\ & & \text { Mean, } 70.546, \pm .0146\end{array}$

Rimbach * based his determination of the atomic weight of boron upon the fact that boric acid is neutral to methyl orange, and that therefore it is possible to titrate a solution of borax directly with hydrochloric acid. His borax was prepared from carefully purified boric acid and sodium carbonate, and his hydrochloric acid was standardized by a series of precipitations and weighings as silver chloride. It contained 1.84983 per cent. of actual $\mathrm{HCl}$. The borax, dissolved in water, was titrated by means of a weight-burette. I give the weights found in the first and second columns of the following table, and in the third column, calculated by myself, the $\mathrm{HCl}$ proportional to 100 parts of crystallized borax. Rimbach himself computes the percentage of $\mathrm{Na}_{2} \mathrm{O}$ and thence the atomic weight of boron, but the ratio $\mathrm{Na}_{2} \mathrm{~B}_{4} \mathrm{O}_{7} \cdot 10 \mathrm{H}_{2} \mathrm{O}: 2 \mathrm{HCl}$ is the ratio actually determined.

$\mathrm{Na}_{2} \mathrm{~B}_{4} \mathrm{O}_{7} . \mathrm{IOH}_{2} \mathrm{O}$.
10.00214
15.32772
15.08870
10.12930
5.25732
15.04324
$15.0476 \mathrm{I}$
10.43409
5.04713

HCl Solution.

$$
\begin{array}{r}
103.1951 \\
158.1503 \\
155.727 \text { I } \\
104.5448 \\
54.2571 \\
155.2307 \\
155.2959 \\
107.6602 \\
52.0897
\end{array}
$$

Ratio.

19.0853

19.0864

I 9.0917

19.0922

19.0908

19.0883

19.0908

19.0868

19.0915

Mean, $\overline{19.0893} \pm .0006$.

Obviously, this error should be increased by the probable errors involved in standardizing the acid, but they are too small to be worth considering.

The following ratios are now available for boron:

(I) Percentage of water in $\mathrm{Na}_{2} \mathrm{~B}_{4} \mathrm{O}_{7} \cdot 10 \mathrm{I}_{2} \mathrm{O}, 47.1756, \pm .0066$

(2) $3 \mathrm{Ag}: \mathrm{BBr}_{3}:: 100: 77.425, \pm .0017$

(3) $\mathrm{Na}_{2} \mathrm{~B}_{4} \mathrm{O}_{7}: 2 \mathrm{NaCl}:: 100: 57.933, \pm .0074$

(4) $2 \mathrm{AgCl}: \mathrm{Na}_{2} \mathrm{~B}_{4} \mathrm{O}_{7}:: 100: 70.546, \pm .0146$

(5) $\mathrm{Na}_{2} \mathrm{~B}_{4} \mathrm{O}_{7} \cdot 10 \mathrm{H}_{2} \mathrm{O}: 2 \mathrm{HCl}:: 100: 19.0893, \pm .0006$ 
For reduction we have the antecedent atomic and molecular weights-

$$
\begin{array}{ll}
\mathrm{O}=15.879, \pm .0003 & \mathrm{Na}=22.88 \mathrm{r}, \pm .0046 \\
\mathrm{Ag}=107.108, \pm .003 \mathrm{I} & \mathrm{NaCl}=58.060, \pm .0017 \\
\mathrm{Cl}=35.179, \pm .0048 & \mathrm{AgCl}=142.287, \pm .0037 \\
\mathrm{Br}=79.344, \pm .0062 &
\end{array}
$$

For the molecular weight of $\mathrm{Na}_{2} \mathrm{~B}_{4} \mathrm{O}_{7}$ we now have-

$$
\begin{aligned}
& \text { From (1) .............. Na } \mathrm{Na}_{2} \mathrm{~B}_{4} \mathrm{O}_{7}=200.198, \pm .0377 \\
& \text { From (3).............. " " }=200.439, \pm .0263 \\
& \text { From }(4) \ldots \ldots \ldots \ldots \ldots \ldots \ldots \text { " " }=200.756, \pm .0419 \\
& \text { From }(5) \ldots \ldots \ldots \ldots \ldots \ldots \ldots \text { " " }=200.260, \pm .05 \mathrm{I} 8
\end{aligned}
$$

Hence $\mathrm{B}=10.876, \pm .0051$.

From ratio (2), $\mathrm{B}=10.753, \pm .0207$. The two values combined give-

$$
\mathrm{B}=10.863, \pm .0050 \text {. }
$$

Or, if $\mathrm{O}=16, \mathrm{~B}=10.946$.

If we consider ratios (1), (3), (4), and (5) separately, they give the following values for $B$ :

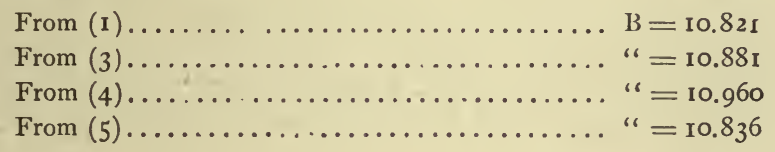

Of these, the second and third involve the data from which, in a previous section of this work, the ratio $\mathrm{NaCl}: \mathrm{AgCl}$ was computed. In using that ratio for measuring the molecular weights of its component molecules, discordance was noted, which again appears here. The chief uncertainty in it seems to be connected with ratio (4), which is therefore entitled to comparatively little credence, although its rejection is not necessary at this point. In ratio (2), Abrahall's determination, the high probable error of $\mathrm{B}$ is due to the also high probable error of $3 \mathrm{Br}$, and it is quite likely that the result is undervalued. The general mean, $\mathrm{B}=$ $10.863, \pm .0050$, however, can hardly be much out of the way. It is certainly more probable than any one of the individual values. 


\section{ALUMINUM.}

The atomic weight of aluminum has been determined by Berzelius, Mather, Tissier, Dumas, Isnard, Terreil, Mallet, and Baubigny. The early calculations of Davy and of Thomson we may properly disregard.

Berzelius'* determination rests upon a single experiment. He ignited 10 grammes of dry aluminum sulphate, $\mathrm{Al}_{2}\left(\mathrm{SO}_{4}\right)_{3}$, and obtained 2.9934 grammes of $\mathrm{Al}_{2} \mathrm{O}_{3}$ as residue.

Hence $\mathrm{Al}=27.103$.

In $1835 \uparrow$ Mather published a single analysis of aluminum chloride, from which he sought to fix the atomic weight of the metal. $0.646 \mathrm{grm}$. of $\mathrm{AlCl}_{3}$ gave him 2.056 of $\mathrm{AgCl}$ and 0.2975 of $\mathrm{Al}_{2} \mathrm{O}_{3}$. These figures give worthless values for $\mathrm{Al}$, and are included here only for the sake of completeness. From the ratio between $\mathrm{AgCl}$ and $\mathrm{AlCl}_{3}, \mathrm{Al}=28.584$.

Tissier's $\ddagger$ determination, also resting on a single experiment, appeared in 1858. Metallic aluminum, containing .135 per cent. of sodium, was dissolved in hydrochloric acid. The solution was evaporated with nitric acid to expel all chlorine, and the residue was strongly ignited until only alumina remained. $1.935 \mathrm{grm}$. of $\mathrm{Al}$ gave $3.645 \mathrm{grm}$. of $\mathrm{Al}_{2} \mathrm{O}_{3}$. If we correct for the trace of sodium in the aluminum, we have $\mathrm{Al}=26.930$.

Essentially the same method of determination was adopted by Isnard, $\S$ who, although not next in chronological order, may fittingly be mentioned here. He found that $9 \mathrm{grm}$. of aluminum gave $17 \mathrm{grm}$. of $\mathrm{Al}_{2} \mathrm{O}_{3}$. Hence $\mathrm{Al}=26.8$

In 1858 Dumas, || in connection with his celebrated revision of the atomic weights, made seven experiments with aluminum chloride. The material was prepared in quantity, sublimed over iron filings, and finally resublimed from metallic aluminum. Each sample used was collected in a small glass tube, after sublimation from aluminum in a stream of dry hydrogen, and hermetically enclosed. Having been weighed in the tube, it was dissolved in water, and the quantity of silver necessary for precipitating the chlorine was determined. Reducing to a common standard, his weighings give the quantities of $\mathrm{AlCl}_{3}$ stated in the third column, as proportional to 100 parts of silver :

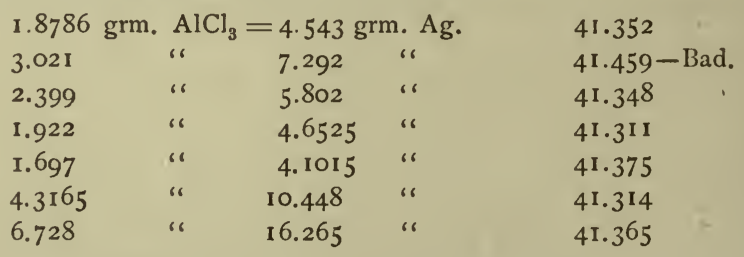

* Poggend. Annal., 8, 177 .

† Silliman's Amer. Journ., 27, 24r.

$\ddagger$ Compt. Rend., 46, 1105 .

\& Compt. Rend., 66, 508 . I868.

\|Ann. Chim. Phys. (3), 55, 151. Ann. Chem. Pharm., Ir3, 26. 
In the second experiment the $\mathrm{AlCl}_{3}$ contained traces of iron. Rejecting this experinent, the remaining six give a mean of $41.344, \pm .007$. These data give a value for $\mathrm{Al}$ approximating to 27.5 , and were for many years regarded as satisfactory. It now seems probable that the chloride contained traces of an oxy-compound, which would tend to raise the atomic weight.

In 1879 Terreil * published a new determination of the atomic weight under consideration, based upon a direct comparison of the metal with hydrogen. Metallic aluminum, contained in a tube of hard glass, was heated strongly in a current of dry hydrochloric acid. Hydrogen was set free, and was collected over a strong solution of caustic potash. $0.410 \mathrm{grm}$. of aluminum thus were found equivalent to $508.2 \mathrm{cc}$., or .045671 grm. of hydrogen. Hence $\mathrm{Al}=26.932$.

About a year after Terreil's determination appeared, the lower value for aluminum was thoroughly confirmed by J.W. Mallet. $\dagger$ After giving a full résumé of the work done by others, exclusive of Isnard, the author describes his own experiments, which may be summarized as follows:

Four methods of determination were employed, each one simple and direct, and at the same time independent of the others. First, pure ammonia alum was calcined, and the residue of aluminum oxide was estimated. Second, aluminum bromide was titrated with a standard solution of silver. Third, metallic aluminum was attacked by caustic soda, and the hydrogen evolved was measured. Fourth, hydrogen was set free by aluminum, and weighed as water. Every weight was carefully verified, the verification being based upon the direct comparison, by J. E. Hilgard, of a kilogramme weight with the standard kilogramme at Washington. The specific gravity of each piece was determined, and also of all materials and vessels used in the weighings. During each weighing both barometer and thermometer were observed, so that every result represents a real weight in vacuo.

The ammonium alum used in the first series of experiments was specially prepared, and was absolutely free from ascertainable impurities. The salt was found, however, to lose traces of water at ordinary temperatures-a circumstance which tended towards a slight elevation of the apparent atomic weight of aluminum as calculated from the weighings. Two sets of experiments were made with the alum; one upon a sample air-dried for two hours at $21^{\circ}-25^{\circ}$, the other upon material dried for twenty-four hours at $19^{\circ}-26^{\circ}$. These sets, marked $\mathrm{A}$ and $B$ respectively, differ slightly, B being the less trustworthy of the two, judged from a chemical standpoint. Mathematically it is the better of the two. Calcination was effected with a great variety of precautions, concerning which the original memoir must be consulted. 'To Mallet's weighings $\mathrm{I}$ append the percentages of $\mathrm{Al}_{2} \mathrm{O}_{3}$ deduced from them : 


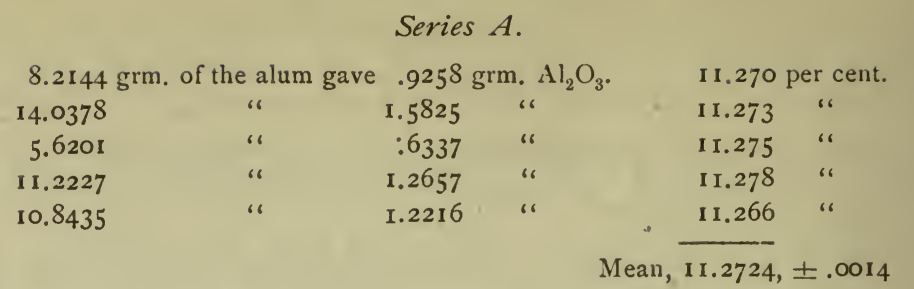

Series $B$.

I2. $1023 \mathrm{grm}$. of the alum gave $\mathbf{1} .3660 \mathrm{grm} . \mathrm{Al}_{2} \mathrm{O}_{3}$.

I 0.4544

6.7962

$8.560 \mathrm{I}$

4.8992

I.1796 " "

.7670 "

.9654 " 6

.5528 "

II. 287 per cent.

II. 283 "

II. 286 " "

11.278 "

II. 283 "

Mean, 1 I .2834, $\pm .001 \mathrm{II}$

Combined, these series give a general mean of $11.2793, \pm .0008$. Hence $\mathrm{Al}=26.952$.

The aluminum bromide used in the second series of experiments was prepared by the direct action of bromine upon the metal. The product was repeatedly distilled, the earlier portions of each distillate being rejected, until a constant boiling point of $263 .{ }^{\circ} 3$ at $747 \mathrm{~mm}$. pressure was noted. The last distillation was effected in an atmosphere of pure nitrogen, in order to avoid the possible formation of oxide or oxy-bromide of aluminum; and the distillate was collected in three portions, which proved to be sensibly identical. The individual samples of bromide were collected in thin glass tubes, which were hermetically sealed after nearly filling. For the titration pure silver was prepared, and after fusion upon charcoal it was heated in a Sprengel vacuum in order to eliminate occluded gases. This silver was dissolved in specially purified nitric acid, the latter but very slightly in excess. The aluminum bromide, weighed in the sealed tube, was dissolved in water, precautions being taken to avoid any loss by splashing or fuming which might result from the violence of the action. To the solution thus obtained the silver solution was added, the silver being something less than a decigramme in deficiency. The remaining amount of silver needed to complete the precipitation of the bromine was added from a burette, in the form of a standard solution containing one milligramme of metal to each cubic centimetre. The final results were as follows, the figures in the third column representing the quantities of bromide proportional to 100 parts of silver. Series A is from the first portion of the last distillate of $\mathrm{AlBr}_{3}$; series $\mathrm{B}$ from the second portion, and series $\mathrm{C}$ from the third portion:

Series $A$.

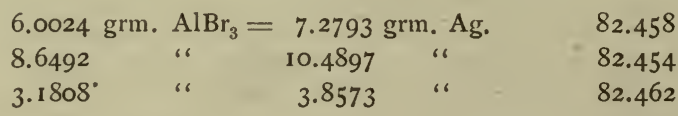


Series $B$.

$\begin{array}{rlrll}6.9617 & \text { grm. } & \mathrm{AlBr}_{3}=8.4429 & \text { grm. Ag. } & 82.456 \\ 11.2041 & \text { “ } & 13.5897 & \text { “ } & 82.445 \\ 3.7621 & \text { “ } & 4.5624 & \text { “ } & 82.459 \\ 5.2842 & \text { “ } & 6.4085 & \text { “ } & 82.456 \\ 9.7338 & \text { “ } & 11.8047 & \text { “ } & 82.457\end{array}$

Series $C$.

9.3515 grm. $\mathrm{AlBr}_{3}=11.3424 \mathrm{grm} . \mathrm{Ag}$.

82.447

4.4426

5.3877

82.458

5.2750

6.3975

82.454

Mean, $\overline{82.455}, \pm .001$

Hence $\mathrm{Al}=26.916$.

The experiments to determine the amount of hydrogen evolved by the action of caustic soda upon metallic aluminum were conducted with pure metal, specially prepared, and with caústic soda made from sodium. The soda solution was so strong as to scarcely lose a perceptible amount of water by the passage through it of a dry gas at ordinary temperature. As the details of the experiments are somewhat complex, the original memoir must be consulted for them. The following results were obtained, the weight of the hydrogen being calculated from the volume, reckoned at .089872 gramme per litre.

$\begin{array}{cccc}\text { Wt. Al. } & \text { Vol. H. } & \text { Wt. H. } & \text { At. Wt. } \\ .3697 & 458.8 & .041234 & 26.898 \\ .3769 & 467.9 & .042051 & 26.889 \\ .3620 & 449.1 & .040362 & 26.907 \\ .7579 & 941.5 & .084614 & 26.872 \\ .7314 & 907.9 & .081595 & 26.891 \\ .7541 & 936.4 & .084156 & 26.882 \\ & & & \text { Mean, } 26.890, \pm .0034\end{array}$

The closing series of experiments was made with larger quantities of aluminum than were used in the foregoing set. The hydrogen, evolved by the action of the caustic alkali, was dried by passing it through two drying tubes containing pumice stone and sulphuric acid, and two others containing asbestos and phosphorus pentoxide. Thence it passed through a combustion tube containing copper oxide heated to redness. A stream of dry nitrogen was employed to sweep the last traces of hydrogen into the combustion tube, and dry air was afterwards passed through the entire apparatus to reoxidize the surface of reduced copper, and to prevent the retention of occluded hydrogen. The water formed by the oxidation of the hydrogen was collected in three drying tubes. 
The results obtained were as follows. The third column gives the amount of water formed from 10 grammes of aluminum.

$\begin{array}{lllll}2.1704 \text { grm. Al gave 2.166 } & \text { grm. } \mathrm{H}_{2} \mathrm{O} . & 9.9802 \\ 2.9355 & \text { " } & 2.9292 & \text { " } & 9.9785 \\ 5.2632 & \text { " } & 5.2562 & \text { " } & 9.9867 \\ & & & & \text { Mean, } 9.9818, \pm .0017\end{array}$

Hence $\mathrm{Al}=26.867$.

From the last two series of experiments an independent value for the atomic weight of oxygen may be calculated. It becomes $\mathrm{O}=15.895$. The closeness of this figure to some of the best determinations affords a good indication of the accuracy of Mallet's work.

In connection with Mallet's work it is worth noting that Torrey* published a series of measurements of the $\mathrm{H}: \mathrm{Al}$ ratio, representing determinations made under his direction by elementary students. These measurements are thirteen in number, and calculated with Regnault's old value for the weight of hydrogen, range from 26.661 to 27.360 , or in mean, $27.049, \pm .323$. Corrected by the latest value for the weight of $\mathrm{H}$, this mean becomes 26.967. The result, of course, has only confirmatory significance.

By Baubigny $\dagger$ we have only two determinations, based upon the calcination of anhydrous aluminum sulphate, $\mathrm{Al}_{2}\left(\mathrm{SO}_{4}\right)_{3}$.

$$
\begin{array}{llll}
3.6745 & \mathrm{grm} \text {. salt gave } \mathrm{I} .0965 & \mathrm{Al}_{2} \mathrm{O}_{3} \text {. } \\
2.539 & .7572
\end{array}
$$

\author{
29.841 per cent. \\ 29.823 \\ Mean, $\overline{29.832}, \pm .006 \mathrm{I}$
}

Hence $\mathrm{Al}=26.858$.

It is clear that the single determinations of Berzelius, Mather, Tissier, Isnard, and Terreil may now be safely left out of account, for the reason that none of them could affect appreciably the final value for Al. The ratios to consider are as follows:

(I.) $3 \mathrm{Ag}: \mathrm{AlCl}_{3}:: 100: 4.1 \cdot 344, \pm .0070$

(2.) Percentage of $\mathrm{Al}_{2} \mathrm{O}_{3}$ in ammonium alum, II.2793, \pm .0008

(3.) $3 \mathrm{Ag}: \mathrm{AlBr}_{3}:: 100: 82.455, \pm .0010$

(4.) $\mathrm{H}: \mathrm{Al}:: \mathrm{I}: 26.890, \pm .0034$

(5.) $\mathrm{Al}_{2}: 3 \mathrm{H}_{2} \mathrm{O}::$ : $10: 9.9818, \pm .0017$

(6.) Percentage of $\mathrm{Al}_{2} \mathrm{O}_{3}$ in $\mathrm{Al}_{2}\left(\mathrm{SO}_{4}\right)_{3}, 29.832, \pm .006 \mathrm{I}$

The antecedent values are-

$$
\begin{array}{ll}
\mathrm{O}=15.879, \pm .0003 & \mathrm{Br}=79.344, \pm .0062 \\
\mathrm{Ag}=107.108, \pm .003 \mathrm{I} & \mathrm{N}=13.935, \pm .002 \mathrm{I} \\
\mathrm{Cl}=35.179, \pm .0048 & \mathrm{~S}=31.828, \pm .0015
\end{array}
$$

* Am. Chem. Journ., I0, 74. 1888.

† Compt. Rend., 97, 1369. 1883. 
Hence for aluminum we have-

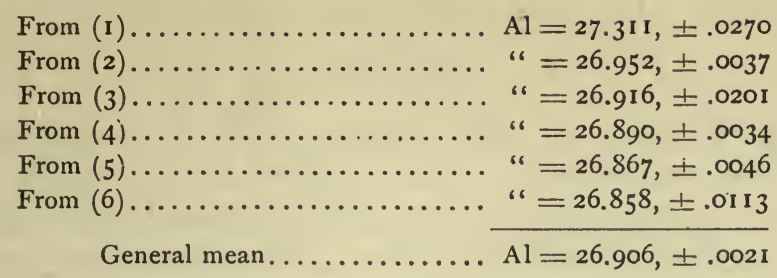

With $\mathrm{O}=16, \mathrm{Al}=27.111$. The rejection of Dumas' data only lowers the result to 26.903 .

\section{GALLIUM.}

Gallium has been so recently discovered, and obtained in such small quantities, that its atomic weight has not as yet been determined with much precision. The following data were fixed by the discoverer, Lecoq de Boisbaudran :*

3.1044 grammes gallium ammonium alum, upon ignition, left .5885 grm. $\mathrm{Ga}_{2} \mathrm{O}_{3}$.

Hence $\mathrm{Ga}=69.595$. If $\mathrm{O}=16, \mathrm{Ga}=70.125$.

.4481 grammes gallium, converted into nitrate and ignited, gave .6024 grm. $\mathrm{Ga}_{2} \mathrm{O}_{3}$.

Hence $\mathrm{Ga}=69.171$. If $\mathrm{O}=16, \mathrm{Ga}=69.698$.

These values, assigned equal weight, give these means :

With $\mathrm{H}=\mathrm{I}, \mathrm{Ga}=69.383 . \quad$ With $\mathrm{O}=\mathrm{I} 6, \mathrm{Ga}=69.912$ 


\section{INDIUM.}

Reich and Richter, the discoverers of indium, were also the first to determine its atomic weight.* They dissolved weighed quantities of the metal in nitric acid, precipitated the solution with ammonia, ignited the precipitate, and ascertained its weight. Two experiments were made, as follows:

$.5 \mathrm{I} 35 \mathrm{grm}$. indium gave $.6243 \mathrm{grm}$. $\mathrm{In}_{2} \mathrm{O}_{3}$.

.699 .8515

Hence, in mean, In $=110.61$, if $\mathrm{O}=16$; a value known now to be too low.

An unweighed quantity of fresh, moist indium sulphide was also dissolved in nitric acid, yielding, on precipitation,

$.2 \mathrm{IO} 5 \mathrm{grm} . \mathrm{In}_{2} \mathrm{O}_{3}$ and $.542 \mathrm{grm} . \mathrm{BaSO}_{4}$.

Hence, with $\mathrm{BaSO}_{4}=233.505, \mathrm{In}=112.03$; also too low.

Soon after the publication of Reich and Richter's paper the subject was taken up by Winkler. $\dagger$ He dissolved indium in nitric acid, evaporated to dryness, ignited the residue, and weighed the oxide thus obtained.

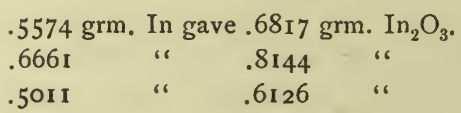

Hence, in mean, if $\mathrm{O}=16$, In $=107.76$; a result even lower than the values already cited.

In a later paper by Winkler $\$$ better results were obtained. Two methods were employed. First, metallic indium was placed in a solution of pure, neutral, sodio-auric chloride, and the amount of gold precipitated was weighed. I give the weighings and, in a third column, the amount of indium proportional to 100 parts of gold :

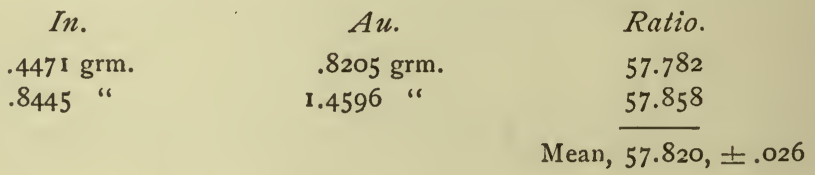

Hence, if $\mathrm{Au}=195.743, \pm .0049, \mathrm{In}=113.179, \pm .0517$.

Winkler also repeated his earlier process, converting indium into oxide by solution in nitric acid and ignition of the residue. An ad-

* Journ. für Prakt. Chem., 92, 484. 
ditional experiment, the third as given below, was made after the method of Reich and Richter. The third column gives the percentage of In in $\mathrm{In}_{2} \mathrm{O}_{3}$ :

$$
\begin{aligned}
& \text { I. } 124 \mathrm{grm} \text {. In gave } 1.36 \mathrm{I} 6 \mathrm{grm} . \mathrm{In}_{2} \mathrm{O}_{3} \text {. Per cent., } 82.550
\end{aligned}
$$

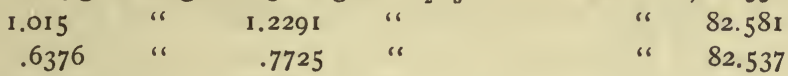

These figures were confirmed by a single experiment of Bunsen's,* published simultaneously with the specific heat determinations which showed that the oxide of indium was $\operatorname{In}_{2} \mathrm{O}_{3}$, and not $\mathrm{InO}$, as had been previously supposed :

I.0592 grm. In gave 1.2825 grm. $\mathrm{In}_{2} \mathrm{O}_{3}$. Per cent. In, 82.589

For convenience we may add this figure in with Winkler's series, which gives us a mean percentage of $\mathrm{In}$ in $\mathrm{In}_{2} \mathrm{O}_{3}$ of $82.564, \pm .0082$. Hence, if $\mathrm{O}=15.879, \pm .0003, \mathrm{In}=112.787, \pm .0542$.

Combining both values, we have-

From gold series............. In $=113.179, \pm .0517$

From oxide series........... " $=112.787, \pm .0542$

General mean........... In $=112.992, \pm .0374$

If $\mathrm{O}=16, \mathrm{In}=113.853$.

* Poggend. Annal., I4I, 28. 


\section{THALLIUM.}

The atomic weight of this interesting metal has been fixed by the researches of Lamy, Werther, Hebberling, Crookes, and Lepierre.

Lamy and Hebberling investigated the chloride and sulphate; Werther studied the iodide; Crookes' experiments involved the synthesis of the nitrate. Lepierre's work is still more recent, and is based upon sereral compounds.

Lamy* gives the results of one analysis of thallium sulphate and three of thallium chloride. 3.423 grammes $\mathrm{Tl}_{2} \mathrm{SO}_{4}$ gave 1.578 grm. $\mathrm{BaSO}_{4}$; whence 100 parts of the latter are equivalent to 216.920 of the former. In the thallium chloride the chlorine was estimated as silver chloride. The following results were obtained. In the third column I give the amount of $\mathrm{TlCl}$ proportional to 100 parts of $\mathrm{AgCl}$ :

$$
\begin{aligned}
& 3.912 \mathrm{grm} \text {. TlCl gave } 2.346 \mathrm{grm} \text {. } \mathrm{AgCl} \text {. } \quad 166.75^{2} \\
& 3.000 \text { " } \\
& 3.912 \text { " } 2.336 \text { " } 207.466 \\
& \text { Mean, } \overline{\mathrm{I} 66.915}, \pm .1905
\end{aligned}
$$

Hebberling's $\dagger$ work resembles that of Lamy. Reducing his weighings to the standards adopted above, we have from his sulphate series, as equivalent to 100 parts of $\mathrm{BaSO}_{4}$, the amounts of $\mathrm{Tl}_{2} \mathrm{SO}_{4}$ given in the third column :

$$
\begin{array}{llllr}
1.4195 \mathrm{grm} . \mathrm{Tl}_{2} \mathrm{SO}_{4} \text { gave } .6534 \mathrm{grm} . \mathrm{BaSO}_{4} . & 217.248 \\
1.1924 & \text { “ } & .5507 & \text { " } & 2 \mathrm{I} 6.524 \\
.8560 & \text { " } & .3957 & & 2 \mathrm{I} 6.325 \\
& & & & \text { Mean, } 216.699
\end{array}
$$

Including Lamy's single result as of equal weight, we get a mean of $216.754, \pm .1387$.

From the chloride series we have these results, with the ratio stated as usual:

$$
\begin{aligned}
& .2984 \mathrm{grm} \text {. TlCl gave .1791 grm. AgCl. } 166.6 \text { I I } \\
& .5452 \text { " } .3278 \text { " } 166.32 \mathrm{I} \\
& \text { Mean, } \overline{166,465}, \pm .097
\end{aligned}
$$

Lamy's mean was $166.915, \pm .1905$. Both means combined give a general mean of $166.555, \pm .0865$.

Werther's $\ddagger$ determinations of iodine in thallium iodide were made by two methods. In the first series TII was decomposed by zinc and potassium hydroxide, and in the filtrate the iodine was estimated as AgI. 
One hundred parts of $\mathrm{AgI}$ correspond to the amounts of TlI given in the last column :

$\begin{array}{cccc}.720 & \text { grm. TII gave } & .5 \mathrm{I} & \text { grm. AgI. } \\ 2.072 & \text { " } & 1.472 & \text { “ } \\ .960 & \text { “ } & .679 & \text { “ } \\ .385 & \text { “ } & .273 & \text { “ } \\ 1.068 & \text { " } & .759 & \text { " }\end{array}$

141.176
140.761
141.384
141.026
140.711
Mean, $141.012, \pm .085$

In the second series the thallium iodide was decomposed by ammonia in presence of silver nitrate, and the resulting AgI was weighed. Expressed according to the foregoing standard, the results are as follows :

$$
\begin{aligned}
& \text { I. } 375 \mathrm{grm} \text {. TII gave } .978 \mathrm{grm} \text {. AgI. } \\
& \text { I.540 " } 1.095 \text { " } \\
& \text { I.380 " . } 981 \text { " } \\
& \text { Ratio, } 140.593 \\
& \text { “ } 140.639 \\
& \text { “ } 140.673 \\
& \text { Mean, } \overline{140.635}, \pm .016
\end{aligned}
$$

General mean of both series, $140.648, \pm .016$.

In 1873 Crookes,* the discoverer of thallium, published his final determination of its atomic weight. His method was to effect the synthesis of thallium nitrate from weighed quantities of absolutely pure thallium. No precaution necessary to ensure purity of materials was neglected; the. balances were constructed especially for the research; the weights were accurately tested and all their errors ascertained; weighings were made partly in air and partly in vacuo, but all were reduced to absolute standards; and unusually large quantities of thallium were employed in each experiment. In short, no effort was spared to attain as nearly as possible absolute precision of results. The details of the investigation are too

\begin{tabular}{|c|c|c|c|}
\hline $\begin{array}{l}\text { Thallium. } \\
497.972995\end{array}$ & $\begin{array}{c}\mathrm{TlNO}_{3}+\text { Glass. } \\
\quad \text { I121.851852 }\end{array}$ & $\begin{array}{l}\text { Glass Vessel. } \\
472.5573^{19}\end{array}$ & $\begin{array}{r}\text { Ratio. } \\
\text { I30. } 3875\end{array}$ \\
\hline 293. 193507 & I I I I. 387014 & 729.082713 & I $30.393^{\circ}$ \\
\hline $288 \quad 562777$ & 971.214142 & 594.949719 & I 30.3926 \\
\hline 324.963740 & I 142.569408 & 718.849078 & I 30.3900 \\
\hline 183.790232 & 1005.779897 & $766.133^{8} 31$ & I 30.3912 \\
\hline 190.842532 & 997.334615 & 748.491271 & 130.3920 \\
\hline 195.544324 & 1022. I 76679 & 767.203451 & 130.3915 \\
\hline 201.816345 & IOI 3.480135 & 750.332401 & I $30.3^{897}$ \\
\hline 295.683523 & 1153.947672 & 768.403621 & 130.3908 \\
\hline 299.203036 & I I 59.870052 & 769.734201 & 130.3917 \\
\hline
\end{tabular}
voluminous, however, to be cited here; the reader who wishes to become familiar with them must consult the original memoir. Suffice it to say that the research is a model which other chemists will do well to copy.

The results of ten experiments by Professor Crookes may be stated as follows. In a final column I give the quantity of nitrate producible from 100 parts of thallium. The weights given are in grains : 
Lepierre's* determinations were published in 1893, and represented several distinct methods. First, thallous sulphate was subjected to electrolysis in presence of an excess of ammonium oxalate, the reduced metal being dried and weighed in an atmosphere of hydrogen. The corrected weights, etc., are as follows:

$$
\begin{aligned}
& \text { I.8935 grm. } \mathrm{Tl}_{2} \mathrm{SO}_{4} \text { gave } 1.5327 \mathrm{Tl} \text {. } 80.945 \text { per cent. } \\
& 2.7243 \text { " } 2.2055 \text { " } 20.957 \text { " } \\
& 2.8112 \quad \text { " } 2.2759 \text { " } 80.958 \text { " } \\
& \text { Mean, } 80.953, \pm .0030
\end{aligned}
$$

Secondly, weighed quantities of crystallized thallic oxide were converted into thallous sulphate by means of sulphurous acid, and the solution was then subjected to electrolysis, as in the preceding series.

$$
\begin{aligned}
& 3.22 \mathrm{I} 6 \mathrm{grm} . \mathrm{Tl}_{2} \mathrm{O}_{3} \text { gave } 2.8829 \mathrm{Tl} \text {. } \quad 89.487 \text { per cent. } \\
& 2.5417 \text { " } 2.2742 \text { “ } \\
& 89.475 \text { " } \\
& \text { Mean, } \overline{89.48 \mathrm{r}}, \pm .0040
\end{aligned}
$$

In the third set of experiments a definite amount of thallous sulphate or nitrate was fused in a polished silver crucible with ten times its weight of absolutely pure caustic potash. Thallic oxide was thus formed, which, with various precautions, was washed with water and alcohol, and finally weighed in the original crucible. One experiment with the nitrate gave-

$$
2.759 \mathrm{I} \text { grm. } \mathrm{TINO}_{3} \text { yields } 2.3649 \mathrm{Tl}_{2} \mathrm{O}_{3} \text {. } \quad 85.7 \mathrm{I} 3 \text { per cent. }
$$

Two experiments were made with the sulphate, as follows :

$$
\begin{array}{lll}
\text { 3. IOI } 2 \text { grm. } \mathrm{Tl}_{2} \mathrm{SO}_{4} \text { gave } 2.8056 \mathrm{Tl}_{2} \mathrm{O}_{3} \text {. } & 90.468 \text { per cent. } \\
2.3478 & 2.1239 \text { " } & \frac{90.463}{\text { " }} \\
& & \text { Mean, } 90.465, \pm .0020
\end{array}
$$

Finally, crystallized thallic oxide was reduced by heat in a stream of hydrogen, and the water so formed was collected and weighed.

$$
\begin{aligned}
& 2.7873 \mathrm{grm} \text {. } \mathrm{Tl}_{2} \mathrm{O}_{3} \text { gave } .33 \text { OI } \mathrm{H}_{2} \mathrm{O} \text {. } \quad \text { II.843 per cent. } \\
& 3.9871 \text { " " . } 4716 \text { " } \\
& 4.0213 \text { " . } 476 \mathrm{r} \text { “ } \\
& \text { Mean, } \overline{11.837}, \pm .0029
\end{aligned}
$$

In a supplementary note $\dagger$ Lepierre states that his weights were all reduced to vacuum standards.

Some work by Wells and Penfield, $₫$ incidentally involving a determination of atomic weight, but primarily intended for another purpose, may also be taken into account. Their question was as to the constancy of thallium itself. The nitrate was repeatedly crystallized, and the last crystallization, with the mother liquor representing the opposite end of

* Bull. Soc. Chim. (3), 9, 166.

† Bull. Soc. Chim. (3), II, 423. 1894.

† Amer. Journ. Sci. (3), 47, 466. I894. 
the series, were both converted into chloride. In the latter the chlorine was estimated as silver chloride, which was weighed on a Gooch filter, with the results given below, which are sensibly identical. The $\mathrm{TlCl}$ equivalent to 100 parts of $\mathrm{AgCl}$ is stated in the last column.

$$
\begin{aligned}
& \text { TlCl. } \quad \mathrm{AgCl} \text {. Ratio. }
\end{aligned}
$$

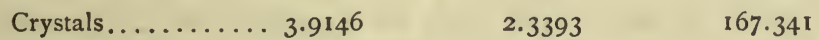

$$
\begin{aligned}
& \begin{array}{llll}
\text { Mother liquor........ } & 3.3415 & \mathbf{1} .9968 & \mathbf{1 6 7 . 3 4 3}
\end{array} \\
& \text { Mean, } \overline{167.342}
\end{aligned}
$$

The general mean of Lamy's and Hebberling's determinations of this ratio gave $166.555, \pm .0865$. If we arbitrarily assign Wells and Penfield's mean equal weight with that, we get a new general mean of $166.948, \pm .0610$.

The ratios to be considered are now as follows:
(r.) $\mathrm{BaSO}_{4}: \mathrm{Tl}_{2} \mathrm{SO}_{4}:: 100: 216.754, \pm .1387$
(2.) $\mathrm{AgCl}: / \mathrm{TlCl}:: 100: 166.948, \pm .0610$
(3.) AgI : TII : : $100: 140.648, \pm .016$
(4.) $\mathrm{Tl}: \mathrm{TlNO}_{3}:: \mathrm{I00}: \mathrm{I} 30.39 \mathrm{r}, \pm .00034$
(5.) $\mathrm{Tl}_{2} \mathrm{SO}_{4}: \mathrm{Tl}_{2}:: 100: 80.953, \pm .0030$
(6.) $\mathrm{Tl}_{2} \mathrm{O}_{3}: \mathrm{Tl}_{2}:: 100: 89.48 \mathrm{I}, \pm .0040$
(7.) $2 \mathrm{TlNO}_{3}: \mathrm{Tl}_{2} \mathrm{O}_{3}:: 100: 85.7 \mathrm{I} 3$
(8.) $\mathrm{Tl}_{2} \mathrm{SO}_{4}: \mathrm{Tl}_{2} \mathrm{O}_{3}:: 100: 90.465, \pm .0020$
(9.) $\mathrm{Tl}_{2} \mathrm{O}_{3}: 3 \mathrm{H}_{2} \mathrm{O}:: 100:$ I I $.837, \pm .0029$

And the antecedent data are these :

$$
\begin{array}{ll}
\mathrm{O}=15.879, \pm .0003 & \mathrm{~N}=\mathrm{I} 3.935, \pm .0021 \\
\mathrm{Ag}=107.108, \pm .003 \mathrm{I} & \mathrm{S}=3 \mathrm{I} .828, \pm .0015 \\
\mathrm{Cl}=35.179, \pm .0048 & \mathrm{AgCl}=142.287, \pm .0037 \\
\mathrm{I}=125.888, \pm .0069 & \mathrm{AgI}=232.996, \pm .0062
\end{array}
$$

Ratio number seven rests upon a single experiment, and the atomic weight of thallium derived from it must therefore be arbitrarily weighted. It has been assumed, therefore, that its probable error is the same as that from number eight. Taking this much for granted, we have nine values for thallium, as given below :

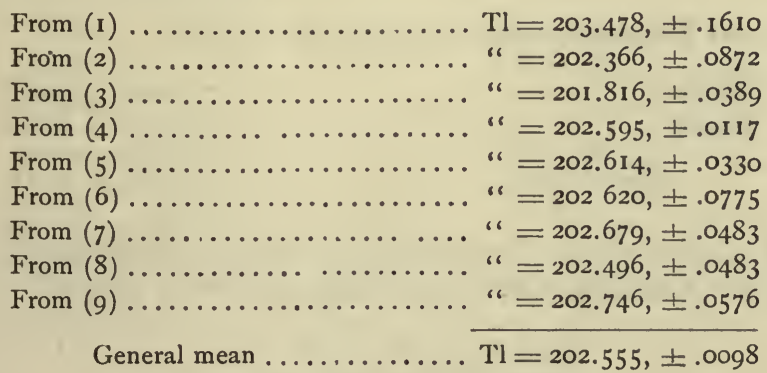

If $\mathrm{O}=16, \mathrm{Tl}=204.098$. 
If we reject the first three values, retaining only those due to the experiments of Crookes and Lepierre, we have-

$$
\mathrm{Tl}=202.605, \pm .0103
$$

If $\mathrm{O}=16$, this becomes 204.149. This mean exceeds Crookes' determination only by 0.01 , and may be regarded as fairly satisfactory. Crookes' ratio evidently outweighs all the others.

\section{SILICON.}

Although Berzelius* attempted to ascertain the atomic weight of silicon, first by converting pure $\mathrm{Si}$ into $\mathrm{SiO}_{2}$, and later from the analysis of $\mathrm{BaSiF}_{6}$, his results were not satisfactory. We need consider only the work of Pelouze, Schiel, Dumas, and Thorpe and Young.

Pelouze, $\uparrow$ experimenting upon silicon tetrachloride, employed his usual method of titration with a solution containing a known weight of silver. One hundred parts of $\mathrm{Ag}$ gave the following equivalencies of $\mathrm{SiCl}_{4}$ :

39.4325

39.4570

Mean, $39.4447, \pm .0083$

Essentially the same method was adopted by Dumas. $\ddagger$ Pure $\mathrm{SiCl}_{4}$ was weighed in a sealed glass bulb, then decomposed by water, and titrated. The results for $100 \mathrm{Ag}$ are given in the third column :

$$
\begin{aligned}
& 2.899 \text { grm. } \mathrm{SiCl}_{4}=7.355^{8} \mathrm{grm} . \mathrm{Ag} . \quad 39.4 \mathrm{I} \mathrm{I} \\
& \begin{array}{llll}
\mathrm{r} .242 & & 3.154 & 39.379
\end{array} \\
& 3.221 \text { " } 8.1875 \text { " } 39.340 \\
& \text { Mean, 39.377, } \pm .014
\end{aligned}
$$

Dumas' and Pelouze's series combine as follows :

$$
\begin{aligned}
& \text { Pelouze ..................... 39.4447, } \pm .0083 \\
& \text { Dumas....................... 39.377, } \pm .014 \\
& \text { General mean.............. } 39.4265, \pm .007 \text { I }
\end{aligned}
$$

Schiel, § also studying the chloride of silicon, decomposed it by ammonia. After warming and long standing it was filtered, and in the

* Lehrbuch, 5 Aufl., 3, I 200.

$\dagger$ Compt. Rend., 20, 1047. 1845 .

† Ann. Chem. Pharm., II3, 3I. 1860 .

\& Ann. Chem. Pharm., I20, 94. 
filtrate the chlorine was estimated as $\mathrm{AgCl}$. One hundred parts of $\mathrm{AgCl}$ correspond to the quantities of $\mathrm{SiCl}_{4}$ given in the last column :

$$
\begin{aligned}
& .673^{8} \mathrm{grm} . \mathrm{SiCl}_{4} \text { gave } 2.277 \mathrm{grm} . \mathbf{A g C l} \quad 29.592 \\
& 1.3092 \text { " } 4.418 \text { " } 29.633 \\
& \text { Mean, } \overline{29.6125}, \pm .0138
\end{aligned}
$$

Thorpe and Young,* working with silicon bromide, seem to have obtained fairly good results. The bromide was perfectly clear and colorless, and boiled constantly at $153^{\circ}$. It was weighed, decomposed with water, and evaporated to dryness, the crucible containing it being finally ignited. The crucible was tared by one precisely similar, in which an

\begin{tabular}{|c|c|c|c|c|c|}
\hline $9.63007 \mathrm{grm}$. & $\mathrm{SiBr}_{4}$ gave & I. 67070 & $\mathrm{SiO}_{2}$ & I7.349 I & $\mathrm{r}$ cent. \\
\hline 12.36099 & “ & 2.14318 & “ & $17.33^{8}$ & “ \\
\hline $12.9^{8} 33^{6}$ & “ & 2.25244 & “ & 17.349 & “" \\
\hline 9.02269 & “" & $1.5^{6} 542$ & " & $17 \cdot 350$ & “ \\
\hline I $5 \cdot 3^{8426}$ & “ & 2.66518 & “ & 17.324 & “ \\
\hline $9.7455^{\circ}$ & “ & 1. 69020 & “ & 17.343 & “" \\
\hline 6.19159 & “ & 1.07536 & “ & 17.368 & “ \\
\hline $9 \cdot 51204$ & “ & I. 65065 & “ & 17.353 & “ \\
\hline 10.69317 & “ & 1.85555 & “ & 17.353 & “ \\
\hline
\end{tabular}
equal volume of water was also evaporated. Results as follows, with weights at vacuum standards :

The ratios now available are-

(1.) $4 \mathrm{Ag}: \mathrm{SiCl}_{4}:: 100: 39.4265, \pm .007 \mathrm{I}$

(2.) $4 \mathrm{AgCl}: \mathrm{SiCl}_{4}:: 100: 29.6125, \pm .0138$

(3.) $\mathrm{SiBr}_{4}: \mathrm{SiO}_{2}:: 100: 17.347, \pm .0027$

Reducing these ratios with-

$$
\begin{array}{ll}
\mathrm{O}=15.879, \pm .0003 & \mathrm{Br}=79.344, \pm .0062 \\
\mathrm{Ag}=107.108, \pm .003 \mathrm{I} & \mathrm{AgCl}=142.287, \pm .0037 \\
\mathrm{Cl}=35.179, \pm .0048 &
\end{array}
$$

we have the following values for the atomic weight of silicon :

$$
\begin{aligned}
& \text { From }(\mathrm{I}) \ldots \ldots \ldots \ldots \ldots \ldots \ldots . \mathrm{Si}=28.200, \pm .0363 \\
& \text { From }(2) \ldots \ldots \ldots \ldots \ldots \ldots \ldots \ldots . \ldots 27.823, \pm .0810 \\
& \text { From }(3) \ldots \ldots \ldots \ldots \ldots \ldots \ldots \ldots \ldots=28.187, \pm .0122 \\
& \text { General mean ............ } \overline{\mathrm{Si}=28.181, \pm .0114}
\end{aligned}
$$

If $\mathrm{O}=16, \mathrm{Si}=28.395$. 


\section{TITANIUM.}

The earliest determinations of the atomic weight of titanium are due to Heinrich Rose.* In his first investigation he studied the conversion of titanium sulphide into titanic acid, and obtained erroneous results; later, in 1829, he published his analyses of the chloride. $\dagger$ This compound was purified by repeated rectifications over mercury and over potassium, and was weighed in bulbs of thin glass. These were broken under water in tightly stoppered flasks; the titanic acid was precipitated by ammonia, and the chlorine was estimated as silver chloride. The following results were obtained. In a fourth column I give the $\mathrm{TiO}_{2}$ in percentages referred to $\mathrm{TiCl}_{4}$ as 100 , and in a fifth column the quantity of $\mathrm{TiCl}_{4}$ proportional to 100 parts of $\mathrm{AgCl}$ :

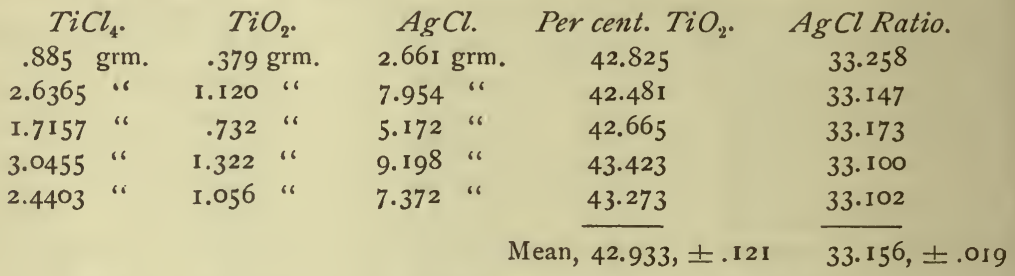

If we directly compare the $\mathrm{AgCl}$ with the $\mathrm{TiO}_{2}$ we shall find 100 parts of the former proportional to the following quantities of the latter:

$$
\begin{gathered}
14.243 \\
14.08 \mathrm{I} \\
14.153 \\
14.373 \\
14.324 \\
\text { Mean, } 14.235, \pm .036
\end{gathered}
$$

Shortly after the appearance of Rose's paper, Mosander $\ddagger$ published some figures giving the percentage of oxygen in titanium dioxide, from which a value for the atomic weight of titanium was deduced. Although no details are furnished as to experimental methods, and no actual weighings are given, I cite his percentages for whatever they may be worth :

$$
\begin{array}{r}
40.814 \\
40.825 \\
40.610 \\
40.180 \\
40.107 \\
40.050 \\
40.780 \\
40.660 \\
39.830 \\
\hline 40.428
\end{array}
$$


These figures, with $\mathrm{O}=15.879$, give values for Ti ranging from 46.03 to 47.98 ; or, in mean, $\mathrm{Ti}=46.80$. They are not, however, sufficiently explicit to deserve any farther consideration.

In 1847 Isidor Pierre made public a series of important determinations.* Titanium chloride, free from silicon and from iron, was prepared by the action of chlorine upon a mixture of carbon with pure, artificial titanic acid. This chloride was weighed in sealed tubes, these were broken under water, and the resulting hydrochloric acid was titrated with a standard solution of silver after the method of Pelouze. I subjoin Pierre's weighings, and add, in a third column, the ratio of $\mathrm{TiCl}_{4}$ to 100 parts of silver:

\begin{tabular}{|c|c|c|}
\hline $\mathrm{TiCl}_{4}$. & $A g$. & Ratio. \\
\hline $.8215 \mathrm{grm}$. & I. $845^{23} \mathrm{grm}$. & $44.5^{20}$ \\
\hline .7740 " & I.73909 “" & $44 \cdot 506$ \\
\hline .7775 “ & 1.74613 & $44.5^{27}$ \\
\hline .7160 & 1.61219 & 44412 \\
\hline .8085 & 1.82344 " & 44.339 \\
\hline .6325 " & 1.42230 " & 44.470 \\
\hline .8155 & r.83705 “ & 44.39 .2 \\
\hline .8165 ، & 1.83899 “ & 44.399 \\
\hline .8065 ، & 1.81965 “" & $44 \cdot 322$ \\
\hline
\end{tabular}

It will be seen that the first three of these results agree well with each other and are much higher than the remaining six. The last four experiments were made purposely with tubes which had been previously opened, in order to determine the cause of the discrepancy. According to Pierre, the opening of a tube of titanium chloride admits a trace of atmospheric moisture. This causes a deposit of titanic acid near the mouth of the tube, and liberates hydrochloric acid. The latter gas being heavy, a part of it falls back into the tube, so that the remaining chloride is richer in chlorine and poorer in titanium than it should be. Hence, upon titration, too low figures for the atomic weight of titanium are obtained. Pierre accordingly rejects all but the first three of the above estimations.

The memoir of Pierre upon the atomic weight of titanium was soon followed by a paper from Demoly, $\uparrow$ who obtained much higher results. He also started out from titanic chloride, which was prepared'from rutile. The latter substance was found to contain 1.8 per cent. of silica; whence Demoly inferred that the $\mathrm{TiCl}_{4}$ investigated by Rose and by Pierre might have been contaminated with $\mathrm{SiCl}_{4}$, an impurity which would lower the value deduced for the atomic weight under consideration. Accordingly, in order to eliminate all such possible impurities, this process was resorted 
to: the chloride, after rectification over mercury and potassium, was acted upon by dry ammonia, whereupon the compound $\mathrm{TiCl}_{4} \cdot 4 \mathrm{NH}_{3}$ was deposited as a white powder. This was ignited in dry ammonia gas, and the residue, by means of chlorine, was reconverted into titanic chloride, which was again repeatedly rectified over mercury, potassium, and potassium amalgam. The product boiled steadily at $135^{\circ}$. This chloride, after weighing in a glass bulb, was decomposed by water, the titanic acid was precipitated by ammonia, and the chlorine was estimated in the filtrate as silver chloride. Three analyses were performed, yielding the following results. I give the actual weighings :

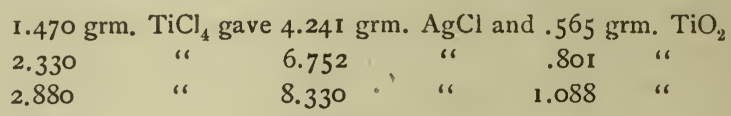

The ".801" in the last column is certainly a misprint for .901. Assuming this correction, the results may be given in three ratios, thus:

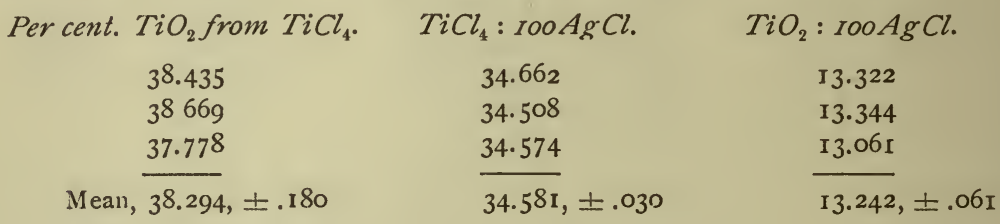

These three ratios give three widely divergent values for the atomic weight of titanium, ranging from about 36 to more than 56 , the latter figure being derived from the ratio between $\mathrm{AgCl}$ and $\mathrm{TiCl}_{4}$. This value, 56 , is assumed by Demoly to be the best, the others being practically ignored.

Upon comparing Demoly's figures with those obtained by Rose, certain points of similarity are plainly to be noted. Both sets of results were reached by essentially the same method, and in both the discordance between the percentages of titanic acid and of silver chloride is glaring. This discordance can rationally be accounted for by assuming that the titanic chloride was in neither case absolutely what it purported to be; that, in brief, it must have contained impurities, such for example as hydrochloric acid, as shown in the experiments of Pierre, or possibly traces of oxychlorides. Considerations of this kind also throw doubt upon the results attained by Pierre, for he neglected the direct estimation of the titanic acid altogether, thus leaving us without means for correctly judging as to the character of his material.

In $1883 *$ Thorpe published a series of experiments upon titanium tetrachloride, determining three distinct ratios and getting sharply concordant results. 'The first ratio, which was essentially like Pierre's, by 
decomposition with water and titration with silver, was in detail as follows :

$\begin{array}{rrc}\mathrm{TiCl}_{4} . & \mathrm{Ag} . & \mathrm{TiCl}_{4}: \mathrm{IOOAg} . \\ 2.43275 & 5.52797 & 44.008 \\ 5.42332 & 12.32260 & 44.015 \\ 3.59601 & 8.1746 \mathrm{I} & 44.000 \\ 3.31222 & 7.5272 \mathrm{I} & 44.003 \\ 4.20093 & 9.54679 & 44.004 \\ 5.68888 & 12.92686 & 44.008 \\ 5.65346 & 12.85490 & 43.979 \\ 4.08247 & 9.28305 & 43.978 \\ & & \text { Mean, } \frac{43.999, \pm .0032}{} \\ & & \text { Pierre found, } 44.432, \pm .0073 \\ & & \text { General mean, } 44.017, \pm .0031\end{array}$

The second ratio, which involved the weights of $\mathrm{TiCl}_{4}$ taken in the last five determinations of the preceding series, included the weighing of the silver chloride formed. The $\mathrm{TiCl}_{4}$ proportional to 100 parts of $\mathrm{AgCl}$ is given in a third column:

$\begin{array}{ccc}\mathrm{TiCl}_{4} . & \mathrm{AgCl} & \text { Ratio. } \\ 3.31222 & 10.00235 & 33.114 \\ 4.20093 & 12.68762 & 33.111 \mathrm{I} \\ 5.68888 & 17.17842 & 33.117 \\ 5.65346 & 17.06703 & 33.125 \\ 4.08247 . & 12.32442 & \frac{33.125}{33.118}, \pm .0019 \\ & & \text { Mean, } 33.115 \pm .019 \\ & & \text { Rose found, 33.156, } \\ & & \text { Demoly found, } 34.581 \pm .030 \\ & & \text { General mean, } 33.123, \pm .0019 .\end{array}$

In the third series the chloride was decomposed by water, and after evaporation to dryness the resulting $\mathrm{TiO}_{2}$ was strongly ignited.

$\begin{array}{rrc}\mathrm{TiCl}_{4} . & \mathrm{TiO}_{2 .} & \text { Per cent. TiO } \\ 6.23398 & 2.62825 & 42.160 \\ 8.96938 & 3.78335 & 42.18 \mathrm{I} \\ 10.19853 & 4.30128 & 42.176 \\ 6.56894 & 2.7701 \mathrm{I} & 42.170 \\ 8.9998 \mathrm{I} & 3.79575 & 42.176 \\ 8.32885 & 3.51158 & 42.162 \\ & & \text { Mean, } 42.17 \mathrm{I}, \pm .0022 \\ & & \text { Rose found, } 42.933, \pm .12 \mathrm{I} \\ & & \text { Demoly found, } 38.294, \pm .180 \\ & & \text { General mean, } 42.17 \mathrm{I}, \pm .0022\end{array}$

In short, the work of Rose, Pierre, and Demoly practically vanishes. Furthermore, as will be seen later, the three ratios now give closely 
agreeing values for the atomic weight of titanium. The cross ratio, $4 \mathrm{AgCl}$ : $\mathrm{TiO}_{2}$ is not directly given by either of Thorpe's series; but the data furnished by Rose and Demoly combine into a general mean of $4 \mathrm{AgCl}: \mathrm{TiO}_{2}:: 100: 13.980, \pm .0303$.

Some two years later Thorpe published his work more in detail,* and added a set of determinations, like those made upon the chloride, in which titanium tetrabromide was studied. Three ratios were measured, as was the case with the chloride. In the first, the bromide was decomposed by water and titrated with a silver solution.

$\begin{array}{ccc}\mathrm{TiBr}_{\text {. }} & \mathrm{Ag} . & \mathrm{TiBr}_{4}: \mathrm{IOOAg} . \\ 2.854735 & 3.34927 & 85.235 \\ 3.120848 & 3.66: 22 & 85.24 \mathrm{I} \\ 4.731 \mathrm{II} 8 & 5.55097 & 85.230 \\ 6.969075 & 8.17645 & 85.234 \\ 6.678099 & 7.83493 & 85.234 \\ & & \text { Mean, } 85.235, \pm .0027\end{array}$

In the four last experiments of the preceding series, the silver bromide formed was weighed. The third column gives the $\mathrm{TiBr}_{4}$ proportional to 100 parts of $\mathrm{AgBr}$.

$\begin{array}{crc}\mathrm{TiBr}_{4} . & \mathrm{AgBr} . & \text { Ratio. } \\ 3.120848 & 6.37539 \mathrm{I} & 48.95 \mathrm{I} \\ 4.731 \mathrm{II} 8 & 9.66390 \mathrm{I} & 48.957 \\ 6.969075 & 14.2277 \mathrm{I} 6 & 48.982 \\ 6.678099 & \mathrm{13.639956} & 48.959 \\ & & \text { Mean, } 48.962, \pm .0049\end{array}$

For the third ratio the bromide was decomposed by water; and after evaporation with ammonia the residual titanic oxide was ignited and weighed :

$\begin{array}{ccc}\mathrm{TiBr}_{4} . & \mathrm{TiO}_{2} . & \mathrm{Percent} . \mathrm{TiO}_{2} . \\ 6.969730 & 1.518722 & 2 \mathrm{r} .790 \\ 8.836783 & 1.923609 & 21.768 \\ 9.096309 & 1.979513 & 2 \mathrm{I.762} \\ & & \text { Mean, } 2 \mathrm{21.773}, \pm .0062\end{array}$

Ignoring Mosander's work as unavailable, we have the following ratios to consider :
(I.) $4 \mathrm{Ag}: \mathrm{TiCl}_{4}:: 100: 44.017, \pm .003 \mathrm{I}$
(2.) $4 \mathrm{AgCl}: \mathrm{TiCl}_{4}:: 100: 33.123, \pm .0019$
(3.) $4 \mathrm{AgCl}: \mathrm{TiO}_{2}:: 100: 13.980, \pm .0303$
(4.) $\mathrm{TiCl}_{4}: \mathrm{TiO}_{2}:: 100: 42.171, \pm .0022$
(5.) $4 \mathrm{Ag}: \mathrm{TiBr}_{4}:: 100: 85.235, \pm .0027$
(6.) $4 \mathrm{AgiBr}: \mathrm{TiBr}_{4}:: 100: 48.962, \pm .0049$
(7.) $\mathrm{TiBr}_{4}: \mathrm{TiO}_{2}:$ : $100: 2 \mathrm{I} .773, \pm .0062$ 
These are to be computed with-

$$
\begin{array}{ll}
\mathrm{O}=15.879, \pm .0003 & \mathrm{Br}=79.344, \pm .0062 \\
\mathrm{Ag}=107.108, \pm .003 \mathrm{I} & \mathrm{AgCl}=142.287, \pm .0037 \\
\mathrm{Cl}=35.179, \pm .0048 & \mathrm{AgBr}=186.454, \pm .0054
\end{array}
$$

For the molecular weight of titanium chloride they give two values:

$$
\begin{aligned}
& \text { From (I) ............. } \mathrm{TiCl}_{4}=188.583 \\
& \text { From }(2) \ldots \ldots \ldots \ldots \ldots \ldots \ldots . " \quad=188.519, \pm .0119 \\
& \text { General mean......... } \mathrm{TiCl}_{4}=188.545, \pm .0092
\end{aligned}
$$

For $\mathrm{TiBr}_{4}$ we have-

$$
\begin{aligned}
& \text { From (5) .............. } \mathrm{TiBr}_{4}=365.174, \pm .0157 \\
& \text { From }(6) \ldots \ldots \ldots \ldots \ldots \ldots \ldots . " \text { " }=365.16_{3}, \pm .0380 \\
& \text { General mean ......... } \mathrm{TiBr}_{4}=365.17^{2}, \pm .0145
\end{aligned}
$$

And for the atomic weight of titanium five values are calculable, as follows :

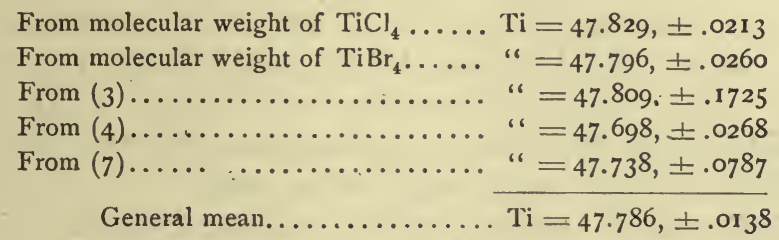

If $\mathrm{O}=16$, this becomes $\mathrm{Ti}=48.150$.

\section{GERMANIUM.}

The data relative to the atomic weight of germanium are rather scanty, and are due entirely to the discoverer of the element, Winkler.* The pure tetrachloride was decomposed by sodium carbonate, mixed with a known excess of standard silver solution, and then titrated back with ammonium sulphocyanate. The data given are as follows:

$\begin{array}{lcc}\mathrm{GeCl}_{4} . & \text { Cl Found. } & \text { Per cent. } \mathrm{Cl} . \\ .1067 & .076112 & 66.177 \\ .1258 & .083212 & 66.146 \\ .2223 & .147136 & 66.188 \\ .2904 & .192190 & 66.182 \\ & & \text { Mean, } 66.173\end{array}$

Hence, with $\mathrm{Cl}=35.179, \mathrm{Ge}=71.933$. If $\mathrm{O}=16, \mathrm{Ge}=72.481$. 


\section{ZIRCONIUM.}

The atomic weight of zirconium has been determined by Berzelius, Hermann, Marignac, Weibull, and Bailey. Berzelius* ignited the neutral sulphate, and thus ascertained the ratio in it between the $\mathrm{ZrO}_{2}$ and the $\mathrm{SO}_{3}$. Putting $\mathrm{SO}_{3}$ at 100 , he gives the following proportional quantities of $\mathrm{ZrO}_{2}$ :

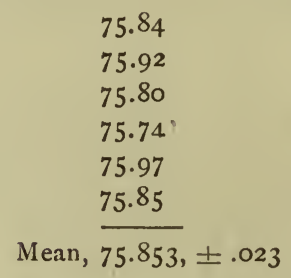

This gives $43.134, \pm .0142$ as the percentage of zirconia in the sulphate. Hermann's $\dagger$ estimate of the atomic weight of zirconium was based upon analyses of the chloride, concerning which he gives no details nor weighings. From sublimed zirconium chloride he finds $\mathrm{Zr}=831.8$, when $\mathrm{O}=100$; and from two lots of the basic chloride $2 \mathrm{ZrOCl}_{2} \cdot 9 \mathrm{H}_{2} \mathrm{O}$, $\mathrm{Zr}=835.65$ and 851.40 respectively. The mean of all three is 839.62 ; whence, with modern formulæ and $\mathrm{O}=15.879, \mathrm{Zr}$ becomes $=88.882$.

Marignac's results $\ddagger$ were obtained by analyzing the double fluoride of zirconium and potassium. His weights are as follows:

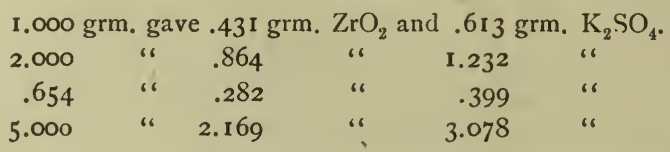

These figures give us three ratios. $\mathrm{A}$, the $\mathrm{ZrO}_{2}$ from 100 parts of salt; $\mathrm{B}$, the $\mathrm{K}_{2} \mathrm{SO}_{4}$ from 100 parts of salt; and C, the $\mathrm{ZrO}_{2}$ proportional to 100 parts of $\mathrm{K}_{2} \mathrm{SO}_{4}$ :

A.

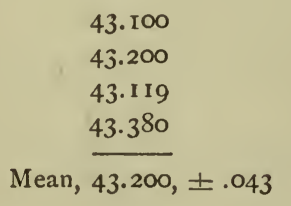

B.

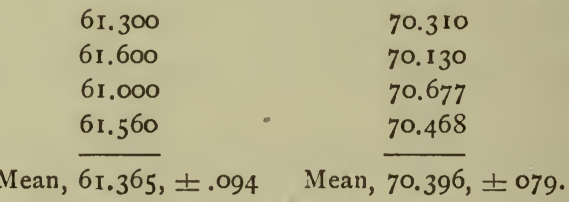

Weibull,§ following Berzelius, ignited the sulphate, and also made a

* Poggend. Annal., 4, 126.1825.

† Journ. für Prakt. Chem., 31, 77. Berz. Jahresb., 25, 147.

$\ddagger$ Ann. Chim. Phys. (3), 60, 270. 1860 .

לे Lund. Arsskrift, v. I8. I88I-'82. 
similar set of experiments with the selenate of zirconium, obtaining results as follows:

Sulphate. $\mathrm{Zr}\left(\mathrm{SO}_{4}\right)_{2}$.

\begin{tabular}{|c|c|c|c|c|c|}
\hline 1. 5499 & sal & .6684 & $\mathrm{ZrO}_{2}$. & 43.126 & er cent. \\
\hline I. 5445 & "، & .6665 & “" & 43.153 & “ \\
\hline 2. 1683 & “ & .9360 & " & 43.168 & “ \\
\hline 1.0840 & ، & .4670 & " & $43.08 \mathrm{I}$ & “ \\
\hline .79 I 3 & “" & .3422 & " & $43.32 \mathrm{I}$ & “" \\
\hline $.625 \mathrm{I}$ & " & .2695 & " & 43. II 3 & " \\
\hline .4704 & " & .2027 & " & 43.09 I & " \\
\hline
\end{tabular}

Selenate. $\mathrm{Zr}\left(\mathrm{SeO}_{4}\right)_{2}$.

\begin{tabular}{|c|c|c|c|c|c|}
\hline 1.0212 & salt & .3323 & $\mathrm{ZrO}_{2}$. & 32.540 & r cent. \\
\hline .8418 & "6 & .2744 & " & 32.597 & “ \\
\hline .6035 & " & .1964 & "“ & 32.544 & “" \\
\hline .8793 & " & .2870 & “ & 32.640 & “ \\
\hline .3089 & " & .1003 & " & $3^{2.470}$ & " \\
\hline
\end{tabular}

Bailey* also ignited the sulphate, after careful investigation of his material, and of the conditions needful to ensure success. He found that the salt was perfectly stable at $400^{\circ}$, while every trace of free sulphuric acid was expelled at $350^{\circ}$. The chief difficulty in the process arises from the fact that the zirconia produced by the ignition is very light, and easily carried off mechanically, so that the percentage found is likely to be too low. This difficulty was avoided by the use of a double crucible, the outer one retaining particles of zirconia which otherwise might be lost. The results, corrected for buoyancy of the air, are as follows:

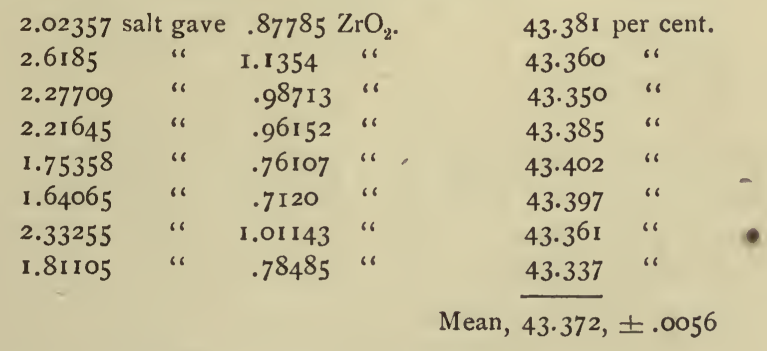

This, combined with previous determinations, gives-

$$
\begin{aligned}
& \text { Berzelius ................... 43.1 34, } \pm .0142 \\
& \text { Weibull .................... 43.150, } \pm .0207 \\
& \text { Bailey..................... 43.372, } \pm .0056 \\
& \text { General mean } . \ldots \ldots \ldots \ldots \ldots \ldots \text { 43.317, } \pm .0051
\end{aligned}
$$


For computing the atomic weight of zirconium we now have the subjoined ratios :

(1.) Percentage $\mathrm{ZrO}_{2}$ in $\mathrm{Zr}\left(\mathrm{SO}_{4}\right)_{2}, 43.317$, 土.005 $\mathrm{I}$

(2.) Percentage $\mathrm{ZrO}_{2}$ in $\mathrm{Zr}\left(\mathrm{SeO}_{4}\right)_{2}, 32.558$, \pm .0192

(3.) Percentage $\mathrm{ZrO}_{2}$ from $\mathrm{K}_{2} \mathrm{ZrF}_{6}, 43.200$, \pm .043

(4.) Percentage $\mathrm{K}_{2} \mathrm{SO}_{4}$ from $\mathrm{K}_{2} \mathrm{ZrF}_{6}, 61.365, \pm .094$

(5.) $\mathrm{K}_{2} \mathrm{SO}_{4}: \mathrm{ZrO}_{2}:: 100: 70.396, \pm .079$

The antecedent atomic weights are-

$$
\begin{array}{ll}
\mathrm{O}=15.879, \pm .0003 & \mathrm{~K}=38.817, \pm .0051 \\
\mathrm{~S}=31.828, \pm .0015 & \mathrm{~F}=18.912, \pm .0029 \\
\mathrm{Se}=78.419 \pm \pm .0042 &
\end{array}
$$

With these data we first get three values for the molecular weight of zirconia :

$$
\begin{aligned}
& \text { From (I) .............. } \mathrm{ZrO}_{2}=121.454, \pm .0182 \\
& \text { From (2) .............. " }=121.708, \pm .0798 \\
& \text { From }(5) \ldots \ldots \ldots \ldots \ldots \ldots \ldots \ldots \text { " }=121.770, \pm .1370 \\
& \text { General mean .......... } \mathrm{ZrO}_{2}=121.471, \pm .0176
\end{aligned}
$$

Finally, there are three independent estimates for the atomic weight of zirconium:

$$
\begin{aligned}
& \text { From molecular weight } \mathrm{ZrO}_{2} \ldots \ldots \ldots \mathrm{Zr}=89.713, \pm .0177 \\
& \text { From ratio }(3) \ldots \ldots \ldots \ldots \ldots \ldots \ldots .6=89.437, \pm .2390 \\
& \text { From ratio }(4) \ldots \ldots \ldots \ldots \ldots \ldots \ldots \text {. }=90.778, \pm .4326 \\
& \text { General mean ........... } \mathrm{Zr}=89.716, \pm .0175
\end{aligned}
$$

If $\mathrm{O}=16, \mathrm{Zr}=90.400$.

Here the first value alone carries appreciable weight. 


\section{TIN.}

The atomic weight of tin has been determined by means of the oxide, the chloride, the bromide, the sulphide, and the stannichlorides of potassium and ammonium.

The composition of stannic oxide has been fixed in two ways: by synthesis from the metal and by reduction in hydrogen. For the first method we may consider the work of Berzelius, Mulder and Vlaanderen, Dumas, Van der Plaats, and Bongartz and Classen.

Berzelius * oxidized 100 parts of tin by nitric acid, and found that 127.2 parts of $\mathrm{SnO}_{2}$ were formed.

The work done by Mulder and Vlaanderen $\dagger$ was done in connection with a long investigation into the composition of Banca tin, which was found to be almost absolutely pure. For the atomic weight determinations, however, really pure tin was taken prepared from pure tin oxide. This metal was oxidized by nitric acid, with the following results. 100 parts of tin gave of $\mathrm{SnO}_{2}$ :

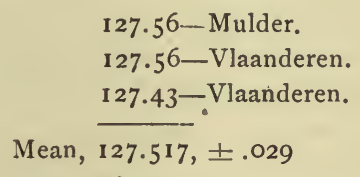

Dumas $\ddagger$ oxidized pure tin by nitric acid in a flask of glass. The resulting $\mathrm{SnO}_{2}$ was strongly ignited, first in the flask and afterwards in platinum. His weighings, reduced to the foregoing-standard, give for dioxide from 100 parts of tin the amounts stated in the third column:

$$
\begin{aligned}
& \text { I } 2.443 \mathrm{grm} \text {. Sn gave } 15.820 \mathrm{grm} \text {. } \mathrm{SnO}_{2} \text {. } \quad 127.14 \\
& \begin{array}{llll}
15.976 & \text { " } & & \\
& &
\end{array} \\
& \text { Mean, } 127.105, \pm .024
\end{aligned}
$$

In an investigation later than that previously eited, Vlaanderen $\S$ found that when tin was oxidized in glass or porcelain vessels, and the resulting oxide ignited in them, traces of nitric acid were retained. When, on the other hand, the oxide was strongly heated in platinum, the latter was perceptibly attacked, so much so as to render the results uncertain. He therefore, in order to fix the atomic weight of tin, reduced the oxide by heating it in a porcelain boat in a stream of hydrogen. Two experiments gave $\mathrm{Sn}=118.08$, and $\mathrm{Sn}=118.24$. These, when $\mathrm{O}=16$, become, if reduced to the above common standard, 


$$
\frac{127.100}{127.064}
$$

Van der Plaats* prepared pure stannic oxide from East Indian tin (Banca), and upon the material obtained made two series of experiments; one by reduction and one by oxidation. The results, with vacuum weights, are as follows, the ratio between $\mathrm{Sn}$ and $\mathrm{SnO}_{2}$ appearing in the third column :

Oxidation Series.

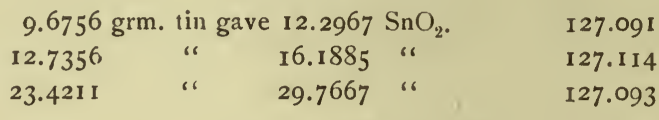

$$
\begin{aligned}
& 5.5015 \mathrm{grm} . \mathrm{SnO}_{2} \text { gave } 4.3280 \mathrm{tin} \text { I } 27.1 \mathrm{I} 4 \\
& 4.9760 \text { " " } 3.9145 \text { " } 127.117 \\
& 3.8225 \text { " " } 3.0078 \text { " } 127.086 \\
& 2.9935 \text { " } 2.3553 \text { " } 27.096 \\
& \text { Mean of both series as one, } \overline{127.102} \pm .0033
\end{aligned}
$$

\begin{tabular}{|c|c|c|}
\hline$S n$. & $\mathrm{SnO}_{2}$ & Ratio. \\
\hline 2.5673 & 3.2570 & 126.865 \\
\hline $3.84 \mathrm{I} 4$ & 4.8729 & 126.852 \\
\hline $7 \cdot 3321$ & 9.2994 & I $26.83 \mathrm{I}$ \\
\hline 5.4367 & 6.8962 & I 26.845 \\
\hline $7 \cdot 3321$ & 9.2994 & I 26.83 I \\
\hline 9.8306 & I 2.4785 & I 26.935 \\
\hline II. 2424 & 14.2665 & I 26.896 \\
\hline 5.5719 & 7.0685 & 126.860 \\
\hline 9.8252 & 12.4713 & I 26.932 \\
\hline 4.3959 & 5.5795 & I 26.925 \\
\hline 6.3400 & 8.0440 & I 26.877 \\
\hline
\end{tabular}

The reductions were effected in a porcelain crucible.

Bongartz and Classen $\uparrow$ purified tin by electrolysis, and oxidized the electrolytic metal by means of nitric acid. The oxide found was dried over a water-bath, then heated over a weak flame, and finally ignited for several hours in a gas-muffle. Some reduction experiments gave values which were too low. The oxidation series was as follows, with the usual ratio added by me in a third column:

We now have six series of experiments showing the amount of $\mathrm{SnO}_{2}$ formed from 100 parts of tin. To Berzelius' single determination may be assigned the weight of one experiment in Mulder and Vlaanderen's series: 


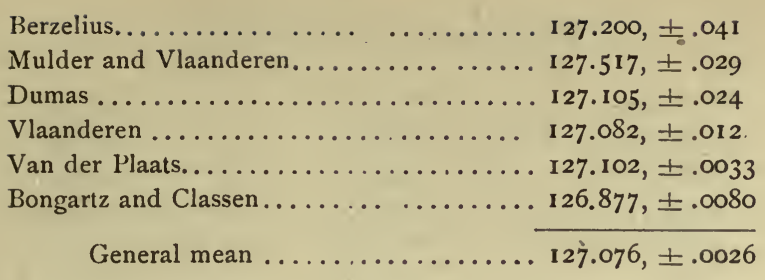

Dumas, in the paper previously quoted, also gives the results of some experiments with stannic chloride, $\mathrm{SnCl}_{4}$. This was titrated with a solution containing a known weight of silver. From the weighings given, 100 parts of silver correspond to the quantities of $\mathrm{SnCl}_{4}$ named in the third column :

$$
\begin{aligned}
& \text { I. } 839 \mathrm{grm} . \mathrm{SnCl}_{4}=3.054 \mathrm{grm} \text {. Ag. } 60.216 \\
& 2.665 \text { " } 4.427 \text { " } 60.199 \\
& \text { Mean, } \overline{60.207}, \pm .006
\end{aligned}
$$

Tin tetrabromide and the stannichlorides of potassium and ammonium were all studied by Bongartz and Classen; who, in each compound, carefully purified, determined the tin electrolytically. The data given are as follows, the percentage columns being added by myself:

\section{Tin Tetrabromide.}

$\mathrm{SnBr}_{4}$ Taken.
8.5781
9.5850
9.9889
10.4914
16.8620
16.6752
11.1086
10.6356
11.0871
19.5167

Sn Found.

2.3270

2.6000

2.7115

2.8445

4.5735

4.5236

3.0125

2.8840

3.0060

5.2935
Percent. Sn.

27.127

27.126

27.145

27.113

27.123

27.119

27.116

27. 113

27.123

27.128

Potassium Stannichloride.

$\begin{array}{rcc}K_{2} \mathrm{SnCl}_{6} . & \text { Sn Found. } & \text { Per cent. Sn. } \\ 2.5718 & .7472 & 29.054 \\ 2.2464 & .6524 & 29.042 \\ 9.3353 & 2.7100 & 29.030 \\ 12.1525 & 3.5285 & 29.035 \\ 12.4223 & 3.6070 & 29.036 \\ 15.0870 & 4.3812 & 29.040 \\ 10.4465 & 3.0330 & 29.034 \\ 18.9377 & 5.5029 & 29.058 \\ 18.4743 & 5.3630 & 29.029 \\ 17.6432 & 5.1244 & 29.045 \\ & & \text { Mean, } 29.040, \pm .0021\end{array}$




$\begin{array}{ccc} & \text { Ammonium Stannichloride. } \\ \mathrm{Am}_{2} \mathrm{SnCl}_{6}{ }^{\circ} & \text { Sn Found. } & \text { Percent. Sn. } \\ 1.6448 & .5328 & 32.393 \\ 1.8984 & .6141 & 32.347 \\ 2.0445 & .6620 & 32.38 \mathrm{I} \\ 2.0654 & .6690 & 32.39 \mathrm{I} \\ 2.0058 & .6496 & 32.386 \\ 2.4389 & .7895 & 32.37 \mathrm{I} \\ 4.0970 & 1.3254 & 32.35 \mathrm{I} \\ 3.4202 & 1.1078 & 32.390 \\ 3.6588 & 1.1836 & 32.349 \\ 1.5784 & .5108 & 32.362 \\ 7.3248 & 2.3710 & 32.370 \\ 13.1460 & 4.2528 & 32.35 \mathrm{I} \\ 1 \mathrm{I} .9483 & 3.8650 & 32.348 \\ 18.4747 & 5.9788 & 32.362 \\ 18.6635 & 6.0415 & 32.37 \mathrm{I} \\ \text { I } 7.8894 & 5.7923 & 32.378 \\ & & 32.369, \pm .0088\end{array}$

One other method of determination for the atomic weight of tin was employed by Bongartz and Classen. Electrolytic tin was converted into sulphide, and the sulphur so taken up was oxidized by means of hydrogen peroxide, by Classen's method, and weighed as barium sulphate. The results, as given by the authors, are subjoined:

Sn Taken.
2.6285
.7495
1.4785
2.5690
2.1765
1.3245
.9897
2.7160

Per cent. of S Gained.

$\begin{array}{r}53.91 \\ 53.87 \\ 53.94 \\ 53.94 \\ 53.85 \\ 53.88 \\ 53.83 \\ 53.86 \\ \hline \text { Mean, } 53.885, \pm .0098\end{array}$

This percentage of sulphur, however, was computed from weighings of barium sulphate. What values were assigned to the atomic weights of barium and sulphur is not stated, but as Meyer and Seubert's figures are used for other elements throughout this paper, we may assume that they apply here also. Putting $\mathrm{O}=15.96, \mathrm{~S}=31.98$, and $\mathrm{Ba}=136.86$, the 53.885 per cent. of sulphur becomes 392.056 , \pm .0713 of $\mathrm{BaSO}_{4}$, the compound actually weighed. This gives us the ratio-

$$
\mathrm{Sn}: 2 \mathrm{BaSO}_{4}:: 100: 392.056, \pm .0713
$$

as the real result of the experiments, from which, with the later values for $\mathrm{Ba}, \mathrm{S}$, and $\mathrm{O}$, the atomic weight of tin may be calculated. 
We now have, for tin, the following available ratios:

(1.) $\mathrm{Sn}: \mathrm{SnO}_{2}:: 100: 127.076, \pm .0026$

(2.) $4 \mathrm{Ag}: \mathrm{SnCl}_{4}:: 100: 60.207, \pm .0060$

(3.) Percentage of tin in $\mathrm{SnBr}_{4}, 27.123, \pm .0020$

(4.) Percentage of tin in $\mathrm{K}_{2} \mathrm{SnCl}_{6}, 29.040, \pm .002 \mathrm{I}$.

(5.) Percentage of tin in $\mathrm{Am}_{2} \mathrm{SnCl}_{6}, 32.369, \pm .0088$

(6.) $\mathrm{Sn}: 2 \mathrm{BaSO}_{4}:: 100: 392.056, \pm .0713$

The antecedent values are-

$$
\begin{array}{ll}
\mathrm{O}=15.879, \pm .0003 & \mathrm{~K}=38.817 \pm .005 \mathrm{I} \\
\mathrm{Ag}=107.108, \pm .0031 & \mathrm{~N}=13.935 \pm .0021 \\
\mathrm{Cl}=35.179, \pm .0048 & \mathrm{~S}=31.828, \pm .0015 \\
\mathrm{Br}=79.344, \pm .0062 & \mathrm{Ba}=136.392, \pm .0086
\end{array}
$$

With these, six independent values for $\mathrm{Sn}$ are computable, as follows:

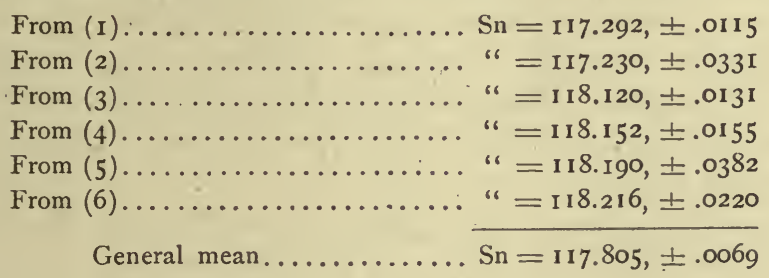

If $\mathrm{O}=16, \mathrm{Sn}=118.701$.

If we reject the first two of these values, which include all of the older work, and take only the last four, which represent the concordant results of Bongartz and Classen, the general mean becomes-

$$
\mathrm{Sn}=118.150, \pm .0089
$$

Or, with $\mathrm{O}=16, \mathrm{Sn}=119.050$. This mean $\mathrm{I}$ regard as having higher probability than the other.

A single determination of the atomic weight of tin, made by Schmidt,* ought not to be overlooked, although it was only incidental to his research upon tin sulphide. In one experiment, $0.5243 \mathrm{grm}$. Sn gave 0.6659 $\mathrm{SnO}_{2}$. Hence, with $\mathrm{O}=16, \mathrm{Sn}=118.49$. This lies about midway between the two sets of values already computed. 


\section{THORIUM.}

The atomic weight of thorium has been determined from analyses of the sulphate, oxalate, formate, and acetate, with widely varying results. The earliest figures are due to Berzelius,* who worked with the sulphate, and with the double sulphate of potassium and thorium. The thoria was precipitated by ammonia, and the sulphuric acid was estimated as $\mathrm{BaSO}_{4}$. The sulphate gave the following ratios in two experiments. The third column represents the weight of $\mathrm{ThO}_{2}$ proportional to 100 parts of $\mathrm{BaSO}_{4}$ :

$$
\begin{aligned}
& .6754 \mathrm{grm} . \mathrm{ThO}_{2}=\mathrm{I} . \mathrm{I} 59 \mathrm{grm} . \mathrm{BaSO}_{4} \text {. Ratio, } 58.274
\end{aligned}
$$

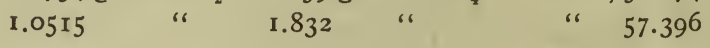

The double potassium sulphate gave $.265 \mathrm{grm}$. $\mathrm{ThO}_{2}, 156 \mathrm{grm} . \mathrm{SO}_{3}$, and $.3435 \mathrm{~K}_{2} \mathrm{SO}_{4}$. The $\mathrm{SO}_{3}$, with the Berzelian atomic weights, represents .4537 grm. $\mathrm{BaSO}_{4}$. Hence $100 \mathrm{BaSO}_{4}$ is equivalent to $58.408 \mathrm{ThO}_{2}$. This figure, combined with the two previous values for the same ratio, gives a mean of $58.026, \pm .214$.

From the ratio between the $\mathrm{K}_{2} \mathrm{SO}_{4}$ and the $\mathrm{ThO}_{2}$ in the double sulphate, $\mathrm{ThO}_{2}=266.895$.

In 1861 new determinations were published by Chydenius, $\dagger$ whose memoir is accessible to me only in an abstract $\ddagger$ which gives results without details. Thoria is regarded as a monoxide, ThO, and the old equivalents $(\mathrm{O}=8)$ are used. The following values are assigned for the molecular weight of $\mathrm{ThO}$, as found from analyses of several salts :

From Sulphate. From K. Th. Sulphate.

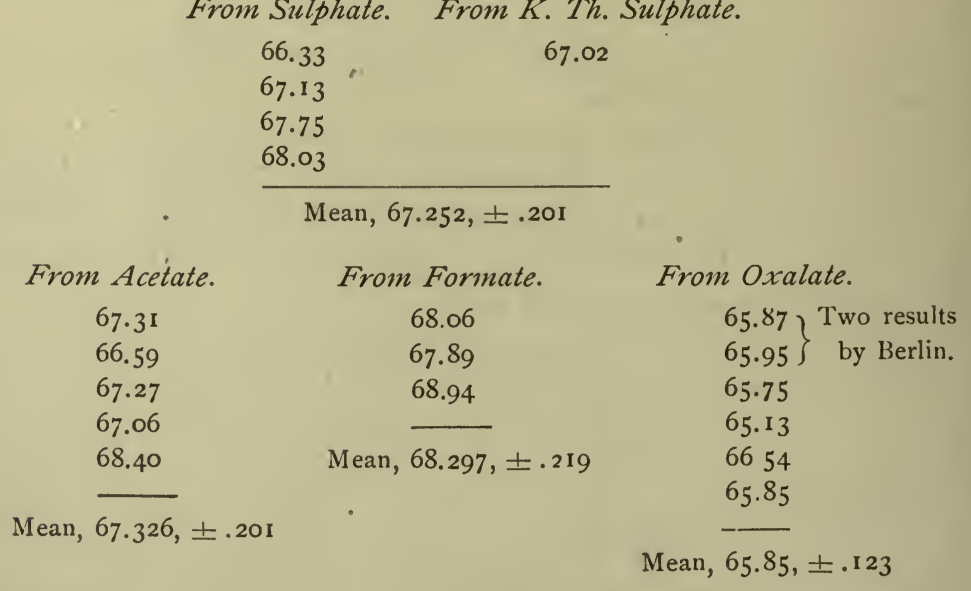

* Poggend. Annal., I6, 398. I829. Lehrbuch, 3, 1224.

† Kemisk undersökning af Thorjord och Thorsalter. Helsingfors, 186r. An academic dissertation.

†·Poggend. Annal., II9, 55. 1863. 
We may fairly assume that these figures were calculated with $\mathrm{O}=8$, $\mathrm{C}=6$, and $\mathrm{S}=16$. Correcting by the values for these elements which have been found in previous chapters, $\mathrm{ThO}_{2}$ becomes as follows:

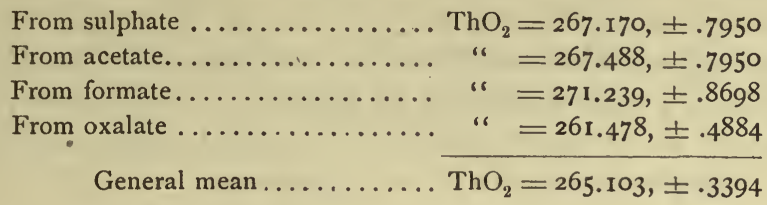

The single result from the double potassium sulphate is included with the column from the ordinary sulphate, and the influence of the atomic weight of potassium is ignored.

Chydenius was soon followed by Marc Delafontaine, whose researches appeared in 1863.* This chemist especially studied thorium sulphate; partly in its most hydrous form, partly as thrown down by boiling. In $\mathrm{Th}\left(\mathrm{SO}_{4}\right)_{2} \cdot 9 \mathrm{H}_{2} \mathrm{O}$, the following percentages of $\mathrm{ThO}_{2}$ were found :

$$
\begin{array}{r}
45.08 \\
44.90 \\
45.06 \\
45.21 \\
45.06 \\
\hline \text { Mean, } 45.062, \pm .0332
\end{array}
$$

The lower hydrate, $2 \mathrm{Th}\left(\mathrm{SO}_{4}\right)_{2} \cdot 9 \mathrm{H}_{2} \mathrm{O}$, was more thoroughly investigated. The thoria was estimated in two ways: First (A), by precipitation as oxalate and subsequent ignition; second (B), by direct calcination. These percentages of $\mathrm{ThO}_{2}$ were found :

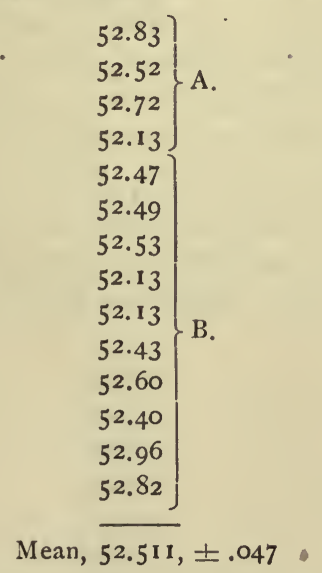

In three experiments with this lower hydrate the sulphuric acid was also estimated, being thrown down as barium sulphate after removal of the thoria: 


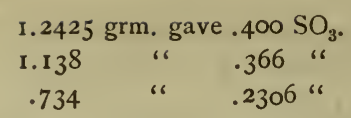

(I. 1656 grm. $\mathrm{BaSO}_{4}$. )

(1.0665

$(.6720$

The figures in parentheses are reproduced by myself from Delafontaine's results, he having calculated his analyses with $\mathrm{O}=100, \mathrm{~S}=200$, and $\mathrm{Ba}=857$. These data may be reduced to a common standard, so as to represent the quantity of $2 \mathrm{Th}\left(\mathrm{SO}_{4}\right)_{2} \cdot 9 \mathrm{H}_{2} \mathrm{O}$, equivalent to 100 parts of $\mathrm{BaSO}_{4}$. We then have the following results :

$$
\begin{gathered}
\text { 106.597 } \\
106.704 \\
\text { Me9.226 } \\
\hline \text { I07.509, } \pm .585
\end{gathered}
$$

Delafontaine was soon followed by Hermann,* who published a single analysis of the lower hydrated sulphate, as follows :

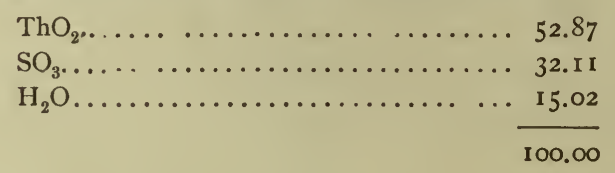

Hence, from the ratio between $\mathrm{SO}_{3}$ and $\mathrm{ThO}_{2}, \mathrm{ThO}_{2}=262.286$. Probably the $\mathrm{SO}_{3}$ percentage was loss upon calcination.

Both Hermann's results and those of Delafontaine are affected by one serious doubt, namely, as to the true composition of the lower hydrated sulphate. The latest and best evidence seems to establish the fact that it contains four molecules of water instead of four and a half, $\uparrow$ a fact which tends to lower the resulting atomic weight of thorium considerably. In the final discussion of these data, therefore, the formula $\mathrm{Th}\left(\mathrm{SO}_{4}\right)_{2} \cdot 4 \mathrm{H}_{2} \mathrm{O}$ will be adopted. As for Hermann's single analysis, his percentage of $\mathrm{ThO}_{2}, 52.87$, may be included in one series with Delafontaine's, giving a mean of $52.535, \pm .0473$.

The next determinations to consider are those of Cleve, $\ddagger$ whose results, obtained from both the sulphate and the oxalate of thorium, agree admirably. The anhydrous sulphate, calcined, gave the subjoined percentages of thoria :

$\begin{array}{r}62.442 \\ 62.477 \\ 62.430 \\ 62.470 \\ 62.357 \\ 62.366 \\ \hline \quad \text { Mean, } 62.423 \\ \hline\end{array}$

* Journ. für Prakt. Chem., 93, I14.

† See Hillebrand, Bull. 9o, U. S. Geol. Survey, p. 29.

$\ddagger$ K. Svenska Vet. Akad. Handling., Bd. 2, No. 6, 1874 . 
The oxalate was subjected to a combustion analysis, whereby both thoria and carbonic acid could be estimated. From the direct percentages of these constituents no accurate value can be deduced, there having undoubtedly been moisture in the material studied. From the ratio between $\mathrm{CO}_{2}$ and $\mathrm{ThO}_{2}$, however, good results are attainable. This ratio I put in a fourth column, making the thoria proportional to 100 parts of carbon dioxide:

\begin{tabular}{|c|c|c|c|}
\hline Oxalate. & $\mathrm{ThO}_{2}$. & $\mathrm{CO}_{2}$. & Ratio. \\
\hline I.71 $35 \mathrm{grm}$. & I.or 89 grm. & $.6736 \mathrm{grm}$. & $151.262^{\circ}$ \\
\hline 1.3800 “" & .8210 & .5433 “ & 151.114 \\
\hline I. 1850 " & $.7030 "$ & .4650 ، & 151.183 \\
\hline I.0755 “ & .6398 & .4240 “ & I 50.896 \\
\hline
\end{tabular}

In 1892, Nilson's determinations appeared.*. This chernist studied both the anhydrous sulphate, and the salt with nine molecules of water, using the usual calcination method, but guarding especially against the hygroscopic eharacter of the dry $\mathrm{Th}\left(\mathrm{SO}_{4}\right)_{2}$ and the calcined $\mathrm{ThO}_{2}$. The hydrated sulphate gave results as follows:

\begin{tabular}{crc}
$\mathrm{Th}_{\left(\mathrm{SO}_{4}\right)_{2} .9 \mathrm{H}_{2} \mathrm{O} .}$ & $\mathrm{ThO}_{2}$. & Percent. $\mathrm{ThO}_{2}$. \\
2.0549 & .9267 & 45.097 \\
2.1323 & .9615 & 45.092 \\
3.0017 & 1.3532 & $45.08 \mathrm{I}$ \\
2.7137 & 1.2235 & 45.086 \\
2.6280 & 1.1849 & 45.088 \\
1.9479 & .8785 & 45.099 \\
& & Mean, $45.09 \mathrm{I}, \pm .0019$ \\
& \multicolumn{2}{c}{ Delafontaine found, $45.062, \pm .0332$} \\
& & General mean, $45.090, \pm .0019$
\end{tabular}

The anhydrous sulphate gave data as follows:

$\begin{array}{ccc}\mathrm{Th}_{\left(\mathrm{SO}_{4}\right)_{2} .} & \mathrm{ThO}_{2} . & \text { Percent. } \mathrm{ThO}_{2} . \\ 1.4467 & .9013 & 62.300 \\ 1.6970 & 1.0572 & 62.298 \\ 2.0896 & 1.3017 & 62.294 \\ 1.5710 & .9787 & 62.298 \\ & . & \text { Mean, } \frac{62.297}{}\end{array}$

The last four determinations appear again in a paper published five years later by Krüss and Nilson, $\dagger$ who, however, give four more made 
upon material obtained from a different source. The new data are subjoined :

$T h\left(\mathrm{SO}_{4}\right)_{2}$.
1.1630
.8607
1.5417
1.5217

$$
\begin{aligned}
& \mathrm{ThO}_{2} . \\
& .7245 \\
& .5362 \\
& .9605 \\
& .9479
\end{aligned}
$$

Per cent. $\mathrm{ThO}_{2}$.

62.296

62.298 .

62.301

- 62.292

Mean, $\overline{62.297}, \pm .0013$

Nilson's series, 62.297, \pm .0009

Cleve found, $62.423, \pm .0140$

General mean, $\overline{62.298, \pm .0007}$

From Chydenius' work we have four values for the molecular weight of thoria, which, combined as usual, give a general mean of $\mathrm{ThO}_{2}=$ $265.103, \pm .3394$. We also have the following ratios:

(I.) $2 \mathrm{BaSO}_{4}: \mathrm{ThO}_{2}:: 100: 58.026, \pm .214$

(2.) $2 \mathrm{BaSO}_{4}: \mathrm{Th}\left(\mathrm{SO}_{4}\right)_{2} \cdot 4 \mathrm{H}_{2} \mathrm{O}:$ : $100: 107.509, \pm .585$

(3.) $4 \mathrm{CO}_{2}: \mathrm{ThO}_{2}:: 100: 151.114, \pm .053$

(4.) Percentage of $\mathrm{ThO}_{2}$ in $\mathrm{Th}\left(\mathrm{SO}_{4}\right)_{2} \cdot 9 \mathrm{H}_{2} \mathrm{O}, 45.090, \pm .0019$

(5.) Percentage of $\mathrm{ThO}_{2}$ in $\mathrm{Th}\left(\mathrm{SO}_{4}\right)_{2} \cdot 4 \mathrm{H}_{2} \mathrm{O}, 52.535, \pm .0473$

(6.) Percentage of $\mathrm{ThO}_{2}$ in $\mathrm{Th}\left(\mathrm{SO}_{4}\right)_{2} \cdot 62.298, \pm .0007$

Reducing with the following data, seven values for the atomic weight of thoria are calculable:

$$
\begin{array}{ll}
\mathrm{O}=15.879, \pm .0003 & \mathrm{C}=11.920, \pm .0004 \\
\mathrm{~S}=31.828, \pm .0015 & \mathrm{Ba}=136.392, \pm .0086
\end{array}
$$

The values for $\mathrm{ThO}_{2}$ are-

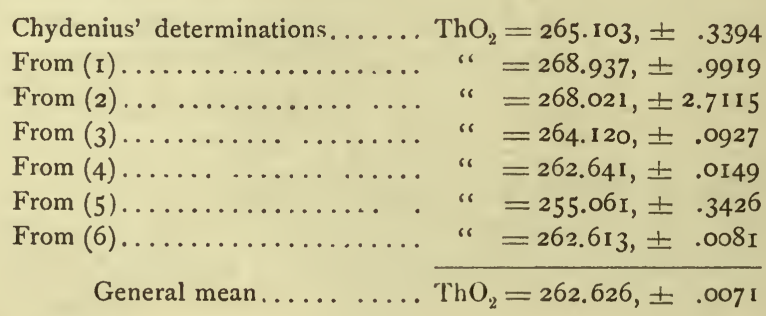

Hence $\mathrm{Th}=230.868, \pm .0071$.

If $\mathrm{O}=16, \mathrm{Th}=232.626$. 


\section{PHOSPHORUS.}

The material from which we are to calculate the atomic weight of phosphorus is by no means abundant. Berzelius, in his Lehrbuch,* adduces only his own experiments upon the precipitation of gold by phosphorus, and ignores all the earlier work relating to the composition of the phosphates. These experiments have been considered with reference to gold.

Pelouze, $\dagger$ in a single titration of phosphorus trichloride with a standard solution of silver, obtained a wholly erroneous result; and Jacquelain, $\ddagger$ in his similar experiments, did even worse. Schrötter's criticism upon Jacquelain sufficiently disposes of the latter. $\S$

Only the determinations made by Schrötter, Dumas, and Van der Plaats remain to be considered.

Schrötter $\|$ burned pure amorphous phosphorus in dry oxygen, and weighed the pentoxide thus formed. One gramme of $\mathrm{P}$ yielded $\mathrm{P}_{2} \mathrm{O}_{5}$ in the following proportions:

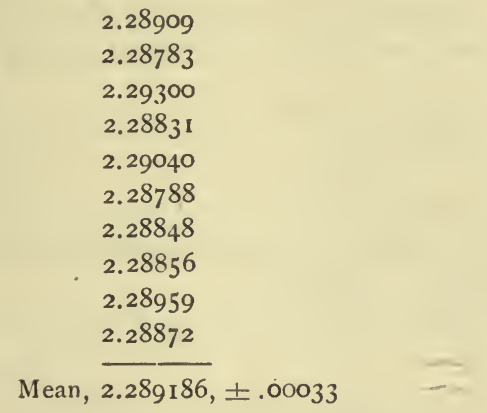

Dumas prepared pure phosphorus trichloride by the action of dry chlorine upon red phosphorus. The portion used in his experiments boiled between $76^{\circ}$ and $78^{\circ}$. This was titrated with a standard solution of silver in the usual manner. Dumas publishes weights, from which I calculate the figures given in the third column, representing the quantity of trichloride proportional to 100 parts of silver :

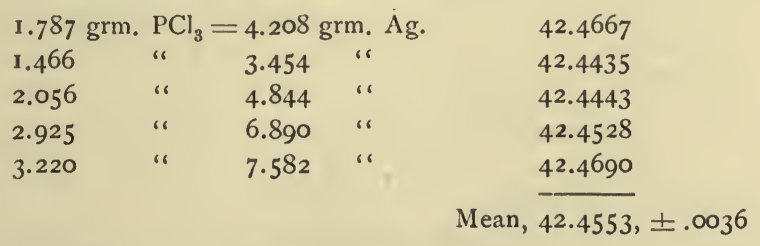

* sth ed., Ir 88.

† Compt. Rend., 20, 1047.

‡ Compt. Rend., 33, 693.

8. Journ. für Prakt. Chem., 57, 315.

\| Journ. für Prakt. Chem., 53, 435. 1851 .

If A 11n. Chem. Pharm., 113, 29. I860. 
By Van der Plaats* three methods of determination were adopted, and all weights were reduced to vacuum standards. First, silver was precipitated from a solution of the sulphate by means of phosphorus. The latter had been twice distilled in a current of nitrogen. The silver, before weighing, was heated to redness. The phosphorus equivalent to 100 parts of silver is given in the third column.

$$
\begin{array}{lrrr}
.9096 \text { grm. P gave } 15.8865 \mathrm{Ag} . & 5.7256 \\
.5832 & \text { " } 10.1622 \text { " } & 5.7389 \\
& & \text { Mean, } 5.7322, \pm .0045
\end{array}
$$

The second method consisted in the analysis of silver phosphate; but the process is not given. Van der Plaats states that it is difficult to be sure of the purity of this salt.

$$
\begin{aligned}
& \text { 6.6300 grm. } \mathrm{Ag}_{3} \mathrm{PO}_{4} \text { gave 5.1250 Ag. } \quad 77.300 \text { per cent. } \\
& 12.7170 \text { " } 9.8335 \text { " } 77.326 \text { " } \\
& \text { Mean, } 77.313, \pm .0088
\end{aligned}
$$

In the third set of determinations, yellow phosphorus was oxidized by oxygen at reduced pressure, and the resulting $\mathrm{P}_{2} \mathrm{O}_{5}$ was weighed.

$$
\begin{aligned}
& \text { I0.8230 grm. } \mathrm{P} \text { gave 24.7925 } \mathrm{P}_{2} \mathrm{O}_{5} \text {. Ratio, } 2.29072 \\
& 7.7624 \text { " } 17.7915 \text { " " } 2.29201
\end{aligned}
$$

As these figures fall within the range of Schrötter's, they may be averaged in with his series, the entire set of twelve determinations giving a mean of $2.28955, \pm .00032$.

From the following ratios an equal number of values for P may now be computed :

$$
\begin{aligned}
& \text { (I.) } 2 \mathrm{P}: \mathrm{P}_{2} \mathrm{O}_{5}:: \mathrm{I} .0: 2.28955, \pm .00032 \\
& \text { (2.) } 3 \mathrm{Ag}: \mathrm{PCl}_{3}:: 100: 42.4553, \pm .0036 \\
& \text { (3.) } 5 \mathrm{Ag}: \mathrm{P}:: 100: 5.7322, \pm .0045 \\
& \text { (4.) } \mathrm{Ag}_{3} \mathrm{PO}_{4}: 3 \mathrm{Ag}:: 100: 77.3 \mathrm{I} 3, \pm .0088
\end{aligned}
$$

Starting with $\mathrm{O}=15.879, \pm .0003, \mathrm{Ag}=107.108, \pm: 0031$, and $\mathrm{Cl}=$ $35.179, \pm .0048$, we have-

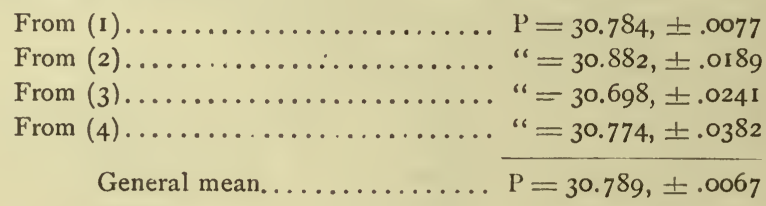

If $\mathrm{O}=16, \mathrm{P}=31.024$.

The highest of these figures is that from ratio number two, representing the work of Dumas. This is possibly due to the presence of oxychloride, in traces, in the trichloride taken. Such an impurity, if present, would tend to raise the apparent atomic weight of phosphorus. 


\section{VANADIUM.}

Roscoe's determination of the atomic weight of vanadium was the first to have any scientific value. The results obtained by Berzelius* and by Czudnowicz $\dagger$ were unquestionably too high, the error being probably due to the presence of phosphoric acid in the vanadic acid employed. This particular impurity, as Roscoe has shown, prevents the complete reduction of $\mathrm{V}_{2} \mathrm{O}_{5}$ to $\mathrm{V}_{2} \mathrm{O}_{3}$ by means of hydrogen. All vanadium ores contain small quantities of phosphorus, which can only be detected with ammonium molybdate - a reaction unknown in Berzelius' time. Furthermore, the complete purification of vanadic acid from all traces of phosphoric acid is a matter of great difficulty, and probably never was accomplished until Roscoe undertook his researches.

In his determination of the atomic weight, Roscoe $\ddagger$ studied two compounds of vanadium, namely, the pentoxide, $\mathrm{V}_{2} \mathrm{O}_{5}$, and the oxychloride, $\mathrm{VOCl}_{3}$. The pentoxide, absolutely pure, was reduced to $\mathrm{V}_{2} \mathrm{O}_{3}$ by heating in hydrogen, with the following results:

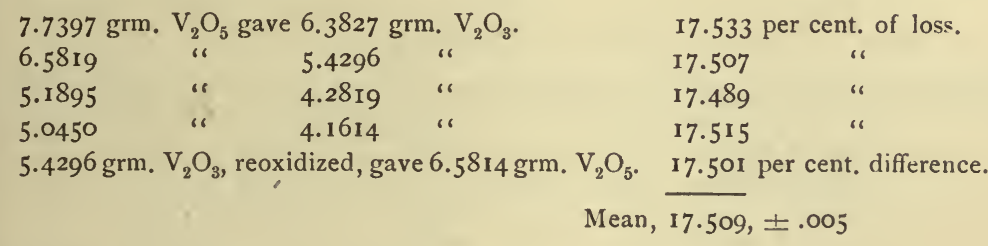

Hence $\mathrm{V}=50.993, \pm .(1219$.

Upon the oxychloride, $\mathrm{VOCl}_{3}$, two series of experiments were madeone volumetric, the other gravimetric. In the volumetric series the compound was titrated with solutions containing known weights of silver, which had been purified according to the methods recommended by Stas. Roscoe publishes his weighings, and gives percentages deduced from them; his figures, reduced to a common standard, make the quantities of $\mathrm{VOCl}_{3}$ given in the third column proportional to 100 parts of silver. He was assisted by two analysts:

Analyst $A$.

\begin{tabular}{|c|c|c|c|c|}
\hline $2.4322 \mathrm{grm}$. & $\mathrm{VOCl}_{3}$ & 4.5525 & Ag. & 53.425 \\
\hline 4.6840 & " & 8.7505 & “ & $53 \cdot 528$ \\
\hline 4.2188 & “ & 7.8807 & “ & 53.533 \\
\hline 3.9490 & " & 7.3799. & “ & 53.5 \\
\hline .9243 & "6 & 1.7267 & “ & $53 \cdot 5$ \\
\hline I. 4330 & " & 2.6769 & “ & 53.5 \\
\hline
\end{tabular}

* Poggend. Annal., 22, I4. 1831.

† Poggend. Annal., 120, 17. 1863.

† Journ. Chem. Soc., 6, pp. 330 and 344. 1868 . 
Analyst $B$.

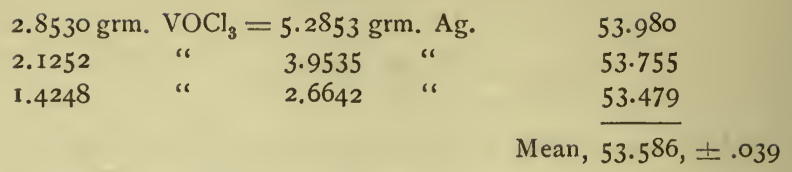

The gravimetric series, of course, fixes the ratio between $\mathrm{VOCl}_{3}$ and $\mathrm{AgCl}$. If we put the latter at 100 parts, the proportion of $\mathrm{VOCl}_{3}$ is as given in the third column:

\section{Analyst $A$.}

\begin{tabular}{|c|c|c|c|c|}
\hline I. $85^{21} \mathrm{I}$ & VOC & 4.5932 & . $\mathrm{AgC}$ & 40.323 \\
\hline .7013 & " & 1.7303 & “" & 40.531 \\
\hline .7486 & " & I. 8467 & “" & 40.537 \\
\hline I. 4408 & " & 3.5719 & “ & 40.337 \\
\hline .9453 & “" & 2. 3399 & “" & 40.399 \\
\hline I. 6183 & " & 4.0282 & " & 40.174 \\
\hline
\end{tabular}

\section{Analyst $B$.}

2.1 $936 \mathrm{grm}$. $\mathrm{VOCl}_{3}$ gave $5.4039 \mathrm{grm}$. AgCl. $\quad 40.39 \mathrm{I}$ 2.5054 " 6.2118 " 40.333

Mean, $\overline{40.378} \pm .028$

These two series give us two values for the molecular tweight of $\mathrm{VOCl}_{3}$ :

$$
\begin{aligned}
& \text { From volumetric series......... } \mathrm{VOCl}_{3}=\mathbf{1} 72.185, \pm .1254 \\
& \text { From gravimetric series....... " }=172.358, \pm .1196 \\
& \text { General mean.......... } \mathrm{VOCl}_{3}=172.277, \pm .0866
\end{aligned}
$$

Hence $\mathrm{V}=50.881, \pm .0877$.

Combining the two values for $\mathrm{V}$, we have :

$$
\begin{aligned}
& \text { From } \mathrm{VOCl}_{3} \ldots \ldots \ldots \ldots \ldots \ldots \ldots . \mathrm{V}=50.88 \mathrm{r}, \pm .0877 \\
& \text { From } \mathrm{V}_{2} \mathrm{O}_{5} \ldots \ldots \ldots \ldots \ldots \ldots \ldots \ldots \text {. }=50.993, \pm .0219 \\
& \text { General mean ............ V V }=50.986, \pm .0212
\end{aligned}
$$

If $\mathrm{O}=16, \mathrm{~V}=51.376$. These values are calculated with $\mathrm{O}=15.879$, $\pm .0003 ; \mathrm{Cl}=35.179, \pm .0048 ; \mathrm{Ag}=107.108, \pm .0031$, and $\mathrm{AgCl}=$ $142.287, \pm .0037$. 


\section{ARSENIC.}

For the determination of the atomic weight of arsenic three compounds have been studied - the chloride, the trioxide, and sodium pyroarsenate. The bromide may also be considered, since it was analyzed by Wallace in order to establish the atomic weight of bromine. His series, in the light of more recent knowledge, may properly be inverted, and applied to the determination of arsenic.

In 1826 Berzelius * heated arsenic trioxide with sulphur in such a way that only $\mathrm{SO}_{2}$ could escape. 2.203 grammes of $\mathrm{As}_{2} \mathrm{O}_{3}$, thus treated, gave a loss of 1.069 of $\mathrm{SO}_{2}$. Hence $\mathrm{As}=74.460$.

In 1845 Pelouze $\uparrow$ applied his method of titration with known quantities of pure silver to the analysis of the trichloride of arsenic, $\mathrm{AsCl}_{3}$. Using the old Berzelian atomic weights, and putting $\mathrm{Ag}=1349.01$ and $\mathrm{Cl}=443.2$, he found in three experiments for As the values $937.9,937.1$, and 937.4. Hence 100 parts of silver balance the following quantities of $\mathrm{AsCl}_{3}$ :

$$
\begin{gathered}
56.029 \\
56.009 \\
\frac{56.016}{56.018}, \pm .004
\end{gathered}
$$

Later, the same method was employed by Dumas, $\$$ whose weighings, reduced to the foregoing standard, give the following results:

$$
\begin{aligned}
& 4.298 \mathrm{grm} . \mathrm{AsCl}_{3}=7.673 \mathrm{grm} \text {. Ag. } \\
& 5.535 \text { " } 9.880 \text { " " } 56.022 \\
& 7.660 \text { " " } 13.686 \text { " " } 55.970 \\
& 4.680 \text { " " } 8.358 \text { " } 455.993 \\
& \text { Mean, } 56.000, \pm .008
\end{aligned}
$$

The two series of Pelouze and Dumas, combined, give a general mean of $56.014, \pm .0035$, as the amount of $\mathrm{AsCl}_{3}$ equivalent to 100 parts of silver. Hence $\mathrm{As}=74.450, \pm .019$, a value closely agreeing with that deduced from the single experiment of Berzelius.

The same process of titration with silver was applied by Wallace $\S$ to the analysis of arsenic tribromide, $\mathrm{AsBr}_{3}$. This compound was repeatedly distilled to ensure purity, and was well crystallized. His weighings show that the quantities of bromide given in the third column are proportional to 100 parts of silver:

$$
\begin{array}{llccc}
8.3246 \text { grm. } & \mathrm{As} \mathrm{Br}_{3}=8.58 \mathrm{grm} . \text { Ag. } & 97.023 \\
4.4368 & \text { “ } & 4.573 & \text { “ } & 97.022 \\
5.098 & \text { “ } & 5.257 & \text { “ } & 96.970 \\
& & & \text { Mean, } 97.005, \pm .012
\end{array}
$$


Hence As $=73.668, \pm .0436$. Why this value should be so much lower than that from the chloride is unexplained.

The volumetric work done by Kessler; * for the purpose of establishing the atomic weights of chromium and of arsenic, is described in the chromium chapter. In that investigation the amount of potassium dichromate required to oxidize 100 parts of $\mathrm{As}_{2} \mathrm{O}_{3}$ to $\mathrm{As}_{2} \mathrm{O}_{5}$ was determined and compared with the quantity of potassium chlorate necessary to produce the same effect. From the molecular weight of $\mathrm{KClO}_{3}$, that of $\mathrm{K}_{2} \mathrm{Cr}_{2} \mathrm{O}_{7}$ was then calculable.

From the same figures, the molecular weights of $\mathrm{KClO}_{3}$ and of $\mathrm{K}_{2} \mathrm{Cr}_{2} \mathrm{O}_{7}$ being both known, that of $\mathrm{As}_{2} \mathrm{O}_{3}$ may be easily determined. The quantities of the other compounds proportional to 100 parts of $\mathrm{As}_{2} \mathrm{O}_{3}$ are as follows :

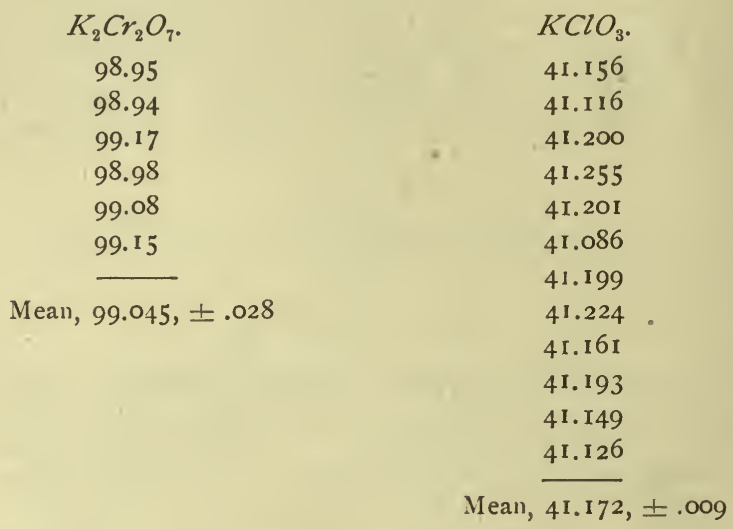

Another series with the dichromate gave the following figures:

$$
\begin{array}{r}
99.08 \\
99.06 \\
99.10 \\
98.97 \\
\frac{98.97}{\text { Mean, } 99.036, \pm .019} \\
\text { Previous series, } \frac{99.045, \pm .028}{\text { General mean, } 99.039, \pm .016}
\end{array}
$$

Other defective series are given to illustrate the partial oxidation of the $\mathrm{As}_{2} \mathrm{O}_{3}$ by the action of the air. From Kessler's data we get two values for the molecular weight of $\mathrm{As}_{2} \mathrm{O}_{3}$, thus :

$$
\begin{aligned}
& \text { From } \mathrm{KClO}_{3} \text { series............ } \mathrm{As}_{2} \mathrm{O}_{3}=196.95 \mathrm{I}, \pm .0445 \\
& \text { From } \mathrm{K}_{2} \mathrm{Cr}_{2} \mathrm{O}_{7} \text { series......... " } \quad=196.726, \pm .0562 \\
& \text { General mean......... } \mathrm{As}_{2} \mathrm{O}_{3}=\mathrm{I} 96.85 \mathrm{I}, \pm .0349
\end{aligned}
$$

And $\mathrm{As}=74.607, \pm .0175$. 
The determinations made by Hibbs* are based upon an altogether different process from any of the preceding measurements. Sodium pyroarsenate was heated in gaseous hydrochloric acid, yielding sodium chloride. The latter was perfectly white, completely soluble in water, unfused, and absolutely free from arsenic. The vacuum weights are subjoined, with a column giving the percentage of chloride obtained from the pyroarsenate.

$\mathrm{Na}_{4} \mathrm{As}_{2} \mathrm{O}_{7}$.
.02177
.04713
.05795
.40801
.50466
.77538
.82897
1.19124
1.67545
3.22637

$\mathrm{NaCl}$
.01439
.03115
.03830
.26981
.33345
.51249
.54791
.78731
1.10732
2.13267

Percentage.

66.100

66.094

66.091

66.128

66.092

66.095

66.095

66.092

66.091

66. 101

Hence As $=74.340, \pm .0235$.

Mean, $\overline{66.098} \pm .0030$

In the calculation of the foregoing values for arsenic, the subjoined atomic weights have been assumed :

$$
\begin{array}{ll}
\mathrm{O}=15.879, \pm .0003 & \mathrm{~K}=38.8 \mathrm{I} 7, \pm .005 \mathrm{I} \\
\mathrm{Ag}=107.108, \pm .003 \mathrm{I} & \mathrm{Na}=22.88 \mathrm{I}, \pm .0046 \\
\mathrm{Cl}=35.179, \pm .0048 & \mathrm{~S}=31.828, \pm .0015 \\
\mathrm{Br}=79.344, \pm .0062 & \mathrm{Cr}=51.742, \pm .0034
\end{array}
$$

To the single determination by Berzelius we may arbitrarily assign a weight equal to that of the result from Wallace's bromide series. The general combination is then as follows:

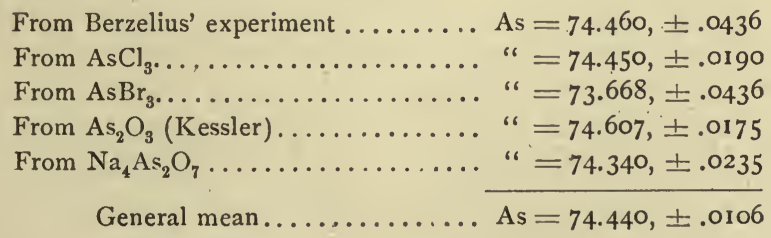

If $\mathrm{O}=16, \mathrm{As}=75.007$.

* Doctoral thesis, University of Pennsylvania, 1896. Work done under the direction of Professor E. F. Smith. In the fifth experiment the weight of $\mathrm{NaCl}$ is printed .33045 . This is evidently a misprint, which I have corrected by comparison with the other data. The rejection of this experiment would not affect the final result appreciably. 


\section{ANTIMONY.}

After some earlier, unsatisfactory determinations, Berzelius,* in 1826, published his final estimation of the atomic weight of antimony. $\mathrm{He}$ oxidized the metal by means of nitric acid, and found that 100 parts of antimony gave 124.8 of $\mathrm{Sb}_{2} \mathrm{O}_{4}$. Hence, if $\mathrm{O}=16, \mathrm{Sb}=129.03$. The value 129 remained in general acceptance until 1855, when Kessler, $\dagger$ by special volumetric methods, showed that it was certainly much too high. Kessler's results will be considered more fully further along, in connection with a later paper; for present purposes a brief statement of his earlieri conclusions will suffice. Antimony and various compounds of antimony were oxidized partly by potassium dichromate and partly by potassium chlorate, and from the amounts of oxidizing agent required the atomic weight in question was deduced:

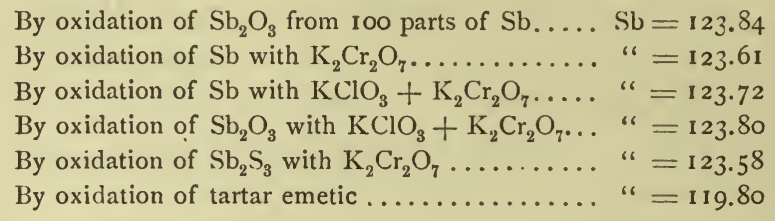

The figures given are those calculated by Kessler himself. A recalculation with our newer atomic weights for $\mathrm{O}, \mathrm{K}, \mathrm{Cl}, \mathrm{Cr}, \mathrm{S}$, and $\mathrm{C}$ would yield lower values. It will be seen that five of the estimates agree closely, while one diverges widely from the others. It will be shown hereafter that the concordant values are all vitiated by constant errors, and that the exceptional figure is after all the best.

Shortly after the appearance of Kessler's first paper, Schneider $\ddagger$ published some results obtained by the reduction of antimony sulphide in hydrogen. The material chosen was a very pure stibnite from Arnsberg, of which the gangue was only quartz. This was corrected for, and corrections were also applied for traces of undecomposed sulphide carried off mechanically by the gas stream, and for traces of sulphur retained by the reduced antimony. The latter sulphur was estimated as bariun sulphate. From 3.2 to 10.6 grammes of material were taken in each experiment. The final corrected percentages of $\mathrm{S}$ in $\mathrm{Sb}_{2} \mathrm{~S}_{3}$ were as follows: 


$$
\begin{array}{r}
28.485 \\
28.492 \\
28.48 \mathrm{I} \\
\hline \text { Mean, } 28.520, \pm .008
\end{array}
$$

Hence, if $\mathrm{S}=32, \mathrm{Sb}=120.3$.

Immediately after the appearance of Schneider's memoir, Rose* published the result of a single analysis of antimony trichloride, previously made under his supervision by $\mathrm{Weber}$. This analysis, if $\mathrm{Cl}=35.5$, makes $\mathrm{Sb}=120.7$, a value of no great weight, but in a measure confirmatory of that obtained by Schneider.

The next research upon the atomic weight of antimony was that of Dexter, $\uparrow$ published in 1857. This chemist, having tried to determine the amount of gold precipitable by a known weight of antimony, and having obtained discordant results, finally resorted to the original method of Berzelius. Antimony, purified with extreme care, was oxidized by nitric acid, and the gain in weight was determined. From 1.5 to 3.3 grammes of metal were used in each experiment. The reduction of the weights to a vacuum standard was neglected as being superfluous. From the data obtained, we get the following percentages of $\mathrm{Sb}^{\text {in }} \mathrm{Sb}_{2} \mathrm{O}_{4}$ :

\begin{tabular}{c}
79.268 \\
79.272 \\
79.255 \\
79.266 \\
79.253 \\
79.271 \\
79.264 \\
79.260 \\
79.286 \\
79.274 \\
79.232 \\
79.395 \\
79.379 \\
\hline Mean, $79.283, \pm .009$
\end{tabular}

Hence, if $\mathrm{O}=16, \mathrm{Sb}=122.46$.

The determinations of Dumas $\ddagger$ were published in 1859. This chemist sought to fix the ratio between silver and antimonious chloride, and obtained results for the atomic weight of antimony quite near to those of Dexter. The $\mathrm{SbCl}_{3}$ was prepared by the action of dry chlorine upon pure antimony; it was distilled several times over antimuny powder, and it seemed to be perfectly pure. Known weights of this preparation were added to solutions of tartaric acid in water, and the silver chloride was precipitated without previous removal of the antimony. Here, as 
Cooke has since shown, is a possible source of error, for under such circumstances the crystalline argento-antimonious tartrate may also be thrown down and contaminate the chloride of silver. But be that as it may, Dumas' weighings, reduced to a common standard, give as proportional to 100 parts of silver, the quantities of $\mathrm{SbCl}_{3}$ which are stated in the third of the subjoined columns:

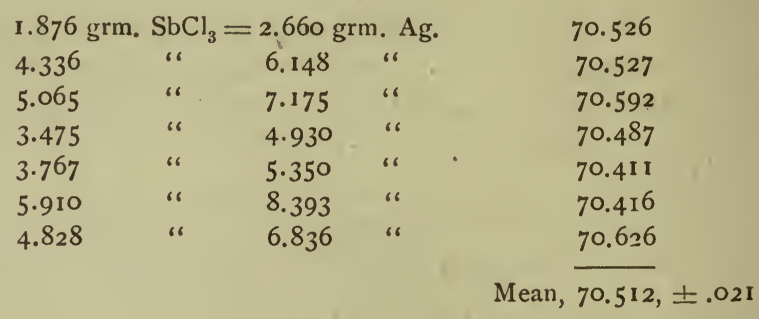

Hence, if $\mathrm{Ag}=108$, and $\mathrm{Cl}=35.5, \mathrm{Sb}=122$.

In 1861 Kessler's second paper* relative to the atomic weight of antimony appeared. Kessler's methods were somewhat complicated, and for full details the original memoirs must be consulted. A standard solution of potassium dichromate was prepared, containing 6.1466 grammes to the litre. With this, solutions containing known quantities of antimony or of antimony compounds were titrated, the end reaction being adjusted with a standard solution of ferrous chloride. In some cases the titration was preceded by the addition of a definite weight of potassium chlorate, insufficient for complete oxidation; the dichromate then served to finish the reaction. The object in view was to determine the amount of oxidizing agent, and therefore of oxygen, necessary for the conversion of known quantities of antimonious into antimonic compounds.

In the later paper Kessler refers to his earlier work, and shows that the values then found for antimony were all too high, except in the case of the series made with tartar emetic. That series he merely states, and subsequently ignores, evidently believing it to be unworthy of further consideration. For the remaining series he points out the sources of error. These need not be rediscussed here, as the discussion would have no value for present purposes; suffice it to say that in the series representing the oxidation of $\mathrm{Sb}_{2} \mathrm{O}_{3}$ with dichromate and chlorate, the material used was found to be impure. Upon estimating the impurity and correcting for it, the earlier value of $\mathrm{Sb}=123.80$ becomes $\mathrm{Sb}=122.36$, according to Kessler's calculations.

In the paper now under consideration four series of results are given. The first represents experiments made upon a pure antimony trioxide which had been sublimed, and which consisted of shining colorless needles. This was dissolved, together with some potassium chlorate, in 
hydrochloric acid, and titrated with dichromate solution. Six experiments were made, but Kessler rejects the first and second as untrustworthy. The data for the others are as follows:

$\begin{array}{ccc}\mathrm{Sb}_{2} \mathrm{O}_{3} . & \mathrm{KClO}_{3} . & \mathrm{K}_{2} \mathrm{Cr}_{2} \mathrm{O}_{7} \text { sol. in cc. } \\ 1.7888 \mathrm{grm} . & .4527 \mathrm{grm} . & 19.2 \mathrm{cc} . \\ 1.6523 \text { “ } & .4506 \text { “ } & 3.9 \text { “" } \\ 3.2998 \text { “ } & .8806 \text { “ } & 16.5 \text { “" } \\ 1.3438 \text { “ } & .3492 \text { " } & 10.2 \text { " }\end{array}$

From these figures Kessler deduces $\mathrm{Sb}=122.16$.

These data, reduced to a common standard, give the following quantities of oxygen needed to oxidize 100 parts of $\mathrm{Sb}_{2} \mathrm{O}_{3}$ to $\mathrm{Sb}_{2} \mathrm{O}_{5}$. Each cubic centimetre of the $\mathrm{K}_{2} \mathrm{Cr}_{2} \mathrm{O}_{7}$ solution corresponds to one milligramme of $\mathrm{O}$ :

$$
\begin{gathered}
10.985 \\
10.939 \\
10.951 \\
\text { Mean, } \frac{10.936}{10.953}, \pm .0075
\end{gathered}
$$

In the second series of experiments pure antimony was dissolved in hydrochloric acid with the aid of an unweighed quantity of potassium chlorate. The solution, containing both antimonious and antimonic compounds, was then reduced entirely to the antimonious condition by means of stannous chloride. The excess of the latter was corrected with a strong hydrochloric acid solution of mercuric chloride, then, after diluting and filtering, a weighed quantity of potassium chlorate was added, and the titration with dichromate was performed as usual. Calculated as above, the percentages of oxygen given in the last column correspond to 100 parts of antimony:

$\begin{array}{cccc}\mathrm{Sb} . & \mathrm{KClO}_{3} . & \mathrm{K}_{2} \mathrm{Cr}_{2} \mathrm{O}_{7} \text { sol. cc." } & \text { Per cent. O. } \\ 1.636 \mathrm{grm} . & 0.5000 \mathrm{grm} . & 18.3 & 13.088 \\ 3.0825 \text { " } & 0.9500 \text { " } & 30.2 & 13.050 \\ 4.5652 \text { " } & 1.4106 \text { " } & 45.5 & 13.098 \\ & & & \text { Mean, } 13.079, \pm .0096\end{array}$

This series gave Kessler $\mathrm{Sb}=122.34$.

The third and fourth series of experiments were made with pure antimony trichloride, $\mathrm{SbCl}_{3}$, prepared by the action of mercuric chloride upon metallic antimony. This preparation, in the third series, was dissolved in hydrochloric acid, and titrated. In one experiment solid $\mathrm{K}_{2} \mathrm{Cr}_{2} \mathrm{O}_{7}$ in weighed amount was added before titration; in the other two estimations $\mathrm{KClO}_{3}$ was taken as usual. The third column gives the percentages of oxygen corresponding to 100 parts of $\mathrm{SbCl}_{3}$. 
Per cent. $O$.

$1.8576 \mathrm{grm} . \mathrm{SbCl}_{3}$ needed $.5967 \mathrm{grm} . \mathrm{K}_{2} \mathrm{Cr}_{2} \mathrm{O}_{7}$ and $33.4 \mathrm{cc}$. sol. 7.0338

1.9118 " 3019 " $\mathrm{KClO}_{3}$ " 16.2 “ 7.0321

4.1235 " 4801 " $\mathrm{KClO}_{3}$ " 23.2 " 7.0222

Mean, $\overline{7.0294} \pm .0024$

The fourth set of experiments was gravimetric. The solution of $\mathrm{SbCl}_{3}$, mixed with tartaric acid, was first precipitated by hydrogen sulphide, in order to remove the antimony. The excess of $\mathrm{H}_{2} \mathrm{~S}$ was corrected by copper sulphate, and then the chlorine was estimated as silver chloride in the ordinary manner. 100 parts of $\mathrm{AgCl}$ correspond to the amounts of $\mathrm{SbCl}_{3}$ given in the third column.

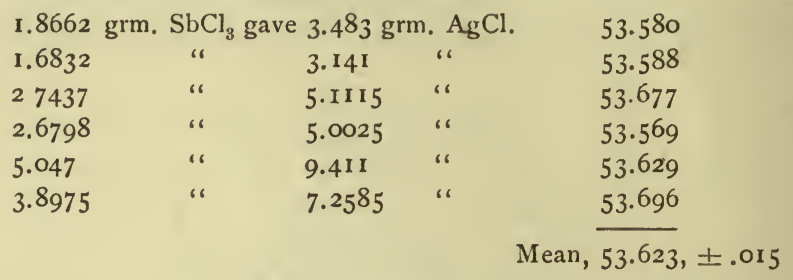

The volumetric series with ${ }^{\circ} \mathrm{SbCl}_{3}$ gave Kessler values for $\mathrm{Sb}$ ranging from 121.16 to 121.47. The gravimetric series, on the other hand, yielded results from $\mathrm{Sb}=124.12$ to 124.67 . This discrepancy Kessler rightly attributes to the presence of oxygen in the chloride; and, ingeniously correcting for this error, he deduces from both sets combined the value of $\mathrm{Sb}=122.37$.

The several mean results for antimony agree so fairly with each other, and with the estimates obtained by Dexter and Dumas, that we cannot wonder that Kessler felt satisfied of their general correctness, and of the inaccuracy of the figures published by Schneider. Still, the old series of data obtained by the titration of tartar emetic with dichromate contained no evident errors, and was not accounted for. This series, $*$ if we reduce all of Kessler's figures to a single common standard, gives a ratio between $\mathrm{K}_{2} \mathrm{Cr}_{2} \mathrm{O}_{7}$ and $\mathrm{C}_{4} \mathrm{H}_{4} \mathrm{KSbO}_{7} \cdot \frac{1}{2} \mathrm{H}_{2} \mathrm{O}$. 100 parts of the former will oxidize of the latter:

$$
\begin{array}{r}
336.64 \\
338.01 \\
336.83 \\
337.93 \\
338.59 \\
335.79 \\
\frac{337.30}{3} \pm .29
\end{array}
$$

From this, if $\mathrm{K}_{2} \mathrm{Cr}_{2} \mathrm{O}_{7}=292.271, \mathrm{Sb}=118.024$.

The newer atomic weights found in other chapters of this work will 
be applied to the discussion of all these series further along. It may, however, be properly noted at this point that the probable errors assigned to the percentages of oxygen in three of Kessler's series are too low. These percentages are calculated from the quantities of $\mathrm{KClO}_{3}$ involved in the several reactions, and their probable errors should be increased with reference to the probable error of the molecular weight of that salt. The necessary calculations would be more laborious than the importance of the figures would warrant, and accordingly, in computing the final general mean for antimony, Kessler's figures will receive somewhat higher weight than they are legitimately entited to.

Naturally, the concordant results of Dexter, Kessler, and Dumas led to the general acceptance of the value of 122 for antimony as against the lower figure, 120, of Schneider. Still, in 1871, Unger* published the results of a single analysis of Schlippe's salt, $\mathrm{Na}_{3} \mathrm{SbS}_{4} \cdot 9 \mathrm{H}_{2} \mathrm{O}$. This analysis gave $\mathrm{Sb}=119.76$, if $\mathrm{S}=32$ and $\mathrm{Na}=23$, but no great weight could be attached to the determination. It served, nevertheless, to show that the controversy over the atomic weight of antimony was not finally settled.

More than ten years after the appearance of Kessler's second paper the subject of the atomic weight of antimony was again taken up, this time by Professor Cooke. His results appeared in the autumn of $1877+$ and were conclusive in favor of the lower value, approximately 120 . For full details the original memoir must be consulted; only a few of the leading points can be cited here.

Schneider analyzed a sulphide of antimony which was already formed. Cooke, reversing the method, effected the synthesis of this "compound. Known weights of pure antimony were dissolved in hydrochloric acid containing a little nitric acid. In this solution weighed balls of antimony were boiled until the liquid became colorless; subsequently the weight of metal lost by the balls was ascertained. To the solution, which now contained only antimonious compounds, tartaric acid was added,oand then, with a supersaturated aqueous sulphhydric acid, antimony trisulphide was precipitated. The precipitate was collected by an ingenious process of reverse filtration, converted into the black modification by drying at $210^{\circ}$, and weighed. After weighing, the $\mathrm{Sb}_{2} \mathrm{~S}_{3}$ was dissolved in hydrochloric acid, leaving a carbonaceous residue unacted upon. This was carefully estimated and corrected for. About two grammes of antimony were taken in each experiment and thirteen syntheses were performed. In two of these, however, the antimony trisulphide was weighed only in the red modification, and the results were uncorrected by conversion into the black variety and estimation of the carbonaceous residue. In fact, every such conversion and correction was preceded by a weighing of the red modification of the $\mathrm{Sb}_{2} \mathrm{~S}_{3}$. The mean result of these weighings, if $\mathrm{S}=32$, gave $\mathrm{Sb}=119.994$. The mean result of the cor-

* Archiv. der Pharmacie, 197, 194. Quoted by Cooke.

† Proc. Amer. Acad., 5, 13. 
rected syntheses gave $\mathrm{Sb}=120.295$. In these eleven experiments the following percentages of $\mathrm{S}$ in $\mathrm{Sb}_{2} \mathrm{~S}_{3}^{\prime}$ were established:

28.57
28.60
28.57
28.43
28.42
28.53
28.50
28.49
28.58
28.50
28.51
Mean, $28.5182, \pm .0120$

These results, confirmatory of the work of Schneider, were presented to the American Academy in 1876. Still, before publication, Cooke thought it best to repeat the work of Dumas, in order to detect the cause of the old discrepancy between the values $\mathrm{Sb}=120$ and $\mathrm{Sb}=122$. Accordingly, various samples of antimony trichloride were taken, and purified by repeated distillations. The final distillate was further subjected to several recrystallizations from the fused state; or, in one case, from a saturated solution in a bisulphide of carbon. The portions analyzed were dissolved in concentrated aqueous tartaric acid, and precipitated by silver nitrate, many precautions being observed. The silver chloride was collected by reverse filtration, and dried at temperatures from $110^{\circ}$ to $120^{\circ}$. In one experiment the antimony was first removed by $\mathrm{H}_{2} \mathrm{~S}$. Seventeen experiments were made, giving, if $\mathrm{Ag}=108$ and $\mathrm{Cl}=35.5$, a mean value of $\mathrm{Sb}=121.94$. If we reduce to a common standard, Cooke's analyses give, as proportional to 100 parts of $\mathrm{AgCl}$, the quantities of $\mathrm{SbCl}_{3}$ stated in the third column:

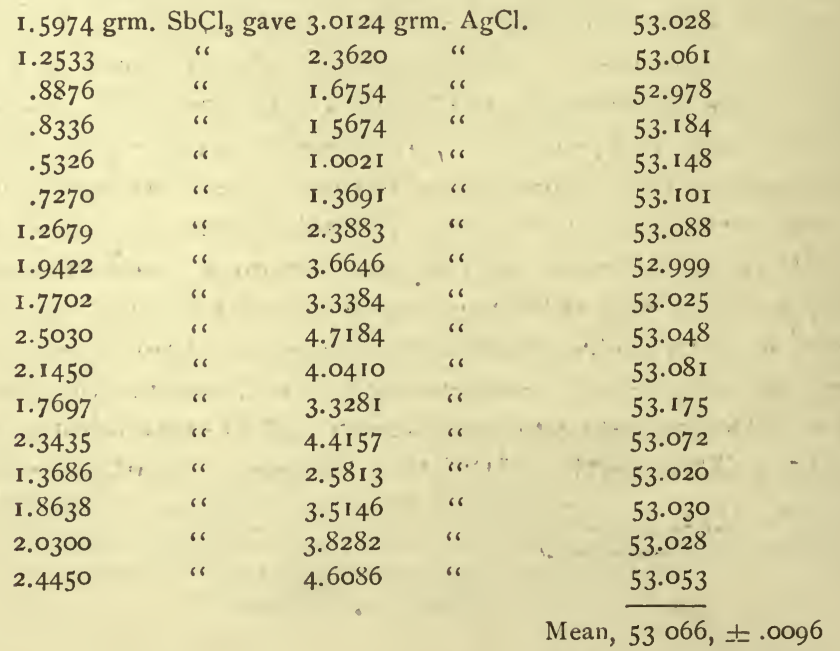


This mean may be combined with that of Kessler's series, as follows:

$$
\begin{aligned}
& \text { Kessler...................... 53.623, } \pm .015 \\
& \text { Cooke....................... 53.066, } \pm .0096 \\
& \text { General mean ............. 53.23II, } \pm .008
\end{aligned}
$$

The results thus obtained with $\mathrm{SbCl}_{3}$ confirmed Dumas' determination of the atomic weight of antimony as remarkably as the syntheses of $\mathrm{Sb}_{2} \mathrm{~S}_{3}$ had sustained the work of Schneider. Evidently, in one or the other series a constant error must be hidden, and much time was spent by Cooke in searching for it. It was eventually found that the chloride of antimony invariably contained traces of oxychloride, an impurity which tended to increase the apparent atomic weight of the metal under consideration. It was also found, in the course of the investigation, that hydrochloric acid solutions of antimonious compounds oxidize in the air during boiling as rapidly as ferrous compounds, a fact which explains the high values for antimony found by Kessler.

In order to render "assurance doubly sure," Professor Cooke also undertook the analysis of the bromide and the iodide of antimony. The bromide, $\mathrm{SbBr}_{3}$, was prepared by adding the finely powdered metal to a solution of bromine in carbon disulphide. It was purified by repeated distillation over pulverized antimony, and by several recrystallizations from bisulphide of carbon. The bromine determinations resemble those of chlorine, and gave, if $\mathrm{Ag}=108$ and $\mathrm{Br}=80$, a mean value for antimony of $\mathrm{Sb}=120$. Reduced to a common standard, the fifteen analyses give the subjoined quantities of $\mathrm{SbBr}_{3}$ proportional to 100 parts of silver bromide:

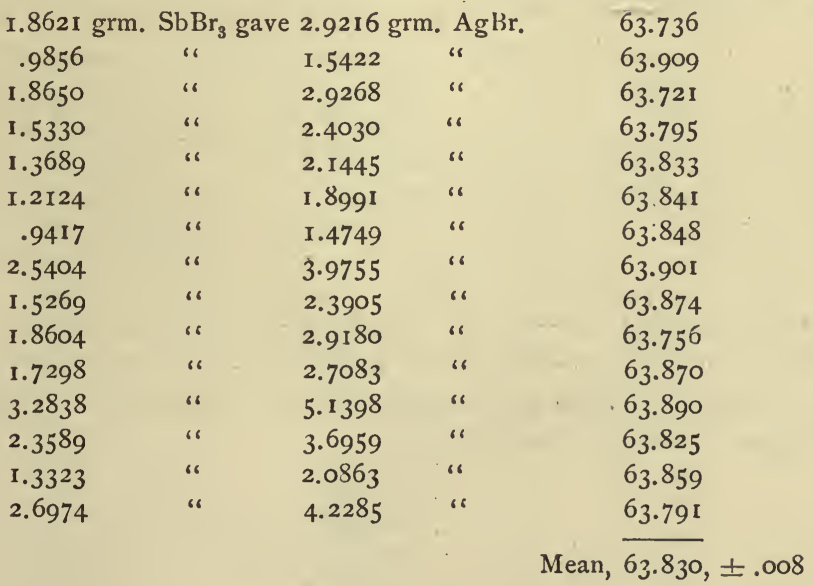

The iodide of antimony was prepared like the bromide, and analyzed in the same way. At first, discordant results were obtained, due to the presence of oxyiodide in the iodide studied. The impurity, however, 
was removed by subliming the iodide in an atmosphere of dry carbon dioxide. With this purer material, seven estimations of iodine were made, giving, if $\mathrm{Ag}=108$ and $\mathrm{I}=127$, a value for antimony of $\mathrm{Sb}=120$. Reduced to a uniform standard, Cooke's weighings give the following quantities of $\mathrm{SbI}_{3}$ proportional to 100 parts of silver iodide :

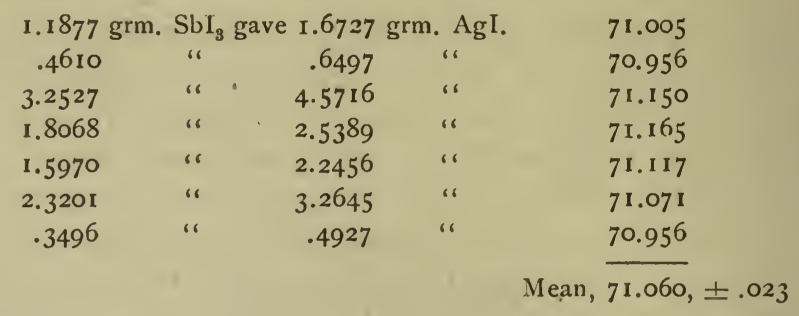

Although Cooke's work was practically conclusive, as between the rival values for antimony, his results were severely criticised by Kessler,* who evidently had read Cooke's paper in a very careless way. On the other hand, Schneider published in Poggendorff's Annalen a friendly review of the new determinations, which so well vindicated his own accuracy. In reply to Kessler, Cooke undertook still another series of experiments with antimony bromide, $\dagger$ and obtained absolute confirmation of his previous results. To a solution of antimony bromide was added a solution containing a known weight of silver not quite sufficient to precipitate all the bromine. The excess of the latter was estimated by titration with a normal silver solution. Five analyses gave values for antimony ranging from 119.98 to 120.02 , when $\mathrm{Ag}=108$ and $\mathrm{Br}=80$. Reduced to a common standard, the weights obtained gave the amounts of $\mathrm{SbBr}$ stated in the third column as proportional to 100 parts of silver:

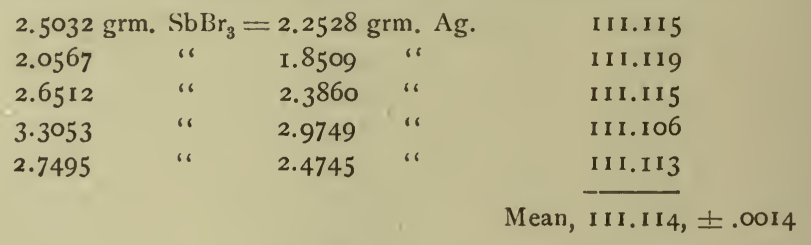

Schneider, $₫$ also, in order to more fully answer Kessler's objections, repeated his work upon the Arnsberg stibnite. This he reduced in hydrogen as before, correcting scrupulously for impurities. The following percentages of sulphur were found :

$$
\begin{aligned}
28.546 \\
28.534 \\
28.542 \\
\hline \text { Mean, } 28541, \pm .0024
\end{aligned}
$$

* Berichte d. Deutsch. Chem. Gesell., I2, 1044. 1879.

† Amer. Journ. Sci. and Arts, May, r880. Berichte, I3, 951.

$\ddagger$ Journ. für Prakt. Chem. (2), 22, 135. 
These figures confirm his old results, and may be fairly combined with them and with the percentages found by Cooke, as follows :

$$
\begin{aligned}
& \text { Schneider, early series............. 28.520, } \pm .008 \\
& \text { Schneider, late series.............. 28.54r, } \pm .0024 \\
& \text { Cooke ..................... 28.5182, } \pm .0120 \\
& \text { General mean............. 28.5385, } \pm .0023
\end{aligned}
$$

In 1881 Pfeifer* determined electrolytically the direct ratios between silver and antimony, and copper and antimony. With copper the following data were obtained :

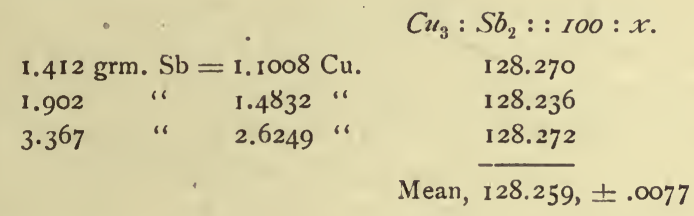

\begin{tabular}{|c|c|c|}
\hline \multicolumn{3}{|c|}{$5.925 \mathrm{grm} . \mathrm{Sb}=15.774$} \\
\hline 6.429 & “" & 17.109 \\
\hline 10. II6 & “ & 26.972 \\
\hline 4865 & “ & 13.014 \\
\hline $4 \cdot 390$ & “ & 11.697 \\
\hline 9.587 & “ & $25.6 \mathrm{II}$ \\
\hline 4.525 & " & I 2.097 \\
\hline
\end{tabular}

If $\mathrm{Cu}=63.6, \mathrm{Sb}=122.36$.

With silver he found-

$A g_{3}: S b:: 100: x$.
37.562

37.577

37.506

37.383

37.531

37.433

37.406

Mean, $\overline{37.485} \pm, 0198$

If $\mathrm{Ag}=108, \mathrm{Sb}=121.45$.

The latter ratio was also determined by Popper, $\uparrow$ several years after-

\begin{tabular}{|c|c|c|}
\hline$S b$. & $A g$. & Ratio. \\
\hline 1.4856$\}$ & 3.0655 & 37.463 \\
\hline I. 4788$\}$ & 3.9055 & 37.292 \\
\hline 2.0120$\}$ & 5.3649 & 37.503 \\
\hline 2.0074$\}$ & & 37.417 \\
\hline 38882$\}$ & 10.3740 & 37.480 \\
\hline 3.8903$\}$ & 10.3140 & 37.500 \\
\hline 4.1893$\}$ & I I. I 847 & 37.455 \\
\hline 4.1885 & & 37.447 \\
\hline
\end{tabular}
wards. The two metals were precipitated simultaneously by the same current; and in some experiments two portions of antimony were thrown down against one of silver. These are indicated in the subjoined table by suitable bracketing, and the ratio is given in the third column: 


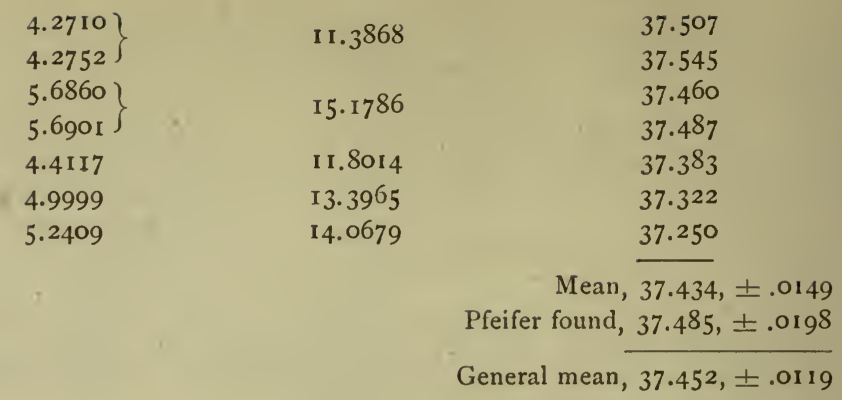

If $\mathrm{Ag}=108$, Popper's figures give in mean $\mathrm{Sb}=121.3$.

I am inclined to attach slight importance to these electrolytic data, for the reasons that it would be very difficult to ensure the absolute purity and freedom from occlusions of the antimony as weighed, or to guarantee that no secondary reactions had modified the ratios.

The work done by Bongartz * in 1883 was quite different from any of the determinations which had preceded it. Carefully purified antimony was weighed as such, and then dissolved in a concentrated solution of potassium sulphide. From this, after strong dilution, antimony trisulphide was thrown down by means of dilute sulphuric acid. After thorough washing, this sulphide was oxidized by hydrogen peroxide, by Classen's method, and the sulphur in it was weighed as barium sulphate. The ratio measured, therefore, was $2 \mathrm{Sb}: 3 \mathrm{BaSO}_{4}$, and the data were as follows. The $\mathrm{BaSO}_{4}$ equivalent to 100 parts of $\mathrm{Sb}$ is the ratio stated :

$\begin{array}{rcc}\text { Sb Taken. } & \text { BaSO }{ }_{4} \text { Found. } & \text { Ratio. } \\ 1.4921 & 4.3325 & 290.362 \\ .6132 & 1.7807 & 290.394 \\ .5388 & 1.5655 & 290.553 \\ 1.2118 & 3.5205 & 290.518 \\ .9570 & 2.7800 & 290.491 \\ .6487 & 1.8855 & 290.349 \\ .7280 & 2.1100 & 289.835 \\ .9535 & 2.7655 & 290.036 \\ 1.0275 & 2.9800 & 290.024 \\ .9635 & 2.7980 & 290.399 \\ .9255 & 2.6865 & 290.275 \\ .7635 & 2.2175 & 290.438 \\ & & -290.306, \pm .0436\end{array}$

We have now before us the following ratios, good and bad, from which to calculate the atomic weight of antimony. The single results obtained by Weber and by Unger, being unimportant, are not included: 
(1.) Percentage of $\mathrm{S}$ in $\mathrm{Sb}_{2} \mathrm{~S}_{3}, 28.5385, \pm .0023$

(2.) Percentage of $\mathrm{Sb}$ in $\mathrm{Sb}_{2} \mathrm{O}_{4}, 79.283, \pm .009$

(3.) O needed to oxidize 100 parts $\mathrm{SbCl}_{3}, 7.0294, \pm .0024$

(4.) O needed to oxidize 100 parts $\mathrm{Sb}_{2} \mathrm{O}_{3}, 10.953, \pm .0075$

(5.) O needed to oxidize Ioo parts $\mathrm{Sb}, \mathbf{1} 3.079, \pm .0096$

(6.) $\mathrm{K}_{2} \mathrm{Cr}_{2} \mathrm{O}_{7}:$ tartar emetic : : $100: 337.30, \pm .29$

(7.) $\mathrm{Ag}_{3}: \mathrm{SbCl}_{3}:: 100: 70.512, \pm .02 \mathrm{I}$

(8.) $3 \mathrm{AgCl}: \mathrm{SbCl}_{3}:: 100: 53.23 \mathrm{II}, \pm .008$

(9.) $\mathrm{Ag}_{3}: \mathrm{SbBr}_{3}::$ I00: III.II $4, \pm .0014$

(10.) $3 \mathrm{AgBr}: \mathrm{SbBr}_{3}:: 100: 63.830, \pm .008$

(II.) $3 \mathrm{AgI}: \mathrm{SbI}_{3}:: 100: 71.060, \pm .023$

(12.) $\mathrm{Cu}_{3}: \mathrm{Sb}_{2}:: 100: 128.259, \pm .0077$

(13.) $\mathrm{Ag}_{3}: \mathrm{Sb}:: 100: 37.452, \pm .0119$

(14.) $\mathrm{Sb}_{2}: 3 \mathrm{BaSO}_{4}:: 100: 290.306, \pm .0436$

In the reduction of these ratios a considerable number of antecedent atomic weights are required, thus :

$\begin{array}{ll}\mathrm{O}=15.879, \pm .0003 & \mathrm{C}=11.92 \mathrm{C}, \pm .0004 \\ \mathrm{Ag}=107.108, \pm .0031 & \mathrm{Cu}=63.119, \pm .0015 \\ \mathrm{Cl}=35.179, \pm .0048 & \mathrm{Ba}=136.392, \pm .0086 \\ \mathrm{Br}=79.344, \pm .0062 & \mathrm{Cr}=51.742 \pm .0034 \\ \mathrm{I}=125.888, \pm .0069 & \mathrm{AgCl}=142.287, \pm .0037 \\ \mathrm{~K}=38.817, \pm .0051 & \mathrm{AgBr}=186.452 \pm .0054 \\ \mathrm{~S}=31.828, \pm .0015 & \mathrm{AgI}=232.996 \pm .0062\end{array}$

Three of the ratios give the molecular weight of antimony trichloride, and two give corresponding values for the bromide. These values may be combined, as follows: First, for the chloride-

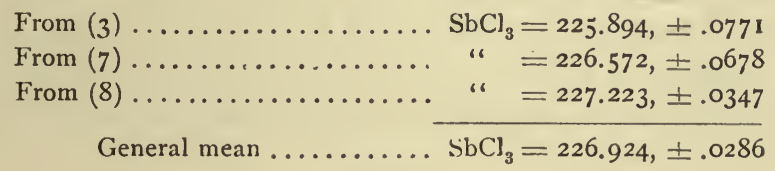

\section{Hence $\mathrm{Sb}=121.387, \pm .0321$.}

For the bromide we have-

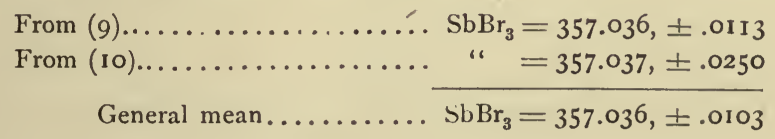

$$
\text { Hence } \mathrm{Sb}=119.005, \pm .0212 \text {. }
$$

All the data yield eleven values for antimony, which are arranged below in the order of their magnitude: 

I. From tartar emetic, ratio (6).... Sb $=118.024, \pm .2827$
2. From $\mathrm{SbBr}_{3} . \ldots \ldots \ldots \ldots \ldots \ldots$. $=119.005, \pm .0212$
3. From $\mathrm{SbI}_{3}$, ratio (II) ........ “ $=119.037, \pm .1626$
4. From $\mathrm{Sb}_{2} \mathrm{~S}_{3}$, ratio (I)........ " $=119.548, \pm .0069$
5. From ratio $(14) \ldots \ldots \ldots \ldots \ldots$. $=119.737, \pm .0188$
6. From ratio $(13) \ldots \ldots \ldots \ldots \ldots \ldots$ " $=120.342, \pm .0384$
7. From ratio (4)............ " $=121.155, \pm .1000$
8. From $\mathrm{SbCl}_{3} \ldots \ldots \ldots \ldots \ldots \ldots \ldots$ " $=\mathrm{I} 2 \mathrm{I} \cdot 3^{87}, \pm .032 \mathrm{I}$
9. From ratio $(5) \ldots \ldots \ldots \ldots \ldots \ldots$ " $=121.408, \pm .089 \mathrm{I}$
10. From ratio $(12) \ldots \ldots \ldots \ldots \ldots$ " $=121.434, \pm .0078$
11. From $\mathrm{Sb}_{2} \mathrm{O}_{4}$, ratio (2)........ “ $=121.542, \pm .0546$
General mean............ $\mathrm{sb}=120.299, \pm .0047$

If $\mathrm{O}=16$, this becomes $\mathrm{Sb}=121.218$.

Among these figures the discordance is so great that the mathematical combination has no real value. We must base our judgment in this case mainly upon chemical evidence, and this, as shown in the investigations of Cooke and of Schneider, favors a lower rather than a higher value for the atomic weight of antimony. Dumas' work was affected by constant errors which are now known, and Dexter's data are also presumably in the wrong. A general mean of values 2, 3, 4, and 5 gives $\mathrm{Sb}=119.521$, \pm .0062 , or, if $\mathrm{O}=16, \mathrm{Sb}=120.432$. Even now the range of uncertainty is greater than it should be, but none of the four values combined can be accepted exclusively or rejected without more evidence. This result, therefore, should be adopted until new determinations, of a more conclusive nature, have been made. 


\section{BISMU'TH.}

Early in the century the combining weight of bismuth was approximately fixed through the experiments of Lagerhjelm.* Effecting the direct union of bismuth and sulphur, he found that ten parts of the metal yield the following quantities of trisulphide:

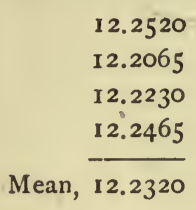

Hence $\mathrm{Bi}=215$ in round numbers, a value now known to be much too high. Lagerhjelm also oxidized bismuth with nitric acid, and, after ignition, weighed the trioxide thus formed. Ten parts of metal gave the following quantities of $\mathrm{Bi}_{2} \mathrm{O}_{3}$ :

$$
\begin{aligned}
& \text { II.1382 } \\
& \text { Mean, } \\
& \frac{11.1275}{1.3285}
\end{aligned}
$$

Hence, if $\mathrm{O}=16, \mathrm{Bi}=211.85$, a figure still too high.

In 1851 the subject of the atomic weight of bismuth was taken up by Schneider, $\uparrow$ who, like Lagerhjelm, studied the oxidation of the metal with nitric acid. The work was executed with a variety of experimental refinements, by means of which every error due to possible loss of material was carefully avoided. For full details the original paper must be consulted; there is only room in these pages for the actual results, as follows. The figures represent the percentages of $\mathrm{Bi}$ in $\mathrm{Bi}_{2} \mathrm{O}_{3}$ :

$$
\begin{gathered}
89.652 \\
89.682 \\
89.644 \\
89.634 \\
89.656 \\
89.666 \\
89.655 \\
89.653 \\
\text { Mean, } 89.655^{2}, \pm .0034
\end{gathered}
$$

Hence, if $\mathrm{O}=16, \mathrm{Bi}=208.05$.

Next in order are the results obtained by Dumas. $\ddagger$ Bismuth tri- 
chloride was prepared by the action of dry chlorine upon bismuth, and repeatedly rectified by distillation over bismuth powder. The product was weighed in a closed tube, dissolved in water, and precipitated with sodium carbonate. In the filtrate, after strongly acidulating with nitric acid, the chlorine was precipitated by a known amount of silver. The figures in the third column show the quantities of $\mathrm{BiCl}_{3}$ proportional to 100 parts of silver:

\begin{tabular}{|c|c|c|c|c|}
\hline $3.506 \mathrm{~g}$ & B & $=3.545$ & Ag. & 98.900 \\
\hline 1. 149 & " & I. 168 & “" & 98.373 \\
\hline I. 5965 & ، & 1.629 & ، & 98.005 \\
\hline 2.1767 & “" & 2.225 & “" & 97.829 \\
\hline $3.08 \mathrm{I}$ & ، & 3. 144 & “ & 97.996 \\
\hline 2.4158 & ، & 2.470 & “ & 97.806 \\
\hline I. 7107 & " & $1.75^{2}$ & “ & 97.643 \\
\hline 3.523 & ، & 3.6055 & "، & 97.712 \\
\hline $5.24 \mathrm{I}$ & ، & $5.36 \mathrm{I}$ & “ & 97.762 \\
\hline
\end{tabular}

Hence, with $\mathrm{Ag}=108$ and $\mathrm{Cl}=35.5, \mathrm{Bi}=211.03$.

The first three of the foregoing experiments were made with slightly discolored material. The remaining six percentages give a mean of 97.791, whence, on the same basis as before, $\mathrm{Bi}=110.79$. Evidently these results are now of slight value, for it is probable that the chloride of bismuth, like the corresponding antimony compound, contained traces of oxychloride. This assumption fully accounts for the discordance between Dumas' determination and the determinations of Schneider and of still more recent investigators.

In 1883 Marignac * took up the subject, attacking the problem by two methods. His point of departure was commercial subnitrate of bismuth, which was purified by re-solution and reprecipitation, and from which he prepared the oxide. First, bismuth trioxide was reduced by heating in hydrogen, beginning with a moderate temperature and closing the operation at redness. The results were as follows, with the percentage of $\mathrm{Bi}$ in $\mathrm{Bi}_{2} \mathrm{O}_{3}$ added:

\begin{tabular}{|c|c|c|c|}
\hline 6.7057 & " & 6910 & “ \\
\hline 3.6649 & “" & .3782 & “ \\
\hline 5.8024 & "، & $.598 \mathrm{I}$ & “" \\
\hline 5.1205 & “" & .5295 & “ \\
\hline 5.5640 & ، & .5742 & “ \\
\hline
\end{tabular}

89.683 per cent.

89.696 “
89.681 “
89.692 “
89.658 “
$\frac{89.680}{89}$ “
Mean, $89.682, \pm .0036$

Hence, if $\mathrm{O}=16, \mathrm{Bi}=208.60$. 
Marignac's second method of determination was by conversion of the oxide into the sulphate. The oxide was dissolved in nitric acid, and then sulphuric acid was added in slight excess from a graduated tube. The mass was evaporated to dryness with great care, and finally heated over a direct flame until fumes of $\mathrm{SO}_{3}$ no longer appeared. The third column gives the sulphate formed from 100 parts of oxide:

\begin{tabular}{llll}
2.6503 & \multicolumn{3}{c}{$\mathrm{Bi}_{2} \mathrm{O}_{3}$ gave $4.0218 \mathrm{Bi}_{2}\left(\mathrm{SO}_{4}\right)_{3}$. } \\
2.8025 & " & 4.2535 & " \\
2.710 & “ & 4.112 & " \\
2.813 & " & 4.267 & " \\
2.8750 & " & 4.3625 & " \\
2.7942 & " & 4.2383 &
\end{tabular}

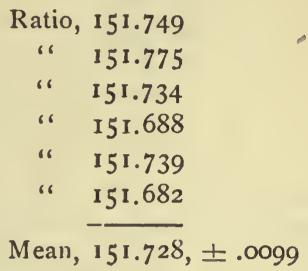

Hence, with $\mathrm{O}=16$ and $\mathrm{S}=32.06, \mathrm{Bi}=208.16$.

This result needs to be studied in the light of Bailey's observation,* that bismuth sulphate has a very narrow range of stability. It loses the last traces of free sulphuric acid at $405^{\circ}$, and begins to decompose at $418^{\circ}$, so that the foregoing ratio is evidently uncertain. The concordance of the data, however, is favorable to it.

The next determination of this atomic weight was by Löwe, $\dagger$ who oxidized the metal with nitric acid, and reduced the nitrate to oxide by ignition. Special care was taken to prepare bismuth free from arsenic, and the oxide was fused before weighing. In the paper just quoted Bailey calls attention to the volatility of bismuth oxide, which doubtless accounts for the low results found in this investigation. The data are as follows:

Bi Taken.

11.309

12.2776
$\mathrm{Bi}_{2} \mathrm{O}_{3}$ Found.

12.616

I3.694
Per cent. Bi.

$$
\begin{gathered}
89.640 \\
\frac{89.656}{89.648}, \pm .0040
\end{gathered}
$$

Hence. if $\mathrm{O}=16, \mathrm{Bi}=207.84$.

In Classen's $\ddagger$ work upon the atomic weight of bismuth, the metal itself was first carefully investigated. Commercial samples, even those which purported to be pure, were found to be contaminated with lead and other impurities, and these were not entirely removable by many successive precipitations as subnitrate. Finally, pure bismuth was obtained by an electrolytic process, and this was converted into oxide by means of nitric acid and subsequent ignition to incipient fusion. Results as follows, with the percentage of $\mathrm{Bi}$ in $\mathrm{Bi}_{2} \mathrm{O}_{3}$ added: 


$\begin{array}{ccc}\text { Bi Taken. } & \mathrm{Bi}_{2} \mathrm{O}_{3} \text { Found. } & \text { Percent. Bi. } \\ 25.0667 & 27.9442 & 89.703 \\ 21.0691 & 23.4875 & 89.7035 \\ 27.2596 & 30.3922 & 89.693 \\ 36.5195 & 40.713 \mathrm{I} & 89.700 \\ 27.9214 & 31.1295 & 89.6944 \\ 32.1188 & 35.8103 & 89.692 \\ 30.1000 & 33.5587 & 89.694 \\ 26.4825 & 59.5257 & 89.693 \\ 19.8008 & 22.0758 & 89.695 \\ & & \end{array}$

Hence, if $\mathrm{O}=16, \mathrm{Bi}=208.92$, or, reduced to vacuum standards, 208.90 . Classen's paper was followed by a long controversy between Schneider and Classen,* in which the former upheld the essential accuracy of the work done by Marignac and himself. Schneider had started out with commercial bismuth, and Classen found that the commercial bismuth which he met with was impure. Schneider, by various analyses, showed that other samples of bismuth were so nearly pure that the common modes of purification were adequate; but Classen replied that the original sample used by Schneider in his atomic weight investigation had not been reëxamined. Accordingly, Schneider published a new series of determinations $\dagger$ made by the old method, but with metal which had been scrupulously purified. Results as follows:

\begin{tabular}{ccc}
\multicolumn{1}{c}{$\mathrm{Bi.}$} & $\mathrm{Bi}_{2} \mathrm{O}_{3}$. & Per cent. Bi. \\
5.0092 & 5.5868 & $89.66 \mathrm{I}$ \\
3.6770 & 4.1016 & 89.648 \\
7.2493 & 8.0854 & 89.659 \\
9.2479 & 10.3142 & 89.662 \\
6.0945 & 6.7979 & 89.653 \\
12.1588 & 13.5610 & 89.660 \\
& & Mean, $89.657, \pm .0015$
\end{tabular}

Hence with $\mathrm{O}=16, \mathrm{Bi}=208.05$, a confirmation of the earlier determinations.

Although the results so far are not final, a combination of the data relative to bismuth oxide is not without interest.

I. Lagerhjelm ................... 89.865, \pm .0650

2. Schneider, $1851 \ldots \ldots \ldots \ldots \ldots \ldots$. 89.655, \pm .0034

3. Marignac ................... 89.682, \pm .0036

4. Löwe ..................... 89.648, \pm .0040

5. Classen .................. 89.696, \pm .0009

6. Schneider, $1894 \ldots \ldots \ldots \ldots \ldots \ldots$. 89.657, \pm . oor 5

General mean.............. 89.68r, \pm .0007

* Journ. für Prakt. Chem. (2), 42, 553; 43, I33; and 44, 23 and $4 \mathrm{II}$. † Journ. für Prakt. Chem. (2), 50, 46r. 1894. 
Omitting the first and fifth means, the other data give a general mean percentage of $89.659, \pm .0012$.

The ratios now before us are as follows:

(1.) Percentage of $\mathrm{Bi}$ in $\mathrm{Bi}_{2} \mathrm{O}_{3}, 89.681, \pm .0007$

(2.) $\mathrm{Bi}_{2} \mathrm{O}_{3}: \mathrm{Bi}_{2}\left(\mathrm{SO}_{4}\right)_{3}:: 100: 151.728, \pm .0099$

(3.) $3 \mathrm{Ag}: \mathrm{BiCl}_{3}:: 100: 98.003, \pm .090$

For computation we have-

$$
\begin{array}{ll}
\mathrm{O}=15.879, \pm .0003 & \mathrm{Ag}=107.108, \pm .0031 \\
\mathrm{~S}=31.828, \pm .0015 & \mathrm{Cl}=35.179, \pm .0048
\end{array}
$$

Hence, reducing the ratios-

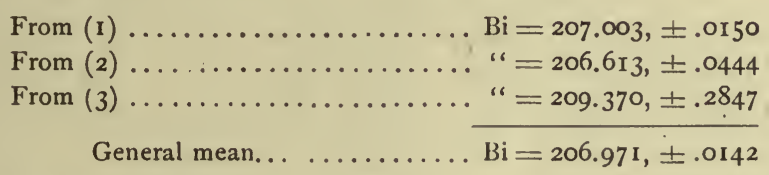

If $\mathrm{O}=16, \mathrm{Bi}=208.548$.

Classen's data alone give $\mathrm{Bi}=207.389$, or, with $\mathrm{O}=16,208.969$. Omitting this set of determinations and rejecting Dumas', the remaining data give-

$$
\begin{aligned}
& \text { From } \mathrm{Bi}_{2} \mathrm{O}_{3} \ldots \ldots \ldots \ldots \ldots \ldots \ldots, \mathrm{Bi}=206.512, \pm .0244 \\
& \text { From } \mathrm{Bi}_{2}\left(\mathrm{SO}_{4}\right)_{3} \ldots \ldots \ldots \ldots \ldots \ldots \ldots \text {. }=206.613, \pm .0444 \\
& \text { General mean ............ Bi }=206.536, \pm .0214
\end{aligned}
$$

If $\mathrm{O}=16$, this becomes $\mathrm{Bi}=208.11$. Between this figure and Classen's, future inrestigation must decide. The confirmation afforded by the sulphate series is in favor of the lower value. 


\section{CQLUMBIUM.*}

The atomic weight of this metal has been determined by Rose, Hermann, Blomstrand, and Marignac. Rose $†$ analyzed a compound which he supposed to be chloride, but which, according to Rammelsberg, $\ddagger$ must have been nearly pure oxychloride. If it was chloride, then the widely varying results give approximately $\mathrm{Cb}=122$; if it was oxychloride, the value becomes nearly 94 . If it was chloride, it was doubtless contaminated with tantalum compounds.

Hermann's $§$ results seem to have no present value, and Blomstrand's \| are far from concordant. The latter chemist studied columbium pentachloride and sodium columbate. In the first case he weighed the columbium as columbium pentoxide, and the chlorine as silver chloride, the oxide being determined by several distinct processes. In some cases it was thrown down by water, in others by sulphuric acid, and in still others by sodium carbonate or ammonia jointly with sulphuric acid. The weights given are as follows:

$\begin{array}{lll}\mathrm{CbCl}_{5} . & \mathrm{Cb}_{2} \mathrm{O}_{5} . & \mathrm{AgCl} . \\ .59 \mathrm{I} & .294 & \ldots \ldots \\ .8085 & .401 & 2.085 \\ .633 & .317 & \ldots \ldots \\ .195 & .0974 & .500 \\ .507 & .2505 & 1.302 \\ .9415 & .472 & 2.454 \\ .563 & .2796 & \ldots \ldots \\ .9385 & .4675 & 2.465 \\ .4788 & .2378 & \ldots \ldots \\ .408 & .204 & 1.067 \\ .9065 & .4515 & \ldots \ldots\end{array}$

Hence the subjoined percentages, and the ratios $5 \mathrm{AgCl}: \mathrm{CbCl}_{5}:: 100: x$, and $5 \mathrm{AgCl}: \mathrm{Cb}_{2} \mathrm{O}_{5}:: 100: x$.

$\begin{array}{ccc}\text { Percent. } \mathrm{Cb}_{2} \mathrm{O}_{5} . & \mathrm{AgCl}: \mathrm{CbCl}_{5} . & \mathrm{AgCl}: \mathrm{Cb}_{2} \mathrm{O}_{5} . \\ 49.788 & \ldots \ldots & \ldots \ldots \\ 49.598 & 38.777 & 19.233 \\ 50.079 & \ldots \ldots . & \ldots \ldots \\ 49.949 & 39.000 & 19.435 \\ 49.408 & 38.940 & 19.240 \\ 50.135 & 38.366 & 19.234\end{array}$

* This name has priority over the more generally accepted " niobium," and therefore deserves preference.

† Poggend. Annal., 104, 439. $185^{8}$.

† Poggend. Annal., 136, 353. 1869 .

\& Journ. für Prakt. Chem., 68, 73. 1856.

I Acta Univ. L,und, I864. 


$\begin{array}{rcc}49.662 & \ldots \ldots & \ldots \ldots \\ 49.813 & 38.073 & 18.966 \\ 49.666 & \ldots \ldots & \ldots \cdots \\ 50.000 & 38.238 & 19.119 \\ 49.807 & \cdots \cdots & \cdots \cdots \\ \text { Mean, } 49.806, \pm .045 & \text { Mean, } \frac{\cdots}{38.566, \pm .108} & \text { Mean, } \frac{19.205, \pm .043}{}\end{array}$

From these means the atomic weight of columbium may be computed, thus:

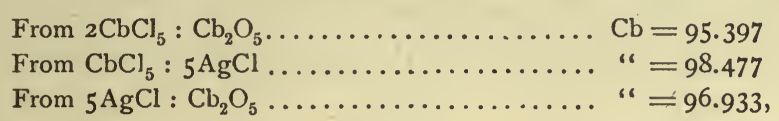

when $\mathrm{O}=15,879, \mathrm{Ag}=107.108$, and $\mathrm{Cl}=35.179$.

The series upon sodium columbate, which salt was decomposed with sulphuric acid, both $\mathrm{Cb}_{2} \mathrm{O}_{5}$ and $\mathrm{Na}_{2} \mathrm{SO}_{4}$ being weighed, is too discordant for discussion. The exact nature of the salt studied is not clear, and the data given, when transformed into the ratio $\mathrm{Na}_{2} \mathrm{SO}_{4}: \mathrm{Cb}_{2} \mathrm{O}_{5}:: 100: x$, give values for $x$ ranging from 151.65 to 161.20 . Further consideration of this series would therefore be useless. It seems highly probable that Blomstrand's materials were not entirely free from tantalum, however, since the atomic weight of columbium derived from his analyses of the chloride are evidently too high.

Marignac* made about twenty analyses of the potassium fluoxycolumbate, $\mathrm{CbOF}_{3} \cdot 2 \mathrm{KF} \cdot \mathrm{H}_{2} \mathrm{O} . \quad 100$ parts of this salt give the following percentages :

\begin{tabular}{|c|c|c|c|}
\hline $\mathrm{Cb}_{2} \mathrm{O}_{5}$. & Extremes & 44.15 to 44.60 & Mean, 44.36 \\
\hline $\mathrm{K}_{2} \mathrm{SO}_{4} \ldots \ldots \ldots \ldots$ & “ & $57.60 " 58.05$ & - \\
\hline$\ldots \ldots$ & “ & $5.75^{\prime \prime} 5.98$ & - \\
\hline$\ldots \ldots$ & " & 30.62 " 32.22 & \\
\hline
\end{tabular}

From the mean percentage of $\mathrm{Cb}_{2} \mathrm{O}_{5}, \mathrm{Cb}=92.852$. If $\mathrm{O}=16$, this becomes 93.56 .

From the mean between the extremes given for $\mathrm{K}_{2} \mathrm{SO}_{4}, \mathrm{Cb}=93.192$. If $\mathrm{O}=16$, this becomes 93.90 .

As Deville and Troost's $\dagger$ results for the vapor density of the chloride and oxychloride agree fairly well with $\mathrm{Cb}=94$, we may adopt this value as approximately correct. The mean of the two values computed from Marignac's data is 93.022 when $\mathrm{H}=1$, and 93.73 when $\mathrm{O}=16$. 


\section{TANTALUM.}

The results obtained for the atomic weight of this metal by Berzelius,* Rose, $\dagger$ and Hermann $\ddagger$ may be fairly left out of account as valueless. These chemists could not have worked with pure preparations, and their data are sufficiently summed up in Becker's "Digest."

Blomstrand's determinations, $\S$ as in the case of columbium, were made upon the pentachloride. His weights are as follows:

$\begin{array}{ccc}\mathrm{TaCl}_{5} . & \mathrm{Ta}_{2} \mathrm{O}_{5}{ }^{\circ} & \mathrm{AgCl} . \\ .9808 & .598 & \ldots \ldots \\ \mathrm{I.4262} & .867 & 2.906 \\ 2.5282 & \mathrm{I} .5375 & 5.0105 \\ 1.0604 & .6455 & 2.156 \\ 2.581 & 1.577 & \ldots \ldots \\ .8767 & .534 & \ldots \ldots\end{array}$

Hence the subjoined percentages of $\mathrm{Ta}_{2} \mathrm{O}_{5}$ from $\mathrm{TaCl}_{5}$, and the ratios $5 \mathrm{AgCl}: \mathrm{TaCl}_{5}:: 100: x$, and $5 \mathrm{AgCl}: \mathrm{Ta}_{2} \mathrm{O}_{5}:: 100: x$.

\begin{tabular}{ccc} 
Percent. $\mathrm{Ta}_{2} \mathrm{O}_{5}$. & $\mathrm{AgCl}: \mathrm{TaCl}_{5}$. & $\mathrm{AgCl}: \mathrm{Ta}_{2} \mathrm{O}_{5}$. \\
$60.97 \mathrm{I}$ & $\ldots \ldots$ & $\ldots \ldots$ \\
60.791 & 49.078 & 29.835 \\
60.814 & 50.458 & 30685 \\
60.873 & 49.297 & 29.940 \\
60.960 & $\ldots \ldots$ & $\ldots \ldots$ \\
60.924 & $\ldots \ldots$ & $\ldots \ldots$ \\
\hline Mean, 60.889, \pm .0208 & $49.611, \pm .289$ & 30.153 \\
\end{tabular}

From these ratios we get for the atomic weight of tantalum :

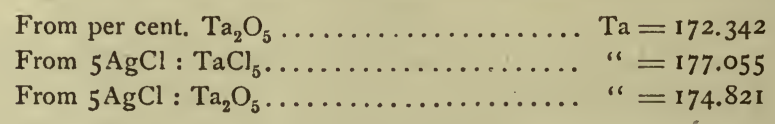

These results are too low. Probably Blomstrand's material still contained some columbium.

In 1866 Marignac's determinations appeared.| He made four analyses of a pure potassium fluotantalate, and four more experiments upon the ammonium salt. The potassium compound, $\mathrm{K}_{2} \mathrm{TaF}_{7}$, was treated with sulphuric acid, and the mixture was then evaporated to dryness. The potassium sulphate was next dissolved out by water, while the residue 
was ignited and weighed as $\mathrm{Ta}_{2} \mathrm{O}_{5}$. 100 parts of the salt gave the following quantities of $\mathrm{Ta}_{2} \mathrm{O}_{5}$ and $\mathrm{K}_{2} \mathrm{SO}_{4}$ :

$$
\begin{array}{cc}
\mathrm{Ta}_{2} \mathrm{O}_{5} . & \mathrm{K}_{2} \mathrm{SO}_{4} . \\
56.50 & 44.37 \\
56.75 & 44.35 \\
56.55 & 44.22 \\
\frac{56.56}{56.59} \pm .037 & \frac{44.24}{44.295} \pm .026
\end{array}
$$

From these figures, 100 parts of $\mathrm{K}_{2} \mathrm{SO}_{4}$ correspond to the subjoined quantities of $\mathrm{Ta}_{2} \mathrm{O}_{5}$ :

$$
\begin{gathered}
127.338 \\
127.960 \\
128.178 \\
127.848 \\
\text { Mean, } 127.831, \pm .120
\end{gathered}
$$

The ammonium salt, $\left(\mathrm{NH}_{4}\right)_{2} \mathrm{TaF}_{7}$, ignited with sulphuric acid, gave these percentages of $\mathrm{Ta}_{2} \mathrm{O}_{5}$. The figures are corrected for a trace of $\mathrm{K}_{2} \mathrm{SO}_{4}$ which was always present:

$$
\begin{gathered}
63.08 \\
63.24 \\
63.27 \\
63.42 \\
\frac{63.25}{63 .} \pm .047
\end{gathered}
$$

Hence we have four values for Ta:

From potassium salt, per cent. $\mathrm{Ta}_{2} \mathrm{O}_{5} \ldots \ldots \ldots \mathrm{Ta}=182.336$

From potassium salt, per cent. $\mathrm{K}_{2} \mathrm{SO}_{4} \ldots \ldots \ldots$. $=180.496$

From potassium salt, $\mathrm{K}_{2} \mathrm{SO}_{4}: \mathrm{Ta}_{2} \mathrm{O}_{5} \ldots \ldots \ldots$. ${ }^{\prime} \ldots \mathrm{I} 8 \mathrm{r} .422$

From ammonium salt, per cent. $\mathrm{Ta}_{2} \mathrm{O}_{5} \ldots \ldots \ldots$ " $=\mathrm{I} 8 \mathrm{I} .559$

Average .................. Ta $=181.453$

Or, if $\mathrm{O}=16, \mathrm{Ta}=182.836$.

These values are computed with $\mathrm{O}=15.879, \mathrm{~K}=38.817, \mathrm{~S}=31.828$, $\mathrm{N}=13.935$, and $\mathrm{F}=18.912$. 


\section{CHROMIUM.}

Concerning the atomic weight of chromium there has been much discussion, and many experimenters have sought to establish the true value. The earliest work upon it having any importance was that of Berzelius,* in 1818 and 1826, which led to results much in excess of the correct figure. His method consisted in precipitating a known weight of lead nitrate with an alkaline chromate and weighing the lead chromate thus produced. The error in his determination arose from the fact that lead chromate, except when thrown down from very dilute solutions, carries with it minute quantities of alkaline salts, and so has its apparent weight notably increased. When dilute solutions are used, a trace of the precipitate remains dissolved, and the weight obtained is too low. In neither case is the method trustworthy.

In 1844 Berzelius' results were first seriously called in question. The figure for chromium deduced from his experiments was somewhat over 56 ; but Peligot $\uparrow$ now showed, by his analyses of chromous acetate and of the chlorides of chromium, that the true number was near 52.5. Unfortunately, Peligot's work, although good, was published with insufficient details to be useful here. For chromous acetate he gives the percentages of carbon and hydrogen, but not the actual weights of salt, carbon dioxide, and water from which they were calculated. His figures vary considerably, moreover-enough to show that their mean would carry but little weight when combined with the more explicit data furnished by other chemists.

Jacquelain's $\ddagger$ work we may omit entirely. He gives an atomic weight for chromium which is notoriously too low (50.1), and prints none of the numerical details upon which his result rests. The researches which particularly command our attention are those of Berlin, Moberg, Lefort, Wildenstein, Kessler, Siewert, Baubigny, Rawson, and Meineke.

Among the papers upon the atomic weight under consideration that by Berlin is one of the most important. $\S$ His starting point was normal silver chromate; but in one experiment the dichromate $\mathrm{Ag}_{2} \mathrm{Cr}_{9} \mathrm{O}_{7}$ was used. These salts, which are easily obtained in a perfectly pure condition, were reduced in a large flask by means of hydrochloric acid and alcohol. The chloride of silver thus formed was washed by decantation, dried, fused, and weighed without transfer. The united washings were supersaturated with ammonia, evaporated to dryness, and the residue treated with hot water. The resulting chromic oxide was then collected upon a filter, dried, ignited, and weighed. The results were as follows:

* Schweigg. Journ., 22, 53, and Poggend. Annal., 8, 22.

†Compt. Rend., 19, 609, and $734 ; 20,1187 ; 21,74$.

$\ddagger$ Compt. Rend., 24,679 . 1847 .

† Journ. für Prakt. Chem., 37, 509, and 38, I49. 1846. 


\begin{tabular}{|c|c|c|c|c|c|}
\hline 3.4568 & " & 2.983 & ". & .7960 & "، \\
\hline 2.5060 & “ & 2. 1605 & “ & .5770 & “ \\
\hline 2. 1530 & “ & 1. 8555 & “ & .4945 & “ \\
\hline $4.3335 \mathrm{grm}$. & $\mathrm{Ag}_{2} \mathrm{Cr}_{2} \mathrm{O}_{7}$ gav & e 2.8692 & “ & I. 5300 & “ \\
\hline
\end{tabular}

From these weighings three values are calculable for the atomic weight of chromium. The three ratios upon which these values depend we will consider separately, taking first that between the chromic oxide and the original silver salt. In the four analyses of the normal chromate the percentages of $\mathrm{Cr}_{2} \mathrm{O}_{3}$ deducible from Berlin's weighings are as follows:

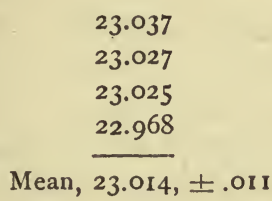

And from the single experiment with $\mathrm{Ag}_{2} \mathrm{Cr}_{2} \mathrm{O}_{7}$ the percentage of $\mathrm{Cr}_{2} \mathrm{O}_{3}$ was 35.306 .

For the ratio between $\mathrm{Ag}_{2} \mathrm{CrO}_{4}$ and $\mathrm{AgCl}$, putting the latter at 100 , we have for the former:

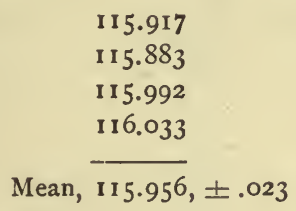

In the single experiment with dichromate $100 \mathrm{AgCl}$ is formed from $151.035 \mathrm{Ag}_{2} \mathrm{Cr}_{2} \mathrm{O}_{7}$.

Finally, for the ratio between $\mathrm{AgCl}$ and $\mathrm{Cr}_{2} \mathrm{O}_{3}$, the five experiments of Berlin give, for 100 parts of the former, the following quantities of the latter:

$$
\begin{gathered}
26.705 \\
26.685 \\
26.707 \\
26.650 \\
26.662 \\
\hline \text { Mean, } 26.682, \pm .0076
\end{gathered}
$$

These results will be discussed, in connection with the work of other investigators, at the end of this chapter.

In 1848 the researches of Moberg* appeared. His method simply consisted in the ignition of anhydrous chromic sulphate and of ammonium chrome alum, and the determination of the amount of chromic 
oxide thus left as residue. In the sulphate, $\mathrm{Cr}_{2}\left(\mathrm{SO}_{4}\right)_{3}$, the subjoined percentages of $\mathrm{Cr}_{2} \mathrm{O}_{3}$ were found. The braces indicate two different samples of material, to which, however, we are justified in ascribing equal value:

$\begin{array}{llll}.542 & \text { grm. sulphate gave } .2 \mathrm{I}_{2} \mathrm{grm} . \mathrm{Cr}_{2} \mathrm{O}_{3} \text {. } \\ \mathrm{I} .337 & \text { "6 } & .523 & \text { " } \\ .5287 & \text { " } & .207 & \text { " } \\ 1.033 & \text { " } & .406 & \text { " } \\ .868 & \text { " } & .34 \mathrm{I} & \text { " }\end{array}$

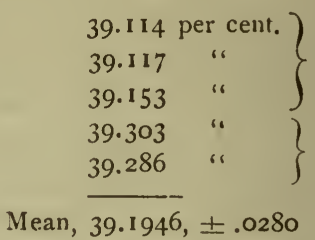

From the alum, $\mathrm{NH}_{4} \cdot \mathrm{Cr}\left(\mathrm{SO}_{4}\right)_{2} \cdot 12 \mathrm{H}_{2} \mathrm{O}$, we have these percentages of $\mathrm{Cr}_{2} \mathrm{O}_{3}$. The first series represents a salt long dried under a bell jar at a temperature of $18^{\circ}$. The crystals taken were clear and transparent, but may possibly have lost traces of water,* which would tend to increase the atomic weight found for chromium. In the second series the salt was carefully dried between folds of filter paper, and results were obtained quite near those of Berlin. Both of these series are discussed together, neither having remarkable value:

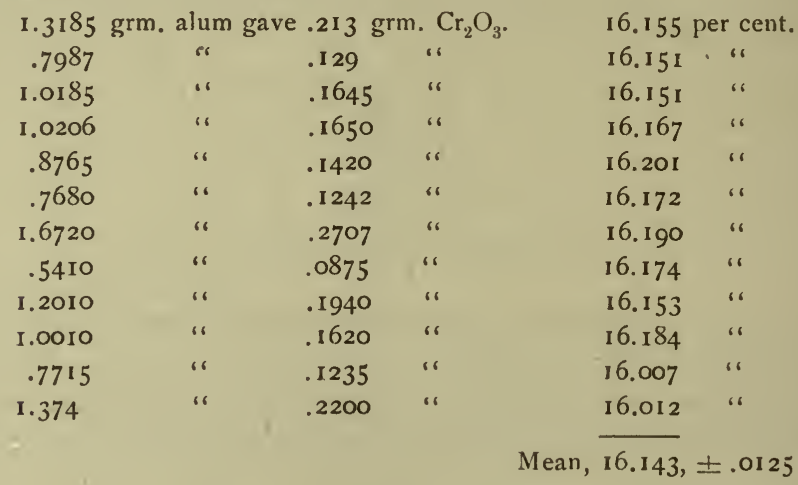

The determinations made by Lefort $\uparrow$ are even less valuable than those by Moberg. This chemist started out from pure barium chromate, which, to thoroughly free it from moisture, had been dried for several hours at $250^{\circ}$. The chromate was dissolved in pure nitric acid, the barium thrown down by sulphuric acid, and the precipitate collected upon a filter, dried, ignited, and weighed in the usual manner. The natural objection to the process is that traces of chromium may be carried down with the sulphate, thus increasing its weight. In fact, Lefort's results are somewhat too high. Calculated from his weighings, 100 parts of $\mathrm{BaSO}_{4}$ correspond to the amounts of $\mathrm{BaCrO}_{4}$ given in the third column:

* This objection is suggested by Berlin in a note upon L,efort's paper. Journ. für Prakt. Chem., 7r, I9r.

† Journ. für Prakt. Chein., 5I, 26r. 1850. 


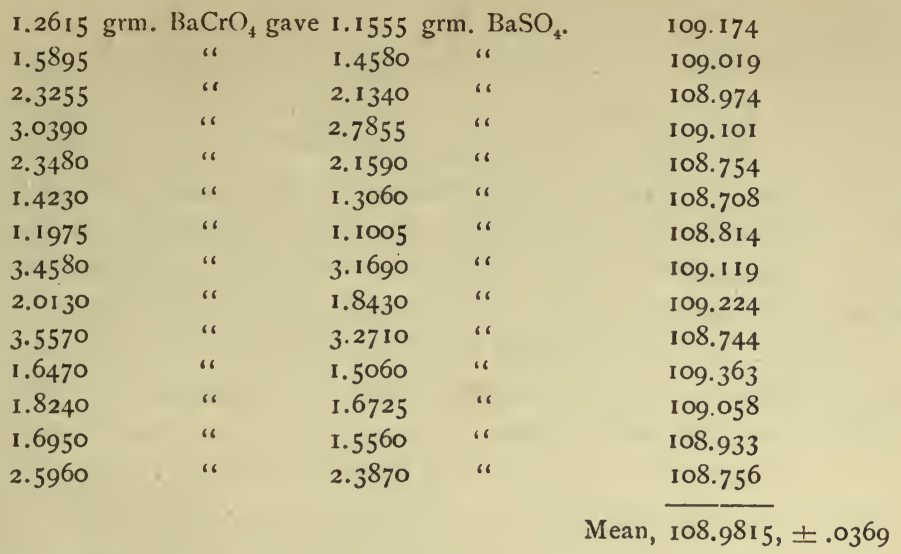

Wildenstein,* in 1853 , also made barium chromate the basis of his researches. A known weight of pure barium chloride was precipitated by a neutral alkaline chromate, and the precipitate allowed to settle until the supernatant liquid was perfectly clear. The barium chromate was then collected on a filter, washed with hot water, dried, gently ignited, and weighed. Here again arises the objection that the precipitate may have retained traces of alkaline salts, and again we find deduced an atomic weight which is too high. One hundred parts $\mathrm{BaCrO}_{4}$ correspond to $\mathrm{BaCl}_{2}$ as follows :

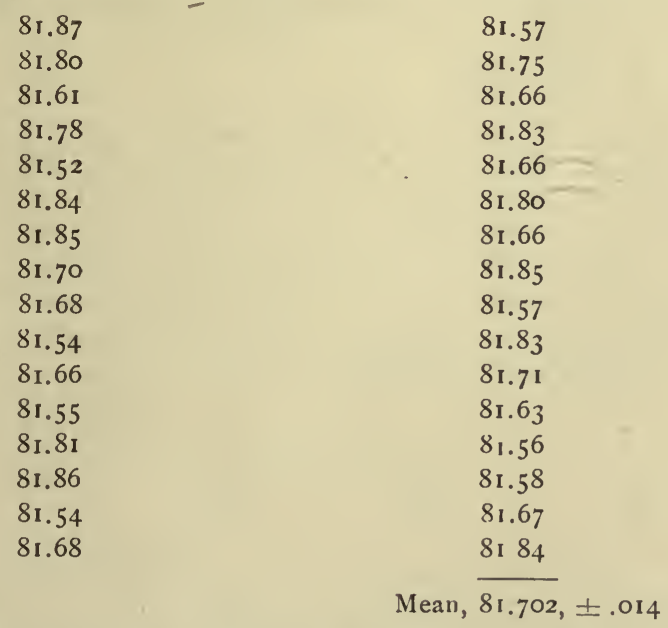

Next in order we have to consider two papers by Kessler, who employed a peculiar volumetric method entirely his own. In brief, he compared the oxidizing power of potassium dichromate with that of the chlorate, and from his observations deduced the ratio between the molecular weights of the two salts. 
In his earlier paper* the mode of procedure was about as follows: The two salts, weighed out in quantities having approximate chemical equivalency, were placed in two small flasks, and to each was added $100 \mathrm{cc}$. of a ferrous chloride solution and $30 \mathrm{cc}$. hydrochloric acid. The ferrous chloride was added in trifling excess, and, when action ceased, the amount unoxidized was determined by titration with a standard solution of dichromate. As in each case the quantity of ferrous chloride was the same, it became easy to deduce from the data thus obtained the ratio in question. I have reduced all of his somewhat complicated figures to a simple common standard, and give below the amount of chromate equivalent to 100 of chlorate:

$$
\begin{gathered}
120.118 \\
120.37 \mathrm{I} \\
120.138 \\
120.096 \\
120.24 \mathrm{I} \\
120.18 \mathrm{I} \\
-\frac{120.19 \mathrm{I}}{\text { Mean, }} \pm .028
\end{gathered}
$$

In his later paper $\uparrow$ Kessler substituted arsenic trioxide for the iron solution. In one series of experiments the quantity of dichromate needed to oxidize 100 parts of the arsenic trioxide was determined, and in another the latter substance was similarly compared with the chlorate. The subjoined columns give the quantity of each salt proportional to 100 of $\mathrm{As}_{2} \mathrm{O}_{3}$ :

\begin{tabular}{cl}
$\mathrm{K}_{2} \mathrm{Cr}_{2} \mathrm{O}_{7^{\circ}}$ & $\mathrm{KClO}_{3}$. \\
98.95 & $4 \mathrm{I} .156$ \\
98.94 & $4 \mathrm{I} .116$ \\
99.17 & $4 \mathrm{I} .200$ \\
98.98 & 41.255 \\
99.08 & $4 \mathrm{I} .201$ \\
99.15 & 41.086 \\
\hline Mean, $99.045, \pm .028$ & 41.199 \\
& $4 \mathrm{I} .224$ \\
& $41.16 \mathrm{I}$ \\
& $4 \mathrm{I} .193$ \\
& $4 \mathrm{I} .149$ \\
& $4 \mathrm{I} .126$ \\
& Mean, \\
& $4 \mathrm{I} .172, \pm .009$
\end{tabular}

Reducing the later series to the standard of the earlier, the two combine as follows:

(I) $2 \mathrm{KClO}_{3}: \mathrm{K}_{2} \mathrm{Cr}_{2} \mathrm{O}_{7}::$ I00: $120.19 \mathrm{I}, \pm .028$

(2) $2 \mathrm{KClO}_{3}: \mathrm{K}_{2} \mathrm{Cr}_{2} \mathrm{O}_{7}:: 100: 120.282, \pm .043$

General mean..... I $120.216, \pm .0235$ 
Siewert's determinations, which do not seem to have attracted general attention, were published in 1861.* He, reviewing Berlin's work, found that upon reducing silver chromate with hydrochloric acid and alcohol, the chromic chloride solution always retained traces of silver chloride dissolved in it. These could be precipitated by dilution with water; but, in Berlin's process, they naturally came down with the chromium hydroxide, making the weight of the latter too high; hence too large a value for the atomic weight of chromium. In order to find a more correct value Siewert resorted to the analysis of sublimed; violet, chromic chloride. This salt he fused with sodium carbonate and a little nitre, treated the fused mass with water, and precipitated from the resulting solution the chlorine by silver nitrate in presence of nitric acid. The weight of the silver chloride thus obtained, estimated after the usual manner, gave means for calculating the atomic weight of chromium. His figures, reduced to a common standard, gire, as proportional to 100 parts of chloride of silver, the quantities of chromic chloride stated in the third of the subjoined columns:

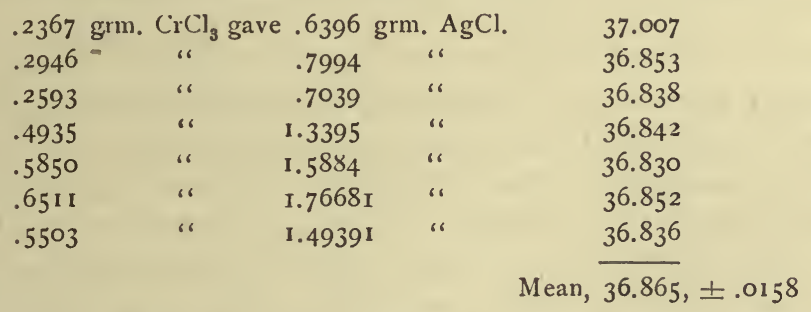

The first of these figures varies so widely from the others that we are justified in rejecting it, in which case the mean becomes $36.842, \pm .0031$.

Siewert also made two analyses of silver dichromate by the following process. The salt, dried at $120^{\circ}$, was dissolved in nitric acid. The silver was then thrown down by hydrochloric acid, and, in the filtrate, chromium hydroxide was precipitated by ammonia. Reduced to a uniform standard, we find from his results, corresponding to 100 parts of $\mathrm{AgCl}$, $\mathrm{Ag}_{2} \mathrm{Cr}_{2} \mathrm{O}_{7}$ as in the last column :

$\begin{array}{lllll}.7866 \mathrm{grm} . \mathrm{Ag}_{2} \mathrm{Cr}_{2} \mathrm{O}_{7} \text { gave } .52202 & \mathrm{AgCl} \text { and } .2764 & \mathrm{Cr}_{2} \mathrm{O}_{3} . & 150.684 \\ 1.089 & .72249 & .3840 & & 150.729\end{array}$

Berlin's single determination of this ratio gave 151.035. Taking all three values together as one series, they give a mean of $150.816, \pm .074$.

Siewert's percentages of $\mathrm{Cr}_{2} \mathrm{O}_{3}$ obtained from $\mathrm{Ag}_{2} \mathrm{Cr}_{2} \mathrm{O}_{7}$ are as follows, calculated from the above weighings:

$$
\text { Mean, } \frac{35.139}{35.262}=05, \pm .0415
$$


Combining, as before, with Berlin's single result, giving the latter equal weight with one of these, we have a general mean of $35.236, \pm .0335$.

For the ratio between silver chloride and chromic oxide, Siewert's two analyses of the dichromate come out as follows. For 100 parts of $\mathrm{AgCl}$ we have of $\mathrm{Cr}_{2} \mathrm{O}_{3}$ :

$$
\begin{gathered}
52.948 \\
\frac{53150}{53.049,} \pm .068
\end{gathered}
$$

This figure, reduced to the standard of Berlin's work on the monochromate, becomes $26.525, \pm .034$. Berlin's mean was $26.682, \pm .0076$. The two means, combined, give a general mean of $26.676, \pm .074$.

By Baubigny * we have only three experiments upon the calcination of anhydrous chromic sulphate, as follows:

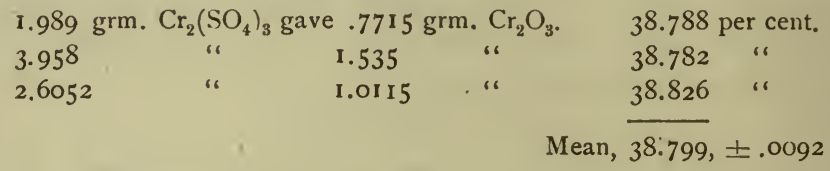

Moberg found for the same ratio the percentage 39.195, \pm .028 . The general mean of both series, Moberg's and Baubigny's, is 38.838, \pm .0087 .

In Rawson's work $\nmid$ ammonium dichromate was the substance studied. Weighed quantities of this salt were dissolved in water, and then reduced by hydrochloric acid and alcohol. After evaporation to dryness the mass was treated with water and ammonia, reëvaporated, dried five hours at $140^{\circ}$, and finally ignited in a muffle. The residual chromic oxide was bright green, and was tested to verify its purity. The corrected weights are as follows:

$\begin{array}{rcc}\mathrm{Am}_{2} \mathrm{Cr}_{2} \mathrm{O}_{7} . & \mathrm{Cr}_{2} \mathrm{O}_{3} . & \text { Percent. } \mathrm{Cr}_{2} \mathrm{O}_{3} . \\ \mathbf{1 . 0 1 2 7 5} & .61134 & 60.365 \\ 1.0818 \mathrm{I} & .65266 & 60.330 \\ 1.29430 & .78090 & 60.334 \\ 1.13966 & .68799 & 60.368 \\ .98778 & .59595 & 60.332 \\ 1.14319 & .68987 & 60.346 \\ & & \text { Mean, } 60.346, \pm .0046\end{array}$

Latest in time and most elaborate of all, we come to the determinations of the atomic weight of chromium made by Meineke, $\$$ who studied the chromate and ammonio-chromate of silver, and also the dichromates of potassium and ammonium. For the latter salt he measured the same ratio that Rawson determined, but by a different method. He precipi- 
tated its solution with mercurous nitrate, and ignited the precipitate, with the subjoined results. Vacuum weights are given:

$\begin{array}{ccc}\mathrm{Am}_{2} \mathrm{Cr}_{2} \mathrm{O}_{7} . & \mathrm{Cr}_{2} \mathrm{O}_{3} . & \text { Per cent. } \mathrm{Cr}_{2} \mathrm{O}_{3} . \\ 2.0416 & 1.2316 & 60.325 \\ 2.1618 & 1.3040 & 60.320 \\ 2.0823 & 1.2562 & 60.328 \\ 2.1913 & 1.3221 * & 60.335 \\ 2.0970 & 1.2656 & 60.353 \\ & & \text { Mean, } \frac{60.332}{6.0037} \\ & & \text { Rawson found, } 60.346, \pm .0046 \\ & & \text { General mean, } \overline{60.337, \pm .0029}\end{array}$

The chromate of silver, $\mathrm{Ag}_{2} \mathrm{CrO}_{4}$, and the ammonio-chromate, $\mathrm{Ag}_{2} \mathrm{CrO}_{4} \cdot 4 \mathrm{NH}_{3}$, both prepared with all necessary precautions to insure purity, were first treated essentially as in Berlin's experiments, except that the traces of silver chloride held in solution by the chromic chloride were thrown out by sulphuretted hydrogen, estimated, and their amount added to the main portion. Thus the chief error in Berlin's work was avoided. I subjoin the data obtained, with vacuum standards, as usual. All of Meineke's results are so corrected:

$\begin{array}{ccr}\mathrm{Ag}_{2} \mathrm{CrO}_{4} . & \mathrm{AgCl} & \mathrm{Cr}_{2} \mathrm{O}_{3} . \\ 2.7826 & 2.4047 & .6384 \\ 3.2627 & 2.8199 & .7480 \\ 3.6362 & 3.1416 & .8338 \\ 4.678 \mathrm{I} & 4.0414 & 1.0726 \\ 3.2325 & 2.7930 & .741 \mathrm{I} \\ 3.9137 & 3.3805 & .8976\end{array}$

Hence we have the following ratios, as in the case of Berlin's data:

\begin{tabular}{|c|c|c|}
\hline Per cent. $\mathrm{Cr}_{2} \mathrm{O}_{3}$. & $100 \mathrm{AgCl}: \mathrm{Ag}_{2} \mathrm{CrO}_{4}$ & $100 \mathrm{AgCl}: \mathrm{Cr}_{2} \mathrm{O}_{3}$ \\
\hline 22.943 & 115.715 & 26.548 \\
\hline 22.926 & 115.703 & 26.526 \\
\hline 22.931 & 115.744 & 26.602 \\
\hline 22.928 & 115.754 & $26.60 \mathrm{I}$ \\
\hline 22.924 & $115.73^{6}$ & 26.531 \\
\hline 22.935 & 115.773 & $26.55^{2}$ \\
\hline $22.931, \pm .0019$ & Mean, I15.737, \pm .0072 & Mean, $26.560, \pm .0093$ \\
\hline $23.014, \pm .0110$ & Berlin, $115.956, \pm .0230$ & \\
\hline
\end{tabular}

With the ammonio-chromate Meineke found as follows:

$\begin{array}{ccr}\mathrm{Ag}_{2} \mathrm{CrO}_{4.4} \mathrm{NH}_{3} . & \mathrm{AgCl} & \mathrm{Cr}_{2} \mathrm{O}_{3} . \\ 4.1518 & 2.9724 & .7904 \\ 4.2601 & 3.0592 & .8125 \\ 5.9348 & 4.2654 & 1.1317\end{array}$

* Calculated back from Meineke's value for $\mathrm{Cr}$, to replace an evident misprint in the original. 
And the ratios become-

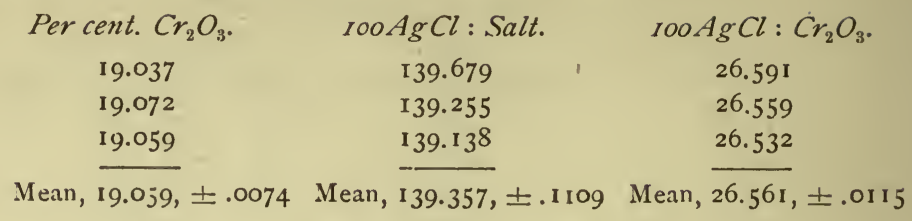

The first of these three analyses is rejected by Meineke as suspicious, but for the present I shall allow it to remain. The data in the third column may now be combined with the corresponding figures from the normal chromate, as found by Meineke and his predecessors.

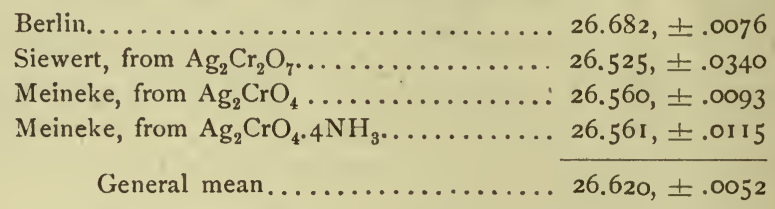

$$
4 \mathrm{AgCl}: \mathrm{Cr}_{2} \mathrm{O}_{3}:: 100: 26.620, \pm .0052
$$

Obviously, this mean is vitiated by the known error in Berlin's work, the ultimate effect of which is yet to be considered.

In all four of the salts studied by Meineke he determined volumetrically the oxygen in excess of the normal oxides by measuring the amount of iodine liberated in acid solutions. With the silver salts the process was essentially as follows: A weighed quantity of the chromate was dissolved in weak ammonia, and the solution was precipitated with potassium iodide. After the silver iodide had been filtered off, five or six grammes of potassium iodide were added to the filtrate, which was then acidulated with phosphoric acid and a little sulphuric. The liberated iodine was then titrated with sodium thiosulphate solution, which had been standardized by means of pure iodine, prepared by Stas' method. From the iodine thus measured the excessive oxygen was computed, and from that datum the atomic weight of chromium was found. For present purposes, however, the data may be used more directly, as giving the ratios $\mathrm{I}_{3}: \mathrm{Ag}_{2} \mathrm{CrO}_{4}$ and $\mathrm{I}_{3}: \mathrm{Ag}_{2} \mathrm{CrO}_{4} \cdot 4 \mathrm{NH}_{3}$. Thus treated, the weights are as follows, reduced to a vacuum. Reckoning the salt as 100 , the third column gives the percentage of iodine liberated:

$\begin{array}{cc}\mathrm{Ag}_{2} \mathrm{CrO}_{4} . & \text { I Set Free. } \\ .43838 & .5025 \mathrm{I} \\ .90258 & \mathrm{1.03432} \\ .89858 & \mathbf{1 . 0 2 9 8 0} \\ .89868 & \mathrm{1.03072}\end{array}$

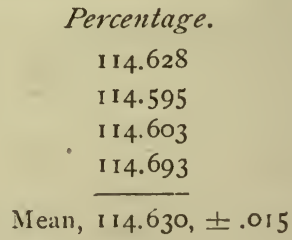

Percentage.

II 4.603

4.693 
The next series, obviously, gives the ratio $\mathrm{I}_{3}: \mathrm{Ag}_{2} \mathrm{CrO}_{4} \cdot 4 \mathrm{NH}_{3}$.

$\begin{array}{ccc}\mathrm{Ag}_{2} \mathrm{CrO}_{4} .4 \mathrm{NH}_{3} . & \text { I Set Free. } & \text { Percentage. } \\ .54356 & .51784 & 95.267 \\ .54856 & .52046 & 94.877 \\ .54926 & .52322 & 95.258 \\ .54906 & .52376 & 95.392 \\ .54466 & .51910 & 95.307 \\ .54536 & .51891 & 95.150 \\ & & \text { Mean, } 95.208, \pm .0497\end{array}$

In dealing with the two dichromates Meineke used the acid potassium iodate in place of potassium iodide, the chromate and the iodate reacting in the molecular ratio of $2: 1$. The thiosulphate was standardized by means of the acid iodate, so that we have direct ratios between the latter and the two chromates. The data are as follows, with the amount of iodate proportional to one hundred parts of the dichromate in the third column :

$\mathrm{K}_{2} \mathrm{Cr}_{2} \mathrm{O}_{7}$
.25090
.25095
.25078
.24979
.24987
.24966
.25015
.25012
.24977
.25034
.25025
.25015

$\mathrm{Am}_{2} \mathrm{Cr}_{2} \mathrm{O}_{7}$.
.21457
.21465
.21464
.21416
.21447
.21427
.22196
.22194
.22180

$\begin{array}{lc}\mathrm{KHI}_{2} \mathrm{O}_{6} \cdot & \text { Percentage. } \\ .16609 & 66.198 \\ .16613 & 66.200 \\ .16601 & 66.197 \\ .16541 & 66.220 \\ .16540 & 66.192 \\ .16543 & 66.262 \\ .16559 & 66.196 \\ .16559 & 66.204 \\ .16546 & 66.245 \\ .16572 & 66.198 \\ .16567 & 66.202 \\ .16568 & 66.234 \\ & \text { Mean, } 66.212, \pm .0044\end{array}$

$\mathrm{KHI}_{2} \mathrm{O}_{6}$.

.16584

.16588

.16584

.16543

.16564

.16559

.17152

.17151

.17139
Percentage.

77.290

77.279

77.264

77.246

77.232

77.28 I

77.272

77.278

77.272

Mean, $\overline{77.268}, \pm .00_{4} \mathrm{I}$

* These figures are not whclly in accord with the percentages of oxygen computed by Meineke. I suspect that there is a misprint among his data as published, probably in the second experiment, but I cannot trace it with certainty. 
The following ratios are now available for computing the atomic weight of chromium :

(I.) Percentage $\mathrm{Cr}_{2} \mathrm{O}_{3}$ from $\mathrm{Ag}_{2} \mathrm{CrO}_{4}, 22.934, \pm .0018$

(2.) Percentage $\mathrm{Cr}_{2} \mathrm{O}_{3}$ from $\mathrm{Ag}_{2} \mathrm{Cr}_{2} \mathrm{O}_{7}, 35.236, \pm .0335$

(3.) $2 \mathrm{AgCl}: \mathrm{Ag}_{2} \mathrm{CrO}_{4}:$ : $100:$ I $15.760, \pm .0069$

(4.) $2 \mathrm{AgCl}: \mathrm{Ag}_{2} \mathrm{Cr}_{2} \mathrm{O}_{7}:: 100: 150.816, \pm .074$

(5.) $4 \mathrm{AgCl}: \mathrm{Cr}_{2} \mathrm{O}_{3}:: 100: 26.620, \pm .0052$

(6.) Percentage $\mathrm{Cr}_{2} \mathrm{O}_{3}$ in $\mathrm{Cr}_{2}\left(\mathrm{SO}_{4}\right)_{3}, 38.838, \pm .0087$

(7.) Percentage $\mathrm{Cr}_{2} \mathrm{O}_{3}$ in $\mathrm{AmCr}\left(\mathrm{SO}_{4}\right)_{2} \cdot 12 \mathrm{H}_{2} \mathrm{O}, 16.143, \pm .0125$

(8.) $\mathrm{BaSO}_{4}: \mathrm{BaCrO}_{4}:: 100: 108.9815, \pm .0369$

(9.) $\mathrm{BaCrO}_{4}: \mathrm{BaCl}_{2}:: 100: 81.702, \pm .014$

(10.) $3 \mathrm{AgCl}: \mathrm{CrCl}_{3}:: 100: 36.842, \pm .003 \mathrm{I}$

(II.) $2 \mathrm{KClO}_{3}: \mathrm{K}_{2} \mathrm{Cr}_{2} \mathrm{O}_{7}:$ : $100: 120.216, \pm .0235$

(12.) Percentage $\mathrm{Cr}_{2} \mathrm{O}_{3}$ in $\mathrm{Ag}_{2} \mathrm{CrO}_{4} \cdot 4 \mathrm{NH}_{3}, 19.059, \pm .0074$

(13) $2 \mathrm{AgCl}: \mathrm{Ag}_{2} \mathrm{CrO}_{4} \cdot 4 \mathrm{NH}_{3}::$ I00: 139.357, 土.1109

(14.) Percentage $\mathrm{Cr}_{2} \mathrm{O}_{3}$ in $\mathrm{Am}_{2} \mathrm{Cr}_{2} \mathrm{O}_{7}, 60.337, \pm .0029$

(15.) $\mathrm{Ag}_{2} \mathrm{CrO}_{4}: 3 \mathrm{I}::$ : $100:$ I I 4.630, \pm .0I 5

(I6.) $\mathrm{Ag}_{2} \mathrm{CrO}_{4} \cdot 4 \mathrm{NH}_{3}: 3 \mathrm{I}:: 100: 95.208, \pm .0497$

(17.) $2 \mathrm{~K}_{2} \mathrm{Cr}_{2} \mathrm{O}_{7}: \mathrm{KHI}_{2} \mathrm{O}_{6}:: 100: 66.2 \mathrm{r} 2, \pm .0044$

(I8.) $2 \mathrm{Am}_{2} \mathrm{Cr}_{2} \mathrm{O}_{7}: \mathrm{KHI}_{2} \mathrm{O}_{6}:: \mathrm{IO0}: 77.268, \pm .004 \mathrm{I}$

The antecedent values to use in the reduction are-

$$
\begin{array}{ll}
\mathrm{O}=\mathrm{I} 5879, \pm .0003 & \mathrm{~S}=31.828, \pm .0015 \\
\mathrm{Ag}=107.108, \pm .003 \mathrm{I} & \mathrm{N}=13.935, \pm .002 \mathrm{I} \\
\mathrm{Cl}=35.179, \pm .0048^{\circ} & \mathrm{Ba}=136.392, \pm .0086 \\
\mathrm{I}=125.888, \pm .0069 & \mathrm{AgCl}=142.287 \pm .0037 \\
\mathrm{~K}=38.817 \pm .005 \mathrm{I} &
\end{array}
$$

For the molecular weight of $\mathrm{Cr}_{2} \mathrm{O}_{3}$, seven values are now calculable, as follows:

$$
\begin{aligned}
& \text { From (I) ............... } \mathrm{Cr}_{2} \mathrm{O}_{3}=151.120, \pm .0130 \\
& \text { From (2) ............. " } \quad=151.105, \pm .1636 \\
& \text { From }(5) \ldots \ldots \ldots \ldots \ldots \ldots \ldots \ldots=151.507, \pm .0299 \\
& \text { From }(6) \ldots \ldots \ldots \ldots \ldots \ldots \ldots \text { " }=151.384, \pm .0341 \\
& \text { From }(7) \ldots \ldots \ldots \ldots \ldots \ldots \ldots \text {. } "=153.756, \pm .1205
\end{aligned}
$$

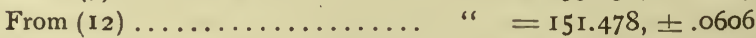

$$
\begin{aligned}
& \text { From }(14) \ldots \ldots \ldots \ldots \ldots \ldots \ldots \text { " }=151.190, \pm .0110 \\
& \text { General mean......... } \mathrm{Cr}_{2} \mathrm{O}_{3}=151.229, \pm .0039
\end{aligned}
$$

For silver chromate there are two values-

$$
\begin{aligned}
& \text { From (3)............... } \mathrm{Ag}_{2} \mathrm{CrO}_{4}=329.423 \\
& \text { From }(15) \ldots \ldots \ldots \ldots \ldots \ldots \text { " }=329.464, \pm .0467 \\
& \text { General mean......... } \mathrm{Ag}_{2} \mathrm{CrO}_{4}=329.430 \text {, } \pm .0180
\end{aligned}
$$

And for the ammonio-chromate we have-

$$
\begin{aligned}
& \text { From (13) ........... } \mathrm{Ag}_{2} \mathrm{CrO}_{4} .4 \mathrm{NH}_{3}=396.574, \pm .315 \mathrm{~S} \\
& \text { From (16)......... " }=396.673, \pm .2082 \\
& \text { General mean.... } \overline{\mathrm{Ag}_{2} \mathrm{CrO}_{4} \cdot 4 \mathrm{NH}_{3}=396.647, \pm .173^{8}}
\end{aligned}
$$




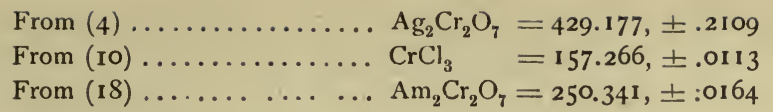

For the molecular weights of $\mathrm{K}_{2} \mathrm{Cr}_{2} \mathrm{O}_{7}$ and $\mathrm{BaCrO}_{4}$ there are two estimates each, as given below :

$$
\begin{aligned}
& \text { From (II } \ldots \ldots \ldots \ldots \ldots \ldots \mathrm{K}_{2} \mathrm{Cr}_{2} \mathrm{O}_{7}=292.433, \pm .0189 \\
& \text { From }(\mathrm{I} 7) \ldots \ldots \ldots \ldots \ldots \ldots \text { " }=292.143, \pm .0224 \\
& \text { General mean........ } \mathrm{K}_{2} \mathrm{Cr}_{2} \mathrm{O}_{7}=292.3 \mathrm{II}, \pm .0144 \\
& \text { From }(8) \ldots \ldots \ldots \ldots \ldots \ldots \mathrm{BaCrO}_{4}=252.549, \pm .0966 \\
& \text { From (9)............ " }=253.054, \pm .0377 \\
& \text { General mean........ } \mathrm{BaCrO}_{4}=252.985, \pm .035 \mathrm{I}
\end{aligned}
$$

Finally, from these molecular weights, eight independent values are obtained for the atomic weight of chromium :

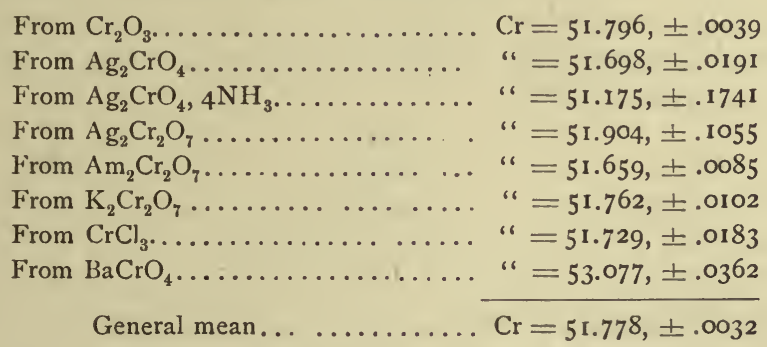

If $\mathrm{O}=16, \mathrm{Cr}=52.172$.

Rejecting the last of the eight values, that from barium chromate, the mean becomes-

$$
\mathrm{Cr}=51.767, \pm .0032 .
$$

Even this result is probably too high, for it includes ratios which are certainly erroneous, and which yet exert appreciable weight. From the ratios which are reasonably concordant a better mean is derivable, as follows :

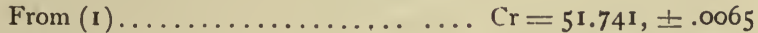

$$
\begin{aligned}
& \text { From }(2) \ldots \ldots \ldots \ldots \ldots \ldots \ldots \ldots \ldots,=51.734, \pm .0818 \\
& \text { From (14)............... }=51.776, \pm .0055 \\
& \text { From (3) and }(15) \ldots \ldots \ldots \ldots \ldots \ldots \text { " }=51.698, \pm .0191 \\
& \text { From }(4) \ldots \ldots \ldots \ldots \ldots \ldots \ldots \ldots \text { " }=51.904, \pm .1055 \\
& \text { From }(10) \ldots \ldots \ldots \ldots \ldots \ldots \ldots \ldots \text { " }=51.729, \pm .0183 \\
& \text { From }(18) \ldots \ldots \ldots \ldots \ldots \ldots \ldots \ldots \text {. }=51.659, \pm .0085 \\
& \text { From }(\mathrm{II}) \text { and }(\mathrm{I} 7) \ldots \ldots \ldots \ldots \ldots \ldots \text { " }=51.762, \pm .0102 \\
& \text { General mean........... } \mathrm{Cr}=5^{1.742, \pm .0034}
\end{aligned}
$$

If $\mathrm{O}=16$, this becomes 52.136 , a value which is probably not very far from the truth. 


\section{MOLYBDENUM.}

If we leave out of account the inaccurate determination made by Berzelius,* we shall find that the data for the atomic weight of molybdenum lead to two independent estimates of its value-one near 92, the other near 96. The earlier results found by Berlin and by Svanberg and Struve lead to the lower number; the more recent investigations, together with considerations based upon the periodic law, point conclusively to the higher.

The earliest investigation which we need especially to consider is that of Svanberg and Struve. $\dagger$ These chemists tried a variety of different methods, but finally based their conclusions upon the two following: First, molybdenum trioxide was fused with potassium carbonate, and the carbon dioxide which was expelled was estimated; secondly, molybdenum disulphide was converted into the trioxide by roasting, and the ratio between the weights of the two substances was determined.

$\mathrm{By}$ the first method it was found that 100 parts of $\mathrm{MoO}_{3}$ will expel the following quantities of $\mathrm{CO}_{2}$ :

$$
\begin{gathered}
31.4954 \\
31.3749 \\
31.4705 \\
\hline \text { Mean, } 31.4469, \pm .0248
\end{gathered}
$$

The carbon dioxide was determined simply from the loss of weight when the weighed quantities of trioxide and carbonate were fused together. It is plain that if, under these circumstances, a little of the trioxide should be volatilized, the total loss of weight would be slightly increased. A constant error of this kind would tend to bring out the atomic weight of molybdenum too low.

By the second method, the conversion by roasting of $\mathrm{MoS}_{2}$ into $\mathrm{MoO}_{3}$, Svanberg and Struve obtained these results. Two samples of artificial disulphide were taken, $\mathrm{A}$ and $\mathrm{B}$, and yielded for each hundred parts the following of trioxide :

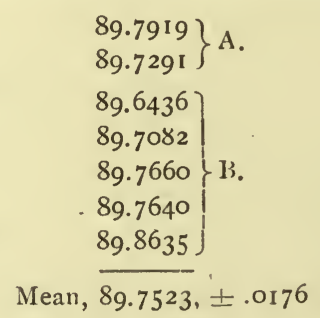

Three other experiments in series B gave divergent results, and, although published, are rejected by the authors themselves. Hence it is 
not necessary to cite them in this discussion. We again encounter in these figures the same source of constant error which apparently vitiates the preceding series, namely, the possible volatilization of the trioxide. Here, also, such an error would tend to reduce the atomic weight of molybdenum.

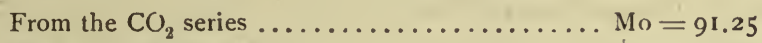

From the $\mathrm{MoS}_{2}$ series............... Mo $=92.49$

Berlin,* a little later than Svanberg and Struve, determined the atomic weight of molybdenum by igniting a molybdate of ammonium and weighing the residual $\mathrm{MoO}_{3}$. Here, again, a loss of the latter by volatilization may (and probably does) lead to too low a result. The salt used was $\left(\mathrm{NH}_{4}\right)_{4} \mathrm{Mo}_{5} \mathrm{O}_{17} \cdot 3 \mathrm{H}_{2} \mathrm{O}$, and in it these percentages of $\mathrm{MoO}_{3}$ were found :

Hence $\mathrm{M} \circ=91.559$.

$$
\begin{array}{r}
8 \mathrm{r} .598 \\
8 \mathrm{r} .6 \mathrm{I} 2 \\
8 \mathrm{r} .558 \\
8 \mathrm{I} .555 \\
\hline \text { Mean, } 8 \mathrm{I} .58 \mathrm{I}, \pm .0095
\end{array}
$$

Until 1859 the value 92 was generally accepted on the basis of the foregoing researches, but in this year Dumas $\dagger$ published some figures tending to sustain a higher number. He.prepared molybdenum trioxide by roasting the disulphide, and then reduced it to metal by ignition in hydrogen. At the beginning the hydrogen was allowed to act at a comparatively low temperature, in order to avoid volatilization of trioxide; but at the end of the operation the heat was raised sufficiently to insure a complete reduction. From the weighings I calculate the percentages of metal in $\mathrm{MoO}_{3}$ :

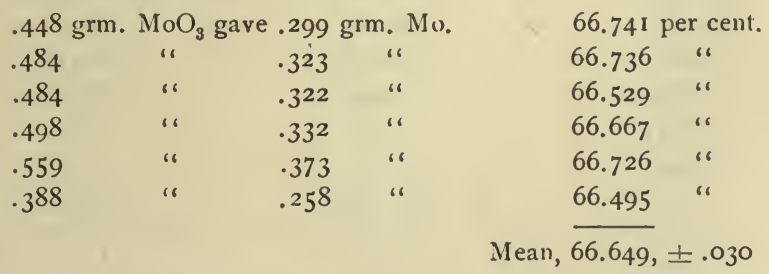

In 1868 the same method was employed by Debray. $\$$ His trioxide was purified by sublimation in a platinum tube. His percentages are as follows:

$5.514 \mathrm{grm}, \mathrm{MoO}_{3}$ gave $3.667 \mathrm{grm}$. Mo.

7.910

9.031
5.265

6.015
66.503 per cent.

$6 \mathrm{I} .56 \mathrm{I}$ “

66.604 “

Mean, $\overline{66.556}, \pm .020$

* Journ. für Prakt. Chem., 49, 444. 1850. 
For the same ratio we have also a single experiment by Rammelsberg,* who, closely following Dumas' method, found in molybdenum trioxide 66.708 per cent. of metal. As this figure falls within the limits of Dumas' series, we may assign it equal weight with one experiment in the latter.

Debray also marle two experiments upon the precipitation of molybdenum trioxide in ammoniacal solution by nitrate of silver. In his results, as published, there is curious discrepancy, which, I have no doubt, is due to a typographical error. These results I am therefore compelled to leave out of consideration. They could not, however, exert a very profound influence upon the final discussion.

In 1873, Lothar Meyer $\uparrow$ discussed the analyses made by Liechti and Kemp $\ddagger$ of four chlorides of molybdenum, and in the former edition of this work the same data were considered in detail. The analyses, however, were not intended as determinations of atomic weight, and since good determinations have been more recently published, the work on the chlorides will be omitted from further consideration. It is enough to state here that they gave values for Mo ranging near 96 , both above and below that number, with an extreme range of over eight-tenths of a unit.

In 1893 the determinations by Smith and Maas appeared, $\$$ representing an entirely new method. Sodium molybdate, purified by many recrystallizations and afterwards dehydrated, was heated in a current of pure, dry, gaseous hydrochloric acid. The compound $\mathrm{MoO}_{3} .2 \mathrm{HCl}$ was thus distilled off, and the sodium molybdate was quantitatively transformed into sodium chloride. The latter salt was afterwards carefully examined, and proved to be free from molybdenum. The data, with all weights reduced to a vacuum standard, are subjoined:

$\begin{array}{ccc}\mathrm{Na}_{2} \mathrm{MoO}_{4} . & \mathrm{NaCl} & \text { Per cent. } \mathrm{NaCl} . \\ \mathrm{I.14726} & .65087 & 56.733 \\ .89920 & .51023 & 56.743 \\ .70534 & .40020 & 56.739 \\ .70793 & .40182 & 56.760 \\ 1.26347 & .71695 & 56.745 \\ \mathrm{I.15217} & .65367 & 56.734 \\ .90199 & .51188 & 56.750 \\ .81692 & .45358 & 56.747 \\ .65098 & .36942 & 56.748 \\ .80563 & .45717 & 56.747 \\ & & \end{array}$

In 1895, Seubert and Pollard || determined the atomic weight of mo-

* Berlin Monatsbericht, 1877, p. 574.

† Ann. Chem. Pharm., 169, 365. 1873.

† $n$ n. Chem. Pharm., 169, 344 .

8. Journ. A mer. Chem. Soc., 15, 397. I893.

|| Zeitsch. Anorg. Chem., 8, 434. 1895 . 
lybdenum by two methods. First, the carefully purified trioxide, in weighed amounts, was dissolved in an excess of a standard solution of caustic soda. This solution was standardized by means of hydrochloric acid, which in turn had been standardized gravimetrically as silver chloride. Hence, indirectly, the ratio $2 \mathrm{AgCl}: \mathrm{MoO}_{3}$ was measured. Sulphuric acid and lime water were also used in the titrations, so that the entire process was rather complicated. Ignoring the intermediate data, the end results, in weights of $\mathrm{MoO}_{3}$ and $\mathrm{AgCl}$, were as follows. The third column gives the $\mathrm{MoO}_{3}$ proportional to 100 parts of $\mathrm{AgCl}$ :

$\begin{array}{lll}\mathrm{MoO}_{3} . & \mathrm{AgCl} & \text { Ratio. } \\ 3.6002 & 7.1709 & 50.206 \\ 3.5925 & 7.1569 & 50.196 \\ 3.731 \mathrm{II} & 7.4304 & 50.214 \\ 3.8668 & 7.7011 & 50.211 \\ 3.9361 & 7.8407 & 50.201 \\ 3.8986 & 7.7649 & 50.208 \\ 3.9630 & 7.894 \mathrm{I} & 50.202 \\ 3.9554 & 7.8806 & 50.192 \\ 3.9147 & 7.7999 & 50.189 \\ 3.8543 & 7.6767 & 50.208 \\ 3.9367 & 7.8437 & \text { Mean, } 50.202, \pm .0018\end{array}$

The second method adopted by Seubert and Pollard was the old one of reducing the trioxide to metal by heating in a current of hydrogen. The weights and percentages of metal are subjoined:

$\begin{array}{ccc}\mathrm{MOO}_{3} . & \text { Mo. } & \text { Percent. } \\ \mathrm{I} .8033 & \mathrm{I} .202 \mathrm{I} & 66.66 \mathrm{I} \\ \mathrm{I} .9345 & \mathrm{I} .1564 & 66.670 \\ 3.9413 & 2.6275 & 66.666 \\ \mathrm{I} .524 \mathrm{I} & \mathrm{I} .0160 & 66.662 \\ 4.0533 & 2.7027 & 66.679 \\ & & \text { Mean, } 66.668, \pm .0022\end{array}$

This mean may be combined with the results of previous investigators, thus:

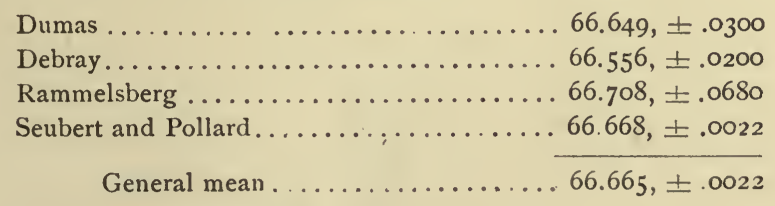

Here the data of Seubert and Pollard alone exert any appreciable influence.

Neglecting all determinations made previous to 1859 , there are now 
three ratios from which to compute the atomic weight of molybdenum, viz :

(1.) Percentage $\mathrm{Mo}$ in $\mathrm{MoO}_{3}, 66.665, \pm .0022$.

(2.) $2 \mathrm{AgCl}: \mathrm{MoO}_{3}:: 100: 50.202, \pm .0018$

(3.) $2 \mathrm{NaCl}: \mathrm{Ma}_{2}, \mathrm{MoO}_{4}: 56.745, \pm .0017: 100$.

These involve the following values:

$$
\begin{array}{ll}
\mathrm{O}=15.879, \pm .0003 & \mathrm{AgCl}=\mathrm{I} 42.287, \pm .0037 \\
\mathrm{Na}=22.88 \mathrm{I}, \pm .0046 & \mathrm{NaCl}=58.060, \pm .0017
\end{array}
$$

Hence for the atomic weight in question-

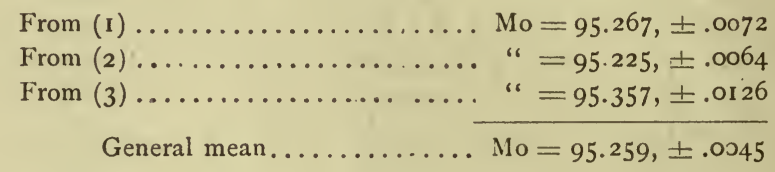

With $\mathrm{O}=16, \mathrm{Mo}=95.985$.

This value is essentially that derived from Seubert and Pollard's data alone. Reducing the latter to a vacuum would affect the result very slightly - so slightly that the correction may be ignored. 


\section{TUNGSTEN.}

The atomic weight of tungsten has been determined from analyses or the trioxide, the hexchloride, and the tungstates of iron, silver, and barium.

The composition of the trioxide has been the subject of many investigations. Malaguti * reduced this substance to the blue oxide, and from the difference between the weights of the two compounds obtained a result now known to be considerably too high. In general, however, the method of investigation has been to reduce $\mathrm{WO}_{3}$ to $\mathrm{W}$ in a stream of hydrogen at a white heat, and afterwards to reoxidize the metal, thus getting from one sample of material two results for the percentage of tungsten. This method is probably accurate, provided that the trioxide used be pure.

The first experiments which we need consider are, as usual, those of Berzelius. $\dagger 899$ parts $\mathrm{WO}_{3}$ gave, on reduction, 716 of metal. 676 of metal, reoxidized, gave $846 \mathrm{WO}_{3}$. Hence these percentages of $\mathrm{W}$ in $\mathrm{WO}_{3}$ :

79.644 , by reduction.

79.905 , by oxidation.

Mean, 79.7745, \pm .0880

These figures are far too high, the error being undoubtedly due to the presence of alkaline impurity in the trioxide employed.

Next in order of time comes the work of Schneider, $\ddagger$ who with characteristic carefulness, took every precaution to get pure material. His percentages of tungsten are as follows:

Reduction Series.

79.336

79.254

79.312

79.326

$79 \cdot 350$

Mean, 79.3156

Oxidation Series.

$79 \cdot 329$

79.324

79.328

Mean, 79.327

Mean of all, $79.320, \pm .0068$ 
Closely agreeing with these figures are those of Marchand,* published in the following year:

Reduction Series.
$\frac{79.307}{79.302}$
Mean, 79.3045
Oxidation Series.
$\frac{79.321}{79.352}$
Mean, 79.3365
Mean of all, $79.3205, \pm .0073$

The figures obtained by $v$. Borch $\dagger$ agree in mean tolerably well with the foregoing. They are as follows:

Reduction Series.

79.310
79.212
79.289
79.313
79.225
79.290
$\frac{79.302}{79.277}$
Mean,
Oxidation Series.
$\frac{79.359}{79.339}$
Mean, 79.349
Mean of all, $79.293, \pm .0108$

Dumas $\ddagger$ gives only a reduction series, based upon trioxide obtained by the ignition of a pure ammonium tungstate. The reduction was effected in a porcelain boat, platinum being objectionable on account of the tendency of tungsten to alloy with it. Dumas publishes only weighings, from which I have calculated the percentages:

$2.784 \mathrm{grm}$. $\mathrm{WO}_{3}$ gave $2.208 \mathrm{grm}$. W.

\begin{tabular}{|c|c|c|}
\hline $\begin{array}{l}2,994 \\
4.600\end{array}$ & " & $\begin{array}{l}2.373 \\
3.649\end{array}$ \\
\hline .985 & " & $.78 \mathrm{I}$ \\
\hline .917 & " & .727 \\
\hline .917 & " & .728 \\
\hline 1.717 & "، & I. 362 \\
\hline 2.988 & "، & 2.370 \\
\hline
\end{tabular}

79.3 10 per cent.

79.259 "

79.326 "

79.289 "

79.280 "

79.389 "

79.324 "

79.317 “

Mean, $79.312, \pm .009$

* Ann. Chem. Pharm., 77, 26r. I851.

† Journ. für Prakt. Chem., 54, 254. 185 I.

\pm Ann. Chem. Pharm., I13, 23. 1860. 
The data furnished by Bernoulli* differ widely from those just given. This chemist undoubtedly worked with impure material, the trioxide having a greenish tinge. Hence the results are too high. These are the percentages of $\mathrm{W}$ :

Reduction Series.
79.556
79.526
79.553
$79.55^{8}$
79.549
$\frac{78.736}{79.413}$
Mean,
Oxidation Series.
79.558
79.656
$\frac{79.555}{79.554}$
Mean of all, 79.58 i
Mean \pm .056

Two reduction experiments by Persoz $\dagger$ give the following results :

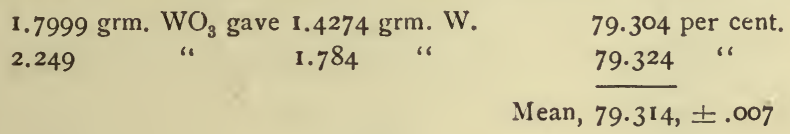

Next in order is the work done by Roscoe. $\ddagger$ This chemist used a porcelain boat and tube, and made six weighings, after successive reductions and oxidations, with the same sample of 7.884 grammes of trioxide. These weighings give me the following five percentages, which, for the sake of uniformity with foregoing series, I have classified under the usual, separate headings :

\section{Reduction Series.}

\begin{tabular}{|c|c|}
\hline & $\begin{array}{l}79.196 \\
79.285 \\
79.308\end{array}$ \\
\hline Mean, 79 & 79.263 \\
\hline $\begin{array}{r}\text { Oxidatic } \\
79 \\
79\end{array}$ & $\begin{array}{l}\text { tion Series. } \\
79.230 \\
79299\end{array}$ \\
\hline $\begin{array}{r}\text { Mean, } 79 \\
\text { Mean of all, } 79\end{array}$ & $\begin{array}{l}79.2645 \\
79.264, \pm .0146\end{array}$ \\
\hline
\end{tabular}


In Waddell's experiments* especial precautions were taken to procure tungstic oxide free from silica and molybdenum. Such oxide, elaborately purified, was reduced in hydrogen, with the following results :

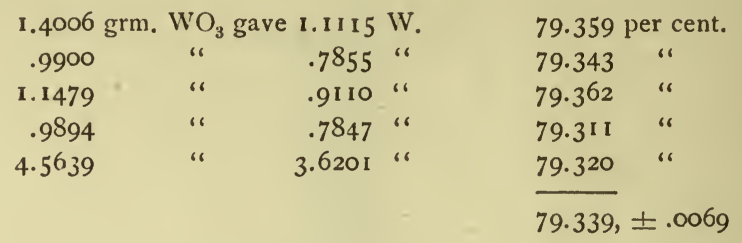

The investigation by Pennington and Smith $\dagger$ started from the supposition that the tungsten compounds studied by their predecessors had not been completely freed from molybdenum. Accordingly, tungstic oxide, carefully freed from all other impurities, was heated in a stream of gaseous hydrochloric acid, so as to volatilize all molybdenum as the compound $\mathrm{MoO}_{3} \cdot 2 \mathrm{HCl}$. The residual $\mathrm{WO}_{3}$, was then reduced in pure hydrogen, and the tungsten so obtained was oxidized in porcelain crucibles. Care was taken to exclude reducing gases, and the trioxide was finally cooled in vacuum desiccators over sulphuric acid. The oxidation data are as follows, with the usual percentage column added. The weights are reduced to a vacuum:

$\begin{array}{ccc}\text { Tungsten. } & \text { Oxygen Gained } & \text { Percentage. } \\ .86287 \mathrm{I} & .22395^{2} & 79.394 \\ .650700 & .168900 & 79.392 \\ .597654 & .155143 & 79.390 \\ .666820 & .173103 & 79.391 \\ .428228 & .111168 & 79.390 \\ .671920 & .174406 & 79.392 \\ .590220 & .153193 & 79.394 \\ .568654 & .147588 & 79.394 \\ 1.080973 & .280600 & 79.392 \\ & & \text { Mean, } 79.392, \pm .0004\end{array}$

With $\mathrm{O}=16$, this series gives $\mathrm{W}=184.92$.

The very high value for tungsten found by Pennington and Smith, nearly a unit higher than that which was commonly accepted, seems to have at once attracted the attention of Schneider, $\$$ who criticised the paper somewhat fully, and gave some new determinations of his own. The tungsten trioxide employed in this new investigation was heated in gaseous hydrochloric acid, and the absence of molybdenum was proved. The data obtained, both by reduction and by oxidation, are as follows:

*Am. Chem. Journ., 8, 280. 1886.

† Read before the Amer. Philos. Soc., Nov. 2, 1894

$\ddagger$ Journ. für Prakt. Chem. (2), 53, 288. 1896. 
Reduction Series.

$\begin{array}{lrrr}2.073^{8} \mathrm{grm} . \mathrm{WO}_{3} \text { gave } 1.6450 \mathrm{~W} & 79.323 \text { per cent. } \\ 4.0853 & \text { " } & 3.2400 \text { “ } & 79.309 \text { " } \\ 6.1547 & \text { " } & 4.8811 \text { " } & 79.307 \text { " }\end{array}$

\section{Oxidation Series.}

$1.5253 \mathrm{grm}$. W gave $1.9232 \mathrm{WO}_{3}$.

$\begin{array}{lllll}3.1938 & \text { " } & 4.0273 & & \\ 4.7468 & & 79.304 & \text { " } \\ & & 5.9848 & 7 & 79.314\end{array}$

Mean of all, $\overline{79.311} \pm .0018$

Hence with $\mathrm{O}=16, \mathrm{~W}=184.007$.

In order to account for the difference between this result and that of Pennington and Smith, an impurity of molybdenum trioxide amounting to about one per cent. would be necessary. Schneider suggests that the quantities of material used by Pennington and Smith were too small, and that there may have been mechanical loss of small particles during the long heatings. Such losses would tend to raise the atomic weight computed from the experiments. On the other hand, the losses could hardly have been uniform in extent, and the extremely low probable error of Pennington and Smith's series renders Schneider's supposition improbable. The error, if error exists, must be accounted for otherwise.

- Since Schneider's paper appeared, another set of determinations by Shinn * has been published from Smith's laboratory. Attempts to verify the results obtained by Smith and Desi having proved abortive, and other experiments having failed, Shinn resorted to the oxidation method and gives the subjoined data. The percentage column is added by myself:

$$
\begin{aligned}
& .22297 \text { grm. W gave .2809o } \mathrm{WO}_{3} \text {. } \\
& .17200 \text { " } .21664 \text { " } 79.394 \\
& \begin{array}{llll}
.10989 & \text { " } 13844 & .19 & 79.377
\end{array} \\
& \text {.10005 “ .12598 " } 79.417 \\
& \text { Mean, } \frac{79.491}{7.0066}
\end{aligned}
$$

This figure is very close to that found in Pennington and Smith's series, and therefore serves as a confirmation. The discordance between these results and Schneider's is still to be explained.

There are still other experiments by Riche, $\dagger$ which I have not been able to get in detail. They cannot be of any value, however, for they give to tungsten an atomic weight of about ten units too low. We nay therefore neglect this series, and go on to combine the others:

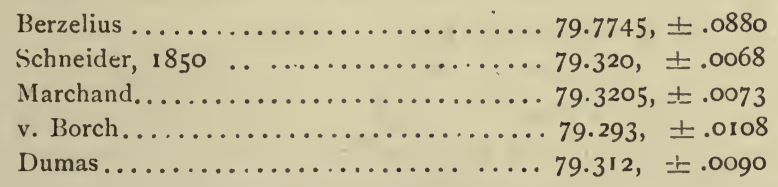

* Doctoral thesis., University of Pennsylvania, 1896. "The atomic mass of tungsten." † Journ. fïr Prakt. Chem., 69, 10. 1857. 


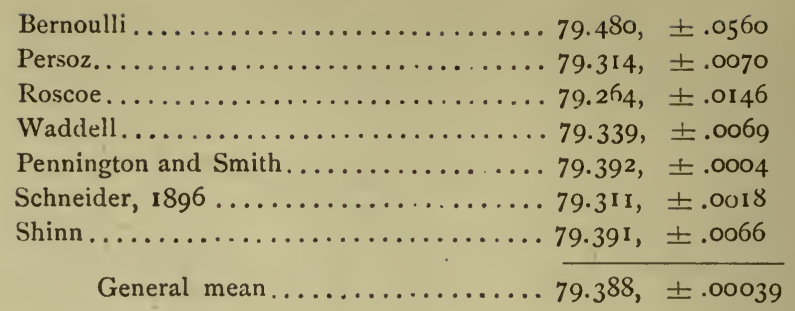

Here the work of Pennington and Smith vastly outweighs everythine else; and if their supposition as to the presence of molybdenum in al the previous investigations is correct, this result is to be accepted.

The rejection of the figures given by Berzelius and by Bernoulli would exert an unimportant influence upon the final result. There is, there fore, no practical objection to retaining them in the discussion.

In 1861 Scheibler* deduced the atomic weight of tungsten from analyses of barium metatungstate, $\mathrm{BaO}_{4} 4 \mathrm{WO}_{3} \cdot 9 \mathrm{H}_{2} \mathrm{O}$. In four experiments he estimated the barium as sulphate, getting closely concordant results, which were, however, very far too low. These, therefore, are rejected. But from the percentage of water in the salt a better result was attained. The percentages of water are as follows :

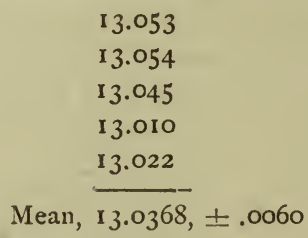

The work of Zettnow, $\dagger$ published in 1867, was somewhat more complicated than any of the foregoing researches. He prepared the pure tungstates of silver and of iron, and from their composition determined the atomic weight of tungsten.

In the case of the iron salt the method of working was this: The pure, artificial $\mathrm{FeWO}_{4}$ was fused with sodium carbonate, the resulting sodium tungstate was extracted by water, and the thoroughly washed, residual ferric oxide was dissolved in hydrochloric acid. This solution was then reduced by zinc, and titrated for iron with potassium permanganate. Corrections were applied for the drop in excess of permanganate needed to produce distinct reddening, and for the iron contained in the zinc. 11.956 grammes of the latter metal contained iron corresponding to $0.6 \mathrm{cc}$. of the standard solution. The permanganate was standardized by comparison with pure ammonium-ferrous sulphate, $\mathrm{Am}_{2} \mathrm{Fe}\left(\mathrm{SO}_{4}\right)_{2} \cdot 6 \mathrm{H}_{2} \mathrm{O}$, so that, in point of fact, Zettnow establishes directly only the ratio between that salt and the ferrous tungstate. From Zett now's four experiments in standardizing I find that $1 \mathrm{cc}$. of his solution 
corresponds to 0.0365457 gramme of the double sulphate, with a probable error of \pm .0000012 .

Three sets of titrations were made. In the first a quantity of ferrous tungstate was treated according to the process given above; the iron solution was diluted to $500 \mathrm{cc}$., and four titrations made upon $100 \mathrm{cc}$. at a time. The second set was like the first, except that three titrations were made with $100 \mathrm{cc}$. each, and a fourth upon $150 \mathrm{cc}$. In the third set the iron solution was diluted to $300 \mathrm{cc}$., and only two titrations upon $100 \mathrm{cc}$. each were made. In sets one and two thirty grammes of zinc were used for the reduction of each, while in number three but twenty grammes were taken. Zettnow's figures, as given by him, are quite complicated; therefore I have reduced them to a common standard. After applying all corrections the following quantities of tungstate, in grammes, correspond to $1 \mathrm{cc}$. of permanganate solution :

$$
\left.\begin{array}{l}
.028301 \\
.028291 \\
.028311 \\
.028301 \\
.028367 \\
.028368 \\
.028367 \\
.028367
\end{array}\right\} \text { Second set. }
$$

With the silver tungstate, $\mathrm{Ag}_{2} \mathrm{WO}_{4}$, Zettnow employed two methods. In two experiments the substance was decomposed by nitric acid, and the silver thus taken into solution was titrated with standard sodium chloride. In three others the tungstate was treated directly with common salt, and the residual silver chloride collected and weighed. Here again, on account of some complexity in Zettnow's figures, I am compelled to reduce his data to a common standard. To 100 parts of $\mathrm{AgCl}$ the following quantities of $\mathrm{Ag}_{2} \mathrm{WO}_{4}$ correspond:

$$
\begin{gathered}
\begin{array}{c}
\text { By First Method. } \\
\text { 161.665 } \\
\text { 161.603 }
\end{array} \\
\text { Mean, } \frac{161.634, \pm .021}{\text { By Second Method. }} \\
\text { 161.687 } \\
\text { 161.65I } \\
\frac{161.613}{161.650,} \pm .014
\end{gathered}
$$

General mean from both series, $161.645, \pm .012$ 
For tungsten hexchloride we have two analyses by Roscoe, published in the same paper with his results upon the trioxide. In one experiment the chlorine was determined as $\mathrm{AgCl}$; in the other the chloride was reduced by hydrogen, and the residual tungsten estimated. By bringing both results into one form of expression we have for the percentage of chlorine in $\mathrm{WCl}_{6}: *$

$$
\text { Mean, } \frac{53.588}{53.632}=
$$

The work done by Smith and Desi $\dagger$ probably ought to be considered in connection with that of Pennington and Smith on the trioxide. Smith and Desi started with tungsten trioxide, freed from molybdenum by means of gaseous hydrochloric acid. This material was reduced in a stream of carefully purified hydrogen, and the water formed was collected in a calcium chloride tube and weighed. To the results found I add the percentage of water obtained from 100 parts of $\mathrm{WO}_{3}$. Vacuum weights are given.

$\begin{array}{ccc}\mathrm{WO}_{3} . & \mathrm{H}_{2} \mathrm{O} . & \text { Percent. } \mathrm{H}_{2} \mathrm{O} . \\ .983024 & .22834 & 23.228 \\ .998424 & .23189 & 23.226 \\ \mathrm{I} .008074 & .23409 & 23.22 \mathrm{I} \\ .911974 & .21184 & 23.229 \\ .997974 & .23179 & 23.226 \\ 1.007024 & .23389 & 23.226 \\ & & \text { Mean, } 23.226, \pm .0008\end{array}$

There are now six ratios from which to calculate the atomic weight of tungsten :

(1.) Perceritage of $\mathrm{W}$ in $\mathrm{WO}_{3}, 79.388, \pm .00039$

(2.) Percentage of $\mathrm{H}_{2} \mathrm{O}$ in $\mathrm{BaO}_{4} \mathrm{WO}_{3} .9 \mathrm{H}_{2} \mathrm{O}, 13.0368, \pm .0060$

(3.) $\mathrm{WO}_{3}: 3 \mathrm{H}_{2} \mathrm{O}:: 100: 23.226, \pm .0008$

(4.) $\mathrm{Am}_{2} \mathrm{Fe}\left(\mathrm{SO}_{4}\right)_{2} \cdot 6 \mathrm{H}_{2} \mathrm{O}: \mathrm{FeWO}_{4}:: .0365457, \pm .0000012: .0283549, \pm .00001 \mathrm{I}_{5}$

(5.) $2 \mathrm{AgCl}: \mathrm{Ag}_{2} \mathrm{WO}_{4}:: 100: 16 \mathrm{r} .645, \pm .012$

(6.) Percentage of $\mathrm{Cl}$ in $\mathrm{WCl}_{6}, 53.6 \mathrm{ro} \pm .0 \mathrm{r} 5$

These are reduced with-

$$
\begin{array}{ll}
\mathrm{O}=15.879, \pm .0003 & \mathrm{~S}=31.828, \pm .0015 \\
\mathrm{Ag}=107.108, \pm .0031 & \mathrm{Ba}=136.392 \pm .0086 \\
\mathrm{Cl}=35.179, \pm .0048 & \mathrm{Fe}=55.597 \pm .0023 \\
\mathrm{~N}=13.935, \pm .002 \mathrm{I} & \mathrm{AgCl}=142.287, \pm .0037
\end{array}
$$

* The actual figures are as follows :

$$
\begin{aligned}
& 19.5700 \text { grm. } \mathrm{WCl}_{6} \text { gave } 42.4 \mathrm{I} 27 \mathrm{grm} \text {. AgCl. } \\
& \text { 10.4.326 } 4.8374 \mathrm{grm} \text {. tungsten. }
\end{aligned}
$$

† Read before Amer. Philos. Soc., Nov. 2, 1894. 
Hence there are six values for the atomic weight of tungsten, as follows :

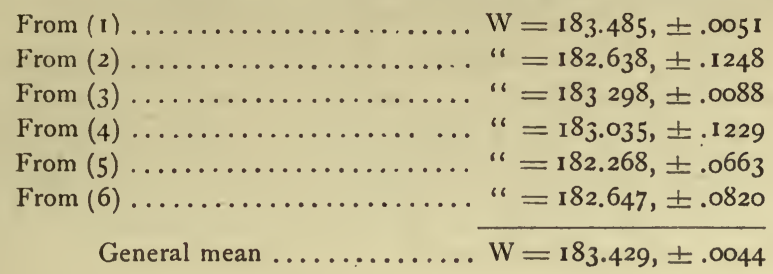

If $\mathrm{O}=16, \mathrm{~W}=184.827$. The rejection of all values except the first and third raises the mean by 0.009 ; that is, four of the ratios count for almost nothing, and the work done in Smith's laboratory dominates all the rest. The questions raised by Schneider in his latest determination, however, are not yet answered, and farther investigation is required in order to fully establish the true atomic weight of tungsten.

\section{URANIUM.}

The earlier attempts to determine the atomic weight of uranium were all vitiated by the erroneous supposition that the uranous oxide was really the metal. The supposition, of course, does not affect the weighings and analytical data which were obtained, although these, from their discordance with each other and with later and better results, have now only a historical value.

For present purposes the determinations made by Berzelius, * by Arfvedson, $\uparrow$ and by Marchand $\ddagger$ may be left quite out of aceount. Berzelius employed various methods, while the others relied upon estimating the percentage of oxygen lost upon the reduction of $\mathrm{U}_{3} \mathrm{O}_{8}$ to $\mathrm{UO}_{2}$. Rammelsberg's $§$ results also, although very suggestive, need no full discussion. $\mathrm{He}$ analyzed the green chloride, $\mathrm{UCl}_{4}$; effected the synthesis of uranyl sulphate from uranous oxide; determined the amount of residue left upon the ignition of the sodio and bario-uranic acetates; estimated the quantity of magnesium uranate formed from a known weight of $\mathrm{UO}_{2}$, and attempted also to fix the ratio between the green and the black oxides. His figures vary so widely that they could count for little in the establishing of any general mean; and, moreover, they lead to estimates of the atomic weight which are mostly below the true value. For instance, twelve lots of $\mathrm{U}_{3} \mathrm{O}_{8}$ from several different sources were reduced to $\mathrm{UO}_{2}$ by heating in hydrogen. The percentages of loss varied from 3.83 to 4.67 , the mean being 4.121 . These figures give values for the atomic

* Schweigg. Journ., 22, 336. 18r8. Poggend. Annalen, r, 359. 1825 .

† Poggend. Annalen, I, 245. Berz. Jahr., 3, 120. 1822.

$\ddagger$ Journ. für Prakt. Chem., 23, 497. 1841.

ל Poggend. Annalen, 55, 318, 1842; 56, 125, 1842; 59, 9, 1843; 66, 91, 1845. Journ. für Prakt. Chem., 29, 324 . 
weight of uranium ranging from 184.33 to 234.05 , or, in mean, 214.53 . Such discordance is due partly to impurity in some of the material studied, and illustrates the difficulties inherent in the problem to be solved. Some of the uranoso-uranic oxide was prepared by calcining the oxalate, and retained an admixture of carbon. Many such points were worked up by Rammelsberg with much care, so that his papers should be scrupulously studied by any chemist who contemplates a redetermination of the atomic weight of uranium.

In 1841 and 1842 Peligot published certain papers * showing that the atomic weight of uranium must be somewhere near 240 . A few years qater the same chemist published fuller data concerning the constant in luestion, but in the time intervening between his earlier and his final researches other determinations were made by Ebelmen and by Wertheim. These investigations we may properly discuss in chronological order. For present purposes the early work of Peligot may be dismissed as only preliminary in character. It showed that what had been previously regarded as metallic uranium was in reality an oxide, but gave figures for the atomic weight of the metal which were merely approximations.

Ebelmen's $\dagger$ determinations of the atomic weight of uranium were based upon analyses of uranic oxalate. This salt was dried at $100^{\circ}$, and then, in weighed amount, ignited in hydrogen. The residual uranous oxide was weighed, and in some cases converted in to $\mathrm{U}_{3} \mathrm{O}_{8}$ by heating in oxygen. The following weights are reduced to a vacuum standard:

Io. $1644 \mathrm{grm}$. oxalate gave $7.2939 \mathrm{grm}$. $\mathrm{UO}_{2}$.

\begin{tabular}{|c|c|c|c|c|c|}
\hline I 2.9985 & “ & $9.33^{12}$ & “ & Gain on oxidation, & .3685 \\
\hline I 1.8007 & " & 8.4690 & “ & “ & .3275 \\
\hline 9.9923 & “ & $7.173^{1}$ & “" & “ & .2812 \\
\hline 11.0887 & “ & 7.9610 & “ & “ & .3105 \\
\hline 10.0830 & “ & 7.2389 & “ & & \\
\hline 6.7940 & “ & 4.8766 & “ & & \\
\hline 16.0594 & “ & 11.5290 & “ & “ & $.453^{\mathrm{I}}$ \\
\hline
\end{tabular}

Reducing these figures to percentages, we may present the results in two columns. Column A gives the percentages of $\mathrm{UO}_{2}$ in the oxalate, while $\mathrm{B}$ represents the amount of $\mathrm{U}_{2} \mathrm{O}_{3}$ formed from 100 parts of $\mathrm{UO}_{2}$ :

\begin{tabular}{ccc}
$A$. & $B$. \\
71.924 & $\ldots \ldots$ \\
71.787 & 103.949 \\
71.767 & 103.867 \\
71.621 & 103.920 \\
71.794 & 103.900 \\
71.793 & $\ldots \ldots$ \\
71.778 & $\ldots \ldots$ \\
71.790 & 103930 \\
\hline Mean, $71.782, \pm .019$ & Mean, $103.913, \pm .009$ \\
\hline
\end{tabular}

* Compt. Rend., 12, 735. r84r. Ann. Chim. Phys. (3), 55. I842.

† Journ. für Prakt. Chem., 27, 385. 1842. 
Wertheim's* experiments were even simpler in character than those of Ebelmen. Sodio-uranic acetate, carefully dried at $200^{\circ}$, was ignited, leaving the following percentages of sodium uranate:

$$
\begin{gathered}
67.5^{1508} \\
67.5455^{8} \\
67.50927 \\
\text { Mean, } 67.5^{2} 33^{1}, \pm .0076
\end{gathered}
$$

The final results of Peligot's $\dagger$ investigations appeared in 1846. Both the oxalate and the acetate of uranium were studied and subjected to combustion analysis. The oxalate was scrupulously purified by repeated crystallizations, and thirteen analyses, representing different fractions, were made. Seven of these gave imperfect results, due to incomplete purification of the material; six only, from the later crystallizations, need to be considered. In these the uranium was weighed as $\mathrm{U}_{3} \mathrm{O}_{8}$, and the carbon as $\mathrm{CO}_{2}$. From the ratio between the $\mathrm{CO}_{2}$ and $\mathrm{U}_{3} \mathrm{O}_{8}$ the atomic weight of uranium may be calculated without involving any error due to traces of moisture possibly present in the oxalate. I subjoin Peligot's weighings, and give, in the third column, the $\mathrm{U}_{3} \mathrm{O}_{8}$ proportional to 100 parts of $\mathrm{CO}_{2}$ :

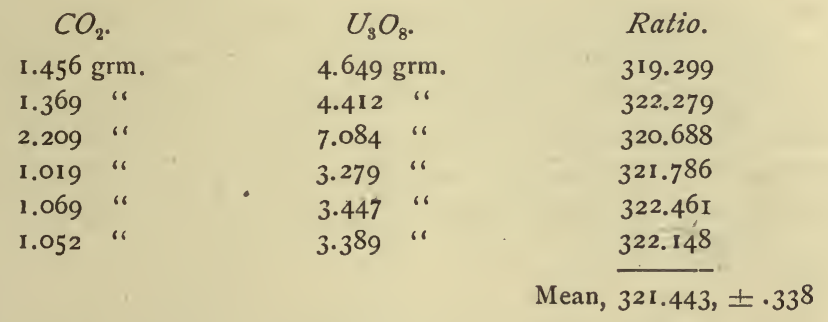

From the acetate, $\mathrm{UO}_{2}\left(\mathrm{C}_{2} \mathrm{H}_{3} \mathrm{O}_{2}\right)_{2} \cdot 2 \mathrm{H}_{2} \mathrm{O}$, the following percentages of $\mathrm{U}_{3} \mathrm{O}_{8}$ were obtained:

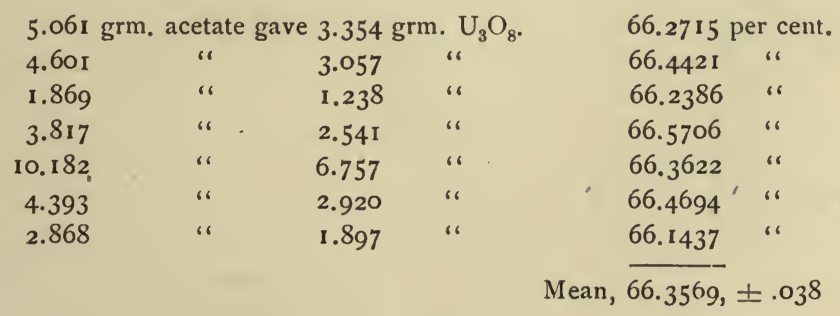

The acetate also yielded the subjoined percentages of carbon and of water. Assuming that the figures for carbon were calculated from known 
weights of dioxide, with $\mathrm{C}=12$ and $\mathrm{O}=16, \mathrm{I}$ have added a third column, in which the carbon percentages are converted into percentages of $\mathrm{CO}_{2}$ :

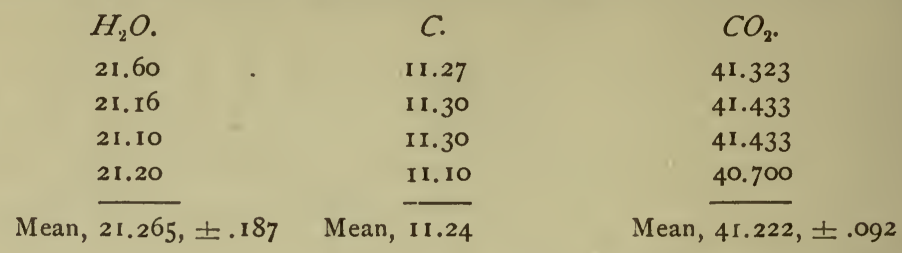

From these data we get the following values for the molecular weight of uranyl acetate:

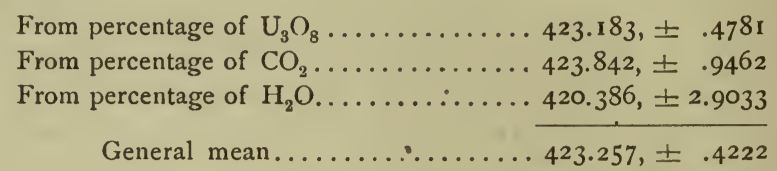

In the posthumous paper of Zimmermann, edited by Krüss and Alibegoff,* the atomic weight of uranium is determined by two methods. First, $\mathrm{UO}_{2}$, prepared by several methods, is converted into $\mathrm{U}_{3} \mathrm{O}_{8}$ by heating in oxygen. To begin with, $\mathrm{U}_{3} \mathrm{O}_{8}$ was prepared, and reduced to $\mathrm{UO}_{2}$ by ignition in hydrogen. When the reduction takes place at moderate temperatures, the $\mathrm{UO}_{2}$ is somewhat pyrophoric, but if the operation is performed over the blast lamp this difficulty is avoided. After weighing the $\mathrm{UO}_{2}$, the oxidation is effected, and the gain in weight observed. The preliminary $\mathrm{U}_{3} \mathrm{O}_{8}$ was derived from the following sources: A, from uranium tetroxide; $\mathrm{B}$, from the oxalate; $\mathrm{C}$, from uranyl nitrate; $\mathrm{D}$, by precipitation with mercuric oxide. The full data, lettered as indicated above, are subjoined :
$\mathrm{UO}_{2}$.
$\mathrm{U}_{3} \mathrm{O}_{8}$.
A. $\left\{\begin{array}{r}8.9363 \\ 7.9659 \\ 12.4385\end{array}\right.$
9.2872
8.2789
I 2.9270
B. $\left\{\begin{array}{r}12.8855 \\ 5.7089 \\ 9.6270\end{array}\right.$
13.391 3
$5.933 \mathrm{I}$
$10.005 \mathrm{I}$
1 3.7036
I0.390I
16. 5242
7.7245
Per cent. of Gain.
C. $\left\{\begin{array}{r}\text { I } 3.1855 \\ 9.9973\end{array}\right.$
D. $\left\{\begin{array}{r}15.8996 \\ 7.4326\end{array}\right.$
3.927
3.929
3.927
3.925
3.927
3.928
3.929
3.929
3.928
3.927
Mean, $\overline{3.9276}, \pm .0003$
Ebelmen found, $3.913, \pm .009$
General mean, 3.9276, \pm .0003

In short, Ebelmen's mean vanishes when combined with Zimmermann's. 
Zimmermann's second method was essentially that of Wertheim, namely, the ignition of the double acetate $\mathrm{UO}_{2}\left(\mathrm{C}_{2} \mathrm{H}_{3} \mathrm{O}_{2}\right)_{2} \cdot \mathrm{NaC}_{2} \mathrm{H}_{3} \mathrm{O}_{2}$, the residue being sodium uranate, $\mathrm{Na}_{2} \mathrm{U}_{2} \mathrm{O}_{7}$.

\begin{tabular}{ccc} 
Double Acetate. & Uranate. & Percent. Uranate. \\
4.272984 & 2.886696 & 67.557 \\
5.272094 & 3.560770 & 67.540 \\
2.912283 & 1.967428 & 67.556 \\
3.181571 & 2.149309 & 67.555 \\
& & Mean, $\overline{67.552}, \pm .0027$ \\
& \multicolumn{3}{r}{ Wertheim found, $67.523, \pm .0076$} \\
& \multicolumn{2}{r}{ General mean, $67.549, \pm .0025$}
\end{tabular}

All the data for uranium now sum up thus:

(r.) Per cent. $\mathrm{UO}_{2}$ from uranyl oxalate, $7 \mathrm{r} .782$, \pm .or 9

(2.) $6 \mathrm{CO}_{2}: \mathrm{U}_{3} \mathrm{O}_{8}:: 100: 321.443, \pm .338$

(3.) Molecular weight of uranyl acetate, $423.842, \pm .4222$

(4.) $3 \mathrm{UO}_{2}: \mathrm{U}_{3} \mathrm{O}_{8}:: 100: 103.9276, \pm .0003$

(5.) Per cent. $\mathrm{Na}_{2} \mathrm{U}_{2} \mathrm{O}_{7}$ from $\mathrm{UO}_{2}, \mathrm{Na}\left(\mathrm{C}_{2} \mathrm{H}_{3} \mathrm{O}_{2}\right)_{3}, 67.549, \pm .0025$

Computing with $\mathrm{O}=15.879, \pm .0003 ; \mathrm{C}=11.920, \pm .0004$, and $\mathrm{Na}=$ $22.881, \pm .0046$, we have-

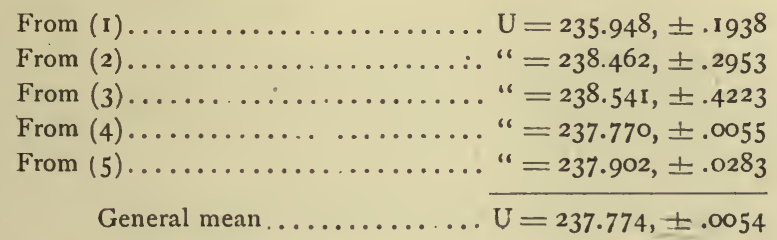

If $\mathrm{O}=16, \mathrm{U}=239.586$.

In this case Zimmermann's data control the final result. All the other determinations might be rejected without appreciable effect. 


\section{SELENIUM.}

The atomic weight of this element was first determined by Berzelius,* who, saturating 100 parts of selenium with chlorine, found that 179 of chloride were produced. Further on these figures will be combined with similar results by Dumas.

We may omit, as unimportant for present purposes, the analyses of alkaline selenates made by Mitscherlich and Nitzsch, $\dagger$ and pass on to the experiments published by Sacc $\ddagger$ in 1847 . This chemist resorted to a variety of methods, some of which gave good results, while others were unsatisfactory, First, he sought to establish the exact composition of $\mathrm{SeO}_{2}$, both by synthesis and by analysis. The former plan, according to which he oxidized pure selenium by nitric acid, gave poor results; better figures were obtained upon reducing $\mathrm{SeO}_{2}$ with ammonium bisulphite and hydrochloric acid, and determining the percentage of selenium set free:

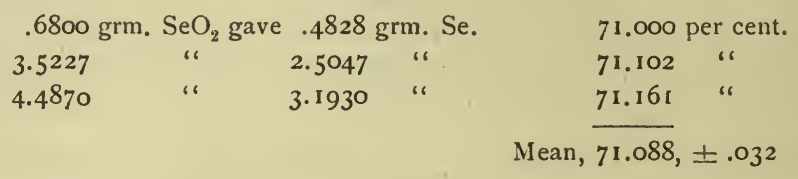

In a similar manner Sacc also reduced barium selenite, and weighed the resulting mixture of barium sulphate and free selenium. This process gave discordant results, and a better method was found in calcining $\mathrm{BaSeO}_{3}$ with sulphuric acid, and estimating the resulting quantity of $\mathrm{BaSO}_{4}$. In the third column I give the amounts of $\mathrm{BaSO}_{4}$ equivalent to 100 of $\mathrm{BaSeO}_{3}$ :

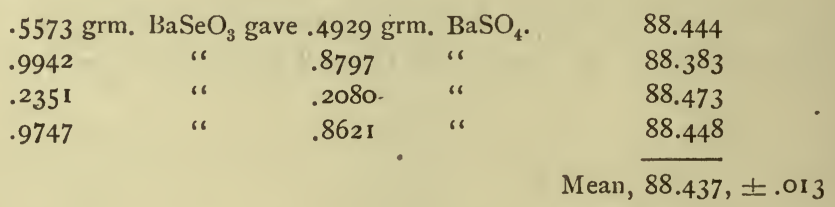

Still other experiments were made with the selenites of silver and lead; but the figures were subject to such errors that they need no further discussion here.

A few years after Sacc's work was published, Erdmann and Marchand made with their usual care a series of experiments upon the atomic weight under consideration. $\S$ They analyzed pure mercuric selenide, which had been repeatedly sublimed and was well crystallized. Their

* Poggend. Annalen, 8, 1. 1826.

† Poggend. Annalen, 9, 623. 1827.

$\ddagger$ Ann. d. Chim, et d. Phys. (3), 21, II9.

\& Jour. für Prakt. Chem., 55, 202. $185^{2}$. 
method of manipulation has already been described in the chapter upon mercury. These percentages of $\mathrm{Hg}$ in $\mathrm{HgSe}$ were found :

$$
\begin{gathered}
7 \mathrm{r} .726 \\
7 \mathrm{r} .73 \mathrm{I} \\
\frac{7 \mathrm{r} .74 \mathrm{I}}{\text { Mean, } 7 \mathrm{r} .7327, \pm .003}
\end{gathered}
$$

The next determinations were made by Dumas,* who returned to the original method of Berzelius. Pure selenium was converted by dry chlorine into $\mathrm{SeCl}_{4}$, and from the gain in weight the ratio between $\mathrm{Se}$ and $\mathrm{Cl}$ was easily deducible. I include Berzelius' single experiment, which I have already cited, and give in a third column the quantity of chlorine absorbed by 100 parts of selenium :

$\begin{array}{llll}1.709 & \text { grm. Se absorb } & 3.049 & \text { grm. } C l \\ 1.810 & \text { " } & 3.219 & \text { " } \\ 1.679 & \text { " } & 3.003 & \text { " } \\ 1.498 \text { " } & \text { " } & 2.688 & \text { " } \\ 1.944 & 3.468 & \text { " } \\ 1.887 & \text { " } & 3.382 \\ 1.935 & \text { " } & 3.452\end{array}$

$$
\begin{gathered}
178.409 \\
177.845 \\
178.856 \\
179.439 \\
178.395 \\
179.226 \\
178.398 \\
179.000-\text { Berzelius. } \\
\text { Mean, } 178.696, \pm .125
\end{gathered}
$$

The question may here be properly asked, whether it would be possible thus to form $\mathrm{SeCl}_{4}$, and be certain of its absolute purity? A trace of oxychloride, if simultaneously formed, would increase the apparent atomic weight of selenium. In point of fact, this method gives a higher value for Se than any of the other processes which have been adopted, and that value has the largest probable error of any one in the entire series. A glance at the table which summarizes the discussion at the end of this chapter will render this point sufficiently clear.

Still later, Ekman and Pettersson $\dagger$ investigated several methods for the determination of this atomic weight, and finally decided upon the two following:

First, pure silver selenite, $\mathrm{Ag}_{2} \mathrm{SeO}_{3}$ was ignited, leaving behind metallic silver, which, however, sometimes retained minute traces of selenium. The data obtained were as follows:

$\begin{array}{ccc}\mathrm{Ag}_{2} \mathrm{SeO}_{3} . & \mathrm{Ag} . & \text { Percent. } \mathrm{Ag} . \\ 5.2102 & 3.2787 & 62.93 \\ 5.9721 & 3.7597 & 62.95 \\ 7.2741 & 4.5803 & 62.97 \\ 7.5390 & 4.7450 & 62.94 \\ 6.9250 & 4.3612 & 62.98 \\ 7.3455 & 4.6260 & 62.98 \\ 6.9878 & 4.3992 & 62.95 \\ & & \text { Mean, } 62.957, \pm .005\end{array}$

*Ann. Chem. Pharm., I13, 32. 1860.

† Ber. d. Deutsch. Chem. Gesell., 9, 1210. 1876. Published in detail by the society at Upsala. 
Secondly, a warm aqueous solution of selenious acid was mixed with $\mathrm{HCl}$, and reduced by a current of $\mathrm{SO}_{2}$. The reduced Se was collected upon a glass filter, dried, and weighed.

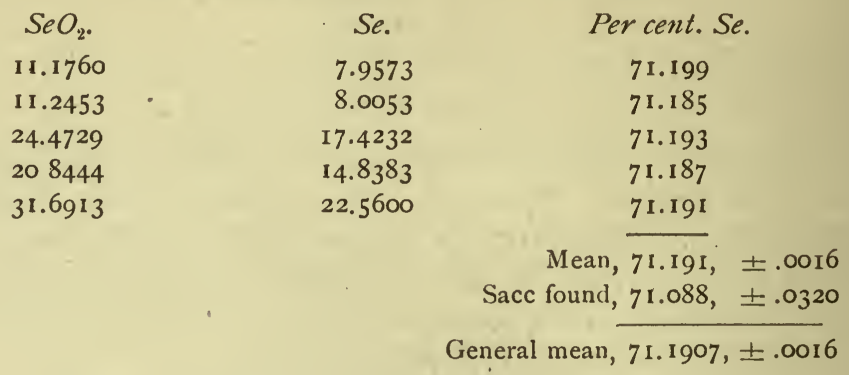

There are now five series of figures from which to deduce the atomic weight of selenium :
(I.) Per cent. of $\mathrm{Se}$ in $\mathrm{SeO}_{2}, 7 \mathrm{I} .1907, \pm, 0016$
(2.) $\mathrm{BaSeO}_{3}: \mathrm{BaSO}_{4}:: 100$ ': $88.437, \pm .013$
(3.) Per cent. of $\mathrm{Hg}$ in $\mathrm{Hgse}, 71.7327, \pm .003$
(4.) $\mathrm{Se}: \mathrm{Cl}_{4}:: 100: 178.696, \pm .125$
(5.) Per cent. of $\mathrm{Ag}$ in $\mathrm{Ag}_{2} \mathrm{SeO}_{3}, 62.957, \pm .005$

From these, computing with-

$$
\begin{array}{ll}
\mathrm{O}=15.879, \pm .0003 & \mathrm{~S}=31.828, \pm .0015 \\
\mathrm{Ag}=107.108, \pm .0031 & \mathrm{Ba}=136.392, \pm .0086 \\
\mathrm{Cl}=35.179, \pm .0048 & \mathrm{Hg}=198.491, \pm .0083,
\end{array}
$$

five values for Se are calculable, as follows:

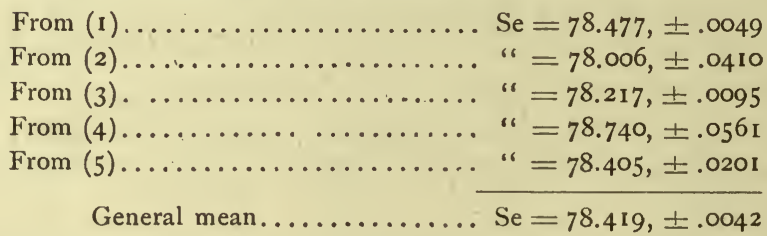

If $\mathrm{O}=16$, this becomes $\mathrm{Se}=79.016$. 


\section{TELLURIUM.}

Particular interest attaches to the atomic weight of tellurium on account of its relations to the periodic law. According to that law, tellurium should lie between antimony and iodine, having an atomic weight greater than 120 and less than 126 . Theoretically, Mendelejeff assigns it a value of $\mathrm{Te}=125$, but all of the best determinations lead to a mean number higher than is admissible under the currently accepted hypotheses. Whether theory or experiment is at fault remains to be discovered.

The first, and for many years the only, determinations of the constant in question were made by Berzelius.* By means of nitric acid he oxidized tellurium to the dioxide, and from the increase in weight deduced a value for the metal. He published only his final results, from which, if $\mathrm{O}=100, \mathrm{Te}=802.121$. The three separate experiments give $\mathrm{Te}=$ $801.74,801.786$, and 802.838 , whence we can calculate the following percentages of metal in the dioxide:

$$
\begin{array}{r}
80.057 \\
80.036 \\
80.034 \\
\frac{80.042, \pm .005}{8 e a n,}
\end{array}
$$

The next determinations were made by von Hauer, $\dagger$ who resorted to the analysis of the well crystallized double salt $\mathrm{TeBr}_{4} \cdot 2 \mathrm{KBr}$. In - this compound the bromine was estimated as silver bromide, the values assumed for $\mathrm{Ag}$ and $\mathrm{Br}$ being respectively 108.1 and 80. Recalculating,

\begin{tabular}{|c|c|c|c|c|}
\hline 2.000 & ${ }_{2} \mathrm{Te}$ & $69.946 p$ & ent. Br. & 164.460 \\
\hline 6.668 & “" & 69.8443 & " & $164.22 \mathrm{I}$ \\
\hline 2.934 & "، & 69.9113 & “6 & 164.379 \\
\hline 3.697 & " & 70.0163 & “ & 164.626 \\
\hline 1.000 & " & 69.901 & " & 164.355 \\
\hline
\end{tabular}
with our newer atomic weights for the above-named elements, we get from von Hauer's analyses, for 100 parts of the salt, the quantities of $\mathrm{AgBr}$ which are put in the third column:

From Berzelius' series we may calculate $\mathrm{Te}=127.366$, and from von Hauer's $\mathrm{Te}=126.454$. Dumas, $₫$ by a method for which he gives absolutely no particulars, found $\mathrm{Te}=129$.

In 1879, with direct reference to Mendelejeff's theory, the subject of the atomic weight of tellurium was taken up by Wills. $\S$ 'The methods

\footnotetext{
* Poggend. Annalen, 28, 395. I833.

† Sitzungsb. Wien Akad., 25, 142.

$\ddagger$ Ann. Chim. Phys. (3), 55,129 . 1859 .

\& Journ. Chem. Soc., Oct., 1879, p. 704.
} 
of Berzelius and von Hauer were employed, with various rigid precautions in the way of testing balance and weights, and to ensure purity of material. In the first series of experiments tellurium was oxidized by nitric acid to form $\mathrm{TeO}_{2}$. The results gave figures ranging from $\mathrm{Te}=$ 125.64 to 128.66 :

\begin{tabular}{|c|c|c|c|}
\hline I. 45313 & “ & I. 81542 & " \\
\hline 2.67093 & “ & $3.33^{8} 3^{8}$ & “ \\
\hline 477828 & “ & $5 \cdot 95748$ & " \\
\hline 2.65029 & “ & 3.31331 & " \\
\hline
\end{tabular}

79.828 per cent. Te.

\begin{tabular}{rr}
80.044 & "“ \\
80.007 & "، \\
80.207 & Mean, 80.989 \\
\hline 0.041
\end{tabular}

In the second series tellurium was oxidized by aqua regia to $\mathrm{TeO}_{2}$, with results varying from $\mathrm{Te}=127.10$ to 127.32 :

$\begin{array}{llll}2.85011 \mathrm{grm} \text {. Te gave } & 3.56158 \mathrm{grm} . \mathrm{TeO}_{2} \text {. } \\ 3.09673 & \text { “ } & 3.86897 & \text { " } \\ 5.09365 & \text { “ } & 6.36612 & \text { “ } \\ 3.26604 & \text { " } & 4.08064 & \text { " }\end{array}$

$\begin{array}{r}80.024 \text { per cent. Te. } \\ 80.040 \text { “" } \\ 80.012 \quad \text { "“ } \\ 80.037 \\ \hline \text { Mean, } 80.028, \pm .004\end{array}$

By von Hauer's process, the analysis of ' $\mathrm{TeBr}_{4} .2 \mathrm{KBr}$, Will's figures give results ranging from $\mathrm{Te}=125.40$ to 126.94 . Reduced to a common standard, 100 parts of the salt yield the quantities of $\mathrm{AgBr}$ given in the third column :

$\begin{array}{lllll}1.70673 \mathrm{grm} . \mathrm{K}_{2} \mathrm{TeBr}_{6} \text { gave } 2.80499 \mathrm{grm} . \mathrm{AgBr} . & 164.349 \\ 1.75225 & \text { “ } & 2.88072 & \text { “ } & 164.398 \\ 2.06938 & \text { “ } & 3.40739 & \text { “ } & 164.657 \\ 3.29794 & \text { “ } & 5.43228 & \text { “ } & 164.717 \\ 2.46545 & \text { “ } & 405742 & \text { " } & 164.57 \mathrm{I} \\ & & & & \end{array}$

Combined with von Hauer's mean, 164.408. \pm .045 , this gives a general mean of $164.468, \pm .033$. Hence $\mathrm{Te}=126.502$.

The next determinations in order of time were those of Brauner.* This chemist tried various unsuccessful methods for determining the atomic weight of tellurium, among them being the synthetic preparation of silver, copper, and gold tellurides, and the basic sulphate, $\mathrm{Te}_{2} \mathrm{SO}_{7}$. None of these methods gave sufficiently concordant results, and they were therefore abandoned. The oxidation of tellurium to dioxide by means of nitric acid was also unsatisfactory, but a series of oxidations with ,aqua regia gave data as follows. The third column contains the percentage of tellurium in the dioxide: 


$\begin{array}{ccc}\text { Te. } & \mathrm{TeO}_{2 .} & \text { Percent. Te. } \\ 2.3092 & 2.900 \mathrm{I} & 79.625 \\ 2.8153 & 3.5332 & 79.68 \mathrm{I} \\ 4.0176 & 5.0347 & 79.798 \\ 3.1613 & 3.9685 & 79.660 \\ .8399 & 1.0526 & \frac{79.793}{79.711} \pm .0239\end{array}$

Hence $\mathrm{Te}=124.709$.

In a single analysis of the dioxide, by reduction with $\mathrm{SO}_{2}, 2.5489$ grammes $\mathrm{TeO}_{2}$ gave 2.0374 of metal. If we give this experiment the weight of one observation in the synthetic series, the percentage of tellurium found by it becomes-

$$
79.932, \pm .0534
$$

Hence $\mathrm{Te}=126.494$.

Brauner's best results were obtained from analyses of tellurium tetrabromide, prepared from pure tellurium and pure bromine, and afterwards sublimed in a vacuum. This compound was titrated with standard solutions of silver, and three series of experiments, made with samples of bromide of different origin, gave results as follows. 'The $\mathrm{TeBr}_{4}$ equivalent to 100 parts of silver appears in the third column:

First Series.

$\begin{array}{ccc}\mathrm{TeBr}_{4} . & \mathrm{Ag}_{4} & \text { Ratio. } \\ 2.14365 & 2.06844 & 103.636 \\ 1.76744 & 1.7053 \mathrm{I} & 103.643 \\ 1.47655 & 1.42477 & 103.634 \\ 1.23354 & 1.19019 & 103.642\end{array}$

Second Series.

$\begin{array}{ccc}\mathrm{TeBr}_{4} . & \mathrm{Ag}_{4} & \text { Ratio. } \\ 3.07912 & 2.97064 & 103.65 \mathrm{I} \\ 5.47446 & 5.28 \mathrm{I} 57 & 103.652 \\ 3.30927 & 3.19313 & 103.637 \\ 7.2698 \mathrm{I} & 7.01414 & 103.645 \\ 3.52077 & 3.39667 & 103.654\end{array}$

Third Series.

$\mathrm{TeBr}_{4}$.
$2.35^{650}$
1.51931
1.43985

$\mathrm{Ag}_{4}$.

Ratio.

$$
\begin{aligned}
& 2.27363 \\
& 1.46564 \\
& \mathrm{I} .38942
\end{aligned}
$$

103.645

103.662

I03.630

Mean of all as one series, $\overline{103.644}, \pm .0018$ 
Hence $\mathrm{Te}=126.668, \pm .0290$. A reduction of the weighings to a vacuum raises this by 0.07 to 126.738 .

Still another series of analyses, made with fractionated material, gave values for tellurium running up to as high as 137 . These experiments led Brauner to believe that he had found in tellurium a higher homologue of that element, a view which he has since abandoned.* Brauner also made a series of analyses of tellurium dibromide, but the results were unsatisfactory.

In the series of determinations by Gooch and Howland $\dagger$ an alkaline solution of tellurium dioxide was oxidized by means of standard solutions of potassium permanganate. This was added in excess, the excess being measured, after acidification with sulphuric acid, by back titration with oxalic acid and permanganate. Two series are given, varying in detail, but for present purposes they may be treated as one. The ratio $\mathrm{TeO}_{2}: \mathrm{O}:: 100: x$ is given in the third column.

$\begin{array}{ccc}\mathrm{TeO}_{2} \text { Taken. } & \text { O Required } & \text { Ratio. } \\ .1200 & .01202 & 10.017 \\ .0783 & .00785 & 10.026 \\ .0931 & .00940 & 10.097 \\ .1100 & .01119 & 10.149 \\ .0904 & .00909 & 10.055 \\ .1065 & .01078 & 10.122 \\ .0910 & .00915 & \\ .0910 & .00910 & 10055 \\ .0911 & .00924 & 10.000 \\ .0913 & .00915 & 10.143 \\ .0912 & .00915 & 10.022 \\ .0914 & .00923 & 10.033 \\ & & 10.098 \\ & & \text { Mean, } 10.068, \pm .0100\end{array}$

Hence $\mathrm{Te}=125.96$.

In Staudenmaier’s $\$$ determinations of the atomic weight of tellurium, crystallized telluric acid, $\mathrm{H}_{6} \mathrm{TeO}_{6}$ was the starting point. By careful heating in a glass bulb this compound can be reduced to $\mathrm{TeO}_{2}$, and $\mathrm{by}$ heating in hydrogen, to metal. In the latter case finely divided silver was added to prevent volatilization of tellurium. The telluric acid was fractionally crystallized, but the different fractions gave fairly constant results. I therefore group Staudenmaier's data so as to bring them into series more suitable for the present discussion.

* Journ. Chem. Soc., 67, 549. 1895 .

+ A mier. Journ. Sci., 58, 375. I894. Some misprints in the original publication have been kindly corrected by Professor Gooch; hence the differences between these data and the figures formerly given.

† Zeitsch. Anorg. Chem., ro, I89. 1895 . 
First. $\mathrm{H}_{6} \mathrm{TeO}_{6}$ to $\mathrm{TeO}_{2}$.

$\begin{array}{ccc}\mathrm{H}_{6} \mathrm{TeO}_{6} . & \text { Loss in Weight. } & \text { Percent. } \mathrm{TeO}_{2} . \\ 1.72 \mathrm{I} 8 & .5260 & 69.45 \mathrm{I} \\ 2.8402 & .8676 & 69.453 \\ 4.0998 & \mathrm{1.2528} & 69.442 \\ 3.0916 & .9450 & 69.433 \\ 1.1138 & .3405 & 69.429 \\ 4.9843 & 1.5236 & 69.432 \\ 4.6716 & 1.4278 & 69.437 \\ & & \text { Mean, } 69.440, \pm .0024\end{array}$

Hence $\mathrm{Te}=126.209$.

Second. $\mathrm{H}_{6} \mathrm{TeO}_{6}$ to $\mathrm{Te}$.

$\mathrm{H}_{6} \mathrm{TeO}_{6}$.

I. 2299

I.OI 75

2.5946
Loss in Weight.

$.547 \mathrm{I}$

.4526

I , I 549
Per cent. Te.

55.517

55.518

55.488

Mean, $55 \cdot 508, \pm .0068$

Hence $\mathrm{Te}=126.303$.

Staudenmaier also gives four reductions of $\mathrm{TeO}_{2}$ to $\mathrm{Te}$, in presence of finely divided silver. The data are as follows:

$\begin{array}{ccc}. \mathrm{TeO}_{2} . & \text { Loss in Weight. } & \text { Per cent. Te. } \\ .917 \mathrm{I} & .1839 & 79.948 \\ 1 \mathrm{1} 972 \mathrm{I} & .3951 & 79.966 \\ 2.4115 & .4835 & 79950 \\ 1.0172 & .204 \mathrm{I} & \underline{79.935} \\ & & \text { Mean, } 79.950, \pm .0043\end{array}$

Hence $\mathrm{Te}=126.636$.

The last series, giving the percentage of tellurium in the dioxide, combines with previous series thus:

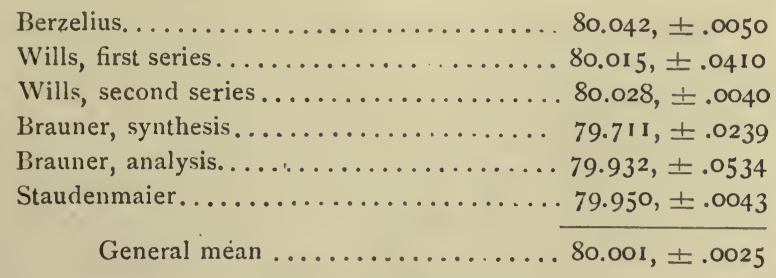

The very recent determinations byChikashigé* were made by Brauner's method, giving the ratio between silver and $\mathrm{TeBr}_{4}$. In all essential particulars the work resembles that of Brauner. except that the tellurium, 
instead of being extracted from metallic tellurides, was derived from Japanese native sulphur, in which it exists as an impurity. This difference of origin in the material studied gives the chief interest to the investigation. The data are as follows:

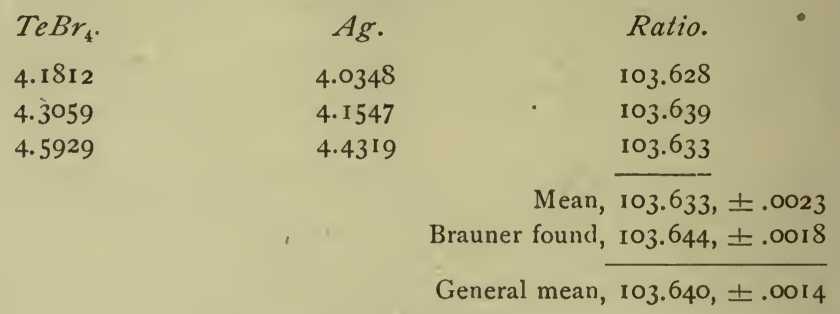

Now, to sum up, the subjoined ratios are available for computing the atomic weight of tellurium:

(1.) Percentage Te in $\mathrm{TeO}_{2}, 80.001, \pm .0025$

(2.) Percentage $\mathrm{Te}$ in $\mathrm{H}_{6} \mathrm{TeO}_{6}, 55.508, \pm .0068$

(3.) Percentage $\mathrm{TeO}_{2}$ in $\mathrm{H}_{6} \mathrm{TeO}_{6}, 64.440, \pm .0024$

(4.) $\mathrm{Ag}_{4}: \mathrm{TeBr}_{4}:: 100: 103.640, \pm .0014$

(5.) $\mathrm{K}_{2} \mathrm{TeBr}_{6}: 6 \mathrm{AgBr}:: 100: 164.468, \pm .0330$

(6.) $\mathrm{TeO}_{2}: \mathrm{O}:$ : $100: 10.068, \pm .0100$

To reduce these ratios we have-

$$
\begin{array}{ll}
\mathrm{O}=15.879, \pm .0003 & \mathrm{~K}=38.817, \pm .005 \mathrm{I} \\
\mathrm{Ag}=\mathrm{I07.108, \pm .0031} & \mathrm{AgBr}=\mathrm{I} 86.452, \pm .0054 \\
\mathrm{Br}=79.344, \pm .0062 &
\end{array}
$$

For the atomic weight of tellurium six values appear, as follows:

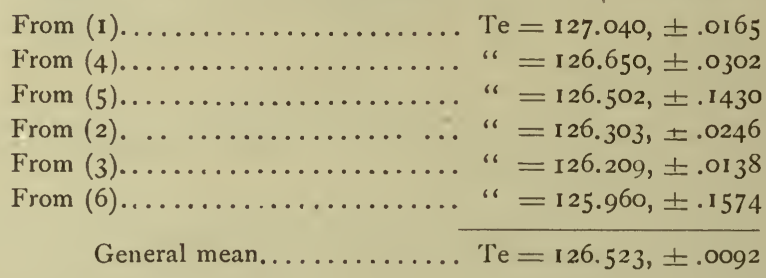

If $\mathrm{O}=16, \mathrm{Te}=127.487$.

A careful consideration of the foregoing figures, and of the experimental methods by which they were obtained, will show that they are not absolutely conclusive with regard to the place of tellurium under the periodic law. The atomic weight of iodine, calculated in a previous chapter, is 125.888. Wills' values for Te, rejecting his first series as relatively unimportant, range from 125.40 to 127.32 ; that is, some of them fall below the atomic weight of iodine, although none descend quite to the 125 assumed by Mendelejeff.

Some of Brauner's data fall even lower; and the same thing is true in 
Gooch and Howland's series, of which the mean gives $\mathrm{Te}=125.96$, a value very little above that of iodine.

In considering the experimental methods, reference may properly be made to the controversy regarding the atomic weight of antimony. It will be seen that Dexter, estimating the latter constant by the conversion of the metal into $\mathrm{Sb}_{2} \mathrm{O}_{4}$, obtained a value approximately of $\mathrm{Sb}=122$. Dumas, working with $\mathrm{SbCl}_{3}$, obtained nearly the same value. Schneider and Cooke, on the other hand, have established an atomic weight for antimony near 120 , and Cooke in particular has traced out the constant errors which lurked unsuspected in the work of Dumas. Now in their physical aspects tellurium and antimony are quite similar. The oxidation of tellurium to dioxide resembles in many particulars that of antimony, and may lead to error in the same way. In each of the six tellurium ratios there is still uncertainty, and a positive measurement, free from objections, of the constant in question is yet to be made.

\section{FLUORINE.}

The atomic weight of fluorine has been chiefly determined by one general method, namely, by the conversion of fluorides into sulphates. The work of Christensen, however, is on different lines. Excluding the early results of Davy,* we have to consider first the experiments of Berzelius, Louyet, Dumas, De Luca, and Moissan with reference to the fluorides of calcium, sodium, potassium, barium, and lead.

The ratio between calcium fluoride and sulphate has been determined by the five investigators above named, and by one general process. The fluoride is treated with strong sulphuric acid, the resulting sulphate is ignited, and the product weighed. In order to insure complete transformation special precautions are necessary, such, for instance, as repeated treatment with sulphuric acid, and so on. For details like these the original papers must be consulted.

The first experiments in chronological order are those of Berzelius, $\dagger$ who operated upon an artificial calcium fluoride. He found, in three experiments, for one part of fluoride the following of sulphate:

$$
\begin{gathered}
1.749 \\
1.750 \\
1.751 \\
\frac{1.750}{\text { Mean, }} \pm .0004
\end{gathered}
$$

Louyet's researches $\ddagger$ were much more elaborate than the foregoing. He began with a remarkably concerdant series of results upon fluor spar, 
.in which one gramme of the fluoride yielded from 1.734 to 1.737 of sulphate. At first he regarded these as accurate, but he soon found that particles of spar had been coated with sulphate, and had therefore escaped action. In the following series this source of error was guarded against.

Starting with fluor spar, Louyet found of sulphate as follows:

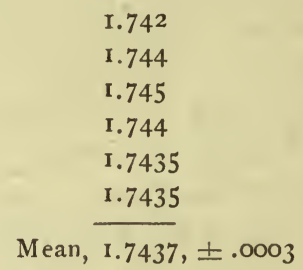

A second series, upon artificial fluoride, gave:

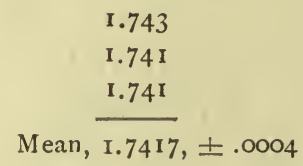

Dumas* published but one result for calcium fluoride. $.495 \mathrm{grm}$. gave $.864 \mathrm{grm}$. sulphate, the ratio being $1: 1.7455$.

De Luca $\dagger$ worked with a very pure fluor spar, and published the following results. The ratio between $\mathrm{CaSO}_{4}$ and one gramme of $\mathrm{CaF}_{2}$ is given in the third column:

$\begin{array}{lcccc}.9305 \text { grm. } \mathrm{CaF}_{2} \text { gave } \mathrm{I} .630 \text { grm. } \mathrm{CaSO}_{4} . & 1.7518 \\ .836 & \text { “ } & 1.459 & \text { “ } & 1.745^{2} \\ .502 & \text { “ } & .8755 & \text { “ } & 1.7440 \\ .3985 & \text { “ } & .6945 & \text { “ } & 1.7428\end{array}$

If we include Dumas' single result with these, we get a mean of 1.7459, \pm .0011 .

Moissan $\ddagger$ unfortunately gives no details nor weighings, but merely states that four experiments with calcium fluoride gave values for $\mathrm{F}$ ranging from 19.02 to 19.08 . To $\mathrm{S}$ he assigned the value 32.074 , and probably $\mathrm{Ca}$ was taken as $=40$. With these data his extreme values as given may be calculated back into uniformity with the ratio as stited above, becoming-

$$
\text { Mean, } \begin{array}{r}
\begin{array}{r}
1.7444 \\
1.7410
\end{array} \\
1.7427
\end{array}
$$


If we assign this equal weight with Berzelius' series, the data for this ratio combine thus:

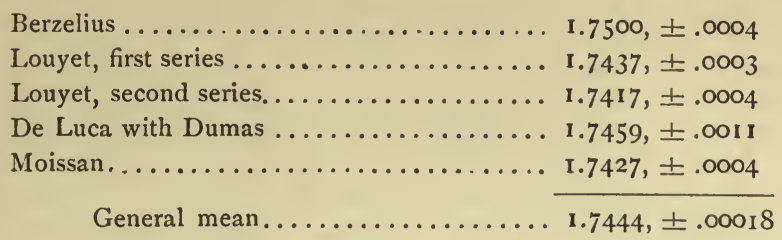

For the ratio between the two sodium salts we have experiments by Dumas, Louyet, and Moissan. According to Louyet, one gramme of $\mathrm{NaF}$ gives of $\mathrm{Na}_{2} \mathrm{SO}_{4}-$

$$
\begin{gathered}
1.686 \\
1.683 \\
\text { Mean, } \frac{1.685}{1.684^{\circ}}, \pm .0006
\end{gathered}
$$

The weighings published by Dumas are as follows:

$$
\begin{aligned}
& .777 \text { grm. NaF give I.312 grm. } \mathrm{Na}_{2} \mathrm{SO}_{4} \text {. Ratio, } 1.689 \\
& \begin{array}{lllll} 
& .737 & & &
\end{array} \\
& \text { Mean, } \overline{1.688}, \pm .0007
\end{aligned}
$$

Moissan says only that five experiments with sodium fluoride gave $\mathrm{F}=19.04$ to 19.08. This was calculated with $\mathrm{Na}=23.05$ and $\mathrm{S}=32.074$. Hence, reckoning backward, the two values give for the standard ratio-

$$
\begin{array}{r}
1.6889 \\
1.6873 \\
\hline \text { Mean, } 1.6881
\end{array}
$$

Giving this equal weight with Dumas' mean, we have-

$$
\begin{aligned}
& \text { Louyet ...................... 1.6847, } \pm .0006 \\
& \text { Dumas........................ 1.688, } \pm .0007 \\
& \text { Moissan ..................... r.688 } \mathrm{r}, \pm .0007 \\
& \text { General mean.............. I.6867, } \pm .00038
\end{aligned}
$$

Dumas also gives experiments upon potassium fluoride. The quantity of sulphate formed from one gramme of fluoride is given in the last column :

$$
\begin{aligned}
& \text { I. } 483 \mathrm{grm} \text {. } \mathrm{KF} \text { give } 2.225 \mathrm{grm} . \mathrm{K}_{2} \mathrm{SO}_{4} \text {. } \quad 1.5002 \\
& \text { I.309 " } 1.96 \mathrm{I} \text { " . } \\
& \text { - Mean, I.499r, } \pm .0007
\end{aligned}
$$

The ratio between barium fluoride and barium sulphate was measured 
by Louyet and Moissan. According to Louyet, one gramme of $\mathrm{BaF}_{2}$ gives of $\mathrm{BaSO}_{4}$ -

$$
\begin{gathered}
1.33^{2} \\
1.33^{1} \\
\text { M.330 } \\
\hline \mathbf{I . 3 3} \mathrm{I}, \pm .0004
\end{gathered}
$$

Moissan, in five experiments, found $\mathrm{F}=19.05$ to 19.09. Assuming that he put $\mathrm{Ba}=137$, and $\mathrm{S}=32.074$ as before, these two extremes become-

$$
\text { Mean, } \begin{array}{r}
\text { I.33II } \\
\text { I.3305 }
\end{array}
$$

Giving this equal weight with Louyet's mean, we get the subjoined combination :

$$
\begin{aligned}
& \text { Loúyet........................ I.331, } \pm .0004 \\
& \text { Moissan...................... 1.3308, } \pm .0004 \\
& \text { Géneral mean.............. 1.3309, } \pm .00028
\end{aligned}
$$

The experiments with lead fluoride are due to Louyet, and a new method of treatment was adopted. The salt was fused, powdered, dissolved in nitric acid, and precipitated by dilute sulphuric acid. The evaporation of the fluid and the ignition of the sulphate was then effected without transfer. Five grammes of fluoride were taken in each opera-

\begin{tabular}{|c|c|c|c|c|}
\hline \multicolumn{3}{|c|}{ 3.1199 grm. $\mathrm{Am}_{2} \mathrm{MnF}_{5}$ gave $2.12748 \mathrm{I}$. } & \multicolumn{2}{|c|}{ 68. Igl per cent. } \\
\hline 3.9190 & “ & 2.67020 " & 68.135 & “ \\
\hline 3.5005 & “ & 2.38429 “ & 68.113 & “ \\
\hline 1.2727 & “ & “ & 68.185 & “ \\
\hline
\end{tabular}
tion, yielding of sulphate:

$$
\begin{gathered}
6.179 \\
6.178 \\
6.178 \\
\frac{6.1783}{6.1783} \pm .0002
\end{gathered}
$$

In Christensen's determinations* we find a method adopted which is radically unlike anything in the work of his predecessors. He started out with the salt $\left(\mathrm{NH}_{4}\right)_{2} \mathrm{MnF}_{5}$. When this is added to a mixture, in solution, of potassium iodide and hydrochloric acid, iodine is set free, and may be titrated with sodium thiosulphate. One molecule of the salt (as written above), liberates one atom of iodine. In four experiments Christensen obtained the following data:

* Journ. für Prakt. Chem. (2), 35, 54r. Christensen assigns to the salt double the formula here given. 
The ratios from which to compute the atomic weight of fluorine are now-
(I.) $\mathrm{CaF}_{2}: \mathrm{CaSO}_{4}:: 1.0: 1.7444, \pm .00018$
(2.) $2 \mathrm{NaF}: \mathrm{Na}_{2} \mathrm{SO}_{4}::$ r.o $:$ r.6867, \pm .00038
(3.) $2 \mathrm{KF}: \mathrm{K}_{2} \mathrm{SO}_{4}:: \mathrm{I} .0: \mathrm{I} .499 \mathrm{I}, \pm .0007$
(4.) $\mathrm{BaF}_{2}: \mathrm{BaSO}_{4}:: \mathrm{I} .0: \mathrm{I} \cdot 3309, \pm .00028$
(5.) $\mathrm{PbF}_{2}: \mathrm{PbSO}_{4}:: 5.0: 6.1783, \pm .0002$
(6.) $\mathrm{Am}_{2} . \mathrm{MnF}_{5}: \mathrm{I}:: \mathrm{I}$ 100:68.156, \pm .0128

To reduce them we have-

$$
\begin{array}{ll}
\mathrm{O}=\mathrm{I} 5.879, \pm .0003 & \mathrm{~K}=38.8 \mathrm{r} 7, \pm .005 \mathrm{I} \\
\mathrm{S}=3 \mathrm{r} .828, \pm .0015 & \mathrm{Ca}=39.764, \pm .0045 \\
\mathrm{~N}=\mathrm{I} 3.935, \pm .002 \mathrm{I} & \mathrm{Ba}=\mathrm{I} 36.392, \pm .0086 \\
\mathrm{I}=\mathrm{I} 25.888, \pm .0069 & \mathrm{lb}=205.358, \pm .0040 \\
\mathrm{Na}=22.88 \mathrm{I}, \pm .0046 & \mathrm{Mn}=54.57 \mathrm{I}, \pm .00 \mathrm{r} 3
\end{array}
$$

And the values derived for fluorine are as follows:

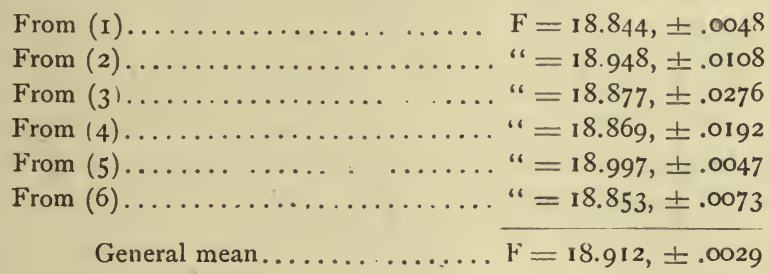

If $\mathrm{O}=16, \mathrm{~F}=19.056$

In all probability these values for fluorine average a trifle too high. It is difficult to be certain that a fluoride has been completely converted into sulphate, and an incomplete conversion tends to raise the apparent atomic weight of fluorine. This possible source of error exists in all of the ratios except the last one, but the fair concordance of the results obtained seems to indicate that the uncertainty cannot be very large. 


\section{MANGANESE.}

The earliest experiments of Berzelius* and of Arfvedson $\uparrow$ gave values for $\mathrm{Mn}$ ranging between 56 and 57, and therefore need no farther consideration here. The first determinations to be noticed are those of Turner $\ddagger$ and a later measurement by Berzelius. $\S$ who both determined gravimetrically the ratio between the chlorides of manganese and silver. The manganese chloride was fused in a current of dry hydrochloric acid, and afterwards precipitated with a silver solution. I give the $\mathrm{MnCl}_{2}$ equivalent to 100 parts of $\mathrm{AgCl}$ in the third column :

$$
\begin{aligned}
4.20775 \mathrm{grm} . \mathrm{MnCl}_{2} & =9.575 \text { grm. } \mathrm{AgCl} \text {. } \\
3.063 & =6.969 \mathrm{I} 2 \text { " } \\
12.47 \text { grains } \mathrm{MnCl}_{2} & =28.42 \text { grains } \mathrm{AgCl} \text {. }
\end{aligned}
$$$$
43.878 \text { - Turner. }
$$

$$
\text { Mean, } \overline{43.924}, \pm .015
$$

Many years later Dumas || also made the chloride of manganese the starting point of some atomic weight determinations. The salt was fused in a current of hydrochloric acid, and afterwards titrated with a standard solution of silver in the usual way. One hundred parts of $\mathrm{Ag}$ are equivalent to the quantities of $\mathrm{MnCl}_{2}$ given in the third column :

$$
\begin{aligned}
& 3.3672 \mathrm{grm} . \mathrm{MnCl}_{2}=5.774 \mathrm{grm} \text {. Ag. } \quad 58.3 \mathrm{I} 7 \\
& \begin{array}{llll}
3.0872 \text { " " } 5.293 & & 58.326
\end{array} \\
& 2.967 \mathrm{I} \text { " " } 5.0875 \text { " } 58.32 \mathrm{I} \\
& \text { I. } 1244 \text { " " } 1.928 \text { " } 58.320 \\
& \text { I.3I } 34 \text { " } 2.25 \mathrm{I} \text { " } 58.32 \mathrm{I} \\
& \text { Mean, } \overline{58.32 \mathrm{I}}, \pm .00 \mathrm{I}
\end{aligned}
$$

An entirely different method of investigation was followed by von Hauer, who, as in the case of cadmium, ignited the sulphate in a stream of sulphuretted hydrogen, and determined the quantity of sulphide thus formed. I subjoin his weighings, and also the percentage of $\mathrm{MnS}$ in $\mathrm{MnSO}_{4}$ as calculated from them:

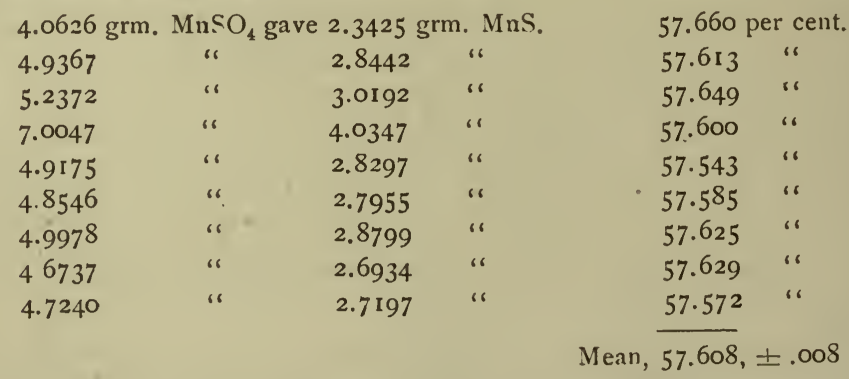

* Poggend. Annalen, 8, 185.1826.

† Berz. Jahresbericht, 9, 136. 1829.

f Trans. Roy. Soc. Edinb., II, I43. 183 I.

3 Lehrbuch, 5 Aufl., 3. 1224.

\| Ann. Chem. Pharm., II3, 25. 1860.

I Journ. für Prakt. Chenı., 72, 360. 1857. 
This method of von Hauer, which seemed to give good results with cadmium, is, according to Schneider,* inapplicable to manganese, for the reason that the sulphide of the latter metal is liable to be contaminated with traces of oxysulphide. Such an impurity would bring the atomic weight out too high. The results of two different processes, one carried out by himself and the other in his laboratory by Rawack, are given by Schneider in this paper.

Rawack reduced manganoso-manganic oxide to manganous oxide by ignition in a stream of hydrogen, and weighed the water thus formed. From his weighings I get the values in the third column, which represent the $\mathrm{Mnn}_{3} \mathrm{O}_{4}$ equivalent to one gramme of water:

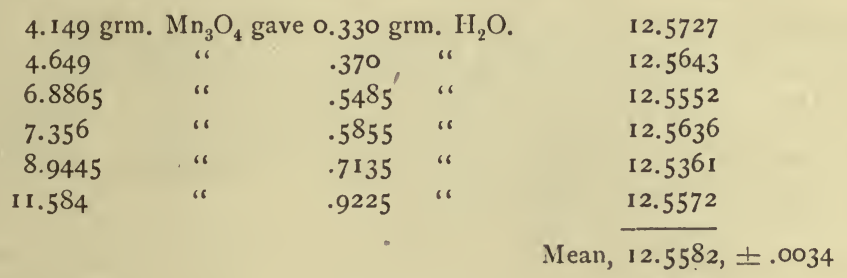

Here the most obvious source of error lies in the possible loss of water. Such a loss, however, would increase the apparent atomic weight of manganese; but we see that the value found is much lower than that obtained either by Dumas or von Hauer.

Schneider himself effected the combustion of manganous oxalate with oxide of copper. The salt was not absolutely dry, so that it was necessary to collect both water and carbon dioxide. 'Then, upon deducting the weight of water from that of the original material, the weight of anhydrous oxalate was easily ascertained. Subtracting from this the $\mathrm{CO}_{\eta}$, we get the weight of $\mathrm{Mn}$. If we put $\mathrm{CO}_{2}=100$, the quantities of manganese equivalent to it will be found in the last column:

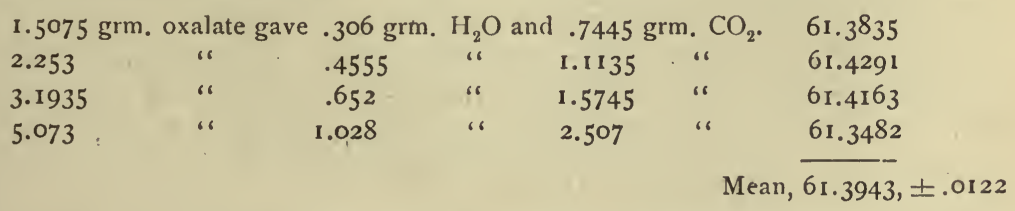

Up to this point the data give two distinct values for $\mathrm{Mn}$-one near 54 , the other approximately 55-and with no sure guide to preference between them. The higher value, however, has been confirmed by later testimony.

In 1883 Dewar and Scott $\uparrow$ published the results of their work upon silver permanganate. This salt is easily obtained pure by recrystallization, and has the decided advantage of not being hygroscopic. Two sets 
of experiments were made. First, the silver permanganate was heated to redness in a glass bulb, first in air, then in hydrogen. Before weighing, the latter gas was replaced by nitrogen. The data are as follows:

$\begin{array}{ccc}\mathrm{AgMnO}_{4} . & \mathrm{Ag}+\mathrm{MnO} & \text { Percent. } \mathrm{Ag}+\mathrm{MnO} . \\ 5.8696 & 4.63212 & 78.917 \\ 5.4988 & 4.33591 & 78.852 \\ 7.6735 & 6.05395 & 78.894 \\ 13.10147 & 10.31815 & 78.756 \\ 12.5799 & \{9.91065 & 78.782 \\ 9.91435, & 78.811 \\ & & \text { Mean, } 78.835, \pm .0174\end{array}$

The duplication of the last weighing is not explained.

In the second series the permanganate was dissolved in dilute nitric acid, reduced by sulphur dioxide, potassium nitrite, or sodium formate, and titrated with potassium bromide. The $\mathrm{AgMnO}_{4}$ equivalent to 100 $\mathrm{KBr}$ appears in the third column.

$\begin{array}{cll}\mathrm{AgMnO} & \\ 6.5289 & \mathrm{KBr} . & \text { Ratio. } \\ 7.5378 & 3.42385 & 190.686 \\ 6.1008 & 3.9553 & 190.575 \\ 5.74647 & 3.20166 & 190.559 \\ 6.16593 & 3.00677 & 191.117 \\ 5.11329 & 3.23602 & 190.540 \\ 5.07438 & 2.6828 & 190.596 \\ 13.4484 & 2.66204 & 190.624 \\ 12.5799 & 7.05602 & 190.604 \\ 12.27025 & 6.60065 & 190.588 \\ & 6.43808 & 190.584\end{array}$

Vacuum weights are given throughout. To the first series of experiments the authors attach little importance, and numbers 1 and 4 of the second series they also regard as questionable. These experiments represent the use of sulphur dioxide as the reducing agent, and were attended by the formation of an insoluble residue, apparently of a sulphide. Excluding them, the remaining eight experiments of the second series give in mean-

$$
\mathrm{KBr}: \mathrm{AgMnO}_{4}:: 100 \vdots 190.584, \pm .0062,
$$

which will be used for the present calculation. Dewar and Scott also made determinations with manganese chloride and bromide. With the first salt they found $\mathrm{Mn}=54.91$, and with the second, $\mathrm{Mn}=54.97$; but they give no details.

Marignac's work upon the atomic weight of manganese also appeared in 1883.* He prepared the oxide, $\mathrm{MnO}$, by ignition of the oxalate and 
subsequent reduction of the resulting $\mathrm{Mn}_{3} \mathrm{O}_{4}$ in hydrogen. The oxide, with various precautions, was then converted into sulphate. The percentage of $\mathrm{MnO}$ in $\mathrm{MnSO}_{4}$ is appended:

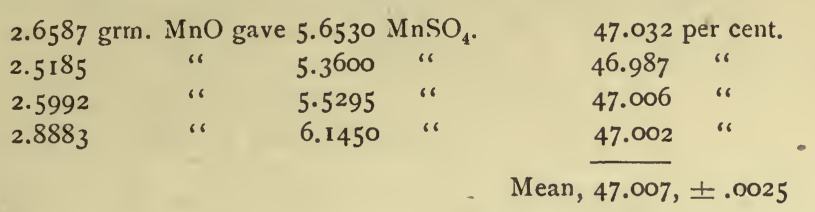

J. M. Weeren, in 1890,* published determinations made by two methods, the one Marignac's, the other von Hauer's. From manganese sulphate he threw down the hydrated peroxide electrolytically, and the latter compound was then reduced in hydrogen which had been proved to be free from oxygen. The resulting monoxide was cooled in a stream of purified nitrogen. After the oxide had been treated with sulphuric acid, converted into sulphate, and weighed, a few drops of sulphuric acid and a little sulphurous acid were added to it, after which it was reheated and weighed again. This process was repeated until four successive weighings absolutely agreed. The results of this set of experiments were as follows, with vacuum standards:

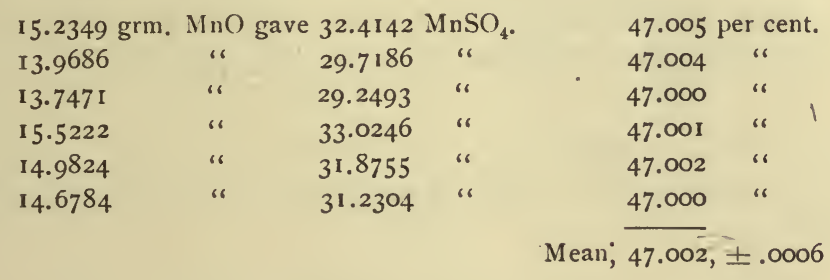

Marignac's mean, combined with this, hardly affects either the percentage itself or its probable error. Fortunately, both Marignac and Weeren are completely in agreement as to the ratio, and either set of measurements would be valid without the other. In order, therefore, to give Marignac's work some proper recognition, we can assume a géneral mean of $47.004, \pm .0006$, without danger of serious error.

The manganese sulphate produced in the foregoing series of experiments was used, with many precautions, for the next series carried out by von Hauer's method. It was transferred to a porcelain boat, dried at $260^{\circ}$ to avoid errors due to retention of water taken up in the process of transfer, and then heated to constant weight in a stream of hydrogen sulphide. Before weighing, the sulphide was heated to redness in hydrogen and cooled in the same gas. The results, with vacuum weights, were as follows:

*Atom-Gewichtsbestimmung des Mangans. Inaugural Dissertation, Halle, 189o. 


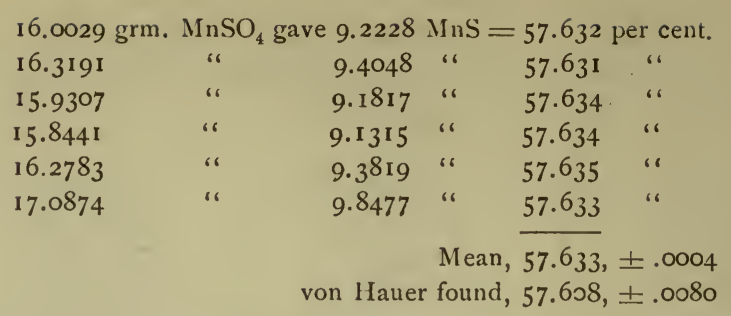

Hence the general mean is identical with Weeren's to the third decimal place, which is unaffected by combination with ron Hauer's data.

We have now to consider the following ratios for manganese:
(I.) $2 \mathrm{AgCl}: \mathrm{MnCl}_{2}:: 100: 41.924, \pm .0150$
(2.) $2 \mathrm{Ag}: \mathrm{MnCl}_{2}:: 100: 58.321, \pm .0010$
(3.) $\mathrm{H}_{2} \mathrm{O}: \mathrm{Mn}_{3} \mathrm{O}_{4}:: 100: 1255.82, \pm .340$
(4.) $2 \mathrm{CO}_{2}: \mathrm{Mn}:: \mathrm{IO0}: 6 \mathrm{I} .3943$, \pm .0122
(5.) $\mathrm{AgMnO}_{4}: \mathrm{Ag}+\mathrm{MnO}:: 100: 78.835, \pm .0174$
(6.) $\mathrm{KBr}: \mathrm{AgMnO}_{4}:: 100: 190.584, \pm .0062$
(7.) $\mathrm{MnSO}_{4}: \mathrm{MnO}:: 100: 47.004, \pm .0006$
(8.) $\mathrm{MnSO}_{4}: \mathrm{MnS}:: 100: 57.633, \pm .0004$

Computing with the subjoined preliminary data-

$$
\begin{array}{ll}
\mathrm{O}=15.879, \pm .0003 & \mathrm{~K}=38.8 \mathrm{I} 7, \pm .005 \mathrm{I} \\
\mathrm{Ag}=107.108, \pm .0031 & \mathrm{C}=\mathrm{II} .920, \pm .0004 \\
\mathrm{Cl}=35.179, \pm .0048 & \mathrm{~S}=3 \mathrm{I} 828, \pm .0015 \\
\mathrm{Br}=79.344, \pm .0052 & \mathrm{AgCl}=\mathrm{I} 42.287 \pm .0037
\end{array}
$$

these ratios reduce as follows:

First, for the molecular weight of manganese chloride, two values are deducible.

$$
\begin{aligned}
& \text { From (I) ............... } \mathrm{MnCl}_{2}=124.996, \pm .0428 \\
& \text { From }(2) \ldots \ldots \ldots \ldots \ldots \ldots \ldots \ldots=124.933, \pm .0042 \\
& \text { General mean .......... } \overline{\mathrm{MuCl}_{2}=124.934, \pm .0042}
\end{aligned}
$$

Hence $\mathrm{Mn}=54.576, \pm .0075$.

For manganese there are seven independent values, as follows:

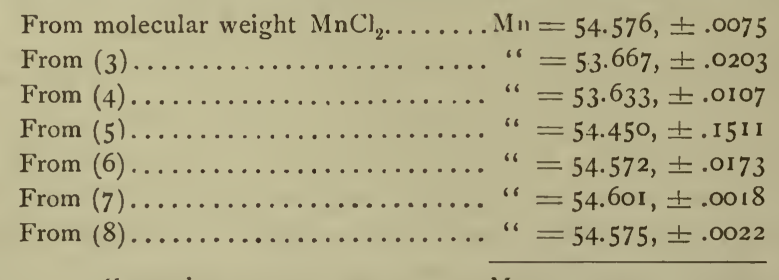

General mean...........Mn $=54.57 \mathrm{I}, \pm .0013$

If $\mathrm{O}=16$, this becomes $\mathrm{Mn}=54.987$.

In this case five of the separate values are well in accord, and the rejection of the two aberrant values, which have high probable errors, is 
not necessary. Their influence is imperceptible. Weeren's marvelouslyconcordant data seem to receive undue weight, but they are abundantly confirmed by the evidence of other experimenters. In short, the atomic weight of manganese appears to be quite well determined.

\section{IRON.}

The atomic weight of iron has been mainly determined from the composition of ferric oxide, with some rather scanty data relative to other compounds.

Most of the earlier data relative to the percentage of metal and oxygen in ferric oxide we may reject at once, as set aside by later investigations. Among this no longer valuable material there is a series of experiments by Berzelius, another by Döbereiner, and a third by Capitaine. The work done by Stromeyer and by Wackenroder was probably good, but I am unable to find its details. The former found 30.15 per cent. of oxygen in the oxide under consideration, while Wackenroder obtained figures ranging from a minimum of 30.01 to a maximum of 30.38 per cent.*

In 1844 Berzelius $\dagger$ published two determinations of the ratio in question. He oxidized iron by means of nitric acid, and weighed the oxide thus formed. He thus found that when $\mathrm{O}=100 \mathrm{Fe}=350.27$ and 350.369 .

Hence the following percentages of $\mathrm{Fe}$ in $\mathrm{Fe}_{2} \mathrm{O}_{3}$ :

$$
\text { Mean, } \frac{70.018}{70.022}, \pm .0013
$$

About the same time Svanberg and Norlin $\ddagger$ published two elaborate series of experiments; one relating to the synthesis of ferric oxide, the other to its reduction. In the first set pure piano-forte wire was oxidized by nitric acid, and the amount of oxide thus formed was determined. The results were as follows:

$\begin{array}{llll}1.5257 & \text { grm. } & \mathrm{Fe} \text { gave } 2.1803 \mathrm{grm} . \mathrm{Fe}_{2} \mathrm{O}_{3} \text {. } \\ 2.405 \mathrm{I} & \text { " } & 3.4390 & \text { " } \\ 2.3212 & \text { " } & 3.3194 & \text { " } \\ 2.32175 & \text { " } & 3.3183 & \text { " } \\ 2.2772 & \text { " } & 3.2550 & \text { " } \\ 2.4782 & \text { " } & 3.5418 & \text { " } \\ 2.3582 & \text { " } & 3.3720 & \end{array}$

69.977 per cent. Fe. 69.936 “ " 69.928 " " 69.968 " " 69.960 " " 69.970 “ “ 69.935

Mean, $69.9534, \pm .0050$

* For additional details concerning these earlier papers I must refer to Oudemans' monograph, pp. 140, I4r.

† Ann. Chem. Pharm., 30, 432. Berz. Jahresb., 25, 43.

$\ddagger$ Berzelius' Jahresbericht, 25, 42 . 
In the second series ferric oxide was reduced by ignition in a current of hydrogen, yielding the subjoined percentages of metal:

\begin{tabular}{|c|c|c|c|c|c|}
\hline 2.98353 & $\mathrm{e}_{2} \mathrm{O}$ & 2.08915 & n. Fe. & 70.025 & r cent. \\
\hline 2.41515 & “ & 1.6010 & “ & 70.015 & “ \\
\hline 2. 99 I 75 & “ & 2.09455 & “" & 70.014 & “" \\
\hline $3 \cdot 5783$ & " & 2.505925 & ." & 70.030 & ". \\
\hline 4.1922 & " & 2.9375 & “ & 70.072 & “ \\
\hline 3.1015 & “ & 2.17275 & “ & 70.056 & “ \\
\hline 2.6886 & ، & 1.88305 & “ & 70.036 & “" \\
\hline
\end{tabular}

It is evident that one or both of these series must be vitiated by constant errors, and that these probably arise from impurities in the materials employed. Impurities in the wire taken for the oxidation series could hardly have been altogether avoided, and in the reduction series it is possible that weighable traces of hydrogen may have been retained by the iron. At all events, it is probable that the errors of both series are in contrary directions, and therefore in some measure compensatory.

In 1844 there was also published an important paper by Erdmann and Marchand.* These chemists prepared ferric oxide by the ignition of pure ferrous oxalate, and submitted it to reduction in a stream of hydrogen. Two sets of results were obtained with two different samples of ferrous oxalate, prepared by two different methods. For present purposes, however, it is not necessary to discuss these sets separately. The percentages of iron in $\mathrm{Fe}_{2} \mathrm{O}_{3}$ are as follows:

$\left.\begin{array}{l}\left.\begin{array}{l}70.013 \\ 69.962 \\ 69.979 \\ 70.030 \\ 69.977\end{array}\right\} \text { A. } \\ 70.044 \\ 70.015 \\ 70.055\end{array}\right\}$ B.

In 1850 Maumenés † results appeared. He dissolved pure iron wire in aqua regia, precipitated with ammonia, filtered off the precipitate, washed thoroughly, ignited, and weighed, after the usual methods of quantitative analysis. The percentages of $\mathrm{Fe}$ in $\mathrm{Fe}_{2} \mathrm{O}_{3}$ are given in the third column :

I.482 grm. Fe gave 2. I I 7 grm. $\mathrm{Fe}_{2} \mathrm{O}_{3}$.

I. 452
I. 3585

2.074

"

70.005 per cent.

I. 420

I.94I

70.010

69.990

70.002

I. 492

2.0285

I. 554

2.1 315

2.220

69.998

70.000 "

Mean, $\overline{70.0008}, \pm .0019$ 
Two more results, obtained by Rivot* through the reduction of ferrie oxide in hydrogen, remain to be noticed. The percentages are:

$$
\text { Mean, } \frac{69.31}{69.33}, \pm .013
$$

We have thus before us six series of results, which we may now combine:

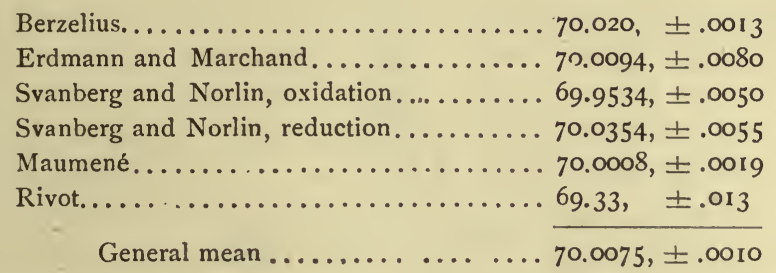

From this we get $\mathrm{Fe}=55.596$.

Dumas' $\dagger$ results, obtained from the chlorides of iron, are of so little weight that they might safely be omitted from our present discussion. For the sake of completeness, however, they must be included.

Pure ferrous chloride, ignited in a stream of hydrochloric acid gas, was dissolved in water and titrated with a silver solution in the usual way. One hundred parts of silver are equivalent to the amounts of $\mathrm{FeCl}_{2}$ given in the third column :

$$
\begin{array}{lll}
3.677 \text { grm. } \mathrm{FeCl}_{2}=6.238 \text { grm. Ag. } & 58.945 \\
3.924 & =6.675 \text { " } & \frac{58.787}{} \\
& \text { Mean, } 58.866, \pm .053
\end{array}
$$

Ferric chloride, titrated in the same way, gave these results:

$$
\begin{aligned}
& \text { I. } 179 \mathrm{grm} . \mathrm{FeCl}_{3}=2.3475 \mathrm{grm} \text {. Ag. } \quad 50.224 \\
& 1.242 \text { " }=2.47 \mathrm{I} \text { " } 50.263 \\
& \text { Mean, } \overline{50.2435}, \pm .0132
\end{aligned}
$$

These give us two additional values for $\mathrm{Fe}$, as follows:

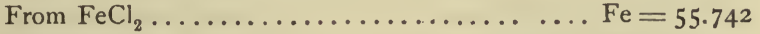

$$
\begin{aligned}
& \text { From } \mathrm{FeCl}_{3} \ldots \ldots \ldots \ldots \ldots \ldots \ldots \ldots \ldots \ldots \ldots \ldots \ldots \ldots
\end{aligned}
$$

A series of determinations of the equivalent of iron, made by students by measuring the hydrogen evolved when the metal is dissolved in an acid, was published by Torrey in $1888 .+$ The data have, of course, slight

\footnotetext{
* Ann. Chem. Pharm., 78, 214. 1851 .

† Ann. Chem. Pharm., Ir3, 26. 1860.

$\ddagger$ A m. Chem. Journ., Io, 74 .
} 
value, but may be considered as being in some measure confirmatory. They are as follows:

56.40
55.60
$55.3 \mathrm{~s}$
55.56
55.48
55.50
55.86
56.06
56.22
55.80
55.78
55.60
55.70
$\frac{55.94}{\text { Mean, }} 55.777, \pm .053^{2}$

These values undoubtedly depend on Regnault's value for the weight of hydrogen. Correcting by the later value, as found in the chapter of this work relating to the density ratio $\mathrm{H}: \mathrm{O}$, the mean becomes $\mathrm{Fe}=$ $55.608, \pm .0532$. Here the probable error in the weight of the hydrogen is ignored, as being of no practical significance.

The four ratios for iron are now as follows:

(I.) Per cent. $\mathrm{Fe}$ in $\mathrm{Fe}_{2} \mathrm{O}_{3}, 70.0075, \pm .0010$

(2.) $\mathrm{Ag}_{2}: \mathrm{FeCl}_{2}::$ I00:58.866, \pm .0530

(3.) $\mathrm{Ag}_{3}: \mathrm{FeCl}_{3}::$ 100 $: 50.2435, \pm .0132$

(4.) $\mathrm{H}: \mathrm{Fe}:: \mathrm{I}: 55.608, \pm .0532$

Reducing these with-

$$
\begin{aligned}
& \mathrm{O}=15.879, \pm .0003 \\
& \mathrm{Ag}=107.108, \pm .0031 \\
& \mathrm{Cl}=35.179, \pm .0048
\end{aligned}
$$

we have-

$$
\begin{aligned}
& \text { From (I) ................. Fe }=55.596, \pm .0023 \\
& \text { From }(2) \ldots \ldots \ldots \ldots \ldots \ldots \ldots \ldots \text {. }=55.742, \pm .1140 \\
& \text { From (3) ................ } "=55.907, \pm .0450 \\
& \text { From (4) ............... " }=55.608, \pm .053^{2} \\
& \text { General mean............ Fe }=55.597, \pm .0023
\end{aligned}
$$

If $\mathrm{O}=16$, then $\mathrm{Fe}=56.021$. Here all the values are absorbed practically by the first, the other three having no real significance. 


\section{NICKEL AND COBALT.}

On account of the close similarity of these metals to each other, their atomic weights, approximately if not actually identical, have received of late years much attention.

The first determinations, and the only ones up to 1852 , were made by Rothhoff,* each with but a single experiment. For nickel 188 parts of the monoxide were dissolved in hydrochloric acid; the solution was evaporated to dryness, the residue was dissolved in water, and precipitated by silver nitrate. 718.2 parts of silver chloride were thus formed; whence $\mathrm{Ni}=58.613$. The same process was applied also to cobalt, 269.2 parts of the oxide being found equivalent to 1029.9 of $\mathrm{AgCl}$; hence $\mathrm{Co}=$ 58.504. These values are so nearly equal that their differences were naturally ascribable to experimental errors. They are, however, entitled to no special weight at present, since it cannot be certain from any evidence recorded that the oxide of either metal was absolutely free from traces of the other.

In 1852 Erdmann and Marchand $\dagger$ published some results, but without details, concerning the atomic weight of nickel. They reduced the oxide by heating in a current of hydrogen, and obtained values ranging from 58.2 to 58.6 , when $\mathrm{O}=16$. Their results were not very concordant, and the lowest was probably the best.

In 1856 , incidentally to other work, Deville $\ddagger$ found that 100 parts of pure metallic nickel yielded 262 of sulphate; whence $\mathrm{Ni}=58.854$.

To none of the foregoing estimations can any importance now be attached. The modern discussion of the atomic weights under consideration began with the researches of Schneider $\$$ in 1857. This chemist examined the oxalates of both metals, determining carbon by the combustion of the salts with copper oxide in a stream of dry air. The carbon dioxide thus formed was collected as usual in a potash bulb, which, in weighing, was counterpoised by a similar.bulb, so as to eliminate errors due to the hygroscopic character of the glass. The metal in each oxalate was estimated, first by ignition in a stream of dry air, followed by intense heating in hydrogen. Pure nickel or cobalt was left behind in good condition for weighing. Four analyses of each oxalate were made, with the results given below. The nickel salt contained three molecules of water, and the cobalt salt two molecules:

* Cited by Berzelius. Poggend. Annalen, 8, 184. 1826.

† Journ. für Prakt. Chem., 55, 202. 1852 .

$\ddagger$ Ann. Chim. Phys. (3), 46, 182. 1856 .

† Poggend. Annalen, ror, 387. 1857 . 


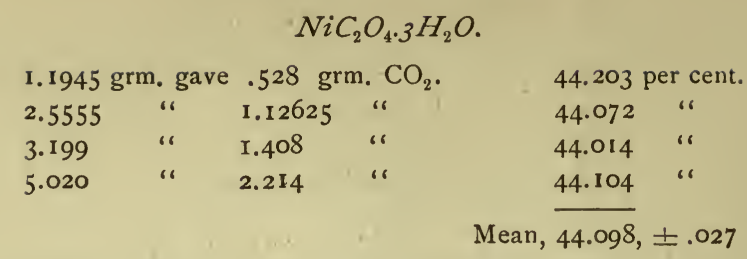

The following percentages of nickel were found in this salt:

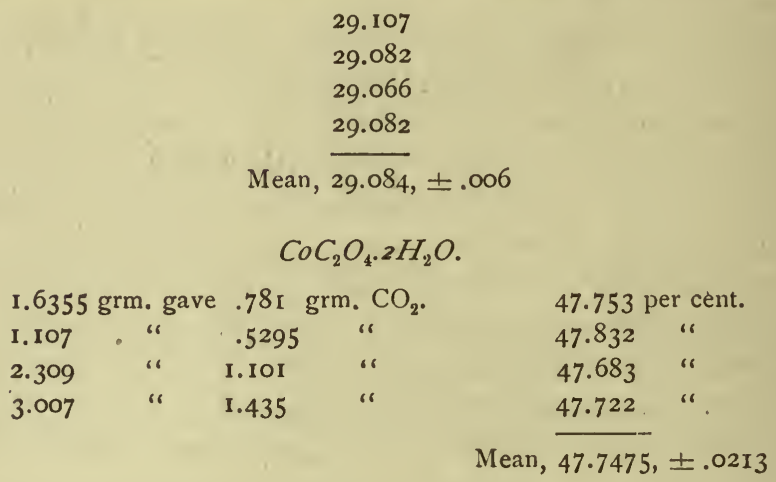

The following were the percentages found for cobalt:

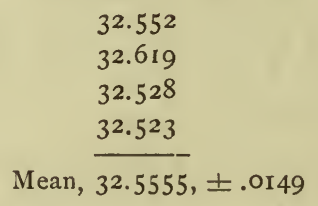

In a later paper* Schneider also gives some results obtained with a nickel oxalate containing but two molecules of water. This gave him 47.605 per cent. of $\mathrm{CO}_{2}$, and the following percentages of nickel:

$$
\text { Mean, } \frac{31.4115}{31.4076, \pm .0026}
$$

The conclusion at which Schneider arrived was that the atomic weights of cobalt and nickel are not identical, being about 60 and 58 respectively. The percentages given above will be discussed at the end of this chapter in connection with all the other data relative to the constants in question.

The next chemist to take up the discussion of these atomic weights was Marignac, in 1858. $\dagger$ He worked with the chlorides and sulphates 
of nickel and cobalt, using various methods, but publishing few details, as he did not consider the determinations final. The sulphates, taken as anhydrous, were calcined to oxides. From the ratio $\mathrm{NiSO}_{4}: \mathrm{NiO}$, he found $\mathrm{Ni}=58.4$ to 59.0 , and from five measurements of the ratio $\mathrm{CoSO}_{4}: \mathrm{Co}, \mathrm{Co}=58.64$ to 58.76 . If oxygen is taken as 16 , these give for the percentages of oxide in sulphate:

$\begin{array}{cc}\mathrm{CoO} \text { in } \mathrm{CoSO}_{4} . & \mathrm{NiO} \text { in } \mathrm{NiSO}_{4} . \\ 48.267 & 48.187 \\ \frac{48.307}{48.287} \pm .0135 & \text { Mean, } \frac{48.387}{48.287}, \pm .0675\end{array}$

The chlorides were dried at $100^{\circ}$, but found to retain water; and in most cases were then either fused in a stream of chlorine or of dry, gaseous hydrochloric acid, or else calcined gently with ammonium chloride. The determinations were then made by titration with a standard solution of silver in nitric acid. Three experiments with anhydrous $\mathrm{CoCl}_{2}$ gave $\mathrm{Co}=58.72$ to 58.84. Three more with $\mathrm{CoCl}_{2}$ dried at $100^{\circ}$ gave $\mathrm{Co}=58.84$ to 59.02 . Three with anhydrous $\mathrm{NiCl}_{2}$ gave $\mathrm{Ni}=58.80$ to 59.00. If the calculations were made with $\mathrm{Ag}=108$ and $\mathrm{Cl}=35.5$, then these data give as proportional to 100 parts of silver:

\begin{tabular}{cc}
$\mathrm{NiCl}_{2}$. & $\mathrm{CoCl}_{2}$. \\
60.093 & 60.056 \\
$\frac{60.185}{60.139, \pm .0310}$ & 60.111 \\
Mean, & 60.111 \\
\hline & $\frac{60.194}{60.118, \pm .0192}$
\end{tabular}

In one more experiment $\mathrm{NiCl}_{2}$ was precipitated with a known quantity of silver. The filtrate was calcined, yielding $\mathrm{NiO}$; hence the ratio $\mathrm{Ag}_{2}$ : NiO, giving $\mathrm{Ni}=59.29$. This experiment needs no farther attention.

In short, according to Marignac, and contrary to Schneider's views, the two atomic weights are approximately the same. Marignac criticises Schneider's earlier paper, holding that the nickel oxalate may have con'tained some free oxalic acid, and that the cobalt salt was possibly contaminated with carbonate or with basic compounds. In his later papers Schneider rejects these suggestions as unfounded, and in turn criticises Marignac. The purity of anhydrous $\mathrm{NiSO}_{4}$ is not easy to guarantee, and, according to Schneider, the anhydrous chlorides of cobalt and nickel are liable to be contaminated with oxides. This is the case even when the chlorides are heated in chlorine, unless the gas is carefully freed from all traces of air and moisture. 
Dumas'* determinations of the two atomic weights were made with the chlorides of nickel and cobalt. The pure metals were dissolved in aqua regia, the solutions were repeatedly evaporated to dryness, and the residual chlorides were ignited in dry hydrochloric acid gas. The last two estimations in the nickel series were made upon $\mathrm{NiCl}_{2}$ formed by heating the spongy metal in pure chlorine. In the third column I give the $\mathrm{NiCl}_{2}$ or $\mathrm{CoCl}_{2}$ equivalent to 100 parts of silver:

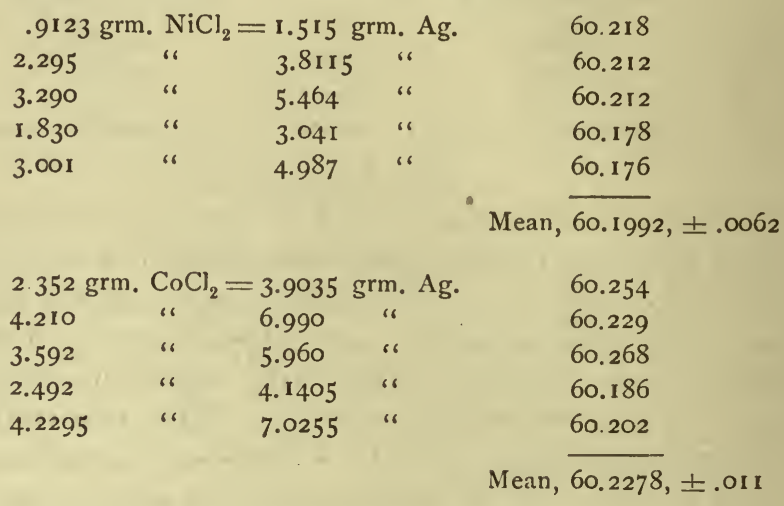

These results give values for $\mathrm{Co}$ and Ni differing by less than a tenth of a unit; here, as elsewhere, the figure for Ni being a trifle the lower.

Combining these data with Marignac's, we have-

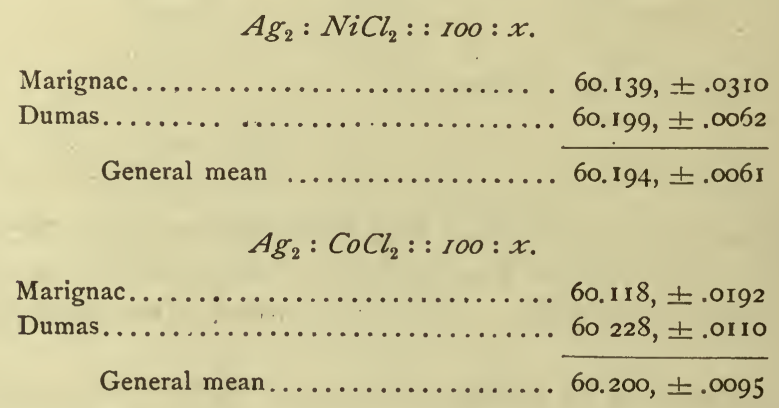

In $1863 \dagger$ the idea that nickel and cobalt have equal atomic weights was strengthened by the researches of Russell. He found that the black oxide of cobalt, by intense heating in an atmosphere of carbon dioxide, became converted into a brown monoxide of constant composition. The ordinary oxide of nickel, on the other hand, was shown to be convertible into a definite monoxide by simple heating over the blast lamp. The pure oxides of the two metals, thus obtained, were reduced by ignition in hydrogen, and their exact composition thus ascertained. 
Several samples of each oxide were taken, yielding the following data. The separate samples are indicated by lettering:

Nickel.

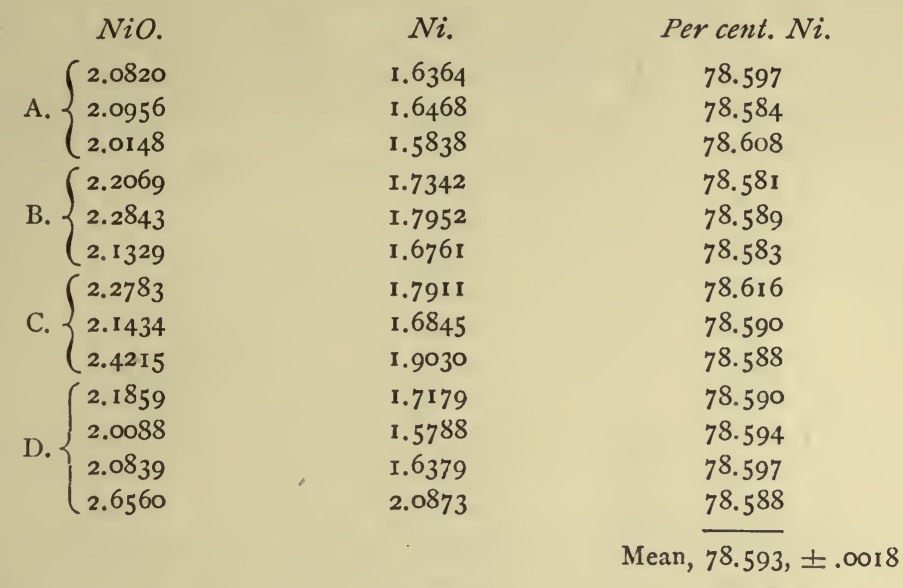

Cobalt.
$\mathrm{CoO}$.
Co.
A. $\left\{\begin{array}{l}2.1211 \\ 2.0241 \\ 2.1226 \\ 1.9947 \\ 3.0628\end{array}\right.$
I. 6670
I. 5907
I. 6673
I. 5678
2.4078
I. $66_{3} 8$
I. 3924
I. 4030
I. 3264
I. $735^{\circ}$
2. 1104
I. 6868
$2.675^{2}$
$1.790 \mathrm{I}$
I. 7163
Per cent. Co.

\begin{tabular}{l}
78.591 \\
78.588 \\
78.550 \\
78.598 \\
78.614 \\
78.603 \\
78.591 \\
78.591 \\
78.588 \\
78.592 \\
78.597 \\
78.598 \\
78.595 \\
78.589 \\
78.596 \\
\hline 78.592 \\
Mean,
\end{tabular}

These percentages are practically identical, and lead to essentially the same mean value for each atomic weight.

In a later paper Russell* confirmed the foregoing results by a different process. He dissolved metallic nickel and cobalt in hydrochloric acid and measured the hydrogen evolved. Thus the ratio between the metal and the ultimate standard was fixed without the intervention of any other element. About two-tenths of a gramme of metal, or less, was 
taken in each experiment. The data obtained were as follows; the last column giving the weight of hydrogen, computed from its volume, yielded by 100 parts of cobalt or nickel :

Nickel.

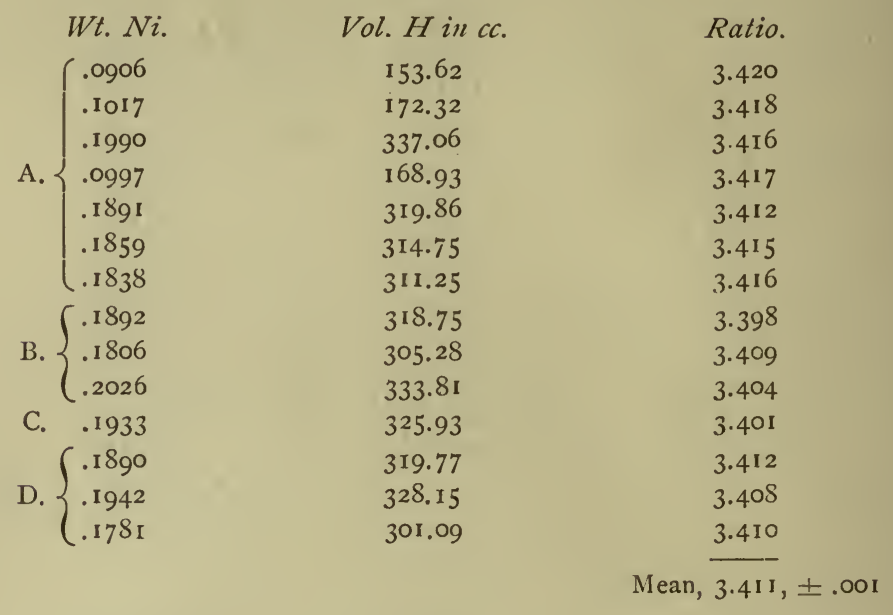

\section{Cobalt.}

Wt. Co. Vol. H in cc.
A. $\left\{\begin{array}{l}.1958 \\ .1905 \\ .1946 \\ .2002\end{array}\right.$
321.36
3.1 2.95
3.395
$3 \cdot 398$
319.63
$3 \cdot 397$
328.96
3.398
B. $\left\{\begin{array}{l}.1996 \\ .2000 \\ .1721\end{array}\right.$
328.43
329:55
290. 17
C. $\left\{\begin{array}{l}.1877 \\ .1935\end{array}\right.$
308.97
318.60
3403
3.401
3.401
3.404
3.405
314.73
3.410
305.40
3.407
Mean, $\overline{3.4017} \pm .0009$

Ratio.

The weight of the hydrogen in these determinations was doubtless computed from Regnault's data concerning the density of that gas. Correcting by the new value for the weight of a litre of hydrogen, .089872 gramme, the ratios become:

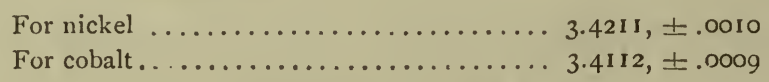

Some time after the publication of Russell's first paper, but before the appearance of his second, some other investigations were made known. 
Of these the first was by Sommaruga,* whose results, obtained by novel methods, closely confirmed those of Schneider and antagonized those of Dumas, Marignac, and Russell. The atomic weight of nickel Sommaruga deduced from analyses of the nickel potassium sulphate, $\mathrm{K}_{2} \mathrm{Ni}\left(\mathrm{SO}_{4}\right)_{2} \cdot 6 \mathrm{H}_{2} \mathrm{O}$, which, dried at $100^{\circ}$, has a perfectly definite composition. In this salt the sulphuric acid was determined in the usual way as barium sulphate, a process to which there are obvious objections. In the third column are given the quantities of the nickel salt proportional to 100 parts of $\mathrm{BaSO}_{4}$ :

\begin{tabular}{|c|c|c|c|c|}
\hline $0.979^{8}$ & . $g$ & 1.0462 & ค. $\mathrm{BaSO}_{4}$. & 93.653 \\
\hline I.0537 & “ & I. $125 \mathrm{I}$ & ، & 93.654 \\
\hline 1.0802 & “ & I. 1535 & ") & 93.645 \\
\hline I. 1865 & “ & 1.2669 & “ & 93.654 \\
\hline 3.2100 & “" & 3.4277 & “ & 93649 \\
\hline 3.2124 & " & 3.4303 & “ & 93.648 \\
\hline
\end{tabular}

For cobalt Sommaruga used the purpureocobalt chloride of Gibbs and Genth. This salt, dried at $110^{\circ}$, is anhydrous and stable. Heated hotter, $\mathrm{CoCl}_{2}$ remains. The latter, ignited in hydrogen, yields metallic cobalt. In every experiment the preliminary heating must be carried on cautiously until ammoniacal fumes no longer appear :

\begin{tabular}{|c|c|c|c|c|c|}
\hline \multicolumn{4}{|c|}{.6656 grm. gave . 1588 grm. Co. } & \multicolumn{2}{|c|}{$23.85^{8}$ per cent. } \\
\hline I.0918 & " & .2600 & “ & 23.814 & “ \\
\hline .9058 & “ & .2160 & “ & 23.846 & “ \\
\hline 1.5895 & “ & $\cdot 3785$ & “ & 23.813 & “ \\
\hline 2.9167 & " & .6957 & “ & 23.847 & “" \\
\hline 1.8390 & “ & .4378 & “ & 23.806 & 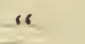 \\
\hline 2.5010 & “ & .5968 & “ & 23.808 & " " \\
\hline
\end{tabular}

Further along this series will be combined with a similar one by Lee. It may here be said that Sommaruga's paper was quickly followed by a critical essay from Schneider, $†$ endorsing the former's work and objecting to the results of Russell.

In 1867 still another new process for the estimation of these atomic weights was put forward by Winkler, $\ddagger$ who deternined the amount of gold which pure metallic nickel and cobalt could precipitate from a neutral solution of sodio-auric chloride.

In order to obtain pure cohalt Winkler prepared purpureocobalt chloride, which, having been four or five times recrystallized, was ignited in hydrogen. His nickel was repeatedly purified by precipitation with sodium hypochlorite. From material thus obtained pure nickel chloride 
was prepared, which, after sublimation in dry chlorine, was also reduced by hydrogen. One hundred parts of gold are precipitated by the quantities of nickel and cobalt given in the third columns respectively. In the cobalt series I include one experiment by Weselsky, which was published by him in a paper presently to be cited:

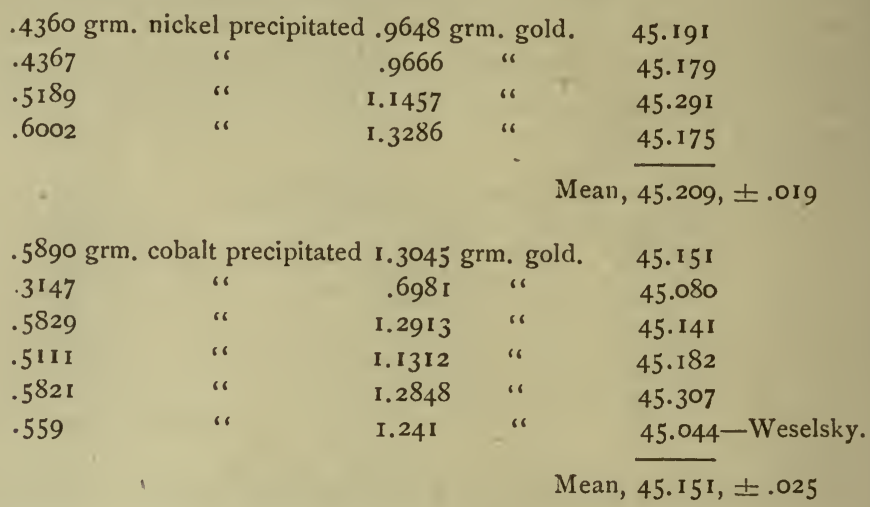

Weselsky's paper,* already quoted, relates only to cobalt. He ignited the cobalticyanides of ammonium and of phenylammonium in hydrogen, and from the determinations of cobalt thus made deduced its atomic weight. His results are as follows:

$$
\begin{aligned}
& .7575 \text { grm. }\left(\mathrm{NH}_{4}\right)_{6} \mathrm{Co}_{2} \mathrm{Cy}_{12} \text { gave .166 grm. Co. } 21.914 \text { per cent. } \\
& .5143 \\
& .113 \text { " } \\
& 21.972 \text { " } \\
& \text { Mean, 21.943, } \pm .029
\end{aligned}
$$

\begin{tabular}{|c|c|c|c|c|}
\hline $6 \mathrm{II} 2$ & & .0723 & " & 11.829 \\
\hline .7140 & " & .0850 & " & 11.905 \\
\hline .9420 & " & . I I 20 & " & 11.890 \\
\hline
\end{tabular}

.8529 grm. $\left(\mathrm{C}_{6} \mathrm{H}_{8} \mathrm{~N}\right)_{6} \mathrm{Co}_{2} \mathrm{Cy}_{12}$ gave .IOIO grm. Co. 1 I .842 per cent.

Next in order is the work done by Lee $\dagger$ in the laboratory of Wolcott Gibbs., Like Weselsky, Lee ignited certain cobalticyanides and also nickelocyanides in hydrogen and determined the residual metal. The double cyanides chosen were those of strychnia and brucia, salts of very high molecular weight, in which the percentages of metal are relatively low. A series of experiments with purpureocobalt chloride was also carried out. In order to avoid admixture of carbon in the metallic residues, the salts were first ignited in air, and then in oxygen. Reduction by hydrogen followed. The salts were in each case covered by a porous septum of earthenware, through which the hydrogen diffused, and which served to prevent the mechanical carrying away of solid particles; fur- 
thermore, heat was applied from above. The results attained were very satisfactory, and assign to nickel and cobalt atomic weights varying from each other by about a unit; Ni being nearly 58 , and Co about 59 , when $\mathrm{O}=16$. The exact figures will appear later. The cobalt results agree remarkably well with those of Weselsky. The following are the data obtained :

$\begin{array}{ccc}\text { Brucia nickelocyanide, } \mathrm{Ni}_{3} \mathrm{Cy}_{12}\left(\mathrm{C}_{23} \mathrm{H}_{26} \mathrm{~N}_{2} \mathrm{O}_{4}\right)_{6} \mathrm{H}_{6} \cdot \mathrm{HOH}_{2} \mathrm{O} . \\ \text { Salt. } & \mathrm{Ni.} & \text { Percent. Ni. } \\ .3966 & .0227 & 5.724 \\ .5638 & .0323 & 5.729 \\ .4000 & .0230 & 5.750 \\ .3 \mathrm{I} 3 \mathrm{I} & .01795 & 5.733 \\ .44 \mathrm{I} 2 & .0252 & 5.712 \\ .4346 & .0249 & 5.729 \\ & & \text { Mean, } 5.7295, \pm .0034\end{array}$

Strychnia nickelocyanide, $\mathrm{Ni}_{3} \mathrm{Cy}_{12}\left(\mathrm{C}_{21} \mathrm{H}_{22} \mathrm{~N}_{2} \mathrm{O}_{2}\right)_{6} \mathrm{H}_{6} .8 \mathrm{H}_{2} \mathrm{O}$.

$\begin{array}{lcc}\text { Salt. } & \text { Ni. } & \text { Percent. Ni. } \\ .5358 & .0354 & 6.607 \\ .5489 & .0363 & 6.613 \\ .3551 & .0234 & 6.589 \\ .4495 & .0297 & 6.607 \\ .2530 & .0166 & 6.56 \mathrm{I} \\ .1956 & .0129 & 6.595 \\ & & \text { Mean, } \overline{6.595} \pm .005\end{array}$

Brucia cobalticyanide, $\mathrm{Co}_{2} \mathrm{Cy}_{12}\left(\mathrm{C}_{23} \mathrm{H}_{26} \mathrm{~N}_{2} \mathrm{O}_{4}\right)_{6} \mathrm{H}_{6} \cdot 2 \mathrm{OH}_{2} \mathrm{O}$.

Salt.

.4097

.3951

.5456

.4402

.4644

.4027
Co.

.0154

.0147

.0204

.0165

.0174

.0151
Percent. Co.

$\begin{array}{r}3.759 \\ 3.720 \\ 3.739 \\ 3.748 \\ 3.747 \\ 3.749 \\ \hline \text { Mean, } 3.7437, \pm .0036\end{array}$

3.759

3.720

3.739

3.748

3.747

3.749

Mean, $3.7437, \pm .0036$

Strychnia cobalticyanide, $\mathrm{Co}_{2} \mathrm{Cy}_{12}\left(\mathrm{C}_{21} \mathrm{H}_{22} \mathrm{~N}_{2} \mathrm{O}_{2}\right)_{6} \mathrm{H}_{6} \cdot 8 \mathrm{H}_{2} \mathrm{O}$.

$\begin{array}{lcc}\text { Salt. } & \text { Co. } & \text { Per cent. Co. } \\ .4255 & .0195 & 4.583 \\ .4025 & .0985 & 4.596 \\ .3733 & .0170 & 4.554 \\ .4535 & .0207 & 4.564 \\ .2753 & .0126 & 4.577 \\ .1429 & .0065 & 4.549 \\ & & \text { Mean }, 4.5705, \pm .005\end{array}$




\begin{tabular}{lcc}
\multicolumn{3}{c}{ Purpureo-cobalt chloride, $\mathrm{Co}_{2}\left(\mathrm{NH}_{3}\right)_{10} \mathrm{Cl}_{6}}$. \\
Salt. & Co. & Per cent. Co. \\
.9472 & .2233 & 23.575 \\
.8903 & .2100 & 23.587 \\
.6084 & .1435 & 23.586 \\
.6561 & .1547 & 23.579 \\
.6988 & .1647 & 23.569 \\
.7010 & .1653 & 23.581 \\
& & Mean, $23.5795, \pm .0019$
\end{tabular}

The last series may be combined with Sommaruga's, thus:

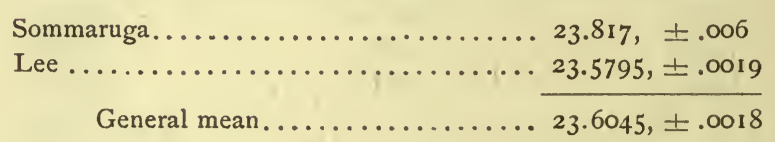

Baubigny's* determinations of the atomic weight of nickel are limited to two experiments upon the calcination of nickel sulphate, and his data are as follows:

$$
\begin{aligned}
& 6.2605 \text { grm. } \mathrm{NiSO}_{4} \text { gave 3.p225 } \mathrm{NiO} \text {. } 48.279 \text { per cent. } \\
& 4.4935 \text { " } 2.1695 \text { " } 48.281 \text { " } \\
& \text { Mean, } \overline{48.280}
\end{aligned}
$$

Zimmermann's work, published after his death by Krüss and Alibegoff, $\uparrow$ was based, like Russell's, upon the reduction of cobalt and nickel oxides in hydrogen. The materials used were purified with great care, and the results were as follows:

$\begin{array}{rcc} & \text { Nickel. } \\ \text { NiO. } & N i . & \text { Percent. Ni. } \\ 6.0041 & 4.7179 & 78.578 \\ 6.4562 & 5.0734 & 78.582 \\ 8.5960 & 6.7552 & 78.585 \\ 4.7206 & 3.7096 & 78.583 \\ 8.2120 & 6.4536 & 78.587 \\ 9.1349 & 7.1787 & 78.585 \\ 10.0156 & 7.8702 & 78.579 \\ 4.6482 & 3.6526 & 78.580 \\ 8.9315 & 7.0184 & 78.580 \\ 10.7144 & 8.4196 & 78.582 \\ 3.0036 & 2.3602 & 78.579 \\ & & \text { Mean, } 78.582, \pm .0006\end{array}$


Cobalt.

$\begin{array}{ccc}\text { CoO. } & \text { Co. } & \text { Percent. Co. } \\ 6.3947 & 5.0284 & 78.634 \\ 6.6763 & 5.2501 & 78.638 \\ 5.6668 & 4.4560 & 78.633 \\ 2.9977 & 2.3573 & 78.637 \\ 8.7446 & 6.8763 & 78.635 \\ 3.2625 & 2.5655 & 78.636 \\ 6.3948 & 5.0282 & 78.630 \\ 8.21560 & 6.4606 & 78.638 \\ 9.4842 & 7.4580 & 78.636 \\ 9.9998 & 7.8630 & \frac{78.632}{78.635}, \pm .0002\end{array}$

Shortly after the discovery of nickel carbonyl, $\mathrm{NiC}_{4} \mathrm{O}_{4}$, Mond, Langer, and Quincke* made use of it with reference to the atomic weight of nickel. The latter was purified by distillation as nickel carbonyl, then converted into oxide, and that was reduced by hydrogen in the usual way.

$\begin{array}{lcc}\mathrm{NiO} . & \mathrm{Ni} & \text { Per cent. Ni. } \\ .2414 & .1896 & 78.542 \\ .3186 & .2503 & 78.562 \\ .3391 & .2663 & \frac{78.53 \mathrm{I}}{} \\ & & \text { Mean, } 78.545, \pm .006 \mathrm{I}\end{array}$

Schutzenberger's experiments, $\dagger$ published in 1892 , were also few in number. First, nickel sulphate, dehydrated at $440^{\circ}$, was calcined to oxide.

$$
\begin{aligned}
& 3.505 \mathrm{grm} . \mathrm{NiSO}_{4} \text { gave } \mathrm{I} .690 \mathrm{NiO} . \quad 48.2 \mathrm{I} 7 \text { per cent. } \\
& 2.6008 \text { " I.2561 “ } \frac{48.297}{\text { Mean, } 48.257} \pm .027
\end{aligned}
$$

Second, nickel oxide was reduced in hydrogen, as follows:

$$
\begin{aligned}
& \text { I.6865 grm. NiO gave I.3245 Ni. } \quad 78.535 \text { per cent. } \\
& 1.2527 \text { " } .9838 \text { “ } 78.533 \text { “ } \\
& \text { Mean, } \overline{78.534}
\end{aligned}
$$

In one experiment with cobalt oxide, $3.491 \mathrm{grm}$. gave $2.757 \mathrm{Co}$, or 78.975 per cent. In view of the many determinations of this ratio by other observers, this single estimation may be neglected. The experiments on nickel sulphate, however, should be combined with those of Marignac and Baubigny, giving the latter equal weight with Schutzenberger's, thus : 


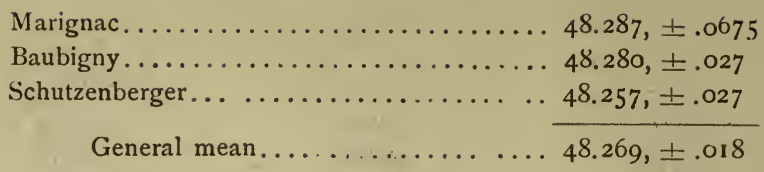

From this point on the determination of these atomic weights is complicated by the questions raised by Krüss as to the truly elementary character of nickel and cobalt. If that which has been called nickel really contains an admixture of some other hitherto unknown element, then all the determinations made so far are worthless, and the investigations now to be considered bear directly upon that question. First in order comes Remmler's research upon cobalt.* This chemist, asking whether cobalt is homogeneous, prepared cobaltic hydroxide in large quantity, and made a series of successive ammoniacal extracts from it, twenty-fire in all. Each extract represented a fraction, from which, by a long series of operations, cobalt monoxide.was prepared, and the latter was reduced in hydrogen after the manner of Russell. The actual determinations began with the second fraction, and the data are subjoined, the number of the fraction being given with each experiment:

\begin{tabular}{|c|c|c|c|c|c|c|}
\hline y & $\mathrm{CoO}$ & & Co. & \multicolumn{3}{|c|}{ Per cent. Co. } \\
\hline $2 \ldots \ldots \ldots \ldots$ & .09938 & & .07837 & 1 & 78.859 & \\
\hline $3 \ldots \ldots \ldots$ & .15021 & & .11814 & & 78.650 & \\
\hline $4 \ldots \ldots \ldots \ldots$ & .22062 & & .17360 & & 78.687 & \\
\hline $5 \ldots \ldots \ldots \ldots$ & .39011 & & .30681 & & 78.647 & \\
\hline $6 \ldots \ldots \ldots \ldots$ & .28820 & & $.2266 \mathrm{I}$ & & 78.629 & \\
\hline $7 \ldots \ldots \ldots \ldots$ & .34304 & & .26968 & & $78.6 r_{5}$ & \\
\hline $8 \ldots \ldots \ldots \ldots$ & .43703 & & .34321 & & 78.532 & \\
\hline $9 \ldots \ldots \ldots \ldots$ & .91477 & & .71864 & & 78.560 & \\
\hline 10........ & .63256 & & $.4966 \mathrm{I}$ & & 78.508 & \\
\hline II .......... & .32728 & & .25701 & & 78.529 & \\
\hline $12 \ldots \ldots \ldots \ldots$ & .38042 & & .29899 & & 78.595 & \\
\hline $13 \ldots \ldots \ldots \ldots$ & .16580 & & .13027 & & 78.571 & \\
\hline $14 \ldots \ldots \ldots \ldots$ & 1.01607 & (f & .79873 & & 78.610 & \\
\hline $15 \ldots \ldots \ldots \ldots$ & I. 31635 & & I.03545 & & 78.661 & \\
\hline I $6 \ldots \ldots \ldots \ldots$ & .91945 & & .72 .315 & & 78.650 & \\
\hline I $7 . \ldots \ldots \ldots$ & .53100 & & .41773 & & 78.668 & , \\
\hline I $8 \ldots \ldots \ldots \ldots$ & .82381 & & .64728 & & 78.572 & \\
\hline I $9 \ldots \ldots \ldots \ldots$ & .81139 & & .63754 & & 78.574 & \\
\hline $20 \ldots \ldots \ldots \ldots$ & .76698 & & .60292 & & 78.610 & \\
\hline $21 \ldots \ldots \ldots \ldots$ & I. 13693 & & .89412 & & 78.643 & \\
\hline $22 \ldots \ldots \ldots \ldots$ & 2.00259 & r & I. 57495 & & 78.646 & \\
\hline $23 \ldots \ldots \ldots \ldots$ & 1.04629 & 1 & .82185 & & 78.549 & \\
\hline $24 \ldots \ldots \ldots \ldots$ & .48954 & + & .38466 & & 78.576 & \\
\hline $25 \ldots \ldots \ldots \ldots$ & .69152 & ? & .54326 & & 78.560 & \\
\hline & & & & & 78.613, & .0099 \\
\hline
\end{tabular}

*Zeit. Anorg. Chem., 2, 221. Also more fully in an Inaugural Dissertation, Erlangen, r8gr. 
Considered with reference to the purpose of the investigation, this mean and its probable error have no real significance. But it is very close to the means of other experimenters, and a study of the variations represented by the several fractions seems to indicate fortuity rather than system. Remmler regards his results as indicating lack of homogeneity in his material ; but it seems more probable that such differences as exist are due to experimental errors and to impurities acquired in the long process of purification to which each fraction was submitted, rather than to any uncertainty regarding the nature of cobalt itself. For either interpretation the data are inconclusive, and I therefore feel justified in treating the mean like other means, and in combining it finally with them.

From the same point of view-that is, with reference to the supposed heterogeneity of nickel-Krüss and Schmidt* carried out a series of fractionations of the metal by distillation in a stream of carbon monoxide. Nickel oxide, free from obnoxious impurities, was first reduced to metal by heating in hydrogen, after which the current of carbon monoxide was allowed to flow. The latter, carrying its small charge of nickel tetracarbonyl was then passed through a Winkler's absorption apparatus containing pure aqua regia, from which, by evaporation, nickel chloride was obtained, and from that, by reduction in hydrogen, the nickel. Ten such fractions were successively prepared and studied; first, by preparation of $\mathrm{NiO}$ and its reduction in hydrogen; and, secondly, in some cases, by the reoxidation of the reduced metal, so as to give a synthetic value for the ratio $\mathrm{Ni}$ : $\mathrm{O}$. The data obtained are as follows, the successive fractions being numbered :

Reduction of $\mathrm{NiO}$.

\begin{tabular}{|c|c|c|}
\hline $\mathrm{NiO}$ & $N i$. & Per cent. Ni. \\
\hline$\{.3722$ & .2926 & 78.614 \\
\hline .7471 & .5870 & $78.57 \mathrm{r}$ \\
\hline .7659 & .60085 & 78.450 \\
\hline .7606 & .5961 & 78.372 \\
\hline 1.0175 & .7984 & 78.467 \\
\hline I. $263 \mathrm{I}$ & .99065 & 78.430 \\
\hline $1.25^{82}$ & .9868 & 78.429 \\
\hline$\{.5193$ & .4076 & 78.490 \\
\hline .9200 & .7215 & 78.424 \\
\hline .4052 & .3179 & 78.455 \\
\hline .6518 & .5111 & 78.414 \\
\hline .5623 & .4399 & 78.232 \\
\hline .5556 & .4350 & 78.294 \\
\hline $\int .9831$ & .7724 & 78.568 \\
\hline$\{.9765$ & .7646 & 78.300 \\
\hline$(.9639$ & .7557 & 78.400 \\
\hline
\end{tabular}

*Zeit. A norg. Chem., 2, 235. 1892. 


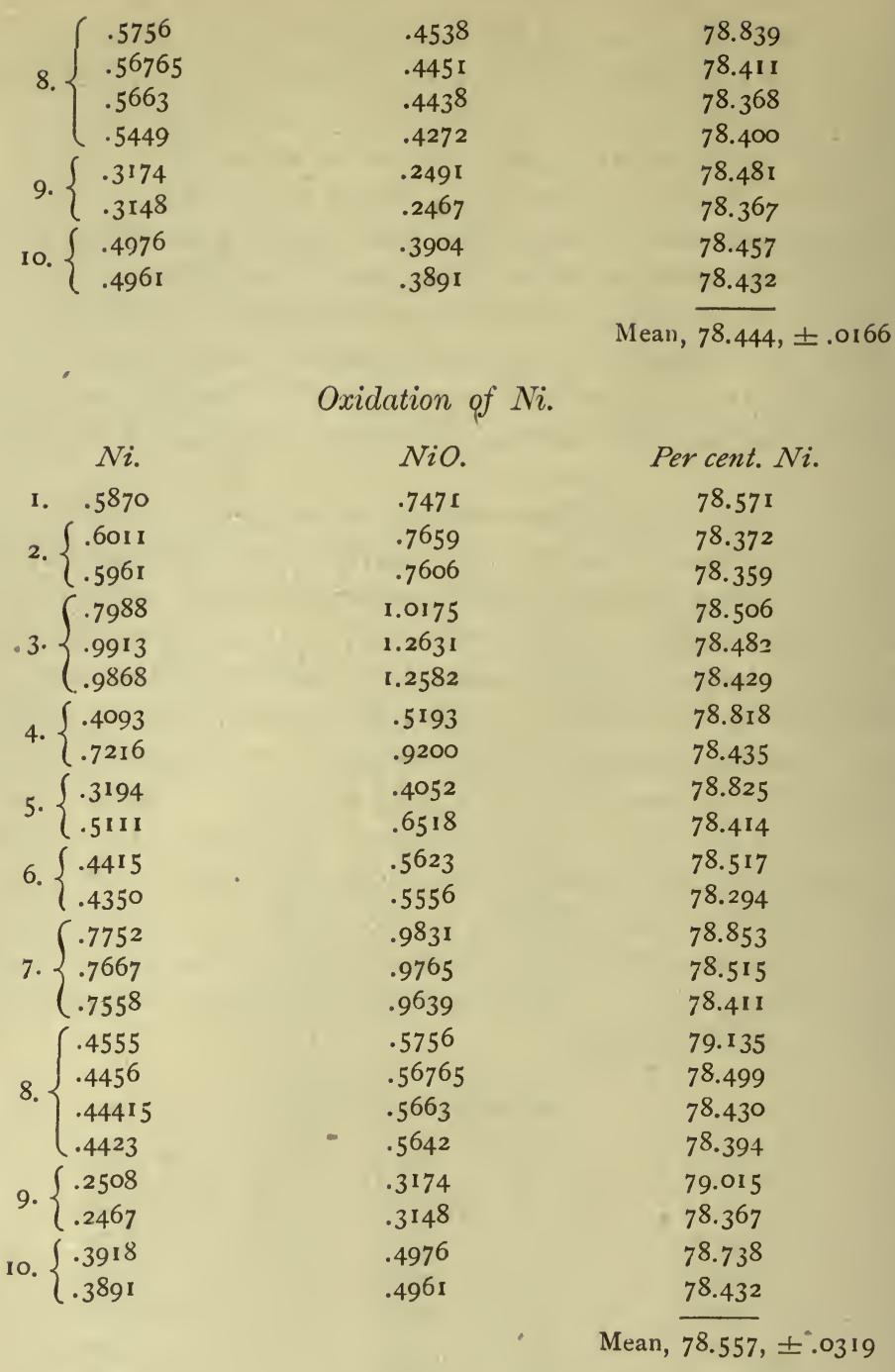

To these data of Krüss and Schmidt the remarks already made concerning Remmler's work seem also to apply. The variations appear to be fortuitous, and not systematic, although the authors seem to think that they indicate a compositeness in that substance which has been hitherto regarded as elementary nickel. There is doubtless something to be said on both sides of the question; but if Krüss and Schmidt are right, all previous atomic weight determinations for cobalt and nickel are invalidated. In view of all the evidence, therefore, I prefer to regard their varying estimations as affected by accidental errors, and to treat their means like others. On this basis, their work combines with previ- 
ous work as follows, Schutzenberger's measurements of the ratio $\mathrm{NiO}: \mathrm{Ni}$ being assigned equal weight with those of Mond, Langer, and Quincke:

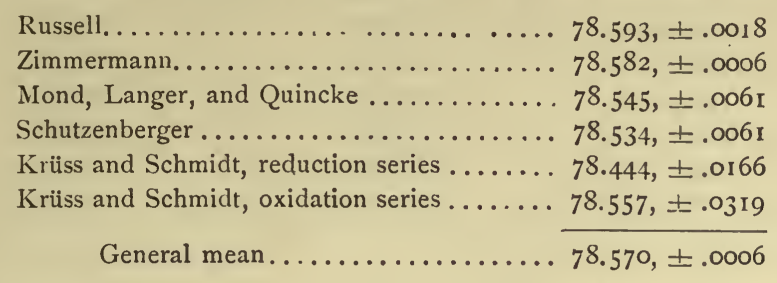

In 1889 Winkler* published a short paper concerning the gold method for determining the atomic weights in question, but gave in it no actual measurements. In $1893 \dagger$ he returned to the problem with a new line of attack, and at the same time he takes occasion to criticise Krüss and Schmidt somewhat severely. He utterly rejects the notion that either nickel or cobalt contain any hitherto unknown element, and ascribes the peculiar results obtained by Krüss and Schmidt to impurities derived from the glass apparatus used in their experiments. For his own part he now works with pure nickel and cobalt precipitated electrolytically upon platinum, and avoids the use of glass or porcelain vessels so far as possible. With material thus obtained he operates by two distinct but closely related methods, both starting with the metal, nickel or cobalt, converting it next into neutral chloride, and then measuring the chloride gravimetrically in one process, volumetrically in the other.

After precipitation in a platinum dish, the nickel or cobalt is washed with water, rinsed with alcohol and ether, and then weighed. It is next dissolved in pure hydrochloric acid, properly diluted, and by evaporation to dryness and long heating to $150^{\circ}$ converted into anhydrous chloride. The nickel chloride thus obtained dissolves perfectly in water, but the cobalt salt always gave a slight residue in which the metal was electrolytically determined and allowed for. In the redissolved chloride, by precipitation with silver nitrate, silver chloride is obtained, giving a direct ratio between that compound and the nickel or cobalt originally taken. The gravimetric data are as follows, with the metal equivalent to 100 parts of silver chloride given in a final column :

Nickel.

$\begin{array}{lll}N i . & \mathrm{AgCl} & \text { Ratio. } \\ .301 \mathrm{I} & \mathrm{I} .462 \mathrm{I} & 20.594 \\ .2242 & 1.008 \mathrm{I} & 20.605 \\ .5166 & 2.5108 & 20.570 \\ .4879 & 2.3679 & 20.605 \\ .3827 & 1.8577 & 20.601 \\ .3603 & 1.7517 & 20.568 \\ & & \text { Mean, } 20.590, \pm .0049\end{array}$




$\begin{array}{ccc} & \text { Cobalt. } & \\ \text { Co. } & \text { AgCl. } & \text { Ratio. } \\ .3458 & 1.6596 & 20.836 \\ .3776 & 1.8105 & 20.856 \\ .4493 & 2.1521 & 20.877 \\ .4488 & 2.1520 & 20.855 \\ .2856 & 1.3683 & 20.873 \\ .2648 & 1.2768 & 20.886 \\ & & \text { Mean, } 20.864, \pm .0050\end{array}$

In the volumetric determinations the neutral chloride, prepared as before, was decomposed by means of a slight excess of potassium carbonate, and in the potassium chloride solution, after removal of the nickel or cobalt, the chlorine was measured by titration by Volhard's method with a standard solution of silver. The amount of silver thus used was comparable with the metal taken.

$\begin{array}{lcc} & \text { Nickel. } \\ N i . & \text { Ag. } & \text { Ratio. } \\ .1812 & .6621260 & 27.366 \\ .1662 & .6079206 & 27.339 \\ .2129 & .7775252 & 27.382 \\ .2232 & .8162108 & 27.346 \\ .5082 & 1.8556645 & 27.386 \\ .1453 & .5315040 & 27.338 \\ & & \text { Mean, } 27.359, \pm .0059\end{array}$

Cobalt.

$\begin{array}{ccc}\text { Co. } & \mathrm{Ag} . & \text { Ratio. } \\ .177804 & .6418284 & 27.702 \\ .26353^{8} & .9514642 & 27.699 \\ .245124 & .8855780 & 27.679 \\ .190476 & .6866321 & 27.741 \\ .266706 & .9629146 & 27.696 \\ .263538 & .950355^{2} & 27.731 \\ & & \text { Mean, } 27.708, \pm .0064\end{array}$

In view of the possibility that the cobalt chloride of the foregoing experiments might contain traces of basic salt; Winkler, in a supplementary investigation, $*$ checked them by another process. To the electrolytic cobalt, in a platinum dish, he added a quantity of neutral silver sulphate and then water. The cobalt gradually went into solution, and metallic silver was precipitated. The weights were as follows:

$\begin{array}{cc}\text { Co. } & \mathrm{Ag} . \\ .2549 & .9187 \\ .4069 & 1.469 \mathrm{I}\end{array}$


On examination of the silver it was found that traces of cobalt were retained-less than $0.5 \mathrm{mg}$. in the first determination and less than 0.2 mg. in the second. Taking these amounts as corrections, the two experiments give for the ratios $\mathrm{Ag}_{2}$ : Co: : 100:x the subjoined values:

$$
\begin{aligned}
& 27.706 \\
& 27.687
\end{aligned}
$$

These figures confirm those previously found, and as they fall within the limits of the preceding series, they may fairly be included in it, when all eight values give a mean of $27.705, \pm .0050$.

Still another method, radically different from all of the foregoing processes, was adopted by Winkler in 1894.* The metals were thrown down electrolytically upon platinum, and so weighed. Then they were treated with a known excess of a decinormal solution of iodine in potassium iodide, which redissolved them as iodides. The excess of free iodine was then determined by titration with sodium thiosulphate, and in that way the direct ratio between metal and haloid was ascertained. The results were as follows, with the metal proportional to 100 parts of iodine given in the third column:

Cobalt.

Wt. Co
First series... $\left\{\begin{array}{l}.4999 \\ .5084 \\ .5290 \\ .6822 \\ .6715\end{array}\right.$
Second series.. $\left\{\begin{array}{l}.5185 \\ .5267 \\ .5319\end{array}\right.$

Wt. Ni
First series.... $\begin{aligned} & .5144 \\ & .4983 \\ & .5265 \\ & .6889 \\ & .6876\end{aligned}$
Second series.. $\left\{\begin{array}{l}.5120 \\ .5200 \\ .5246\end{array}\right.$
$W t . I$.

2.128837

2.166750

2.254335

2.908399

2.861617

2.209694

2.246037

2.268736

Nickel.

Wt. $I$.

2.217494

2.148502

2.268742

2.970709

2.965918

2. 205627

2.240107

2. 259925
Ratio.

23.482

23.463

23.466

23.456

23.466

23.465

23.450

23.445

Mean, $\overline{23.462} \pm .0027$

Ratio.

$23.25 \mathrm{I}$

23.246

23.260

23.243

23.237

23.267

23.267

23.267

Mean, 23.255, $\pm .009 \mathrm{I}$

In these experiments, as well as in some previous' series, a possible source of error is to be considered in the occlusion of hydrogen by the 
metals. Accordingly, in a supplementary paper, Winkler* gives the results of some check experiments made with iron, which, however, was not absolutely pure. The conclusion is that the error, if existent, must be very small.

In 1895 Hempel and Thiele's work on cobalt appeared. $\dagger$ First, cobalt oxide, prepared from carefully purified materials, was reduced in hydrogen. The weights of metal and oxygen are subjoined, with the percentage of cobalt in the oxide deduced from them:

Co.

.90068
.79159
$\mathbf{1} .31558$
0.

.24429
.21445
.35716

\section{Percentage.}

78.664

78.686

78.648

Mean, $\overline{78.666}, \pm .0074$

This mean combines with former means as follows:

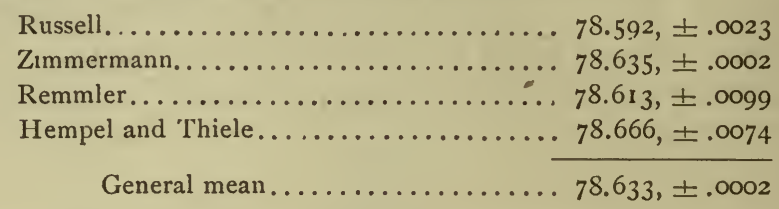

In their next series of experiments, excluding a rejected series, Hempel and Thiele weighed cobalt, converted it into anhydrous chloride, and noted the gain in weight. In four of the experiments the chloride was afterwards dissolved, precipitated with silver nitrate, and then the silver chloride was weighed. The data are as follows:

$\begin{array}{ccc}\text { Co. } & \text { Cl Taken Up. } & \text { AgCl. } \\ .7010 & .8453 & \ldots \ldots \\ .3138 & .3793 & \ldots \ldots \\ .2949 & .3562 & 1.4340 \\ .4691 & .5657 & 2.2812 \\ .5818 & .7026 & 2.8303 \\ .5763 & .6947 & \ldots \ldots \\ .5096 & .6142 & 2.4813\end{array}$

From these weights we get two ratios, thus :

$$
\begin{array}{cc}
\mathrm{Cl}_{2}: \text { Co }: 100: x . & 2 \mathrm{AgCl}: \text { Co: }: \text { IOO : } x . \\
82.929 & 20.565 \\
82.731 & 20.564 \\
82.791 & 20.556 \\
82.924 & 20.538 \\
82.807 & \\
82.957 & \text { Mean, } 20.556, \pm .0043 \\
82.970 & \\
\text { Mean, } 82.873, \pm .024 \mathrm{r} &
\end{array}
$$


The second of these ratios was also studied by Winkler f $_{\text {and }}$ the two series combine as follows:

$$
\begin{array}{r}
\text { Winkler.......................... 20.864, } \pm .0050 \\
\text { Hempel and Thiele................ } 20.556, \pm .0043 \\
\text { General mean............... }
\end{array}
$$

Hempel and Thiele apply to it a correction for silver chloride retained in solution, but its amount is small and not altogether certain. For present purposes the correction may be neglected.

For the atomic weight of nickel we now have ratios as follows:
(I.) Per cent. of $\mathrm{Ni}$ in $\mathrm{NiC}_{2} \mathrm{O}_{4} \cdot 3 \mathrm{H}_{2} \mathrm{O}, 29.084, \pm .006$
(2.) Per cent. of $\mathrm{CO}_{2}$ from $\mathrm{NiC}_{2} \mathrm{O}_{4} \cdot 2 \mathrm{H}_{2} \mathrm{O}, 44.098, \pm .027$
(3.) Per cent. of $\mathrm{Ni}$ in $\mathrm{NiC}_{2} \mathrm{O}_{4} .2 \mathrm{H}_{2} \mathrm{O}, 3 \mathrm{I} .408, \pm .0026$
(4.) Per cent. of $\mathrm{CO}_{2}$ from $\mathrm{NiC}_{2} \mathrm{O}_{4} .2 \mathrm{H}_{2} \mathrm{O}, 47.605, \pm .053$
(5.) Per cent. of $\mathrm{Ni}$ in brucia nickelocyanide, 5.7295, \pm .0034
(6.) Per cent. of $\mathrm{Ni}$ in strychnia nickelocyanide, 6.595, \pm .005
(7.) Per cent. of $\mathrm{NiO}$ in $\mathrm{NiSO}_{4}, 48.269, \pm .01 \mathrm{~S}$
(8.) Per cent. of $\mathrm{Ni}$ in $\mathrm{NiO}, 78.570, \pm .0006$
(9.) $\mathrm{Ag}_{2}: \mathrm{NiCl}_{2}:: 100: 60.194, \pm .006 \mathrm{I}$
(Io.) $2 \mathrm{AgCl}: \mathrm{Ni}:: 100: 20.590, \pm .0049$
(II.) $\mathrm{Ag}_{2}: \mathrm{Ni}:: 100: 27.359, \pm .0059$
(I2.) $\mathrm{Au}_{2}: \mathrm{Ni}_{3}:: \mathrm{I00}: 45.209$, \pm .019
(13.) $\mathrm{BaSO}_{4}: \mathrm{K}_{2} \mathrm{Ni}\left(\mathrm{SO}_{4}\right)_{2} \cdot 6 \mathrm{H}_{2} \mathrm{O}:: 100: 93.6505: \pm .00 \mathrm{I}$
(14.) $\mathrm{Ni}: \mathrm{H}_{2}:: \mathrm{IOO}: 3.42 \mathrm{II}, \pm .00 \mathrm{I}$
(I5.) $\mathrm{I}_{2}: \mathrm{Ni}:: 100: 23.255, \pm .009 \mathrm{I}$

To the reduction of these ratios the following atomic and molecular weights are applicable:

$$
\begin{aligned}
& \mathrm{O}=\mathrm{I} 5.879, \pm .0003 \quad \mathrm{I}=\mathrm{I} 25.888, \pm .0069 \\
& \mathrm{C}=\mathrm{II} .920, \pm .0004 \quad \mathrm{~K}=38.8 \mathrm{I} 7, \pm .005 \mathrm{I} \\
& \mathrm{N}=\mathrm{r} 3.935, \pm .002 \mathrm{I} \quad \mathrm{Ba}=\mathrm{r} 36.392, \pm .0086 \\
& \mathrm{~S}=31.828, \pm .0035 \quad \mathrm{Au}=195.743, \pm .0049 \\
& \mathrm{Ag}=107.108, \pm .0031 \quad \mathrm{AgCl}=142.287, \pm .0037 \\
& \mathrm{Cl}=35.179, \pm .0048
\end{aligned}
$$

Since the proportion of water in the oxalates is not an absolutely certain quantity, the data concerning them can be best handled by employing the ratios between carbon dioxide and the metal. Accordingly, ratios (1) and (2) give a single value for $\mathrm{Ni}$, and ratios (3) and (4) another. In all, there are thirteen values for the atomic weight in question :

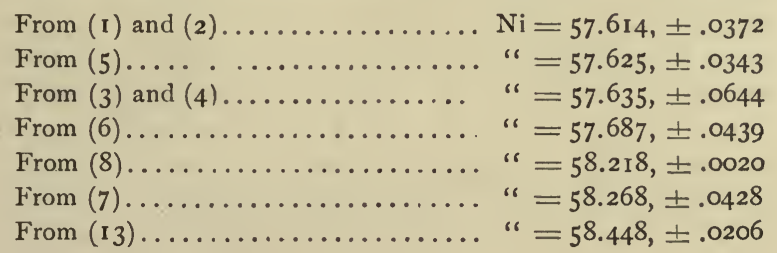




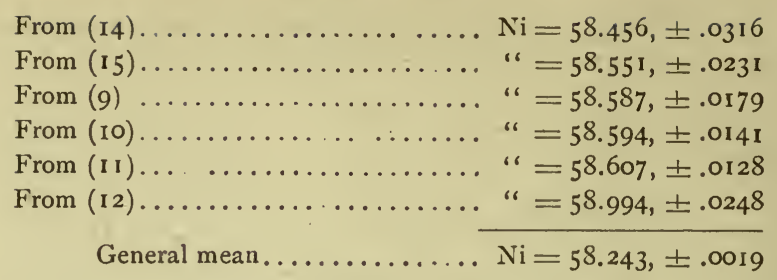

If $\mathrm{O}=16$, this becomes $\mathrm{Ni}=58.687$.

It is quite evident here that ratio (8), which includes the marvelously concordant determinations of Zimmermann, far outweighs all the other data. Whether so excessive a weight can justifiably be assigned to one set of measurements is questionable, but the general mean thus reached is not far from midway between the highest and lowest of the values, and hence it may fairly be entitled to provisional acceptance. No one of the individual values rests upon absolutely conclusive evidence, so that no one can be arbitrarily chosen to the exclusion of the others. Further investigation is evidently necessary.

For cobalt we have sixteen ratios, as follows:
(I.) Per cent. of $\mathrm{Co}$ in $\mathrm{CoC}_{2} \mathrm{O}_{4} \cdot 2 \mathrm{H}_{2} \mathrm{O}, 32.5555, \pm .0149$
(2.) Per cent. of $\mathrm{CO}_{2}$ from $\mathrm{CoC}_{2} \mathrm{O}_{4} \cdot 2 \mathrm{H}_{2} \mathrm{O}, 47.7475, \pm .02 \mathrm{I} 3$
(3.) Per cent. of $\mathrm{Co}$ in $\mathrm{CuO}, 78.633, \pm .0002$
(4.) Per cent. of Co in purpureocobalt chloride, $23.6045, \pm .0018$
(5.) Per cent. of Co in phenylammonium cobalticyanide, I I.8665, \pm .0124
(6.) Per cent, of Co in ammonium cobalticyanide, $21.943, \pm .029$
(7.) Per cent. of Co in brucia cobalticyanide, 3.7437, 上.0036
(8.) Per cent. of Co in strychnia cobalticyanide, $4.5705, \pm .005$
(9.) Per cent. of $\mathrm{CoO}$ in $\mathrm{CoSO}_{4}, 48.287, \pm .0135$
(Io.) $\mathrm{Ag}_{2}: \mathrm{CoCl}_{2}::$ : $100: 60.200, \pm .0095$
(II.) $2 \mathrm{AgCl}: \mathrm{Co}:: \mathrm{I00}: 20.687, \pm .0033$
(12.) $\mathrm{Ag}_{2}$ : Co: : $100: 27.705, \pm .0050$
(13.) $\mathrm{Au}_{2}: \mathrm{Co}_{3}:: 100: 45.15 \mathrm{I}, \pm .025$
(14.) $\mathrm{Co}: \mathrm{H}_{2}:: 100: 3.4110, \pm .0009$
(I5.) $\mathrm{I}_{2}: \mathrm{Co}:: \mathrm{IOO}: 23.462, \pm .0027$
(I6.) $\mathrm{Cl}_{2}: \mathrm{Co}::$ I00: $82.873, \pm .024 \mathrm{I}$

From these, using the atomic weights already cited under nickel, and combining ratios (1) and (2), we get-

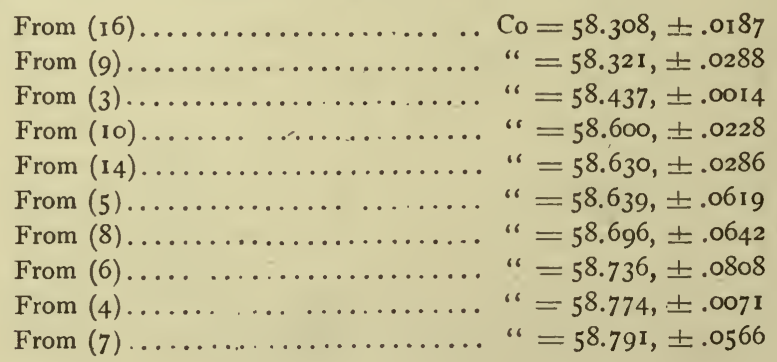




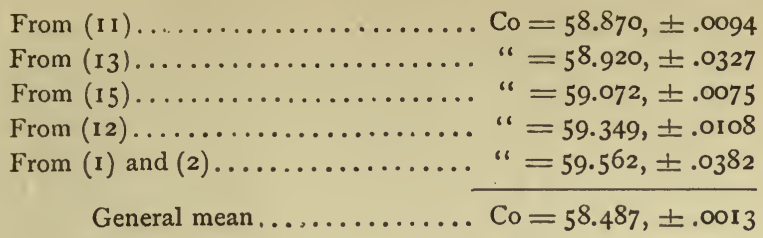

If $\mathrm{O}=16$, this becomes $\mathrm{Co}=58.932$.

Here again the oxide ratio, because of Zimmermann's work, receives excessive and undue weight. The arithmetical mean of the fifteen values is $\mathrm{Co}=58.781$. Between this and the weighted general mean the truth probably lies, but the evidence is incomplete, and more determinations are needed.

\section{RUTHENIUM.}

The atomic weight of this metal has been determined by Claus and by Joly. Although Claus* employed several methods, we need only consider his analyses of potassium rutheniochloride, $\mathrm{K}_{2} \mathrm{RuCl}_{5}$. The salt was dried by heating to $200^{\circ}$ in chlorine gas, but even then retained a trace of water. The percentage results of the analyses are as follows:

\begin{tabular}{rrr}
$R u$. & $2 \mathrm{KCl}$ & $\mathrm{Cl}_{3}$. \\
28.96 & 40.80 & 30.24 \\
28.48 & $4 \mathrm{r} .39$ & 30.22 \\
$28.9 \mathrm{r}$ & $4 \mathrm{r} .08$ & $\frac{30.04}{40.17}$ \\
\hline$\overline{28.78}$ & $4 \mathrm{r} .09$ & 3
\end{tabular}

Reckoning directly from the percentages, we get the following discordant values for $\mathrm{Ru}$ :

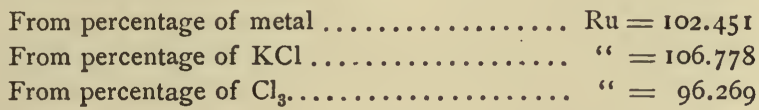

These results are obviously of little importance, especially since the best of them is not in accord with the position of ruthenium in the periodic system. The work of Joly is more satisfactory. $\dagger$ Several compounds of ruthenium were analyzed by reduction in a stream of hydrogen with the following results: 
First, reduction of $\mathrm{RuO}_{2}$ :

$\begin{array}{ccc}\mathrm{RuO}_{2} . & \mathrm{Ru} . & \text { Percent. Ru. } \\ 2.1387 & 1.6267 & 76.060 \\ 2.5846 & 1.9658 & 76.058 \\ 2.3682 & 1.8016 & 76.075 \\ 2.8849 & 2.1939 & \frac{76.046}{} \\ & & \text { Mean, } 76.060, \pm .0040\end{array}$

Second, reduction of the salt $\mathrm{RuCl}_{3} \cdot \mathrm{NO}_{2} \mathrm{H}_{2} \mathrm{O}$ :

Percent. Ru.

39.78

39.66

Mean, $39.72, \pm .0405$

Third, reduction of $\mathrm{RuCl}_{3} \cdot \mathrm{NO} \cdot 2 \mathrm{NH}_{4} \mathrm{Cl}$ :

Per cent. Ru.

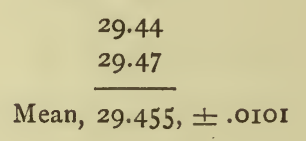

Computing with $\mathrm{O}=15.879, \pm .0003 ; \mathrm{N}=13.935, \pm .0021$, and $\mathrm{Cl}=$ $35.179, \pm .0048$, these data give three values for ruthenium, as follows:

I. From $\mathrm{RuO}_{2} \ldots \ldots \ldots \ldots \ldots \ldots, \mathrm{Ru}=100.922, \pm .0178$

2. From $\mathrm{RuCl}_{3}$. NO. $\mathrm{H}_{2} \mathrm{O} \ldots \ldots \ldots \ldots$ " $=100.967, \pm .1102$

3. From $\mathrm{KuCl}_{3} . \mathrm{NO} .2 \mathrm{AmCl} \ldots \ldots \ldots$... $=100.868, \pm .0387$

General mean .......... Ru $=100.913, \pm .0160$

If $\mathrm{O}=16, \mathrm{Ru}=101.682$. 


\section{RHODIUM.}

Berzelius * determined the atomic weight of this metal by the analysis of sodium and potassium rhodiochlorides, $\mathrm{Na}_{3} \mathrm{RhCl}_{6}$, and $\mathrm{K}_{2} \mathrm{RhCl}_{5}$. The latter salt was dried by heating in chlorine. The compounds were analyzed by reduction in hydrogen, after the usual manner. Reduced to percentages, the analyses are as follows:

\begin{tabular}{|c|c|c|}
\hline & In $\mathrm{Na}_{3} \mathrm{RhCl}_{6}$ & \\
\hline$R h$. & ${ }_{3} \mathrm{NaCl}$. & $\mathrm{Cl}_{3}$. \\
\hline 26.959 & 45.853 & 27.189 \\
\hline 27.229 & $45 \cdot 301$ & 27.470 \\
\hline ....... & $\ldots \ldots$ & 27.616 \\
\hline Mean, 27.094 & Mean, 45.577 & Mean, 27.425 \\
\hline & In $K_{2} R h C l_{5}$. & it \\
\hline$R h$. & $2 K C l$. & $\mathrm{Cl}_{3}$ \\
\hline 28.989 & 41.450 & $29.56 \mathrm{I}$ \\
\hline
\end{tabular}

From the analyses of the sodium salt we get the following values for $\mathrm{Rh}$ :

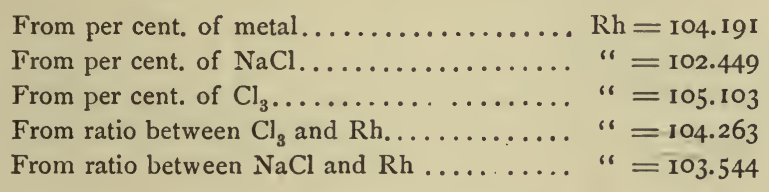

These are discordant figures; but the last one fits in fairly well with the values calculated from the potassium compound, which are as follows :

From per cent. of metal............. Rh $=103.499$

"From per cent. of $\mathrm{KCl} . . . . . . . . . . . . .4 "=103.648$

From per cent. of $\mathrm{Cl}_{3} \ldots \ldots \ldots \ldots \ldots \ldots \ldots$ " $=103.485$

From $\mathrm{Rh}: \mathrm{Cl}_{3}$ ratio............... $"=103.495$

From $\mathrm{Rh}: \mathrm{KCl}$ ratio............... $"=103.540$

Mean................... $\overline{\mathrm{Rh}}=\mathrm{I0} 3.533$

If $\mathrm{O}=16$, this becomes $\mathrm{Rh}=104.323$.

Jörgensen's determination, $\dagger$ so far as I can ascertain, was published only as a preliminary note, to the effect that the atomic weight of rhodium is 103 , nearly. No details are given. 
Seubert and Kobbe * determine the atomic weight by igniting rhodium pentamine chloride in hydrogen, and weighing the residual metal. Their results are given below :

$\mathrm{Rh}\left(\mathrm{NH}_{3}\right)_{5} \mathrm{Cl}_{3}$.
1.8585
1.5560
1.5202
2.0111
1.8674
2.4347
2.3849
2.5393
1.4080
1.4654

$R h$.
.6496
.5435
.5310
.7031
.6528
.8513
.8338
.8881
.4920
.5123

Percent. Rh.

34.953

34.929

34.930

34.961

$34.95^{8}$

34.965

34.962

- 34.974

34.943

34.960

Mean, 34.954, \pm .0032

In the sixth experiment the ammonium chloride formed was collected in a bulb tube, and estimated by weighing as silver chloride. 3.5581 grms. of $\mathrm{AgCl}$ were obtained.

Computing with $\mathrm{N}=13.935, \pm .0021 ; \mathrm{Cl}=35.179, \pm .0048$, and $\mathrm{AgCl}=$ $142.287, \pm .0037$, we have-

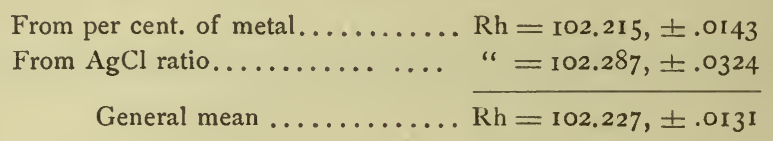

If $\mathrm{O}=16, \mathrm{Rh}=103.006$.

In the second of these values the probable error given is only that due to the antecedent atomic weights of $\mathrm{N}, \mathrm{Cl}$, and $\mathrm{AgCl}$. It is therefore lower than it should be. The two values, however, are fairly in agreement, and the result is satisfactory. 


\section{PALLADIUM.}

The first work upon the atomic weight of palladium seems to have been done by Berzelius. In an early paper* he states that 100 parts of the metal united with 28.15 of sulphur. Hence $\mathrm{Pd}=113.06$, a result which is clearly of no present value.

In a later paper $\dagger$ Berzelius published two analyses of potassium palladiochloride, $\mathrm{K}_{2} \mathrm{PdCl}_{4}$. The salt was decomposed by ignition in hydrogen, as was the case with the double chlorides of potassium with platinum, osmium, and iridium. Reducing his results to percentages, we get the following composition for the substance in question:

$\begin{array}{rrr}P d . & 2 \mathrm{KCl} & C l_{2} . \\ 32.726 & 46.044 & 21.229 \\ \frac{32.655}{32.690} & \text { Mean, } \frac{45.741}{45.892} & 21.604 \\ \text { Mean } & \text { Mean, } 21.416\end{array}$

From these percentages, calculating directly, very discordant results are obtained:

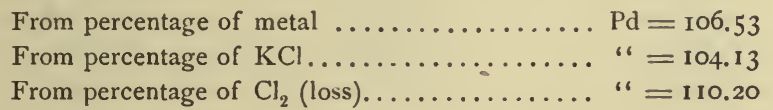

Obviously, the only way to get satisfactory figures is to calculate from the ratio between the $\mathrm{Pd}$ and $2 \mathrm{KCl}$, eliminating thus the influence of water in the salt. The two experiments give, as proportional to 100 parts of $\mathrm{KCl}$, the following of $\mathrm{Pd}$ :

$$
\begin{gathered}
71.075 \\
\frac{71.391}{71.233,} \pm .1066
\end{gathered}
$$

Hence $\mathrm{Pd}=105.419$.

In 1847 Quintus Icilius $\ddagger$ published a determination, which need be given only for the sake of completeness. He ignited potassium palladiochloride in hydrogen, and found the following amounts of residue. His weights are here recalculated into percentages :

$$
\begin{array}{r}
64.708 \\
64.965 \\
64.781 \\
\hline \text { Mean, } 64.818
\end{array}
$$

From this mean, $\mathrm{Pd}=111.258$. This result has no present value.

* Poggend. Annalen, 8, 177. 1826.

† Poggend. Annalen, I3, 454. I828.

f "Die Atomgewichte vom $\mathrm{Pd}, \mathrm{K}, \mathrm{Cl}, \mathrm{Ag}, \mathrm{C}$, und $\mathrm{H}$, nach der Methode der kleinsten Quadrate berechnet." Inaug. Diss. Göttingen, 1847. Contains no other original a nalyses. 
In 1889 Keiser's first determinations of this constant appeared.* Finding the potassium palladiochloride to contain "water of decrepitation," he abandoned its use, and resorted to palladiammonium chloride, $\mathrm{Pd}\left(\mathrm{NH}_{3} \mathrm{Cl}\right)_{2}$, as the most available compound for his purpose. This salt, heated in hydrogen, yields spongy palladium, which was allowed to cool in a current of dry air, in order to avoid gaseous occlusions. The salt itself was dried, previous to analysis, first over sulphuric acid, and then in an air bath at a temperature from $120^{\circ}$ to $130^{\circ}$. Two series of experiments were made, the second series starting out from palladium produced by the first series. The data are as follows:

First Series.

$\mathrm{Pd}\left(\mathrm{NH}_{3} \mathrm{Cl}\right)_{2}$
.83260
1.72635
1.40280
1.57940
1.89895
1.48065
1.56015
1.82658
2.40125
1.10400
.93310

$P d$.

.41965

.86992

.70670

.79562

.95650

.74570

.78585

.92003

I. 20970

.55629

.47010

Per cent. Pd.

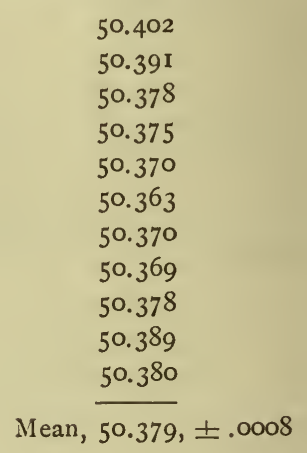

Reduced to vacuum this becomes 50.360 .

Second Series.

$P d\left(\mathrm{NH}_{3} \mathrm{Cl}\right)_{2}$.
2.61841
2.23420
1.73553
1.69160
1.72403
1.12222
1.17457
2.42760

$P d$.

I. 31900

I. 1256 I

.87445

.85210

.86825

.56535

.59200

I. 22280

Per cent. Pd.

50.374

50.381

$50.3^{85}$

50.372

50.362

50.378

50.401

$50.37 \mathrm{I}$

Mean, $\overline{50.378}, \pm .0028$

Reduced to vacuum, 50.359

The reductions to vacuum are neglected by Keiser himself, but are here added in order to secure uniformity with later results by the same author. The mean of both series, thus corrected, gives $\mathrm{Pd}=105.74$.

Bailey and Lamb $\dagger$ made experiments upon several compounds of palladium, but finally settled upon palladiammonium chloride, like Keiser. 
Two preliminary experiments, however, with potassium palladiochloride are given, in which the salt was reduced in hydrogen, and both $\mathrm{Pd}$ and $\mathrm{KCl}$ were weighed. The data are as follows, with the ratio (calculated as with Berzelius' experiments) given in a third column:

$\begin{array}{rrc}2 \mathrm{KCl} . & \mathrm{Pd} . & \text { Ratio. } \\ \mathrm{r} .49767 & \mathrm{1.05627} & 70.528 \\ .90484 & .6 .373^{8} & \frac{70.441}{} \\ & & \text { Mean, } 70.485, \pm .0290\end{array}$

Hence $\mathrm{Pd}=104.312$.

The palladiammonium chloride was studied by two methods. First, weighed quantities of the salt were reduced in hydrogen, the ammonium chloride so formed was collected in an absorption apparatus, and then precipitated with silver nitrate. The weights found were as follows, with the $\mathrm{Pd}\left(\mathrm{NH}_{3} \mathrm{Cl}\right)_{2}$ proportional to 100 parts of silver chloride given in the third column :

$P d\left(\mathrm{NH}_{3} \mathrm{Cl}\right)_{2}$.
1.24276
1.08722
1.47666
1.34887
1.74569

$\mathrm{AgCl}$.

Ratio.

I.682249

73.879

I. 468448

2.000164

1. 837957

74.040

73.828

73.390

2.362320

73.898

Mean, $\overline{73.807}, \pm .0742$

Hence $\mathrm{Pd}=105.808$. Bailey and Lamb regard this as too high, and suspect loss of $\mathrm{NH}_{4} \mathrm{Cl}$ during the operation.

The second series of data resemble Keiser's. The salt was reduced in hydrogen, and the spongy palladium was weighed in a Sprengel vacuum. The data are as follows:
$\mathrm{Pd}\left(\mathrm{NH}_{3} \mathrm{Cl}\right)_{2}$.
$P d$.
Percent. Pd.
A. $\left\{\begin{array}{l}\text { I. } 890597 \\ 1.874175\end{array}\right.$
.947995
$.94027 \mathrm{I}$
.654687
B. $\left\{\begin{array}{l}\text { I. } 307076 \\ 1.340045 \\ 1.905536 \\ 1.685582\end{array}\right.$
.633207
.955950
.846472
50.143
50.170
50.088
50.238
50.167
.849120
C. $\left\{\begin{array}{l}\text { 1.691028 } \\ 2.112530 \\ 2.110653 \\ 1.969100\end{array}\right.$
I. 059690
I.057910
.988155
50.218
50.213
50.162
50.122
50.184
Mean, $50.171, \pm .0099$

Hence $\mathrm{Pd}=104.943$. Bailey and Lamb's weighings are all reduced to a vacuum. 
Keller and Smith,* reviewing Keiser's work, find that palladiammonium chloride, prepared as Keiser prepared it, may retain traces of foreign metals, and especially of copper. Accordingly, they prepared a quantity of the salt, after a thorough and elaborate process of purification, dried it with extreme care, and then determined the palladium by electrolysis in silver-coated platinum dishes. The precipitated palladium was dried under varying conditions, concerning which the original memoir must be consulted, and was proved to be free from occluded hydrogen. By this method two sets of experiments were made to determine the atomic weight of palladium; but for present purposes the two may fairly be treated as one. The data obtained are as follows, but the weights do not appear to have been reduced to a vacuum:

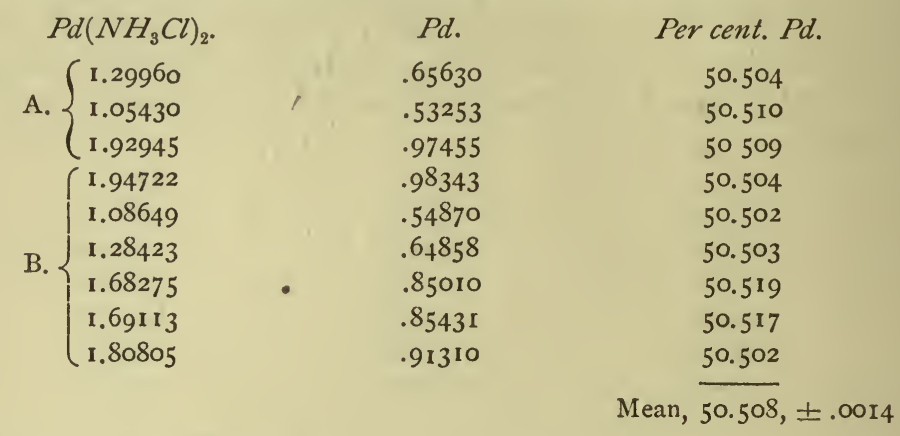

Hence $\mathrm{Pd}=106.368$, a result notably higher than Keiser's.

Keller and Smith account for the difference between their determinations and Keiser's partly by the assumption that the materials used by the latter were not pure, and partly by considerations based on the process. In order to clarify the latter part of the question they made three sets of experiments by Keiser's method, slightly varying the conditions. First, the chloride was not pulverized before ignition, and slight decrepitation took place, while dark stains of palladium appeared in the reduction tube, indicating loss by volatilization. Secondly, the chloride was prepared from crude palladium exactly as described by Keiser, but was pulverized before reduction. No decrepitation ensued, but traces of palladium were volatilized. The third series, also on finely pulverized material, was like the second; but the palladiammonium chloride was purified by Keller and Smith's process. The three series, here treated as one, are as follows:

$\begin{array}{rcc}P d\left(\mathrm{NH}_{3} \mathrm{Cl}\right)_{2}{ } & P d . & P \text { Pr cent. Pd. } \\ \text { First series.... } & .31743 & 50.422 \\ .62955 & .38942 & 50.397 \\ .77270 & .41918 & 50.350 \\ .83252 & .49895 & 50.37 \mathrm{I} \\ .99055 & \end{array}$

*Amer. Chem. Journ., 14, 423. 1892. 


\begin{tabular}{|c|c|c|c|}
\hline \multirow{5}{*}{ Second series. } & $\mathrm{Pd}\left(\mathrm{NH}_{3} \mathrm{Cl}\right)_{2}$ & $P d$. & Percent. Pd. \\
\hline & $\int 1.02175$ & .51468 & 50.372 \\
\hline & 1.10325 & .55590 & 50.388 \\
\hline & .66690 & $\cdot 33590$ & 50.367 \\
\hline & .86840 & .43733 & 50.360 \\
\hline \multirow{6}{*}{ Third series. } & 1.41430 & .71255 & 50.382 \\
\hline & I.15234 & .58050 & 50.376 \\
\hline & .96229 & .48502 & 50.403 \\
\hline & .97804 & .49294 & $50.40 \mathrm{I}$ \\
\hline & .94253 & .47517 & 50.414 \\
\hline & .86090 & .43405 & 50.430 \\
\hline
\end{tabular}

The three series seem to be fairly in agreement between themselves, and with Keiser's work, but diverge seriously from the electrolytic data.

Keller and Smith also attempted to determine the atomic weight of palladium by heating the palladiammonium chloride in sulphuretted hydrogen, and so converting it into the sulphide, PdS. These data were obtained :

$\begin{array}{ccc}\mathrm{Pd}\left(\mathrm{NH}_{3} \mathrm{Cl}\right)_{2} . & \text { PdS. } & \text { Percent. CdS. } \\ .71699 & .47066 & 65.644 \\ 1.31688 & .86445 & 65.659 \\ & & \text { Mean, } 65.65 \mathrm{I}, \pm .005 \mathrm{I}\end{array}$

Hence $\mathrm{Pd}=106.55$. This result, however, is affected by the work of Petrenko-Kritschenko,* who has shown the existence of the sulphide PdS to be uncertain.

Joly and Leidié, $\dagger$ in their determinations of this atomic weight, returned to the potassium palladiochloride, $\mathrm{K}_{2} \mathrm{PdCl}_{4}$. In their first series of experiments the salt was dried in vacuo at ordinary temperatures. It was then electrolyzed in a solution acidulated with hydrochloric acid, both the deposited palladium and the potassium chloride being weighed. The palladium was dried, ignited in a stream of hydrogen, and cooled in an atmosphere of carbon dioxide. The results were as follows, with the column added by me giving the $\mathrm{Pd}$ equivalent to 100 parts of $\mathrm{KCl}$ :

$\begin{array}{cccc}\mathrm{K}_{2} \mathrm{PdCl}_{4} . & \mathrm{Pd} & 2 \mathrm{KCl} & \text { Ratio. } \\ \mathrm{I.0255} & .3919 & .5520 & 70.996 \\ \mathrm{I.2178} & .3937 & .555 \mathrm{I} & 70.924 \\ \mathbf{1 . 2 5 1 8} & .4048 & .5687 & 7 \mathrm{r.016} \\ & & & \text { Mean, } 70.979, \pm .0188\end{array}$

This series was rejected by the authors, because the salt was found to contain water-in one case 0.23 per cent. This error, however, should 
not invalidate the $\mathrm{Pd}: \mathrm{KCl}$ ratio. In a second series the palladiochloride was dried in vacuo at $100^{\circ}$, giving the following data:

\begin{tabular}{|c|c|c|c|}
\hline $\mathrm{K}_{2} \mathrm{PdCl}_{4}$ & $P d$. & $2 \mathrm{KCl}$. & Ratio. \\
\hline 1.3635 & .4422 & .6186 & 71.484 \\
\hline 3.0628 & .9944 & 1.3929 & $7 \mathrm{I} .39 \mathrm{I}$ \\
\hline I. 4845 & .4816 & .6782 & $71.01 \mathrm{r}$ \\
\hline I.7995 & $.5^{8} 3^{8}$ & .8206 & 71.143 \\
\hline
\end{tabular}

These experiments seem to be less concordant than the preceding set. It must be noted, however, that the authors reject the $\mathrm{KCl}$ determinations and compute directly from the ratio between the salt and the metal. But the ratio here chosen agrees best with the determinations made by other observers, giving for this series the mean value $\mathrm{Pd}=105.455$, and is, moreover, uniform with the data given by Berzelius and by Bailey and Lamb.

Joly and Leidié also give two experiments made by reducing the $\mathrm{K}_{2} \mathrm{PdCl}_{4}$ in hydrogen, with the subjoined results :

$\begin{array}{cccc}\mathrm{K}_{2} \mathrm{PdCl}_{4} . & \mathrm{Pd} . & 2 \mathrm{KCl} & \text { Ratio. } \\ 2.448 \mathrm{I} & .7949 & \mathrm{1.1168} & 71 . \mathrm{r} 77 \\ \mathrm{r} .8250 & .5930 & .8360 & 70933 \\ & & & \text { Mean, } 7 \mathrm{r} .055, \pm .0823\end{array}$

Combining these data with previous series, we have-

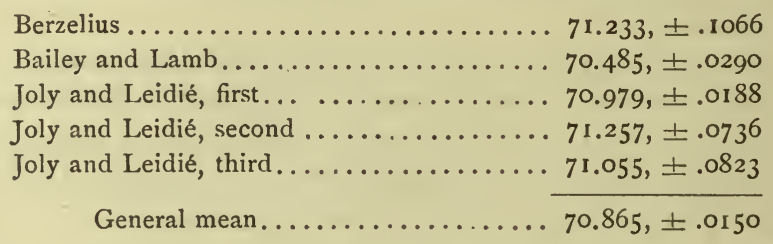

In view of the discordance among the determinations hitherto cited and because of the criticisms made by Keller and Smith, Keiser, jointly with Miss Mary B. Breed,* repeated his former work, with some variations and added precautions to ensure accuracy. His general method was the same as before, namely, the reduction of palladiammonium chloride by a stream of hydrogen. First, palladium was purified by distillation as $\mathrm{PdCl}_{2}$ at low red heat in a current of chlorine. From this chloride the palladiammonium salt was then prepared. Upon heating the compound gently in a stream of hydrogen, decomposition ensued absolutely without decrepitation or loss of palladium by volatilization. Neither source of error existed. The results obtained were these: 


$\begin{array}{ccc}\mathrm{Pd}\left(\mathrm{NH}_{3} \mathrm{Cl}\right)_{2} . & \text { Pd. } & \text { Per cent. Pd. } \\ 1.60842 & .80997 & 50.358 \\ 2.08295 & 1.04920 & 50.37 \mathrm{I} \\ 2.02440 & 1.01975 & 50.373 \\ 2.54810 & 1.28360 & 50.375 \\ 1.75505 & .88410 & 50.375 \\ & & \text { Mean, } 50.370, \pm .0023\end{array}$

Reduced to vacuum, 50.351

In a second series of experiments, palladium was purified as in the earlier investigation, but with special care to eliminate rhodium, iron, copper, gold, mercury, etc. The palladiammonium salt prepared from this material gave as follows:

$\begin{array}{ccc}\mathrm{Pd}\left(\mathrm{NH}_{3} \mathrm{Cl}\right)_{2} . & \mathrm{Pd} . & \text { Per cent. Pd. } \\ \mathrm{I} .50275 & .75685 & 50.364 \\ \mathrm{I} .23672 & .62286 & 50.365 \\ \mathrm{I} .34470 & .67739 & 50.375 \\ \mathrm{I} .49059 & .75095 & 50.379 \\ & & \text { Mean, } \frac{50.37 \mathrm{I}}{} \pm .0026\end{array}$

Reduced to vacuum, $50.35^{2}$

Here, again, no loss from decrepitation or volatilization occurred, although evidence of such loss was carefully sought for. The data thus obtained may now be combined with the previous series, thus:

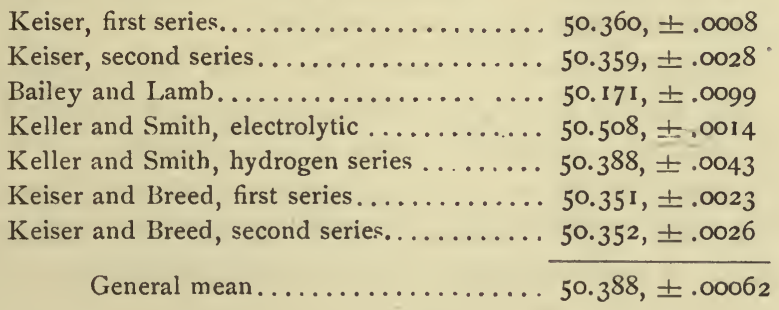

For palladium, ignoring the work of Quintus Icilius, the subjoined ratios are now available:
(I.) $2 \mathrm{KCl}: \mathrm{Pd}:: 100: 70.865$, \pm .0150
(2.) Per cent. $\mathrm{Pd}$ in $\mathrm{Pd}\left(\mathrm{NH}_{3} \mathrm{Cl}\right)_{2}, 50.388, \pm .00062$
(3.) $2 \mathrm{AgCl}: \mathrm{Pd}\left(\mathrm{NH}_{3} \mathrm{Cl}\right)_{2}::$ : $100: 73.807, \pm .0742$
(4.) $\mathrm{Pd}\left(\mathrm{NH}_{3} \mathrm{Cl}\right)_{2}: \operatorname{PdS}:: 100: 65.65 \mathrm{I}, \pm .005 \mathrm{I}$

The antecedent data are-

$$
\begin{array}{ll}
\mathrm{Cl}=35.179, \pm .0048 & \mathrm{~S}=31.828, \pm .0015 \\
\mathrm{~K}=38.8 \mathrm{I} 7, \pm .005 \mathrm{I} & \mathrm{AgCl}=142.287, \pm .0037 \\
\mathrm{~N}=\mathrm{I} 3.935, \pm .002 \mathrm{r} &
\end{array}
$$


Hence, for the atomic weight of palladium, we have-

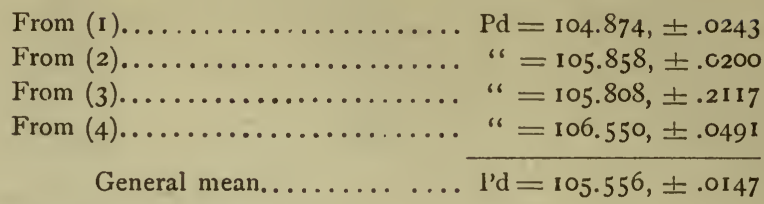

With $\mathrm{O}=16, \mathrm{Pd}=106.364$.

Taking the values separately, the second is probably the best; but in view of the work done by Bailey and Lamb on one side, and by Keller and Smith on the other, it cannot be accepted unreservedly. Until the cause of variation in the results is clearly determined, it is better to take the general mean of all the data, as given above.

\section{OSMIUM.}

The atomic weight of this metal has been determined by Berzelius, by Fremy, and by Seubert.

Berzelius* analyzed potassium osmichloride, igniting it in hydrogen like the corresponding platinum salt. 1.3165 grammes lost .3805 of chlorine, and the residue consisted of $.401 \mathrm{grm}$. of potassium chloride, with $.535 \mathrm{grm}$. of osmium. Calculating only from the ratio between the Os and the $\mathrm{KCl}$, the data give $\mathrm{Os}=197.523$.

Fremy's determination $\dagger$ is based upon the composition of osmium tetroxide. No details as to weighings or methods are given; barely the final result is stated. This, if $\mathrm{O}=16$, is $\mathrm{Os}=199.648$.

When the periodic law came into general acceptance, it became clearly evident that both of the foregoing values for osmium must be sereral units too high. A redetermination was therefore undertaken by Seubert, $\$$ who adopted methods based upon that of Berzelius. First, ammonium osmichloride was reduced by heating in a stream of hydrogen. The residual osmium was weighed, and the ammonium chloride and hydrochloric acid given off were collected in a suitable apparatus, so that the total chlorine could be estimated as silver chloride. The weights were as follows:

\begin{tabular}{ccc}
$\mathrm{Am}_{2} \mathrm{OsCl}_{6}{ }^{\circ}$ & $\mathrm{Os.}$ & $6 \mathrm{AgCl}$. \\
1.8403 & 7996 & 3.5897 \\
2.0764 & .9029 & 4.0460 \\
2.1501 & .9344 & .4 .1950 \\
2.1345 & .9275 & 4.1614 \\
\hline
\end{tabular}

* Poggend. Annalen, 13, 530. 1828.

† Compt. Rend., 19, 468 . Journ. für Prakt. Chem., 31, 4 10. I844. † Bericnte Deutsch. Chem. Gesell., 21, 1839. I888. 
Hence we have for the percentage of osmium and for the osmichloride proportional to 100 parts of $\mathrm{AgCl}-$

Percent. Os.

43.446

43.484

$43.45^{8}$

43.453
AgCl : Salt.

51.266

51.320

51.254

$5 \mathrm{I} .293$

Mean, $51.283, \pm .0099$

In a later paper* two more reductions are given, in which only osmium was estimated.

\section{Salt.}

2.6687

2.6937
Os.

$$
\text { I. I } 597
$$$$
\text { I. } 1706
$$

Percent. Os.

43.456

43.457

These determinations, included with the previous four as one series, give a mean percentage of $\mathrm{Os}$ in $\mathrm{Am}_{2} \mathrm{OsCl}_{6}$ of $43.459, \pm .0036$.

Secondly, potassium osmichloride was treated in the same way, but the residue weighed consisted of $\mathrm{Os}+2 \mathrm{KCl}$. From this the potassium chloride was dissolved out, recovered by evaporating the solution, and weighed separately. The volatile portion, $4 \mathrm{HCl}$, was also measured by precipitation as silver chloride. In Seubert's first paper these data are given :

$$
\begin{array}{cccc}
\mathrm{K}_{2} \mathrm{OSCl}_{6} & \mathrm{Os.} & 2 \mathrm{KCl} . & 4 \mathrm{AgCl} . \\
2.5148 & \ldots . & .7796 & 2.9837 \\
2.1138 & .8405 & .6547 & -2.5076
\end{array}
$$

Hence, with salt proportional to 100 parts of $\mathrm{AgCl}$ in the last column we have-

Percent. Os.

39.762
Per cent. $\mathrm{KCl}$.

$3 \mathrm{r} .000$

30.973
$\mathrm{AgCl}:$ Salt

$$
\text { Mean, } \frac{84.091}{84.097, \pm .0030}
$$

In his second paper Seubert gives fuller data relative to the potassium osmichloride, but treats it somewhat differently. The salt was reduced by a stream of hydrogen as before, but after that the boat containing the $\mathrm{Os}+2 \mathrm{KCl}$ was transferred to a platinum tube, in which, by prolonged heating in the gas, the potassium chloride was completely volatilized. The determinations of $4 \mathrm{Cl}$ as $4 \mathrm{AgCl}$ were omitted. Two series of data are given, as follows: 


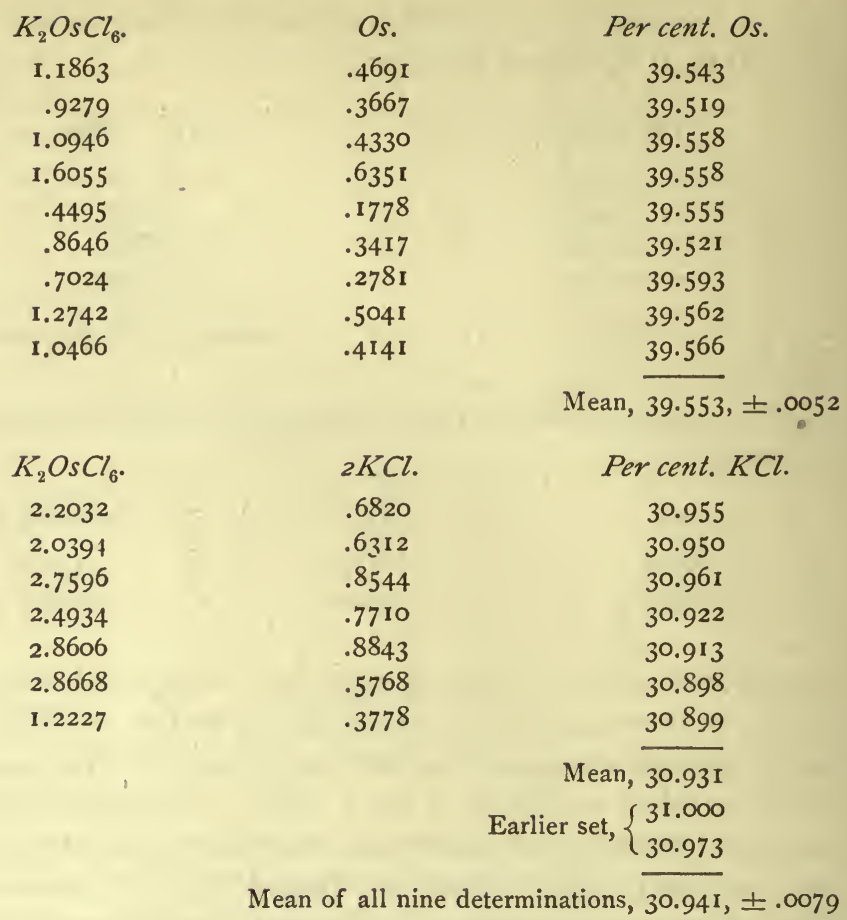

The single percentage of osmium in the earlier memoir is obviously to be rejected.

The ratios to examine are now as follows:
(I.) Per cent. Os in $\mathrm{Am}_{2} \mathrm{OsCl}_{6}, 43.459, \pm .0036$
(2.) $6 \mathrm{AgCl}: \mathrm{Am}_{2} \mathrm{OsCl}_{6}:: 100: 5 \mathrm{I} .283, \pm .0099$
(3.) $4 \mathrm{AgCl}: \mathrm{K}_{2} \mathrm{OsCl}_{6}:: 100: 84.097, \pm .0030$
(4.) Per cent. Os in $\mathrm{K}_{2} \mathrm{OsCl}_{6}, 39.553, \pm .0052$
(5.) Per cent. $\mathrm{KCl}$ in $\mathrm{K}_{2} \mathrm{OsCl}_{6}, 30.95 \mathrm{I}, \pm .0079$

To reduce these ratios we have-

$$
\begin{array}{ll}
\mathrm{Cl}=35.179, \pm .0048 & \mathrm{KCl}=74.025, \pm .0019 \\
\mathrm{~K}=38.817, \pm .005 \mathrm{I} & \mathrm{AgCl}=\mathrm{r} 42.287, \pm .0037 \\
\mathrm{~N}=13.935, \pm .002 \mathrm{I} &
\end{array}
$$

Hence there are five independent values for osmium, as follows :

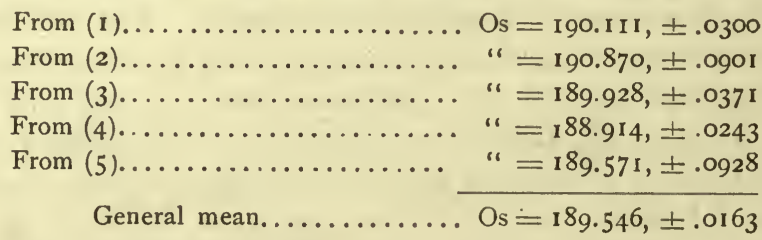

If $\mathrm{O}=16, \mathrm{Os}=190.990$. 
These figures serve to fix the place of osmium below iridium in the periodic classification of the elements, but are not concordant enough to be fully satisfactory. More determinations are evidently needed.

\section{IRIDIUM.}

The only early determination of the atomic weight of iridium was made by Berzelius,* who analyzed potassium iridichloride by the same method employed with the platinum and the osmium salts. The result found from a single analysis was not far from $\operatorname{Ir}=196.7$. This is now known to be too high. I have not, therefore, thought it worth while to recalculate Berzelius' figures, but give his estimation as it is stated in Roscoe and Schorlemmer's "Treatise on Chemistry."

In 1878 the matter was taken up by Seubert, $\dagger$ who had at his disposal 150 grammes of pure iridium. From this he prepared the iridichlorides of ammonium and potassium $\left(\mathrm{NH}_{4}\right)_{2} \mathrm{IrCl}_{6}$ and $\mathrm{K}_{2} \mathrm{IrCl}_{6}$, which salts were made the basis of his determinations. The potassium salt was dried by gentle heating in a stream of dry chlorine.

Upon ignition of the ammonium salt in hydrogen, metallic iridium was left behind in white coherent laminæ. The results obtained were as follows :

$\begin{array}{ccc}A m_{2} I_{r C l} . & \text { Ir. } & \text { Per cent. Ir. } \\ 1.3164 & .5755 & 43.725 \\ 1.7122 & .7490 & 43.745 \\ 1.2657 & .5536 & 43.739 \\ 1.3676 & .5980 & 43.726 \\ 2.6496 & 1.1586 & 43.739 \\ 2.8576 & 1.2489 & 43.705 \\ 2.9088 & 1.2724 & \frac{43.742}{43.732}, \pm .0035\end{array}$

The potassium salt was also analyzed by decomposition in hydrogen with special precautions. In the residue the iridium and the potassium chloride were separated after the usual method, and both were estimated. Eight analyses gave the following weights :

$\begin{array}{cccc}\mathrm{K}_{2} \mathrm{IrCl}_{6} . & \mathrm{Cl}_{4}, \text { Loss. } & \mathrm{Ir} . & \mathrm{KCl} . \\ 1.6316 & .4779 & .6507 & .5030 \\ 2.2544 & .6600 & .8993 & .6953 \\ 2.1290 & .6238 & .8488 & .6560 \\ 1.8632 & .5457 & .7430 & .5745 \\ 2.6898 & .7878 & 1.0726 & .829 \mathrm{I} \\ 2.3719 & .6952 & .9459 & .7308 \\ 2.6092 & .764 \mathrm{I} & 1.0406 & .8040 \\ 2.5249 & .7395 & 1.0070 & .7775\end{array}$

* Poggend. Annalen, 13, 435. 1828.

† Ber. Deutsch. Chem. Gesell., II, 1757. 1878. 
Hence we have the following percentages, reckoned on the original salt :

$\begin{array}{ccc}I r . & 2 K C l . & C l_{4^{\circ}} \\ 39.88 \mathrm{I} & 30.829 & 29.290 \\ 39.890 & 30.842 & 29.277 \\ 39.868 & 30.813 & 29.300 \\ 39.876 & 30.835 & 29.289 \\ 39.877 & 30.825 & 29.287 \\ 39.879 & 30.81 \mathrm{II} & 29.310 \\ 39.882 & 30.814 & 29.285 \\ 39.883 & \underline{30.792} & 29.288 \\ \frac{\text { Mean, } 39.880,}{30.0015} & \text { Mean, } 30.820, \pm .0037 & \text { Mean, } 29.291, \pm .0024\end{array}$

Joly* studied derivatives of iridium trichloride. The salts were dried at $120^{\circ}$, and reduced in hydrogen. With $\mathrm{IrCl}_{3} \cdot 3 \mathrm{KCl} \cdot 3 \mathrm{H}_{2} \mathrm{O}$ he found as follows :

$\begin{array}{ccc}\text { Salt. } & \mathrm{Ir} . & \mathrm{KCl} . \\ \mathbf{1} .5950 & .588 \mathrm{r} & .6803 \\ \mathbf{1} 6386 & .6037 & .7000 \\ 2.6276 & .9689 & \mathrm{I.123 \textrm {r }}\end{array}$

These data, if the weight of the salt itself is considered, give discordant results, but the ratio $\mathrm{Ir}: 3 \mathrm{KCl}:: 100: x$ is satisfactory. The values of $x$ are as follows:

$$
\begin{gathered}
115.677 \\
115.952 \\
I 15.915
\end{gathered}
$$

The ammonium salt, $\mathrm{IrCl}_{3} .3 \mathrm{NH}_{4} \mathrm{Cl}$, gave the subjoined data :

$$
\begin{array}{ccc}
\text { Wt. of Salt. } & \text { Wt. of Ir. } & \text { Per cent. Ir. } \\
1.5772 & .6627 & 42.017 \\
1.6056 & .6742 & 41.990 \\
& & \text { Mean, } \frac{42.003}{} \pm .0094
\end{array}
$$

To sum up, the ratios available for iridium are these :
(I.) Per cent. Ir in $\mathrm{Am}_{2} \mathrm{IrCl}_{6}, 43.732, \pm .0035$
(2.) Per cent. Ir in $\mathrm{K}_{2} \mathrm{IrCl}_{6}, 39.880, \pm .0015$
(3.) Per cent. $\mathrm{KCl}$ in $\mathrm{K}_{2} \mathrm{IrCl}_{6}, 30.820, \pm .0037$
(4.) Per cent. $\mathrm{Cl}_{4}$ in $\mathrm{K}_{2} \mathrm{IrCl}_{6}, 29.29 \mathrm{I}, \pm .0024$
(5.) Per cent. Ir in $\mathrm{Am}_{3} \mathrm{IrCl}_{6}, 42.003, \pm .0094$
(6.) $\mathrm{Ir}: 3 \mathrm{KCl}:: 100: 115.848, \pm .05^{8} 3$

The data for computation are-

$$
\begin{array}{ll}
\mathrm{O}=\mathrm{r} 5.879, \pm .0003 & \mathrm{~N}=\mathrm{I} 3.935, \pm .002 \mathrm{I} \\
\mathrm{Cl}=35.179, \pm .0048 & \mathrm{KCl}=74.025, \pm .0019 \\
\mathrm{~K}=38.817, \pm .005 \mathrm{I} & \mathrm{H}=\mathrm{I}
\end{array}
$$


And the six independent values for the atomic weight of iridium become-

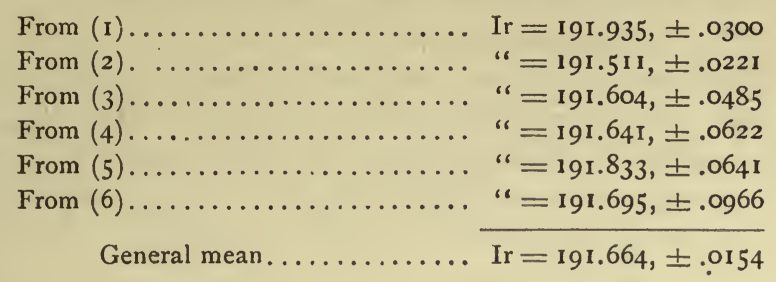

If $\mathrm{O}=16, \mathrm{Ir}=193.125$.

\section{PLATINUM.}

The earliest work upon the atomic weight of this metal was done by Berzelius, * who reduced platinous chloride and found it to contain 73.3 per cent. of platinum. Hence $\mathrm{Pt}=193.155$. In a later investigation $\dagger$ he studied potassium chloroplatinate, $\mathrm{K}_{2} \mathrm{PtCl}_{6} .6 .981$ parts of this salt, ignited in hydrogen, lost 2.024 of chlorine. The residue consisted of 2.822 platinum and 2.135 potassium chloride. From these data we may calculate the atomic weight of platinum in four ways:

I. From loss of $\mathrm{Cl}$ upon ignition...........Pt $=\mathbf{I} 96.637$

2. From weight of $\mathrm{Pt}$ in residue........... " $=195.897$

3. From weight of $\mathrm{KCl}$ in residue......... " $=195.384$

4. From ratio between $\mathrm{KCl}$ and $\mathrm{Pt} . \ldots \ldots \ldots$.... $=195.690$

The last of these values is undoubtedly the best, for it is not affected by errors due to the possible presence of moisture in the salt analyzed.

The work done by Andrews $\ddagger$ is even less satisfactory than the foregoing, partly for the reason that its full details seem never to have been published. Andrews dried potassium chloroplatinate at $105^{\circ}$, and then decomposed it by means of zinc and water. The excess of zinc having been dissolved by treatment with acetic and nitric acids, the platinum was collected upon a filter and weighed, while the chlorine in the filtrate was estimated by Pelouze's method. Three determinations gave as follows for the atomic weight of platinum:

$$
\begin{array}{r}
197.86 \\
197.68 \\
198.12 \\
\hline \text { Mean, } 197.887
\end{array}
$$

Unfortunately, Andrews does not state how his calculations were made. 
In 1881 Seubert* published his determinations, basing them upon very pure chloroplatinates of potassium and ammonium. The ammonium salt, $\left(\mathrm{NH}_{4}\right)_{2} \mathrm{PtCl}_{6}$, was analyzed by heating in a.stream of hydrogen, expelling that gas by a current of carbon dioxide, and weighing the residual metal. In three experiments the hydrochloric acid formed during such a reduction was collected in an absorption apparatus, and estimated by precipitation as silver chloride. Three series of experiments are given, representing three distinct preparations, as follows:

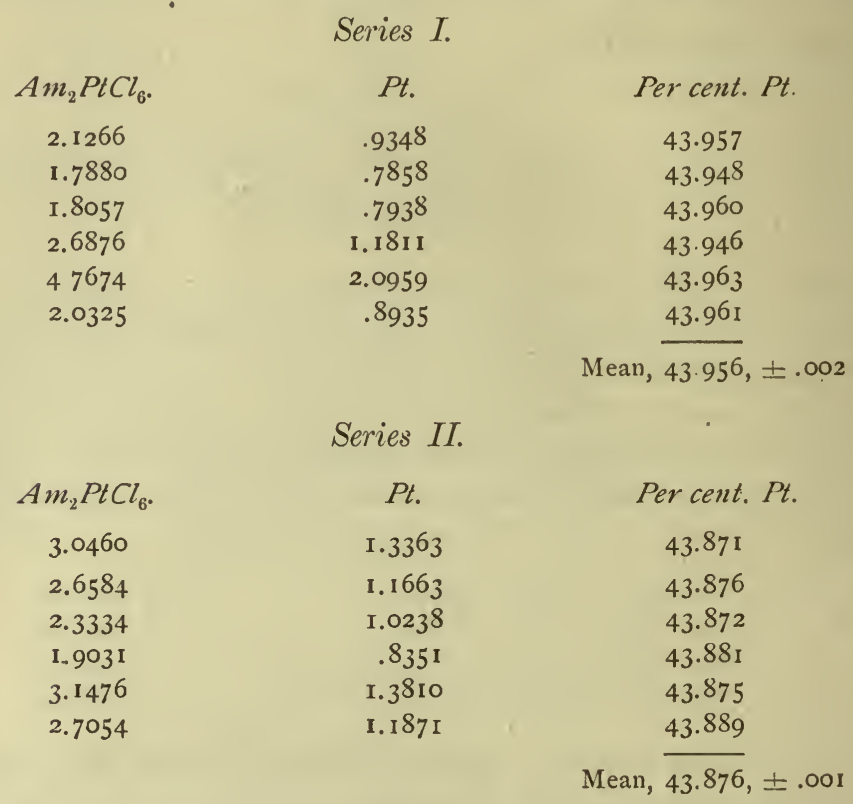

Another portion of this preparation, recrystallized from water, of 1.4358 grm. gave 0.6311 of platinum, or 43.955 per cent.

Series III.

$\begin{array}{ccc}\text { A }{ }_{2} \mathrm{PtCl}_{6} . & \text { Pt. } & \text { Per cent. Ft. } \\ 2.5274 & \text { I.1 I1 } 8 & 43.990 \\ 3.2758 & \text { I. } 4409 & 43.986 \\ 1.9279 & .8483 & 44.001 \\ 2.0182 & .8884 & 44.020 \\ 1.8873 & .8303 & 43.994 \\ 2.2270 & .9798 & 43.996 \\ 2.4852 & 1.0936 & 44.004 \\ 2.5362 & 1.1166 & 44.026 \\ 3.0822 & 1.3561 & 43999\end{array}$

Mean, $\overline{44.00 r}, \pm .003$ 
If these series are treated as independent and combined, giving each a weight as indicated by its probable error, and regarding the single experiment with preparation II as equal to one in the first series, we get a mean percentage of $43.907, \pm .0009$. On the other hand, if we regard the twenty-two experiments as all of equal weight in one series, the mean percentage of platinum becomes $43.953, \pm .0078$. Upon comparing the work with that done later by Halberstadt, the latter mean seems the fairer one to adopt.

For the chlorine estimations in the ammonium salt, Seubert gives the subjoined data. I add in the last column the weight of salt proportional to 100 parts of silver chloride.

$\begin{array}{cccc}\mathrm{Am}_{2} \mathrm{PtCl}_{6} . & \text { Pt. } & 6 \mathrm{AgCl} & \text { Ratio. } \\ 2.7054 & \mathrm{I} .187 \mathrm{I} & 5.2226 & 5 \mathrm{I} .802 \\ 2.2748 & .995^{8} & 4.3758 & 5 \mathrm{I} .986 \\ 3.0822 & 1.356 \mathrm{I} & 5.9496 & 5 \mathrm{II.805} \\ & & & \text { Mean, } 5 \mathrm{I} .864, \pm .04 \mathrm{I}\end{array}$

The potassium salt, $\mathrm{K}_{2} \mathrm{PtCl}_{6}$, was also analyzed by ignition in hydrogen, treatment with water, and weighing both the platinum and the potassium chloride. The weights given are as follows:

$\begin{array}{ccc}K_{2} P_{C C l} . & P t . & 2 K C l . \\ 5.0283 & 2.0173 & 1.5440 \\ 7.0922 & 2.8454 & 2.1793 \\ 3.5475 & 1.4217 & 1.0890 \\ 3.2296 & 1.2941 & .9904 \\ 35834 & 1.4372 & 1.1001 \\ 4.4232 & 1.7746 & 1.3547 \\ 4.0993 & 1.6444 & 1.2589 \\ 4.4139 & 1.7713 & 1.3516\end{array}$

Hence we have these percentages, reckoned on the original salt:

Pt.

$$
\text { 40. } 119
$$$$
40.120
$$$$
40.076
$$$$
40.070
$$$$
40.107
$$$$
40.120
$$$$
\text { 40. } 114
$$$$
40.130
$$$$
\text { Mean, } \overline{40.107} \pm .005
$$

\section{$\mathrm{KCl}$.}

30.706

30.728

30.698

30.666

30.700

30.627

30.710

30.621

Mean, $\overline{30.682}, \pm .009$

As with the ammonium salt, three experiments were made upon the potassium compound to determine the amount of chlorine (four atoms in this case) lost upon ignition in hydrogen. In the fourth column I add the amount of $\mathrm{K}_{2} \mathrm{PtCl}_{6}$ corresponding to 100 parts of $\mathrm{AgCl}$ : 
THE ATOMIC WEIGHTS.

$\begin{array}{cccc}\mathrm{K}_{2} \mathrm{PtCl}_{6} . & \mathrm{Pt.} & 4 \mathrm{AgCl} . & \text { Ratio. } \\ 6.777 \mathrm{I} & 2.7158 & 7.9725 & 85.006 \\ 3.5834 & 1.4372 & 4.2270 & 84.774 \\ 4.4139 & 1.7713 & 5.2144 & 84.648 \\ & & & \text { Mean, } 84.809, \pm .07 \mathrm{I}\end{array}$

Halberstadt,* like Seubert, studied the chloroplatinates of potassium and ammonium, and also the corresponding double bromides and platinic bromide as well. The metal was estimated partly by reduction in hydrogen, as usual, and partly by electrolysis. Platinic bromide gave the following results :

I. By Reduction in $H$.

$\begin{array}{rcc}\text { PtBr }_{4} . & \text { Pt. } & \text { Per cent. Pt. } \\ .6396 & .2422 & 37.867 \\ 1.7596 & .6659 & 37.844 \\ .9178 & .3476 & 37.873 \\ 1.1594 & .4388 & 37.847 \\ 1.9608 & .7420 & 37.842 \\ 2.0865 & .7898 & 37.853 \\ 4.0796 & 1.5422 & 37.852 \\ 6.8673 & 2.5985 & 37.8 .39\end{array}$

II. By Electrolysis.

$$
\begin{array}{lcc}
1.2588 & .4763 & 37.837 \\
1.4937 & .5649 & 37.819 \\
& \text { Mean of all ten experiments, } & 37.847, \pm .0033
\end{array}
$$

The ammonium platinbromide, $\left(\mathrm{NH}_{4}\right)_{2} \mathrm{PtBr}_{6}$, was prepared in two ways, and five distinct lots were studied. With this salt, as well as with those which follow, the data are given in distinct series, with from one to several experiments in each group, but for present purposes it seems best to consolidate the material and so put it in more manageable form.

\begin{tabular}{|c|c|c|}
\hline $\mathrm{Am}_{2} P t B r_{6}$. & Pt. & Percent. Pt. \\
\hline $\int .6272$ & .1719 & 27.408 \\
\hline $1.043^{8}$ & .2865 & 27.447 \\
\hline 1.1724 & .3215 & 27.422 \\
\hline 1.4862 & .4076 & $27.426^{\prime}$ \\
\hline I. 08 I I & .2966 & 27.435 \\
\hline $1.33^{8} 3$ & .3672 & 27.437 \\
\hline
\end{tabular}
The percentages of platinum and weights found are as follows:

I. By Reduction in $H$.

* Ber. Deutsch. Chem. Gesell., 17, 2962.1884. 
PLATINUM.

Am ${ }_{2}$ PtBr $_{6}$.
$\left\{\begin{array}{lcc}1.0096 & \text { Pt. } & \text { Per cent. Pt } \\ 1.1935 & .2769 & 27.426 \\ 1.3182 & .3269 & 27.390 \\ 2.2476 & .3611 & 27.393\end{array}\right.$
$\left\{\begin{array}{lll}1.3358 & .6159 & 27.402 \\ 1.7859 & .3668 & 27.451 \\ 4.1641 & .4899 & 27.431 \\ 1.1835 & 1.1427 & 27.441 \\ 2.4003 & .3250 & 27.460 \\ 2.5293 & .6591 & 27.459\end{array}\right.$
$\left\{\begin{array}{lll}1.7147 & .6940 & 27.438 \\ 2.3014 & .4705 & 27.439 \\ 3.0052 & .6316 & 27.444 \\ 4.8592 & .8245 & 27.435\end{array}\right.$
$\left\{\begin{array}{lll}1.5337 & 1.3329 & 27.430 \\ 2.0373 & .4210 & 27.449 \\ 2.0939 & .5594 & 27.457\end{array}\right.$

II. By Electrolysis.

\begin{tabular}{|c|c|c|}
\hline $\int 1.5586$ & .4272 & 27.409 \\
\hline 1.6052 & .4397 & 27.392 \\
\hline (3.1229 & .8569 & 27.439 \\
\hline 1.1612 & .3180 & 27.386 \\
\hline $\int 2.5817$ & $.708 \mathrm{I}$ & 27.427 \\
\hline $1.023 \mathrm{I}$ & .2809 & 27.456 \\
\hline ( I.6744 & $.459 \mathrm{I}$ & 27.418 \\
\hline 1.6744 & $.459 \mathrm{I}$ & 27.418 \\
\hline 1.6052 & .4397 & 27.392 \\
\hline
\end{tabular}

Mean of all thirty-two experiments, $\overline{27.429}, \pm .0027$

With potassium platinbromide Halberstadt found as follows:

I. By Reduction in $H$.

\begin{tabular}{|c|c|c|c|c|}
\hline$K_{2} P t B r_{6}$. & Pt. & $2 K B r$ & Per cent. Pt. & Per cent. KBr. \\
\hline 2.5549 & .6630 & $.807 \mathrm{I}$ & 25.940 & 31.590 \\
\hline 2.6323 & .6831 & .8318 & 25.947 & 31.599 \\
\hline 2.9315 & .7598 & .9259 & 25.910 & 31.584 \\
\hline 3.4463 & .8939 & I.0895 & 25.938 & $3^{1.613}$ \\
\hline $4.008 \mathrm{I}$ & I.0404 & I. 2653 & 25.957 & 31.568 \\
\hline 3.9554 & 1.0266 & I. 2495 & 25.954 & 31.589 \\
\hline $\int 2.0794$ & .5388 & $.655^{8}$ & 25.9 II & 31.538 \\
\hline 2.1735 & .5635 & .6849 & 25.926 & $3 \mathrm{I} .5^{\mathrm{II}}$ \\
\hline$(2.3099$ & .5986 & .7297 & 25.914 . & 31.590 \\
\hline $\int 1.4085$ & $\cdot 3645$ & .4446 & 25.880 & $3^{1.565}$ \\
\hline$\{2.6 \mathrm{~J} 66$ & .6772 & .8279 & $25.88 \mathrm{I}$ & 31.640 \\
\hline$(2.6729$ & .6923 & .8469 & 25.900 & 31.684 \\
\hline
\end{tabular}


THE ATOMIC WEIGHTS.

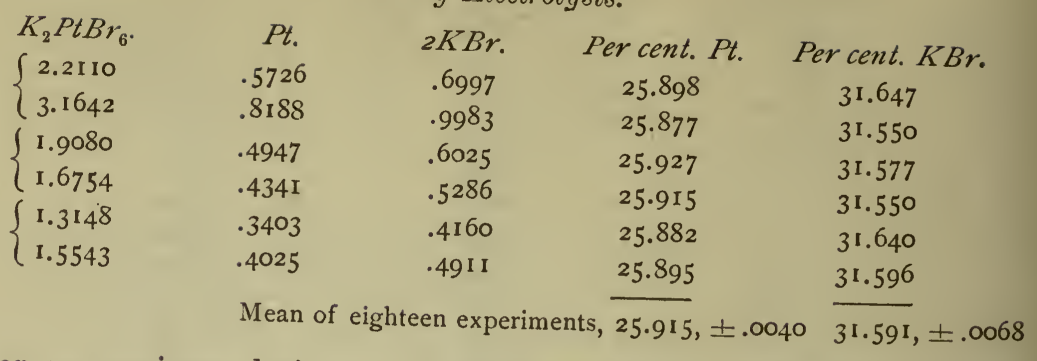

II. By Electrolysis.

For ammonium platinchloride Halberstadt gives the following data:

I. By Reduction in $H$.

$$
\begin{aligned}
& \mathrm{Am}_{2} \mathrm{PtCl}_{6} \text {. } \\
& \left\{\begin{array}{l}
1.0604 \\
1.3846 \\
1.5065 \\
2.3266
\end{array}\right. \\
& \left\{\begin{array}{l}
1.3808 \\
1.7396
\end{array}\right. \\
& \left\{\begin{array}{l}
1.7396 \\
\text { I. }
\end{array}\right. \\
& \left\{\begin{array}{l}
2.7420 \\
3.1882 \\
5.4644
\end{array}\right. \\
& 3.4859 \\
& \left\{\begin{array}{r}
.9474 \\
1.1069 \\
1.5101
\end{array}\right. \\
& \left\{\begin{array}{r}
.5345 \\
1.6035 \\
1.9271
\end{array}\right. \\
& \left\{\begin{array}{l}
\text { I. } 1046 \\
\text { I.4179 }
\end{array}\right.
\end{aligned}
$$

\begin{tabular}{|c|c|c|c|c|}
\hline $\begin{array}{l}K_{2} P_{t C l} . \\
\left\{\begin{array}{l}1.6407\end{array}\right.\end{array}$ & $\begin{array}{l}P t . \\
.6574\end{array}$ & $\begin{array}{l}2 \mathrm{KCl} . \\
.5029\end{array}$ & $\begin{array}{c}\text { Per cent. Pt. } \\
40.069\end{array}$ & $\begin{array}{c}\text { Per cent. } \mathrm{KCl} \\
30.65 \mathrm{I}\end{array}$ \\
\hline I.9352 & .7757 & .5921 & 40.084 & 30.600 \\
\hline I. 5793 & .6334 & .4836 & 40. 106 & $30.62 \mathrm{I}$ \\
\hline I.6446. & .6595 & .5049 & 40. IOI & 30.700 \\
\hline 1.0225 & .4102 & $\cdot 3^{1} 33$ & 40. I I 7 & 30.640 \\
\hline 2.4046 & .9641 & .7388 & 40.094 & 30.724 \\
\hline$\{5.8344$ & 2.3412 & 1.7905 & 40.127 & 30.688 \\
\hline$(7.1732$ & 2.8776 & 2. 1998 & 40.116 & 30.666 \\
\hline
\end{tabular}

$$
\begin{gathered}
P t . \\
.4662 \\
.6087 \\
.6617 \\
1.0227 \\
.6059 \\
.7638 \\
1.2068 \\
1.4019 \\
2.4035 \\
1.5321
\end{gathered}
$$

II. By Electrolysis.

$$
\begin{array}{cc}
.4161 & 43.920 \\
.4865 & 43.951 \\
.6634 & 43.930 \\
.2347 & 43.910 \\
.7044 & 43.928 \\
.8459 & 43.894 \\
.4858 & 43.979 \\
.6233 & 43.959 \\
\text { Mean of eighteen experiments, } \frac{43.943, \pm .0054}{43.953, \pm .0078} \\
& \text { Seubert found, } \frac{43.946, \pm .0044}{4}
\end{array}
$$$$
\text { Percent. Pt. }
$$$$
\begin{aligned}
& 43.964 \\
& 43.962 \\
& 43.923 \\
& 43.956 \\
& 43.880 \\
& 43.906 \\
& 44.011 \\
& 43.971 \\
& 43.984 \\
& 43.951
\end{aligned}
$$

For potassium platinchloride Halberstadt's data are-

I. By Reduction in $H$. 
PLATINUM.

II. By Electrolysis.

\begin{tabular}{|c|c|c|c|c|}
\hline$K_{2} \mathrm{PlCl}_{6}$ & Pt. & $2 K C l$. & Percent. Pt. & Per cent. $K C l$. \\
\hline$\{1.2354$ & .4953 & .3792 & 40.092 & 30.695 \\
\hline 2.5754 & 1.0318 & .7898 & 40.063 & 30.667 \\
\hline 1.0933 & .4387 & .3355 & 40.126 & 30.668 \\
\hline I. 3560 & $.543^{8}$ & .4167 & 40.103 & 30.730 \\
\hline 1.7345 & .6956 & .5298 & 40.104 & 30.545 \\
\hline 2.0054 & .8038 & $.6 r 47$ & 40.081 & 30.652 \\
\hline 2.0666 & .8291 & .6356 & 40.117 & 30.755 \\
\hline 1.2759 & .5118 & $\cdot 3908$ & 40. 112 & 30.629 \\
\hline 1.9376 & .7763 & .5927 & 40.065 & $30.5^{89}$ \\
\hline 2.3972 & .9608 & .7355 & 40.080 & $30.68 \mathrm{I}$ \\
\hline \multirow[t]{4}{*}{2.7249} & 1.0929 & .8364 & 40. 108 & $30.69 \mathrm{I}$ \\
\hline & \multicolumn{3}{|c|}{ Mean of nineteen experiments, $40.098, \pm .003 \mathrm{I}$} & $30.66_{3}, \pm .0080$ \\
\hline & & Seuber & and, $40.107, \pm .0050$ & $30.682, \pm .0090$ \\
\hline & & $\mathrm{Ge}$ & an, 40.1 & $30.671, \pm .0060$ \\
\hline
\end{tabular}

The work of Dittmar and M'Arthur* on the atomic weight of platinum is difficult to discuss and essentially unsatisfactory. They investigated potassium platinchloride, and came to the conclusion that it contains traces of hydroxyl replacing chlorine and also hydrogen replacing potassium. It is also liable, they think, to carry small quantities of potassium chloride. In their determinations, which involve corrections indicated by the foregoing considerations, they are not sufficiently explicit, and give none of their actual weighings. They attempt, however, to fix the ratio $2 \mathrm{KCl}: \mathrm{Pt}$, and after a number of discordant, generally high results, they give the following data for the atomic weight of platinum based upon the assumption that $2 \mathrm{KCl}=149.182$ :

$$
\begin{gathered}
195.54 \\
195.48 \\
195.60 \\
195.37 \\
\text { Mean, } 195.50, \pm .0330 .
\end{gathered}
$$

Dittmar and M'Arthur also discuss Seubert's determinations, seeking to show that the latter also, properly treated, lead to a value nearer to 195.5 than to 195 . Seubert at once replied to them, $\dagger$ pointing out that the concordance between his determinations by very different methods (a concordance verified by Halberstadt's investigation) precluded the existence of errors due to impurities such as Dittmar and M'Arthur assumed. 
The ratios from which to compute the atomic weight of platinum are now as follows, rejecting the work of Berzelius and of Andrews:

(I.) Percentage of $\mathrm{Pt}$ in ammonium platinchloride, 43.946, \pm .0044

(2.) Percentage of $\mathrm{Pt}$ in ammonium platinbromide, $27.429, \pm .0027$

(3.) Percentage of $\mathrm{Pt}$ in potassium platinchloride, 40.101, \pm .0026

(4.) Percentage of $\mathrm{Pt}$ in potassium platinbromide, 25.915, \pm .0040

(5.) Percentage of $\mathrm{Pt}$ in platinic bromide, 37.847, \pm .0033

(6.) Percentage of $\mathrm{KCl}$ in potassium platinchloride, $30.67 \mathrm{I}, \pm .0060$

(7.) Percentage of $\mathrm{KBr}$ in potassium platinbromide, $3 \mathrm{I} .59 \mathrm{I}, \pm .0068$

(8.) $6 \mathrm{AgCl}: \mathrm{Am}_{2} \mathrm{PtCl}_{6}:: \mathrm{IO0}: 5 \mathrm{r} .864, \pm .04 \mathrm{I}$

(9.) $4 \mathrm{AgCl}: \mathrm{K}_{2} \mathrm{PtCl}_{6}::$ I $00: 84.809, \pm .07 \mathrm{I}$

(10.) $2 \mathrm{KCl}: \mathrm{Pt}::$ I 49.182 : 195.50, \pm .033

Computing with the subjoined atomic and molecular weights-

$$
\begin{array}{ll}
\mathrm{Cl}=35 . \mathrm{I} 79, \pm .0048 & \mathrm{KCl}=74.025, \pm .0019 \\
\mathrm{Br}=79.344, \pm .0062 & \mathrm{KBr}=118.200 \pm .0073 \\
\mathrm{~K}=38.817, \pm .005 \mathrm{I} & \mathrm{AgCl}=142.287, \pm .0037 \\
\mathrm{~N}=13.935, \pm .002 \mathrm{I} &
\end{array}
$$

we have the following ten values for platinum:

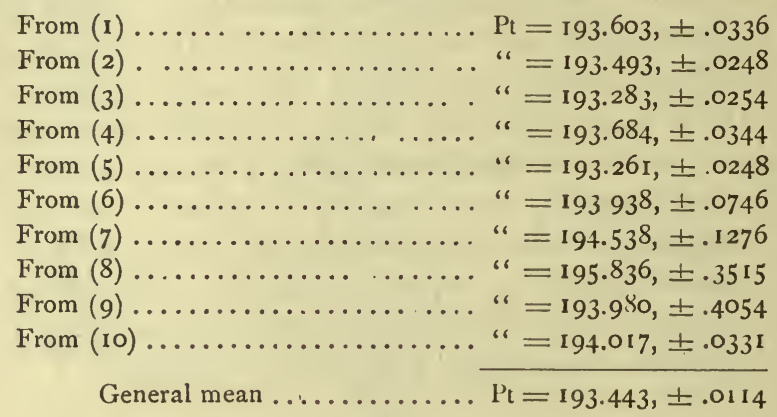

If $\mathrm{O}=16, \mathrm{Pt}=194.917$.

Of these ten values the first five are obviously the most trustworthy. Their general mean is $\mathrm{Pt}=193.414, \pm .0124$; or, if $\mathrm{O}=16, \mathrm{Pt}=194.888$. This result is preferable to the mean of all, even though the latter varies little from it. The five high values carry very little weight because of their larger probable errors. 


\section{CERIUM.}

Although cerium was discovered almost at the beginning of the present century, its atomic weight was not properly determined until after the discovery of lanthanum and didymium by Mosander. In 1842 the investigation was undertaken by Beringer,* who employed several methods. His cerium salts, however, were all rose-colored, and therefore were not wholly free from didymium; and his results are further affected by a negligence on his part to fully describe his analytical processes.

First, a neutral solution of cerium chloride was prepared by dissolving the carbonate in hydrochloric acid. This gave weights of ceric oxide and silver chloride as follows. The third column shows the amount of $\mathrm{CeO}_{2}$ proportional to 100 parts of $\mathrm{AgCl}$ :

\begin{tabular}{|c|c|c|}
\hline $\mathrm{CeO}_{2}$. & $\mathrm{AgCl}$. & Ratio. \\
\hline $\begin{array}{l}.5755 \mathrm{grm} . \\
.6715 \text { ، }\end{array}$ & $\begin{array}{l}\text { I. } 419 \mathrm{grm} . \\
\text { I.6595 " }\end{array}$ & $\begin{array}{l}40.557 \\
40.464\end{array}$ \\
\hline 1.1300 " & 2.786 & 40.560 \\
\hline .5366 & $1.33^{16}$ " & 40.297 \\
\hline
\end{tabular}

The analysis of the dry cerium sulphate gave results as follows. In a fourth column I show the amount of $\mathrm{CeO}_{2}$ proportional to 100 parts of $\mathrm{BaSO}_{4}$ :

\begin{tabular}{|c|c|c|c|}
\hline Sulphate. & $\mathrm{CeO}_{2}$. & $\mathrm{BaSO}_{4}$ & Ratio. \\
\hline $\begin{array}{l}1.379 \text { grm. } \\
1.276 \text { "، }\end{array}$ & $\begin{array}{l}.8495 \text { grm. } \\
.7875 \text { ، }\end{array}$ & $\begin{array}{l}\text { I.7 I I grm. } \\
1.580 \text { "6 }\end{array}$ & $\begin{array}{r}49.649 \\
-\quad 49.836\end{array}$ \\
\hline 1.246 " & .7690 & I. 543 " & 49.838 \\
\hline 1.553 " & . & 1.921 " & 49.948 \\
\hline
\end{tabular}

Beringer also gives a single analysis of the formate and the results of one conversion of the sulphide into oxide. -The figures are, however, not valuable enough to cite.

The foregoing data involve one variation from Beringer's paper. Where I put $\mathrm{CeO}_{2}$ as found he puts $\mathrm{Ce}_{2} \mathrm{O}_{3}$. The latter is plainly inadmissible, although the atomic weights calculated from it agree curiously well with some other determinations. Obviously, the presence of didymium in the salts analyzed tends to raise the apparent atomic weight of cerium.

Shortly after Beringer, Hermann $\dagger$ published the results of one experiment. $23.532 \mathrm{grm}$. of anhydrous cerium sulphate gave $29.160 \mathrm{grm}$. of $\mathrm{BaSO}_{4}$. Hence 100 parts of the sulphate correspond to 123.926 of $\mathrm{BaSO}_{4}$.

* Ann. Chem. Pharm., 42, 134. 1842.

† Journ. für Prakt. Chem., 30, 185. 1843. 
In 1848 similar figures were published by Marignac,* who found the following amounts of $\mathrm{BaSO}_{4}$ proportional to 100 of dry cerium sulphate:

$$
\begin{gathered}
122.68 \\
122.00 \\
\text { Mean, } \frac{122.5 \mathrm{I}}{122.40,} \pm .138
\end{gathered}
$$

If we give Hermann's single result the weight of one experiment in this series, and combine, we get a mean value of $122.856, \pm .130$.

Still another method was employed by Marignac. A definite mixture was made of solutions of cerium sulphate and barium chloride. To this were added, volumetrically, solutions of each salt successively, until equilibrium was attained. The figures published give maxima and minima for the $\mathrm{BaCl}_{2}$ proportional to each lot of $\mathrm{Ce}_{2}\left(\mathrm{SO}_{4}\right)_{3}$. In another column, using the mean value for $\mathrm{BaCl}_{2}$ in each case, I put the ratio between 100 parts of this salt and the equivalent quantity of sulphate. The latter compound was several times recrystallized:

$$
\mathrm{Ce}_{2}\left(\mathrm{SO}_{4}\right)_{3} . \quad \mathrm{BaCl}_{2} . \quad \text { Ratio. }
$$

First crystallization...... II.0I I grm. II.990-12.050 grm. 91.606

First crystallization..... I 3.194 " $14.365-14.425$ " 91.657

Second crystallization.... 13.961 " $15.225-15.285$ " 991.518

Second crystallization... 12.627 " $13.76 \mathrm{I}-\mathrm{I} 3.82 \mathrm{I}$ “ $9 \mathrm{I} .559$

Second crystallization.... II.915 " $12.970-13.030$ " 91.654

Third crystallization.... I4.888 “ $16.223-16.283$ " 91.602

Third crystallization..... 14.113 “ $15.383-15.423$ “ 91.755

Fourth crystallization.... I3.1II “ $14.270-14.330$ " 91.685

Fourth crystallization.... 13.970 " $15.223-15.283$ " 91.588

Mean, $\overline{91.625} \pm .016$

Omitting the valueless experiments of Kjerulf, $\uparrow$ we come next to the figures published by Bunsen and Jegel $\ddagger$ in 1858. From the air-dried sulphate of cerium the metal was precipitated as oxalate, which, ignited, gave $\mathrm{CeO}_{2}$. In the filtrate from the oxalate the sulphuric acid was estimated as $\mathrm{BaSO}_{4}$ :

$1.5726 \mathrm{grm}$. sulphate gave $.7899 \mathrm{grm} . \mathrm{CeO}_{2}$ and $1.6 \mathrm{I} 85 \mathrm{grm} . \mathrm{BaSO}_{4}$.

$\begin{array}{lllll}\text { I.6967 “ } & .8504 & \text { " }\end{array}$

Hence, for 100 parts $\mathrm{BaSO}_{4}$, the $\mathrm{CeO}_{2}$ is as follows:

$$
\begin{array}{r}
48.804 \\
\frac{48.575}{\text { Mean, }} \\
48.689, \pm .077
\end{array}
$$

* Arch. Sci. Phys. et Nat. (I), 8, 273. I848.

†Ann. Chem. Pharm., 87, 2 .

$\ddagger$ Ann. Chem. Pharm., 105, 45. 1858 . 
One experiment was also made upon the oxalate:

$.3530 \mathrm{grm}$. oxalate gave $.1913 \mathrm{CeO}_{2}$ and $.0506 \mathrm{H}_{2} \mathrm{O}$.

Hence, in the dry salt, we have 63.261 per cent. of $\mathrm{CeO}_{2}$.

In each sample of $\mathrm{CeO}_{2}$ the excess of oxygen over $\mathrm{Ce}_{2} \mathrm{O}_{3}$ was estimated by an iodometric titration; but the data thus obtained need not be further considered.

In two papers by Rammelsberg* data are given for the atomic weight of cerium, as follows. In the earlier paper cerium sulphate was analyzed, the cerium being thrown down by caustic potash, and the acid precipitated from the filtrate as barium sulphate:

$.413 \mathrm{grm}, \mathrm{Ce}_{2}\left(\mathrm{SO}_{4}\right)_{3}$ gave $.244 \mathrm{grm} . \mathrm{CeO}_{2}$ and $.5 \mathrm{I} 3 \mathrm{grm}, \mathrm{BaSO}_{4}$.

Hence $100 \mathrm{BaSO}_{4}=47.563 \mathrm{CeO}_{2}$, a value which may be combined with others, thus; this figure being assigned a weight equal to one experiment in Bunsen's series:

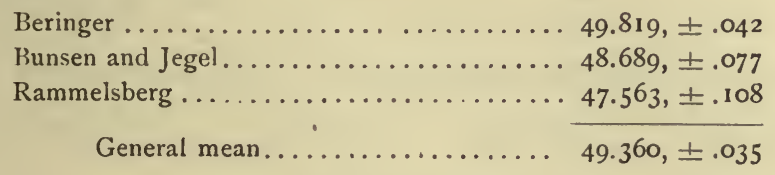

It should be noted here that this mean is somewhat arbitrary, since Bunsen and Rammelsberg's cerium salts were undoubtedly freer from didymium than the material studied by Beringer.

In his later paper Rammelsberg gives these figures concerning cerium oxalate. One hundred parts gave 10.43 of carbon and 21.73 of water. Hence the dry salt should yield 48.862 per cent. of $\mathrm{CO}_{2}$, whence $\mathrm{Ce}=$ 137.14 .

In all of the foregoing experiments the ceric oxide was somewhat colored, the tint ranging from one shade to another of light brown according to the amount of didymium present. Still, at the best, a color remained, which was supposed to be characteristic of the oxide itself. In 1868, however, some experiments of Dr. C. Wolf $\dagger$ were posthumously made public, which went to show that pure ceroso-ceric oxide is white, and that all samples previously studied were contaminated with some other earth, not necessarily didymium but possibly a new substance, the removal of which tended to lower the apparent atomic weight of cerium very perceptibly.

Cerium sulphate was recrystallized at least ten times. Even after twenty recrystallizations it still showed spectroscopic traces of didymium. The water contained in each sample of the salt was cautiously estimated, and the cerium was thrown down by boiling concentrated solutions of

* Poggend. Annalen, 55, 65 ; 108, 44. 
oxalic acid. The resulting oxalate was ignited with great care. I deduce from the weighings the percentage of $\mathrm{CeO}_{2}$ given by the anhydrous sulphate:

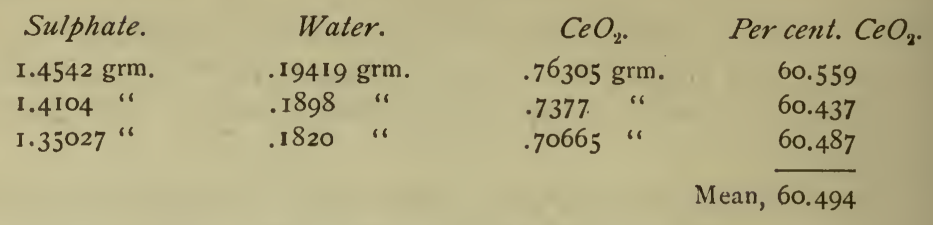

After the foregoing experiments the sulphate was further purified by solution in nitric acid and pouring into a large quantity of boiling water. The precipitate was converted into sulphate and analyzed as before:

\begin{tabular}{|c|c|c|c|}
\hline Sulphate. & Water. & $\mathrm{CeO}_{2}$. & Per cent. $\mathrm{CeO}_{2}$. \\
\hline $\begin{array}{l}1.4327 \mathrm{grm} . \\
1.5056 \text { " }\end{array}$ & $\begin{array}{l}.2733 \mathrm{grm} . \\
.2775 \text { " }\end{array}$ & $\begin{array}{l}.69925 \mathrm{grm} . \\
.7405\end{array}$ & $\begin{array}{l}60.311 \\
60.296\end{array}$ \\
\hline \multirow[t]{2}{*}{ I. $44045^{\prime \prime}$} & .2710 & $.705^{2}$ & 60.300 \\
\hline & & & 0.302 \\
\hline
\end{tabular}

From another purification the following weights were obtained:

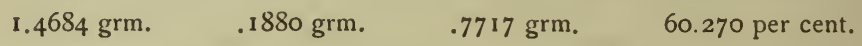

A last purification gave a still lower percentage:

I.3756 grm. $\quad .183^{2}$ grm. $\quad .7186 \mathrm{grm} . \quad 60.265$ per cent.

The last oxidde was perfectly white, and was spectroscopically free from didymium. In each case the $\mathrm{CeO}_{2}$ was titrated iodometrically for its excess of oxygen. It will be noticed that in the successive series of determinations the percentage of $\mathrm{CeO}_{2}$ steadily and strikingly diminishes to an extent for which no ordinary impurity of didymium can account. The death of Dr. Wolf interrupted the investigation, the results of which were edited and published by Professor F. A. Genth.

In the light of more recent evidence, little weight can be given to these observations. All the experiments, taken equally, give a mean percentage of $\mathrm{CeO}_{2}$ from $\mathrm{Ce}_{2}\left(\mathrm{SO}_{4}\right)_{3}$ of $60.366, \pm .0308$. This mean has obviously little or no real significance.

The experiments of Wolf attracted little attention, except from Wing,* who partially verified certain aspects of them. This chemist, incidentally to other researches, purified some cerium sulphate after the method of Wolf, and made two similar analyses of it, as follows:

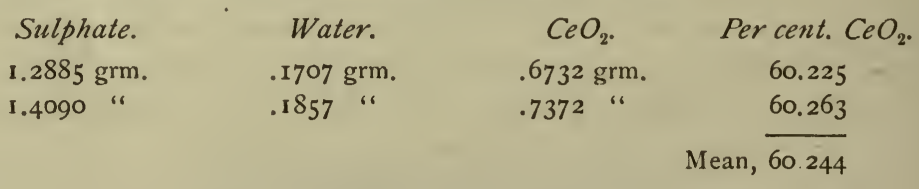

*Am. Journ. Sci. (2), 49, 358. 1870. 
The ceric oxide in this case was perfectly white. The cerium oxalate which yielded it was precipitated boiling by a boiling concentrated solution of oxalic acid. The precipitate stood twenty-four hours before filtering.

In 1875 Buehrig's * paper upon the atomic weight of cerium was issued. He first studied the sulphate, which, after eight crystallizations, still retained traces of free sulphuric acid. He found, furthermore, that the salt obstinately retained traces of water, which could not be wholly expelled by heat without partial decomposition of the material. These sources of error probably affect all the previously cited series of experiments, although, in the case of Wolf's work, it is doubtful whether they could have influenced the atomic weight of cerium by more than one or two tenths of a unit. Buehrig also found, as Marignac had earlier shown, that upon precipitation of cerium sulphate with barium chloride the barium sulphate invariably carried down traces of cerium. Furthermore, the ceric oxide from the filtrate always contained barium. For these reasons the sulphate was abandoned, and the atomic weight determinations of Buehrig were made with air-dried oxalate. This salt was placed in a series of platinum boats in a combustion tube behind copper oxide. It was then burned in a stream of pure, dry oxygen, and the carbonic acid and water were collected after'the usual method. Ten experiments were made; in all of them the above-named products were estimated, and in five analyses the resulting ceric oxide was also weighed. By deducting the water found from the weight of the air-dried oxalate, the weight of the anhydrous oxalate is obtained, and the percentages of its constituents are easily determined. In weighing, the articles weighed were always counterpoised with similar materials. The following weights were found:

\begin{tabular}{|c|c|c|c|c|c|c|c|}
\hline Oxalo & & Wate & & $\mathrm{CO}_{2}$. & & $\mathrm{CeO}_{2}$ & \\
\hline $9.854 \mathrm{I}$ & rrm. & 2.1987 & $\mathrm{rm}$. & 3.6942 & rm. & & \\
\hline $9 \cdot 5368$ & " & 2. I 269 & " & 3.5752 & " & & \\
\hline 9.2956 & " & 2.0735 & " & 3.4845 & "، & & \\
\hline 10.0495 & “" & 2.2364 & “" & 3.7704 & " & & \\
\hline 0.8249 & "6 & 2.4145 & " & 4.0586 & “ & & \\
\hline 9.3679 & “ & 2.0907 & ". & 3.5118 & “ & 4.6150 & grm. \\
\hline 9.7646 & " & 2.1769 & “" & 3.6616 & “ & $4.8 \mathrm{I} 33$ & “ \\
\hline 9.9026 & " & 2.2073 & " & 3.7139 & " & 4.8824 & " \\
\hline 9.9376 & " & 2.2170 & “" & $3.725 \mathrm{I}$ & “" & 4.8971 & “ \\
\hline 9.5324 & " & 2.1267 & “ & 3.5735 & “" & 4.6974 & “ \\
\hline
\end{tabular}

These figures give us the following percentages for $\mathrm{CO}_{2}$ and $\mathrm{CeO}_{2}$ in the anhydrous oxalate: 


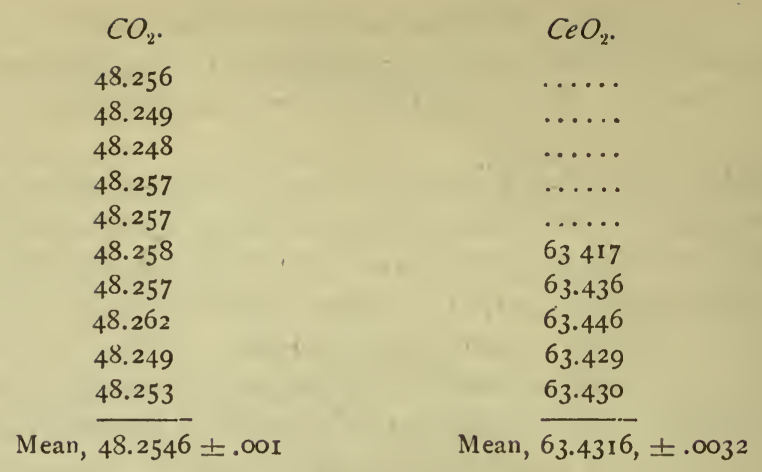

These results could not be appreciably affected by combination with the single oxalate experiments of Jegel and of Rammelsberg, and the latter may therefore be ignored.

Robinson's work, published in 1884 ,* was based upon pure cerium chloride, prepared by heating dry cerium oxalate in a stream of dry, gaseous hydrochloric acid. This compound was titrated with standard solutions of pure silver, prepared according to Stas, and these were weighed, not measured. In the third column I give the ratio between $\mathrm{CeCl}_{3}$ and 100 parts of silver :

$\begin{array}{lcc}\mathrm{CeCl}_{3} . & \mathrm{Ag} . & \text { Ratio. } \\ 5.536 \mathrm{1} & 7.26630 & 76.189 \\ 6.0791 & 7.98077 & 76172 \\ 6.4761 & 8.50626 & 76.133 \\ 6.98825 & 9.18029 & 76.122 \\ 6.6873 & 8.78015 & 76.164 \\ 7.0077 & 9.20156 & 76.158 \\ 6.9600 & 9.13930 & 76.150 \\ & & \text { Mean, } 76.155, \pm .0065\end{array}$

Reduced to a vacuum this becomes 76.167 .

In a later paper, $\uparrow$ Robinson discusses the color of ceric oxide, and criticises the work of Wolf. He shows that the pure oxide is not white, and makes it appear probable that Wolf's materials were contaminated with compounds of lanthanum. He also urges that Wolf's cerium sulphate could not have been absolutely definite, because of defects in the method by which it was dehydrated.

Brauner, $\ddagger$ in 1885 , investigated cerium sulphate with extreme care, and appears to have obtained material free from all other earths and absolutely homogeneous. The anhydrous salt was calcined with all

* Chemical News, 50, 251. Nov. 28, 1884. Proc. Roy. Soc., 37, I5o.

† Chemical News, 54, 229. 1886.

‡ Sitzungs. Wien. A kad., Bd. 92. July, 1885 . 
necessary precautions, and the data obtained, reduced to a vacuum, were as follows:

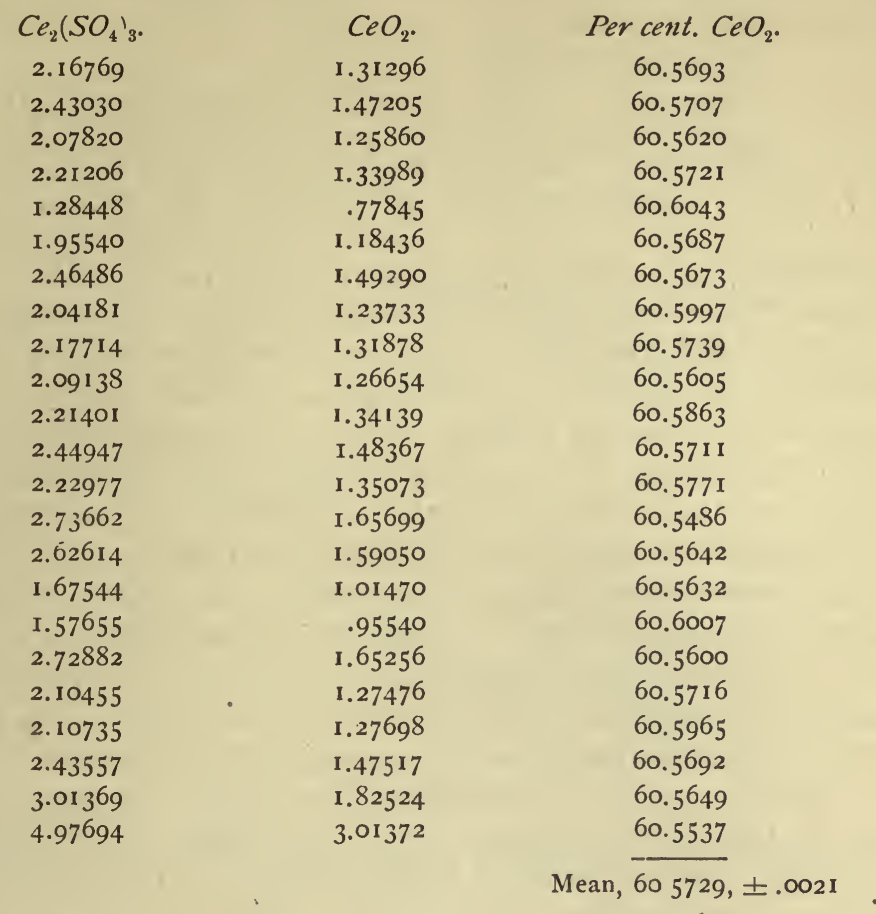

This mean completely outweighs the work done by Wolf and Wing, so that upon combination the latter practically vanish. Wing's mean is arbitrarily given equal weight with Wolf's, and the combination is as follows:

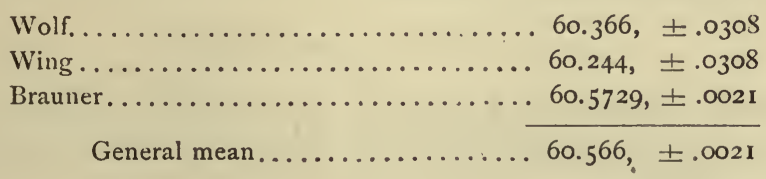

In 1895 several papers upon the cerite earths were published by Schutzenberger.* In the first of these a single determination of atomic weight is given. Pure $\mathrm{CeO}_{2}$, of a yellowish white color, was converted into sulphate, which was dried in a current of dry air at $440^{\circ}$. This salt, dissolved in water, was poured into a hot solution of caustic soda, made from sodium, and, after filtration and washing, the filtrate, acidulated with hydrochloric acid, was precipitated with barium chloride. The trace of sulphuric acid retained by the cerium hydroxide was recovered by re-solution and a second precipitation, and added to the main amount. 
100 parts of $\mathrm{Ce}_{2}\left(\mathrm{SO}_{4}\right)_{3}$ gave 123.30 of $\mathrm{BaSO}_{4}$. This may be assigned equal weight with one experiment in Marignac's series, giving the following combination :

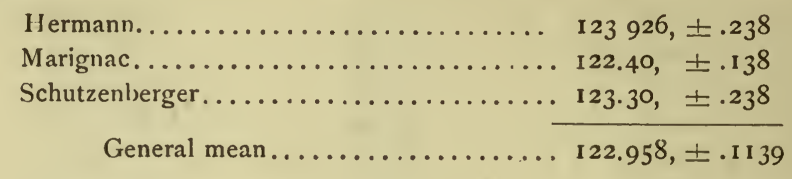

Schutzenberger, criticising Brauner's work, claims that the latter was affected by a loss of oxygen during the calcination of the cerium dioxide.

In his second and third papers Schutzenberger describes the results obtained upon the fractional crystallization of cerium sulphate. Preparations were thus made yielding oxides of various colors-canary yellow, rose, yellowish rose, reddish, and brownish red. These oxides, by synthesis of sulphates, the barium-sulphate method, etc., gave varying values for the atomic weight of cerium, ranging from 135.7 to 143,3. Schutzenberger therefore infers that cerium oxide from cerite contains small quantities of another earth of lower molecular weight; but the results as given are not sufficiently detailed to be conclusive. The third paper is essentially a continuation of the second, with reference to the didymiums.

Schutzenberger's papers were promptly followed by one from Brauner,* who claims priority in the matter of fractionation, and gives some new data, the latter tending to show that cerium oxide is a mixture of at least two earths. One of these, of a dark salmon color, he ascribes to a new element, "meta-cerium." The other he calls cerium, and gives for it a preliminary atomic weight determination. The pure oxalate, by Gibbs' method, gave 46.934 per cent. of $\mathrm{CeO}_{2}$, and, on titration with potassium permanganate, 29.503 and 29.506 per cent. of $\mathrm{C}_{2} \mathrm{O}_{3}$. Hence $\mathrm{Ce}=138.799$. In mean, this ratio may be written-

$$
{ }_{3} \mathrm{C}_{2} \mathrm{O}_{3}: 2 \mathrm{CeO}_{2}:: 29.5045: 46.934 \text {, }
$$

and to each of its numerical terms we may roughly assign the probable error \pm .001 . This is derived from the average of the two titrations, and is altogether arbitrary.

The ratios, good and bad, for cerium now are-

(I.) $\mathrm{Ce}_{2}\left(\mathrm{SO}_{4}\right)_{3}:{ }_{3} \mathrm{BaSO}_{4}:: 100: \mathbf{1 2 2 . 9 5 8}$, \pm . II 39

(2.) $3 \mathrm{BaSO}_{4}: 2 \mathrm{CeO}_{2}:: 100: 49 \cdot 360, \pm .035$

(3.) ${ }_{3} \mathrm{BaCl}_{2}: \mathrm{Ce}_{2}\left(\mathrm{SO}_{4}\right)_{3}:: 100: 91.625, \pm .016$

(4.) $3 \mathrm{AgCl}: \mathrm{CeO}_{2}:: \mathrm{IO0}: 40.469, \pm .04 \mathrm{I} 5$

(5.) Percentage $\mathrm{CeO}_{2}$ from $\mathrm{Ce}_{2}\left(\mathrm{SO}_{4}\right)_{3}, 60.566, \pm .002 \mathrm{I}$

(6.) Percentage $\mathrm{CeO}_{2}$ from $\mathrm{Ce}_{2}\left(\mathrm{C}_{2} \mathrm{O}_{4}\right)_{3}, 63.4316$, \pm .0032

(7.) Percentage $\mathrm{CO}_{2}$ from $\mathrm{Ce}_{2}\left(\mathrm{C}_{2} \mathrm{O}_{4}\right)_{3}, 48.2546, \pm .001$.

(8.) $3 \mathrm{Ag}: \mathrm{CeCl}_{3}:: 100: 76.167, \pm .0065$

(9.) $3 \mathrm{C}_{2} \mathrm{O}_{3}: 2 \mathrm{CeO}_{2}:: 29.5045, \pm .00 \mathrm{I}: 46.934, \pm .00 \mathrm{I}$ 
To reduce these ratios we have-

$$
\begin{array}{ll}
\mathrm{O}=15.879, \pm .0003 & \mathrm{C}=1 \mathrm{Ir} .920, \pm .0004 \\
\mathrm{Cl}=35.179, \pm .0048 & \mathrm{~S}=31.828, \pm .0015 \\
\mathrm{Ag}=107.108, \pm .003 \mathrm{I} & \mathrm{Ba}=\mathrm{r} 36.392, \pm .0086 \\
\mathrm{AgCl}=142.287, \pm .0037 &
\end{array}
$$

From the ratios, with these intermediate data, we can get two values for the molecular weight of $\mathrm{Ce}_{2}\left(\mathrm{SO}_{4}\right)_{3}$, and five for that of $\mathrm{CeO}_{2}$. For cerium sulphate we have-

$$
\begin{aligned}
& \text { From }(\mathrm{I}) \ldots \ldots \ldots \ldots \ldots \ldots \mathrm{Ce}_{2}\left(\mathrm{SO}_{4}\right)_{3}=565.404, \pm .1670 \\
& \text { From (3)............ " }=568.304, \pm .1054 \\
& \text { General mean........ } \overline{\mathrm{Ce}_{2}\left(\mathrm{SO}_{4}\right)_{3}=567.478, \pm .089 \mathrm{I}}
\end{aligned}
$$

Hence $\mathrm{Ce}=140.723, \pm .0451$.

For ceric oxide the values are-

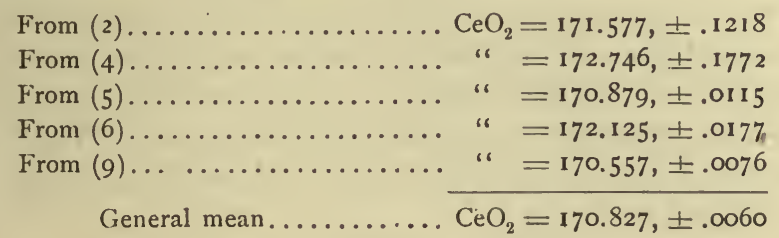

And $\mathrm{Ce}=139.069, \pm .0061$.

For cerium itself, four independent values are now calculable, as follows :

$$
\begin{aligned}
& \text { From molecular weight of sulphate... Ce }=140.723, \pm .045 \mathrm{I} \\
& \text { From molecular weight of dioxide ... " }=139.069, \pm .006 \mathrm{r} \\
& \text { From ratio (8) .............. " }=139.206, \pm .0263 \\
& \text { From ratio }(7) \ldots \ldots \ldots \ldots \ldots \ldots \ldots \text {. }=140.516, \pm .0047 \\
& \text { General mean........... } \mathrm{Ce}=140.113, \pm .0036
\end{aligned}
$$

If $\mathrm{O}=16, \mathrm{Ce}=141.181$.

It must be admitted that this combination is of very questionable utility. Its component means vary too widely from each other, and involve too many uncertainties. Furthermore, Schutzenberger and Brauner hoth impugn the homogeneity of the supposed element, as it has hitherto been recognized. Even if no "meta-elements" are involved in the discussion, it seems clear, on chemical grounds, that the two lower values are really preferable to the two higher, and that ratio (7) receives excessive weight. The general mean obtained is probably a full unit too high. The value 139.1 is perhaps nearly correct. 


\section{LANTHANUM.}

Leaving out of account the work of Mosander, and the valueless experiments of Choubine, we may consider the estimates of the atomic weight of lanthanum which are due to Hermann, Rammelsberg, Marignac, Czudnowicz, Holzmann, Zschiesche, Erk, Cleve, Brauner, Bauer, and Bettendorff.

From Rammelsberg* we have but one analysis. $.700 \mathrm{grm}$. of lanthanum sulphate gave $.883 \mathrm{grm}$. of barium sulphate. Hence 100 parts of $\mathrm{BaSO}_{4}$ are equivalent to 79.276 of $\mathrm{La}_{2}\left(\mathrm{SO}_{4}\right)_{3}$.

Marignac, $\dagger$ working also with the sulphate of lanthanu:n, employed two methods. First, the salt in solution was mixed with a slight excess of barium chloride. The resulting barium sulphate was filtered off and weighed; but, as it contained some occluded lanthanum compounds, its weight was too high. In the filtrate the excess of barium was estimated, also as sulphate. This last weight of sulphate, deducted from the total sulphate which the whole amount of barium chloride could form, gave the sulphate actually proportional to the lanthanum compound. The following weights are given:

$\begin{array}{llll}\mathrm{La}_{2}\left(\mathrm{SO}_{4}\right)_{3} . & \mathrm{BaCl}_{2} . & \text { Ist } \mathrm{BaSO}_{4} . & \text { 2d } \mathrm{BaSO}_{4} . \\ 4.346 \mathrm{grm} . & 4.758 \mathrm{grm} . & 5.364 \mathrm{grm} . & .115 \mathrm{grm} . \\ 4.733 \text { “ } & 5.178 \text { " } & 5.848 \text { " } & .147 \text { " }\end{array}$

Hence we have the following quantities of $\mathrm{Ia}_{2}\left(\mathrm{SO}_{4}\right)_{3}$ proportional to 100 parts of $\mathrm{BaSO}_{4}$. Column $\mathrm{A}$ is deduced from the first $\mathrm{BaSO}_{4}$ and column $\mathrm{B}$ from the second, after the manner above described:

A.

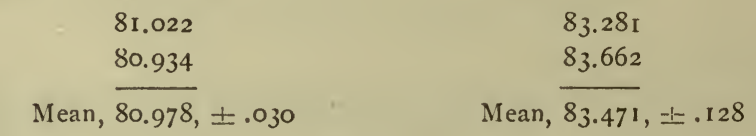

From A...................... $\mathrm{La}=1 \mathrm{I} 39.47$

From B .................. $=147.13$

A agrees best with other determinations, although, theoretically, it is not so good as B.

Marignac's second method, described in the same paper with the foregoing experiments, consisted in mixing solutions of $\mathrm{La}_{2}\left(\mathrm{SO}_{4}\right)_{3}$ with solutions of $\mathrm{BaCl}_{2}$, titrating one with the other until equilibrium was established. The method has already been described under cerium. The weighings

* Poggend. Annalen. 55, 65.

† Arch. Sci. Phys, et Nat. (1), II, 29. 1849. 
give maxima and minima for $\mathrm{BaCl}_{2}$. In another column I give $\mathrm{La}_{2}\left(\mathrm{SO}_{4}\right)_{3}$ proportional to 100 parts of $\mathrm{BaCl}_{2}$, mean weights being taken for the latter:

Hence La $=140.2$.

\begin{tabular}{|c|c|c|}
\hline$L a_{2}\left(\mathrm{SO}_{4}\right)_{3}$ & $\mathrm{BaCl}_{2}$. & Ratio. \\
\hline $\begin{array}{l}\text { I 1 .644 grm. } \\
\text { I } 2.035 \text { “" }\end{array}$ & $\begin{array}{l}12.765-12.825 \mathrm{grm} . \\
13.195-13.2650 "\end{array}$ & $\begin{array}{l}91.004 \\
90.968\end{array}$ \\
\hline 10.690 " & $11.669-11.749$ “" & 91.297 \\
\hline 12.750 " & $13.920-14.000 "$ & $91.33^{2}$ \\
\hline 10.757 “ & $11.734-11.814^{\circ} "$ & 91.362 \\
\hline $12.672 "$ & $13.813-13.893$ & 91.475 \\
\hline 9.246 “ & $10.080-10.160$ & $9^{1 .} \cdot 3^{64}$ \\
\hline 10.292 “ & $11.204-11.2640$ & 91.615 \\
\hline 10.192 “" & 11.11I-II.171" & 91.482 \\
\hline
\end{tabular}

Although not next in chronological order, some still more recent work of Marignac's * may properly be considered here. The salt studied was the sulphate of lanthanum, purified by repeated crystallizations. In two experiments the salt was calcined, and the residual oxide weighed; in two others the lanthanum was precipitated as oxalate, and converted into oxide by ignition. The following percentages are given for $\mathrm{La}_{2} \mathrm{O}_{3}$ :

$$
\begin{aligned}
& \left.\begin{array}{l}
57 \cdot 5^{6} \\
57.5^{8}
\end{array}\right\} \text { By calcination. } \\
& \left.\begin{array}{l}
57.5^{\circ} \\
57.55
\end{array}\right\} \text { Ppt. as oxalate. } \\
& \text { Mean; } \overline{57.5475}, \pm .0115
\end{aligned}
$$

The atomic weight determinations of Holzmann $\dagger$ were made by analyses of the sulphate and iodate of lanthanum, and the double nitrate of magnesium and lanthanum. In the sulphate experiments the lanthanum was first thrown down as oxalate, which, on ignition, yielded oxide. The sulphuric acid was precipitated as $\mathrm{BaSO}_{4}$ in the filtrate.

$\begin{array}{lcc}\mathrm{La}_{2}\left(\mathrm{SO}_{4}\right)_{3} . & \mathrm{La}_{2} \mathrm{O}_{3} . & \mathrm{BaSO}_{4} . \\ .9663 \mathrm{grm}, & .5157 \mathrm{grm} & 1.1093 \mathrm{grm} . \\ .6226 \text { “ } & .3323 \text { “ } & .7123 \text { “ } \\ .8669 \text { “ } & .4626 \text { “ } & .9869 \text { " }\end{array}$

These results are best used by taking the ratio between the $\mathrm{BaSO}_{4}$, put at 100 , and the $\mathrm{La}_{2} \mathrm{O}_{3}$. The figures are then as follows:

$$
\begin{gathered}
46.489 \\
46652 \\
\frac{46.873}{\text { Mean, }} \frac{46.67 \mathrm{I}}{} \pm .075
\end{gathered}
$$


In the analyses of the iodate the lanthanum was thrown down as oxalate, as before. The iodic acid was also estimated volumetrically, but the figures are hardly available for present discussion. The following percentages of $\mathrm{La}_{2} \mathrm{O}_{3}$ were found:

$$
\begin{array}{r}
23.454 \\
23.419 \\
23.468 \\
\hline \text { Mean, } 23.447, \pm .0216
\end{array}
$$

\begin{tabular}{|c|c|c|c|}
\hline Salt. & $\mathrm{H}_{2} \mathrm{O}$. & $\mathrm{MgO}$ & $L a_{2} O_{3}$ \\
\hline $\begin{array}{l}.5327 \mathrm{grm} . \\
.5931\end{array}$ & $\begin{array}{l}.1569 \mathrm{grm} . \\
.1734\end{array}$ & $\begin{array}{l}.0417 \mathrm{grm} . \\
.0467 \text { “" }\end{array}$ & $\begin{array}{l}.113 \mathrm{Igrm} . \\
.1262 " \text { " }\end{array}$ \\
\hline .5662 & .1647 " & $.0442 "$ & " \\
\hline .3757 “ & $\ldots$ & “ & ".0813 \\
\hline $.326_{3}$ & $\ldots$ & .0256 “" & ، \\
\hline
\end{tabular}

The formula of this salt is $\mathrm{La}_{2}\left(\mathrm{IO}_{3}\right)_{6} \cdot 3 \mathrm{H}_{2} \mathrm{O}$.

The double nitrate, $\mathrm{La}_{2}\left(\mathrm{NO}_{3}\right)_{6} \cdot 3 \mathrm{Mg}\left(\mathrm{NO}_{3}\right)_{2} \cdot 24 \mathrm{H}_{2} \mathrm{O}$, gave the following analytical data:

These weighings give the subjoined percentages of $\mathrm{La}_{2} \mathrm{O}_{3}$ :

$$
\begin{gathered}
21.231 \\
21.278 \\
21.141 \\
21.640 \\
21.238 \\
\text { Mean, } 21.3056, \pm .058
\end{gathered}
$$

These data of Holzmann give values for the molecular weight of $\mathrm{La}_{2} \mathrm{O}_{3}$ as follows:

$$
\begin{aligned}
& \text { From sulphate.................. } \mathrm{La}_{2} \mathrm{O}_{3}=322.460 \\
& \text { From iodate.................. " }=320.726 \\
& \text { From magnesian nitrate............. " }=322.904
\end{aligned}
$$

Czudnowicz * based his determination of the atomic weight of lanthanum upon one analysis of the air-dried sulphate. The salt contained 22.741 per cent. of water.

$$
.598 \mathrm{grm} \text {, gave } .272 \mathrm{grm}, \mathrm{La}_{2} \mathrm{O}_{3} \text { and } .586 \mathrm{grm} . \mathrm{BaSO}_{4} \text {. }
$$

The $\mathrm{La}_{2} \mathrm{O}_{3}$ was found by precipitation as oxalate and ignition. The $\mathrm{BaSO}_{4}$ was thrown down from the filtrate. Reduced to the standards already adopted, these data give for the percentage of $\mathrm{La}_{2} \mathrm{O}_{3}$ in the anhydrous sulphate the figure 58.668. 79.117 parts of the salt are proportional to 100 parts of $\mathrm{BaSO}_{4}$. 
Hermann* studied both the sulphate and the carbonate of lanthanum. From the anhydrous sulphate, by precipitation as oxalate and ignition, the following percentages of $\mathrm{La}_{2} \mathrm{O}_{3}$ were obtained :

$$
\begin{gathered}
57.690 \\
57.663 \\
\frac{57.610}{57.654}, \pm .016
\end{gathered}
$$

The carbonate, dried at $100^{\circ}$, gave the following percentages:

$$
\begin{gathered}
68.47 \mathrm{La}_{2} \mathrm{O}_{3} . \\
27.67 \mathrm{CO}_{2} . \\
3.86 \mathrm{H}_{2} \mathrm{O} .
\end{gathered}
$$

Reckoning from the ratio between $\mathrm{CO}_{2}$ and $\mathrm{La}_{2} \mathrm{O}_{3}$, the molecular weight of the latter becomes 324.254 .

Zschiesche's $\dagger$ experiments consist of six analyses of lanthanum sulphate, which salt was dehydrated at $230^{\circ}$, and afterwards calcined. I subjoin his percentages, and in a fourth column deduce from them the percentage of $\mathrm{La}_{2} \mathrm{O}_{3}$ in the anhydrous salt:

$\begin{array}{lccc}\mathrm{H}_{2} \mathrm{O} . & \mathrm{SO}_{3} . & \mathrm{La}_{2} \mathrm{O}_{3} . & \mathrm{La}_{2} \mathrm{O}_{3} \text { in Anhydrous Salt. } \\ 22.629 & 33.470 & 43.909 & 56.745 \\ 22.562 & 33.306 & 44.13^{2} & 56.964 \\ 22.730 & 33.200 & 44.070 & 57.034 \\ 22.570 & 33.333 & 44.090 & 56.947 \\ 22.610 & 33.160 & 44.240 & 57.150 \\ 22.630 & 33.05 \mathrm{I} & 44.310 & \frac{57.277}{} \\ & & & \text { Mean, } 57.02 \mathrm{I}, \pm .05 \mathrm{I}\end{array}$

Erk $\ddagger$ found that $474 \mathrm{grm}$. of $\mathrm{La}_{2}\left(\mathrm{SO}_{4}\right)_{3}$, by precipitation as oxalate and ignition, gave $.2705 \mathrm{grm}$. of $\mathrm{La}_{2} \mathrm{O}_{3}$, or 57.068 per cent. $.7045 \mathrm{grm}$. of the sulphate also gave $.8815 \mathrm{grm}$. of $\mathrm{BaSO}_{4}$. Hence 100 parts of $\mathrm{BaSO}_{4}$ are equivalent to 79.921 of $\mathrm{La}_{2}\left(\mathrm{SO}_{4}\right)_{3}$.

From Cleve we have two separate investigations relative to the atomic weight of lanthanum. In his first series $§$ strongly calcined $\mathrm{La}_{2} \mathrm{O}_{3}$, spectroscopically pure, was dissolved in nitric acid, and then, by evaporation with sulphuric acid, converted into sulphate:

$1.9215 \mathrm{grm} . \mathrm{La}_{2} \mathrm{O}_{3}$ gave $3.3365 \mathrm{grm}$. sulphate.

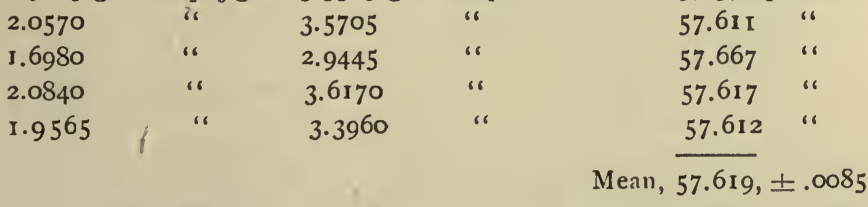

* Journ. für Prakt. Chem., 82, 396. I861.

† Journ. für Prakt. Chem., I04, 174.

$\ddagger$ Jenaisches Zeitschrift, 6, 306. I871.

z K. Svensk. Vet. Akad. Handlingar, Bd. 2, No. 7. 1874. 
From the last column, which indicates the percentage of $\mathrm{La}_{2} \mathrm{O}_{3}$ in $\mathrm{La}_{2}\left(\mathrm{SO}_{4}\right)_{3}$, we get, if $\mathrm{SO}_{3}=80, \mathrm{La}=139.15$.

In his second paper,* published nine years later, Cleve gives results similarly obtained, but with lanthanum oxide much more completely freed from other earths. The data are as follows, lettered to correspond to different fractions of the material studied:
B. .8390 grm. $\mathrm{La}_{2} \mathrm{O}_{3}$ gave $\mathrm{I} .4600$ sulphate.
C. $\left\{\begin{array}{l}1.186 \mathrm{I} \\ .8993 \\ .8685 \\ .8515\end{array}\right.$
"
"
"
"
"
",
"
2.0643
1.5645
1.5108
I. 4817
1.1282 "
D. $\left\{\begin{array}{l}.6486 \\ .7329\end{array}\right.$
I. 2746 "
57.466 per cent.
E. 1.2477
2.1703
F. $\left\{\begin{array}{l}1.1621 \\ 1.5749\end{array}\right.$
2.0217
2.7407
G. $\left\{\begin{array}{l}1.3367 \\ 1.4455\end{array}\right.$
2.3248
2.5146
57458
57.482
57.486
57.468
57.490
57.500
57.490
$57.48 \mathrm{I}$
57.463
57.497
57.484
Mean, $57.480, \pm .0040$

Hence with $\mathrm{SO}_{3}=80, \mathrm{La}=138.22$.

From Brauner we also have two sets of determinations, both based upon the conversion of pure $\mathrm{La}_{2} \mathrm{O}_{3}$ into $\mathrm{La}_{2}\left(\mathrm{SO}_{4}\right)_{3}$.

In his first paper, Brauner $\dagger$ gives only two syntheses, as follows:

$$
\begin{aligned}
& \text { I.75933 grm. } \mathrm{La}_{2} \mathrm{O}_{3} \text { gave } 3.05707 \mathrm{La}_{2}\left(\mathrm{SO}_{4}\right)_{3} \text {. } \quad 57.566 \text { per cent. } \\
& .92417 \\
& \text { 1. } 60589 \\
& 57.549 \text { “ }
\end{aligned}
$$

This mean we may regard as of equal weight with Marignac's, and

\begin{tabular}{|c|c|c|c|c|c|}
\hline .7850 & $\mathrm{La}_{2} \mathrm{C}$ & 1. $365^{8}$ & $\left({ }_{2}\left(\mathrm{SO}_{4}\right)_{3}\right.$ & 57.476 & r cent. \\
\hline $2.105^{2}$ & “ & 3.6633 & "، & 57.467 & " \\
\hline 1.0010 & " & $\mathrm{I} .74 \mathrm{II}$ & " & 57.525 & " \\
\hline 1.3807 & ، & 2.4021 & " & 57.479 & “ \\
\hline 1.5275 & “ & 2.6588 & “ & $57.45^{1}$ & " \\
\hline
\end{tabular}
assign to it the same probable error.

In Brauner's second paper $\ddagger$ six experiments are given; but the weights are affected by a misprint in the second determination, which I am unable to correct. Only five of the syntheses, therefore, are given below.

Brauner's weighings are all reduced to a vacuum.

Both Bauer and Bettendorff made their determinations of the atomic

* K. Svensk. Vet. Akad. Handlingar, No. 2, 1883.

† Journ. Chem. Soc., Feb., 1882, p. 68.

† Sitzungsb. Wien. Akad., June, 1892, Bd. 86, II Abth. 
weight of lanthanum by the same general method as the preceding Bauer's data $*$ are as follows :

$.643^{1} \mathrm{grm} . \mathrm{La}_{2} \mathrm{O}_{3}$ gave I. I I 7 sulphate. .7825

1.0112

.7325

$\begin{array}{lll}\text { "6 } & 1.3613 & 6 \\ \text { " } & 1.7571 & 6\end{array}$

57.569 per cent. 57.482 " 57.549 " 57.564 “

Mean, $\overline{57.541}, \pm .0136$

Bettendorff found $\dagger$ -

\begin{tabular}{|c|c|c|c|c|c|}
\hline $.9146 \mathrm{grm}$. & $\mathrm{La}_{2} \mathrm{O}_{3}$ gave & I. 5900 & phate. & 57.522 & er cent. \\
\hline .9395 & “ & 1.6332 & "، & 57.525 & “ \\
\hline $.9^{1} 33$ & “ & I. 5877 & “ & 57.523 & “ \\
\hline 1.0651 & “ & 1.8515 & “ & 57.526 & “ \\
\hline
\end{tabular}

We may now combine the similar means into general means, and deduce a value for the atomic weight of lanthanum. For the percentage of oxide in sulphate we have estimates as follows. The single experiments of Czudnowicz and of Erk are assigned the probable error and weight of a single experiment in Hermann's series :

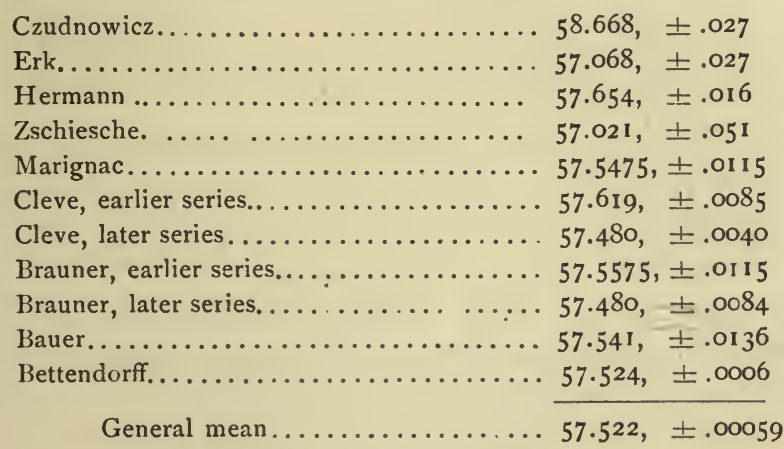

This result is practically identical with that of Bettendorff, whose work seems to receive excessive weight. The figure, however, cannot be far out of the way.

For the quantity of $\mathrm{La}_{2}\left(\mathrm{SO}_{4}\right)_{3}$ proportional to 100 parts of $\mathrm{BaSO}_{4}$, we have five experiments, which may be given equal weight and averaged together :

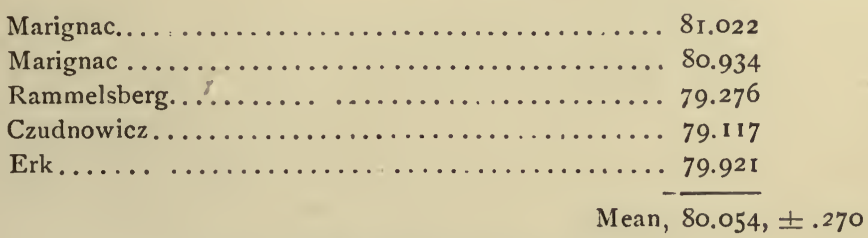

* Freiburg Inaugural Dissertation, 1884 .

† Ann. d. Chem., 256, 68. 
In all, there are six ratios from which to calculate:

(I.) Percentage of $\mathrm{La}_{2} \mathrm{O}_{3}$ in $\mathrm{La}_{2}\left(\mathrm{SO}_{4}\right)_{3}, 57.522, \pm .00059$

(2.) ${ }_{3} \mathrm{BaCl}_{2}: \mathrm{La}_{2}\left(\mathrm{SO}_{4}\right)_{3}::$ : $000: 9 \mathrm{I} .322, \pm .048$-Marignac

(3.) $3 \mathrm{BaSO}_{4}: \mathrm{La}_{2}\left(\mathrm{SO}_{4}\right)_{3}:: 100: 80.054, \pm .270$

(4.) $3 \mathrm{BaSO}_{4}: \mathrm{La}_{2} \mathrm{O}_{3}::$ I $00: 46.67 \mathrm{I}, \pm .075-H o l z m a n n$

(5.) Percentage of $\mathrm{La}_{2} \mathrm{O}_{3}$ in iodate, $23.447, \pm .0216-$ Holzmann

(6.) Percentage of $\mathrm{La}_{2} \mathrm{O}_{3}$ in magnesian nitrate, 21.3056, $\pm .058-$ Holzmann

Hermann's single experiment on the carbonate is omitted from this scheme as being unimportant.

For the reduction of these data we have-

$$
\begin{aligned}
& \mathrm{O}=15.879, \pm .0003 \\
& \mathrm{Cl}=35.179, \pm .0048 \\
& \mathrm{I}=125.888, \pm .0069 \\
& \mathrm{~S}=31.828, \pm .0015
\end{aligned}
$$

$$
\begin{aligned}
& \mathrm{N}=13.935, \pm .0021 \\
& \mathrm{C}=11.920, \pm .0004 \\
& \mathrm{Mg}=24.100, \pm .0011 \\
& \mathrm{Ba}=136.392, \pm .0086
\end{aligned}
$$

For lanthanum sulphate two values are obtainable:

$$
\begin{aligned}
& \text { From (2) } \ldots \ldots \ldots \ldots \ldots . \quad \mathrm{La}_{2}\left(\mathrm{SO}_{4}\right)_{3}=566.425, \pm .2999 \\
& \text { From (3) ........... " }=556.542, \pm 1.8729 \\
& \text { General mean....... } \overline{\mathrm{La}_{2}\left(\mathrm{SO}_{4}\right)_{3}=566.182, \pm .296 \mathrm{I}}
\end{aligned}
$$

Hence $\mathrm{La}=140.075, \pm .1481$.

For the oxide there are four independent values, as follows:

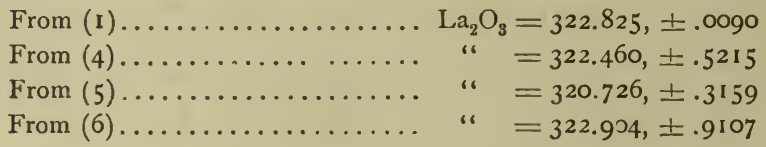

A glance at these figures shows that the first alone deserves consideration, and that a combination of all would vary inappreciably from it. Taking, then, $\mathrm{La}_{2} \mathrm{O}_{3}=322.825, \pm .0090$, we get-

$$
\mathrm{La}=137.594, \pm .0046
$$

or, with $\mathrm{O}=16, \mathrm{La}=138.642$.

If we take the concordant results of Cleve's and Branuer's later series, which give the percentage of $\mathrm{La}_{2} \mathrm{O}_{3}$ in $\mathrm{La}_{2}\left(\mathrm{SO}_{4}\right)_{3}$ as 57.480 , then $\mathrm{La}=$ 137.316. Possibly this value may be better than the other, but the evidence is not conclusive. 


\section{THE DIDYMIUMS.}

Leaving Mosander's early experiments out of account, the atomic weight of the so-called " didymium " was determined by Marignac, Hermann, Zschiesche, Erk, Cleve, Brauner, and Bauer. All of these data now have only historical value, and may be disposed of very briefly.

Marignac* determined the ratios between didymium sulphate and barium sulphate, between silver chloride and didymia, and between didymium sulphate and didymium oxide. The other determinations all relate to the sulphate-oxide ratio. Leaving all else out of account, the earlier data for the percentage of $\mathrm{Di}_{2} \mathrm{O}_{3}$ in $\mathrm{Di}_{2}\left(\mathrm{SO}_{4}\right)_{3}$ are as follows. The atomic weight of $\mathrm{Di}$ in the last column is based upon $\mathrm{SO}_{3}=80$ :

Per cent. $\mathrm{Di}_{2} \mathrm{O}_{3}$. At. Wt. Di.

\begin{tabular}{|c|c|}
\hline Marignac, $\dagger$ five experiments........ 58.270 & 143.56 \\
\hline Hermann $\ddagger$ one experiment......... 58.140 & 142.67 \\
\hline Zschiesche, 8 five experiments . . . . . 57.926 & 141.21 \\
\hline Erk, $\|$ two experiments. . & 142.33 \\
\hline Cleve, $\mathbb{\uparrow}$ six experiments............ 58.766 & 147.02 \\
\hline Brauner, ${ }^{* *}$ three experiments.$\ldots \ldots \ldots 58.68 \mathrm{I}$ & 146.42 \\
\hline
\end{tabular}

The discordance of the determinations is manifest, and yet up to 1883 the elementary nature of didymium seems to have been undoubted. In that year, however, Cleve and Brauner both showed, independently, that the didymia previously studied by them contained samaria, and that source of disturbance was eliminated.

In Brauner's investigation † the didymium compounds were carefully fractionated, and the determinations of atomic weight were made by synthesis of the sulphate from the oxide in the usual way. Neglecting details, his first series gave results as follows:

$\begin{array}{cc}\text { Per cent. } \mathrm{Di}_{2} \mathrm{O}_{3} . & \text { At. } W t . \\ 58.506 & 145.36 \\ 58.526 & 145.50 \\ 58.500 & \mathrm{I} 45.3 \mathrm{I} \\ 58.515 & 145.42 \\ 58.53 \mathrm{I} & \mathrm{I} 45.53\end{array}$

* Two papers: Arch. Sci. Phys. et Nat. (1), 11, 29. 1849. Ann. Chim. Phys. (3), 38, 148. 1853. † Ann. Chim. Phys. (3), 38, 148. 1853.

$\ddagger$ Journ. für Prakt. Chem., 82, 367. 1861.

\& Journ. für Prakt. Chem., 107, 74.

IJenaisches Zeitschrift, 6, 306. 1871 .

If K. Svensk. Vet. Akad. Handl., Bd. 2, No. 8. 1874 .

** Berichte, 15, 109. 1882 .

†† Journ. Chem. Soc., June, 1883 . The values given are as conputed by Brauner, with $\mathrm{O}=16$ and $\mathrm{S}=32.07$. 
Another determination, with material refractionated from that used in his investigation of the previous year, gave 58.512 per cent. $\mathrm{Di}_{2} \mathrm{O}_{3}$ and $\mathrm{Di}=145.40$.

These determinations, although concordant among themselves, are still about a unit lower than those published in 1882, indicating that in the earlier research some earth of higher molecular weight was present. Accordingly, another series of fractionations was carried out, and the several fractions of "didymia " obtained gave the following values:

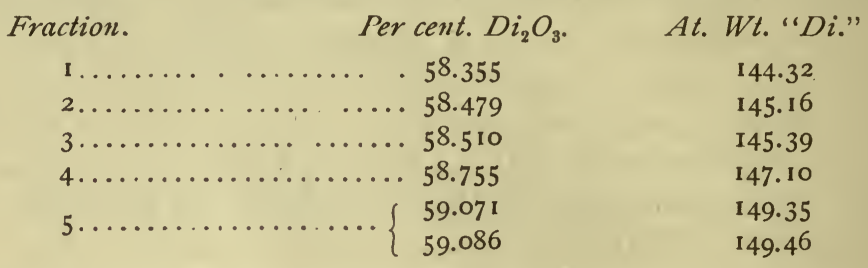

The last fraction is evidently near samaria $(\mathrm{Sm}=150)$, and this earth was proved to be present by a study of the absorption spectra of the material investigated.

Similar results, but in some respects more explicit, were obtained by Cleve, * who also found that his earlier research had been vitiated by the presence of samaria. He gives two series of syntheses of sulphate from oxide, with two different lots of material, after eliminating samaria, and obtains, computing with $\mathrm{SO}_{3}=80$, values for Di as follows :

First Series.

Per cent. $\mathrm{Di}_{2} \mathrm{O}_{3}$.

58.088

58.113

58.047

58.099

58. 104

58.098

58.104

58. 103

58.070

58.079
At. Wt. Di.

$$
\begin{aligned}
& 142.31 \\
& 142.49 \\
& 142.03 \\
& 142.39 \\
& 142.42 \\
& 142.38 \\
& 142.42 \\
& 142.42 \\
& 142.19 \\
& 142.25
\end{aligned}
$$

Second Series.

Percent. $\mathrm{Di}_{2} \mathrm{O}_{3}$.

58.125

58.093

58.088

58.111

58.056

58.097

58.057
At. Wt. Di.

142.57

142.35

142.31

142.47

I42. 10

142.38

I42.10

In short, the atomic weight of this "didymium" is not far from 142.

* Bull. Soc. Chim., 39, 289. ז883. Öfv. K. Vet. Akad. Förhaudl., No. 2, I883. 
Bauer's little known determinations* were also made by the synthesis of the sulphate. They have corroborative value and are as follows:

$\begin{array}{cc}\text { Percent. } \mathrm{Di}_{2} \mathrm{O}_{3} . & \text { At. Wt. Di. } \\ 58.285 & 143.56 \\ 58.100 & 142.40 \\ 58.133 & 142.64 \\ 58.098 & 142.38\end{array}$

In 1885 all of the foregoing determinations were practically brushed aside by Auer von $\mathrm{Welsbach}, \uparrow$ who by the most laborious fractionations proved that the so-called "didymia" was really a mixture of oxides, whose metals he names neodidymium and praseodidymium, names which are now commonly shortened into neodymium and praseodymium. One of these metals gives deep rose-colored salts, the other forms green compounds, and the difference of color is almost as strongly marked as in the cases of cobalt and nickel. Their atomic weights, determined by the sulphate method, are given by Welsbach a :-

$$
\begin{aligned}
& \mathrm{Pr}=143.6 \\
& \mathrm{Nd}=140.8
\end{aligned}
$$

No further details as to these determinations are cited, and whether they rest upon $\mathrm{O}=16, \mathrm{SO}_{3}=80$, or $\mathrm{O}=15.96$ is uncertain. Fuller determinations are evidently needed. 


\section{SCANDIUM.}

Cleve, * who was the first to make accurate experiments on the atomic weight of this metal, obtained the following data: $1.451 \mathrm{grm}$. of sulphate, jonited, gave .5293 grm. of $\mathrm{Sc}_{2} \mathrm{O}_{3}$. $.4479 \mathrm{grm}$. of $\mathrm{Sc}_{2} \mathrm{O}_{3}$, converted into sulphate, yielded $1.2255 \mathrm{grm}$. of the latter, which, upon ignition, gave $.4479 \mathrm{grm}$. of $\mathrm{Sc}_{2} \mathrm{O}_{3}$. Hence, for the percentage of $\mathrm{Sc}_{2} \mathrm{O}_{3}$ in $\mathrm{Sc}_{2}\left(\mathrm{SO}_{4}\right)_{3}$ we have:

$$
\begin{gathered}
36.478 \\
36.55^{6} \\
\frac{36.55^{6}}{3^{6.530}} \pm .0175
\end{gathered}
$$

Hence, if $\mathrm{SO}_{3}=79.465, \mathrm{Sc}=44.882$.

Later results are those of Nilson, $\dagger$ who converted scandium oxide into the sulphate. I give in a third column the percentage of oxide in sulphate:

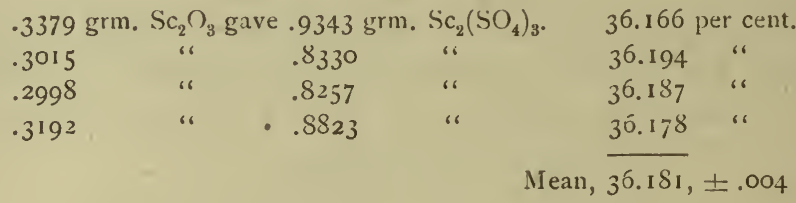

Hence $\mathrm{Sc}=43.758$.

Combining the two series, we have-

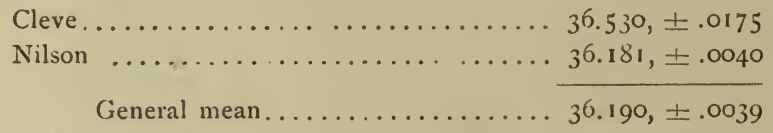

Hence, with $\mathrm{SO}_{3}=79.465, \pm .00175$,

$$
S c=43.784, \pm .0085 \text {. }
$$

If $\mathrm{O}=16, \mathrm{Sc}=44.118$.

As between the two values found, the presumption is in faror of the lower. The most obvious source of error would be the presence in the scandia of earths of higher molecular weight. 


\section{YTTRIUM.}

All the regular determinations of the atomic weight of yttrium depend upon analyses or syntheses of the sulphate. A series of analyses of the oxalate, howerer, by Berlin,* is sometimes cited, and the data are as follows. In three experiments upon the salt $\mathrm{Yt}_{2}\left(\mathrm{C}_{2} \mathrm{O}_{4}\right)_{3} 3 \mathrm{H}_{2} \mathrm{O}$ the subjoined percentages of oxide were found:

$$
\begin{array}{r}
45.70 \\
45.65 \\
45.72 \\
\hline \text { Mean, } 45.69, \pm .0141
\end{array}
$$

Hence with $\mathrm{O}=15.879$ and $\mathrm{C}=11.920$,

$$
\mathrm{Yt}=88.943 \text {. }
$$

Ignoring the early work of Berzelius, $\uparrow$ the determinations to be considered are those of Popp, Delafontaine, Bahr and Bunsen, Cleve, and Jones.

Popp $\ddagger$ evidently worked with material not wholly free from earths of higher molecular weight than yttria. The yttrium sulphate was dehy-

\begin{tabular}{|c|c|c|c|}
\hline Sulphate. & $\mathrm{BaSO}_{4}$. & $\mathrm{Yt}_{2} \mathrm{O}_{3}$. & $\mathrm{H}_{2} \mathrm{O}$. \\
\hline $\begin{array}{l}\text { I.1805 grm. } \\
1.4295 \text { " }\end{array}$ & $\begin{array}{l}\mathrm{I} .3145 \mathrm{grm} . \\
\mathrm{r} .593\end{array}$ & $\begin{array}{l}.474^{2} \mathrm{grm} \text {. } \\
.5745 \text { " }\end{array}$ & $\begin{array}{c}.255 \mathrm{grm} \text {. } \\
.308 \text { " }\end{array}$ \\
\hline .8455 & .9407 “ & .3392 & .1825 " \\
\hline $\mathrm{I} .045$ " & I.1635 “ & .4195 “ & .2258 " \\
\hline
\end{tabular}
drated at $200^{\circ}$; the sulphuric acid was then estimated as barium sulphate, and after the excess of barium in the filtrate had been removed the yttrium was thrown down as oxalate and ignited to yield oxide. The following are the weights given by Popp:

Eliminating water, these figures give us for the percentages of $\mathrm{Yt}_{2} \mathrm{O}_{3}$ in $\mathrm{Yt}_{2}\left(\mathrm{SO}_{4}\right)_{3}$ the values in column A. In column B I put the quantities of $\mathrm{Yt}_{2} \mathrm{O}_{3}$ proportional to 100 parts of $\mathrm{BaSO}_{4}$ :

A.

$$
\begin{aligned}
& 51.237 \\
& 5 \text { I. } 226 \\
& 5 \text { I. } 6 \text { I } \\
& 51.209
\end{aligned}
$$$$
\text { Mean, } \overline{51.208} \pm \text {.0II }
$$

B.

$$
\begin{array}{r}
36.075 \\
36.064 \\
36.058 \\
\frac{36.055}{36.063}=.003
\end{array}
$$

From $\mathrm{B}, \mathrm{Yt}=101.54$. The values in A will be combined with similar data from other experimenters. 
In 1865 Delafontaine* published some results obtained from yttrium sulphate, the yttrium being thrown down as oxalate and weighed as oxide. In the fourth column $\mathrm{I}$ give the percentages of $\mathrm{Yt}_{2} \mathrm{O}_{3}$ reckoned from the anhydrous sulphate:

\begin{tabular}{|c|c|c|c|}
\hline Sulphate. & $\mathrm{Yt}_{2} \mathrm{O}_{3}$. & $\mathrm{H}_{2} \mathrm{O}$. & Percent. $\mathrm{Yt}_{2} \mathrm{O}_{3}$. \\
\hline $\begin{array}{l}.9545 \text { grm. } \\
2.485\end{array}$ & $\begin{array}{l}.37 \text { I grm. } \\
.9585 \text { ، }\end{array}$ & $\begin{array}{l}.216 \mathrm{grm} . \\
.565\end{array}$ & $\begin{array}{l}50.237 \\
49.922\end{array}$ \\
\hline 2.153 " & .827 “ & .4935 " & 49.834 \\
\hline
\end{tabular}

In another paper $\dagger$ Delafontaine gives the following percentages of $\mathrm{Yt}_{2} \mathrm{O}_{3}$ in dry sulphate. The mode of estimation was the same as before:

$$
\begin{gathered}
48.23 \\
48.09 \\
\frac{48.37}{\text { Mean, }} \overline{48.23}, \pm .055
\end{gathered}
$$

Bahr and Bunsen, $\ddagger$ and likewise Cleve, adopted the method of converting dry yttrium oxide into anhydrous sulphate, and noting the gain in weight. Bahr and Bunsen give us the two following results. I add the usual percentage column :

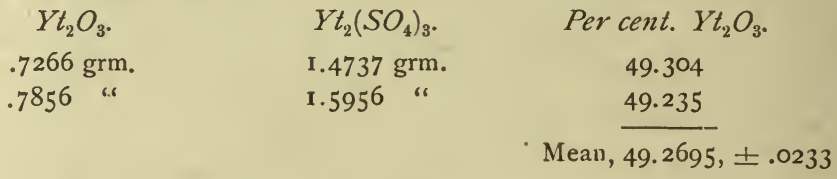

Cleve's first results are published in a joint memoir by Cleve and Hoeglund,§ and are as follows :

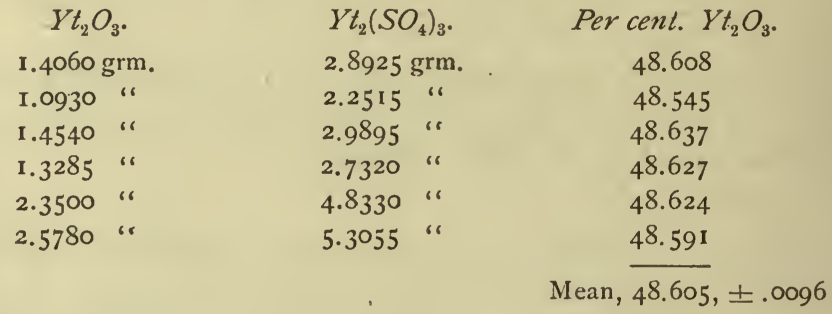

In a later paper Cleve $\|$ gives syntheses of yttrium sulphate made with yttria, which was carefully freed from terbia. The weights and percentages are as follows:

* Ann. Chem. Pharm., I34, 108. I865.

+ Arch. Sci. Phys. et Nat. (2), 25, I19. 1866.

$\ddagger$ Ann. Chem. Pharm., I37, 21. 1866.

子 K. Svenska Vet. Akad. Handlingar, Bd. I, No. 8. 1873.

|| K. Svenska Vet. Akad. Handlingar, No. 9, r882. See also Bull. Soc. Chim., 39, 120. 1883. 


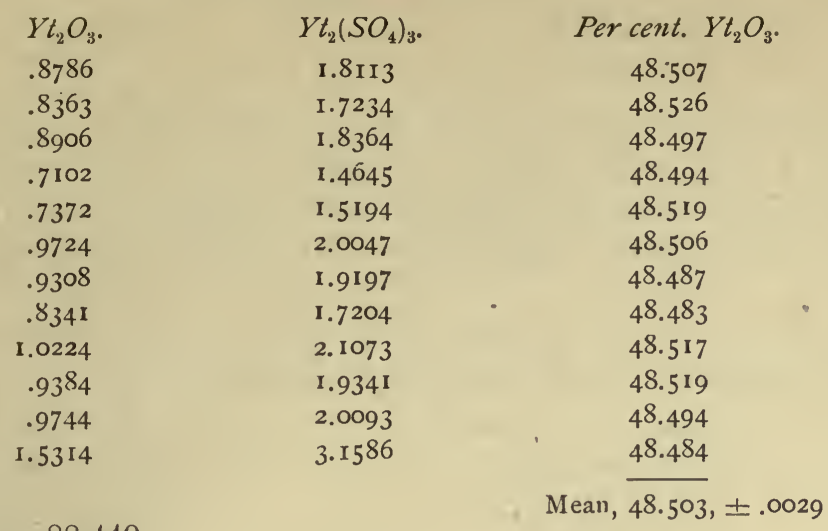

Hence $\mathrm{Yt}=88.449$.

The yttria studied by Jones* had been purified by Rowland's methodthat is, by precipitation with potassium ferrocyanide-and certainly contained less than one-half of one per cent. of other rare earths as possible impurities. Two series of determinations were made-one by ignition of the sulphate, the other by its synthesis. The results were as follows, with the usual percentage column added:

First Series. Syntheses.

$\begin{array}{cc}\mathrm{Yt}_{2} \mathrm{O}_{3} . & \mathrm{Yt}_{2}\left(\mathrm{SO}_{4}\right)_{3} . \\ .2415 & .4984 \\ .4112 & .8485 \\ .2238 & .4617 \\ .3334 & .6879 \\ .3408 & .7033 \\ .3418 & .7049 \\ .2810 & .5798 \\ .3781 & .7803 \\ .4379 & .9032 \\ .4798 & .9901\end{array}$

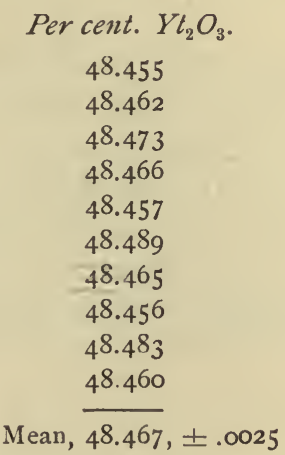

Second Series. Analyses.

$\mathrm{Yt}_{2}\left(\mathrm{SO}_{4}\right)_{3}$.
.5906
.4918
.5579
.6430
.6953
$\mathrm{I} .4192$
.8307
.7980
.8538
$\mathrm{I} .1890$

$$
\begin{aligned}
& \mathrm{Yt}_{2} \mathrm{O}_{3} . \\
& .2862 \\
& .2383 \\
& .2705 \\
& .3117 \\
& .3369 \\
& .6880 \\
& .4027 \\
& .3869 \\
& .4139 \\
& .576 .3
\end{aligned}
$$

Per cent. $\mathrm{Yt}_{2} \mathrm{O}_{3}$.
48.459
48.455
48.485
48.478
48.454
48.478
48.477
48.484
48.477
48.469
Mean, $48.472, \pm .0024$ 
From syntheses................ Yt $=88.287$

From analyses................

These data of Jones were briefly criticised by Delafontaine,* who regards a lower value as more probable. In a brief rejoinder $\dagger$ Jones defended his own work; but neither the attack nor the reply needs farther consideration here. They are referred to merely as part of the record.

For the percentage of yttria in the sulphate we now have eight series of determinations, to be combined in the usual way:

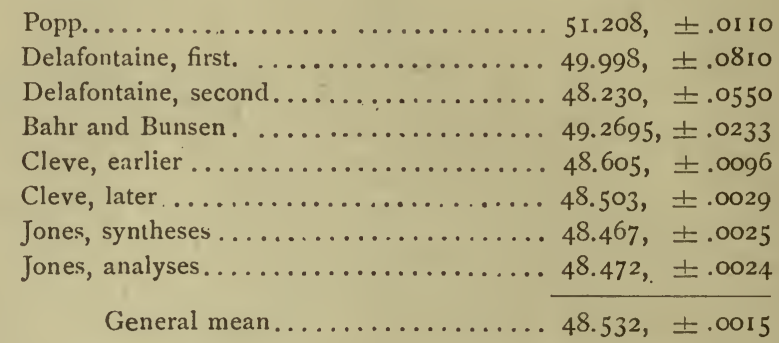

Hence, if $\mathrm{O}=15.879, \pm .0003$, and $\mathrm{S}=31.828, \pm .0015$,

$$
\mathrm{Yt}=88.580, \pm .0053 \text {. }
$$

If $\mathrm{O}=16, \mathrm{Yt}=89.255$.

If only the four series by Cleve and by Jones are considered, the mean percentage of yttria in the sulphate becomes 48.481. Hence $\mathrm{Yt}=88.350$, or, with $\mathrm{O}=16,89.023$.

This result is preferable to that derived from all the data, for it throws out determinations which are certainly erroneous. Cleve's early series might also be rejected, but its influence is insignificant. 


\section{SAMARIUM, GADOLINIUN, ERBIUM, AND Y'T'TERBIUM.}

The data relative to the atomic weights of these rare elements are rather scanty, and all depend upon analyses or syntheses of the sulphates.

\section{SAMARIUM.}

Atomic weight given by Marignac,* without details, as 149.4, and by Brauner, $\dagger$ as 150.7 in maximum. The first regular series of determinations was by Cleve, $\ddagger$ who effected the synthesis of the sulphate from the oxide. Data as follows:

$\begin{array}{rcc}\mathrm{Sm}_{2} \mathrm{O}_{3} . & \mathrm{Sm}_{2}\left(\mathrm{SO}_{4}\right)_{3} . & \text { Per cent. } \mathrm{Sm}_{2} \mathrm{O}_{3} . \\ 1.6735 & 2.8278 & 59.180 \\ 1.9706 & 3.3301 & 59.175 \\ 1.1122 & 1.8787 & 59.201 \\ 1.0634 & 1.7966 & 59.190 \\ .8547 & 1.4440 & 59.190 \\ .7447 & 1.2583 & 59.183 \\ & & \text { Mean, } 59.1865, \pm .0025\end{array}$

Hence $\mathrm{Sm}=149.038$.

Another set of determinations by Bettendorff, $\S$ after the same general method, gave as follows:

$\begin{array}{cc}\mathrm{Sm}_{2} \mathrm{O}_{3} . & \mathrm{Sm}_{2}\left(\mathrm{SO}_{4}\right)_{3} . \\ 1.0467 & 1.7675 \\ 1.0555 & 1.7818 \\ 1.0195 & 1.7210\end{array}$

Per cent. $\mathrm{Sm}_{2} \mathrm{O}_{3}$. 59.219

59.238

59.225

Hence $\mathrm{Sm}=149.328$.

Mean, $\overline{59,227} \pm .003 \mathrm{~S}$

Combining the two series, we have-

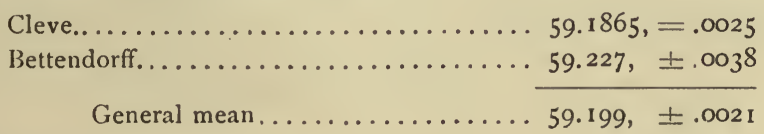

Hence, if $\mathrm{SO}_{3}=79.465, \pm .00175$,

$$
\mathrm{Sm}=149.127, \pm .0115 \text {. }
$$

If $\mathrm{O}=16, \mathrm{Sm}=150.263^{\circ}$.

According to Demarçay, $\|$ samaria contains an admixed earth whose properties are yet to be described.

* Arch. Sci. Phys. et Nat. (3), 3, 435. 1880.

† Journ. Chem. Soc., June, 1883.

† Journ. Chem. Soc., August, 1883. Compt. Rend., 97, 94.

\& Ann. Chem. Pharm., 263. I64. 1891.

॥ Compt. Rend., 122, 728. I896. 


\title{
GADOLINIUM.
}

This element, discovered by Marignac, must not be confounded with the mixture of metals from the gadolinite earths to which Nordenskiöld gave the same name. Several determinations of its atomic weight have been made, but Bettendorff's only were published with proper details.* $\mathrm{He}$ effected the synthesis of the sulphate from the oxide, and his weights were as follows. The percentage of $\mathrm{Gd}_{2} \mathrm{O}_{3}$ in $\mathrm{Gd}_{2}\left(\mathrm{SO}_{4}\right)_{3}$ is given in the third column :

$\begin{array}{cc}\mathrm{Gd}_{2} \mathrm{O}_{3} . & \mathrm{Gd}_{2}\left(\mathrm{SO}_{4}\right)_{3} . \\ 1.0682 & \mathrm{I} .7779 \\ 1.0580 & \mathrm{I} .76 \mathrm{II} \\ 1.0796 & \mathrm{1} .7969\end{array}$

\author{
Percent. $\mathrm{Gd}_{2} \mathrm{O}_{3}$. \\ 60.082 \\ 60.076 \\ 60.081 \\ Mean, $\overline{60.080} \pm .0013$
}

Hence, with $\mathrm{SO}_{3}=79.465, \mathrm{Gd}=155.575$.

If $\mathrm{O}=16, \mathrm{Gd}=156.761$.

Boisbaudran $\dagger$ found $\mathrm{Gd}=155.33,156.06,155.76$, and 156.12. The last he considers the best, but gives no details as to antecedent values. $\mathrm{He}$ also quotes Marignac, who found $\mathrm{Gd}=156.75$, and Cleve, who found 154.15, 155.28, 155.1, and 154.77. Probably these all depend upon $\mathrm{SO}_{3}=80$.

\section{ERBIUM.}

Since the earth which was formerly regarded as the oxide of this metal is now known to be a mixture of two or three different oxides, the older determinations of its molecular weight have little more than historical interest. Nevertheless the work done by several investigators may properly be cited, since it sheds some light upon certain important problems.

First, Delafontaine's $\ddagger$ early investigations may be considered. A sulphate, regarded as erbium sulphate, gave the following data. An oxalate was thrown down from it, which, upon ignition, gave oxide. The percentages in the fourth column refer to the anhydrous sulphate. In the last experiment water was not estimated, and I assume for its water the mean percentage of the four preceding experiments:

\begin{tabular}{|c|c|c|c|}
\hline Sulphate. & $E r_{2} O_{3}$ & $\mathrm{H}_{2} \mathrm{O}$. & Fer cent. $\mathrm{Er}_{2} \mathrm{O}_{3}$ \\
\hline $.827 \mathrm{grm}$. & $.353 \mathrm{grm}$. & . 177 grm. & $54 \cdot 308$ \\
\hline $\begin{array}{c}1.0485 “ \\
.803 “\end{array}$ & .4475 " & & 54.407 \\
\hline $\begin{array}{r}.803 \text { “" } \\
1.232 \text { “ }\end{array}$ & $.3415^{\prime \prime}$ & .171 & 54.035 \\
\hline 1.232 " & .523 & $.264^{\circ}$ “ & 54.028 \\
\hline 1.1505 “" & .495 ، & ......... & 54.760 \\
\hline
\end{tabular}

Hence $\mathrm{Er}=117.86$. 
Bahr and Bunsen* give a series of results, representing successive purifications of the earth which was studied. The final result, obtained by the conversion of oxide into sulphate, was as follows:

$.7870 \mathrm{grm}$. oxide gave I. $2765 \mathrm{grm}$. sulphate. 6I.653 per cent. oxide.

Hence $\mathrm{Er}=167.82$.

Hoeglund, $\dagger$ following the method of Bahr and Bunsen, gives these results :

\begin{tabular}{|c|c|c|}
\hline $\mathrm{Er}_{2} \mathrm{O}_{3}$. & $\mathrm{Er}_{2}\left(\mathrm{SO}_{4}\right)_{3}$ & Percent. $\mathrm{Er}_{2} \mathrm{O}_{3}$. \\
\hline $\begin{array}{l}1.8760 \mathrm{grm} . \\
1.7990 \text { " }\end{array}$ & $\begin{array}{l}3.0360 \mathrm{grm} . \\
2.9100 " \text { " }\end{array}$ & $\begin{array}{l}61.792 \\
61.821\end{array}$ \\
\hline $2.8410 \quad "$ & 4.5935 “ & 61.848 \\
\hline I.2850 “ & 2.0775 " & 6 เ. 853 \\
\hline $1.1300 "$ & $\mathrm{I} .827$ & 61.850 \\
\hline .8475 “ & $1.370 \quad$ " & $6 \mathrm{r} .86 \mathrm{r}$ \\
\hline
\end{tabular}

Hence $\mathrm{Er}=169.33$.

According to Thalén, $\$$ spectroscopic evidence shows that the "erbia" studied by Hoeglund was largely ytterbia.

Humpidge and Burney $\S$ give data as follows:

$$
\begin{aligned}
& \text { I. } 9596 \mathrm{grm} . \mathrm{Er}_{2}\left(\mathrm{SO}_{4}\right)_{3} \text { gave I. } 2 \mathrm{I} 47 \mathrm{grm} . \mathrm{Er}_{2} \mathrm{O}_{3} \text {. } 6 \mathrm{I} .987 \text { per cent. } \\
& \text { I.90II " } 1.178 \mathrm{I} \text { " } 6 \mathrm{r} .965 \text { " } \\
& \text { Mean, } \overline{61.976}, \pm .0074
\end{aligned}
$$

Hence $\mathrm{Er}=170.46$.

The foregoing data were all published before the composite nature of the supposed erbia was fully recognized. It will be seen, however, that three sets of results were fairly comparable, while Delafontaine evidently studied an earth widely different from that investigated by the others. Since the discovery of ytterbium, some light has been thrown on the matter. The old erbia is a mixture of several earths, to one of which, a rose-colored body, the name erbia is now restricted. For the atomic weight of the true erbium Cleve $\|$ gives three determinations, based on syntheses of the sulphate after the usual method. His weights were as follows, with the percentage ratio added:

$\begin{array}{cc}\mathrm{Er}_{2} \mathrm{O}_{3} . & \mathrm{Er}_{2}\left(\mathrm{SO}_{4}\right)_{3} . \\ \mathrm{I} .0692 & 1.7436 \\ \mathrm{~T} .2153 & \mathrm{I} .9820 \\ .7850 & 1.2808\end{array}$
Per cent. $\mathrm{Er}_{2} \mathrm{O}_{3}$.
61.321
$6 \mathrm{I} .317$
61.290

Mean, $\overline{6 \mathrm{r} \cdot 309,} \pm .0068$

Hence, with $\mathrm{SO}_{3}=79.465, \mathrm{Er}=165.059$.

If $\mathrm{O}=16, \mathrm{Er}=166.316$.

*Ann. Chem. Pharm., 137, 21. 1866.

$\dagger$ K. Svenska Vet. Akad. Handlingar, Bd. I, No. 6.

‡ Wiedemann's Beiblätter, 5, I22. I88I.

\& Journ. Chem. Soc., Feb., 1879, p. I16.

$\|$ K. Svensk. Vet. Akad. Handlingar, No. 7, 1880. Abstract in Compt. Rend., 91, 382. 
It is not worth while to combine this result with the earlier determinations, for they are now worthless.

\section{YTTERBIUM.}

For ytterbium we have one very good set of determinations by Nilson.* The oxide was converted into the sulphate after the usual manner:

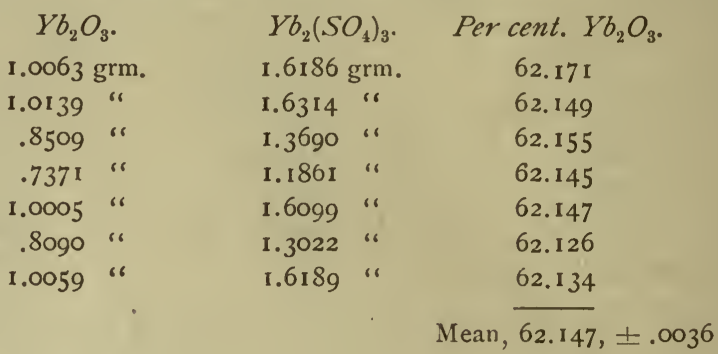

Hence, with $\mathrm{SO}_{3}=79.465, \mathrm{Yb}=171.880$.

If $\mathrm{O}=16, \mathrm{Yb}=173.190$.

TERBIUM, THULIUM, HOLMIUM, DYSPROSIUM, ETC.

For these elements the data are both scanty and vague. Concerning the atomic weights of holmium and dysprosium, practically nothing has been determined. To thulium, Cleve $\dagger$ assigns a value of $\mathrm{Tm}=170.7$, approximately, but with no details as to weighings. Probably the value was computed with $\mathrm{SO}_{3}=80$.

For terbium, ignoring older determinations, Lecoq de Boisbaudran has published two separate estimates. $\ddagger$ "First, for two preparations, one with a lighter and one with a darker earth, he gives $\mathrm{Tb}=161.4$ and 163.1 respectively. In his second paper he gives $\mathrm{Tb}=159.01$ to 159.95 . 'These values probably are all referred to $\mathrm{SO}_{3}=80$.

* Compt. Rend., 91, 56. 1880. Berichte, 13, 1430.

† Compt. Rend., 9r, 329. r880.

$\ddagger$ Compt. Rend., I02, 396, and III, 474 . 


\section{ARGON AND HELIUM.}

The true atomic weights of these remarkable gases are still in doubt, and so far can only be inferred from their specific gravities.

For argon, the discoverers, Rayleigh and Ramsay,* give various determinations of density, ranging, with hydrogen taken as unity, from 19.48 to 20.6. In an addendum to the same paper, Ramsay alone gives for the density of argon prepared by the magnesium method the mean value of 19.941. In a later communication $\uparrow$ Rayleigh gives determinations made with argon prepared by the oxygen method, and puts the density at 19.940 .

For the density of helium, Ramsay $\ddagger$ gets 2.18 , while Langlet $\S$ finds the somewhat lower value 2.00 .

From one set of physical data both gases appear to be monatomic, but from other considerations they are supposably diatomic. Upon this question controversy has been most active, and no final settlement has yet been reached. If diatomic, argon and helium have approximately the atomic weights two and twenty respectively; if monatomic, these values must be doubled. In either case helium is an element lying between hydrogen and lithium, but argon is most difficult to classify. With the atomic weight 20, argon falls in the eighth column of the periodic system between fluorine and sodium, but if it is 40 the position of the gas is anomalous. A slightly lower value would place it between chlorine and potassium, and again in the eighth column of Mendelejeff's table; but for the number 40 no opening can be found.

It must be noted that neither gas, so far, has been proved to be absolutely homogeneous, and it is quite possible that both may contain admixtures of other things. This consideration has been repeatedly urged by various writers. If argon is monatomic, a small impurity of greater density, say of an unknown element falling between bromine and rubidium, would account for the abnormality of its atomic weight, and tend towards the reduction of the latter. If the element is diatomic, its classification is easy enough on the basis of existing data. Its resemblances to nitrogen, as regards density, boiling point, difficulty of liquefaction, etc., lead me personally to favor the lower figure for its atomic weight, and the same considerations may apply to helium also. Until further evidence is furnished, therefore, I shall assume the values two and twenty as approximately true for the atomic weights of helium and argon.

* Phil. Trans., 186, pp. 220 to 223 , and $238 . \quad 1895$.

† Chem. News, 73, 75. I896.

$\ddagger$ Journ. Chem. Soc., I895, p. 684 .

\& Zeitsch. Anorg. Chem., I0, 289. 1895. 


\section{TABLE OF ATOMIC WEIGHTS.}

The following table contains the values for the various atomic weights found or adopted in the preceding calculations. As the table is intended for practical use, the figures are given only to the second decimal, the third being rarely, if ever, significant. In most cases even the first decimal is uncertain, and in some instances whole units may be in doubt.

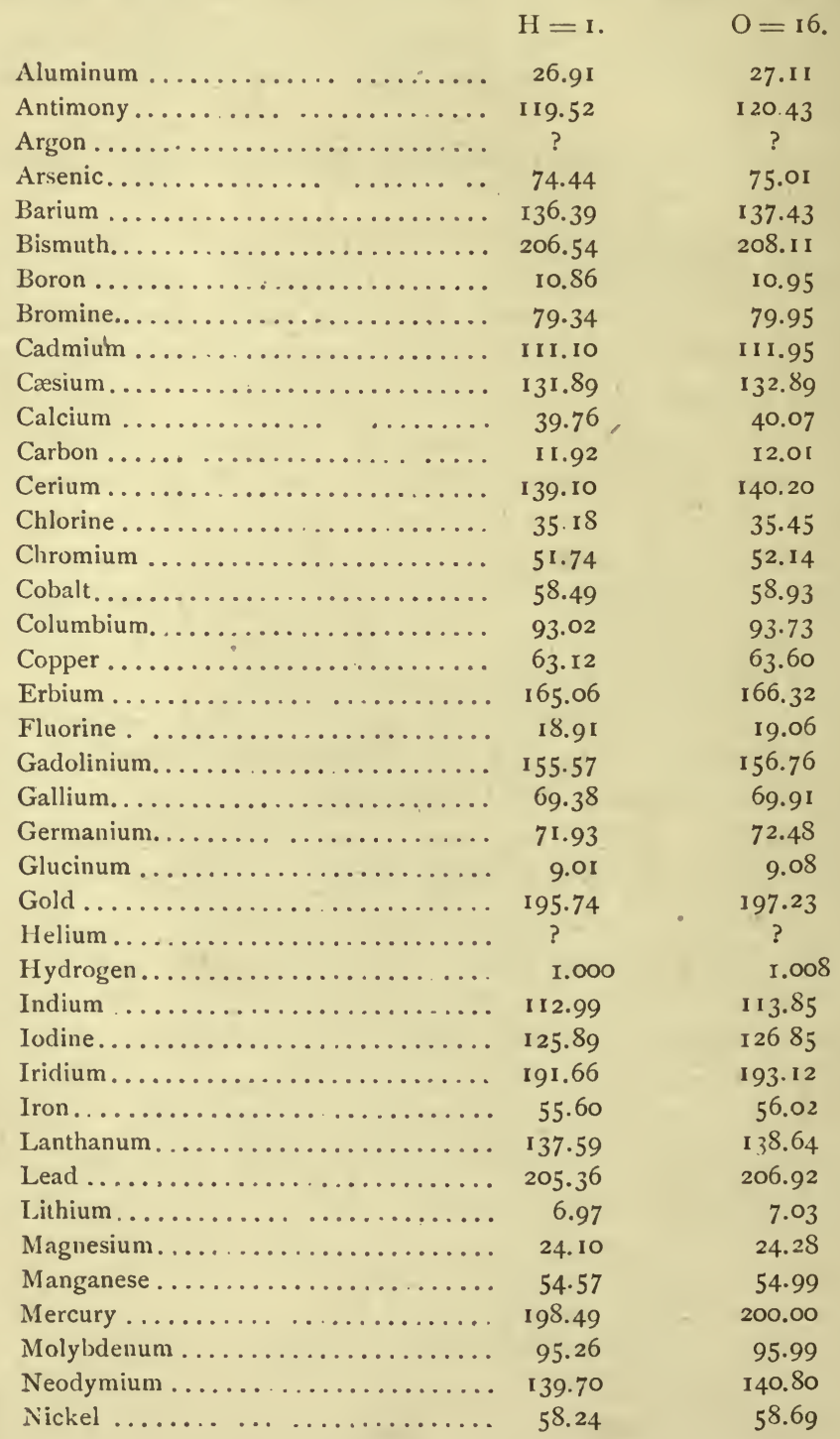




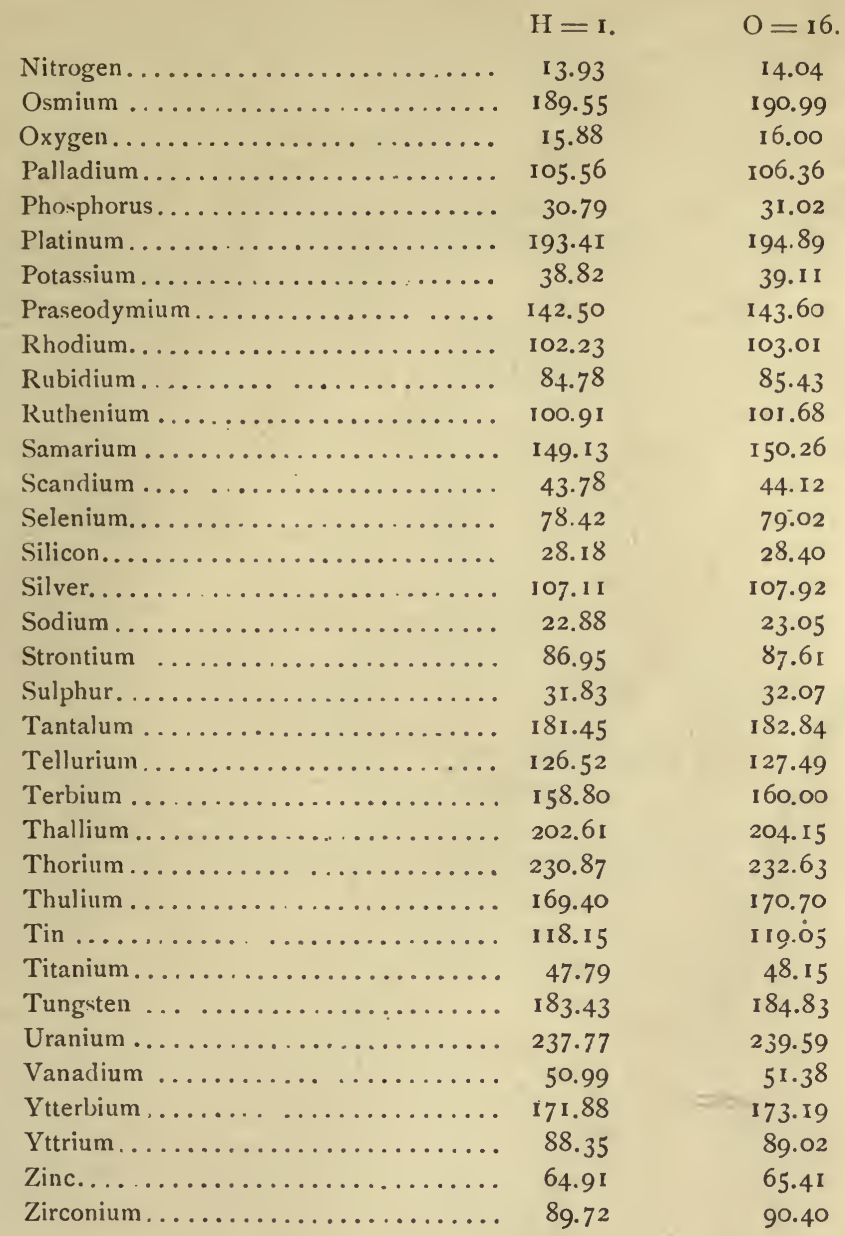





\section{INDEX TO AUTHORITIES.}

A

Agamennone............. 14, 25

Allen................... 89

Allen and Pepys.............. 24

Alibegoff ..............266, 300

Anderson .................. 130

Andrews. .............. I18, 327

Arago.............. 24, 58, $7^{2}$

Arfvedson .......... 84, 263, $28_{2}$

Aston ................. 52, 172

Awdejew............... I32

B

Balır................... $\mathrm{r}_{37}$

Bahr and Bunsen.......... 356, $36 \mathrm{r}$

Bailey................ I97, 23 I

Bailey and Lamb................. 316

Balard................... 44

Baubigny....... 93, I48, I80, 244, 300

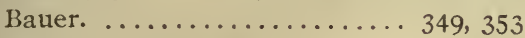

Becker................. I I

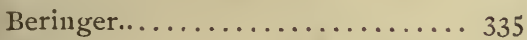

Berlin............238, 251, 355

Bernot1li ................ 257

Berzelius. . 5, 8, 24, 34, 38, 43, 44, 50, 58, $72,82,84,91$, IOI, I10, I12, I2I, I23, 127, I 32, I35, I46, I71, 176, I88, 196, 204, 209, 2II, 2I3, 216, 236, 238, 250, 255. 263, 268, 271, 277, 282, 257, 31 3 , $315,322,325,327,355$

Bettendorff................. 349, 359, 360 Biot and Arago ......... 24, 58, 72 Blomstrand............ 234, 236 Boisbaudran........... IS1, 360, 362 Bongartz................. 226 Bongartz and Classen....... 200, 201 Borch, von.... .............. 256 Boussingault............ 24, 58 Brauner. . 272, 274, 340, 342, 348, 351, 359 Breed..................... 320 Bucher..................... 160 Buehrig... ................ 339 Buff.................24, 72 Bunsel1.......... 87, 89, 356, 36r Bunsen and Jegel............ 336 Burney .................. 36 I
Burton.................... I5I

Burton and Vorce............ I42

\section{C}

Capitaine ................. $288_{7}$

Cavendish.................. 24

Chikashigé .................. 275

Choubine .................. 344

Christensen .................. 280

Chydenius.................. 204

Clark..................... 9

Clarke................... 159

Classen.......... 200, 20I, 23I, 232

Claus................... . $31 \mathrm{r}$

Cleve.. 206, 347, 348, 351, 352, 354, 356

$359,360,36 \mathrm{r}, 362$

Cleve and Hoeglund.................................

Commaille................ 91

Cooke...... 27, 8I, 157, 221, 222, 224

Cooke and Richards ........... I 3

Crafts..................25, 58

Crookes.. ................ 185

Czudnowicz..............2 21 1,346

\section{D}

Davy ................... 24

Debray ............... I33, $25 \mathrm{I}$

Delafontaine ...... 205, 356, 358, 36o

De Luca................... 278

Demarçay.................... 359

Demoly ................... 19 I

De Saussure............. 24,72

Desi ...................... 262

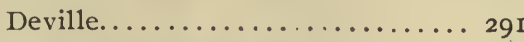

Deville and Troost............ 235

Dewar and Scott............, 283

Dexter.................... 217

Dieh1.................. 84

Dittmar......................... 85

Dittmar and Henderson ....... 12, 19

Dittmar and M'Arthur......... 333

Döbereiner............. I27, 287

Dulong and Berzelius.... 8, 24, 58, 72

Dumas. . 9, 39, 45, 50, 5 r, 72, 80, 91 r I ro II 2 II $3,119,129,140,156,176,188$, 199, 201, 209, 213, 2 r 7, 229, 25 I, 256, $269,278,279,282,289,294$

(367) 
Dumas and Boussingault...... 24, 58 Dumas and Stas............. 76

\section{$\mathbf{E}$}

Ebelmen.................. 264

Ekman and Pettersso11......... 269

Erdmann ................ 146

Erdmant and Marchand... II, 76, I 10, II I, I66, 268, 288, 29 I

Erk ............... 347, 35 I

Ewan and Hartog ........... I7 I

$\mathbf{F}$

Faget.................. 37

Favre.................. 147

Fourcroy................. 24

Fownes ................ 72

Fremy.................. 322

Friedel.................. 77

G

Gay-Lussac. . ....... 32, 1 35, I46

Genth.. .................. 338

Gerhardt................... ${ }_{36} 6$

Gibbs.................298, 342

Gladstone and Hibbard......... 152

Gmelin .................. 84

Godeffroy.................. 87,90

Gooch and Howland ........... 274

Gray................... 98

\section{$\mathbf{H}$}

Hagen................... 84

Halberstadt .............. 330

Hampe.................. 92

Hardin .......... 34, 63, 74, 163, I67

Hartog.................. I 7 I

Hauer, vol1.......... 156, 271, 283

Hebberling................ 184

Hempel and Thiele........... 308

Henry .................. 6

Hermann ...... 84, 196, 206, 234, 236, $335,347,35^{\mathbf{I}}$

Heycock ................ 88

Hibbard................. 152

Hibbs.............6 67, 68, 2 I 5

Hinrichs................. 6

Hoeglund............. 356, 36r

Holzmann.................. 345

Hoskyns-Abrahall ............ I7I

Howland... ................. 274

Humboldt and Gay-Lussac...... 32

Humpidge and Burney......... 36r

Huntington............. 46, I57
I

Isnard $\ldots \ldots \ldots \ldots \ldots \ldots \ldots \ldots$ I 76

J

Jacquelain........... 136, 146, $23 \mathrm{~S}$

Jegel.................... 336

Johnson................. 17

Johnson and Allen............. 89

Jolly................... 59

Joly ................ 3II, 326

Joly and Leidié.............. 319

Jones.............. 159, 3i7, 358

Jörgensen. . ............. 313

\section{$\mathbf{K}$}

Keiser ............. 15, 150, 316

Keiser and Breed............. 320

Keller and Smith........... $3^{18}$

Kenip................ 252

Kessler.....2I4, 216, 218, 224, 24I, 242

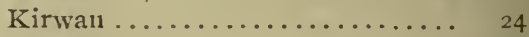

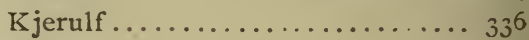

Klatzo .................. 132

Kobbe..................................... $3^{14}$

Kralovanzky .............. 84

Krüss................. 102

Krüss and Alibegoff........ 266, 300

Krüss and Moraht........... I33

Krüss and Nilson .......... 207

Krüss and Schmidt.......... 303

\section{I}

Lagerhjelı1 ................ 229

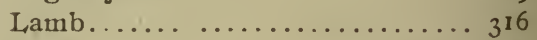

Lamy.................. 184

Langer................. 3 or

Langlet.................... 363

Laurent ............. 34, 171

Laurie.................. 10

Lavoisier............ 24, 58, 72

Le Conte................ 25

Leduc .......... 20, $27,32,59,78$

Lee..................... 298

Lefort .................. 240

Leidié .................... 319

Lenssen.................... ${ }_{156}$

Lepierre ................. I86

Levol ... ............... I02

Liebig ................... 44

Liebig and Redtenbacher ...... 72

Liechti and Kemp...................... 252

Longchamp............ I27, 135 
Lorimer and Smith............ I59 Louyet............. 277, 279, 280 Löwe................... 23I Löwig ................... 44

\section{M}

Maas 252

M'Arthur................. 333

Macdonnell............... I 36

Malaguti................... 255

Mallet........... 84, I05, 150, 177 Marchand........ I I , 72, 76, I Io, I I I, I66, 256, 263, 268, 288, $29 \mathrm{I}$

Marchand and Scheerer.......... I3 8

Marignac. . 34, 35, 36, 38, 39, 41, 43, 44, $45,47,48,49,60,62,65,74$, I Io, I I 4 , I I 5, I I $8, I_{21}, I_{22}, I_{23}, I_{29}, I_{4}$ I, I48, I96, 230, 235, 236, 284, 292, 336, 344, $345,35 \mathrm{I}, 359,360$.

Mather ................. I 76 Maumené...... 34, 36, 39, 43, 75, 288 Meineke...................... 244 Meyer................... 252 Meyer and Seubert.......... I, 5, 6 Millon................ 48, 167 Millon and Conmaille......... 9I Mitscherlich ............. 72 Mitscherlich and Nitzsch ......... 268 Moberg.................... 239 Moissa11............ 278, 279, 280 Mond, Langer, and Quincke..... 30I Moraht.................. I33 Morley........... 12, 2I, 27, 32 Morse and Burton............ I5I Morse and Jones....... ....... I 59 Morse and Keiser............... I 50 Mosander.......... I90, 335, 344, 351 Mulder................... 6 Mulder and Vlaanderen.......... I99

\section{$\mathbf{N}$}

Nilson............. 207, 354, 362 Nilson and Pettersson........... I33 Nitzsch . . . . . . . . . . . . . . . . . 268 Nordenfeldt................. I 37 Nordenskiöld ............... 360 Norlin..................... 287 Noyes................... I6, I7 Ostwald......... I, 6, 57, 71, 83, I3I Oudemans.
$\mathbf{P}$

Parker.................... 142

Partridge ................. I57

Peligot.............. 238, 264, 265

Pelouze............. 35, 51, 60, I 13, I I $8,188,209,2$ I3

Penfield................... I 86

Pennington and Smith.......... 258

Penny...... 35, 39, 50, 62, 64, 66, 67

Pepys.................... 24

Persoz.................... 257

Petrenko-Kritschenko ......... 319

Pettersson............... I33, 269

Pfeifer................... 225

Piccard ................. 87

Pierre.................. 191

Pollard ................. 252

Popp..................... 355

Popper.................. 225

Q

Quincke.................... 30I

Quintus Icilius.............. 3I5

\section{$\mathbf{R}$}

Rammelsberg... 234, 252, 263, 337, 344 Ramsay................ I49, 363 Ramsay and Aston ........ 52, 172 Rawack.................. 283

Rawson..................... 244 Rayleigh. . I4, I6, 25, 26, 58, 59, 98, 363 Rayleighi and Ramsay . ....... 363 Rayleigh and Sidgewick........ 98 Redtenbacher.............. 72 Regnault............. 24, 25, 72 Reich and Ricliter .......... I82 Remmler................ 302 Reynolds and Ramsay.......... I 49 Richards.... 13, 46, 82, 92, 93, 94, 96, 97, I1 5, I19, I 2 I, 123, I 24, 154 Richards and Parker.......... I42 Richards and Rogers..... I41, I52, I53 Riche.................... 259 Richter................. 182 Rimbach................. I74 Rivot...................... 289 Robinson ................. 340 Rogers .............. 141, I52, I53 Roscoe.......... 77, 2 I I , 257, 262 Rose............. 190, 21 7, 234, 236 Rothloff.................. 291 Russell................. 294, 295 
$\mathbf{s}$

Sacc ..................... 268

Salvétat ........... I I0, II 3 , II 8

Scheerer.......... 135, 136, 138, I39

Scheibler .................. 260

Schiel................... I 88

Schmidt...............203, 303

Schneider..... 216, 224, 229, 232, 255,

$258,282,29$ I, 292, 297

Schrötter ................ 209

Schuizenberger............ 301, 34 I

Scott.................. 32, 283

Sebelien ................ I, 7

Sefström................. 165

Seubert..... I, 322, 323, 325, 328, 333

Seubert and Kobbe ........... 314

Seubert and Pollard. ........... 252

Shaw .................... 98

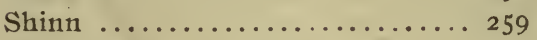

Sidgewick................ 98

Siewert... .............. 243

Smith............. I59, 258, 318

Smith and Desi.............. 262

Smith and Maas.............. 252

Sommaruga................. 297

Spring.................... 6

Stas. . 6, 37, 38, 40, 4I, 42, 44, 45, 47, 48, 49, 5I, 52, 57, 61, 62, 64, 65, 66, 7 I, $73,76,78,80,82,83,85$, I 28, I 30, I 3 I Staudenmaier .............. 274

Strecker................. 73

Stromeyer.......... 84, 156, 287

Struve...........81, 82, 123, 250

Svanberg.............. I30, I67

Svanberg and Nordenfeldt ....... 137

Svanberg and Norlin.......... 287

Svanberg and Struve........ 82, 250

\section{$\mathbf{T}$}

Terreil................ I 77

Thalén................. 36I

Thiele................. 308

Thomsen.. 13, 22, 30, 57, 69, 71, 83, r3 I

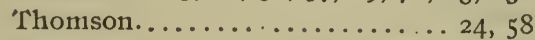

Thorpe................. 192

Thorpe and Laurie........... ro3
Thorpe and Young......... 189

Tissier................. 176

Torrey............ I51, 180, 289

Troost................ 84, 235

Turner. . 38, 64, I2 I, I22, I 23, 128, 166,

U

I 67,282

Unger .

221

\section{V}

Van der Plaats... 6, 57, 7 I, 77, 83, I3r,

149, 200, 210

Van Geuns... . ............ 5

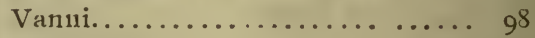

Vauquelin ................. 24

vlaanderen ................. 199

Vogel.................... 6

Vorce ................... I42

W

Wackenroder.............. 287

Waddell .................. 258

Wallace............... 44, 213

Warrington................ 33

Weber.................. 217

Weerell................ I32, 285

Weibull ................. 196

Wells and Penfield ............ 186

Welsbach ................. 353

Wertheim .................. 265

Werther ................ 184

Weselsky .................. 298

Wildenstein $\ldots \ldots \ldots \ldots \ldots \ldots \ldots .24 \mathrm{r}$

Wills .................... 27 I

Wing ...................... $33^{8}$

Winkler.... I82, 195, 297, 305, 306, 307

Wolf.................. 337, 340

Woskresensky............. 72

Wrede................. 24, 72

$\mathbf{Y}$

Young $\ldots \ldots \ldots \ldots \ldots \ldots \ldots \ldots$ I 89

$\mathbf{z}$

Zettnow..................260

Zimmermann........... 266, 300

Zschiesche...............47, 35 I 
$$
\text { . }
$$

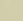
-

$$
=
$$




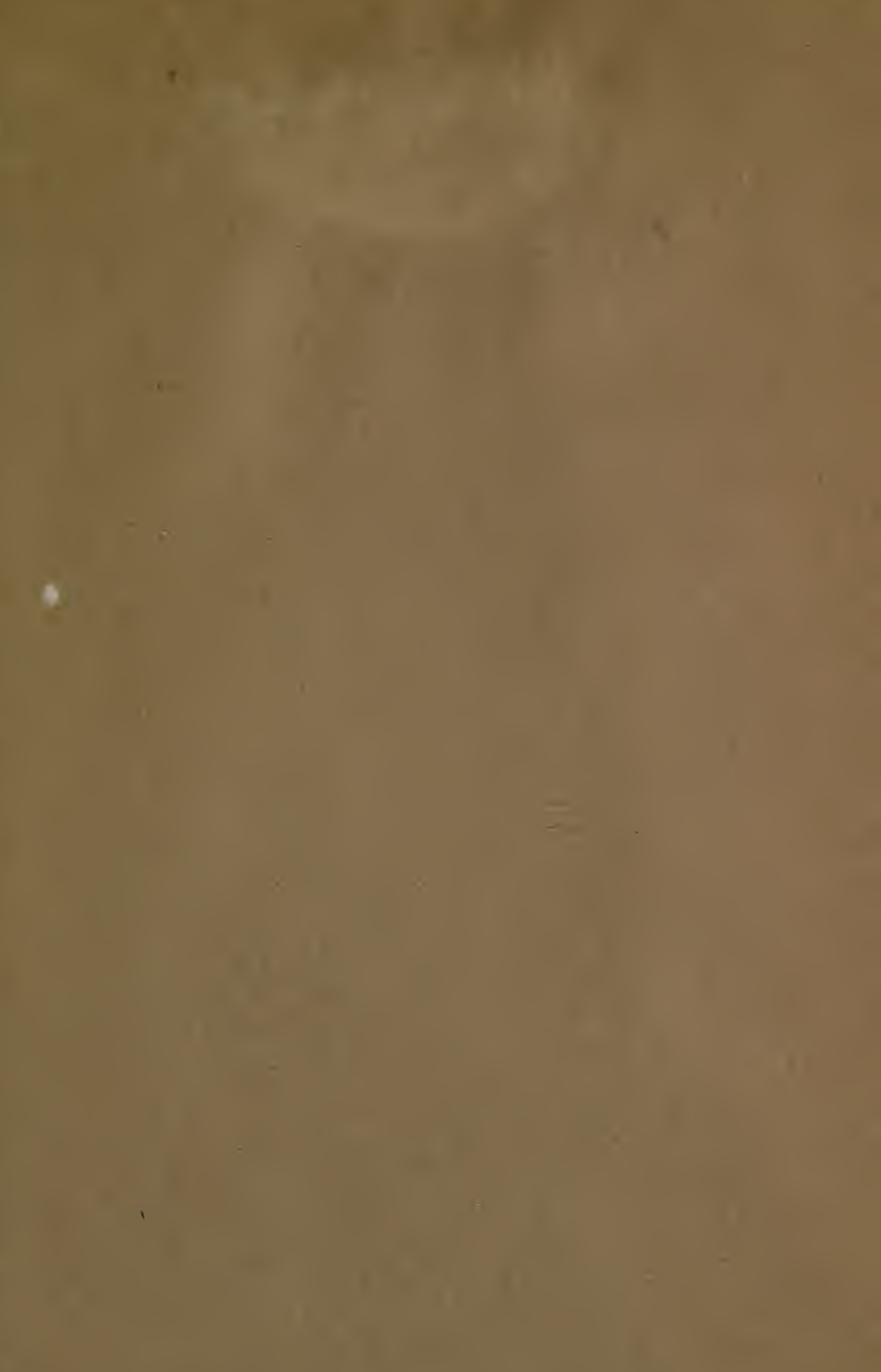
DATE DUE SLIP

UNIVERSITY OF CALIFORNIA MEDICAL SCHOOL LIBRARY

THIS BOOK IS DUE ON THE LAST DATE STAMPED BELOW

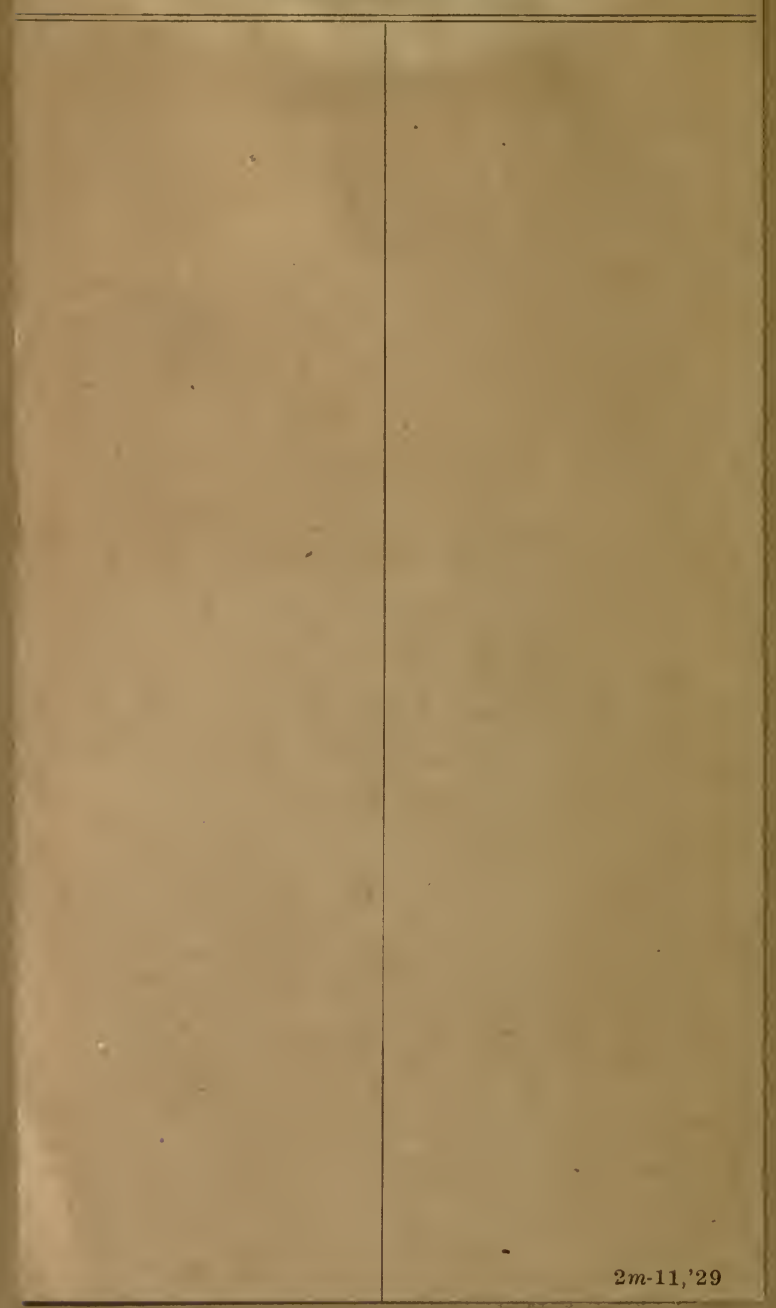


$\sigma$

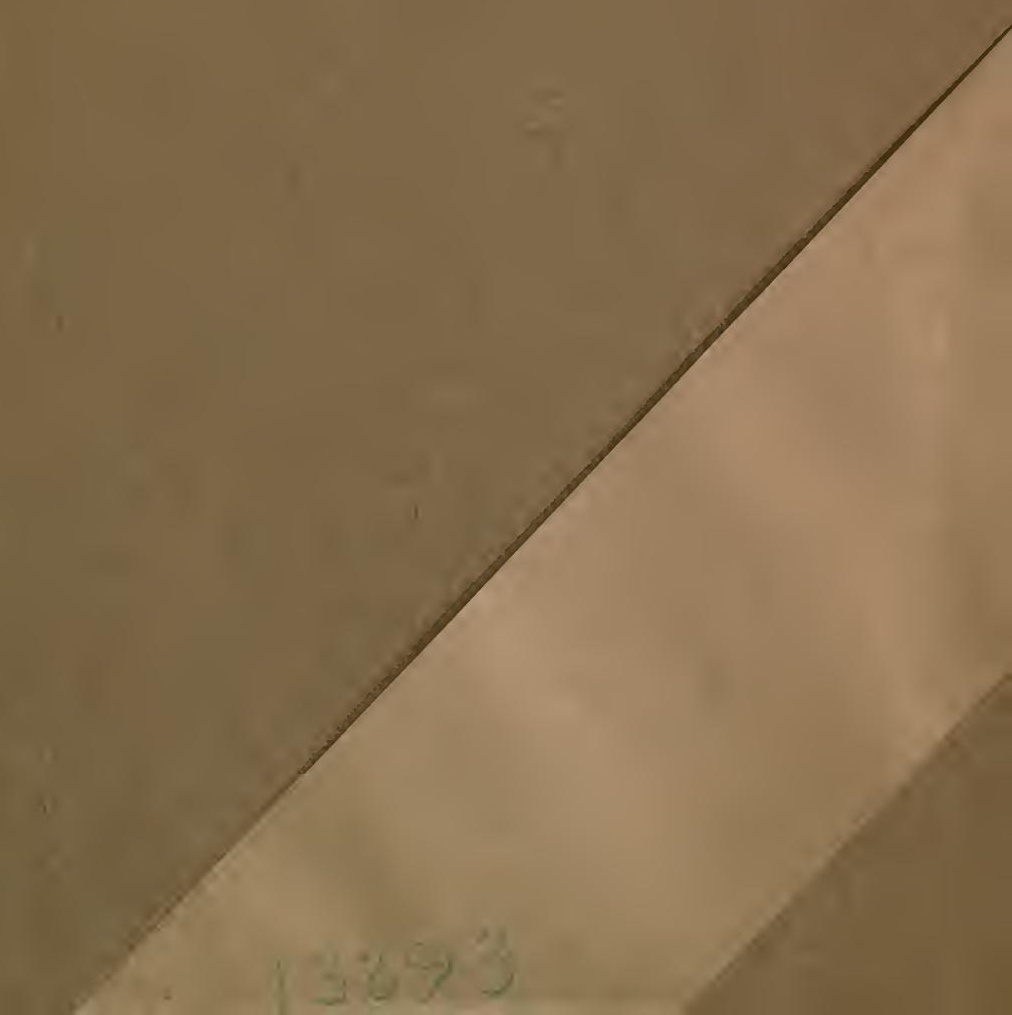


